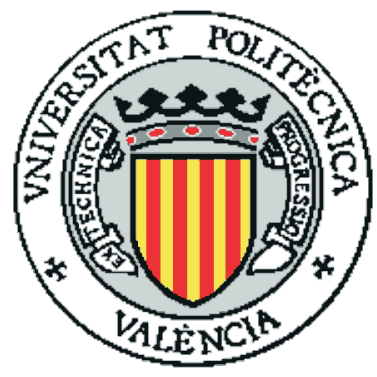

\title{
GORMAS: GUÍAS PARA EL DESARROLLO DE SISTEMAS MULTIAGENTE ABIERTOS BASADOS EN ORGANIZACIONES
}

Autor: Estefanía Argente Villaplana

Directores: Dr. Vicente J. Botti Navarro

Dr. Vicente Julián Inglada

PARA LA OBTENCIÓN DEL GRADO DE DOCTOR EN INFORMÁTICA

POR LA

UNIVERSIDAD POLITÉCNICA DE VALENCIA

Valencia, España

JUNIO 2008 
Fecha: Junio 2008

Autor: $\quad$ Estefanía Argente Villaplana

Directores: $\quad$ Dr. Vicente J. Botti Navarro

Dr. Vicente Julián Inglada

Título: GORMAS: Guías para el desarrollo de Sistemas Multiagente abiertos basados en organizaciones

Departamento: Sistemas Informáticos y Computación

Universidad: Universidad Politécnica de Valencia

Grado: Doctor Mes: Junio Año: 2008

Firma del Autor 
A mi familia. 


\section{Índice general}

Índice de Tablas

Índice de Figuras

Resumen

Abstract $\quad$ XXV

Resum $\quad$ XXVII

Agradecimientos $\quad$ XXIX

1. Introducción 1

1.1. Motivación . . . . . . . . . . . . . . . . . 4

1.2. Objetivos ....................... 5

1.3. Estructura del trabajo . . . . . . . . . . . . . 7

2. Organizaciones 11

2.1. Introducción . . . . . . . . . . . . . . . . . 11

2.2. Concepto de Organización . . . . . . . . . . . . . . . . . 12

2.2.1. Organizaciones humanas . . . . . . . . . . . 13

2.2.2. Organizaciones de agentes . . . . . . . . . . . 14

2.3. Factores de la organización . . . . . . . . . . . . . . 16

2.3.1. Estructura . . . . . . . . . . . . . . . . 18

2.3.2. Funcionalidad . . . . . . . . . . . . . . 20

2.3.3. Normalización . . . . . . . . . . . . . . . . 22 
2.3.4. Dinamicidad . . . . . . . . . . . . 24

2.3.5. Entorno . . . . . . . . . . . . . . 25

2.4. Taxonomía de Organizaciones . . . . . . . . . . . . 26

2.4.1. Tipos de organizaciones humanas . . . . . . . . 26

2.4.2. Tipos de organizaciones de agentes . . . . . . . . . . 34

2.4.3. Comparación de taxonomías . . . . . . . . . . . . . 42

2.5. Sistemas abiertos . . . . . . . . . . . . . . . 43

2.6. Conclusiones . . . . . . . . . . . . . . . 46

3. Estado del arte $\quad 49$

3.1. Introducción . . . . . . . . . . . . . . . . . . . . . 49

3.2. Met. MAS orientadas al agente . . . . . . . . . . 51

3.2.1. Discusión . . . . . . . . . . . . . . . 60

3.3. Met. MAS orientadas a la organización . . . . . . . . . . . . 62

3.3.1. Discusión . . . . . . . . . . . . . . . . 90

3.4. Plataformas de agentes . . . . . . . . . . . . . . . . 95

3.4.1. Discusión . . . . . . . . . . . . . . 100

3.5. Conclusiones . . . . . . . . . . . . . . . . . . 101

4. Modelado de Organizaciones 107

4.1. Introducción . . . . . . . . . . . . . . . . . . . 107

4.2. Unidad Organizativa . . . . . . . . . . . . . . . 110

4.2.1. Vista parcial de la Ontología de Organización . . . . 112

4.2.2. Propuestas similares . . . . . . . . . . . . 113

4.3. Servicios . . . . . . . . . . . . . . . . . . 114

4.3.1. Vista parcial de la Ontología de Organización . . . . 117

4.3.2. Propuestas similares . . . . . . . . . . . . 117

4.4. Normas . . . . . . . . . . . . . . . . . . . . . . . 121

4.4.1. Vista parcial de la Ontología de Organización . . . . 123

4.4.2. Propuestas similares . . . . . . . . . . . . . 123

4.5. Entorno . . . . . . . . . . . . . . . . . . . . 124

4.6. Meta-modelos del Sistema multiagente . . . . . . . . . . 125

4.6.1. Entidades básicas . . . . . . . . . . . . . . . . . . 132 
4.6.2. Meta-modelo de Organización . . . . . . . . . . . 135

4.6.3. Meta-modelo de Actividad . . . . . . . . . . . . . . . 148

4.6.4. Meta-modelo de Interacción . . . . . . . . . . . . . 154

4.6.5. Meta-modelo del Entorno . . . . . . . . . . . . 156

4.6.6. Meta-modelo de Agente . . . . . . . . . . . . . 160

4.6.7. Meta-modelo Normativo . . . . . . . . . . . . . 167

4.7. Modelo organizativo de MAS . . . . . . . . . . . . 177

4.7.1. Unidades Organizativas básicas . . . . . . . . . . 178

4.7.2. Estructuras Organizativas Complejas . . . . . . . . . 189

4.8. Conclusiones . . . . . . . . . . . . . . . . . 197

5. Guía Metodológica 203

5.1. Introducción . . . . . . . . . . . . . . . . . . 203

5.2. Guías de diseño de organizaciones humanas . . . . . . . . . . 205

5.3. Secuencia-Guía . . . . . . . . . . . . . . . . . 209

5.4. Fase A. Misión . . . . . . . . . . . . . . . . . . . . . 216

5.4.1. Definir la misión . . . . . . . . . . . . . 217

5.4.2. Definir el contexto organizativo . . . . . . . . . . 220

5.4.3. Aplicación de la fase al caso de estudio . . . . . . . . 227

5.4.4. Síntesis de la fase . . . . . . . . . . . . . . . . . . 232

5.5. Fase B. Tareas y procesos . . . . . . . . . . . . . . 233

5.5.1. Analizar la tecnología . . . . . . . . . . . . . . 234

5.5.2. Analizar los objetivos de la organización . . . . . . 245

5.5.3. Aplicación de la fase al caso de estudio . . . . . . . . 247

5.5.4. Síntesis de la fase . . . . . . . . . . . . . . . . 254

5.6. Fase C. Dimensiones Organizativas . . . . . . . . . . . 258

5.6.1. Asignar tareas . . . . . . . . . . . . . . . 259

5.6.2. Identificar restricciones . . . . . . . . . . . 265

5.6.3. Aplicación de la fase al caso de estudio . . . . . . . . 271

5.6.4. Síntesis de la fase . . . . . . . . . . . . . . . 273

5.7. Fase D. Estructura organizativa . . . . . . . . . . . . 275

5.7.1. Aplicación de la fase al caso de estudio . . . . . . . . . . 282

5.7.2. Síntesis de la fase . . . . . . . . . . . . . . . . 284 
5.8. Fase E. Procesos de información y decisión . . . . . . . . . 285

5.8.1. Analizar los procesos de decisión . . . . . . . . . 285

5.8.2. Analizar los procesos de información . . . . . . . . . 287

5.8.3. Aplicación de la fase al caso de estudio . . . . . . . . 293

5.8.4. Síntesis de la fase . . . . . . . . . . . . . . . 300

5.9. Fase F. Dinamicidad del Sistema Abierto . . . . . . . . . . . 302

5.9.1. Aplicación de la fase al caso de estudio . . . . . . . 307

5.9.2. Síntesis de la fase . . . . . . . . . . . . . . . . 312

5.10. Fase G. Sistemas de control . . . . . . . . . . . . . . . . 314

5.10.1. Aplicación de la fase al caso de estudio . . . . . . . . 317

5.10.2. Síntesis de la fase . . . . . . . . . . . . . . . . . . 319

5.11. Fase H. Sistemas de recompensas . . . . . . . . . . . . . . . 321

5.11.1. Aplicación de la fase al caso de estudio . . . . . . . . 326

5.11.2. Síntesis de la fase . . . . . . . . . . . . . . . . . . 328

5.12. Conclusiones . . . . . . . . . . . . . . . . . . . . . . 329

6. Caso de Estudio 331

6.1. Introducción . . . . . . . . . . . . . . . . . 331

6.2. Análisis de Requisitos del Sistema . . . . . . . . . . . . . . 332

6.3. Diseño de la Estructura Organizativa . . . . . . . . . . . . . 346

6.4. Diseño de la Dinámica de la Organización . . . . . . . . . . 358

6.5. Conclusiones . . . . . . . . . . . . . . . . . . 374

7. Conclusiones y Trabajos Futuros $\quad 377$

7.1. Aportaciones . . . . . . . . . . . . . . . . . 377

7.2. Líneas Futuras de Investigación . . . . . . . . . . . . . . 381

7.3. Publicaciones Relacionadas con la Tesis . . . . . . . . . . . . 382

$\begin{array}{ll}\text { Bibliografía } & 385\end{array}$ 


\section{Índice de tablas}

4.1. Descripción BNF del lenguaje normativo. . . . . . . . . . . . 175

4.2. Descripción BNF del lenguaje normativo. . . . . . . . . . . 176

5.1. Documento A.1-Misión Organizativa. Plantilla de descripción de la misión de una organización. . . . . . . . . . . . . 223

5.2. Documento A.2-Grupos de interés. Plantilla de descripción de los grupos de interés de la organización. . . . . . . . . . 224

5.3. Documento A.3-Condiciones Entorno. Plantilla de descripción de las condiciones del entorno. . . . . . . . . . . 226

5.4. Documento A1.Misión Organizativa del sistema de información. (Parte I) . . . . . . . . . . . . . . . . . . . . . . . . 229

5.5. Documento A1.Misión Organizativa del sistema de información. (Parte II) ． . . . . . . . . . . . . . . . . . . . . . . . 230

5.6. Documento A2.Grupos de Interés del sistema de información. 231

5.7. Documento A.3-Condiciones Entorno del sistema de información. . . . . . . . . . . . . . . . . 231

5.8. Documento B.1-Tecnología esencial (Parte I - Productos). Plantilla de descripción de la tecnología esencial. . . . . . . . 237

5.9. Documento B.1-Tecnología esencial (Parte II - Servicios). Plantilla de descripción de la tecnología esencial. . . . . . . . 240

5.10. Documento B.2-Tecnología de Unidad de Trabajo (Parte I Servicios). Plantilla de descripción de las características del servicio. 
5.11. Documento B.2-Tecnología de Unidad de Trabajo (Parte II Productos). Plantilla de descripción de las características del producto. . . . . . . . . . . . . . . . . . 244

5.12. Documento B.1-Tecnología esencial para el Sistema de Información. . . . . . . . . . . . . . . . 248

5.13. Documento B.2-Tecnología de Unidad de Trabajo. Descripción de las características del servicio Proporcionar Información. . . . . . . . . . . . . . . . 252

5.14. Documento C.Dimensiones Organizativas (Parte I). Plantilla de descripción de las dimensiones organizativas para la asignación de tareas. . . . . . . . . . . . . . . 266

5.15. Documento C.Dimensiones Organizativas (Parte II). Plantilla de descripción de las dimensiones organizativas para la identificación de restricciones. . . . . . . . . . . . . 267

5.16. Documento C.Dimensiones Organizativas del sistema de información . . . . . . . . . . . . . . . . . . 272

5.17. Documento H. Sistema de Recompensas. . . . . . . . . . . . 323

6.1. Documento A.1-Misión Organizativa del sistema de agencia de viajes. . . . . . . . . . . . . . . . . . . . . . 334

6.2. Documento A2.Grupos de Interés del sistema de agencia de viajes. . . . . . . . . . . . . . . . 336

6.3. Documento A.3-Condiciones Entorno del sistema de agencia de viajes. . . . . . . . . . . . . . . . 337

6.4. Documento B.1-Tecnología esencial del sistema de agencia de viajes. . . . . . . . . . . . . . . . . . 337

6.5. Documento B.2-Tecnología de Unidad de Trabajo. Descripción de las características del servicio ReservarViaje. . . . . 343

6.6. Documento C.Dimensiones Organizativas del sistema de agencia de viajes. . . . . . . . . . . . . . . . . 350

6.7. Actualización del documento C.Dimensiones Organizativas del sistema de agencia de viajes, con orientación basada en los productos a ofrecer. 


\section{Índice de figuras}

2.1. Ejemplo de estructura matricial en una organización humana. 31

2.2. Características de organizaciones humanas . . . . . . . . . 43

2.3. Características de las estructuras de organización . . . . . . 44

3.1. Comparación de modelos de metodologías orientadas al agente 61

3.2. Ejemplo de cheeseboard diagram . . . . . . . . . . . . 65

3.3. Comparación de características organizativas de AGR, Civil Agent Societies, E-Institutions y SODA . . . . . . . . . 93

3.4. Comparación de características organizativas de MESSAGE, INGENIAS, GaiaExOA, Tropos y OperA . . . . . . . . . . 94

3.5. Comparativa de las metodologías orientadas al agente versus orientadas a la organización . . . . . . . . . . . . . 102

4.1. Ontología de Organización. Unidad Organizativa. . . . . . . 113

4.2. Ontología de Organización. Servicios. . . . . . . . . . . . 117

4.3. Ontología de Organización. Norma. . . . . . . . . . . . . . . 123

4.4. Relación entre los meta-modelos y los factores de la organización. . . . . . . . . . . . . . . . . 131

4.5. Elementos de la notación gráfica de los modelos. . . . . . . . 132

4.6. Entidades Básicas. Conceptos de A-Tarea, Consulta Entidad Autónoma, Producto, A-Agente, Rol y Puerto. . . . . . . . . 133

4.7. Entidades Básicas. Conceptos sobre Entidad Mental, Estado Mental e Interacción. . . . . . . . . . . . . . . . . . . . . . . 134

4.8. Meta-modelo de Organización. Vista estructural. . . . . . . . 136 
4.9. Diagrama de modelo de organización, vista estructural del sistema de agencia de viajes. . . . . . . . . . . . . . . 137

4.10. Meta-modelo de Organización. Vista funcional. Misión. . . . 138

4.11. Diagrama del modelo de organización, vista funcional. Misión del sistema de agencia de viajes. . . . . . . . . . . . 140

4.12. Meta-modelo de Organización. Vista funcional. Funcionalidad Externa. . . . . . . . . . . . . . . . . . . . . . . 141

4.13. Diagrama del modelo de organización, vista funcional. Funcionalidad externa del sistema de agencia de viajes. . . . . . 142

4.14. Diagrama del modelo de organización, vista funcional. Funcionalidad externa de la unidad Vuelos, del sistema de agencia de viajes. . . . . . . . . . . . . . . . . . . . . . 143

4.15. Meta-modelo de Organización. Vista funcional. Funcionalidad Interna. . . . . . . . . . . . . . . . . . . 144

4.16. Diagrama del modelo de organización, vista funcional. Funcionalidad interna del sistema de agencia de viajes. Asociación del rol Cobrador con el agente específico (Banco) que lo desempeña. . . . . . . . . . . . . . . . . . . . . . 144

4.17. Meta-modelo de Organización. Vista social. . . . . . . . . . 145

4.18. Diagrama del modelo de Organización. Vista social. . . . . . 145

4.19. Meta-modelo de Actividad. . . . . . . . . . . . . . . . . . . . 149

4.20. Tipos de relación entre Tareas y Objetivos . . . . . . . . . . 150

4.21. Descomposición Objetivos Organización. . . . . . . . . . . . 150

4.22. Descomposición Objetivos Operativos y dependencia. . . . . 151

4.23. Descripción de tareas. . . . . . . . . . . . . . . . . . . . 152

4.24. Descripción de un Flujo de Trabajo . . . . . . . . . . . . . . 153

4.25. Diagrama del modelo de actividad. Descripción del servicio BuscarViaje. . . . . . . . . . . . . . . . . 153

4.26. Meta-modelo interacción. . . . . . . . . . . . . . . . . 154

4.27. Meta-modelo interacción. Acceso a servicios. . . . . . . . . . 155

4.28. Ejemplo de activación de una interacción al producirse el acceso a un servicio a través de su puerto . . . . . . . . 156 
4.29. Meta-modelo de entorno. Entidad Producto. . . . . . . . . . 157

4.30. Meta-modelo de entorno. Acceso a puertos. . . . . . . . . . . 158

4.31. Meta-modelo de entorno. Pertenencia de un recurso. Características del recurso. . . . . . . . . . . . . . . 159

4.32. Meta-modelo de entorno. Aplicaciones. . . . . . . . . . . 160

4.33. Especialización de la relación WFUtilizaPuerto . . . . . . . . 161

4.34. Ejemplo de utilización de recursos y especificación de permisos de acceso . . . . . . . . . . . . . . . . . 162

4.35. Ejemplo de acceso a un servicio a través de su puerto. . . . . 163

4.36. Meta-modelo de agente. Tareas, roles y estado mental asignado. . . . . . . . . . . . . . . . . . . . 164

4.37. Consulta de Entidad Autonoma . . . . . . . . . . . . . 165

4.38. Entidades Mentales. . . . . . . . . . . . . . . . 166

4.39. Meta-modelo de agente. Servicios ofrecidos. . . . . . . . . 166

4.40. Meta-modelo de agente. Objetivos perseguidos. . . . . . . . 167

4.41. Diagrama del modelo de agente. Descripción de un Agente de Cadena Hotelera. . . . . . . . . . . . . . . . . . . . . 168

4.42. Meta-modelo normativo. . . . . . . . . . . . . . . . . 169

4.43. Patrón de diseño de una Obligación. . . . . . . . . . . . . 170

4.44. Patrón de diseño de una Prohibición. . . . . . . . . . . . . . 171

4.45. Patrón de diseño de un Permiso. . . . . . . . . . . . . . . . 171

4.46. Diagrama de modelo normativo. Descripción de la norma 1. 173

4.47. Diagrama de modelo normativo. Descripción de la norma 2. 174

4.48. Patrón de diseño de la Unidad Organizativa . . . . . . . . . 177

4.49. Unidad Organizativa . . . . . . . . . . . . . . . . 178

4.50. Esquema de una Jerarquía Simple. . . . . . . . . . . . . 179

4.51. Patrón de diseño del modelo de organización de la Unidad Organizativa de tipo Jerarquía Simple. . . . . . . . . . . 180

4.52. Patrón de diseño del modelo de interacción de la Jerarquía Simple. . . . . . . . . . . . . . . . . 181

4.53. Patrón de diseño del modelo normativo de la Unidad Organizativa de tipo Jerarquía Simple. . . . . . . . . . . . . . . . 181 
4.54. Refinamiento del rol supervisor. . . . . . . . . . . . . . . 182

4.55. Patrón de diseño del modelo de organización (vista dinámica) de la Jerarquía Simple. . . . . . . . . . . . . . . . . . . 182

4.56. Patrón de diseño del modelo de actividad de la Jerarquía Simple. . . . . . . . . . . . . . . . . . 183

4.57. Patrón de diseño del modelo de entorno de la Jerarquía Simple. 183

4.58. Esquema de una unidad organizativa de tipo Equipo. . . . . 184

4.59. Patrón de diseño del modelo de organización de la Unidad Organizativa de tipo Equipo. . . . . . . . . . . . . 185

4.60. Patrón de diseño del modelo de agente de la Unidad Organizativa de tipo Equipo. . . . . . . . . . . . . . 186

4.61. Patrón de diseño del modelo de entorno de la Unidad Organizativa de tipo Equipo. . . . . . . . . . . . . . . 187

4.62. Patrón de diseño del modelo de organización para la unidad organizativa de tipo Estructura Plana. . . . . . . . . . . . . 188

4.63. Esquema de una Burocracia. . . . . . . . . . . . . . . . . 189

4.64. Patrón de diseño del modelo de organización para la burocracia190

4.65. Patrón de diseño del modelo de actividad para la burocracia funcional . . . . . . . . . . . . . . . . . . . . . . . . 190

4.66. Patrón de diseño del modelo de organización para la burocracia divisional . . . . . . . . . . . . . . . . . . 191

4.67. Patrón de diseño del modelo de organización de una Federación. 192

4.68. Patrón de diseño del modelo de organización de de la estructura matricial. . . . . . . . . . . . . . . . . . . . . . . 194

4.69. Patrón de diseño del modelo de organización de una Coalición. 195

4.70. Patrón de diseño del modelo de organización de la congregación 196

4.71. Modelo de interacción de la congregación. . . . . . . . . . . 196

5.1. Variables de diseño de las organizaciones propuestas por Mintzberg. . . . . . . . . . . . . . . 206

5.2. Dimensiones básicas de la organización propuestas por Galbraith. . . . . . . . . . . . . . . 207 
5.3. Fase de ajuste a las circunstancias condicionantes de la empresa y los requisitos de la estrategia. . . . . . . . . . . 208

5.4. Fase de aplicación del diseño. . . . . . . . . . . . . . . . . . 209

5.5. Elementos de definición de procesos de SPEM . . . . . . . . 213

5.6. Proceso de Desarrollo extendido del Sistema Multiagente . . 214

5.7. Integración de las fases de la secuencia-guía en el proceso de desarrollo del MAS. . . . . . . . . . . . . . . . . . 215

5.8. Fase de Análisis de la misión de la organización. . . . . . . . 216

5.9. Composición del producto de trabajo Misión. . . . . . . . . 217

5.10. Definición de la tarea Definir la misión. . . . . . . . . . . . . 219

5.11. Definición de la tarea Definir el Contexto. . . . . . . . . . . 221

5.12. Diagrama de vista funcional (misión) del modelo de organización para el sistema de información. . . . . . . . . . . 228

5.13. Fase de Análisis de tareas y procesos. . . . . . . . . . . . . . 233

5.14. Documentos que componen el producto de trabajo Tecnología.234

5.15. Definición del trabajo Analizar la tecnología. . . . . . . . . . 236

5.16. Definición de la tarea Analizar los objetivos de la organización.246

5.17. Diagrama de la vista estructural del modelo de organizacion del sistema de información. . . . . . . . . . . . . . . . . 249

5.18. Diagrama de la vista funcional del modelo de organización del sistema de información. . . . . . . . . . . . . . . . 250

5.19. Diagrama del modelo de actividad para el servicio Proporcionar Información. . . . . . . . . . . . . . . . . . . . . 251

5.20. Diagrama del modelo de actividad para el servicio Proporcionar Información. Descripción detallada de la relación existente entre las A-Tareas que lo componen. . . . . . . . . . . 253

5.21. Diagrama del modelo de entorno. . . . . . . . . . . . . . . 254

5.22. Diagrama del modelo de actividad. Relación entre servicios y objetivos funcionales. . . . . . . . . . . . . . . . 255

5.23. Fase Análisis de las dimensiones organizativas . . . . . . . . 259

5.24. Definición de la tarea Asignar Tareas . . . . . . . . . . . . 260

5.25. Definición de la tarea Identificar Restricciones . . . . . . . . 268 
5.26. Fase Análisis de la estructura organizativa . . . . . . . . . 275

5.27. Arbol de decisión de la estructura organizativa . . . . . . . . 276

5.28. Diagrama actualizado del modelo de organización del sistema de información. Utiliza la estructura de congregación. . . . . 283

5.29. Fase Diseño de los procesos de información y decisión . . . . 285

5.30. Definición de la tarea Análisis de los procesos de decisión. . . 286

5.31. Definición de la tarea Análisis de los procesos de información. 289

5.32. Diagrama actualizado del modelo de organización (funcionalidad externa) para la unidad organizativa que representa al sistema de información. . . . . . . . . . . . . . . . . 293

5.33. Diagrama actualizado del modelo de organización (funcionalidad externa) para la UO Temática. . . . . . . . . . . 294

5.34. Diagrama del modelo de actividad del servicio RegistrarUnidad.295

5.35. Diagrama del modelo de actividad del servicio RegistrarUnidad. Descripción de su flujo de tareas. . . . . . . . . . . 296

5.36. Diagrama del modelo de actividad. Descomposición de los objetivos funcionales en objetivos operativos. . . . . . . . 297

5.37. Diagrama actualizado del modelo de entorno del sistema de información. Acceso al recurso Base de Datos. . . . . . . . . 298

5.38. Diagrama del modelo de interacción para el servicio Proporcionar Información. . . . . . . . . . . . . . . . . . . . . . 298

5.39. Diagrama de colaboración que especifica la interacción Proporcionar Información. . . . . . . . . . . . . . . . . . . . . . 299

5.40. Fase Dinamicidad del Sistema Abierto. . . . . . . . . . . . . 303

5.41. Diagrama del modelo de organización para la unidad organizativa Temática. Asociación de agentes a roles. . . . . . . . . 308

5.42. Diagrama del modelo de organización para la unidad organizativa Sistema de Información. Asociación de agentes a roles. 309

5.43. Diagrama del modelo de actividad para el servicio AdquirirRol.309

5.44. Diagrama del modelo de actividad para el servicio AdquirirRol. Descripción de su flujo de tareas al solicitar el rol evaluador en una UO Temática. . . . . . . . . . . . . . 310 
5.45. Diagrama del modelo de agente para el AgentePersonal. . . . 311

5.46. Fase Sistemas de Medición, Evaluación y Control. . . . . . . 314

5.47. Fase Diseño de los Sistemas de Recompensas. . . . . . . . . 322

6.1. Diagrama del modelo de organización (vista funcional). Misión del sistema de agencia de viajes. . . . . . . . . . . 335

6.2. Diagrama del modelo de organización (vista estructural) para el sistema de agencia de viajes. . . . . . . . . . . . 338

6.3. Diagrama del modelo de organización (vista funcional, funcionalidad interna) para el sistema de agencia de viajes. . . . 339

6.4. Diagrama del modelo de organización (vista funcional, funcionalidad externa). . . . . . . . . . . . . . . 340

6.5. Diagrama del modelo de actividad del servicio Buscar Viaje. 341

6.6. Diagrama del modelo de actividad del servicio Buscar Viaje. Descripción detallada de la relación existente entre las ATareas que lo componen. . . . . . . . . . . . . . . . . . 341

6.7. Diagrama del modelo de entorno del sistema agencia de viajes. 342

6.8. Diagrama actualizado de la vista estructural del modelo de organización. Relaciones entre la unidad organizativa Agencia Viajes y las entidades que contiene. . . . . . . . . . . . . 344

6.9. Diagrama del modelo de actividad. Relación entre servicios y objetivos funcionales. . . . . . . . . . . . . . . . 345

6.10. Diagrama actualizado de la vista estructural del modelo de organización. Agrupación funcional. . . . . . . . . . . . 346

6.11. Diagrama actualizado de la vista funcional (funcionalidad externa) del modelo de organización. Agrupación funcional. . 347

6.12. Diagrama de la vista estructural del modelo de organización al optar por una agrupación divisional. . . . . . . . . . 348

6.13. Diagrama actualizado de la vista estructural del modelo de organización al adoptar una estructura de tipo federación. . 351

6.14. Diagrama actualizado del modelo de actividad (asociación de objetivos) al adoptar una estructura de tipo federación. . . . 352 
6.15. Diagrama actualizado de la vista estructural del modelo de organización al optar por una agrupación divisional. . . . . . 354

6.16. Diagrama actualizado de la vista funcional (funcionalidad externa) del modelo de organización al optar por una agrupación divisional. . . . . . . . . . . . . . . . . 355

6.17. Diagrama actualizado de la vista estructural del modelo de organización al adoptar una estructura de tipo congregación. 355

6.18. Diagrama actualizado de la vista funcional (funcionalidad externa) del modelo de organización al adoptar una estructura de tipo congregación. . . . . . . . . . . . . . . . . 357

6.19. Diagrama actualizado de la vista estructural del modelo de organización para la unidad organizativa Agencia Viajes. . . 358

6.20. Diagrama actualizado de la vista funcional (funcionalidad externa) del modelo de organización para la unidad Agencia Viajes. . . . . . . . . . . . . . . . . . . 359

6.21. Diagrama actualizado de la vista funcional (funcionalidad externa) del modelo de organización para la unidad organizativa Hoteles. . . . . . . . . . . . . . . . . . . . . . . . . . . 360

6.22. Diagrama del modelo de actividad del servicio Buscar Hotel. 361

6.23. Diagrama del modelo de actividad del servicio Buscar Hotel. Descripción del flujo de tareas en el que se descompone. . . . 361

6.24. Diagrama actualizado del modelo de actividad. Relaciones entre servicios y objetivos funcionales de la unidad Hoteles. . 362

6.25. Diagrama actualizado del modelo de actividad. Descomposición de objetivos funcionales en objetivos operativos de la unidad Hoteles. . . . . . . . . . . . . . . . . . . . . . 363

6.26. Diagrama actualizado del modelo de actividad. Asociación de objetivos operativos a A-Tareas para el servicio Buscar Hotel. 364

6.27. Diagrama actualizado del modelo de entorno de la organización AgenciaViajes. Acceso a los puertos del entorno. . . . . 364

6.28. Diagrama del modelo de interacción para el servicio Buscar Hotel. . . . . . . . . . . . . . . . . . 365 
6.29. Diagrama de colaboración de la interacción Búsqueda Hotel.

6.30. Diagrama de la vista social del modelo de organización para el sistema de agencia de viajes. . . . . . . . . . . 366

6.31. Diagrama del modelo de interaccion para las interacciones generadas por la relación AGOInformación entre los roles GestorUnidad. . . . . . . . . . . . . . . . 366

6.32. Diagrama del modelo de entorno para la publicitación de los servicios de AgenciaViajes. . . . . . . . . . . . . . . . . 367

6.33. Diagrama del modelo de entorno para la publicitación de los servicios de la unidad Hoteles. . . . . . . . . . . . . . . 368

6.34. Diagrama actualizado del modelo de organización, en el que se muestran los agentes internos, externos y los roles que juegan. . . . . . . . . . . . . . . . . . . . . . . 369

6.35. Diagrama del modelo de actividad para el servicio AdquirirRol.370

6.36. Diagrama del modelo de actividad para el servicio AdquirirRol. Descripción de su flujo de tareas al solicitarse el rol ProveedorHoteles en la unidad Hoteles. . . . . . . . . . . . . 370

6.37. Diagrama del modelo de agente para el AgenteCH, que representa a una cadena hotelera. . . . . . . . . . . . . . 372 



\section{Resumen}

Las organizaciones resultan ser un medio efectivo para la coordinación de las actividades, no sólo de los humanos sino también de los agentes. Precisamente, en los últimos años el concepto de organización ha adquirido gran relevancia en el área de los sistemas multiagente, al facilitar el análisis y diseño de mecanismos de coordinación y colaboración en sistemas abiertos.

Dado que la Teoría de Organización aborda las propiedades de las organizaciones humanas y sus aspectos de diseño, en esta tesis se revisa dicha Teoría para así adoptar de ella ciertos mecanismos y guías que faciliten el diseño de sistemas multiagente complejos basados en organizaciones.

Para ello, se han analizado cuáles son los factores principales que determinan las características de las organizaciones y su estructura y que deben ser tenidos cuenta en el diseño de la organización del sistema. Asimismo, se ha realizado un estudio del estado del arte sobre el enfoque dado al concepto de organización, tanto en las principales metodologías de sistemas multiagente como en las plataformas de agente. De este modo, se han determinado sus carencias y necesidades con respecto a la gestión y manejo de las organizaciones.

En base a estos estudios, se ha propuesto un Modelo de Organización que permite describir los principales aspectos de las organizaciones: estructura, funcionalidad, normalización, dinamicidad y entorno. Este modelo constituye la primera aportación de esta tesis. Consta de un conjunto de meta-modelos que extienden las propuestas de INGENIAS y ANEMONA, empleando fundamentalmente los conceptos de unidad organizativa, servicio, norma y entorno. Además se ha elaborado un conjunto de patrones de 
diseño, con los que facilitar el modelado de la estructura de la organización.

El Modelo de Organización sirve de apoyo, junto al análisis de la Teoría de Organización, para la adaptación del proceso de diseño de las organizaciones al área de los sistemas multiagente. De esta forma, como segunda y principal aportación de esta tesis, se ha definido una Guía Metodológica que permite el análisis y diseño de sistemas multiagente abiertos, desde la perspectiva de las organizaciones. La Guía Metodológica consta de un conjunto de fases que cubren el análisis de requisitos, el diseño de la estructura organizativa y el diseño de la dinámica de la organización. Con estas fases se especifica, principalmente, cuáles son los servicios que ofrece la organización, cuál es su estuctura interna y qué normas rigen su comportamiento.

Finalmente, la Guía Metodológica y el Modelo de Organización se han aplicado en dos casos de estudio (un sistema de agencia de viajes y un sistema de información personalizada), permitiendo así su validación en distintos dominios de sistemas abiertos. En el primer caso, el sistema actúa como un punto de encuentro regulado, donde los proveedores y clientes contactan entre sí para consumir y/o producir servicios turísticos. En el segundo caso, el sistema controla las diferentes agrupaciones que realicen los usuarios del sistema, así como su actuación como evaluadores o suministradores de información. 


\section{Abstract}

Organizations represent an effective mechanism for activity coordination, not only for humans but also for agents. Nowadays, the organization concept has become a relevant issue in the multi-agent system area, as it enables analysing and designing coordination and collaboration mechanisms in an easier way, specially for open systems.

Organization Theory has largely tackled with human organizations and their designing features. Thus, this thesis deeply takes into account the Organization Theory approach in order to adopt some specific mechanisms and guidelines that help with designing complex multi-agent systems based on organizations.

In this way, the main features of an organization that are needed for its effective design have been analyzed. Moreover, a state of art study of how the organization concept has been employed in both multi-agent system methodologies and agent platforms has been carried out. Thus, their necessities for an appropiate management of organizations have been extracted.

Based on all those studies, an Organizational Model has been defined, which constitutes the first main contribution of this thesis. This model is composed of six meta-models that detail the specific features of an organization: structure, functionality, normativity, dynamicity and environment. Those meta-models, which are extensions of both INGENIAS and ANEMONA ones, are mainly based in the following concepts: organizational unit, service, norm and environment. Furthermore, a set of design patterns has been developed that contributes to an easier modeling of the organizational structure. 
The Organizational Model, combined with the Organization Theory, has been employed for adapting the organizational design process to the multi-agent system domain. In this way, as second main contribution of this thesis, a Methodological Guideline has been developed, which gives support for the analysis and design of open multi-agent systems, following a human organizational point of view. This guideline is composed of a set of phases for requirement analysis, structure design and organizational dynamics design. In these phases, designers mainly specify which are the services that the system offers, which is its internal structure and which are the norms that control its behavior, taking into account the specific features of open multiagent systems.

Finally, both the Methodological Guideline and the Organizational Model have been applied in two case-studies (a travel agency system and a personalized information system), so then they have been validated in different open systems. In the first case, the system acts as a regulated meetingpoint, in which providers and clients contact between them for consuming or producing touristic services. In the second case, the system controls the different groups that users create and also their behavior as information providers or reviewers. 


\section{Resum}

Les organitzacions són un mitjà efectiu per a la coordinació de les activitats, no solament per als humans, sinó també per als agents. Precisament, en els últims anys, el concepte d'organització ha adquirit gran importància en l'àrea dels sistemes multiagent, al facilitar l'anàlisi i el disseny de mecanismes de coordinació i col-laboració en sistemes oberts.

La Teoria de l'Organització ha tractat exhaustivament les propietats de les organitzacions humanes i els seus aspectes de disseny. Per aquest motiu, en esta tesi s'analitza eixa Teoria amb la finalitat d'adaptar determinats mecanismes i guies que faciliten el disseny de sistemes multiagent complexos basats en organitzacions.

Per això, s'han analitzat quins són els factors principals que determinen les característiques de les organitzacions i la seua estructura, obtenint així els aspectes primordials que s'han de tindre en compte per al disseny de l'organització del sistema. Així mateix, s'ha realitzat un estudi de l'estat de l'art en quant al tractament que s'ha donat al concepte d'organització per les principals metodologies de sistemes multiagent, així com per les plataformes d'agent. A més, s'ha determinat quines són les seues carències i necessitats respecte a la gestió de les organitzacions.

Amb aquestos estudis s'ha proposat un Model d'Organització que constitueix la primera principal aportació d'aquesta tesi. Aquest model consta de sis meta-models que descriuen els factors específics de les organitzacions: estructura, funcionalitat, normativitat, dinamisme i entorn. Els esmentats meta-models, extensions dels d'INGENIAS i ANEMONA, es basen principalment en els conceptes d'unitat organitzativa, servici, norma i entorn. 
També s'ha elaborat un conjunt de patrons de disseny amb els quals es facilita el procés de modelatge de l'estructura organitzativa.

El Model d'Organització i l'estudi del disseny de les organitzacions humanes serveixen de suport per a l'adaptació del seu procés de disseny a l'àrea dels sistemes multiagent. D'aquesta manera, s'ha definit una Guia Metodològica, segona principal aportació d'aquesta tesi, que permet l'anàlisi i el disseny de sistemes multiagent oberts, des de la perspectiva de les organitzacions humanes. La Guia Metodològica consta d'un conjunt de fases per a l'anàlisi de requisits, el disseny de l'estructura organitzativa i el disseny de la dinàmica de l'organització. Amb aquestes fases s'especifica, principalment, quins són els servicis que l'organització ofereix, quina és la seua estructura interna i quines són les normes que controlen el seu comportament.

Finalment, la Guia Metodològica i el Model d'Organització s'han aplicat a dos casos d'estudi (un sistema d'agència de viatges i un sistema d'informació personalitzada), de manera que han sigut validats en distints dominis de sistemes oberts. En el primer cas, el sistema actua com a punt d'encontre regulat, on els proveedors i els clients contacten per a consumir i/o produir servicis turístics. En el segon cas, el sistema controla les diferents agrupacions que els usuaris poden realitzar, així com les seues actuacions com a avaluadors o bé subministradors d'informació. 


\section{Agradecimientos}

A mi primer director de tesis, D. Vicente Botti Navarro, gracias al cual debo toda mi labor como investigadora y docente. Quiero agradecerle el interés y confianza que ha mostrado siempre por mi persona, así como su constante apoyo y orientación en mi trabajo.

A mi segundo director de tesis, D. Vicente Julián Inglada, que ha revisado con paciencia y dedicación cada una de mis aportaciones e ideas y que ha sabido aconsejarme y orientarme en todo momento.

A mi familia, que ha vivido junto a mí el largo proceso que ha supuesto la elaboración de este trabajo y me ha animado mucho en aquellos momentos que más lo necesitaba. Y en especial a mi marido, Quique, por su inmenso apoyo en las etapas más difíciles que surgen en el arduo proceso investigador. Siempre ha sabido tener la paciencia suficiente para escucharme, comprenderme y compaginar nuestro tiempo juntos.

Y finalmente, a mis compañeros del grupo de investigación GTI-IA, con los que se agradece mucho trabajar y compartir el día a día, pues siempre están ahí para ayudarte, aconsejarte y, por supuesto, para disfrutar contigo de la buena compañía. En especial, quiero agradecer a Adriana por aclararme todas mis dudas sobre ANEMONA. También a Sole, por todos los congresos y buenos momentos que hemos vivido, así como nuestros eternos esfuerzos con el trabajo de los químicos. 



\section{Capítulo 1}

\section{Introducción}

El avance tecnológico de los últimos años y la utilización masiva de Internet, de redes inalámbricas, comercio electrónico, etc. ha propiciado el desarrollo de nuevas propuestas de computación basadas en la interacción o comunicación entre las entidades, enmarcadas en un nuevo paradigma de computación: la computación como interacción [Luck et al., 2005]. Así, la computación ocurre mediante y a través de la comunicación entre entidades computacionales, pasando a ser una actividad inherentemente social. Por ejemplo, en las arquitecturas orientadas a servicios, las funcionalidades a ofrecer se conciben como servicios que pueden ser publicitados, localizados, solicitados e incluso combinados entre sí por las distintas entidades del sistema.

Satisfacer los requisitos de este nuevo paradigma exige que la tecnología utilizada cuente con características de interacción entre entidades independientes y de alguna manera inteligentes, que se adaptan, coordinan y organizan entre ellas. Por su parte, la tecnología de sistemas multiagente resulta especialmente prometedora como soporte a este paradigma, pues precisamente una de las características principales de los agentes consiste en la sociabilidad, es decir, en su capacidad para comunicarse con otros agentes, a través del uso de ontologías, lenguajes y protocolos de interacción comunes.

Los sistemas multiagente (Multiagent Systems, MAS) son una tecnología 
software que se centra principalmente en aspectos de autonomía, cooperación, formación de grupos, etc. Para el diseño y desarrollo de MAS se necesita de metodologías que den soporte a los diseñadores de una manera robusta y fiable. La mayoría de las metodologías diseñadas para MAS son extensiones de metodologías ya existentes en otros campos [Iglesias et al., 1999], como la ingeniería del conocimiento o la orientación a objetos, a las que se les han adaptado ciertos aspectos concretos del mundo de los agentes. Otras metodologías se centran en sistemas de agente y arquitecturas específicas [Bussmann, 1998], por lo que les falta generalidad.

Las propuestas más actuales definen metodologías específicamente pensadas para el análisis y diseño de MAS. Muchas de ellas detallan la estructura del sistema multiagente en términos de un modelo de roles. En este modelo se identifican los roles que los agentes juegan en el sistema, así como los protocolos de interacción en los que participan los roles. La utilización de este modelo de roles supone la concepción de un MAS en el que los agentes son cooperativos y están claramente definidas sus tareas y habilidades. Se tratan, pues, de sistemas cerrados, en los que no se permite la participación de agentes con comportamientos interesados, egoístas o bien no autorizados.

Estas metodologías se tipifican como orientadas al agente, pues asumen una perspectiva individualista, cuya entidad principal es el agente, el cual persigue sus propios objetivos individuales basándose en sus propias creencias y habilidades. Además, las estructuras sociales no se modelan de forma específica, sino que se supone que emergen como resultado de la interacción de los agentes.

En los últimos años, los investigadores han llevado a cabo diversos estudios para ofrecer procedimientos y metodologías que permitan diseñar MAS abiertos, en los que los agentes con comportamientos auto-interesados o egoístas puedan operar. Un sistema abierto es aquel que permite la entrada y salida dinámica de sus entidades. Los MAS abiertos deberían permitir también la participación de agentes heterogéneos, con arquitecturas e incluso lenguajes distintos [Zambonelli et al., 2003]. Por tanto, no se puede 
confiar en el comportamiento de los agentes, siendo necesario establecer controles en base a normas o reglas sociales. Para ello, los desarrolladores se han centrado en los aspectos organizativos de la sociedad de agentes, guiando el proceso de desarrollo del sistema mediante los conceptos de organización, normas, roles, etc.

Esto ha dado lugar a un nuevo enfoque denominado metodologías orientadas a la organización, con ejemplos como Agent-Group-Role [Ferber et al., 2003], Tropos [Castro et al., 2001], MOISE ${ }^{\text {Inst }}$ [Gateau et al., 2005], OMNI [Vazquez-Salceda et al., 2004], E-Institutions [Esteva et al., 2001b]. No obstante, la mayoría de estos métodos no son completos, limitándose principalmente al análisis de requisitos, al diseño de los grupos, roles y, en algunos casos, a las normas que regulan el comportamiento. Además, las abstracciones y herramientas disponibles todavía son insuficientes para muchos tipos de sistemas multiagente abiertos que atacan problemas del mundo real.

El concepto de organización, como vemos, se ha empleado recientemente para modelar la coordinación de los agentes en los sistemas abiertos y asegurar el orden social en las aplicaciones de estos sistemas [Dignum y Dignum, 2006]. Dicho concepto no es algo exclusivo de los sistemas multiagente, sino más bien se fundamenta en las organizaciones humanas, que han permitido establecer, a lo largo de los siglos, las bases y mecanismos necesarios para la coordinación y distribución de las tareas.

La denominada Teoría de la Organización [Daft, 1998] [Fox, 1981] se encarga del estudio y análisis de las organizaciones humanas. Esta teoría determina cuáles son los conceptos básicos, relaciones y características intrínsecas de cada tipo de organización existente. Las organizaciones humanas resultan muy eficientes para la gestión de la coordinación de sus miembros y la consecución de sus objetivos. Muchos de sus mecanismos de coordinación se han empleado también en distintas aplicaciones de sistemas multiagente [Horling y Lesser, 2004], pero éstas se desarrollaron generalmente siguiendo una metodología orientada al agente y, por tanto, sin una correlación clara con los sistemas humanos ni con el comportamiento global esperado en el 
sistema. Por tanto, todavía no existe una metodología de desarrollo de sistemas multiagente que proporcione una correspondencia directa entre las estructuras organizativas a nivel de sistemas humanos y su aplicabilidad a nivel de agente, ni que permita una especificación completa de la estructura social del sistema.

\subsection{Motivación}

El trabajo presentado en esta tesis se enmarca dentro del proyecto THOMAS (MeTHods, Techniques and Tools for Open Multi-Agent Systems), cuyo objetivo principal consiste en la investigación y desarrollo de la tecnología basada en agentes/sistemas multiagente necesaria para el desarrollo de organizaciones virtuales en entornos abiertos (sistemas abiertos de servicios basados en agentes). Dicha tecnología incluye la necesidad de una metodología para el análisis y diseño de este tipo de sistemas, la implementación de una plataforma multi-dispositivo de soporte adecuada, así como la inclusión de los servicios e infraestructura necesarios para una gestión inteligente de este tipo de organizaciones.

En concreto, la propuesta de THOMAS, entre otras cosas, persigue definir tanto un modelo de organización, que permita expresar a alto nivel cómo será la descripción estructural, funcional y social de una organización, como un método específico para el desarrollo de sistemas multiagente abiertos, orientado al concepto de organización, que integrará los principios de ingeniería del software apropiados para la gestión de la complejidad del sistema y del proceso de desarrollo asociado. Dicho método deberá cubrir de manera completa el ciclo de vida de un sistema abierto, permitiendo la gestión adecuada de sistemas complejos y de gran escala; y dando soporte específico a los posibles requisitos de este tipo de sistemas. Además, se desarrollarán mecanismos basados en estructuras organizativas y organizaciones virtuales para optimizar y regular la coordinación de servicios en sistemas multiagente abiertos.

En el trabajo de esta tesis nos centraremos en el desarrollo de modelos y 
métodos que ayuden en el análisis y diseño de sistemas multiagente abiertos, tomando como partida los fundamentos de las organizaciones humanas. Así, se trabajará con la hipótesis que la Teoría de la Organización nos va a proporcionar determinadas guías para facilitarnos el diseño de organizaciones de agentes.

\subsection{Objetivos}

El objetivo principal de este trabajo consiste en el establecimiento de modelos, procesos y guías metodológicas que permitan la construcción de sistemas multiagente abiertos, aplicando la Teoría de la Organización en el análisis y diseño de sistemas multiagente.

Para ello, se realizará un estudio del arte de las metodologías MAS existentes, que permita comprender cómo dichas propuestas abordan el diseño e implementación de sistemas multiagente, considerando el tipo de sistemas (abiertos o cerrados) a los que se pueden aplicar. De las metodologías orientadas a sistemas abiertos, se estudiarán con detalle sus características, virtudes y carencias. Tras dicho estudio se propondrán nuevos métodos, guías y procedimientos para el diseño de sistemas multiagente, utilizando conceptos organizativos extraídos de la Teoría de la Organización. Además, se hará énfasis en el diseño de los sistemas abiertos, permitiendo el acceso y control, dentro del sistema, de agentes con comportamientos interesados. Asimismo, se definirá un modelo de organización que integre todos los conceptos organizativos relevantes y permita la descripción de los aspectos estructurales, funcionales, sociales y normativos del sistema.

A un nivel más detallado, los objetivos en los que se desglosa el objetivo principal de la presente investigación son los siguientes:

- Estudio de las características necesarias para modelar organizaciones. Se identificarán qué características o cualidades son inherentes a las organizaciones desde un punto de vista genérico, tanto para las organizaciones humanas como para las de agente. En concreto: 
- Analizar las características de las organizaciones humanas y adaptar técnicas y procedimientos de la Teoría de la Organización (que estudia estas organizaciones) a los sistemas multiagente.

- Analizar las estructuras organizativas de ejemplos de aplicaciones multiagente existentes, a fin de caracterizar y aprovechar ciertas de sus características.

- Análisis de metodologías y métodos relacionados existentes. Se realizará un análisis de las metodologías y métodos de sistemas multiagente existentes, especialmente de aquellos que se orientan o basan de algún modo en el concepto de organización. Se estudiará su grado de adecuación a las características identificadas previamente. En su caso, se planteará la posible adaptación de propuestas existentes, el estudio de las carencias detectadas o bien el planteamiento de posibles alternativas.

- Definición de meta-modelos que permitan cubrir todos los aspectos identificados anteriormente, para el análisis y diseño de organizaciones en sistemas abiertos. Se definirá a partir de ellos la notación de modelado asociada, así como el desarrollo de ontologías que describan estructuras organizativas de diferentes niveles de abstracción.

- Adaptación de los métodos y desarrollo de guías metodológicas para el desarrollo de MAS basadas en las organizaciones. Se analizarán las guías existentes en el diseño de organizaciones humanas y se adaptarán dichas guías para los sistemas multiagente. Además, se incorporarán esas guías metodológicas en el ciclo de vida y proceso de desarrollo de software.

- Validación de la propuesta de modelado y de las guías metodológicas mediante el desarrollo de ejemplos. 


\subsection{Estructura del trabajo}

En este punto se presenta la estructuración en capítulos de esta investigación. Aparte de este primer capítulo de introducción, el resto de capítulos se organiza de la siguiente manera:

Capítulo 2. Se analizan cuáles son las características generales de las organizaciones, de acuerdo a la siguiente estructura:

- En primer lugar se comparan los conceptos de organizaciones humanas con los de las organizaciones de agentes existentes, para así ver cuáles son sus similitudes y diferencias.

- Posteriormente, se extraen los factores o conceptos clave a tener en cuenta a la hora de diseñar organizaciones.

- Finalmente, se definen las características particulares de los sistemas abiertos, con el objetivo de ver cómo diseñarse o implementarse como organizaciones de agentes.

Capítulo 3. Se analizan los trabajos y métodos existentes sobre el diseño de MAS, especialmente enfocados a las organizaciones de agentes. En concreto:

- En primer lugar se comparan las metodologías orientadas al agente más relevantes, detallando las carencias que presentan para modelar organizaciones de agentes y sistemas abiertos.

- A continuación se comparan las metodologías orientadas a la organización, analizando su grado de adecuación a las características de las organizaciones y de los sistemas abiertos contempladas en el capítulo anterior.

- Finalmente, se definen qué componentes les faltaría por abordar a estos trabajos y en qué podemos contribuir con esta tesis. 
Capítulo 4. Se define un modelo de organización, en base a las características identificadas en los capítulos anteriores y centrada en tres componentes: unidad organizativa, servicios y normas. En concreto:

- En primer lugar, se describen las características de estos tres componentes, así como su relación con conceptos similares de otras propuestas.

- Posteriormente, se extienden los meta-modelos de las metodologías de INGENIAS y ANEMONA para dar cabida a los conceptos e ideas propuestos.

- Finalmente, se aplican dichos meta-modelos en la definición de modelos de estructuras organizativas existentes.

Capítulo 5. Se define una guía metodológica de diseño de sistemas multiagente abiertos, basada en el diseño de organizaciones de agentes. Para ello:

- Inicialmente se revisan las guías de diseño de organizaciones humanas más relevantes, describiendo las fases que comprenden la guía concreta que se ha tomado como base.

- A continuación se detalla la guía metodológica propuesta, integrada en un proceso de análisis y diseño de sistemas multiagente.

- Para cada fase de la guía metodológica se explican las actividades que comprenden, sus productos de trabajo así la como las guías o plantillas que se han elaborado para facilitar la tarea del desarrollador de MAS. Se incluyen también ejemplos de aplicación de cada fase a un caso de estudio concreto.

Capítulo 6. Se aplica la guía metodológica a un caso real de sistema multiagente abierto para así evaluar la validez de la propuesta. 
En concreto, se analiza y diseña un sistema de gestión de viajes, donde distintas entidades (Demandantes) requieren uno o varios servicios de otras entidades (Oferentes). Estos oferentes representan a cadenas hoteleras, compañías aéreas, etc., que ofrecen información sobre hoteles, vuelos, así como la posibilidad de realizar reservas e incluso el pago adelantado de las mismas.

La descripción de los servicios a ofrecer por estas entidades está controlada por el sistema, a través de sus normas; aunque la funcionalidad interna de dichos servicios será responsabilidad de los agentes que los ofrezcan.

Capítulo 7. Se muestran las conclusiones de esta tesis, los trabajos futuros y líneas de investigación abiertas, así como la relación de publicaciones resultantes del trabajo realizado. 



\section{Capítulo 2}

\section{Organizaciones}

En este capítulo se analizan las características principales de las organizaciones con el propósito de utilizarlas para el análisis y diseño de sistemas multiagente abiertos. Para ello se revisan cuáles son los factores o dimensiones necesarios para su modelado, realizando también una comparativa entre las organizaciones humanas y las de los sistemas multiagente.

\subsection{Introducción}

Tal y como se ha comentado en el capítulo anterior, el objetivo de esta tesis consiste en adaptar las técnicas y métodos del diseño de organizaciones humanas al diseño de organizaciones de agentes, de modo que se facilite el desarrollo de MAS abiertos. Para ello deberemos comprender en primer lugar cuáles son las características principales de las organizaciones y qué factores o dimensiones son necesarios para su análisis y modelado.

Por tanto, en este capítulo realizamos un análisis de las organizaciones humanas y las organizaciones de agentes existentes, estableciendo sus semejanzas y diferencias. Extraeremos también cuáles son los factores principales que afectan y definen a las organizaciones y qué aspectos se han tenido en cuenta en el modelado de las organizaciones humanas.

Por otro lado, revisaremos las características de los sistemas multiagente abiertos, para así establecer cómo las organizaciones de agentes facilitan 
la tarea de implementar y regular dichos sistemas. La principal complejidad de este tipo de sistemas reside en que se permite la incorporación de agentes heterogéneos durante la ejecución del sistema, los cuales posiblemente presenten comportamientos interesados y no conformes a las normas establecidas.

Por último, se extraerán las ventajas que nos ofrecen las organizaciones para el diseño de los sistemas multiagentes, en especial para los MAS abiertos.

El presente capítulo se estructura de la siguiente manera. En la sección 2.2 se comparan entre sí las definiciones y características generales de las organizaciones humanas y las organizaciones de agentes. En la sección 2.3 se detallan los factores que describen y/o afectan a la organización. Posteriormente, en la sección 2.4 se comparan distintos tipos de organizaciones humanas con aquellas más relevantes de las organizaciones de agentes, indicando ejemplos de sistemas en los que se han empleado. En la sección 2.5 se muestran las características principales de los sistemas abiertos, sobre los cuales convendrá aplicar el modelado de organizaciones de agentes. Finalmente, en la sección 2.6 se indican las conclusiones de este capítulo.

\subsection{Concepto de Organización}

Para comprender mejor cómo modelar organizaciones en los sistemas multiagente, deberemos partir de los conceptos propios de las organizaciones humanas, ya que existen muchos estudios sobre diseño de este tipo de organizaciones. Así, en esta sección incluimos en primer lugar distintas definiciones de organización y una síntesis de sus características más relevantes. En segundo lugar, se muestran diversos usos y adaptaciones del término organización en el área de los sistemas multiagentes, finalizando esta sección con un resumen de las características propias de las organizaciones de agentes. 


\subsubsection{Organizaciones humanas}

La organización, según el diccionario de la Real Academia de la Lengua Española, se define como una "asociación de personas regulada por un conjunto de normas en función de determinados fines".

J.M. Peiro define a la organización como "una formación o entidad social con un número de miembros que puede ser precisado y una diferenciación interna de las funciones que son desempeñadas por dichos miembros" [Peiro, 1991].

Según I. Guzmán, "la organización es la coordinación de las actividades de todos los individuos que integran una empresa con el propósito de obtener el máximo aprovechamiento posible de elementos materiales, técnicos y humanos, en la realización de los fines que la propia empresa persigue" [Guzmán, 1983].

Otra definición similar es la que propone J. Massie, donde la organización se ve como "un grupo cooperativo de seres humanos que asigna las tareas entre los miembros, identifica las relaciones e integra sus actividades hacia objetivos comunes, de manera estructurada" [Massie, 1973].

Por tanto, una organización consiste en una serie de individuos que realizan unas actividades o funciones específicas y diferenciadas. Además, estos individuos se estructuran siguiendo unas pautas y reglas determinadas que les permitan alcanzar los fines u objetivos de la organización. Los fines deben ser objetos de conocimiento común, que cumplan principalmente las funciones de guiar los esfuerzos de los miembros en vistas a su consecución [Peiro, 1991]. Asimismo, deben proporcionar una fuente de legitimidad que determine las conductas y acciones adecuadas en el contexto de la organización y establezcan los niveles mínimos o estándares que han de conseguirse.

De forma esquemática, la organización humana se caracteriza por [Hodge et al., 2003]:

- Está compuesta por personas.

- Persigue unos fines determinados, que guían las actividades de sus miembros, a través de mecanismos de coordinación y control de la 
acción.

- Existe una subdivisión del trabajo entre los individuos, mediante la especialización y la división de las tareas.

- Precisa de una estructura formal, con unos roles definidos (independientes de la persona que realice dicho rol); unas responsabilidades asociadas a esos roles; y ciertas relaciones preestablecidas entre los miembros de la organización.

- Todas las actividades establecidas deben relacionarse con los objetivos globales de la organización, pues la existencia de un rol determinado sólo es justificable si sirve para alcanzar realmente esos objetivos.

- Posee unos límites definidos, que establecen quiénes son los miembros de la organización (bien por la especificación directa de cada miembro; o bien por el lugar donde se realiza la actividad).

\subsubsection{Organizaciones de agentes}

En el área de los sistemas multiagentes, el término organización se ha empleado fundamentalmente para describir a un conjunto de agentes que, mediante unos roles y patrones de interacción establecidos, se coordinan entre sí, tratando de alcanzar los objetivos globales del sistema. A continuación se muestran distintas definiciones y consideraciones del término organización por diversos autores expertos en la materia.

Según L. Gasser, las organizaciones son sistemas estructurados con patrones de actividad, conocimiento, cultura, historia y habilidades distintas de cualquier agente particular. Las organizaciones existen a un nivel completamente independiente de los agentes individuales que los constituyan, los cuales pueden ser reemplazables. Además, ocupan alguna región del espacio, bien sea geográfico, temporal, simbólico, etc. [Gasser, 2001]. Por tanto, una organización de agentes proporciona un marco de trabajo para la actividad e interacción de los agentes a través de la definición de roles, expectativas de comportamiento y relaciones de autoridad, como el control. 
F. Zambonelli adopta también la visión de la organización de agentes como una colección de roles, que mantienen ciertas relaciones entre sí y que toman parte en patrones de interacción con otros roles de forma institucionalizada y sistemática [Zambonelli et al., 2003].

Por su parte, J. Ferber indica que la organización proporciona una forma para dividir el sistema, separándolo en grupos o unidades que constituyen el contexto de interacción de los agentes [Ferber et al., 2003]. Además, la organización se basa en dos aspectos: estructural y dinámico.

La estructura de la organización representa todo aquello que persiste cuando los componentes e individuos entran o salen de la organización, es decir, el conjunto de relaciones que permiten ver un agregado de elementos como un todo. La estructura define cómo los agentes se agrupan en unidades organizativas y cómo dichas unidades se relacionan unas con otras. También define los roles necesarios para desarrollar las actividades propias de la organización, así como sus relaciones y restricciones.

La dinámica organizativa se centra en los patrones de interacción institucionalizados que se definen para los roles, describiendo la manera de entrar y salir de la organización, las obligaciones y permisos requeridos a los roles, así como el modo en el que se realiza la asignación de roles a los agentes.

Para V. Dignum, las organizaciones de agentes asumen la existencia de objetivos globales, aparte de los objetivos individuales de los agentes; y además existen de manera independiente a los agentes, sin asumir ninguna característica interna específica de los mismos [Dignum y Dignum, 2006]. Los roles representan posiciones organizativas responsables de alcanzar parte de esos objetivos globales, de acuerdo a ciertas reglas de interacción predeterminadas. Los agentes pueden tener sus propios objetivos y decidir si adoptan o no unos roles específicos del sistema, así como determinar cuáles de los protocolos disponibles resultan más apropiados para alcanzar los objetivos marcados por esas posiciones o roles que han adoptado.

Finalmente, J. Hubner considera a la organización como un conjunto de restricciones de comportamiento que un grupo de agentes adopta para 
controlar la autonomía de los agentes y conseguir alcanzar sus objetivos globales fácilmente [Hubner et al., 2006].

En resumen, una organización de agentes se caracteriza por :

- Está compuesta por agentes (software, físicos y/o humanos), con independencia de sus características internas y objetivos individuales.

- Persigue un objetivo común global, que no depende directamente de los objetivos individuales de los agentes particulares que participen en ella en cada momento.

- Existe una subdivisión de las tareas de los agentes, mediante su asignación a roles, los cuales describen las actividades y funcionalidad propia de la organización.

- Proporciona una partición del sistema en grupos o unidades, en los cuales tienen lugar la interacción de los agentes.

- Posee unos límites bien definidos, determinados por: el entorno de la organización; los agentes internos y externos; así como por la funcionalidad de la organización y sus servicios ofrecidos.

Comparando los listados de resumen de las características de las organizaciones humanas y de agentes se observa que ambas presentan características muy similares, ya que generalmente estas últimas se han desarrollado a partir de la simulación y adaptación de los comportamientos humanos organizativos. Por tanto, es razonable pensar que si profundizamos en el estudio de las organizaciones humanas podremos extraer nuevos métodos y guías de diseño, así como nuevos conceptos, dimensiones y aspectos a tener en cuenta que nos faciliten el análisis, diseño e implementación de las organizaciones de agentes.

\subsection{Factores de la organización}

En el estudio y análisis de las organizaciones se debe tener en cuenta no sólo las entidades que la componen y sus relaciones sino también los 
objetivos que se persiguen, la funcionalidad del sistema, el entorno con el que se relaciona y las reglas que rigen el comportamiento de sus miembros. Por tanto, los factores a considerar en el modelado de una organización son los siguientes:

- Estructura: comprende todos aquellos elementos que persisten en la organización, independientemente de cuáles sean los individuos finales de la misma en cada momento. Vendrá definida en base a los roles, sus agrupaciones, dependencias y sus patrones de interrelación.

- Funcionalidad: especifica cuáles son los objetivos globales de la organización; los servicios y funcionalidades que ofrece; los objetivos que persiguen los distintos componentes de la organización y qué tareas y planes deben seguir para alcanzarlos.

- Normalización: determina el conjunto de normas y acciones definidas para controlar los comportamientos de los miembros de la organización. Se incluyen aquí tanto las normas sobre la actuación (obligaciones, permisos y prohibiciones), como las sanciones y recompensas a efectuar sobre sus miembros.

- Dinamicidad: especifica cómo evoluciona la organización a lo largo del tiempo, indicando el modo en que los agentes entran y salen de la organización de forma dinámica; adoptan determinados roles en función de sus capacidades y habilidades; y participan en aquellas unidades o agrupaciones de la organización en las que sean admitidos.

- Entorno: comprende tanto los recursos de los que depende la organización, como los proveedores de dichos recursos y los clientes o beneficiarios de la existencia de la organización.

A continuación se detallan estos aspectos con más profundidad. 


\subsubsection{Estructura de la organización}

En las organizaciones humanas, la estructura de la organización define cómo se dividen, agrupan y coordinan formalmente las tareas laborales. Además, un elemento clave en la composición de las organizaciones son los grupos [Peiro, 1991], que están compuestos por un limitado número de individuos que tienen interacciones comunes y un cierto grado de valores y normas compartidos (estándares de conducta).

Los elementos fundamentales que caracterizan la estructura de la organización son: la especialización, la departamentalización, la cadena de mando, el tramo de control, la centralización/descentralización y la formalización de las tareas [Hodge et al., 2003].

La especialización o división del trabajo indica el grado en el que las tareas de la organización se dividen en cometidos separados. Cuanto mayor especialización exista, más rutinarias serán las tareas.

La departamentalización consiste en agrupar los trabajos de manera que se puedan coordinar las tareas comunes. Dicha agrupación se realiza de distintos modos: (i) por funciones, que consiste en reunir a los especialistas en los mismos departamentos, para así lograr economías de escala al colocar a gente con habilidades y orientaciones similares en una misma unidad; (ii) por producto, que agrupa tareas en departamentos según el producto o servicio que la organización genera, aumentando así la responsabilidad por el desempeño del producto; (iii) por geografía, organizando los departamentos por regiones o territorios; (iv) por procesos, de modo que cada departamento se especializa en una fase de la producción; o (v) por tipo de cliente, de forma que se puedan satisfacer mejor los problemas y necesidades de cada cliente.

Por su parte, la cadena de mando representa la línea continua de autoridad que se extiende desde la parte superior de la empresa al último peldaño y aclara quién informa a quién. La autoridad se refiere al derecho para dar órdenes y esperar que sean obedecidas. El tramo de control, por contra, determina el número de empleados que un gerente dirige con eficacia y eficiencia, estableciendo así el número de niveles y gerentes de las 
empresas.

El grado de centralización de las empresas es también un aspecto importante de su estructura, pues indica dónde se toman las decisiones. Así, el término centralización se refiere al grado en que la toma de decisiones se concentra en un único punto en la organización. Por su parte, la descentralización implica que las decisiones se delegan a los gerentes que están más cerca de la acción.

Finalmente, la formalización indica el grado en que los puestos de la organización están estandarizados, es decir, la cantidad de reglas organizativas, procedimientos de los procesos de trabajo y descripciones explícitas de los puestos de trabajo que se tiene. En concreto, describe los patrones de interrelación establecidos entre los miembros, que permiten coordinar sus tareas.

Por tanto, en el análisis de la estructura se determina cuáles son las agrupaciones de sus miembros, dónde se produce la toma de decisiones y el control de las tareas y qué patrones de relación existen entre los miembros.

En el capítulo 5 se adaptan estas variables de la estructura de las organizaciones humanas al modelado de las organizaciones de agentes. En concreto, en la tercera fase de la guía metodológica propuesta se analizan estas variables o dimensiones para así determinar, posteriormente, el tipo de estructura organizativa que resulta más adecuada.

En las organizaciones de agentes la estructura de la organización se define normalmente en base a roles y grupos, donde los roles representan las funcionalidades o actividades de los agentes, mientras que los grupos especifican el contexto o localidad para las actividades de los agentes, de modo que la comunicación se lleva a cabo dentro de los grupos [Dignum y Dignum, 2006]. Además, se suelen especificar distintos tipos de dependencias entre los roles: de herencia, de compatibilidad, de comunicación y coordinación, de autoridad o poder, de control, etc. Estas dependencias determinan las relaciones a seguir entre los roles, a través de las cuales se coordinan las acciones de los agentes.

El lenguaje de modelado Moise ${ }^{\text {Inst }}$ [Gateau et al., 2005] ofrece una de 
las especificaciones de la estructura de una organización de agentes más completa que existe. La estructura del MAS se define en base a roles, grupos y relaciones.

Un rol consiste en un conjunto de restricciones que un agente debe seguir cuando acepta entrar en un grupo jugando dicho rol. Dichas restricciones afectan a su relación con otros roles, así como a los objetivos y planes que debe seguir.

Un grupo consiste en un conjunto de relaciones y roles, determinando restricciones de cardinalidad (mínimo y máximo número de agentes jugando un determinado rol dentro de un grupo); así como relaciones de herencia y compatibilidad. También se permite la especificación de subgrupos.

Finalmente, las relaciones de tipo social determinan los vínculos de conocimiento (qué agentes pueden obtener información sobre otros agentes); de comunicación (quiénes tienen permiso para comunicarse con otros agentes); y de autoridad (quiénes tienen control sobre otros).

Por su parte, F. Zambonelli define la estructura organizativa no sólo por los roles y sus relaciones, sino también por su topología y régimen de control [Zambonelli et al., 2000]. La topología determina los patrones de interacción entre los miembros, mientras que el régimen de control especifica dónde recae la autoridad y cómo se produce la supervisión y monitorización de las tareas.

\subsubsection{Funcionalidad}

En las organizaciones humanas, la misión describe el motivo de la existencia de la organización, especificando cuáles son los resultados (productos o servicios) que proporciona, quiénes son los grupos de interés a los que se dirige y qué beneficios globales se espera obtener. Por tanto, determina: (i) los objetivos globales del sistema; (ii) los servicios que se ofrecen o requieren, así como los productos asociados a dichos servicios; y (iii) los clientes, usuarios, etc. que se verán afectados por el sistema.

Los fines de la organización deben ser objetos de conocimiento común, 
que cumplan principalmente las funciones de guiar los esfuerzos de los miembros en vistas a su consecución; proporcionen una fuente de legitimidad que determine las conductas y acciones adecuadas en el contexto de la organización; establezcan los niveles mínimos o estándares que han de conseguirse; determinen, al menos parcialmente, el tipo de estructura que la organización debe establecer para la consecución de esos fines y proporcionen información sobre las características fundamentales de la propia organización [Peiro, 1991].

Por otro lado, dado un fin general para una organización, podemos identificar las funciones básicas necesarias para su realización. La complejidad del diseño de la organización consistirá en reducir estas categorías generales de actividad a subcategorías específicas, hasta llegar finalmente a las tareas individuales, que deben ser agrupadas de modo tal que procuren la máxima productividad y eficiencia con el mínimo coste [Peiro, 1991].

De modo similar, en las organizaciones de agentes se definen también unos objetivos globales que especifican el comportamiento general deseado por el sistema; y unos objetivos particulares de los roles y grupos, para los cuales se establecen el conjunto de tareas y acciones que permiten alcanzaros.

Por ejemplo, en MOISE ${ }^{\text {Inst }}$ [Gateau et al., 2005] los objetivos globales del sistema se descomponen, a través de planes, en objetivos concretos que se distribuyen entre los agentes. Los planes especifican las secuencias entre los objetivos. A los roles se les asigna un conjunto de objetivos coherentes, a los que el agente que juegue dicho rol debe comprometerse a alcanzar.

Otro aspecto a tener en cuenta en las organizaciones es el concepto de servicio, que se define como un bloque coherente de funcionalidad que se realiza sirviendo a otra entidad. Detallar los servicios que ofrece una organización permitirá que los agentes del sistema puedan descubrirlos, invocarlos, monitorizarlos e incluso realizar composiciones de servicios.

La especificación OWL-S ${ }^{1}$ permite especificar qué es lo que un servicio ofrece a los usuarios y/o agentes y qué requiere de ellos; cómo funciona y

\footnotetext{
${ }^{1}$ http://www.w3.org/Submission/OWL-S/
} 
cómo se utiliza. Para ello, describe los servicios en términos de sus entradas, salidas, precondiciones y efectos. También se indica el flujo de tareas inherentes al servicio, detallando los distintos procesos que lo componen y sus relaciones. Asimismo, OWL-S ofrece la implementación de los servicios en base a operaciones de servicios Web. De este modo, un determinado servicio podrá implementarse con uno o más servicios Web relacionados.

Sin embargo, la especificación de los servicios apenas ha sido tratada por las metodologías y entornos de trabajo de agentes, las cuales se centran principalmente en los protocolos de interacción y en las tareas de los roles y agentes. Tan sólo AML (Agent Modeling Language) [Cervenka y Trencansky, 2007] permite especificar qué servicios son ofrecidos o requeridos por las distintas entidades del sistema (roles, agentes o unidades organizativas) aunque no emplea la especificación OWL-S, sino sus propios modelos basados en UML.

\subsubsection{Normalización}

En las organizaciones humanas, la coordinación de las tareas se consigue a través de tres mecanismos: adaptación mutua, supervisión directa y normalización [Wagner y Hollenbeck, 2004]. Con la adaptación mutua, los miembros comparten la información relacionada con su trabajo y deciden entre sí sobre el modo en que se debería realizar una tarea y quién debería realizarla. En la supervisión directa, una persona asume la responsabilidad del trabajo de un grupo, adquiriendo autoridad para decidir qué tareas han de realizarse, quién las realizará y cómo se vincularán para producir el resultado final.

Por su parte, la normalización proporciona los estándares y procedimientos para ayudar a los miembros de la organización a determinar cómo realizar sus tareas. Existen cuatro tipos de normalización: de tareas, de resultados, de habilidades y de comportamientos [Wagner y Hollenbeck, 2004]. La normalización de tareas implica la especificación de las tareas concretas y los procedimientos de trabajo que los empleados deben seguir para cumplir con sus responsabilidades. En la normalización de resultados, se definen 
formalmente los objetivos de los resultados o las metas de rendimiento esperadas, por lo que los miembros de la organización tienen mayor flexibilidad sobre la funcionalidad de las tareas a realizar, siempre que sus resultados sean acordes a las metas especificadas. En la normalización de habilidades, se indican las cualificaciones, conocimientos y habilidades necesarias para desarrollar las tareas de forma competente. Finalmente, en la normalización de los comportamientos, los miembros de un grupo u organización comparten un conjunto de creencias sobre la aceptabilidad de determinados tipos de comportamiento, como por ejemplo la calidad en los procesos de trabajo.

En las organizaciones de agentes, la coordinación entre los agentes se consigue mediante el uso de normas sociales. Éstas describen el comportamiento esperado de los miembros, es decir, qué acciones son permitidas, requeridas o necesarias y cuáles se deben evitar. También indican las sanciones que se deben aplicar en el caso de acciones no deseables, así como las recompensas o reconocimientos a ofrecer para aquellas acciones cumplidas según lo establecido por la norma. Las normas suelen ser definidas y controladas por instituciones que tienen un estatus legal y, por tanto, conceden legitimidad y seguridad a los miembros de la sociedad. Las normas resultan indispensables para solucionar problemas de coordinación en sistemas grandes, complejos y heterogéneos, en los que el control social directo y total no puede ejercerse [López et al., 2006].

En Moise ${ }^{\text {Inst }}$ [Gateau et al., 2005] las normas definen los permisos, obligaciones y prohibiciones de los agentes mientras juegan un rol determinado o pertenecen a un grupo, con respecto a la ejecución de determinados objetivos que conforman su misión, dentro de un contexto particular y durante un periodo de tiempo establecido. El cumplimiento de las normas se supervisa por el rol issuer, quien puede aplicar una sanción sobre el rol afectado por la norma.

En las Instituciones Electrónicas [Esteva et al., 2001b], existe una capa social formada por agentes internos que conocen cuáles son las normas de la interacción y que garantizan que las interacciones se produzcan de acuerdo 
a dichas normas. Por su parte, en OperA [Dignum, 2003] se propone el establecimiento de contratos de interacción para controlar el comportamiento de los agentes cuando interactúan entre sí. Estos contratos describen las condiciones y reglas a aplicar mientras se produce dicha interacción.

En la propuesta de F. López las normas se subdividen en generales, que establecen cuál debe ser el comportamiento de los agentes; legisladoras, para crear nuevas normas, modificarlas o abolirlas; de refuerzo, para controlar a los agentes y establecer sanciones; y de recompensas, para fomentar el cumplimiento de determinadas regulaciones [López et al., 2006]. Los agentes decidirán sobre la adopción de ciertas normas en función de sus propios objetivos y de las sanciones o recompensas que reciban según su comportamiento final.

\subsubsection{Dinamicidad}

En las organizaciones humanas, cualquier organización debe permitir que sus miembros puedan entrar y salir de ella de forma dinámica. La organización incorpora a sus miembros en función de unas determinadas habilidades, conocimientos o aptitudes para la consecución de sus fines [Peiro, 1991].

En el caso de las organizaciones de agentes se deben establecer, pues, mecanismos que controlen cuándo los agentes pueden entrar a participar en la organización y cuál será su posición en ella (es decir, qué roles adoptarán y en qué grupos se integrarán). También se deben considerar los procesos de expulsión de los agentes con comportamientos anómalos dentro de la organización. Por otro lado, el aspecto dinámico de una organización implica también el proceso de creación y eliminación de las distintas agrupaciones y unidades que contiene.

En las Instituciones Electrónicas [Esteva et al., 2001b], el agente Institution Manager controla la llegada de los agentes externos al sistema y se encarga de crear un agente interno representante, llamado governor, por cada agente externo autorizado a participar en la institución.

En OperA [Dignum, 2003] los agentes se asocian a los roles mediante el 
establecimiento de contratos sociales. Cada contrato describe las condiciones y reglas que adquiere un agente al jugar un rol.

\subsubsection{Entorno}

En las organizaciones humanas, el entorno abarca todo aquello que se encuentra fuera de la misma: sus proveedores, clientes, la competencia, los organismos gubernamentales que regulan sus operaciones, las instituciones financieras e inversores que le suministran fondos y el mercado laboral que aporta a sus empleados. También son parte del entorno las condiciones económicas, geográficas y políticas [Wagner y Hollenbeck, 2004]. Por tanto, el entorno es la fuente de recursos necesarios para sobrevivir [Hodge et al., 2003], pues le proporciona los materiales, tecnología e incluso los miembros requeridos para desarrollar sus productos y servicios, así como los clientes suficientes que consuman dichos productos y ofrezcan beneficios a la organización. Por tanto, todas las oportunidades de éxito y amenazas para su existencia provienen del entorno [Hodge et al., 2003].

En los sistemas multiagente, el entorno se asocia principalmente con los recursos y aplicaciones de los que hacen uso los agentes. Así, en Gaia [Wooldridge et al., 2000] se establecen los modos de acceso a los recursos (para lectura, interacción, extracción de información, etc.).

En AML [Cervenka y Trencansky, 2007] se tienen también en cuenta los perceptores y actuadores de los agentes sobre su entorno. Los perceptores permiten modelar la habilidad de los agentes para observar, percibir estados o recibir señales; mientras que los actuadores modelan su habilidad para producir un determinado efecto sobre otros objetos o entidades.

Por otro lado, también pertenecen al entorno los denominados stakeholders o entidades externas a la organización, pero que se benefician, dependen o facilitan la existencia de la misma. Se incluyen en este grupo a los proveedores, clientes y usuarios de la organización.

En OMNI [Vazquez-Salceda et al., 2004] se establecen quiénes son los stakeholders o grupos de interés, es decir, aquellas entidades con determinados requisitos o necesidades sobre el sistema. Se identifican también cuáles 
son sus objetivos y dependencias con respecto a la organización.

\subsection{Taxonomía de Organizaciones}

Las organizaciones de agente presentan ciertos patrones estructurales o topologías similares a las organizaciones humanas, pues en muchos casos se diseñaron para simular o representar a estas últimas. A continuación se explicarán los distintos tipos de organizaciones existentes en ambas áreas, comparando sus semejanzas y diferencias. Estos patrones estructurales son empleados posteriormente en el capítulo 4 para modelar los sistemas multiagente.

\subsubsection{Tipos de organizaciones humanas}

Según la literatura [Robbins, 2004; Daft, 1998], se distingue entre organizaciones mecánicas y orgánicas. En las organizaciones mecánicas las tareas están definidas rígidamente y se desglosan en partes especializadas y separadas. Además, existe una estricta jerarquía de autoridad y control, identificándose claramente roles de supervisor y subordinado, entre los que se establecen principalmente las comunicaciones, de tipo vertical. Estas organizaciones resultan interesantes para entornos estables, donde se produzcan pocos cambios relevantes. Ejemplos de este tipo de organizaciones son la estructura simple, la burocracia y la estructura matricial [Argente et al., 2005].

En las organizaciones orgánicas las tareas se ajustan y redefinen por medio del trabajo en equipo. Constan de menor jerarquía de autoridad y control, de modo que el conocimiento y control de las tareas está distribuido. Los miembros contribuyen juntos a la tarea común del departamento. Además, las comunicaciones son principalmente horizontales, entre miembros del mismo departamento o incluso entre departamentos. De este modo se ofrecen respuestas rápidas y flexibles. Estas organizaciones resultan adecuadas para entornos dinámicos, que cambian con rapidez. Ejemplos de este 
tipo de organizaciones son el grupo y la organización virtual [Argente et al., 2005].

H. Mintzberg propone un modelo general de organización, llamado Structure-in-Five, basado en cinco unidades básicas [Mintzberg, 1993] : Strategic Apex (centro directivo de la compañía), Operating core (unidades productivas del negocio), Middle Line (supervisor de las actividades del centro operacional), Technostructure (ayuda para la coordinación de las tareas) y Support Staff (servicios especializados fuera del flujo de trabajo básico). En función de la topología del sistema, estas unidades básicas adquieren mayor o menor relevancia. Así, la unidad Technostructure resulta esencial en un sistema burocrático, ya que ofrece la estandarización de los procedimientos y las salidas. Por otro lado, la unidad Middle Line es crucial en una estructura de grupo, al controlar la creación de equipos multi-disciplinarios en la unidad Operating Core.

A continuación se explica con mayor detalle las características principales de distintas organizaciones mecánicas y orgánicas existentes.

ESTRUCTURA SIMPLE. Representa a aquella organización con poca departamentalización, donde un individuo centraliza la toma de decisiones [Robbins, 2004]. Suele tener un gran tramo de control (es decir, el gerente dirige a un número elevado de empleados) y una estructura plana o, como mucho, con dos o tres niveles verticales. Además tiene poca formalización (es decir, poca estandarización de los puestos de trabajo y pocas reglas). Este tipo de organizaciones se practica especialmente en pequeñas empresas, en las que el gerente y el dueño son la misma persona, así como en épocas de crisis temporales, al centralizar el control sobre un único individuo.

Como ventajas, esta organización es muy simple de establecer, no es costosa de mantener y las responsabilidades están claras. Además, las comunicaciones son rápidas (pues son prácticamente directas entre los miembros interesados), así como la toma de decisiones y su ejecución. Por contra, resulta complicada de sostener salvo en organizaciones pequeñas, pues tiene 
poca formalización y una elevada centralización que tiende a sobrecargar de información a la directiva. Además, como todo depende de una única persona, si ésta falla o se equivoca en sus decisiones la empresa posiblemente quebrará.

Podemos encontrar modelos similares a esta estructura, como la singleperson, la jerarquía simple y la cadena de valores.

La estructura single-person [Fox, 1981] consiste en un único actor, el cual realiza todas las tareas, reaccionando a su entorno cuando sea necesario. El actor tiene a su alcance todos los recursos precisos para alcanzar los objetivos del sistema. Por tanto, se trata de una organización de estructura simple muy reducida, en la que solamente existe un único miembro que se ocupa de todo.

En la jerarquía simple [Fox, 1981] la organización se divide en dos niveles: superior e inferior. El nivel superior está compuesto por un único actor, que realiza la toma de decisiones y coordina las tareas del nivel inferior. Además, dispone de autoridad suficiente para efectuar cambios en el comportamiento de la organización, al tener información completa del sistema. Por su parte, el nivel inferior está formado por los actores que realizan las tareas básicas de la organización. Estos actores se comunican entre sí a través del nivel superior. De este modo la coordinación del sistema se lleva a cabo mediante relaciones jerárquicas y de autoridad.

Finalmente, la cadena de valores o supply chain [Giorgini et al., 2003] consta de varios actores, dispuestos en cadena, que tratan de alcanzar sus objetivos en diferentes estados de un proceso de producción. Cada participante de la cadena añade un nuevo valor en cada paso. Por ejemplo, una cadena productiva integra el conjunto de eslabones que conforma un proceso económico, desde la materia prima a la distribución de los productos terminados.

BUROCRACIA. Se caracteriza por la existencia de tareas operativas muy rutinarias, con mucha especialización y de reglas muy formalizadas [Robbins, 2004]. Asimismo, se dispone de diversos departamentos con unos 
cometidos claros, en los que existe poco tramo de control (es decir, los gerentes dirigen a un grupo de personas no muy elevado), de modo que se establecen muchos niveles de gerencia (en función del tamaño total de la empresa). Además, la autoridad está centralizada y la toma de decisiones sigue la cadena de mando. Este tipo de organizaciones fue muy popular en los años cincuenta y sesenta, especialmente entre las grandes corporaciones del mundo.

Como ventajas, esta estructura permite desempeñar actividades estandarizadas de manera muy eficaz. Además, reúne las especialidades en departamentos, facilitando así la comunicación entre los empleados. Por otro lado, gracias a la presencia generalizada de reglas y regulaciones y a la estandarización de las operaciones, se permite centralizar la toma de decisiones en la ejecutiva.

Como desventajas, la elevada especialización de las tareas suele crear conflictos en las unidades o departamentos, de modo que los jefes de departamentos se preocupan más por los objetivos propios de sus unidades que por las metas generales de la organización. Además, normalmente se produce una preocupación desmedida por seguir las reglas, no dejando claro cómo actuar si se presentan situaciones no contempladas anteriormente. Por tanto, este tipo de organizaciones tiene dificultad para responder a los cambios del entorno.

Se distinguen dos modelos burocráticos distintos [Albors y Martinez, 2002]: funcional y divisional.

La estructura de tipo funcional es aquella en la que las tareas y los departamentos están agrupados de acuerdo a la especialización técnica o funciones de negocio. Esta estructura predomina en pequeñas y medianas empresas y permite lograr economías de escala, con ahorro de personal, mejor contacto entre los especialistas (al estar juntos en el mismo departamento) y mejor formación de éstos. Además, los mecanismos de toma de decisiones y las líneas de comunicación son sencillas e inteligibles. Por contra, los mandos tienden a convertirse en especialistas más que en generalistas por lo que suelen surgir conflictos entre las funciones de distintos 
departamentos.

En la estructura de tipo divisional los departamentos se establecen por divisiones autónomas que contienen todas las funciones que necesitan. Estas divisiones son por productos fabricados, por tipos de clientes, por áreas geográficas, etc. Presenta una estructura más flexible y autónoma, aunque suele necesitar de la duplicación de recursos.

ESTRUCTURA MATRICIAL. Combina la estructura funcional y la divisional, de modo que los empleados tienen dos jefes, el gerente del departamento funcional y el gerente del producto, por lo que hay dos cadenas de mando [Robbins, 2004]. Este tipo de estructura es muy habitual en empresas de ingeniería y en la gestión de proyectos.

Como ventajas, esta organización facilita la coordinación entre los empleados cuando se tienen numerosas actividades complejas e interdependientes. Además, mejora la comunicación y amplía la flexibilidad. También aminora la tendencia de los miembros de los departamentos a centrarse en los objetivos individuales del departamento y no tanto en las metas generales de la organización. Asimismo, facilita la ubicación eficaz de los especialistas, gracias a su tipología funcional.

Por contra, suele crear mucha confusión en los miembros al existir dos cadenas de mando. Además, fomenta las luchas de poder y la tensión en los individuos. Esta tensión se reduce utilizando actitudes burocráticas, principalmente una mayor formalización de las reglas a seguir.

En la figura 2.1 se muestra un esquema de la estructura matricial, donde se observa que cada operario tiene dos o más supervisores distintos: el supervisor funcional y el supervisor divisional. El jefe funcional se ocupa del control sobre las funciones de negocio y las actividades, ofreciendo una visión global de toda una funcionalidad completa. En este caso existe un jefe funcional que se ocupa de todos los aspectos relacionados con $\mathrm{I}+\mathrm{D}$; otro que se ocupa de la contabilidad de la organización y otro del proceso de manufactura. Por su parte, el supervisor divisional efectúa el control sobre el producto fabricado, proporcionando una visión tanto global como parcial 
de dicho producto. En este ejemplo se requieren tres jefes divisionales, centrados en los tres productos que ofrece la empresa.

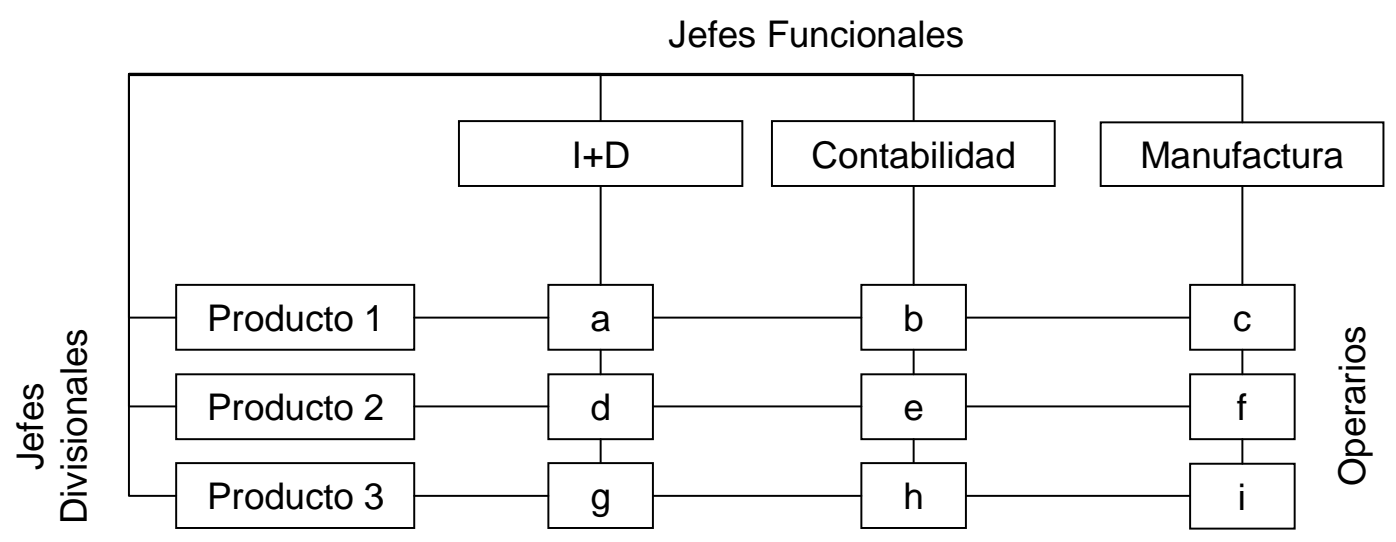

Figura 2.1: Ejemplo de estructura matricial en una organización humana.

ESTRUCTURA DE EQUIPOS. Este tipo de organización elimina las barreras departamentales y descentraliza la toma de decisiones para llevarla al nivel de los equipos de trabajo [Robbins, 2004][Fox, 1981].

Los equipos o grupos representan a un sistema que consta de varios actores que tienen un objetivo compartido: la realización de la tarea global del sistema. Dicha tarea global se encuentra dividida en subtareas, las cuales son asignadas a los miembros del grupo más capacitados para ejecutarlas. Además, los miembros se comunican entre sí y comparten toda la información. La coordinación entre los actores se consigue a través de decisiones aceptadas mutuamente y planes consensuados y/o elaborados por todos.

En muchas empresas se emplean también los denominados equipos autodirigidos [Daft, 1998], consistentes en grupos permanentes de 5 a 30 trabajadores con diferentes habilidades y que producen todo un producto o servicio, adoptando además actividades administrativas. El equipo tiene acceso a los recursos necesarios para realizar una tarea completa, como materiales, información, maquinaria, etc. Además, incluye una diversidad de habilidades de los empleados, como ingeniería, manufactura, finanzas, mercadotecnia, eliminando así las barreras ente departamentos. En muchos 
casos, los integrantes del grupo rotan sus puestos y son capaces de desempeñar los puestos de otros. Por otro lado, el equipo tiene facultad suficiente para la toma de decisiones relacionadas con su producto o servicio, actuando de forma completamente autónoma.

Para que la estructura de equipos funcione adecuadamente, los procesos deben basarse en la satisfacción de las necesidades del cliente. Por ello, los miembros del equipo deben estar en contacto directo y regular con clientes y proveedores, cuyos representantes son, en ocasiones, incluidos también dentro del equipo. De este modo se agilizan los tiempos de respuesta y la toma de decisiones, mejorando la satisfacción de los clientes.

El trabajo en equipo se emplea en muchas empresas de manufactura, como las automovilísticas, donde se dispone de diversos equipos a turnos, cuyos miembros están capacitados para realizar todas las tareas del montaje. Como ventajas, el trabajo en equipo por turnos crea mayor motivación y reduce el ausentismo. También se incrementa la competitividad de la empresa y la productividad de las plantas. Además, los equipos se suelen fijar metas más altas de lo que habría establecido la administración. Por otro lado, las barreras entre los departamentos se reducen, de modo que los miembros del equipo cooperan entre sí con el conocimiento total de la tarea que se está tratando. Finalmente, se reducen los costos administrativos indirectos, pues los equipos asumen también las tareas de administración.

Como desventajas, el cambio a una estructura orgánica, como el trabajo en equipo, suele ser un proceso largo y difícil, que requiere modificaciones importantes en el diseño de puestos, sistemas de información, administración y política de compensaciones. Así, los ejecutivos deben desarrollar habilidades de capacitadores y facilitadores; los empleados deben amoldarse a trabajar de forma colaborativa; los sistemas de información deben proporcionar todos los recursos y datos necesarios para los equipos; se necesita de un mayor número de reuniones para la coordinación y toma de decisiones; las políticas de compensación deben apoyar el desempeño y compromiso del equipo; etc. 
ADHOCRACIA. Las adhocracias están formadas por constelaciones de trabajo, es decir, por grupos dinámicos de individuos que toman las decisiones según su nivel jerárquico, de modo que el poder está descentralizado. Está orientada a ofrecer mayor flexibilidad y dinamismo al sistema. En la adhocracia la estrategia está bien definida pero no así los medios para llegar a alcanzar los objetivos. Cada constelación trata subobjetivos independientes y se coordinan por adaptación mutua, empleando técnicas de negociación (como por ejemplo el control a través del precio del producto) o bien aplicando estructuras de tipo matricial.

ORGANIZACIÓN VIRTUAL. Consiste en que una empresa contrata a otras empresas las principales funciones comerciales que necesita [Robbins, 2004]. Así, se crean redes de contactos que les permiten contratar la manufactura, la distribución, la mercadotecnia y otras funciones comerciales que la gerencia cree que otros pueden realizar mejor o a menor costo. Por su parte, la organización interna de la empresa adquiere una configuración centralizada con pocos departamentos, pues la mayor parte de sus funciones están subcontratadas. Esta estructura ofrece flexibilidad pero reduce el control de la gerencia sobre partes fundamentales de la organización, ya que dicho control lo ejercerán cada una de las empresas subcontratadas.

Se distinguen tres tipos de organización virtual [Fox, 1981]: mercado simple, organización colectiva y mercado general. El mercado simple consiste en varias organizaciones disjuntas que negocian la producción o contratación de servicios, estableciendo contratos. De este modo, una empresa u organización no necesita crear una nueva unidad para cada nueva función que tenga, sino que contrata dicha función en el mercado. El control de la organización global se ejerce a través del precio del producto. Así, si el precio es demasiado alto, el producto no se comprará. Si es demasiado bajo, las unidades que lo suministran acabarán en bancarrota. Por tanto, el precio debe reflejar el coste marginal del producto, para que los recursos se utilicen sin desperdicio. 
Por su parte, la organización colectiva consiste en varias organizaciones separadas que cooperan para alcanzar objetivos comunes, estableciendo contratos a largo plazo. Las organizaciones deciden juntas cómo adaptarse a las situaciones. Además, la información se comparte por el grupo y no aparece el oportunismo. La estructura Joint Venture [Giorgini et al., 2003], similar a la organización colectiva, consiste en la unión de dos o más asociados intra-industriales para conseguir beneficios a mayor escala con menor coste de mantenimiento. En dicho sistema, un actor específico, denominado joint manager, se hace cargo de las operaciones estratégicas, de la coordinación de las tareas y el reparto de recursos entre asociados.

Finalmente, en el mercado general varias organizaciones contratan entre sí servicios para periodos de tiempo cortos o largos, estableciéndose una gran competitividad. Además, cada organización debe examinar si sus propios objetivos se corresponden con las necesidades de otras organizaciones.

Como ventajas, la organización virtual ofrece una gran flexibilidad y capacidad de adaptación a cambios del entorno y de los objetivos de la propia organización. Sin embargo, resulta más complicada de controlar y mantener que las estructuras anteriores, pues el control está totalmente distribuido y además muchas de las funciones de la organización se delegan o subcontratan a otras organizaciones.

\subsubsection{Tipos de organizaciones de agentes}

Aunque en los sistemas multiagente no existen dos instancias de organización completamente iguales, se identifican clases o modelos de organización que compartan características comunes. El trabajo de B. Horling describe los diferentes paradigmas de organización empleados en los sistemas multiagente, que incluyen jerarquías, holarquías, coaliciones, equipos, congregaciones, federaciones y organizaciones matriciales [Horling y Lesser, 2004]. Estos paradigmas presentan mucha similitud con las organizaciones humanas y, en muchos casos, los diseñadores de agentes se han basado en éstas para el desarrollo de sus aplicaciones. A continuación se explican brevemente cada uno de estos paradigmas. 
JERARQUÍAS. En la organización jerárquica los agentes se ordenan siguiendo una estructura de tipo árbol, en la que los agentes situados en las partes superiores del árbol tienen una visión más global que aquellos por debajo. En su interpretación más estricta, las interacciones solamente se dan lugar entre entidades conectadas (de niveles inmediatamente superiores a niveles inmediatamente inferiores), aunque en trabajos recientes se permite también la comunicación directa entre unidades al mismo nivel.

Los datos producidos por los agentes en los niveles inferiores de la jerarquía se transmiten hacia los niveles superiores, para así proveer de una visión más amplia del sistema, mientras que el flujo de control viaja de los niveles altos a los bajos. La instancia más simple de esta estructura consiste en una jerarquía de dos niveles, donde las acciones de los agentes en el nivel más bajo son especificadas por completo en el nivel superior, el cual produce una visión global a partir de la información resultante. Instancias más complicadas constan de múltiples niveles.

El protocolo Contract-Net de FIPA ${ }^{2}$ permite construir una serie de conexiones jerárquicas entre los agentes. Así, si un agente no es capaz de resolver el problema que le ha sido asignado mediante su conocimiento o recursos locales, divide el problema en subproblemas y tratará de encontrar a otros agentes con los conocimientos y recursos necesarios para resolver dichos subproblemas.

Como ejemplo de jerarquía en sistemas de agentes, el DDM (Distributed Dispatcher Manager)[Yadgar et al., 2003] permite manejar una red de miles de agentes sensores mediante una organización jerárquica en la que el proceso de solución se distribuye en fragmentos más pequeños del problema que son resueltos de forma parcial por agentes simples.

HOLARQUÍAS. Estas organizaciones se basan en el concepto de holón.

\footnotetext{
${ }^{2}$ http://www.fipa.org/specs/fipa00029/SC00029H.pdf
} 
El término holón representa una entidad que existe de forma simultánea como parte de una entidad mayor y como resultado de la agrupación de entidades subordinadas. El propio término holón proviene de la palabra griega holos (que significa "todo") y de on (que significa "parte"). Los holones constan de componentes software y hardware [Giret, 2005].

Las holarquías representan estructuras anidadas y jerárquicas de holones. Se han empleado en los sistemas multiagente principalmente por su habilidad para modelar sistemas de negocio y manufactura. Normalmente, se aplican más fácilmente a dominios en donde los objetivos se descompongan de forma recursiva en subtareas, que serán asignadas a holones individuales.

Entre los ejemplos de sistemas holárquicos destacan los trabajos de [Fischer, 1999] [Zhang y Norrie, 1999] y [Ulieru et al., 2001], que organizan el sistema de agentes mediante el modelado explícito de divisiones de trabajo de sistemas del mundo real empleando el concepto de holón. Así, en el trabajo de X. Zhang se emplea un modelo de holones estáticos junto con holones mediadores, para crear y adaptar la organización [Zhang y Norrie, 1999]. Los grupos estáticos consisten en holones de producto, de modelo de producto y de recursos. Cada uno se corresponde con un grupo de objetos físicos o de información dentro del entorno. Por su parte, los holones mediadores unen a estos grupos entre sí, mediante el manejo de órdenes, la búsqueda de información del producto y la coordinación de recursos.

En ANEMONA [Giret, 2005] se parte del concepto de holón para diseñar sistemas multiagente recursivos. Los métodos de modelado propuestos se han aplicado en el diseño de un sistema holónico de fabricación de una empresa de cerámica. Dicho sistema permite automatizar la gestión de los almacenes de materia prima, ayudar en la gestión de las compras, facilitar la definición del plan maestro, automatizar la configuración y seguimiento del calendario de lanzamientos de tareas y procesos y controlar la fabricación de los productos.

COALICIONES. Representan conjuntos de agentes que se agrupan de forma temporal para la consecución de un objetivo concreto, disolviendo 
la agrupación cuando se consigue dicho objetivo, o bien cuando ya no existe la necesidad de dicha agrupación, o bien una cantidad crítica de agentes ha dejado la agrupación.

Por tanto, las coaliciones son de corta duración y están dirigidas a un objetivo concreto. Dentro de una coalición, la estructura organizativa suele ser plana, aunque puede existir un agente líder que actúe como representante e intermediario del grupo. Una vez que se establece una coalición, ésta se trata como una entidad única y atómica. Las coaliciones se forman porque los participantes tienen la noción que con dicha unión obtendrán cierta utilidad o beneficios y se reducirán determinados costes.

Por otro lado, las coaliciones son disjuntas o superpuestas. En el primer caso, un miembro solamente pertenece a una coalición como máximo en cada momento. Si decide entrar en una coalición, podrá seguir considerando la posibilidad de entrar en otras, pero deberá abandonar la coalición actual antes de entrar en otra coalición más interesante para sus necesidades y objetivos. En el caso de las coaliciones superpuestas, un miembro podrá estar a la vez en varias coaliciones distribuyendo en ellas sus capacidades, habilidades y recursos. Para ello debe conocer cuáles son las otras coaliciones existentes en cada momento, valorando así su posible pertenencia a ellas. Una vez que agota sus recursos, deja de analizar dicha posibilidad.

En la propuesta de O. Shehory se emplean coaliciones de agentes para permitir la realización de tareas por un grupo de agentes [Shehory y Kraus, 1998]. En este caso, se debe cumplir un conjunto de tareas interdependientes entre sí y algunas de ellas requieren que sean realizadas por múltiples agentes. De forma iterativa se analizan las posibles coaliciones de agentes, teniendo en cuenta determinados requisitos de capacidad y ordenación de las tareas, hasta encontrar las mejores coaliciones.

En la propuesta de K. Lerman también se emplean coaliciones formadas por agentes interesados, que toman sus decisiones de forma local [Lerman y Shehory, 2000]. Los agentes trabajan en un mercado electrónico y forman coaliciones al añadir solicitudes de compra a una orden. Abandonan la coalición mediante la eliminación de dicha orden. Además, los agentes se 
mueven entre órdenes de compra, buscando aquella que les ofrezca el mejor valor (menor coste).

Finalmente, L. Soh utiliza coaliciones creadas de forma dinámica en respuesta al reconocimiento de tareas de rastreo en una red de sensores distribuidos [Soh et al., 2003]. Así, un agente inicia la formación de una coalición seleccionando a un conjunto de candidatos que puedan satisfacer sus requisitos y emplea para ello conocimiento local. A continuación, entabla negociaciones con dichos candidatos para solicitarles su pertenencia a la coalición.

EQUIPOS. Los equipos de agentes consisten en agentes cooperativos que trabajan juntos en la consecución de un objetivo común, intentando maximizar la utilidad del equipo más que la de los miembros individuales. Los sistemas que mantienen una representación explícita de los equipos de trabajo tienen también representaciones de objetivos comunes, creencias mutuas y planes a nivel de equipo. Por ello, posibilitan a los agentes razonar de forma explícita sobre comportamientos a nivel de equipo.

El propósito de la formación del equipo se fundamenta en que un grupo de agentes es capaz de abordar problemas de mayor envergadura que si actuasen de forma individual, permitiendo aspectos de redundancia, mayor adaptación a restricciones globales y mejor aprovechamiento de los recursos y reducción de costes, atendiendo a economías de escala.

Las interacciones entre los miembros del equipo son arbitrarias: todos con todos, unos con otros. Existe, pues, un gran número de comunicaciones. Además, cada agente juega uno o más roles necesarios para realizar las tareas requeridas, que pueden cambiar con el tiempo en respuesta a eventos, aunque el objetivo global de alto nivel normalmente se mantiene consistente.

En el trabajo de N. Jennings se describe un sistema de gestión de trasporte de electricidad que emplea la estructura de equipos para organizar las actividades de agentes de diagnóstico [Jennings, 1995]. Por su parte, en el trabajo de M. Tambe los equipos se utilizan para permitir a los agentes que alcancen objetivos interdependientes en entornos dinámicos, como ejercicios 
tácticos militares y juegos competitivos [Tambe, 1997].

CONGREGACIONES. Consisten en grupos de individuos con características similares o complementarias que se unen para facilitar el proceso de encontrar a colaboradores adecuados y obtener beneficios adicionales. Así se reduce la complejidad de las búsquedas, al restringir el tamaño de la población en la que buscar la funcionalidad requerida; y se limitan las interacciones entre los agentes. Las congregaciones surgen a raíz de la motivación de los agentes en unas determinadas habilidades o requisitos. Se crean para largo plazo y no conllevan la consecución de un objetivo específico. Los agentes se unen o abandonan la congregación de forma dinámica, según la utilidad que obtengan con dicha unión. Sin embargo, para la existencia de la congregación debe existir un número estable de participantes que le confiera utilidad a la misma.

Para C. Brooks y E. Durfee la congregación consiste en una localización o punto de encuentro (meeting place) y los agentes que se reúnen allí [Brooks y Durfee, 2000]. El propósito de su formación es la reducción del espacio de búsqueda de los agentes sobre posibles colaboradores, de forma que cada agente considera como potencial colaborador solamente a los miembros de la congregación a la que se una y no a todo el mundo del sistema.

Las congregaciones se forman entre agentes interesados que presentan características similares o bien complementarias sobre un área de interés común. Los agentes buscan maximizar su utilizad local a largo plazo, en función de su interacción con los agentes de la congregación. Su objetivo principal es poder colaborar con aquellos agentes con los que ya se han tenido buenas relaciones anteriormente. De este modo, si las colaboraciones previas han sido beneficiosas, el agente permanecerá en la misma congregación (y así lo harán los otros miembros).

Se considera la congregación como un mecanismo para que poblaciones grandes de agentes se organicen en pequeños grupos, sin tener conocimiento de qué otros agentes están en la población o cómo deben describirse a 
sí mismos [Brooks y Durfee, 2003]. Es más, los agentes no tienen el concepto de grupo como tal y no les importan los objetivos que persigan los otros agentes, aunque sí dependen de otros para satisfacer sus propias necesidades. Además, se asume que las comunicaciones entre agentes consumen tiempo y esfuerzos, en función de la distancia de los agentes, el número de mensajes a enviar y la complejidad de los mensajes. Por ello, los agentes preferirán relacionarse con grupos reducidos de agentes y no con todo el sistema al completo.

Dentro de una congregación, sus miembros se organizan de maneras distintas para facilitar su coordinación. Por ejemplo, adquiriendo estructuras de tipo jerárquico y empleando así mecanismos de subastas o Contract-Net para la asignación de colaboradores. O bien formando coaliciones o incluso equipos.

En el trabajo de C. Brooks se emplea la formación de congregaciones en un sistema económico con compradores y vendedores [Brooks y Durfee, 2000]. En dichas congregaciones se tiene en cuenta el coste asociado con el tamaño de la congregación y también el modo de identificarla, mediante etiquetas que describen las características de los miembros de la congregación.

FEDERACIONES. Consisten en grupos de agentes que ceden cierta cantidad de su autonomía a un delegado que representa al grupo. Los miembros del grupo interaccionan solamente con este agente, que actúa también de intermediario entre el grupo y el mundo exterior. El intermediario recibe mensajes de su grupo, incluyendo requisitos de tareas, información de estado, descripción de habilidades, etc. Además, envía y recibe información a otros intermediarios de otros grupos, solicitándoles tareas, notificando habilidades, etc.

El agente intermediario actúa como un broker o facilitador, como un mediador, un monitor o un agente embassy. Como broker, se encarga de distribuir las tareas requeridas entre los miembros del grupo.

Como mediador, conoce los protocolos de comunicación de los agentes 
de su federación y permite mediar entre las interacciones entre diferentes agentes, de modo que un agente iniciador contacta con el mediador en vez de preguntar directamente al otro agente. Como agente monitor, controla los estados de los agentes de la federación y permite que los agentes se suscriban a él sobre eventos relevantes, informándoles de los cambios ocurridos sobre los eventos u objetos monitorizados.

Finalmente, como agente embassy proporciona una capa de seguridad a los miembros de su federación, controlando la comunicación de agentes externos con los agentes de la federación, traduciendo los mensajes entre ellos de acuerdo a una ontología estándar y pudiendo denegar a los agentes externos la solicitud de comunicación con los agentes de la federación.

Las arquitecturas MetaMorph I [Maturana et al., 1990] y MetaMorph II [Shen y Norrie, 1998] emplean un sistema de agentes federados para procesos de manufactura inteligentes. En él los agentes se encargan de la manufactura y diseño de productos, enfrentándose a recursos heterogéneos, condiciones dinámicas cambiantes y restricciones de comportamiento.

ORGANIZACIONES MATRICIALES. En estas organizaciones los comportamientos de un agente o de un grupo de agentes son influenciados por múltiples líneas de autoridad. Es decir, un agente podrá ser controlado por más de un agente supervisor.

Sin embargo, el agente comparte sus habilidades entre las distintas líneas de autoridad. Así, si una determinada habilidad es necesaria en dos tareas separadas, el agente será empleado para realizar ambas, siempre que tenga suficiente capacidad computacional. En caso de que el agente tenga múltiples maneras de realizar la tarea, selecciona el método que mejor satisfaga a sus supervisores. Pueden surgir problemas si las decisiones tomadas por sus supervisores son contradictorias. Para un correcto funcionamiento, el agente debe poseer un mecanismo de evaluación de compromisos y una autonomía suficiente para resolver conflictos locales, o bien la capacidad de promover los conflictos a un nivel superior donde se resuelvan. 
Un ejemplo de organización matricial es la arquitectura MACRON [Decker et al., 1995], en la que múltiples agentes buscan información relevante en respuesta a la solicitud del usuario. Los agentes están separados en grupos funcionales predefinidos, que contienen agentes que acceden a un tipo particular de información. Estos grupos están bajo el control de un supervisor funcional, que asigna agentes a tareas de tipo pregunta. Además, los agentes ofrecen sus respuestas a dos agentes: un supervisor funcional estático y un supervisor de preguntas, que cambia según la acción del usuario.

En el trabajo de B. Horling se describe una aplicación de una red de sensores distribuidos, donde un track manager se encarga de coordinar y descubrir los sensores necesarios para seguir la pista a su objetivo [Horling et al., 2003]. Cuando se acercan múltiples blancos al mismo sensor se forma una matriz en la que los managers relevantes interaccionan con dicho sensor. Como resultado, un individuo está bajo la autoridad de varios managers y debe decidir cómo adecuarse mejor a sus demandas.

\subsubsection{Comparación de taxonomías}

En la tabla 2.2 se muestra un resumen de las características más relevantes que presentan las organizaciones humanas analizadas anteriormente y en la figura 2.3 se resumen las características, ventajas y desventajas de sus diferentes tipos de estructuras.

Dichas estructuras de organización humanas presentan grandes similitudes con las organizaciones de agentes vistas anteriormente. Así, las jerarquías, holarquías y las organizaciones matriciales son aplicaciones de las organizaciones mecánicas y se relacionan, por tanto, con la estructura simple, la burocracia y la estructura matricial.

Por su parte, los equipos, las coaliciones, las congregaciones y federaciones representan ejemplos de organizaciones orgánicas, relacionándose por tanto con la estructura de equipos, la adhocracia y la organización virtual.

Esto confirma que el estudio de las organizaciones humanas y, en concreto, de los mecanismos de diseño de este tipo de organizaciones sirve de base para el análisis y diseño de sistemas multiagente. 


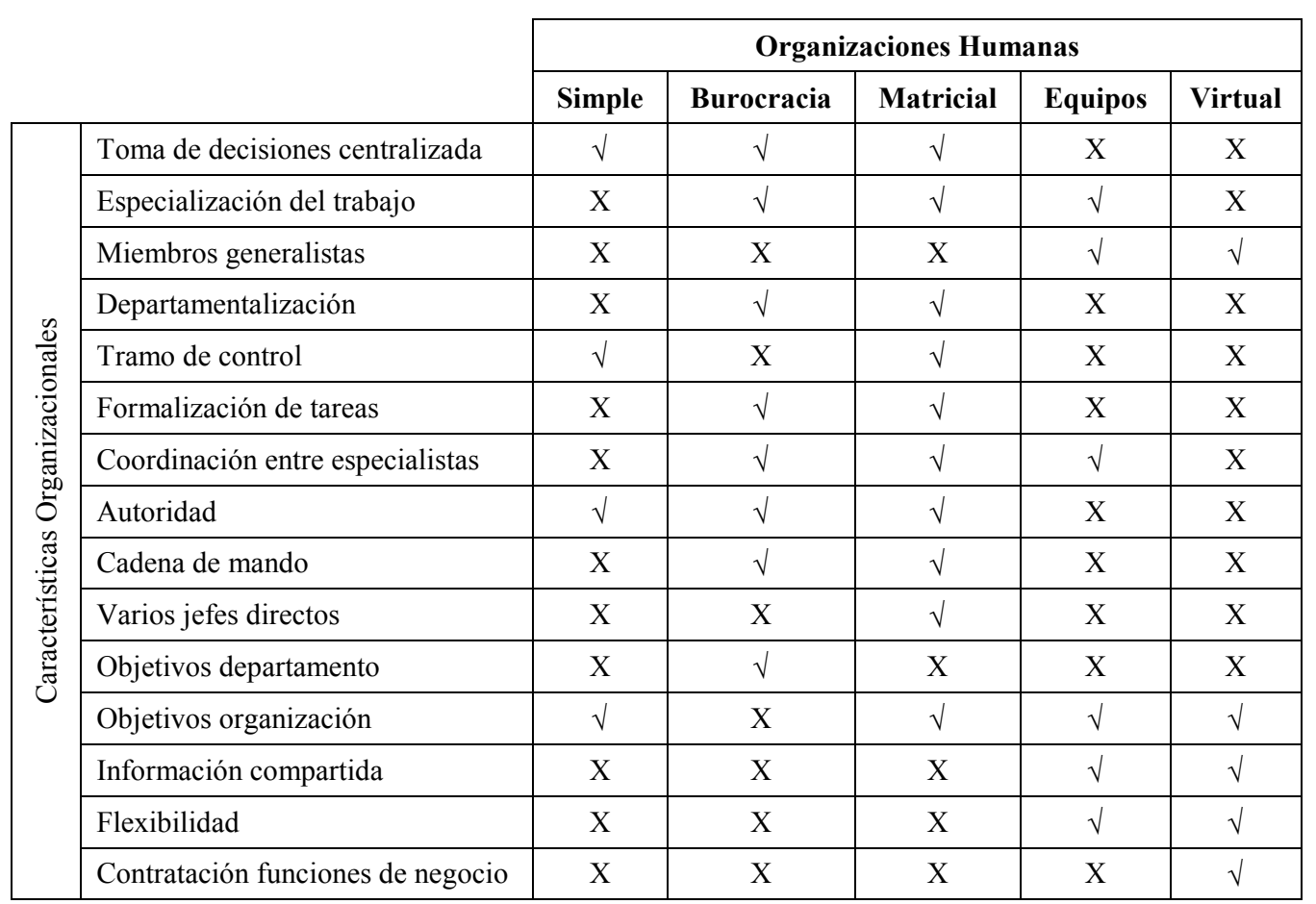

Figura 2.2: Características de organizaciones humanas

\subsection{Sistemas abiertos}

Un sistema abierto es aquel que permite la incorporación de componentes durante la ejecución del sistema que no tienen por qué haber sido conocidos durante la fase de diseño [Gonzalez-Palacios y Luck, 2007]. Normalmente, los componentes de un sistema abierto no han sido diseñados ni desarrollados por los mismos grupos de investigación, o no representan a los mismos clientes o usuarios. Además, los agentes podrían emplear diferentes protocolos, usar lenguajes distintos e incluso estar implementados con diferentes arquitecturas. Por tanto, son sistemas heterogéneos. Sin embargo, independientemente de cómo se haya desarrollado, un componente adoptará un determinado rol en la organización, para el cual se habrán establecido los derechos, permisos, obligaciones y restricciones necesarias que 


\begin{tabular}{|c|c|c|c|c|}
\hline & Estructura & Características & Ventajas & Desventajas \\
\hline \multirow{3}{*}{ 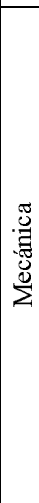 } & Simple & $\begin{array}{l}\text { Poca departamentalización } \\
\text { Decisiones centralizadas } \\
\text { Gran tramo de control } \\
\text { Estructura plana } \\
\text { Poca formalización }\end{array}$ & $\begin{array}{l}\text { Simple } \\
\text { Fácil de mantener } \\
\text { Responsabilidades claras } \\
\text { Comunicaciones rápidas } \\
\text { Decisiones rápidas }\end{array}$ & $\begin{array}{l}\text { Poca formalización } \\
\text { Elevada centralización } \\
\text { Sobrecarga información en directiva } \\
\text { Dependencia de un individuo }\end{array}$ \\
\hline & Burocracia & $\begin{array}{l}\text { Tareas operativas muy rutinarias } \\
\text { Mucha especialización } \\
\text { Mucha formalización } \\
\text { Gran departamentalización } \\
\text { Autoridad centralizada } \\
\text { Cadena de mando }\end{array}$ & $\begin{array}{l}\text { Eficacia actividades } \\
\text { estandarizadas } \\
\text { Comunicación empleados } \\
\text { Decisiones centralizadas }\end{array}$ & $\begin{array}{l}\text { Seguimiento elevado de reglas } \\
\text { Prioridad en objetivos departamento } \\
\text { Relaciones rígidas y jerárquicas } \\
\text { Dificultad respuesta ante cambios } \\
\text { entorno }\end{array}$ \\
\hline & Matricial & $\begin{array}{l}\text { Funcional + Divisional } \\
\text { Dos cadenas de mando } \\
\text { Más flexible } \\
\text { Prioridad objetivos organización } \\
\text { Ubicación especialistas }\end{array}$ & $\begin{array}{l}\text { Mejora coordinación } \\
\text { Mejora comunicación }\end{array}$ & $\begin{array}{l}\text { Confusión } \\
\text { Luchas de poder } \\
\text { Tensiones }\end{array}$ \\
\hline \multirow{2}{*}{ 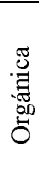 } & Grupo & $\begin{array}{l}\text { Poca departamentalización } \\
\text { Decisiones descentralizadas } \\
\text { Equipos de trabajo }\end{array}$ & $\begin{array}{l}\text { Coordinación } \\
\text { Flexibilidad }\end{array}$ & Necesidad de normas \\
\hline & Org. Virtual & $\begin{array}{l}\text { Contratación de funciones } \\
\text { Descentralización } \\
\text { Poca departamentalización }\end{array}$ & Flexibilidad & $\begin{array}{l}\text { Poco control de gerencia } \\
\text { Complejidad }\end{array}$ \\
\hline
\end{tabular}

Figura 2.3: Características de las estructuras de organización

regulen su comportamiento.

La gran mayoría de las implementaciones de sistemas multiagente se corresponden con sistemas cerrados, donde ningún agente externo está habilitado para entrar a participar en la sociedad. En estos sistemas, se conoce a priori el conjunto de agentes durante la fase de diseño. Además se asume que los agentes son benevolentes y confían entre sí en sus interacciones [Zambonelli et al., 2000]

Los sistemas abiertos existen en entornos operativos dinámicos, en los que se integran nuevos componentes, o bien componentes existentes abandonan el sistema de forma continua y donde las propias condiciones de operación cambian de forma impredecible [Zambonelli et al., 2003]. Por tanto, los participantes entran o salen del sistema de forma dinámica, de modo que no se conoce de antemano (en la fase de diseño) el número total de participantes que existe en cada momento. Por ello, al diseñar el sistema se debe tener en cuenta la llegada dinámica de agentes desconocidos y la posibilidad de comportamientos auto-interesados en el transcurso de las interacciones. 
En resumen, los sistemas abiertos se caracterizan por la heterogeneidad de sus participantes, la confianza limitada, la existencia de objetivos individuales en conflicto y una gran probabilidad de no conformidad a las especificaciones [Dastani et al., 2003]. En este tipo de sistemas la complejidad principal reside en las comunicaciones, pues el diseñador del agente no siempre va a conocer qué otros tipos de agente existirán en el sistema ni cómo se comunicará con ellos. Por tanto, resultan muy complicados de diseñar e implementar.

Ejemplos típicos de sistemas abiertos son las aplicaciones de e-commerce y los sistemas de agentes de información [Dastani et al., 2003]. Los agentes (por ejemplo, asistentes personales para comprar por Internet) adoptarán de forma temporal ciertos roles (como el rol comprador en una subasta on-line).

Algunos trabajos y entornos de modelado, como las Instituciones Electrónicas [Esteva et al., 2001b], abordan la complejidad de la implementación de los sistemas abiertos a través de la utilización de agentes internos que actúan como representantes de los agentes externos que desean participar en la organización. De este modo, los agentes externos no participan directamente en este sistema, sino que solicitan a la institución la creación de uno o varios agentes dentro de la sociedad, para que éstos participen allí en su nombre. La institución creará estos agentes, que serán conocidos y controlados por la propia institución, pero que tratarán de alcanzar los objetivos definidos por los agentes externos [Davidsson, 2001].

La utilización de organizaciones de agentes para el diseño y modelado de sistemas abiertos permitirá establecer qué estructura de roles y agrupaciones tendrá el sistema, qué mecanismos se adoptarán para la entrada y salida dinámica de sus componentes y cómo gestionar y controlar las normas que rigen el comportamiento de los miembros del sistema. 


\subsection{Conclusiones}

Como se ha visto en este capítulo, las organizaciones humanas establecen una serie de mecanismos que permiten restringir y canalizar las actividades a realizar, en vistas a coordinarlas.

En primer lugar, la especificación de los objetivos y sub-objetivos de la organización determina las tareas que se han de llevar a cabo. Éstas requieren de ciertos roles bien diferenciados, cada uno de los cuales lleva asignada una o más actividades específicas para situaciones concretas. Estos roles dan lugar a una estructura que permite la coordinación de las actividades y la transmisión de información.

En segundo lugar, en la organización se dispone de sistemas de selección e incorporación de miembros, con los que se trata de elegir a aquellos cuyas conductas resulten más adecuadas.

Finalmente, la organización dispone de mecanismos de entrenamiento y socialización, no sólo respecto de las tareas, sino también respecto de los roles, normas y valores, para así crear una mente de grupo. Los grupos están compuestos por un limitado número de individuos que tienen interacciones comunes y un cierto grado de valores y normas compartidos.

Para determinar cuál es la estructura de organización más adecuada para el sistema, los diseñadores deberán realizarse las siguientes preguntas: cómo subdividir las tareas en subtareas independientes, formalizadas y estandarizadas (si es que ello es posible); qué tareas tienen dependencias entre sí; cómo agrupar las tareas y en base a qué (por producto, por proceso, cliente, geográfico); dónde se deben tomar las decisiones y llevar el control de la organización; qué tipo de entorno se debe considerar (dinámico, estático, abierto, cerrado); a quién deben proporcionar sus resultados los miembros de la sociedad; cuáles son las reglas y formalizaciones necesarias, etc. La resolución de todas estas cuestiones permitirá que los diseñadores puedan distinguir mejor cuáles son las características de la organización.

Las organizaciones resultan ser un paradigma útil para el análisis y diseño de MAS [den Broek et al., 2005], pues permiten limitar el alcance de 
las interacciones de los agentes, proporcionando patrones de interacción previamente establecidos. También ofrecen mecanismos para la subdivisión de las tareas y la especialización del trabajo. Además permiten formalizar los objetivos del sistema a alto nivel, estableciendo los fines de la organización. Por otro lado, las unidades o grupos que contiene la organización proporcionan ciertos límites de visibilidad entre sí, de tal manera que la estructura interna de cada unidad podrá ser conocida por los agentes pertenecientes a ella, pero no por los agentes externos a la misma [Ferber et al., 2003].

Según V. Dignum, las organizaciones de agentes representan un paso adelante de los sistemas multiagente, al permitir la coordinación y colaboración en los sistemas abiertos [Dignum y Dignum, 2006]. Es más, la organización existe como tal independientemente de los agentes que participen en ella, los cuales entrarán y saldrán del sistema de forma dinámica. Y además se asume la existencia de objetivos globales, que determinan la existencia de la propia organización. Como sistema abierto, permite la llegada de nuevos agentes, que normalmente necesitarán registrarse mediante contratos, en los que especifiquen sus intereses y habilidades.

En el análisis realizado sobre los tipos de organizaciones de agentes existentes, sus características y componentes hemos comprobado que, en general, se basan precisamente en las organizaciones humanas. Es más, si ahondamos en el estudio de estas últimas, podremos definir nuevas guías y métodos de diseño para los sistemas multiagente que faciliten la implementación de organizaciones. Esto confirma la posibilidad de llevar a cabo nuestra hipótesis inicial que, tal y como se comentó en el capítulo 1, pretende aplicar el diseño de las organizaciones humanas en el área de los sistemas multiagente. 



\section{Capítulo 3}

\section{Estado del arte}

En este capítulo se realiza una revisión de los trabajos sobre análisis y diseño de sistemas multiagente, centrándonos principalmente en los métodos basados en las organizaciones de agentes. Para cada método se identifican sus resultados más relevantes, los mecanismos que proporcionan para la descripción de los diferentes factores o dimensiones de las organizaciones, así como el grado de apoyo que ofrecen para el desarrollo de organizaciones de agentes y la implementación de sistemas abiertos. Asimismo, se realiza una revisión de las plataformas de agente que proporcionan algún tipo de soporte para los conceptos de organización.

\subsection{Introducción}

En los desarrollos iniciales de sistemas multiagente, los diseñadores se centraron en el estudio del agente, es decir, en la estructura interna del mismo y en su comportamiento. Las organizaciones, como mucho, emergían de las interacciones de los agentes [O. Boissier, 2007], por ejemplo con los protocolos de tipo Contract Net o la formación de coaliciones de dependencia. Sin embargo, los métodos de análisis y diseño de sistemas multiagente no consideraban a las organizaciones como entidades propias, ni tampoco los agentes las trataban como conceptos sobre los que razonar. En realidad, los 
agentes eran vistos como entidades autónomas y dinámicas que evolucionaban en función de sus propios objetivos, sin que existieran restricciones explícitas externas sobre sus comportamientos ni comunicaciones [O. Boissier, 2007].

Para facilitar la localización de los otros agentes del sistema, el estándar FIPA $^{1}$ propone una arquitectura de plataforma de agente que ofrece dos servicios básicos: el servicio de páginas blancas (AMS), para obtener la dirección de los agentes del sistema; y el servicio de páginas amarillas (DF), donde se describen los servicios o funcionalidades de los agentes.

Por su parte, la plataforma RETSINA [Sycara, 2001] desarrolló una serie de agentes intermedios (middle-agents), como brokers, matchmakers, monitores, mediadores, etc., que facilitan la localización de los mejores proveedores de servicios a los agentes clientes que los solicitan.

En los últimos años, el interés de los desarrolladores se ha dirigido a los aspectos organizativos de la sociedad de agentes [Ferber y Gutknetch, 1998] [Rocha y Demazeau, 1996]. De este modo, el proceso de desarrollo del sistema se guía por los conceptos de organización, grupo, normas, roles, funciones, etc., estableciéndose dos niveles descriptivos: el de la organización y el del agente [O. Boissier, 2007]. Los agentes son vistos ahora como entidades dinámicas que evolucionan dentro de las organizaciones, las cuales restringen sus comportamientos y son también el resultado de las propias actividades de los agentes.

Debido a la nueva concepción de los sistemas multiagente como sociedades de agentes, autores como J. Ferber o V. Dignum consideran que existen dos tipos diferentes de metodologías, según el proceso de desarrollo realizado [Ferber et al., 2003; Dignum et al., 2002]. Así, si el proceso viene guiado por la organización del sistema, se dice que la metodología es orientada a la organización (organizational-oriented methodology). Por su parte, si el proceso se centra en la especificación de las acciones individuales de los agentes, se dice que la metodología es orientada al agente (agent-oriented methodology).

\footnotetext{
${ }^{1}$ www.fipa.org
} 
Respecto a las plataformas multiagente, suelen ofrecer una infraestructura estándar de comunicación para los agentes y la implementación de conceptos básicos, como objetivos, planes y protocolos. Además, las plataformas más conocidas también incluyen los servicios de AMS y DF propuestos por FIPA.

Sin embargo, en relación a las organizaciones de agentes, los diseñadores deben implementar por sí mismos la mayoría de las características organizativas, como las restricciones de comunicación impuestas por la topología organizativa. Recientemente se han desarrollado algunas plataformas ligadas a metodologías orientadas a la organización, como AMELI [Esteva et al., 2004] o S-MOISE+ [Hubner et al., 2006], que recogen algunos de los aspectos más relevantes de las sociedades de agentes, como son la implementación de normas.

En este capítulo se realiza un estudio de las metodologías de agente más importantes, tanto de las orientadas al agente (sección 3.2) como de las orientadas a la organización (sección 3.3), haciendo especial hincapié en estas últimas. El objetivo de este estudio se centra en analizar sus características más relevantes y relacionarlas con las variables y componentes organizativos vistos en el capítulo anterior. De este modo se determina cuál o cuáles de las metodologías analizadas facilitan en mayor grado el desarrollo de organizaciones de agentes y la implementación de sistemas abiertos. Por otro lado, en la sección 3.4 se explican aquellas plataformas de agente empleadas por estas metodologías que ofrecen algún tipo de soporte para la implementación de organizaciones de agentes. Finalmente, la sección 3.5 contiene las conclusiones del capítulo.

\subsection{Metodologías MAS orientadas al agente}

En este tipo de metodologías, el diseñador de MAS se centra en las acciones individuales de los agentes, por lo que los sistemas se diseñan en términos de los estados mentales de los agentes (como creencias, intenciones, 
objetivos, obligaciones, etc.). Las estructuras sociales no se modelan explícitamente, sino que se supone que emergen como resultado de la interacción de los agentes.

Muchas de las metodologías orientadas al agente son extensiones de otras metodologías existentes (como la Orientación a Objetos y la Ingeniería del Conocimiento), a las que se les añaden ciertos aspectos concernientes a los agentes. Suelen asumir una perspectiva individualista en la que los agentes se consideran como entidades autónomas que persiguen sus propios objetivos individuales basándose en sus propias creencias y habilidades [Dignum et al., 2002]. Por tanto, el comportamiento global del sistema emerge a raíz de las interacciones individuales de los agentes y no puede ser fácilmente manejado o especificado externamente.

Ejemplos de estas metodologías son Gaia ( $1^{\text {a }}$ versión) [Wooldridge et al., 2000], Tropos (1 $1^{a}$ versión) [Giunchiglia et al., 2002], Prometheus [Padgham y Winikoff, 2002], MaSE [Wood et al., 2001], MAS-CommonKADS [Iglesias et al., 1996] y MASSIVE [Lind, 2001]. En [Iglesias et al., 1999], [Gomez, 2003], [Julian, 2002], [Wooldridge y Ciancarini, 2001], [Shehory y Sturm, 2001] se muestran diversas comparativas de metodologías orientadas al agente.

La mayoría de estas metodologías cubren las fases de análisis, diseño y en mucha menor medida la de implementación. Además, en algunos casos se hace uso de herramientas CASE. Asimismo, ciertas metodologías, como Tropos y Prometheus, están focalizadas en plataformas de agente específicas, como la plataforma JACK [Howden et al., 2001].

A continuación se comenta con mayor detalle las metodologías orientadas al agente más conocidas y relevantes.

GAIA. Una de las metodologías más estudiadas es Gaia [Wooldridge et al., 2000], que permite el análisis y diseño de sistemas multiagente concibiéndolos como organizaciones computacionales de agentes, los cuales juegan roles específicos de la organización y cooperan entre sí para alcanzar el objetivo común de la aplicación. Consta solamente de una fase de análisis 
y de una fase de diseño, mientras que no se incluye ni la fase de especificación de requisitos ni la de implementación, por lo que se debería utilizar otra metodología para detallarlas.

En la fase de análisis se definen los modelos de rol y de interacción. Para cada rol se especifican sus responsabilidades, permisos, actividades y protocolos. Las responsabilidades determinan su funcionalidad, expresan su ciclo de vida y las condiciones que el rol debe preservar. Los permisos determinan los recursos disponibles por el rol. Las actividades representan las acciones que no implican interacción con otros agentes. Finalmente, los protocolos definen el propósito de las interacciones entre agentes. Dichas interacciones se detallan en profundidad en el modelo de interacción, que describe los protocolos entre roles, capturando sus dependencias y relaciones.

En la fase de diseño se definen los modelos de agente, de servicio y de comunicación. El modelo de agente describe los tipos de agentes que compondrá el sistema y su cardinalidad. A cada tipo de agente se le asigna uno o más roles. El modelo de servicio define los servicios asociados con los tipos de agente. Un servicio representa un bloque de funcionalidad coherente, que se deriva de las actividades y protocolos de los roles. Finalmente, el modelo de relaciones define los enlaces de comunicación entre los tipos de agente.

Esta metodología asume un objetivo común entre los agentes del sistema, por lo que no se ha diseñado para sistemas multiagente abiertos. Además, la fase de diseño aborda aspectos a muy alto nivel y no especifica ninguna arquitectura de agente concreta, de modo que a la hora de implementar el sistema será necesario hacer uso de otras metodologías que permitan especificar con mayor detalle la fase de diseño y realizar una correcta implementación del sistema. Actualmente existe una ampliación o extensión de esta metodología a sistemas organizativos, llamada también Gaia, que se explica en el punto 3.3.

TROPOS. Esta metodología [Giunchiglia et al., 2002] cubre el proceso completo de desarrollo de software desde los requisitos iniciales hasta la implementación, utilizando el entorno de modelado $i^{*}$ [Yu, 1996]. La 
construcción del sistema MAS se divide en cinco fases: requisitos iniciales, requisitos tardíos, diseño de arquitectura, diseño detallado e implementación.

En los requisitos iniciales se modelan los actores principales del dominio del sistema y sus intenciones, mediante diagramas de actores y de objetivos. Un actor representa tanto agentes físicos como agentes software, roles o grupos de roles. El diagrama de actores detalla los actores principales y sus dependencias sociales, es decir las relaciones necesarias entre actores para cumplir sus objetivos, ejecutar planes y suministrar recursos. El diagrama de objetivos permite analizar los objetivos y los planes respecto a cada actor. Así, se identifican los requisitos funcionales, los no funcionales, los planes y recursos necesarios para cumplir los objetivos y cuáles son las relaciones existentes entre ellos. Por su parte, en los requisitos tardíos se modela el sistema con su entorno, incluyéndolo como otro actor más. Para ello se extienden los modelos anteriores y se definen de forma completa los requisitos funcionales y no funcionales del sistema.

En el diseño de la arquitectura se descompone el sistema añadiendo nuevos actores, derivados de la elección del estilo arquitectónico, que permitan cumplir los requisitos no funcionales y los sub-objetivos. Además se identifican las habilidades, agrupándolas en tipos de agente. En el diseño detallado se especifica la estructura interna de los agentes, mediante diagramas de habilidades, de planes y de interacciones entre agentes. Finalmente, en la fase de implementación, la especificación se transforma en esqueletos de agente para la plataforma JACK [Howden et al., 2001], utilizando una arquitectura BDI.

Actualmente existe una ampliación o extensión de esta metodología a sistemas organizativos, llamada también Tropos, que se explica en el punto 3.3, en la que se propone la agrupación de los agentes y su estructuración, utilizando topologías específicas de organización.

PROMETHEUS. Esta metodología [Padgham y Winikoff, 2002; 2004] 
considera el ciclo completo del software para el diseño de sistemas multiagente, es decir, especificación, análisis, diseño, implementación, test y mantenimiento.

Las fases de especificación y análisis se integran en la denominada system specification phase, donde se identifican las percepciones y acciones del sistema, así como los objetivos y funcionalidades del mismo. Las funcionalidades equivalen a los roles del sistema. Por cada funcionalidad se define el listado de acciones y percepciones que las activan, los datos utilizados y producidos y las interacciones que se establecen con otras funcionalidades. También se definen los escenarios, formados por una secuencia de pasos, un contexto (situaciones en las que ocurre el escenario) y un resumen de las informaciones utilizadas en los pasos del mismo. Por su parte, cada paso del escenario define un evento o percepción de entrada, un mensaje (con su emisario y receptor) y la actividad y acción implicadas (funcionalidad).

La fase de diseño se divide en diseño de la arquitectura y diseño detallado. La fase de diseño de la arquitectura se centra en la parte interna de cada agente y cómo realizará sus tareas. Inicialmente se define el Data coupling diagram, que muestra la relación entre las funcionalidades y los datos. Además, permite ver qué funcionalidades interaccionan entre sí. A partir de él se obtiene el Agent acquaintance diagram, que relaciona los agentes con las funcionalidades y muestra las interacciones entre los agentes. Por su parte, los descriptores de agentes describen las características de cada agente, indicando su cardinalidad, funcionalidades asociadas, los datos que leen y que escriben, con quién interaccionan, sus objetivos, percepciones y eventos.

A partir de los escenarios se definen los diagramas de interacción, que muestran las interacciones entre agentes, usando diagramas de secuencia UML. De estos diagramas se determinan los protocolos de interacción, especificados en AUML, que definen las secuencias de interacción válidas entre los agentes, describiendo el comportamiento dinámico del sistema. Otro resultado importante de esta fase es el System Overview Diagram, que describe cómo el sistema funciona como un todo, indicando las relaciones entre 
los agentes, los datos, las entradas y salidas, así como la comunicación entre los agentes.

En la fase de diseño detallado se desarrolla la estructura interna de cada agente especificando cómo realizarán sus tareas en el sistema. El modelo particular de agente a emplear es el de agentes basados en planes, que pueden ser implementados directamente en arquitecturas basadas en BDI. A partir de los descriptores de agente se construye el Agent overview diagram, que detalla la estructura interna de agente a alto nivel y el Capability overview diagram, que describe las habilidades de los agentes, indicando sus planes, eventos y habilidades anidadas.

La implementación del sistema se realiza sobre la plataforma JACK, para la cual se han desarrollado varias herramientas de soporte en las fases de diseño. En concreto, JACK Development Environment (JDE) ${ }^{2}$, que permite dibujar los diagramas generales (system overview, agent overview, capability overview) y Prometheus Design Tool(PDT) [Thangarajah et al., 2005], que permite diseñar entidades en términos de conceptos Prometheus.

Respecto a la fases de implementación, test y mantenimiento, la propia herramienta JDE permite obtener de forma automática esqueletos de código para JACK y JADEX [Pokahr et al., 2005].

Esta metodología facilita en gran medida el desarrollo de sistemas cerrados, en donde la funcionalidad de los agentes es conocida, pero no resulta tan útil para los sistemas abiertos, pues no tiene en cuenta que los agentes presenten comportamientos interesados. Así, no se diseñan normas para controlar las interacciones, ni tampoco métodos para la entrada y salida dinámica de sus componentes. Además, las agrupaciones de los agentes y sus posibles patrones de interacción y estructuración tampoco son considerados.

MASE. La metodología Multiagent Systems Engineering (MaSE) [Wood, 2000] provee guías para el desarrollo del MAS, desde la especificación inicial del sistema hasta su implementación. El proceso de desarrollo consiste en

\footnotetext{
${ }^{2}$ http://www.agents.org.au/20010427Winikoff-slides/index.htm
} 
siete pasos, dividido en dos fases (análisis y diseño).

En la fase de análisis, se emplean los requisitos para definir casos de uso y objetivos, así como para identificar los roles y sus interacciones. En primer lugar, en la captura de objetivos se identifican los objetivos y su estructura, representada mediante una jerarquía de objetivos. A continuación, en la aplicación de casos de uso se modelan los principales escenarios y se construyen diagramas de secuencia (en UML), para tener en cuenta las secuencias de eventos. Posteriormente, en el refinamiento de roles se construye un modelo de roles y un modelo de tareas concurrentes. El modelo de roles describe los roles del sistema, los objetivos de los que son responsables dichos roles, sus tareas y los caminos de comunicación entre los roles. El modelo de tareas concurrentes detalla las tareas mediante máquinas de estados finitos.

En la fase de diseño, las clases de agente y los protocolos de interacción se derivan de la salida de la fase de análisis, dando lugar a una definición completa de la arquitectura del sistema. En primer lugar, en la creación de las clases de agente se detalla el diagrama de clases de agente, que describe al sistema multiagente completo, mostrando los agentes, los roles que juegan y sus conversaciones. En segundo lugar, en la construcción de conversaciones se detallan con mayor precisión las conversaciones de los agentes, mediante diagramas de clases de comunicación. En tercer lugar, en la unión de clases de agentes se define la arquitectura de agente y los componentes que la constituyen, utilizando el lenguaje UML+OCL [Robinson, 2000]. Finalmente, en el diseño del sistema se especifica la localización de los agentes dentro del sistema (con un diagrama de utilización) y se instancian las clases de agente.

La metodología MaSE no especifica ninguna plataforma de implementación particular, sino que el diseñador debe decidir, durante la unión de clases de agentes, la arquitectura a utilizar. Sí que ofrece herramientas de soporte para el análisis y diseño. Por ejemplo, la versión 2.0 de la herramienta agentTool implementa los siete pasos de la metodología. También provee soporte automático para la transformación de los modelos de análisis en 
construcciones de diseño. Por otro lado, como indican sus propios autores, MaSE solamente resulta adecuada para sistemas multiagente cerrados al no contemplar comportamientos auto-interesados de los agentes.

MAS-COMMONKADS. Esta metodología [Iglesias et al., 1996], basada en la metodología CommonKADS [Schreiber et al., 2000] para sistemas expertos, aporta nuevos modelos para el desarrollo de las fases de análisis y diseño de sistemas multiagente.

Inicialmente, en la fase de conceptualización se obtiene una descripción preliminar del problema mediante casos de uso. Así se consigue una idea de los requisitos del sistema y de las interacciones de sus elementos.

La fase de análisis permite realizar la especificación de los requisitos del MAS empleando diversos modelos que se construyen iterativamente: (i) modelo de agente, que describe las propiedades y características de cada agente; (ii) modelo de tareas, que describe las funciones o tareas que desarrolla el sistema para alcanzar sus objetivos; (iii) modelo de coordinación, que describe las interacciones entre los agentes; (iv) modelo de conocimiento, que detalla el conocimiento del dominio, de los agentes y del entorno; (v) modelo de organización, que estudia la viabilidad de la solución en la organización de la empresa y establece una jerarquía de agentes; y (vi) modelo de comunicación, que describe las interacciones entre agentes software y humanos, detallando las interfaces de usuario.

En la fase de diseño se desarrollan los modelos propios del diseño: (i) diseño de la red de agente, que describe los aspectos relevantes de la infraestructura de red; (ii) diseño del agente, donde se dividen o agrupan los agentes del análisis y se selecciona la arquitectura de agente más adecuada para cada agente; y (iii) diseño de la plataforma, donde se escoge la plataforma de agente para cada arquitectura.

Aunque se hace uso de un modelo de organización, en éste no se describe cómo se agrupan los agentes entre sí ni cuáles son los objetivos globales de la organización, entre otros aspectos, sino que simplemente se analiza cómo el sistema multiagente se integrará dentro del sistema informático de 
la empresa en la que funcione. Por tanto, no se consideran los factores de estructura, funcionalidad, dinamicidad y normalización de la organización.

MASSIVE. Este método de desarrollo de sistemas multiagente (MultiAgent SystemS Iterative View Engineering) [Lind, 2001] consta de un conjunto de vistas del sistema que se van refinando de forma iterativa. La vista de tareas indica qué debe realizar el sistema, analizando para ello los aspectos funcionales del sistema y generando una jerarquía de tareas. En esta vista no se asume aún el empleo de una aproximación multiagente, sino que solamente muestra una visión de la funcionalidad del sistema a alto nivel.

La vista de entorno analiza el entorno del sistema según la perspectiva del desarrollador (que tiene una visión global) y la del agente (con conocimiento local de su entorno). La vista de roles indica quién debe realizar cada tarea, determinando así las abstracciones de rol necesarias para cubrir la funcionalidad y las restricciones físicas de la especificación del problema. También se considera aquí cómo asignar uno o más roles particulares a agentes concretos.

En la vista de interacción se muestran las interacciones entre los agentes, no sólo comunicativas sino de cualquier tipo (resolución de conflictos). La vista de sociedad, que parte del modelo de roles, clasifica la sociedad existente. Una sociedad es una colección estructurada de entidades que persiguen un objetivo común. La vista de arquitectura transforma la especificación del resto de vistas en una arquitectura de sistema donde se definen sus atributos estructurales, indicando la arquitectura de agente a emplear.

Finalmente, la vista de sistema trata con aspectos del sistema que afectan al resto de vistas o al sistema en su conjunto, como el diseño de interfaces de usuario, el manejo de errores, la implementación propia del sistema, etc.

En este método, la vista de sociedad se encarga de establecer agrupaciones de los roles en función del contexto y de ciertas medidas de funcionamiento del sistema, aunque no se ofrecen patrones de diseño específicos que guíen en la elección de la agrupación más adecuada. 


\subsubsection{Discusión sobre las metodologías orientadas al agente}

A partir del estudio realizado, se observan los siguientes aspectos de las metodologías orientadas al agente analizadas: (i) se asume un objetivo común entre los agentes; (ii) se asumen agentes benevolentes y cooperativos; (iii) muchas están centradas en una arquitectura de agente específica; (iv) resultan apropiadas para sistemas cerrados, pero no para sistemas abiertos.

Como hemos visto, estas metodologías están bien documentadas, han sido utilizadas en muchas aplicaciones de forma efectiva y proporcionan una buena base para las fases de análisis y diseño del sistema. Además, algunas de ellas detallan también una fase previa de captura de requisitos del sistema, así como las fases posteriores de implementación e implantación del sistema. En la figura 3.1 se muestra un resumen comparativo de los modelos empleados por cada metodología en cada aspecto relevante de estas fases.

Como puntos negativos, destacamos que al centrarse en la visión del agente y no en la del sistema como un todo, no permiten llevar a cabo un análisis previo de las características organizativas del sistema y, por tanto, no es posible estudiar previamente aspectos como su estabilidad en el tiempo, cierto nivel de predecibilidad, los compromisos entre las metas y estrategias, etc.

Es más, el comportamiento final del sistema se asume que emerge de las interrelaciones entre los agentes diseñados, pero en ningún momento se analiza con detalle dicho comportamiento global. Si todos los agentes han sido definidos e implementados por los desarrolladores del sistema (i.e. sistema cerrado), se podrá esperar entonces que el sistema no conlleve ningún comportamiento anómalo. Sin embargo, si se permitiera la entrada al sistema de agentes externos, al no haberse establecido ningún tipo de control sobre ellos, ni definido ninguna norma que imponga obligaciones a los agentes, prohibiciones y sanciones para cuando no cumplan con lo establecido, entonces el comportamiento global del sistema será impredecible.

Otra carencia importante que presentan estas metodologías es que, al no 


\begin{tabular}{|c|c|c|c|c|c|c|c|}
\hline & & Gaia & Tropos & Prometheus & MaSE & $\begin{array}{c}\text { MAS- } \\
\text { CommonKADS }\end{array}$ & MASSIVE \\
\hline \multicolumn{2}{|c|}{$\begin{array}{l}\text { Captura } \\
\text { Requisitos }\end{array}$} & & $\begin{array}{l}\text { Goal Diagram } \\
\text { Early Require. } \\
\text { Late Require. }\end{array}$ & System Spec. & $\begin{array}{l}\text { Casos de Uso } \\
\text { Escenarios }\end{array}$ & Casos de Uso & Vista Tareas \\
\hline \multirow{4}{*}{ 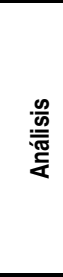 } & Roles & Mod. Roles & Actor Diagram & Funcionalidades & Mod. Rol & $\begin{array}{c}\text { Mod. Agente } \\
\text { Mod. Tareas } \\
\text { Mod. Organización }\end{array}$ & $\begin{array}{l}\text { Vista Roles } \\
\text { Vista Sociedad }\end{array}$ \\
\hline & Interaccion & $\begin{array}{c}\text { Mod. } \\
\text { Interacción }\end{array}$ & & Escenarios & $\begin{array}{c}\text { Concurrent Task } \\
\text { Model }\end{array}$ & Mod. Coordinación & Vista Interacción \\
\hline & Entorno & Permisos rol & Late Require. & $\begin{array}{c}\text { System Spec. } \\
\text { System Overview }\end{array}$ & & Mod. Conocimiento & Vista Entorno \\
\hline & Interfaces & & & & & $\begin{array}{c}\text { Mod. } \\
\text { Comunicación }\end{array}$ & Vista Sistema \\
\hline \multirow{3}{*}{ 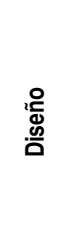 } & Agentes & Mod. Agentes & Actor Diagram & Agent descriptors & Agent Class & Mod. Agente & Vista Roles \\
\hline & Tareas & Mod. Servicio & $\begin{array}{l}\text { Capability } \\
\text { Diagram }\end{array}$ & $\begin{array}{l}\text { Agent Acquaintance } \\
\text { Data Coupling Agent } \\
\text { Capability Overview }\end{array}$ & & & Vista Roles \\
\hline & Relaciones & $\begin{array}{c}\text { Mod. } \\
\text { Relaciones }\end{array}$ & $\begin{array}{c}\text { Plan Diagram } \\
\text { Agent Interaction }\end{array}$ & $\begin{array}{l}\text { Interaction Diagram } \\
\text { Interaction protocol }\end{array}$ & $\begin{array}{l}\text { Comunication } \\
\text { Class }\end{array}$ & Diseño Red & \\
\hline \multirow{2}{*}{$\frac{\dot{E}}{\frac{\dot{\sigma}}{0}}$} & Arquitect. & & $\mathrm{BDI}$ & $\begin{array}{l}\text { Detailed Design } \\
\text { (BDI) }\end{array}$ & $\begin{array}{l}\text { Deployment } \\
\text { Diagram }\end{array}$ & Diseño Agente & Vista Arquitectura \\
\hline & Plataforma & & JACK & JACK & & Diseño Plataforma & Vista Sistema \\
\hline
\end{tabular}

Figura 3.1: Comparación de modelos desarrollados en las fases de Requisitos, Análisis, Diseño e Implementación, para diversas metodologías orientadas al agente

contemplar al sistema como un todo, no aprovechan las características organizativas intrínsecas del dominio en el que se integrará el sistema. Por ejemplo, si se desea implementar un sistema multiagente de información en una empresa donde existen grupos de trabajo colaborativos, resultaría interesante imitar dicha estructura en el sistema de agentes, formando así grupos de agentes autodirigidos que compartan la información.

Además, si se tiene en cuenta la estructura de la organización desde las primeras fases de la metodología, dicha estructura conducirá mejor a un diseño e implementación del sistema multiagente basado. Es más, se podrían construir ciertos patrones de comportamiento para cada tipo de organización (por ejemplo, para los vistos en el capítulo 2) y así reutilizarlos en el diseño de los sistemas.

Cabe comentar que existen algunas metodologías que consideran un modelo de organización durante la fase de análisis, aunque dicho modelo se 
limita a una relación de los roles del sistema (como en MASSIVE), o bien al estudio de la viabilidad de la solución en la organización de la empresa (como es el caso de MAS-CommonKADS). Por tanto, ni abordan los objetivos globales del sistema, ni cuál es su estructura o topología, ni su funcionalidad global y mucho menos cómo controlar su dinamicidad, es decir, el comportamiento final de los agentes y su entrada o salida dinámica en las agrupaciones del sistema.

En los últimos años, un nuevo enfoque metodológico trata de contemplar al sistema como un todo y establecer mecanismos normativos para el control del comportamiento de los agentes y facilitar la participación de agentes externos dentro del sistema. Por tanto, este enfoque intenta superar las carencias anteriormente comentadas. A continuación estudiaremos dicho enfoque de metodologías orientadas a la organización. Así determinaremos en qué medida se realiza el análisis y diseño del sistema en base a organizaciones y cómo se contempla la implementación de sistemas abiertos.

\subsection{Metodologías MAS orientadas a la or- ganización}

En este tipo de metodologías el diseñador del MAS se centra desde un principio en la organización del sistema. Por tanto, analiza el MAS desde una perspectiva global, de modo que el proceso de desarrollo se guía por los conceptos organizativos [Argente et al., 2006].

Estos métodos aparecen como consecuencia de la necesidad de diseñar sistemas que permitan tener en consideración aspectos como la estructura de la organización, sus objetivos, sus normas, etc. desde las etapas iniciales del desarrollo del sistema.

Los objetivos de la organización representan una descripción a alto nivel de los propósitos de la sociedad. Permiten guiar las decisiones sobre cómo se debe diseñar la estructura de la organización. Así, los objetivos determinan qué tareas se deben llevar a cabo, el tipo de agentes y sus habilidades requeridas, y el reparto de los recursos entre los miembros de la organización. 
La estructura de la organización queda formalizada cuando los principios que gobiernan su comportamiento se formulan de forma precisa y los roles y sus relaciones se definen de forma independiente de los atributos y dependencias de las personas o agentes que ocupen una posición particular en la estructura de la organización. Por tanto, dicha estructura viene descrita por los roles, sus interacciones y el lenguaje de comunicación que empleen. Los roles representan las diferentes entidades o actividades necesarias para cumplir con el propósito de la organización. Además, los objetivos globales de la sociedad conforman el punto de partida para especificar los objetivos y acciones a asignar a los roles.

Finalmente, las normas sociales describen el comportamiento esperado de los miembros (desde el punto de vista del diseño de la organización) y qué sanciones se deben aplicar en el caso de acciones no deseables. Las normas suelen ser establecidas y ejecutadas por instituciones que tienen un estatus legal y, por tanto, conceden legitimidad y seguridad a los miembros de la sociedad.

Tras el estudio de distintos trabajos que siguen esta perspectiva metodológica, se observan dos tendencias bien diferenciadas. Por un lado, algunas metodologías se centran solamente en la estructura organizativa, sin realizar de forma explícita el análisis y diseño de las normas sociales. Ejemplos de estas metodologías son Agent-Group-Role [Ferber et al., 2003], Roadmap [Juan et al., 2002], la extensión de Tropos [Giorgini et al., 2003], MESSAGE [Caire et al., 2002], INGENIAS [Gomez, 2002], ANEMONA [Giret, 2005] y AML [Cervenka y Trencansky, 2007].

Por otro lado, algunas metodologías se centran en las normas sociales y definen de forma explícita mecanismos de control para establecer las normas y controlar su ejecución. Además, estas metodologías consideran ciertos mecanismos para incluir agentes externos en la sociedad y controlar su comportamiento. Por tanto, resultan adecuadas para el diseño de sistemas multiagente abiertos.

Ejemplos de este tipo de metodologías son OperA [Dignum, 2003], Civil Agent Societies [Dellarocas y Klein, 1999], SODA [Omicini, 2001], MOISE 
[Gateau et al., 2005] y la extensión de Gaia [Zambonelli et al., 2003].

Además, el marco de trabajo Electronic Institutions [Esteva et al., 2001b] se centra en la perspectiva organizativa y el control de las normas sociales. Asimismo, el marco de trabajo HARMONIA [Vazquez-Salceda y Dignum, 2003] permite modelar las normas de las organizaciones electrónicas en varios niveles, desde el más abstracto, tomando como base los estatutos de la organización, hasta el nivel procedural en el que se implementan los procedimientos y protocolos finales de las normas. Posteriormente, este marco de trabajo se unió a la metodología OperA, definiendo así un nuevo método denominado OMNI [Vazquez-Salceda et al., 2004].

A continuación se explican con más detalle las metodologías y marcos de trabajo orientados a la organización, indicando sus aspectos más relevantes. Además se analizará cómo estos métodos llevan a cabo la identificación de la estructura del sistema, qué topologías consideran, en qué fase de la metodología se lleva a cabo dicha identificación y qué tipo de procesos o modelos generan. También se discutirá si los métodos tienen en cuenta a las organizaciones humanas (vistas en el capítulo 2) y, si es así, cuáles de ellas.

AGENT-GROUP-ROLE. La metodología AGR (Agent-Group-Role) [Ferber et al., 2003], también conocida históricamente como modelo Aalaadin [Ferber y Gutknetch, 1998], se basa en los conceptos de agente (entidad activa y comunicativa que juega roles dentro de grupos, sobre la que no se determina ninguna restricción en su arquitectura ni en sus capacidades mentales); grupo (conjunto de agentes que comparten características comunes) y rol (representación abstracta de una funcionalidad de un agente dentro de un grupo). Dos agentes se comunican entre sí solamente si pertenecen al mismo grupo. Además, un agente puede pertenecer a varios grupos, jugando uno o más roles determinados en cada uno de ellos.

En la metodología, el diseñador debe identificar en primer lugar los grupos principales de la aplicación, teniendo en cuenta si el grupo representa conjuntos de agentes similares o bien a un sistema basado en funciones. En 


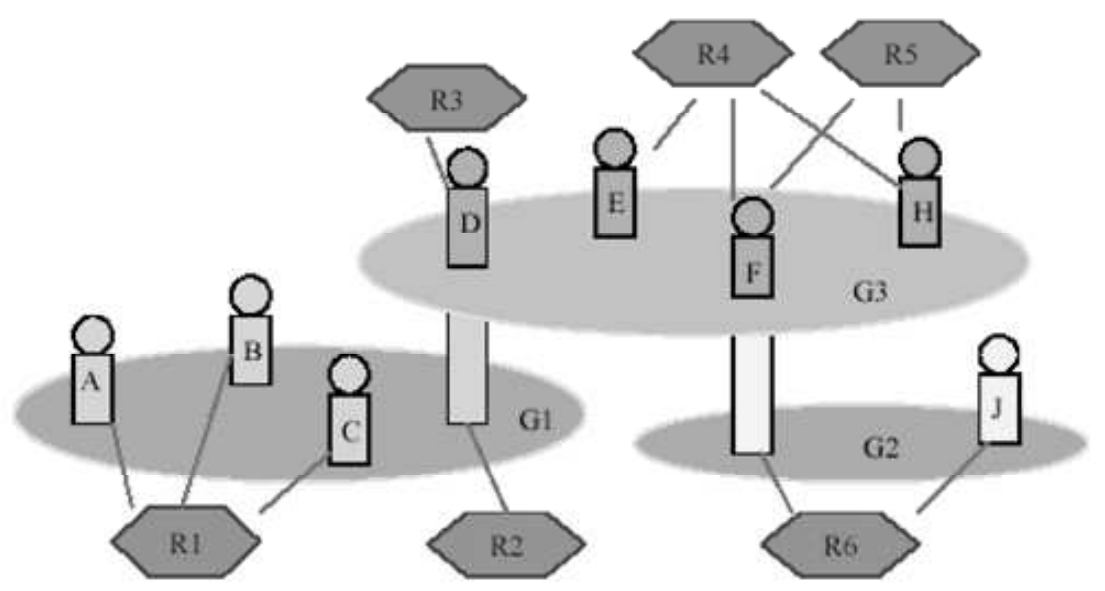

Figura 3.2: Ejemplo de cheeseboard diagram. Los grupos se representan mediante óvalos, sobre los que se dibujan a los agentes, representados por bolos. Los roles se indican mediante hexágonos.

este caso cada rol se corresponde con una función o subsistema del sistema completo. Los agentes actúan como especialistas caracterizados por sus habilidades para cumplir funciones asociadas con los roles. Para representar los grupos de la organización, los agentes que incluyen, así como los roles que éstos adoptan dentro del grupo se emplean los cheeseboard diagrams (figura 3.2).

Una vez identificados los grupos se construye la estructura organizativa general. Esta estructura se expresa mediante una notación gráfica en la que se representan a los grupos, los roles que incluyen, las restricciones entre los roles, así como sus interacciones. Estas interacciones se detallan mediante distintos tipos de diagramas: autómatas, redes de Petri o diagramas de secuencia. Respecto a las restricciones entre los roles, se definen dos tipos de restricciones estructurales: de correspondencia y de dependencia. Las restricciones de correspondencia implican que un agente que juega un rol automáticamente jugará otro rol, debido a relaciones de herencia o especialización. Las restricciones de dependencia expresan dependencias entre pertenencia a grupos y asignación de roles. Por ejemplo, se autoriza a un agente ser director de un laboratorio solamente si también es investigador 
del laboratorio.

A continuación, se determina la dinámica de la organización, definiendo la creación de los grupos, la adhesión o salida de los agentes a los grupos, la adquisición de un rol dentro de un grupo, etc. Además, los agentes deben pasar una fase previa de autorización para poder entrar en un grupo. En dicha fase un agente gatekeeper comprueba la conformidad del agente solicitante con la especificación de la estructura y los roles del grupo. La dinámica de la organización se expresa mediante un diagrama de secuencia organizativa, que es una variación del diagrama de secuencia de AUML [Bauer et al., 2001]. En dicho diagrama se muestra el ciclo de vida de un agente jugando un rol específico dentro de un grupo determinado. Este tipo de diagramas permite representar el hecho que un agente pertenezca a distintos grupos y juegue varios roles a la vez. Además, con un cheeseboard diagram se muestra el proceso de adhesión a los grupos.

En el paso final se definen los roles de forma funcional, siguiendo alguna metodología orientada al agente para especificar los roles y, posteriormente, asociarles una arquitectura. Los autores proponen el uso de Gaia.

En resumen, esta metodología considera al grupo (conjunto de agentes que comparten características comunes) como estructura topológica y asume que los grupos se crean de forma dinámica durante la ejecución del sistema. Sin embargo, no tiene en cuenta otras posibles relaciones estructurales entre los agentes (como burocracias, matriciales, etc.). Tampoco dispone de herramientas para el desarrollo e implementación del sistema.

Por otro lado, los aspectos a nivel de agente (como las principales características del rol, funcionalidades, etc.) deben ser completados utilizando una metodología orientada al agente. Pero los autores no indican cómo establecer la correspondencia entre los modelos definidos en AGR y los modelos de la metodología orienta a agentes seleccionada (por ejemplo Gaia). Finalmente, resulta complicado identificar los grupos sin realizar un análisis previo de cuáles son los objetivos, tareas y roles relevantes en el sistema. Por tanto, sería interesante disponer de diversas guías o pautas para realizar un análisis inicial de requisitos y determinación de los grupos a desarrollar. 
ROADMAP. La metodología Roadmap [Juan et al., 2002], según indica su autor, extiende la metodología Gaia [Wooldridge et al., 2000] para el análisis y diseño de sistemas abiertos complejos. Al igual que Gaia, consta de dos fases: análisis y diseño.

En la fase de análisis se definen seis modelos: de roles, de casos de uso, del entorno, del conocimiento, de protocolo y de interacción. El modelo de roles extiende el modelo propio de Gaia incluyendo una jerarquía de roles. Se distinguen dos tipos de roles: atómicos y compuestos. Los roles atómicos representan características de agentes individuales y conservan la misma semántica que en Gaia. Vienen caracterizados por cuatro atributos: responsabilidades (que determinan la funcionalidad del rol); permisos (que limitan los recursos disponibles para el rol); actividades (tareas privadas que un rol lleva a cabo sin interaccionar con otros) y protocolos (que definen las interacciones). Los roles compuestos representan una organización localizada de agentes y se definen en términos de otros roles, tanto atómicos como compuestos. Sus cuatro atributos (responsabilidades, permisos, actividades y protocolos) modelan aspectos sociales de la organización.

El modelo de casos de uso recoge los requisitos del sistema empleando diagramas gráficos y escenarios. El modelo del entorno se deriva del modelo de casos de uso y describe las diferentes zonas que se aprecian en el entorno, así como sus objetos, restricciones, recursos y supuestos. A partir de estos dos modelos, el desarrollador identifica el conocimiento requerido para repartir los comportamientos de los agentes entre las distintas zonas de cada caso de uso. Este conocimiento se descompone en bloques coherentes más pequeños, llamados componentes de conocimiento. En el modelo del conocimiento se establece la relación o jerarquía entre dichos componentes, proveyendo así una visión general del dominio de conocimiento del sistema. El modelo de protocolo, al igual que el modelo de interacción de Gaia, define los protocolos mediante descripciones a alto nivel. Finalmente, el modelo de interacción permite especificar los protocolos utilizando diagramas de interacción en AUML. 
En la fase de diseño se mantienen los modelos propios de Gaia, es decir, el modelo de agentes (que asigna roles a clases de agente), el modelo de servicios (que indica los servicios requeridos por los roles) y el modelo de relaciones (que muestra las comunicaciones entre las clases de agente).

La metodología Roadmap ofrece una separación clara de las fases de análisis y diseño. Además, no está comprometida con ningún entorno de agente o producto particular. También permite que se combine con otras metodologías, gracias al empleo de meta-modelos. Sin embargo, en contra de lo que afirma su autor, no queda claro que sirva para diseñar sistemas abiertos, pues no se definen normas para el control de los comportamientos ni se tiene en cuenta la dinamicidad de las entidades del sistema.

TROPOS (Extensión). La extensión de la metodología Tropos [Castro et al., 2001] [Giorgini et al., 2003] adopta la metáfora organizativa y enfatiza el estudio explícito y la identificación de la estructura organizativa. Así propone la utilización de las organizaciones humanas para sugerir un conjunto de estilos genéricos de sistemas de agente, en base a las teorías de diseño de organizaciones. En concreto, hace uso de la Teoría de la Organización, que describe las estructuras internas y de diseño de las organizaciones, y de las teorías de alianzas estratégicas, que modelan la colaboración de organizaciones independientes.

$\mathrm{Al}$ igual que en la metodología original de Tropos, se proponen cuatro fases de desarrollo: (i) requisitos iniciales; (ii) requisitos tardíos; (iii) diseño arquitectónico; y (iv) diseño detallado.

En la fase de requisitos iniciales se estudia el problema desde un punto de vista organizativo, definiéndose un modelo con los actores relevantes, sus objetivos y dependencias. En dicho modelo se deben tener en cuenta las diversas topologías de organizaciones que se proponen: Flat-Structure, Cadena de valores, Pirámide, Matriz, Structure-in-Five, Co-optation, Joint Venture, Bidding, Arm's Length y Hierarchical Contracting.

Si comparamos estas organizaciones con las vistas en el capítulo 2, se observa que tanto Flat-Structure (sistema con estructura plana, en el que 
no se asume que exista control de un agente sobre otro) como la Cadena de Valores (o supply chain, donde varios actores, dispuestos normalmente en cadena, tratan de alcanzar sus objetivos en diferentes estados de un proceso de producción) se corresponden con la topología de estructura simple.

Por su parte, los tipos Pirámide y Structure-in-Five se engloban en un sistema burocrático. La pirámide consta de un vértice superior (encargado de la supervisión directa de la organización), un nivel inferior (que realiza las tareas básicas de la organización) y de gestores y supervisores en los niveles intermedios (encargados de enlazar las decisiones estratégicas y la autoridad desde el vértice superior al nivel operativo). La topología Structure-in-Five consta además de una estructura tecnológica (encargada de estandarizar el proceso de control) y de una estructura de soporte (que provee servicios especializados).

El sistema matricial se corresponde directamente con la estructura matricial, pues los miembros de la organización se disponen en forma de matriz, creando varios canales de información y autoridad, tanto horizontales como verticales, que operan simultáneamente.

Finalmente, el resto de organizaciones se engloban dentro de las organizaciones virtuales, al tratar todas ellas con aspectos de contratación de funciones. Así, la topología Co-optation implica la incorporación de representantes de sistemas externos en el proceso de decisión de construcción de la estructura y comportamiento de una organización. La topología Joint Venture consiste en la unión de dos o más socios intra-industriales, donde un actor específico se encarga de la operación estratégica y la coordinación de la organización. En la topología Bidding, los actores se comportan como en una subasta, utilizando mecanismos competitivos. Arm's Length implica acuerdos entre socios independientes y competitivos, que actúan y ponen sus recursos y conocimientos en común para alcanzar objetivos comunes determinados. Por último, la topología Hierarchical Contracting implica la utilización de negociadores, mediadores y observadores en diferentes niveles, para monitorizar, manejar posibles contingencias, negociar y resolver conflictos. 
En las fases de diseño se integran diversos patrones sociales de agentes en las topologías organizativas escogidas para el sistema. Entre los patrones sociales de agente, los autores han estudiado los siguientes: broker, matchmaker, mediator, monitor, embassy, wrapper, contract-net. Estos agentes actúan de intermediarios o middle-agents y se emplean normalmente en organizaciones de tipo federación.

La extensión de Tropos permite analizar el sistema desde el punto de vista organizativo, determinar la estructura más adecuada para el mismo e integrar aquellos patrones sociales que mejor se adapten. Sin embargo, en ninguna fase de la metodología se identifican explícitamente las reglas organizativas. Así, ningún modelo de Tropos permite capturar leyes globales que se apliquen a múltiples roles organizativos o bien a la organización como un todo.

Por otro lado, aunque se ofrecen ciertas guías sobre cómo determinar qué estructura topológica de las propuestas resulta más adecuada para el sistema concreto a tratar, éstas se basan en aspectos muy generales del rendimiento del sistema (como tolerancia a fallos, adaptabilidad, coordinación) y no en los componentes propios del sistema organizativo, como la estandarización, departamentalización, etc. Además, la relación entre las estructuras que se proponen y su aplicación en los sistemas multiagente no queda lo suficientemente clara.

MESSAGE. La metodología MESSAGE (Methodology of Engineering Systems of Software Agents) [Caire et al., 2002] incorpora técnicas ya empleadas en la ingeniería del software. En concreto, utiliza la notación UML y el proceso de modelado propuesto por Rational (RUP) [Jacobson et al., 1999], que consta de cuatro partes: Inicio, Elaboración, Construcción y Transición. Además, se dispone de las fases típicas del ciclo de vida del software, es decir, Requisitos, Análisis, Diseño, Implementación, Prueba e Implantación, cada una de ellas dividida en las partes anteriormente citadas. En la metodología solamente se presentan de forma detallada las fases de análisis y diseño, mientras que para el resto se proponen guías de ayuda. 
En la fase de análisis se desarrolla un modelo de sistema multiagente y su entorno, a un alto nivel de abstracción. Para ello se hace uso de varios meta-modelos que definen los conceptos a emplear en el lenguaje de modelización: agente, organización, rol, recurso, tarea, protocolo, objetivo, etc. En el análisis se construyen varias vistas siguiendo un refinamiento de diversos pasos.

Inicialmente se define el sistema a desarrollar respecto a sus actores principales y su entorno, construyéndose la vista de la organización (que detalla las entidades de agente, organización, rol y recurso, así como sus relaciones) y la vista de tareas y objetivos (que detalla los objetivos, tareas y dependencias entre sí). A partir de ellos, se define la vista de agente/rol (que se centra en los agentes individuales y sus roles) y la vista del dominio (que muestra los conceptos específicos del dominio y sus relaciones). Por último se define la vista de interacción (que describe los iniciadores y colaboradores de una interacción, la información suministrada, los eventos que la provocan, etc.).

En la fase de diseño se plantean dos posibles aproximaciones: a) el diseño es dirigido por la organización del sistema multiagente y la arquitectura; b) el diseño es específico para una plataforma de agente concreta. En el primer caso, el modelo de organización obtenido en el análisis dirige el proceso de diseño, teniéndose también en cuenta los requisitos funcionales, como seguridad, distribución, rendimiento, etc. En el segundo caso, el diseño se adecúa a la plataforma escogida, que provee ciertos servicios, como un entorno de ejecución, protocolos de coordinación, etc. Toda esta fase de diseño está menos documentada que la parte de análisis.

En esta metodología, la organización representa a un conjunto de agentes que trabajan juntos por un objetivo común, en la que su estructura se refleja solamente a través de relaciones de tipo supervisor-subordinados, así como de las interacciones existentes entre sus elementos.

INGENIAS. Esta metodología [Gomez, 2002] está basada en MESSAGE [Caire et al., 2002] y emplea meta-modelos y la construcción de modelos 
usando lenguajes de meta-modelado. Un meta-modelo define primitivas y propiedades sintácticas y semánticas de un modelo y consta de objetos, atributos y relaciones.

Durante las fases de análisis y diseño se emplean cinco meta-modelos distintos: (i) meta-modelo de agente, que describe los agentes particulares y sus estados mentales; (ii) meta-modelo de organización, que define cómo se agrupan los agentes, la funcionalidad del sistema y las restricciones existentes sobre el comportamiento de los agentes (iii) meta-modelo de interacción, que detalla cómo se coordinan y comunican los agentes; (iv) meta-modelo del entorno, que define qué existe alrededor del sistema (recursos, aplicaciones); y (v) meta-modelo de tareas y objetivos, que asocia el estado mental del agente con las tareas que ejecuta.

La metodología INGENIAS sigue un proceso iterativo de desarrollo del sistema, según el Rational Unified Process (RUP). De este modo, las fases de análisis y diseño se dividen en tres partes: inicio, elaboración y construcción. En el análisis-inicio, se identifican los casos de uso (por ejemplo, mediante diagramas en UML), se especifica el modelo de organización (identificando los grupos, sus miembros, los flujos de trabajo y los objetivos de la organización) y se modela el entorno (identificando sus aplicaciones y las operaciones a realizar sobre ellas). En el diseño-inicio se genera un prototipo del sistema (por ejemplo, en HTML). Dicho prototipo muestra cómo interactúa el usuario con la aplicación y qué tipo de resultados se obtendrán.

En el análisis-elaboración se completan el resto de modelos. Así, se refinan los casos de uso y se asocian a modelos de interacción y de agente, de modo que se identifican los agentes, sus objetivos, funcionalidades y se especifican sus interacciones mediante diagramas de colaboración. Posteriormente se refinan los modelos de tareas y objetivos (descomponiéndolos en subtareas y subobjetivos y estableciendo relaciones entre sí) y el modelo del entorno (identificando aplicaciones internas). Finalmente se refina el modelo de organización, generando nuevos miembros y descomponiendo los flujos de trabajo.

En el diseño-elaboración se detalla el control de los agentes (asociando 
estados mentales a la ejecución de acciones). Además, se refina el modelo del entorno respecto a los recursos y la percepción de los agentes así como el modelo de tareas y objetivos, identificando precondiciones y postcondiciones de las tareas. Finalmente, en el análisis-construcción y en el diseño-construcción se completa el modelo de organización, estableciendo y refinando las dependencias sociales del sistema respecto a otras organizaciones.

Tanto la metodología MESSAGE como INGENIAS especifican un modelo organizativo, en el que se detallan los grupos, sus miembros, flujos de trabajo y objetivos de la organización. Sin embargo, no se profundiza en los mecanismos o estructuras de agrupación que adoptan los agentes al formar los grupos. Tampoco se modelan de forma explícita las normas sociales (que se asumen de forma implícita en la estructura de la organización), ni la dinámica de la organización (es decir, cómo los agentes entran o salen del sistema, cómo forman grupos de forma dinámica, cuál es su ciclo de vida, etc.).

ANEMONA. Esta metodología de sistema multiagente se centra principalmente en el diseño de sistemas holónicos de fabricación [Giret, 2005]. Para ello extiende INGENIAS con el concepto de Agente Abstracto, el cual agrega una perspectiva estructural al concepto de agente, ya que un Agente Abstracto puede ser un agente; o puede ser un SMA que a su vez está compuesto de Agentes Abstractos.

Por otro lado, incluye los requisitos de modelado de Sistemas Holónicos de Fabricación (HMS), ofreciendo un proceso de desarrollo mixto, en el que se proporcionan guías específicas para HMS que ayudan al diseñador a identificar e implementar holones desde el punto de vista de los agentes. El análisis del sistema consta de las fases de análisis de requisitos e identificación y especificación de holones, proporcionando una especificación de alto nivel del HMS desde un enfoque descendente recursivo. En el diseño se realiza un proceso ascendente para producir la arquitectura del sistema. Finalmente, en la etapa de implementación de holones se produce el código 
ejecutable, para su posterior instalación, configuración y mantenimiento.

La metodología ANEMONA, con su noción de Agente Abstracto, facilita la representación de organizaciones en el sistema multiagente, a las que se les asocian objetivos globales, funcionalidad específica y su relación con el entorno. Sin embargo, al igual que INGENIAS, no tiene en cuenta la dinamicidad del sistema ni su normalización.

AML. El lenguaje de modelado de agentes AML [Cervenka y Trencansky, 2007] extiende UML con conceptos de agentes, a través de un lenguaje visual semi-formal. En concreto, permite la definición de un sistema multiagente que se utilizará en un determinado entorno de ejecución y estará formado por varias entidades, que engloban tanto agentes como recursos, entornos y unidades organizativas.

Los agentes son entidades autónomas que presentan ciertos comportamientos, se comunican con otras entidades y tienen sus propios estados mentales. Persiguen unos objetivos determinados, estructurados a través de planes, que marcarán los comportamientos a realizar. Los recursos representan entidades físicas o de información, sobre los que interesa conocer su disponibilidad, derechos de acceso, condiciones de consumo y utilización.

Por su parte, el entorno permite modelar entornos lógicos o físicos y proporciona las condiciones bajo las cuales las entidades funcionan. Los agentes acceden a su entorno a través de sus perceptores (para observar, percibir estados o recibir señales) y sus efectores (para producir efectos sobre otros objetos).

Finalmente, las unidades organizativas modelan tipos de entornos sociales. Externamente, se comportan como entidades autónomas coherentes que tienen objetivos, comportamientos, interacciones e incluso ofrecen o requieren servicios y juegan determinados roles dentro de otros entornos. Internamente, las unidades organizativas especifican la estructura, interacciones, roles y restricciones de las entidades que la componen.

Las entidades del sistema tendrán asociados unos roles, que ofrecen un conjunto coherente de características, comportamientos, servicios, así como 
una participación determinada en las interacciones. Por otro lado, los servicios modelan una determinada funcionalidad que una entidad ofrece a otras entidades. Los servicios requerirán de unos puertos o puntos de interacción entre las entidades, a través de los cuales las entidades harán uso de dichos servicios.

AML también permite describir la ontología del sistema, así como las relaciones sociales que se produzcan entre las entidades, discriminando entre relaciones de tipo peer (entre iguales), superordinate o subordinate, donde se ha establecido una autoridad o control de una entidad sobre otra. Sin embargo, AML no proporciona ninguna estructura directa para el modelado de las normas y restricciones entre los agentes.

GAIA (Extensión). La extensión de Gaia, llamada GaiaEXOA Gaia extended with Organisational Abstractions [Zambonelli et al., 2003], pretende diseñar sistemas abiertos empleando conceptos organizativos.

En la fase de análisis se describe cómo se espera que trabaje la organización. Para ello, se identifican los objetivos de la organización y su comportamiento global esperado, lo que permite dividir la organización en suborganizaciones. Cada suborganización exhibe un comportamiento específicamente orientado a alcanzar un objetivo o subobjetivo determinado. Posteriormente, se definen los siguientes modelos: del entorno, preliminar de roles, preliminar de interacción y las reglas organizativas.

En el modelo del entorno se trata al entorno en términos de recursos computacionales abstractos, sobre los que se realizan tres operaciones distintas: percibir (leer), actuar (modificar), consumir (extraer). Se genera así una lista de recursos o variables de entorno, representados mediante notación inspirada en FUSION [Coleman et al., 1994]. Además, se generan esquemas gráficos que representan las relaciones entre los recursos e identifican cómo y por dónde se accede a un determinado recurso.

En el modelo de roles preliminar se definen las aptitudes básicas requeridas por la organización. Por cada rol se detallan dos tipos de atributos: 
permisos y responsabilidades. Los permisos identifican los recursos utilizados por cada rol, así como sus limitaciones. Las responsabilidades indican los comportamientos esperados de los roles y se dividen en propiedades de vivencia, que definen tareas que el rol debe realizar si se dan ciertas condiciones; y propiedades de seguridad, que definen estados aceptables que se deben mantener. En el modelo de interacción preliminar se determinan las dependencias e interacciones entre los roles mediante la especificación de protocolos.

Finalmente, las reglas organizativas representan las responsabilidades de la organización vista como un todo. Se dividen en reglas de vivencia (liveness rules) y reglas de seguridad (safety rules). Las primeras definen la dinámica de la organización, indicando cuándo permitir a los agentes entrar en la organización y cuál será su posición en ella. Por ejemplo, que un rol sea adoptado por una entidad siempre que ésta haya ejercido previamente otro rol específico. Por su parte, las reglas de seguridad muestran qué comportamientos deben ser evitados por los agentes, definiendo invariantes globales independientes del tiempo. Por ejemplo, que un rol solamente sea adoptado por una única entidad, o bien que dos roles no sean adoptados por la misma entidad.

En la fase de diseño se describe qué tipo de organización se ajusta mejor, produciendo una completa especificación del MAS. Consta de dos sub-fases: diseño arquitectónico y diseño detallado.

En el diseño arquitectónico se especifica la estructura organizativa, seleccionando la topología y el régimen de control más apropiado. Como topologías de organización a tener en cuenta se dispone de: (i) centralizado, con una única unidad, sin costes de coordinación pero con gran complejidad en las tareas; (ii) Peers colectivos o network, donde todos los miembros tienen la misma autoridad sobre la organización global aunque con diferentes roles; (iii) jerarquía simple, donde los líderes asumen responsabilidades de coordinación sobre los miembros; (iv) jerarquía multinivel, para tamaños mayores de organizaciones y una mayor necesidad de coordinación; (v) topología compleja compuesta, que mezcla varias topologías. 
Por su parte, se distinguen los siguientes regímenes de control: (i) partición de trabajo, donde cada miembro tiene el mismo rol y provee los mismos servicios; (ii) especialización de trabajo, donde cada miembro provee una actividad o servicio específico; (iii) modelos basados en mercado, en los que se requieren actividades de competición y subasta. Además, en el diseño se explotan patrones organizativos conocidos y reutilizarlos. Así, si se dispone de un catálogo de posibles "estructuras organizativas" modulares y descomponibles, se podría indicar cuándo y cómo hacer uso de una estructura específica y reutilizarla.

Una vez escogida una topología y un régimen de control, se completa el modelo de roles y el modelo de interacción añadiendo los roles y protocolos organizativos, obtenidos a partir de la estructura escogida. Finalmente, se deben distinguir claramente qué características resultan intrínsecas, es decir, independientes de la estructura adoptada, y cuáles son extrínsecas, es decir, derivan de la adopción de una estructura determinada. De este modo, en caso de cambio de la topología de la organización, se observa claramente qué características se mantendrían y cuáles sería necesario modificar. Respecto al diseño detallado, éste es idéntico a la fase de diseño de Gaia, donde se define el modelo de agente y el modelo de servicios.

En resumen, esta metodología considera que una topología específica del sistema debe imponer una serie de roles y relaciones entre ellos que dependen directamente del diseño topológico seleccionado. Sin embargo, no se dispone de un catálogo completo de patrones organizativos que den soporte al desarrollo de aplicaciones.

SODA. La metodología SODA (Societies in Open and Distributed Agent Spaces) [Omicini, 2001] permite el diseño de sociedades abiertas basándose en medios de coordinación adecuados y reglas sociales, según sus autores. Define a los agentes en términos de sus comportamientos observables requeridos y de sus roles en el sistema, por lo que se necesita emplear una metodología orientada al agente para el diseño de los aspectos internos del mismo, aunque no restringe ni delimita la metodología a adoptar. 
En la fase de análisis se definen tres modelos: modelo de roles, modelo de recursos y modelo de interacción. El modelo de roles describe los objetivos de la aplicación en base a las tareas a realizar, asociadas a roles y grupos. Las tareas se expresan mediante las responsabilidades que implican, las competencias que requieren y los recursos de los que dependen. Existen dos tipos de tareas: individuales, que necesitan recursos o competencias bien limitados y están asociadas a roles individuales; y sociales, que requieren diferentes competencias, el acceso a varios recursos y están asociadas a grupos.

El modelo de recursos modela el entorno de la aplicación mediante servicios, que expresan funcionalidades proporcionadas por el entorno y se asocian a recursos abstractos, los cuales determinan los permisos de acceso asociados a roles y a grupos. El modelo de interacción modela las interacciones de los agentes mediante protocolos, que indican la información requerida y suministrada por los roles y los recursos; y reglas de interacción, que gobiernan las interacciones de los roles y recursos dentro de los grupos.

Durante la fase de diseño se construyen otros tres modelos: de agente, social y del entorno.

En el modelo de agente, los roles sociales e individuales se asignan a clases de agente. Permite definir el comportamiento observable del agente en base a sus interacciones con el entorno.

En el modelo social los grupos se asignan a sociedades de agentes, caracterizadas por las tareas sociales, los permisos, los roles sociales que participan y las reglas de interacción. Estas sociedades se diseñan sobre medios de coordinación específicos, de modo que para cada sociedad se selecciona el modelo de coordinación y se establecen las reglas de coordinación que lo controlan.

Finalmente, en el modelo del entorno los recursos se asignan a clases de infraestructuras, caracterizadas por sus servicios. Permite definir los servicios que provee cada componente de infraestructura y sus interfaces.

Por tanto, esta metodología considera ciertos modelos de coordinación, 
como FCFS (first come/first served), orden de prioridad, estandarización, descomposición de tareas, subastas, etc., que también aparecen en las sociedades humanas. Por ello, aunque esta metodología no tiene en cuenta de forma explícita las topologías de organización humanas, sí que considera diversos mecanismos de coordinación humanos.

CIVIL AGENT SOCIETIES. Este entorno de trabajo [Dellarocas y Klein, 1999] está basado en las sociedades civiles humanas, en las que se han desarrollado las instituciones sociales para establecer y controlar la ejecución de las leyes; y para monitorizar y responder ante emergencias.

Civil Agent Societies consta de los siguientes servicios: (i) servicio de socialización, en el que se realiza una negociación explícita de las habilidades y capacidades del agente respecto a las normas de la sociedad, estableciéndose un contrato social entre el agente y la sociedad (que indica su afiliación); (ii) servicio notarial, que verifica que las interacciones deseadas entre los agentes son legales y genera un contrato privado apropiado para cada una de ellas; (iii) servicio de manejo de excepciones, que inicia agentes centinela siempre que se crean nuevos contratos. Estos agentes centinela tratan de evitar excepciones y detectar sus síntomas. Cuando se detecta una excepción se lanzan agentes firefighter para devolver a la sociedad a un estado aceptable.

Los contratos definen una obligación común de un número de agentes para tomar parte en una interacción social legalmente aceptable, es decir, conforme a las normas de la sociedad. Existen dos tipos de contratos: privado y el social. El contrato privado define las obligaciones de dos o más miembros de la sociedad para tomar parte en una transacción legal. Así, la sociedad protege a los agentes de excepciones locales (violaciones del comportamiento normal del agente). Por su parte, el contrato social define las obligaciones de los agentes para participar en la sociedad y obedecer sus normas.

En el diseño de MAS siguiendo el entorno de trabajo Civil Agent Societies, en primer lugar se definen las normas de la sociedad. Para ello se 
enumeran los roles y los protocolos de interacción permitidos y se añaden a la Base de Conocimiento de las Normas Sociales. A continuación se diseña la Institución Social de Manejo de Excepciones, en la que, para cada protocolo, se identifican las posibles excepciones que se podrían producir y se diseñan los procesos para evitarlas, detectarlas, diagnosticarlas y resolverlas. Todos estos procesos se añaden a la Base de Conocimiento de los Manejadores de Excepciones. Finalmente, se diseñan implementaciones prototipo que permitan comprobar el funcionamiento del sistema.

Este entorno de trabajo resulta interesante ya que ofrece un procedimiento para controlar el comportamiento de los agentes y la dinamicidad de la organización durante la ejecución de los sistemas abiertos, pero necesita de metodologías complementarias para el análisis y diseño del sistema. Además, el único diseño topológico que se tiene en cuenta es el mercado, en el que se establecen procesos de contratación entre los agentes. Como hemos visto, le faltaría tener en cuenta otras opciones, como burocracia, grupos, para dotar así de mayor generalidad a su propuesta.

Se ha implementado una versión prototipo de un mercado civil de agentes de tipo contract-net, siguiendo la metodología propuesta. Con dicho prototipo se ha medido la utilidad de una institución de tipo monitor social en un entorno dinámico de agentes de contract-net. Sin embargo, este entorno de trabajo no ofrece ninguna herramienta concreta para el desarrollo de nuevas aplicaciones.

ELECTRONIC INSTITUTIONS. El marco de trabajo Electronic Institutions [Esteva et al., 2001b] pretende modelar los sistemas en términos de instituciones electrónicas, que representan a instituciones reales empleando sistemas multiagente. Las instituciones electrónicas definen las reglas del juego en la sociedad de agentes del mismo modo que las instituciones humanas lo hacen en las sociedades humanas. Así, describen lo que los agentes tienen permitido realizar y las consecuencias de sus acciones.

En el marco de trabajo se ha definido formalmente el concepto de institución electrónica y se ha desarrollado una plataforma, denominada AMELI 
[Esteva et al., 2004], que permite implementarlas y ejecutarlas. La especificación formal de una institución electrónica provee una descripción de lo que se espera que el sistema realice. Está basada en un lenguaje de especificación diseñado a propósito, que produce especificaciones visuales y textuales de la institución. Dicha formalización permite describir el marco dialógico de la institución, su estructura performativa y las normas que rigen en ella.

El marco dialógico contiene los elementos necesarios para la construcción de las expresiones del lenguaje de comunicación. Así, determina las ilocuciones válidas que se intercambian los participantes y define la ontología del dominio. Además, describe los roles (internos o externos) que adoptan los agentes que participan en la institución. La estructura performativa define cuáles son las actividades dentro de la institución, y cómo se pasa de una actividad a otra. Cada actividad, llamada escena, describe un protocolo de conversación para un grupo de roles. Por tanto, la estructura performativa define cuáles son las escenas de la institución (conversaciones) y cómo los agentes, en función de su rol y sus acciones pasadas, se mueven entre las escenas. Finalmente, las normas detallan las consecuencias u obligaciones que las acciones de los agentes dentro de las escenas tendrán en el futuro.

El entorno de trabajo de las Instituciones Electrónicas permite la implementación de sistemas multiagente abiertos, gracias a la arquitectura en tres capas de AMELI. En dicha plataforma (detallada en el apartado 3.4), los agentes externos no participan directamente en el sistema, sino que lo hacen a través de un agente interno que los representa, denominado Governor. De este modo, la plataforma ofrece una capa de agentes autónomos, para los agentes externos que se conecten al sistema; una capa social donde interaccionan los agentes internos de la institución, así como los representantes (Governor) de cada agente externo; y una capa de comunicación sobre JADE.

Asimismo, este marco de trabajo cuenta con la herramienta software Islander, que permite la descripción gráfica de la estructura performativa de la institución y la generación de ficheros en XML y plantillas de agente en Java para la plataforma JADE. 
Sin embargo, este entorno de trabajo se limita a la descripción de las acciones dialógicas de los agentes, por lo que no contempla otro tipo de actividades, como acciones individuales o bien interacciones no dialógicas entre agentes. Tampoco proporciona una descripción formal del entorno ni de los recursos existentes en el mismo. Por otro lado, aunque se describe el uso de normas, todavía no ofrece una expresividad suficiente para especificar normas de prohibiciones, permisos y sanciones. Finalmente, no se tiene en cuenta de forma explícita ninguna topología para el sistema y solamente se consideran diversas relaciones jerárquicas entre roles. Resultaría interesante que, previo a la identificación y descripción de las escenas y transiciones, se determinara una estructura adecuada del sistema, a fin que dicha estructura facilitase la identificación de los actos comunicativos entre sus miembros.

OPERA. Esta metodología [Dignum, 2003] realiza el diseño de sociedades de agentes desde una perspectiva organizativa. Concibe la sociedad de agentes en tres niveles: modelo organizacional, modelo social y modelo de interacción.

El modelo organizacional describe el comportamiento deseado o intencionado de la sociedad y su estructura general, desde la perspectiva de la organización, en términos de roles, normas sociales y reglas de interacción. El primer paso para el desarrollo del modelo organizacional consiste en identificar el modelo de coordinación del sistema en base a: (i) el propósito de la sociedad (intercambio, colaboración o producción); (ii) sus objetivos (individuales o globales); (iii) las formas de relación y las capacidades de comunicación entre los componentes del sistema; (iv) el interfaz hacia el exterior y (v) el tipo de sociedad a diseñar (abierta, semi-abierta o cerrada).

Únicamente se distinguen tres modelos de coordinación: mercado, jerarquía y red. En el modelo de mercado, adecuado para sistemas abiertos, los agentes son auto-interesados y valoran más su libertad para asociarse con otros y sus propios juicios que los temas de seguridad y confianza. La interacción se lleva a cabo a través de la comunicación y la negociación. 
En el modelo jerárquico, los agentes no son interesados y todos contribuyen en la obtención del objetivo global común. La coordinación se consigue mediante líneas de control y autoridad. Además, las interacciones están bien definidas y se asume un control global de la sociedad.

Finalmente, en el modelo de red los agentes son auto-interesados pero negocian parte de su libertad para obtener relaciones seguras y confiables. La coordinación se consigue por interés mutuo, posiblemente empleando terceras partes confiables, y de acuerdo a reglas bien definidas.

El modelo de coordinación seleccionado no sólo determina la estructura de la sociedad de agente a aplicar (jerárquica, de mercado o en red), sino también el conjunto de agentes (como matchmaker, gatekeeper, notary, etc.) que proporcionan los servicios necesarios para la implementación de dicha estructura. Estos agentes contribuyen la denominada capa de facilitación.

El siguiente paso consiste en extender la estructura seleccionada con los roles específicos del dominio y las formas de interacción que caracterizan el problema. Así, se determinan los principales aspectos de la sociedad, basándose en el nivel de coordinación, la identificación de los actores principales (stakeholders), la identificación de casos de uso y el análisis de los comportamientos normativos o éticos esperados. Para ello, se realizan unas tablas de roles en las que se indican: el nombre del rol, su relación con la sociedad (actor principal, miembro potencial o bien rol derivado del modelo topológico), los objetivos del rol y sus dependencias con otros roles. Además se identifican las normas sociales, especificando su contexto, responsabilidades, recursos a los que afectan, eventos que las disparan y descripción.

Posteriormente se analiza el comportamiento interno del sistema, obteniéndose una completa especificación del modelo organizacional. Para ello, se completan las descripciones de los roles, indicando sus objetivos, subobjetivos, derechos, normas y tipo de rol (interno/externo). Además, se definen las escenas de interacción, detallando para cada una su descripción, los roles que participan en ella, sus resultados, los patrones de interacción y las normas. Después se especifica la estructura de interacción de la sociedad, 
indicando cómo se pasa de una escena a otra mediante transiciones. Finalmente se refinan y especifican las normas sociales, dividiéndolas en normas de rol, de escena y de transición.

En el modelo social se rellena el modelo organizacional con agentes que se asocian a los roles a través de contratos sociales. Los contratos sociales describen los comportamientos acordados para un agente dentro de la sociedad en términos de los eventos observables externamente. Así, indican las condiciones y reglas que adquiere un agente cuando juega un rol en la sociedad de agentes. De este modo, se verifica la adopción de los roles, detallando también cómo proceder si se viola alguna norma. Además, se indica explícitamente el comportamiento esperado del agente al ejecutar el rol dentro de la sociedad, proporcionando así una interfaz hacia otros agentes para que éstos conozcan qué es lo que realiza.

Finalmente, el modelo de interacción especifica los acuerdos de interacción entre actores y describe el comportamiento actual de la sociedad durante su ejecución. Este modelo está compuesto por el modelo social y el conjunto de contratos de interacción entre agentes. Un contrato de interacción describe las condiciones y reglas a aplicar durante una determinada interacción, definiendo el protocolo a seguir, de acuerdo a las normas, objetivos y escenas de interacción existentes, así como a las necesidades específicas y los deseos de los agentes participantes de dicha interacción. Por tanto, un contrato de interacción especifica la actual instanciación de una escena de interacción, indicando también los actores implicados y los acuerdos y sanciones específicas relacionadas con la escena a tratar.

En resumen, esta metodología representa un importante avance en el modelado de sistemas multi-agent abiertos, pues tiene en cuenta no sólo un modelo formal en el que se define la estructura de la organización y sus normas, sino también un modelo social y un modelo de interacción donde se describe la dinámica organizativa y los procesos de control de acceso de agentes externos al sistema, así como el control del comportamiento de las interacciones entre agentes. Además, los modelos de coordinación que contempla están muy relacionados con los diseños de las organizaciones 
humanas vistas en el capítulo 2. Así, el modelo de mercado es similar a la organización virtual; el modelo de jerarquía es equivalente a una burocracia; y el modelo de red, empleado en sociedades confiables con intereses mutuos, resulta equiparable al modelo de equipos o grupos.

Sin embargo, no se tienen en cuenta otros modelos de topologías, como la estructura matricial o la cadena de valores. Además, si el sistema está compuesto de diversos modelos topológicos o subestructuras, OperA no ofrece ninguna guía para distinguir y combinar dichas subestructuras entre sí. Asimismo, ni el modelo social ni el modelo de interacción se describen durante las fases de análisis y diseño del sistema, ya que solamente tienen existencia durante la ejecución del propio sistema final, con la participación de los agentes concretos. Por otro lado, OperA propone la utilización de diversos agentes facilitadores derivados de la metodología, pero no existen guías para introducirlos en el sistema final y combinarlos con el resto de roles.

HARMONIA. Este marco de trabajo [Vazquez-Salceda y Dignum, 2003] modela las organizaciones electrónicas teniendo en cuenta distintos niveles de refinamiento de las normas de la organización. No se trata en sí de una metodología de diseño de MAS, sino de un marco de trabajo que permite definir y modelar las normas de la organización. Este trabajo está relacionado con el entorno de desarrollo de las Instituciones Electrónicas [Esteva et al., 2001b], así como con la metodología OperA [Dignum, 2003] y la metodología OMNI [Vazquez-Salceda et al., 2004].

En HARMONIA las normas de la organización se definen en cuatro niveles: (i) abstracto; (ii) concreto; (iii) de reglas; y (iv) procedural.

En el nivel abstracto se describen los estatutos de la organización y se determinan cuáles son sus objetivos, valores y reglas abstractas, así como el contexto en el que la organización realizará sus actividades. Los valores representan creencias que tenemos de lo que es importante, tanto para nosotros como para la sociedad. Nos dicen lo que pensamos que está bien o está mal, pero no indican cómo deberemos comportarnos apropiadamente 
en una situación dada. Cada valor tiene asociado una lista de normas u obligaciones que definen su significado en el contexto de la organización. Las obligaciones o reglas abstractas relacionadas con los valores de los estatutos vienen descritas en un lenguaje deóntico temporal, según el cual una obligación para realizar una acción o alcanzar un estado: (i) puede ser condicional a algún otro estado; (ii) tiene significado para algún rol y (iii) deberá ser realizada antes de un cierto límite de tiempo.

En el nivel concreto se traducen las normas abstractas en normas concretas, relacionadas con acciones descritas en términos de la ontología de la organización, o bien con situaciones comprobadas directamente por la institución. Se categorizan en obligaciones, prohibiciones y permisos.

En el nivel de reglas, se traducen las normas concretas en reglas, pasando de un lenguaje en lógica deóntica a un lenguaje de lógica proposicional dinámico, más adecuado para expresar acciones y restricciones de tiempo.

Finalmente, en el nivel procedural se implementan las reglas en base a dos propuestas: (i) la creación de un intérprete de reglas que cualquier agente que entre en la organización electrónica debe incorporar; (ii) la traducción de las reglas en procedimientos que sean seguidos fácilmente por los agentes. Las violaciones especificadas en el nivel de reglas deberán ser también traducidas a algún mecanismo de detección que compruebe que el comportamiento de los agentes sea el adecuado.

Este marco de trabajo ofrece la posibilidad de emplear la herramienta de desarrollo ISLANDER [Esteva et al., 2001a], que permite la construcción de instituciones electrónicas. Esta herramienta, donde los agentes externos deben seguir ciegamente los protocolos definidos en ella, resulta eficiente desde la perspectiva computacional. Sin embargo, los agentes no tienen autonomía para aceptar o rechazar el protocolo propuesto. Como alternativa, HARMONIA propone que la institución debe suministrar a los agentes tanto la descripción de los protocolos a bajo nivel como las reglas relacionadas. Así, los agentes autónomos que solamente sean capaces de seguir protocolos los seguirán ciegamente, mientras que los que también puedan interpretar 
las reglas (norm autonomous agents o deliberative normative agents) escogerán entre seguir el protocolo o razonar sobre las reglas.

OMNI. El entorno de trabajo OMNI (Organizational Model for Normative Institutions) [Vazquez-Salceda et al., 2004] combina aspectos de otros dos entornos de trabajo anteriormente comentados: OperA [Dignum, 2003] y HARMONIA [Vazquez-Salceda y Dignum, 2003]. Está formado por tres dimensiones: (i) la dimensión normativa de la organización, que especifica los mecanismos de orden social mediante normas y reglas; (ii) la dimensión organizativa, que describe la estructura de la organización; y (iii) la dimensión ontológica, que define el entorno y las relaciones contextuales, así como los aspectos de comunicación de la organización.

Cada una de estas tres dimensiones se divide a su vez en tres niveles: abstracto, concreto y de implementación. Así en el nivel abstracto de la dimensión normativa se modelan los estatutos de la organización; en su nivel concreto se especifican las normas y reglas; mientras que en su nivel de implementación se realiza la implementación propia de las normas.

Por su parte, en el nivel abstracto de la dimensión organizativa se analizan los requisitos y se determinan los objetivos y contexto de la organización; en su nivel concreto se especifica el modelo organizativo, describiendo los roles, relaciones, protocolos y escenas de interacción; y en su nivel de implementación se definen los agentes, asumiendo una arquitectura multiagente dada como base para la implementación del modelo organizativo. Además, se incluyen mecanismos para el seguimiento y control de las normas y la aceptación de agentes en el sistema. Estos mecanismos se detallan en los modelos sociales y de interacción, según se propone en OperA.

Finalmente, en el nivel abstracto de la dimensión ontológica se determinan los términos genéricos para cualquier organización, así como la ontología del modelo; en su nivel concreto se especifican los conceptos ontológicos concretos y los actos de comunicación genéricos; y en su nivel de implementación se define la ontología del dominio procedural y los actos de comunicación específicos a la plataforma seleccionada. 
Los aspectos de definición de estatutos, objetivos y contexto, realizados en los niveles abstractos de las tres dimensiones existentes, así como el nivel concreto de la dimensión normativa se basan en HARMONIA. Por su parte, el modelo organizativo, el modelo social y el modelo de interacción, definidos en la dimensión Organizacional, se basan en OperA.

En el análisis y diseño en OMNI se construyen de forma paralela las tres dimensiones (Organizacional, Normativa y Ontológica). Según el dominio de aplicación, una de las dimensiones será más importante que el resto y, por tanto, guiará el proceso de diseño. Los autores distinguen tres tipos de dominio:

- Dominios donde no se necesita ninguna especificación normativa, pues todas las interacciones siguen estándares de patrones de interacción universalmente aceptados (ej. una subasta). En este caso las normas están implícitas en los propios patrones estándar.

- Dominios con un componente normativo reducido, donde solamente se necesitan algunas reglas organizativas para dar soporte a la estructura.

- Dominios altamente regulados, donde se necesita de un importante número de normas, que serán incluidas en el análisis y diseño del MAS.

En los dos primeros casos la dimensión Organizacional es la más importante y será la que guíe el proceso de desarrollo del sistema. Para dominios altamente regulados, la dimensión Normativa será la que guíe el proceso.

Esta metodología carece todavía de herramientas adecuadas para el análisis y diseño del sistema. Aunque la herramienta de ISLANDER se emplee para describir normas, escenas y transiciones, el modelo organizativo de OperA se debe completar a mano.

MOISE. El lenguaje de modelado normativo y organizacional MOISE ${ }^{\text {Inst }}$ [Gateau et al., 2005](denominado MOISE+ [Hubner et al., 2002] en versiones anteriores) permite definir la organización de un sistema multiagente y 
sus normas a partir de cuatro especificaciones: estructural, funcional, contextual y normativa.

En la especificación estructural se emplean las nociones de rol, grupo y enlace (o relación social). Así, un rol representa las restricciones sobre funcionalidad, objetivos, planes y relaciones con otros roles, que un agente debe seguir cuando juega dicho rol en un grupo determinado. Por su parte, un grupo consiste en un conjunto de roles y enlaces, determinando también restricciones de cardinalidad, relaciones de herencia y de compatibilidad entre roles. Además, se permite la especificación de subgrupos. Por último, los enlaces o relaciones sociales son de tres tipos: acquaintance, que indican qué agentes tienen una representación formal de otros agentes; communication, que especifica quiénes tienen permiso para comunicarse con otros agentes; y authority, que indica quiénes tienen control sobre otros agentes.

En la especificación funcional se estructuran los objetivos de la organización en esquemas sociales. En cada esquema se realiza una descomposición de los objetivos, los cuales se agrupan en misiones. Cada misión representa a un conjunto de objetivos coherentes que se asignan a los roles. Si un agente acepta una misión determinada, entonces se compromete a alcanzar todos los objetivos de dicha misión.

La especificación contextual determina los distintos contextos o situaciones por los que pasa la organización a lo largo del tiempo, así como las transiciones entre dichos contextos. Cada contexto especifica un estado en el que los agentes que juegan ciertos roles deben respetar unas normas determinadas. Esta especificación se asemeja, en cierta manera, a la estructura performativa de las instituciones electrónicas, comentada anteriormente.

Finalmente, en la especificación normativa se detallan las normas aplicables a cada contexto, en concreto los permisos, prohibiciones y obligaciones de los agentes para ejecutar misiones en un contexto particular y durante cierto tiempo. El cumplimiento de cada norma está supervisado por el rol issuer, quien aplica las sanciones sobre el rol afectado por la norma.

Este lenguaje de modelado se apoya en la arquitectura SYNAI [Gateau et al., 2005] (denominada S-MOISE+ [Hubner et al., 2006] en versiones 
anteriores). Está formada por agentes genéricos supervisores, que controlan y refuerzan las normas del sistema. En el apartado 3.4 se explica con mayor profundidad esta arquitectura.

En resumen, esta propuesta contempla en gran medida los factores de estructura, funcionalidad, dinamicidad y normalización del sistema. Sin embargo, no aborda con detalle el aspecto del entorno. Respecto a las normas, aunque se han tenido en cuenta las sanciones a aplicar, no se incluyen mecanismos que permitan recompensar el cumplimiento de dichas restricciones.

\subsubsection{Discusión sobre las metodologías orientadas a la organización}

Las metodologías orientadas a la organización están centradas principalmente en los aspectos organizativos, como la estructura, los objetivos y las normas de la organización. Prácticamente en todas las propuestas analizadas (a excepción de MESSAGE, INGENIAS y ANEMONA), sus autores afirman que dichas propuestas permiten el desarrollo de sistemas multiagente abiertos, en donde participen agentes con comportamientos interesados. Gracias al análisis y diseño de la estructura de la organización y sus normas sociales se controlan los comportamientos de los agentes y evitan así comportamientos no deseados. Respecto a la funcionalidad interna de los agentes, se precisa de metodologías orientadas al agente para su desarrollo.

Por tanto, las metodologías orientadas a la organización detallan, en general, cuáles son los objetivos de la organización, su estructura organizativa (topología, jerarquía de roles e interacciones), su dinámica (cómo los agentes entran/salen de la organización, cómo adoptan roles, el ciclo de vida de los agentes y las normas sociales) y el entorno de la organización.

En las figuras 3.3 y 3.4 se muestra una comparativa de los aspectos organizativos considerados por diversas metodologías, teniendo en cuenta los conceptos y componentes básicos de las organizaciones vistos en el capítulo anterior. 
Como se observa en dichas figuras, los objetivos globales de la organización son tenidos en cuenta por las siguientes propuestas: Roadmap (en cuyo modelo de casos de uso se analizan los objetivos y propósito del sistema y se establece una jerarquía de objetivos funcionales y de calidad), SODA (en cuyo modelo de roles se detallan los objetivos de la aplicación en base a las tareas a realizar), MESSAGE e INGENIAS (donde el modelo de organización describe la funcionalidad del sistema, de modo que a una organización se le asocie un flujo de trabajo, que implica la realización de una serie de tareas para satisfacer unos objetivos concretos), GaiaExOA (en cuya fase de análisis se identifican inicialmente los objetivos del sistema y el comportamiento global esperado, especificándose distintas suborganizaciones o casos de uso, cada una de ellas orientada a un objetivo concreto) y OperA (cuyo modelo de coordinación describe el propósito de la sociedad y sus objetivos globales).

Respecto a la estructura organizativa, todas las propuestas consideradas describen los roles del sistema, sus interacciones y relaciones, empleando conceptualizaciones diversas: modelo de roles (Roadmap, SODA, GaiaE$\mathrm{xOA}$ ), cheeseboard diagram (AGR); base de conocimiento de normas sociales (Civil Agent Societies), marco dialógico (E-Institutions), requisitos iniciales y tardíos (Tropos), modelo organizativo (MESSAGE, INGENIAS, OperA).

Las normas sociales son detalladas de forma clara y explícita en las propuestas de GaiaExOA (mediante las reglas de seguridad, que muestran qué comportamientos deben ser evitados por los agentes), Civil Agent Societies (donde se modela el sistema en base a las normas sociales a tratar y el manejo de excepciones al violarse alguna norma), E-Institutions (donde la estructura performativa delimita las actividades futuras que los agentes podrán realizarán en función de los roles que adquieran y además las normas detallan las consecuencias u obligaciones de las acciones de los agentes) y OperA (cuyo modelo de organización describe las normas sociales del sistema).

En OMNI se amplia la descripción de las normas sociales incluyendo 
abstracciones a alto nivel y un proceso de refinamiento hasta el nivel de implementación de las normas. En otras propuestas, como AGR y Roadmap, se describen solamente ciertas restricciones de herencia y especialización en las relaciones entre los roles.

La topología o estructura propia de la organización solamente es contemplada en el modelo organizativo de OperA (con el modelo de coordinación), en Tropos (donde se identifican durante la fase de requisitos distintas topologías organizativas de tipo jerárquico y de mercado) y en GaiaExOA (donde se selecciona la topología y régimen de control más adecuado durante la fase de diseño arquitectónico).

Respecto a la dinámica de la organización, todas las propuestas contemplan la asociación de los agentes a uno o más roles, pero solamente algunas tienen en cuenta el proceso de entrada o salida de un agente dentro de la organización (o bien dentro de un grupo o escena).

En concreto, AGR analiza detalladamente, en su fase de dinámica de la organización, cómo se produce la creación de los grupos, la adhesión o salida de los agentes a los grupos, la adquisición de un rol dentro de un grupo; Civil Agent Societies emplea el servicio de socialización, para permitir una negociación explícita de las habilidades del agente (en función de las normas de la sociedad) y establecer un contrato de acceso o participación en la organización; E-Institutions define con la estructura perfomativa cómo los agentes, en función de su rol y acciones pasadas, se mueven entre las escenas y además, durante la implementación de la institución, utiliza un Institution Manager para autorizar a los agentes externos a entrar en la institución; GaiaExOA emplea las reglas de vivencia para indicar cuándo permitir a los agentes entrar en la organización y cuál será su posición en ella; y OperA ofrece el modelo social para describir los contratos sociales que adquieren los agentes al participar en la organización.

Respecto al entorno, en Roadmap se describen los recursos del entorno, objetos y restricciones. En SODA se identifican los servicios y aplicaciones del entorno y se asocian a recursos abstractos, determinando también los 


\begin{tabular}{|c|c|c|c|c|c|c|}
\hline \multicolumn{2}{|c|}{$\begin{array}{l}\text { Características } \\
\text { Organizacionales }\end{array}$} & Roadmap & $A G R$ & $\begin{array}{l}\text { Civil Agent } \\
\text { Societies }\end{array}$ & E-Institutions & SODA \\
\hline \multicolumn{2}{|c|}{ Objetivos } & $\sqrt{ }$ & & & & $\sqrt{ }$ \\
\hline \multirow{4}{*}{ 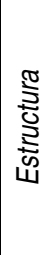 } & Topología & & & & & \\
\hline & Roles & $\sqrt{ }$ & $\sqrt{ }$ & $\sqrt{ }$ & $\sqrt{ }$ & $\sqrt{ }$ \\
\hline & Interacciones & $\sqrt{ }$ & $\sqrt{ }$ & $\sqrt{ }$ & $\sqrt{ }$ & $\sqrt{ }$ \\
\hline & Normas sociales & & & $\sqrt{ }$ & $\sqrt{ }$ & \\
\hline \multirow{3}{*}{ 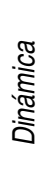 } & Entrada agentes & & $\sqrt{ }$ & $\sqrt{ }$ & $\sqrt{ }$ & \\
\hline & Adopción roles & $\sqrt{ }$ & $\sqrt{ }$ & $\sqrt{ }$ & $\sqrt{ }$ & $\sqrt{ }$ \\
\hline & Control comportamiento & & $\sqrt{ }$ & $\sqrt{ }$ & $\sqrt{ }$ & \\
\hline \multicolumn{2}{|c|}{ Entorno } & $\sqrt{ }$ & & & & $\sqrt{ }$ \\
\hline \multicolumn{2}{|c|}{ Implementación } & & & & $\sqrt{ }$ & \\
\hline
\end{tabular}

Figura 3.3: Comparación de características organizativas consideradas en las propuestas Agent-Group-Role (AGR), Civil Agent Societies, Electronic Institutions y SODA

permisos de acceso que tienen los roles sobre ellos. En MESSAGE el entorno se contempla en la vista de la organización, describiendo los recursos y sus relaciones con los roles y agentes de la organización. En INGENIAS se define un modelo del entorno, que detalla todos los recursos y aplicaciones existentes. En GaiaExOA se trata al entorno en términos de recursos abstractos, sobre los que se lee, actúa y extrae información. Además, en Tropos se modela al sistema con su entorno en los requisitos tardíos, incluyéndolo como un actor más.

Finalmente, las propuestas que contemplan aspectos de implementación son E-Institutions, que ofrece la plataforma AMELI para la ejecución de instituciones electrónicas y además proporciona herramientas para el desarrollo automático de esqueletos de agente en lenguaje Java; INGENIAS, que sigue un proceso iterativo de desarrollo del sistema (incluyendo la fase de implementación) y proporciona también una herramienta gráfica para el diseño de los modelos y la generación automática de código; y Tropos, en 


\begin{tabular}{|c|c|c|c|c|c|c|}
\hline \multicolumn{2}{|c|}{$\begin{array}{l}\text { Características } \\
\text { Organizacionales }\end{array}$} & MESSAGE & INGENIAS & GaiaExOA & Tropos & OperA \\
\hline \multicolumn{2}{|c|}{ Objectives } & $\sqrt{ }$ & $\sqrt{ }$ & $\sqrt{ }$ & & $\sqrt{ }$ \\
\hline \multirow{4}{*}{ 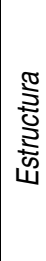 } & Topología & & & $\sqrt{ }$ & $\sqrt{ }$ & $\sqrt{ }$ \\
\hline & Roles & $\sqrt{ }$ & $\sqrt{ }$ & $\sqrt{ }$ & $\sqrt{ }$ & $\sqrt{ }$ \\
\hline & Interacciones & $\sqrt{ }$ & $\sqrt{ }$ & $\sqrt{ }$ & $\sqrt{ }$ & $\sqrt{ }$ \\
\hline & Normas sociales & & & $\sqrt{ }$ & & $\sqrt{ }$ \\
\hline \multirow{3}{*}{ 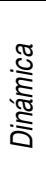 } & Entrada agentes & & & $\sqrt{ }$ & & $\sqrt{ }$ \\
\hline & Adopción roles & $\sqrt{ }$ & $\sqrt{ }$ & $\sqrt{ }$ & $\sqrt{ }$ & $\sqrt{ }$ \\
\hline & Control comportamiento & & $\sqrt{ }$ & $\sqrt{ }$ & & $\sqrt{ }$ \\
\hline \multicolumn{2}{|c|}{ Entorno } & $\sqrt{ }$ & $\sqrt{ }$ & $\sqrt{ }$ & $\sqrt{ }$ & \\
\hline \multicolumn{2}{|c|}{ Implementación } & & $\sqrt{ }$ & & $\sqrt{ }$ & \\
\hline
\end{tabular}

Figura 3.4: Comparación de características organizativas consideradas en las propuestas MESSAGE, INGENIAS, Gaia Extended with Organizational Abstractions (GaiaExOA), Tropos y OperA

cuya fase de implementación se transforma la especificación en esqueletos de agente para la plataforma JACK, utilizando una arquitectura BDI.

Como hemos visto, las metodologías orientadas a la organización son todavía bastante recientes y no están aún bien definidas. Se centran principalmente en la fase de análisis, mientras que las fases de diseño e implementación presentan ciertas limitaciones. Así, en algunas metodologías estas dos fases no están presentes. En otras, se indica explícitamente que se deben cubrir estas fases empleando metodologías orientadas al agente. Sin embargo, dichas metodologías no ofrecen las herramientas necesarias para modelar los conceptos organizativos. Por tanto, existe una laguna en la conexión de las fases de análisis y diseño en la perspectiva organizativa. Dicha conexión debería ser especificada de forma correcta y completa. Además, en la fase de diseño se debería emplear una plataforma de agente específica que fuera capaz de incluir aspectos organizativos. 
En resumen, tras este estudio se constata que no existe ninguna metodología actual que ofrezca un procedimiento completo para analizar, diseñar e implementar sistemas multiagente abiertos. Sí que existen propuestas interesantes, como OMNI, que permiten controlar el comportamiento de los agentes externos y la dinámica de la organización. Además, otras propuestas como MESSAGE o INGENIAS ofrecen buenas herramientas software para el análisis y diseño del sistema, aunque no tienen en cuenta el diseño de las normas sociales. Respecto a la topología organizativa, muchos de los métodos comentados solamente consideran al grupo como diseño topológico. Resultaría interesante que también tuvieran en cuenta otros diseños organizativos, como las jerarquías, burocracias, estructuras matriciales, equipos y organizaciones virtuales para así mejorar el análisis del sistema.

\subsection{Plataformas de agentes}

Existe un gran número de plataformas y arquitecturas de agente, muchas de ellas basadas en la propuesta de arquitectura abstracta de FIPA. Las más conocidas, como JADE [Bellifemine et al., 1999], ofrecen las funcionalidades básicas de los agentes, especialmente los servicios de AMS y DF. Sin embargo, los diseñadores deben implementar prácticamente todas las características organizativas por sí mismos.

Para la implementación de un sistema multiagente abierto, especialmente si ha sido diseñado siguiendo conceptos organizativos, conviene emplear una plataforma de agentes que proporcione un amplio soporte para dichos conceptos. Por tanto, las plataformas de agente deberían ofrecer principalmente: (i) la representación de la organización (su estructura, su reconocimiento por parte de los agentes); (ii) mecanismos de control, especialmente normas; (iii) descripción de la organización en un lenguaje estándar; (iv) mecanismos de monitorización; y (v) soporte a los conceptos de modelado de la organización.

A continuación se comentan las plataformas de agente que, en cierta 
medida, ofrecen algún tipo de soporte para la implementación de organizaciones de agentes. En concreto, se analizan las plataformas AMELI, Madkit, Jack Teams y S-MOISE+. En [Argente et al., 2004] se muestra una revisión más general de las plataformas de agentes disponibles, tanto públicas como comerciales.

AMELI. La plataforma AMELI [Esteva et al., 2004] se desarrolló para dar soporte a las Instituciones Electrónicas, aunque también se ha empleado con otras metodologías, como OperA y OMNI. Consta de una arquitectura compuesta por tres capas: (i) capa de agentes autónomos, formada por los agentes que participan en la institución; (ii) capa social, que garantiza que las interacciones de los agentes se produzcan de acuerdo a las normas y convenciones de la institución; y (iii) capa de comunicación, que utiliza la plataforma JADE para establecer las comunicaciones entre los agentes.

La capa social está formada por tres tipos de agente distintos: Institution Manager, Scene Manager y Governor. El Institution Manager controla la ejecución global del sistema, autorizando a los agentes externos a entrar en la institución, vigilando los movimientos de agentes entre escenas, permitiendo que se unan a las escenas que solicitan, etc. El Scene Manager es el responsable de controlar una escena, autorizando a los agentes a entrar o salir de ella.

Finalmente, existe un Governor por cada agente autónomo que participe en la institución, encargado de mediar la comunicación entre el agente autónomo al que está conectado y el resto de agentes de la capa social. Así, proporciona al agente autónomo la información que necesite sobre la escena en la que se encuentra y, en su nombre, realiza las comunicaciones pertinentes con el resto de agentes de la capa social. Además, comprueba que las acciones de los agentes sean correctas, respecto a la especificación y al estado actual; y mantiene la lista de obligaciones pendientes para el agente.

Esta plataforma se usa junto con la herramienta ISLANDER, que sirve 
para la especificación de instituciones electrónicas, permitiendo la implementación de cualquier institución de manera independiente del dominio. Sin embargo, la plataforma no proporciona soporte para la definición de otras organizaciones de agentes con topologías más complejas. Así, AMELI está centrada en el control de las normas y obligaciones, pero en la definición de las escenas no se tiene en consideración la topología de la organización. Además, para diseñar un agente externo que participe en una institución de esta plataforma el programador debe conocer cómo es la estructura de la institución, sus normas y su ontología para poder implementar un agente capaz de comunicarse eficientemente dentro de la institución.

MADKIT. La plataforma multiagente Madkit ${ }^{3}$ (MulitAGent Development Kit), desarrollada en Java, se basa en el modelo AGR, comentado anteriormente, y utiliza los conceptos básicos de agentes, grupos y roles de dicho modelo para determinar la estructura de la organización. En la plataforma, los agentes son vistos como entidades activas y sociales que toman roles dentro de los grupos, aunque no se impone ninguna restricción acerca de su arquitectura interna.

Además, la plataforma permite el desarrollo de aplicaciones distribuidas mediante el uso de un micro-kernel, que ofrece los siguientes servicios:

- Control de los grupos locales y roles: se encarga de mantener la información acerca de los miembros de los grupos y de los roles asumidos por ellos.

- Control del ciclo de vida de los agentes: lanza los agentes, les asigna su identificador y mantiene la información acerca de los mismos.

- Paso de mensajes: gestiona el encaminamiento y distribución de los mensajes entre los agentes locales.

El microkernel se implementa a través de un agente especial, que se lanza en el inicio de la plataforma, permitiendo así su control y monitorización.

\footnotetext{
${ }^{3}$ http:www.madkit.org
} 
El agente genérico Madkit es una clase que define el ciclo de vida básico, indicando qué hacer en la inicialización, ejecución y terminación del agente. Esta clase define una serie de primitivas relacionadas con el envío y recepción de mensajes y la gestión de los grupos y roles. No existe ninguna restricción acerca del comportamiento de los agentes, de modo que los programadores deben programarlos por completo.

A diferencia de otras plataformas, MadKit emplea agentes para el control de las migraciones, la seguridad, el paso de mensajes distribuido y otras tareas que normalmente vienen integradas en las plataformas. Estos servicios son representados como roles dentro de unos determinados grupos. Al crearse un grupo, los agentes podrían asumir muchos roles dentro de dicho grupo, pero a medida que el grupo crece los servicios se delegan en los demás miembros. Así, por ejemplo, para permitir la comunicación con agentes externos a la plataforma es necesario definir un agente que asuma el rol de comunicador con otras plataformas.

El modelo gráfico de MadKit está basado en componentes gráficos independientes (Java Beans). Cada agente únicamente es responsable de su interfaz gráfica. Una consola gráfica permite lanzar el kernel, inicializar las interfaces de los agentes y administrarlas en una interfaz global.

Por todo ello, la plataforma es ampliamente configurable, pero tareas que tradicionalmente eran ofrecidas por la plataforma ahora recaen en los agentes, por lo que deben ser implementadas por el desarrollador.

JACK TEAMS. La plataforma JACK Teams ${ }^{4}$ es una extensión del entorno JACK Intelligent Agents [Howden et al., 2001] que proporciona un entorno de programación de agentes orientado a equipos. Al igual que JACK, está basada en el modelo de agente BDI y se ha construido sobre Java.

En la programación orientada a equipos, la colaboración entre agentes se especifica desde el punto de vista del grupo como un todo, para obtener

\footnotetext{
${ }^{4}$ http:www.agentsoftware.comshareddemosNdocsJACK_Teams_Manual.pdf
} 
así comportamientos coordinados. Los conceptos que usa la plataforma son:

- Equipo: entidad caracterizada por los roles que tiene y/o los roles que necesita que otros asuman. Se representa como una estructura recursiva que a su vez puede contener cualquier combinación de equipos o subequipos. Es más, la formación de un equipo se consigue mediante la unión de subequipos capaces de realizar los roles requeridos por el equipo.

- Rol: un rol en un equipo es una entidad que contiene una descripción de las funcionalidades que los participantes en un equipo/subequipo deben proporcionar. Además define una relación entre equipos y subequipos.

- Teamdata: permite la propagación de creencias de un equipo a un subequipo y viceversa. Un elemento teamdata define cómo una creencia propagada es aceptada por el equipo receptor y cómo se incorpora a sus estructuras de creencias.

- Teamplan: especifica cómo una tarea se consigue en términos de uno o más roles. Normalmente contiene pasos que determinan cuál de sus equipos asumirá cada rol.

Por tanto, la plataforma permite la definición de lo que un equipo es capaz de realizar, el conocimiento que comparte y los roles que participan en él. Además, los equipos tienen las mismas propiedades que un agente JA$\mathrm{CK}$, es decir, son entidades BDI, que ejecutan planes (teamplan) y razonan mediante la propagación de creencias dentro del equipo (teamdata).

JACK Teams proporciona soporte para la coordinación de actividades entre agentes mediante la formación de equipos complejos que contienen subequipos. Sin embargo la plataforma JACK, aunque permite la creación de equipos de agentes, no ofrece soporte para topologías de organizaciones más complejas ni tampoco tiene en cuenta aspectos fundamentales de las organizaciones como son las normas y las reglas. 
S-MOISE+. La plataforma S-MOISE+ [Hubner et al., 2006; Gateau et al., 2005] se basa en el modelo MOISE, anteriormente comentado. Su planteamiento es similar al de la plataforma AMELI, pues actúa como un middleware que se sitúa entre los agentes y el nivel de comunicación. Distingue también tres capas: aplicación, organizacional y de comunicación.

La capa de aplicación se compone de los agentes externos que se conecten al sistema, y cada uno tendrá asociado un agente interno, denominado OrgBox, en la capa organizacional. Además, en dicha capa organizacional está también otro agente interno, llamado OrgManager, que se ocupa de controlar, gestionar y permitir la modificación del estado de la organización. Dicho estado se representa a través de una Entidad Organizativa (EO). Cualquier cambio sobre la EO que un agente desee realizar, debe solicitarse al OrgManager a través de su OrgBox correspondiente. Por ejemplo, si desea adoptar un rol determinado. Del mismo modo, cuando los agentes quieran comunicarse entre sí o conocer cuál es el actual estado de la EO, deben realizarlo a través del OrgManager con la intermediación de su OrgBox.

Por otro lado, esta plataforma no necesita de una arquitectura específica de agente, tan sólo que los agentes empleen el API del OrgBox para interactuar con el sistema.

\subsubsection{Discusión sobre las plataformas de agente}

Los conceptos organizativos se han plasmado en las plataformas de agente principalmente de dos maneras distintas: (i) la gestión de agrupaciones de agentes; y (ii) la gestión de las normas de la organización. De este modo, tanto en Madkit como en JackTeams el enfoque principal se ha centrado en la gestión de los grupos o equipos de agente, estableciendo mecanismos para controlar el ciclo de vida de los grupos, conocer los roles que adquieren los agentes dentro de cada grupo, su movilidad entre grupos, así como las comunicaciones.

Por otro lado, en AMELI y S-MOISE+ la gestión de la plataforma se centra más bien en la descripción y control de las normas del sistema. Así, 
la adopción de roles, la comunicación entre agentes y la movilidad entre diferentes escenarios de comunicación viene marcado por normas, controladas por agentes internos del sistema. Los agentes externos no participan directamente en el sistema, sino que son representados a través de agentes interno, encargados de realizar todas las interacciones y gestionar el conocimiento de las normas en su nombre.

Resultaría interesante disponer de una plataforma de agentes, o al menos de una arquitectura abstracta, que contemplara todos los conceptos organizativos y facilitara la implementación de sistemas multiagente abiertos. Por ejemplo, servicios como la gestión de los grupos de la organización, su creación y eliminación dinámica, la movilidad de los agentes, la adopción de sus roles, la obtención de información sobre la estructura de la organización, etc., deberían ser proporcionados directamente por la plataforma.

\subsection{Conclusiones}

En el análisis y diseño de sistemas multiagente se ha producido una evolución de las metodologías MAS, partiendo de una visión inicial centrada en los aspectos individuales de los agentes hasta la visión actual del sistema como una organización, en la que los agentes están estructurados, formando grupos y jerarquías, con unas normas de comportamiento bien determinadas.

La visión organizativa permite concebir al sistema como un sistema abierto en el que agentes externos solicitan la participación dentro del mismo. En dicho caso, una metodología orientada a la organización debe proporcionar herramientas para definir los mecanismos de acceso y control del comportamiento de los agentes (especialmente de los agentes externos) dentro de la organización.

En la figura 3.5 se muestra una comparativa entre las características generales de las metodologías orientadas al agente y las metodologías orientadas a la organización.

En las metodologías orientadas al agente, el enfoque principal se centra 


\begin{tabular}{|c|c|c|}
\hline & \multicolumn{2}{|c|}{ Orientación Metodologías MAS } \\
\hline & Agente & Organización \\
\hline Enfoque & Acciones de agentes individuales & Organización del sistema \\
\hline Fases & Análisis, diseño, implementación & Análisis, diseño \\
\hline Supuestos & $\begin{array}{l}\text { Objetivos comunes, benevolencia, } \\
\text { cooperación }\end{array}$ & $\begin{array}{l}\text { Agentes heterogéneos, internos/externos, } \\
\text { no benevolencia }\end{array}$ \\
\hline $\begin{array}{l}\text { Arquitectura } \\
\text { de agente }\end{array}$ & Independiente o dirigida/específica & Independiente o no definida \\
\hline $\begin{array}{l}\text { Tipo de } \\
\text { sistema }\end{array}$ & Sistemas cerrados & Sistemas Cerrados y Abiertos \\
\hline Orientación & $\begin{array}{l}\text { Extensión OO, Ing. Conocimiento } \\
\text { u otras }\end{array}$ & $\begin{array}{l}\text { Extensiones de met. orientadas al agente o } \\
\text { plataformas organizacionales }\end{array}$ \\
\hline $\begin{array}{l}\text { Estructura } \\
\text { social }\end{array}$ & $\begin{array}{l}\text { Emerge de las interacciones de los } \\
\text { agentes }\end{array}$ & $\begin{array}{l}\text { Definida claramente: objetivos, roles, } \\
\text { jerarquías, grupos, escenas de interacción }\end{array}$ \\
\hline $\begin{array}{l}\text { Normas } \\
\text { sociales }\end{array}$ & No definido & $\begin{array}{l}\text { Mecanismos para incluir agentes externos } \\
\text { en la sociedad } \\
\text { Control del comportamiento interno del } \\
\text { agente (obligaciones, sanciones) }\end{array}$ \\
\hline
\end{tabular}

Figura 3.5: Comparativa de las características de las metodologías orientadas al agente vs. las orientadas a la organización

en las acciones individuales de los agentes. Muchas de ellas se han desarrollado a partir de extensiones a metodologías de orientación a objetos, o bien de la ingeniería del conocimiento, mientras otras parten de desarrollos totalmente independientes. La mayoría de estas metodologías definen las fases de análisis y diseño, mientras que solamente algunas (como Tropos, Prometheus, MaSE, MASSIVE) detallan también las fases de implementación.

Respecto a la arquitectura de agente a utilizar, o bien la propuesta metodológica es independiente de la arquitectura final que se emplee, o bien se centra en arquitecturas específicas, de tipo BDI, como JACK (ej. metodologías Tropos, Prometheus) o JADE.

Por otro lado, asumen que los agentes tienen objetivos comunes, son benevolentes y cooperan entre sí para alcanzar dichos objetivos en común. 
Tampoco proporcionan herramientas para controlar comportamientos interesados de los agentes. Así, las normas sociales no están definidas expresamente y la estructura social que presente el sistema emerge de las interacciones de los agentes, pero no está predefinida ni en el análisis ni en el diseño de la propia metodología.

Por todo ello, este tipo de metodologías no sirven por sí solas para el desarrollo de sistemas multiagente abiertos y solamente permiten el desarrollo de sistemas cerrados, en los que no se admite la participación de agentes externos, normalmente no confiables, ni cooperativos y con comportamientos auto-interesados.

Respecto a las metodologías orientadas a la organización, su enfoque principal se centra en la propia organización del sistema, teniendo en cuenta sus objetivos, estructura y normas sociales. Estas metodologías detallan principalmente la fase de análisis y, en algunos casos, la de diseño, necesitando una metodología orientada al agente para completar los aspectos internos de los agentes y la implementación del sistema, aunque en la mayoría de los casos no se explica cómo realizar dicho apoyo. Además, algunas de las propuestas son extensiones de metodologías orientadas al agente, como Roadmap, aunque muchas son desarrollos independientes que toman como base las teorías y entornos organizativos.

$\mathrm{Al}$ considerar como punto central de la metodología el concepto de organización, la estructura social se define expresamente, indicando los objetivos, roles, jerarquías, grupos, interacciones (escenas, transiciones) y topología del sistema. Por otro lado, se asume que los agentes son heterogéneos, de modo que se permite la participación de agentes externos e internos. Además, los agentes no tienen por qué ser benevolentes, apareciendo así comportamientos interesados. Asimismo, las normas sociales definen tanto los mecanismos para incluir agentes externos dentro de la sociedad, como mecanismos de control del comportamiento de los agentes según las restricciones impuestas por el sistema.

Por todo ello, estas propuestas resultan adecuadas para el modelado de sistemas multiagente, tanto abiertos como cerrados. Sin embargo, tal y 
como se ha evidenciado tras el estudio realizado, todavía son muy incipientes y carecen de suficientes formalismos y guías metodológicas apropiadas para realizar un análisis, diseño e implementación completo de un sistema multiagente y, en especial, de un sistema abierto. Además, se centran principalmente en el aspecto normativo de la sociedad, sin incidir demasiado en la estructura de la organización.

Un análisis organizativo del sistema permitirá guiar mejor en el desarrollo del sistema multiagente, aprovechando y reutilizando patrones de comportamiento propios de la estructura topológica seleccionada. En dicho análisis se debe determinar las características claves del problema, en función de su dominio de aplicación y de la estructura topológica más adecuada para el sistema. En las extensiones de Tropos y Gaia se plantea la reutilización de patrones sociales, aunque no se detallan con claridad cuáles son dichos patrones ni los roles, relaciones y comportamientos que conllevan. Por su parte, en OperA se asumen tres tipos de organización (jerárquica, en red y mercado) y se describen ciertos roles propios de esas organizaciones, pero no se proporciona ningún tipo de guía para combinar dichos roles con el resto de la organización.

Respecto a las plataformas de agente, la mayoría se basa en la arquitectura abstracta de FIPA, donde no se tiene en cuenta ningún concepto organizativo. Las pocas plataformas o arquitecturas de agente que abordan estos conceptos, lo hacen principalmente desde dos enfoques distintos: (i) la gestión de las agrupaciones de agentes, su ciclo de vida y paso de mensajes (ej. MadKit o JACK Teams); y (ii) la gestión de las normas de la organización, estableciendo escenarios de comunicación regulados (ej. AMELI y S-MOISE).

Resulta necesario el desarrollo de arquitecturas de sistemas multiagente abstractas que contemplen la generación de organizaciones virtuales en entornos abiertos, así como el desarrollo de plataformas de soporte que permitan la implantación de este tipo de sistemas.

En el trabajo de esta tesis se propone la utilización de la Teoría de la Organización para profundizar en el análisis organizativo y establecer unas 
guías metodológicas lo suficientemente potentes que permitan el desarrollo de MAS desde el punto de vista organizativo, cubriendo las carencias detectadas. Así, dichas guías ayudarán a la identificación de la mejor estructura topológica para el sistema.

Además, permitirán definir patrones sociales, correspondientes con cada estructura organizativa identificada en el trabajo. Dichos patrones detallarán los roles, protocolos y relaciones intrínsecos y necesarios a cada topología, facilitando así su utilización durante las fases de análisis y diseño del sistema.

Por otro lado, estos patrones podrán también extrapolarse a arquitecturas y organizaciones de agente similares a aplicaciones ya existentes, de modo que se aproveche la tecnología diseñada. 



\section{Capítulo 4}

\section{Modelado de Organizaciones}

En el presente capítulo se presenta el primer resultado relevante de esta investigación, una propuesta de modelado de organizaciones de agentes, basada en cuatro conceptos clave: la unidad organizativa, el servicio, el entorno y la norma. Para ello se definen y extienden un conjunto de meta-modelos, que proporcionan los conceptos y primitivas necesarios con los que describir la estructura, funcionalidad, dinamicidad, normalización y entorno de una organización. Además, haciendo uso de esos meta-modelos se han definido modelos o patrones de diseño para distintas topologías organizativas.

\subsection{Introducción}

Como se comentó en el capítulo 2, hemos definido la organización de agentes como una entidad social compuesta por un número específico de miembros, que llevan a cabo distintas tareas o funciones; y que están estructurados siguiendo unos patrones de comunicación y topología específicos, para así conseguir el objetivo global de la organización, en base a unas normas de comportamiento. Sus aspectos o factores principales son su estructura, funcionalidad, dinamicidad, normalización y su entorno.

Para modelar las características de dichos componentes se emplean cuatro conceptos clave: la unidad organizativa, el servicio, el entorno y la norma. Estos conceptos permiten representar: (i) cómo se agrupan las entidades 
entre sí, definiendo también la relación entre los elementos y su entorno; (ii) qué funcionalidad ofrecen, incluyendo servicios para la entrada y salida dinámica de los agentes en la organización; y (iii) qué restricciones existen sobre los comportamientos de las entidades del sistema.

Por tanto, proponemos considerar que una organización se compone de una o más unidades organizativas y de las interacciones entre los agentes y unidades; persigue un objetivo global (también denominado misión); ofrece servicios, tanto a sus miembros como a sus clientes y proveedores con los que se relaciona; necesita de normas sociales para controlar los comportamientos de sus miembros; y está inmersa en un entorno específico.

Para modelar la organización hemos hecho uso de los meta-modelos propuestos en INGENIAS y ANEMONA, que proporcionan los conceptos y primitivas necesarios para definir las diferentes vistas de la organización, sus componentes, funcionalidad, entorno, agentes y sus interacciones.

En nuestra propuesta se han extendido estos meta-modelos con nuevas entidades y relaciones que permiten integrar los conceptos de unidad organizativa, servicios y normas, descritos en este capítulo; así como los factores de estructura, funcionalidad, normalización, dinamicidad y entorno vistos en el capítulo 2.

Mediante el empleo de estos meta-modelos se han definido los modelos o patrones de diseño para cada uno de los tipos de organizaciones de agentes analizados en el capítulo 2, basados en la Teoría de Organizaciones humanas y de las organizaciones de agentes. Estos modelos y meta-modelos se integran posteriormente en las guías de análisis y diseño de sistemas multiagente que se proponen en el siguiente capítulo. De esta forma, el diseñador dispone de una especificación más clara y detallada de los roles, relaciones e interacciones existentes entre las entidades, en función de la estructura de cada unidad organizativa.

Por otro lado, el entorno requiere de una ontología que cubra tanto los conceptos estructurales de la organización como las características observables de los objetivos, recursos, agentes, así como del contenido de sus mensajes [Weyns et al., 2004]. Por tanto se requiere de una ontología de 
la organización y de una ontología del dominio, que depende del problema concreto a tratar. En este capítulo se muestra la ontología de organización que hemos desarrollado, en la que se integran todos los conceptos empleados en nuestro modelo de organización.

Para facilitar la comprensión de los meta-modelos extendidos, hacemos uso del caso de estudio que se explica con mayor detalle en el capítulo 6 . En dicho caso de estudio se modela y diseña un sistema para la gestión inteligente y personalizada de eventos de ocio para usuarios demandantes del servicio. Se trata de sistemas en los que existen varias entidades (Demandantes) que requieren uno o varios elementos u objetivos de otras entidades diferentes (Oferentes).

En concreto, nos centramos en el dominio de los viajes (de placer o negocio), donde los proveedores representan a cadenas hoteleras, compañías aéreas, etc., que ofrecen información sobre hoteles, vuelos, así como la posibilidad de realizar reservas e incluso el pago adelantado de las mismas. La descripción de los servicios a ofrecer por estas entidades está controlada por el sistema, a través de sus normas; aunque la funcionalidad interna de dichos servicios es responsabilidad de los agentes que los ofrezcan.

El presente capítulo se organiza de la siguiente manera. En la sección 4.2 se explica el concepto de unidad organizativa, para qué sirve y cuáles son las semejanzas y diferencias con conceptos o entidades similares de otras propuestas metodológicas. Además, se presentan las estructuras de las unidades organizativas básicas que hemos identificado.

En la sección 4.3 se detalla el concepto de servicio, tanto desde el punto de vista de las organizaciones humanas como en los sistemas multiagente, así como en el diseño de sistemas software. Asimismo, se explican las características principales de los servicios y sus componentes.

En la sección 4.4 se explica el concepto de norma, detallando los distintos elementos que la comprenden. Además se revisa brevemente la utilización de las normas en los trabajos de MAS más relevantes en ese aspecto.

En la sección 4.5 se detalla el concepto de entorno, analizando las distintas perspectivas bajo las cuales se modela. 
En la sección 4.6 se muestran las extensiones a los meta-modelos de MAS que se han realizado sobre la metodología de ANEMONA. Dichos meta-modelos serán posteriormente utilizados en las guías de análisis y desarrollo que se proponen en el capítulo 5.

En la sección 4.7, tomando como notación los meta-modelos anteriormente explicados, se presenta el modelo organizativo de MAS que definimos en este trabajo para las distintas estructuras organizativas estudiadas.

Finalmente, en la sección 4.8 se presentan las conclusiones del capítulo.

\subsection{Unidad Organizativa}

La unidad organizativa (UO) representa una agrupación de agentes que llevan a cabo determinadas tareas específicas y diferenciadas y que siguen cierto patrón de comunicación y cooperación predefinido. Esta agrupación puede ser vista desde el exterior como una entidad única, que persigue ciertos objetivos, ofrece y/o requiere determinados servicios e, incluso, juega un rol específico al interaccionar con otras entidades. Por tanto, la unidad organizativa tiene también un carácter recursivo, pues no sólo contendrá agentes, sino también otras unidades organizativas, actuando como entidades atómicas.

El concepto de unidad organizativa permite que durante el proceso de análisis y diseño del sistema se realicen distintas perspectivas o abstracciones de la composición y estructura de la organización: desde el enfoque más abstracto en el que sólo se contemplan las UO que la conforman hasta el enfoque más detallado en el que se especifican los agentes finales que integran cada unidad. Además, en los niveles más abstractos se definen servicios y normas en función de las UO, es decir, qué servicios ofrece cada unidad a los miembros que la componen, o bien a las entidades externas a la unidad; qué servicios requiere que ofrezcan sus miembros; qué servicios utiliza de otras entidades; y cuáles son las normas que rigen los comportamientos de sus miembros. En el nivel más bajo, se debe concretar qué agentes de la unidad se encargan de ofrecer cada uno de los servicios identificados, así como 
qué agentes controlan el cumplimiento de las normas establecidas.

Por otro lado, las relaciones entre los miembros o patrones de interacción están condicionadas por la estructura de la unidad. Como hemos visto en el capítulo 2, las organizaciones presentan distintas topologías en función de su entorno, del mercado al que se dirigen y del tipo de actividades que se realizan. Estas topologías definen con quién se relaciona cada miembro y qué poder tiene sobre sus acciones, así como sobre las tareas de los demás. Por ello, reflejan el conocimiento que dispone un miembro sobre las entidades que le rodean, de manera que agentes de una unidad probablemente no conozcan cuáles son los agentes de otras unidades y, en ocasiones, ni tan siquiera los de su propia unidad. Así, la UO permite establecer los límites de visibilidad entre las entidades.

Del estudio de las organizaciones de agentes [Horling y Lesser, 2004] y de la Teoría de Organizaciones humanas [Fox, 1981][Robbins, 2004], hemos identificado tres topologías básicas a partir de las cuales se construyen organizaciones más complejas. Dichas topologías representan los patrones mínimos de relaciones que existen entre los miembros de una organización y además proporcionan restricciones tanto de interacción como de visibilidad a los agentes. Estas tres topologías básicas son:

- jerarquía simple, formada por un miembro supervisor (que tiene autoridad y control sobre los otros miembros de la unidad; centraliza y captura las decisiones y coordina las tareas) y varios subordinados (que llevan a cabo las tareas básicas y se comunican entre sí a través del supervisor).

- equipo, en el cual todos los miembros colaboran entre sí para alcanzar un objetivo global y común, compartiendo su información y consiguiendo la coordinación a través de decisiones y planes mutuamente aceptados.

- estructura plana, que representa una anarquía en la que no existe una estructura fija ni un control de un miembro sobre otro, aunque los 
miembros pueden conocerse entre sí y obtener información unos de otros.

En la sección 4.6 se muestra el modelo organizativo que hemos diseñado para cada una de estas topologías.

Además, utilizando el concepto de unidad organizativa, se pueden diseñar estructuras mucho más elaboradas y complejas, como las estructuras vistas en el capítulo 2 (en concreto, la burocracia, la estructura matricial, la federación, la coalición o bien la congregación). En la sección 4.6 se muestra detalladamente cómo modelar dichas estructuras, a partir de las estructuras básicas.

\subsubsection{Vista parcial de la Ontología de Organización}

Con el objeto de facilitar la descripción de las organizaciones en las comunicaciones de los agentes, se ha desarrollado una ontología de organización con la que describir los conceptos de la Unidad Organizativa. En la figura 4.1 se muestra el esquema visual de dicha ontología.

El concepto Entity engloba a la entidad Unidad Organizativa y a la entidad Agente. Toda entidad tiene un identificador, persigue un conjunto de objetivos y puede actuar como miembro de alguna unidad jugando en ella un rol específico. Además, las entidades pueden ser propiertarias de recursos y ejercer control sobre ellos a través de sus puertos.

Por su parte, la UO consta además de una serie de roles sobre los cuales se definen ciertas relaciones, un conjunto de normas y una ontología específica del dominio en el que se centra. Toda UO tiene un tipo o estructura predefinido y durante su ciclo de vida tendrá distintos miembros (has_member), entidades de tipo agente o UO, que adoptan los roles definidos en la unidad (relación plays).

Los roles se organizan jerárquicamente (relación is_a), proporcionan y utilizan servicios (provides y uses_service), además de estar regidos por ciertas normas de la unidad (relación is_affected_by_norm). 


\begin{tabular}{|c|c|c|}
\hline \multicolumn{3}{|c|}{ Entity } \\
\hline EntitylD & String & \\
\hline pursues & Instance ${ }^{\star}$ & Goal \\
\hline is_member & Instance ${ }^{*}$ & Member \\
\hline has_resource & Instance ${ }^{\star}$ & Resource \\
\hline has_portControl & Instance ${ }^{*}$ & Port \\
\hline \multicolumn{3}{|c|}{ OrganizationalUnit: Entity } \\
\hline has_role & Instance ${ }^{*}$ & Role \\
\hline has_relationship & Instance ${ }^{*}$ & Relationship \\
\hline has_norm & Instance ${ }^{*}$ & Norm \\
\hline has_domain_ontology & Instance ${ }^{*}$ & Ontology \\
\hline has_member & Instance* & Member \\
\hline type & FLAT & | TEAM | HIERARCHY \\
\hline
\end{tabular}

\begin{tabular}{|c|c|c|}
\hline \multicolumn{3}{|c|}{ Role } \\
\hline RolelD & String & \\
\hline is a & Instance* & Role \\
\hline provides & Instance ${ }^{\star}$ & Service \\
\hline uses_service & Instance* & Service \\
\hline is affected by norm & Instance ${ }^{\star}$ & Norm \\
\hline is_played_by & Instance* & Member \\
\hline \multicolumn{3}{|c|}{ Member } \\
\hline is_member_of & Instance & OrganizationalUnit \\
\hline corresponds_to & Instance & Entity \\
\hline plays & Instance* & Role \\
\hline \multicolumn{3}{|c|}{ Relationship } \\
\hline origin & Instance & TRole \\
\hline 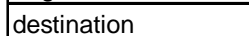 & Instance & Role \\
\hline type & INFORMA & $\begin{array}{l}\text { TION |MONITORING | } \\
\text { SUPERVISION }\end{array}$ \\
\hline
\end{tabular}

Figura 4.1: Ontología de Organización. Unidad Organizativa.

\subsubsection{Propuestas similares}

En el área de las organizaciones humanas, el concepto de unidad organizativa equivaldría al del departamento o grupo [Wagner y Hollenbeck, 2004]. El departamento se compone de personas que realizan el mismo tipo de trabajo (por ejemplo, el departamento de marketing lo forman los miembros que comercializan los bienes o servicios de la organización). Un grupo es un conjunto de dos o más personas que interactúan entre sí, influyéndose unas a otras. Generalmente, los integrantes del grupo se identifican a sí mismos como miembros, interactúan de forma frecuente, adquieren roles que están relacionados entre sí, comparten normas comunes, siguen objetivos interdependientes y/o compartidos, tienen una percepción colectiva de unidad y se benefician de alguna manera de su pertenencia al grupo.

En el capítulo 3, con la revisión de los métodos de análisis y diseño de los sistemas multiagente, vimos otros conceptos similares al de unidad organizativa, en concreto el grupo y la escena. Así, el grupo en MAS representa a un conjunto de agentes que comparten características comunes y además las comunicaciones se llevan a cabo solamente dentro de los grupos. Es utilizado en métodos como AGR [Ferber et al., 2003] y MOISE [Gateau et al., 
2005], entre otros. Por su parte, la escena describe un protocolo de conversación para un conjunto de roles, indicando cuáles son las comunicaciones permitidas dentro de la escena. Se emplea en los métodos E-Institutions [Esteva et al., 2001b], OperA [Dignum, 2003] y OMNI [Vazquez-Salceda et al., 2004].

Por otro lado, en AML [Cervenka y Trencansky, 2007] se utiliza también el propio término unidad organizativa, el cual permite modelar tipos de entornos sociales o sus partes. Como entorno, proporciona las condiciones bajo las que las entidades funcionan y existen. Como tipo de entorno, ofrece dos perspectivas: interna y externa. Desde la perspectiva externa, representa a entidades autónomas coherentes que tienen unos objetivos determinados, un comportamiento asociado, cierta interacción con su entorno y que además ofrecen servicios y juegan roles. Desde una perspectiva interna, describe tipos de entornos que contienen roles, agentes, recursos y relaciones entre sus entidades.

Nuestra propuesta se asemeja a la de AML al asociar a la unidad organizativa aspectos tanto de entidad global y atómica como de agrupación de sus entidades internas, relacionadas entre sí en base a sus roles, funcionalidad, recursos y entorno. En nuestro caso profundizamos en el detalle de la estructura interna de la unidad organizativa, definiendo los patrones de diseño de su topología y de sus servicios.

\subsection{Servicios}

En las organizaciones humanas, los servicios son ofrecimientos intangibles de valor que se proporcionan a un consumidor o cliente y que no poseen una forma física determinada [Hodge et al., 2003]. Se caracterizan por su grado de tangibilidad, estandarización, participación del cliente y sincronización de la producción y el consumo. Así, en los servicios puros no existen resultados o productos concretos y tangibles; suelen estar menos estandarizados y más adecuados a las necesidades de los clientes; e implican 
normalmente la participación directa del cliente en el proceso de producción, requiriendo que la producción y el consumo del servicio se realicen de forma simultánea.

En los sistemas multiagente, los servicios representan cierta funcionalidad que los agentes ofrecen a otras entidades (otros agentes), independientemente del agente concreto que haga uso de ello. Las características principales de estos servicios son:

- Sincronización: se requiere la interacción entre las entidades que ofrecen el servicio y las entidades que lo requieren y hacen uso de él.

- Publicación: se registra en un directorio de servicios, para que las entidades puedan localizarlo. Permite así atraer a nuevas entidades que requieran el servicio.

- Participación: las entidades que consumen el servicio podrán variar a lo largo del tiempo. Si siempre fueran las mismas, resultaría más sencillo plantear la funcionalidad a través de interacciones preestablecidas y no como servicios.

- Estandarización de entidades: los consumidores y productores del servicio se asocian a determinados roles, para los cuales se definen restricciones específicas (como habilidades requeridas, funcionalidad, acceso a recursos, etc.). De este modo se obliga a que las entidades que utilicen o bien ofrezcan el servicio jueguen el rol indicado y, por tanto, cumplan con dichas restricciones impuestas en el rol.

- Estandarización de la funcionalidad: los servicios se describen en términos de entradas, salidas, precondiciones y postcondiciones. De esta manera se facilita su publicación (conociendo así fácilmente qué ofrece el servicio) y la composición de servicios, pudiendo concatenar unos servicios con otros en base a sus entradas y salidas. Además, en la publicación del servicio se indica qué hace, pero no cómo lo hace, ofreciendo así independencia de su funcionalidad interna. 
- Tangibilidad: en ocasiones los servicios llevan asociados productos concretos y tangibles, con los que se podrá evaluar mejor la calidad, eficiencia del servicio y la satisfacción del cliente.

- Coste: la producción y consumo del servicio llevan asociados ciertos costes y/o beneficios, tanto para el cliente como para el servidor.

La funcionalidad propia de los servicios se lleva a cabo a través de la ejecución de determinadas tareas, propias del agente que ofrece el servicio o bien delegadas en otros agentes. Dicha delegación implica la solicitud directa de determinadas tareas o el requisito de nuevos servicios.

Para saber si una funcionalidad concreta debe ser considerada como un servicio, compuesto de una o varias tareas; o bien como un flujo de tareas sin servicio asociado, deberemos tener en cuenta el aspecto de la publicación. Así, si una funcionalidad específica de un agente requiere ser registrada en un directorio de servicios para que cualquiera que lo necesite pueda encontrarla y hacer uso de ella, entonces se verá como un servicio. Por contra, si no se necesita su publicación la trataremos como un flujo de tareas, independientemente de si provoca o no una interacción entre entidades.

Por ejemplo, consideraremos flujo de tareas a toda aquella funcionalidad interna del agente que no implica ninguna interacción con otros agentes. O bien a aquella funcionalidad en la que el agente requiere contactar con otros agentes previamente definidos y establecidos, que siempre serán los mismos, para suministrarles información u obtener de ellos ciertos recursos.

Por tanto, las interacciones entre agentes que ejecutan flujos de tareas vienen preestablecidas en el propio diseño del sistema, mientras que para el caso de servicios se requerirá realizar una búsqueda previa, en algún directorio de servicios, para así encontrar qué agente proporciona el servicio solicitado y cómo contactar con él (es decir, qué tipo de interacción se debe establecer con dicho agente). 


\subsubsection{Vista parcial de la Ontología de Organización}

La ontología de organización propuesta incluye también el concepto de servicio, sus características y relaciones. En la figura 4.2 se muestra el esquema visual de la ontología para la entidad Servicio.

Todo servicio lleva asociado uno o más proveedores (is_provided_by), es utilizado por uno o varios roles (is_used_by) y tiene incidencia sobre determinados objetivos del sistema (affects_goal). Se emplea la ontología OWL-S sobre perfiles, procesos y groundings de servicios para describir qué hace el servicio (service_description), de qué manera (service_activity) y qué interacciones se producen (service_interaction).

\begin{tabular}{|l|l|l|}
\hline \multicolumn{3}{|c|}{ Service } \\
\hline ServicelD & String \\
\hline is_provided_by & Instance & Role \\
\hline is_used_by & Instance & Role \\
\hline affects_goal & Instance & Goal \\
\hline service_description & Instance & OWL-S: ServiceProfile \\
\hline service_activity & Instance & OWL-S: ServiceProcess \\
\hline service_interaction & Instance & OWL-S: ServiceGrounding \\
\hline
\end{tabular}

Figura 4.2: Ontología de Organización. Servicios.

\subsubsection{Propuestas similares}

En los últimos años, el concepto de servicio se ha utilizado ampliamente para el desarrollo de sistemas software, de forma totalmente independiente al uso de los agentes. En concreto, la arquitectura orientada a los servicios (SOA - Service Oriented Architecture) ${ }^{1}$, evolución de la computación distribuida y la programación modular, agrupa las funcionalidades del sistema en servicios atómicos, que podrán ser combinados entre sí para ofrecer nuevos servicios más complejos.

Por tanto, las aplicaciones se implementan a partir de bloques de funcionalidad reutilizables, representados por los servicios. Cada servicio lleva

\footnotetext{
${ }^{1}$ http://www.oasis-open.org/committees/download.php/19679/soa-rm-cs.pdf
} 
asociado una descripción de la funcionalidad que proporciona, la cual posibilita que la integración de los servicios se lleve a cabo tanto en la fase de diseño, como en la ejecución del sistema. De esta manera, los servicios pueden ser descubiertos, utilizados y coordinados de forma dinámica.

Para ello se requiere la utilización de tres tipos de roles distintos: el proveedor del servicio (service provider), que se encarga de realizar la funcionalidad propia del servicio; el registrador del servicio (service registry o service broker), que contiene el listado de los servicios accesibles, facilitando así su publicación; y el consumidor del servicio (service requester), quien hace uso del servicio.

La arquitectura SOA es independiente de la tecnología que se utilice, por lo que podemos encontrarnos implementaciones en SOAP, RPC, DCOM, CORBA, Servicios Web, etc. Es más, se podrían combinar servicios con tecnologías distintas, siempre que: (i) se utilice un lenguaje común de descripción del servicio (por ejemplo WSDL); (ii) se emplee un lenguaje común de contenido (por ejemplo, mensajes definidos usando XML Schema o XSD); y (iii) se registren en un directorio de servicios, para que sean descubiertos e invocados, usando por ejemplo UDDI (Universal Description, Definition and Integration), que es el estándar empleado para el registro de servicios. Además, cada servicio tendrá asociado una calidad de servicio (QoS, quality of service), en la que se describen ciertos requisitos de seguridad, como autorización, autentificación y políticas sobre quién puede invocar el servicio.

Conviene indicar que dadas las características de autonomía, proactividad y sociabilidad de los agentes, ante una petición de servicio un agente podrá indicar como respuesta que se encuentra ocupado, que no puede atender al cliente en ese momento; o bien que no entiende con claridad los datos que se le proporcionan, porque son incompletos; o que le contestará más adelante. Por tanto, los agentes aportan mayor flexibilidad y sociabilidad a un sistema orientado a servicios. Es por ello que se está produciendo un acercamiento entre las propuestas de SOA y de los MAS, de manera que en ciertas implementaciones de arquitecturas orientadas a servicios se hace 
uso de agentes para el registro o el descubrimiento de servicios; mientras que en los MAS se amplía el concepto de servicio para la descripción y publicitación de la funcionalidad de los agentes.

En nuestra propuesta nos centramos en la integración de las tecnologías de servicios Web y de Sistemas multiagente, más que en el uso de una tecnología por parte de la otra. De este modo, permitimos que los agentes describan su funcionalidad de forma similar a los servicios Web, siendo también capaces de realizar composición de servicios y búsqueda activa. Además, la unidad organizativa facilita la publicitación de requisitos de servicio, para que otras entidades, de forma proactiva, decidan participar dentro de la unidad para así dar soporte a esa funcionalidad requerida.

A la hora de publicitar o dar a conocer los servicios es necesario el empleo de estándares, que permitan homogenizar la descripción de sus parámetros y funcionalidad, para así permitir que sus usuarios entiendan claramente su cometido. En ese sentido, desde hace ya algún tiempo la Web semántica [Castells, 2003] se centra en automatizar las tareas relacionadas con los servicios web, es decir, el descubrimiento, selección y composición de los servicios. Su objetivo consiste en permitir que los servicios sean procesables por máquinas (en nuestro caso, por los agentes) de forma autónoma.

Dentro de las tendencias actuales de la Web Semántica, destaca el lenguaje OWL-S ${ }^{2}$, que ofrece una especificación de servicios basada en el estándar WSDL (empleado principalmente en servicios web y modelos cliente/servidor) y que puede ser procesada por agentes. En dicho lenguaje se tratan tres aspectos distintos: (i) qué ofrece el servicio al usuario o agente y qué requiere de éste, descrito a través del profile; (ii) cómo funciona el servicio (process), indicando los distintos procesos de los que se compone; y (iii) cómo se utiliza, haciendo uso del grounding propio de WSDL.

En el profile se describen las entradas y salidas del servicio, sus precondiciones (valores requeridos de las entradas para que se ejecute el servicio adecuadamente) y efectos (valores de los datos de salida según ciertas condiciones, así como los productos resultantes del servicio). En el process se

\footnotetext{
${ }^{2}$ http://www.w3.org/Submission/OWL-S/
} 
describe el flujo de tareas del servicio, a través de su descomposición en uno o más procesos atómicos. Permite especificar mejor la relación entre los datos que se suministran y las distintas precondiciones y efectos que se generan. Finalmente, en el grounding se especifican los detalles concretos de cómo acceder al servicio, es decir, el protocolo a emplear, los formatos de los mensajes, serialización, transporte y direccionamiento.

En nuestro modelo de servicios nos hemos basado en las descripciones del profile y del process de OWL-S para definir la funcionalidad del servicio, debido tanto a la popularidad de dicho lenguaje, como a su nivel de estandarización y a su sencillez. Además no sólo indicamos los servicios que una entidad ofrece, sino también aquellos servicios que requiere. Es decir, aquella funcionalidad que necesita para poder suministrar la suya propia, pero que no la implementa internamente $y$, por tanto, requiere de otras entidades para su realización.

Por otro lado, aunque en la especificación del servicio (profile) se describen los valores de entrada y salida del mismo, éstos no tienen por qué proporcionarse todos juntos en el momento de solicitarlo, ni tampoco se devuelven todas las salidas al terminar el servicio, sino que normalmente se establece un protocolo o flujo de intercambio de mensajes entre cliente y servidor (o incluso entre otras entidades intermedias). Dicho protocolo se describe en el process del servicio, donde se indican las distintas tareas en las que se descompone, el flujo de conexión entre ellas y qué entradas y salidas se requieren. En ocasiones, estas tareas harán uso de la funcionalidad de otras entidades, estableciéndose así conexiones con otros servicios.

En OWL-S se ofrecen diferentes constructores de control, como sequence, split, if-then-else, repeat-while, etc., que detallan en qué procesos o tareas se descompone el servicio. De este modo, protocolos de comunicación típicos de los sistemas multiagente, como los clásicos de FIPA de Request, ContractNet, Subscribe o los diferentes tipos de subastas, entre otros, pueden también representarse a través de servicios.

Con todo ello, el concepto de servicio nos es muy válido para modelar la funcionalidad que los agentes ofrecen a otros, con independencia del agente 
concreto que haga uso de ella.

\subsection{Normas}

Desde el punto de vista de las organizaciones, las normas representan un mecanismo de coordinación que debe tratar, por un lado, de promover que los agentes realicen ciertas acciones beneficiosas para la organización, contribuyendo así a la consecución de sus objetivos globales; y por otro, debe evitar que lleguen a realizar acciones que le resulten perjudiciales, es decir, que provoquen la insatisfacción de sus clientes, o bien dejen al sistema en un estado inestable. En este caso, cuando el contexto así lo requiera, se obligará a la realización de determinadas acciones por parte de los agentes y se establecerán las medidas de corrección oportunas para devolver la estabilidad al sistema.

En nuestro modelo, el diseñador asume que se trata de un sistema normativo, con agentes normativos a los que se les informa de las normas. Además la organización se gestiona en base a normas. Si el agente concreto no es normativo (internamente no sabe razonar sobre las normas) probablemente actuará de forma totalmente egoísta y sin tener en consideración cuáles serán las consecuencias de sus acciones sobre el resto del sistema.

Para toda norma tenemos los siguientes componentes:

- Identificación: la norma dispone de identidad única.

- Condición de activación: estado del entorno que provoca que la norma pase a estar activa. Su activación provoca la creación de uno o más objetivos normativos.

- Afectado: indica la entidad (A-Agente o rol) sobre la cual se aplica la norma. Esta entidad deberá ser informada de la existencia de la norma, así como de cuándo se produce su activación. Si se trata de un agente normativo, tras ser informado se añadirán nuevos objetivos, de tipo normativo, a su estado mental, con los que determinar si debe o 
no seguir la norma, en base a las sanciones o recompensas que ello le supondrá.

En caso de un agente no normativo, a éste le es indiferente la existencia de la norma, por lo que no añade ningún nuevo objetivo, basando su comportamiento solamente en sus objetivos propios.

- Deadline: Condición de vivencia de la norma. Tiempo máximo establecido en el que la norma estará activa.

- Valor deóntico: indica si se trata de una Obligación, de un Permiso o de una Prohibición.

- Sanción: objetivo a cumplir por el sancionador si la obligación falla; o bien si la prohibición se satisface. Lleva asociada una tarea, que implica por ejemplo la expulsión del miembro que ha provocado la activación de la sanción.

- Recompensa: objetivo a cumplir por el recompensador si la obligación o permiso se satisface. Es un elemento opcional. Lleva asociada una tarea, por ejemplo la asignación de nuevos recursos a la entidad que ha generado la activación de la recompensa.

- Controlador: entidad que se encarga de monitorizar la activación y desactivación de la norma.

- Sancionador: se encarga de controlar el fallo de la obligación o la satisfacción de la prohibición y persigue el objetivo indicado por la sanción.

- Recompensador: Se encarga de controlar la satisfacción de la obligación o del permiso y persigue el objetivo indicado en la recompensa.

Con todos estos componentes es posible desarrollar un modelo normativo que permita controlar el comportamiento de las entidades de una UO y establecer relaciones entre distintas unidades. 


\subsubsection{Vista parcial de la Ontología de Organización}

La ontología propuesta incluye también el concepto de Norma. En la figura 4.3 se muestra el esquema visual de la ontología para dicha entidad.

La descripción de la norma incluye un identificador (NormID), su tipo (deontic_concept), una condición de activación (stateCondition) y de finalización (deadline), la unidad en la cual se define (norm_defined_in), el rol o roles afectados por la norma (affects), así como roles encargados de su control (issuer), de la ejecución de las sanciones (defender) o bien de las recompensas (promoter).

\begin{tabular}{|l|l|l|}
\hline \multicolumn{3}{|c|}{ Norm } \\
\hline NormID & String & \\
\hline norm_defined_in & Instance & OrganizationalUnit \\
\hline deontic_concept & Instance & DeonticConcept \\
\hline affects & Instance & Role \\
\hline issuer & Instance & Role \\
\hline promoter & Instance* & Role \\
\hline defender & Instance & Role \\
\hline stateCondition & Instance & NormativeCondition \\
\hline deadline & Instance & TemporalCondition \\
\hline action & Instance & Action \\
\hline service & Instance & Service \\
\hline sanction & Instance* & Norm \\
\hline reward & Instance* & Norm \\
\hline
\end{tabular}

Figura 4.3: Ontología de Organización. Norma.

\subsubsection{Propuestas similares}

Existen muchos trabajos relacionados con las normas de los agentes, que van desde investigaciones sobre la importancia de las normas para los comportamientos de los agentes [Conte et al., 1999]; la representación interna de las normas [Lopez-Lopez y Luck, 2003]; el modelado de agentes normativos [Boella y der Torre, 2004; 2003]; el desarrollo de lógicas para su formalización, especialmente de lógicas deónticas [Dignum y Dignum, 2007; Wieringa et al., 1996]; así como la definición de lenguajes normativos dentro del marco de instituciones electrónicas [Garcia-Camino et al., 2005; 
Torres, 2007].

En especial, resultan de interés para nuestro trabajo la utilización de las normas en sistemas de agentes para representar sociedades, instituciones y organizaciones [Dellarocas y Klein, 2001; Esteva et al., 2001a; Dignum et al., 2001]. En dichos sistemas, las normas se emplean como mecanismos para conseguir la coordinación entre los miembros. Por ejemplo, en el entorno de trabajo E-Institutions [Esteva et al., 2001a], las normas describen acciones dialógicas que los agentes deben llevar a cabo (o bien tienen prohibida su realización) y que dependen de restricciones temporales o de la ocurrencia de eventos.

Por su parte, Lopez y Luck describen un entorno de trabajo normativo que facilita la descripción de los componentes de una norma, su proceso de razonamiento y su implementación [Lopez-Lopez y Luck, 2004]. Tienen en cuenta un sistema normativo, en el que los agentes son capaces de razonar sobre las normas. Se distinguen tres tipos de normas: legisladoras, sancionadoras y recompensadoras. La descripción del patrón de comportamiento de una norma se realiza a través de objetivos normativos. Así, los agentes escogen el modo de satisfacer esos objetivos normativos con mayor grado de autonomía.

\subsection{Entorno}

Siguiendo las propuestas de las organizaciones humanas y del trabajo de [Weyns et al., 2004], el entorno se debe tratar desde dos perspectivas distintas: la estructural y la funcional. La perspectiva estructural determina cuáles son los elementos que componen el sistema (agentes, objetos, recursos); cómo se relacionan entre sí (i.e. qué agrupaciones se establecen entre los agentes, qué normas rigen su comportamiento, cómo se produce el acceso a los recursos); y cómo representar conceptualmente estos elementos con una ontología.

Por otro lado, la perspectiva funcional determina las actividades que se 
desarrollan en el entorno, en concreto, cómo se produce la comunicación entre los agentes (mensajes directos, indirectos, a través de elementos propios del entorno); cómo se percibe y se actúa sobre el entorno; y qué otros tipos de entidades producen actividad en el entorno (como objetos o recursos).

En nuestra propuesta nos centramos en la descripción de los elementos que componen el entorno, en la percepción y actuación sobre estos elementos, así como en la asignación de permisos que regulan su acceso.

\subsection{Meta-modelos del Sistema multiagente}

El meta-modelado es un mecanismo que permite definir formalmente lenguajes de modelado, estableciendo las primitivas y propiedades sintácticas y semánticas de un modelo [Giret, 2005]. Por ejemplo, el meta-modelo de UML describe los conceptos y reglas que se necesitan para crear modelos UML.

Las metodologías INGENIAS [Gomez, 2002] y ANEMONA [Giret, 2005] ofrecen diversos meta-modelos para el análisis y diseño de un sistema multiagente, a través de la descripción de sus componentes (organizaciones, roles, agentes); funcionalidad (tareas y objetivos); entorno (recursos y aplicaciones); así como de las interacciones entre los agentes y sus aspectos internos de autonomía y gestión de su estado mental. El lenguaje que utilizan para la definición de los meta-modelos es la notación UML siguiendo las restricciones indicadas en GOPRR (Graph, Object, Property, Relationship and Role) [Kelly et al., 1996]. Como se explicó en el capítulo 3, ANEMONA es una metodología Multiagente para el desarrollo de Sistemas Holónicos de Fabricación. Está basada en INGENIAS, la cual sigue un proceso iterativo de desarrollo del sistema, extendiendo las fases empleadas en la metodología MESSAGE.

Como vimos en el capítulo 2, los factores relevantes de una organización son su estructura, funcionalidad, normalización, dinamicidad y entorno. Tanto INGENIAS como ANEMONA definen, a través de sus meta-modelos, gran parte de las entidades y relaciones requeridas por dichos factores. Por 
tanto, para el modelado de las organizaciones en los sistemas multiagente nos hemos basado en los meta-modelos que proponen estas dos metodologías, realizando extensiones para incluir nuevos conceptos, tales como la unidad organizativa, la norma o el servicio.

Los meta-modelos de ANEMONA, basados en los de INGENIAS, ofrecen la noción de Agente Abstracto (A-Agente) [Giret, 2005], que permite tratar colecciones de agentes como entidades de más alto nivel, de modo que durante las fases de análisis y diseño del sistema se considere, en algunos momentos, a la colección o agrupación de agentes como una entidad completa y única, que juega un rol determinado, que persigue unos objetivos, ejecuta unas tareas, etc.; en definitiva, que actúa como si se tratase de una entidad de tipo agente.

En otros momentos del proceso de análisis y diseño, la entidad A-Agente se refina y especifica internamente, detallándose así los elementos o entidades que la componen, bien sean agentes simples o bien nuevas agrupaciones de agentes. Por tanto, el A-Agente se define de forma recursiva, de modo que puede ser tanto un ente atómico como un sistema multiagente (con entidad única) constituido por Agentes Abstractos no necesariamente homogéneos.

Este concepto de Agente Abstracto está ligado a las organizaciones en la medida en que, como hemos indicado anteriormente, las organizaciones se componen de una o más unidades organizativas, las cuales, por un lado, estarán formadas por agentes u otras unidades, siguiendo unos patrones de interacción y normas estructurales establecidos; por otro, la unidad ofrecerá ciertos servicios a entidades externas a la misma (o incluso a sus propios miembros) como si de una entidad única se tratase, es decir, sin importar realmente quién desempeñará dicho servicio. Además, podrá jugar un determinado rol dentro de otras unidades y perseguirá ciertos objetivos, denominados objetivos funcionales, que determinarán el rendimiento y efectividad de la unidad. Por tanto, los conceptos de A-Agente y Unidad Organizativa están relacionados entre sí y podremos emplearlos para el modelado de organizaciones de agentes. 
Respecto a los conceptos de norma y servicio, ni INGENIAS ni ANEMONA definen entidades en sus meta-modelos con características similares a las contempladas en nuestro trabajo. Por tanto, hemos refinado sus metamodelos para hacerlos compatibles con nuestra propuesta, incluyendo en ellos, entre otros aspectos, las entidades Servicio y Norma.

En ANEMONA se define un total de cinco meta-modelos distintos, a partir de los cuales hemos desarrollado los meta-modelos de nuestra propuesta: de agente, de tareas y objetivos, de interacción, del entorno y de organización. A continuación comentamos brevemente en qué consiste cada uno de estos meta-modelos y las extensiones realizadas a los mismos. En las secciones posteriores de este capítulo se profundizará en la explicación de cada uno de ellos.

El meta-modelo de agente permite describir los agentes concretos, excluyendo sus interacciones con otros agentes. Por tanto, se definen las responsabilidades del A-Agente: qué roles juega; qué habilidades o tareas sabe ejecutar (y, por tanto, es responsable de la ejecución de dichas tareas); y qué objetivos persigue, comprometiéndose a alcanzarlos. Dada la definición recursiva (holónica) del A-Agente, dichas responsabilidades se aplican no sólo a agentes atómicos, sino también a las agrupaciones de agentes, vistas como organización. Así, una organización podrá jugar un rol (dentro de otra organización que la contenga), será responsable de las tareas asignadas a ese rol, tendrá las capacidades definidas en ese rol, perseguirá los objetivos definidos para el rol, etc.

Dadas las características de sociabilidad, asumimos que un agente ofrece una serie de servicios, es decir, un conjunto de funcionalidades que serán solicitadas por otros agentes, con independencia de los agentes concretos con los que se interactúe. Dichos servicios serán proporcionados a través de las tareas que el agente implementa. Por ejemplo, un agente encargado de la venta de entradas de un cine ofrece el servicio Venta de entradas a cualquier agente que requiera de dicho servicio. Además, cuando el agente se incorpore como miembro en una organización determinada, lo hará adoptando (o jugando) un determinado rol, en el que se especifica qué servicios concretos 
podrá servir y el modo en el que se deben ofrecer dichos servicios. De esta manera, un agente individual podrá tener implementado internamente un conjunto de servicios, pero al actuar como miembro de una organización solamente se le permita ofrecer la funcionalidad de un conjunto restringido de los mismos, para así adecuarse a los requisitos impuestos en la organización.

En nuestra propuesta, en el meta-modelo de agente se especifica la funcionalidad concreta de cada agente, en base a tareas y servicios; los objetivos que persigue; las normas que conoce; y los mecanismos de razonamiento que utiliza, que permiten la evolución de su comportamiento. Además, si se conoce en qué organizaciones participa el agente, en este meta-modelo se especifica qué roles juega el agente en ellas.

El meta-modelo de tareas y objetivos permite modelar el control del agente, describiendo cuándo se pueden ejecutar las tareas, qué cambios sobre el estado mental del agente se producen y cuál es la motivación del agente para ejecutar dichas tareas (es decir, qué objetivos se persiguen). En este meta-modelo se realiza también la descomposición de las tareas y objetivos en sub-tareas y sub-objetivos más concretos, respectivamente. Por su parte, las tareas se llevan a cabo al darse ciertas condiciones del entorno, reflejadas mediante entidades mentales. Durante su ejecución pueden consumir recursos, utilizar aplicaciones y producir nuevos recursos y nuevos estados o entidades mentales. En ocasiones, la ejecución de las tareas produce también interacciones de los A-Agentes entre sí.

En nuestra propuesta, se integra el concepto de servicio, indicando qué servicios ofrecen y/o requieren las unidades organizativas; y se relacionan con las tareas que los desempeñan. Debido a esta extensión, se ha renombrado el meta-modelo, pasándose a llamar meta-modelo de actividad, ya que en él se describe la funcionalidad de los agentes y de las unidades organizativas en base a servicios, tareas y objetivos.

El meta-modelo de interacción permite definir las interacciones del sistema. Así, se describen quiénes son los A-Agentes que participan en la interacción, en concreto un iniciador (o emisor) y uno o más colaboradores (receptores); así como los objetivos que se persiguen. La especificación 
concreta de la interacción se lleva a cabo mediante unidades de interacción, donde se definen los protocolos a seguir.

En nuestra propuesta se mantiene el mismo meta-modelo de interacción de ANEMONA, aunque las interacciones serán provocadas no sólo por la activación de Objetivos, sino también por la utilización de los servicios.

En el meta-modelo del entorno se definen los recursos y aplicaciones que utilizan los A-Agentes. Un recurso representa un objeto del entorno que resulta indispensable para la ejecución de las tareas; mientras que una aplicación es todo aquel objeto del entorno que proporciona una funcionalidad concreta pero cuyo comportamiento no satisface el principio de racionalidad [Gomez, 2002].

En nuestra propuesta se extiende este meta-modelo para incluir las actuaciones y percepciones de los agentes, así como el acceso a los servicios a través de sus puertos.

Finalmente, en el meta-modelo de organización se describen los flujos de trabajo existentes, cómo se coordinan los participantes de la organización, cuáles son las tareas relevantes para la organización, los objetivos que se persiguen globalmente y las restricciones en el comportamiento de los agentes, como la relación de subordinación. En ANEMONA el concepto de organización representa simplemente a un conjunto de agentes, sin que se les asocie aspectos normativos ni dinámicos.

En nuestra propuesta se integra el concepto de unidad organizati$\boldsymbol{v a}$, que describe las agrupaciones existentes entre los miembros del sistema. Las unidades llevan una estructura interna asociada; unas posiciones o roles que definen un conjunto de funcionalidad (servicios que ofrece y requiere), asi como unos objetivos asociados, representando las expectativas de la organización para dicha posición; recursos y aplicaciones propios de la unidad, que podrán ser accedidos por determinados miembros de la misma; y normas específicas que dictan el comportamiento de los miembros dentro de la organización. El concepto de Unidad Organizativa extiende al de A-Agente, proporcionando nuevas relaciones entre las entidades del sistema. 
La utilización del concepto de Unidad Organizativa permite tratarla durante el análisis e incluso en el diseño del sistema como una entidad autónoma, con características propias tales como estructura, funcionalidad, dinamicidad y con un entorno propio, que tiene además asociados una serie de servicios para la gestión de sus miembros. Además, los meta-modelos propuestos permiten al diseñador optar por dos soluciones distintas: a) refinarlos para asignar la funcionalidad de la UO y el control de sus componentes a agentes internos específicos; b) delegar en una arquitectura de MAS organizativa dicha funcionalidad y control, a través de agentes o elementos propios de la arquitectura que se encarguen de ofrecer esos servicios.

En nuestra propuesta la normalización queda expresada con un nuevo meta-modelo, el meta-modelo normativo, no contemplado en ANEMO$N A$, en el que se detallan las normas de la organización, los objetivos normativos a seguir por los agentes, asi como las sanciones y recompensas que afectan a dichas normas.

En resumen, las extensiones realizadas a los meta-modelos permiten describir los cinco factores que se requieren en el modelado de las organizaciones (estructura, funcionalidad, dinamicidad, entorno y normalización), según se muestra en la figura 4.4 .

De este modo, la estructura de la organización se define en base al metamodelo de organización. La funcionalidad de la organización se describe mediante el meta-modelo de actividad, en el que se definen los servicios que ofrece y requiere la organización, así como las tareas que los desempeñan y los objetivos que se persiguen. También por el meta-modelo de agente, el cual permite concretar las responsabilidades específicas de los agentes. Por último, por el meta-modelo de interacción, donde se definen las interacciones concretas de los agentes, así como la invocación de los servicios a través de sus puertos.

Por otro lado, la dinamicidad se describe en el meta-modelo de organización (a través de la vista dinámica) y en el meta-modelo de interacción. El entorno de la organización se refleja a través del meta-modelo de entorno, 
donde se describen no sólo los recursos y aplicaciones del sistema, sino también las actuaciones y percepciones de los agentes, así como los permisos de acceso a los puertos, recursos y aplicaciones de la organización. Finalmente, la normalización queda expresada en el nuevo meta-modelo normativo, que describe las regulaciones a aplicar en el sistema.

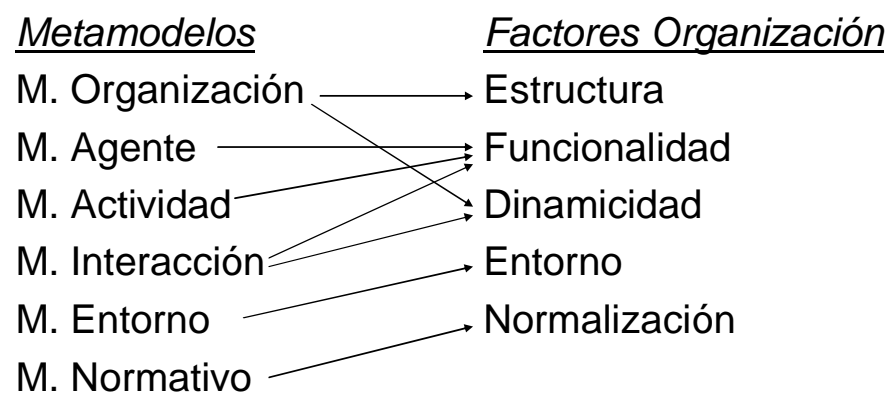

Figura 4.4: Relación entre los meta-modelos y los factores de la organización.

Las reglas nemotécnicas, que se definen en INGENIAS (y se mantienen en ANEMONA) para facilitar la lectura de los meta-modelos, son:

- Al nombre de la relación le precede un conjunto de letras que denotan su procedencia (O para la organización; GT para los objetivos y tareas; WF para el flujo de trabajo; AGO para las relaciones sociales; $\mathbf{E}$ para el entorno; I para las interacciones y $\mathbf{N}$ para las normas).

- Por cada asociación entre una entidad relationship y un object existe una instancia de la primitiva GOPRR Role, nombrándose ésta con el mismo nombre que la relación pero antecedido por la letra $\mathbf{R}$ y terminado con la letra $\mathbf{D}$ u $\mathbf{O}$, para indicar el sentido de la relación (D de Destino, $\mathbf{O}$ de Origen).

En nuestra propuesta se ha mantenido también la misma notación para facilitar la comparación de las extensiones y modificaciones que hemos realizado sobre los meta-modelos, en relación a los originales.

En la figura 4.5 se muestran los elemento gráficos que se utilizan en los modelos. Se mantienen los elementos propios de ANEMONA e INGENIAS, 


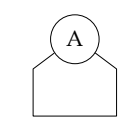

A-Agente

(A)

A-Objetivo

(N)

Objetivo

Normativo
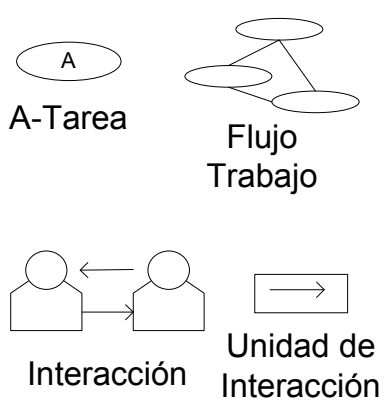
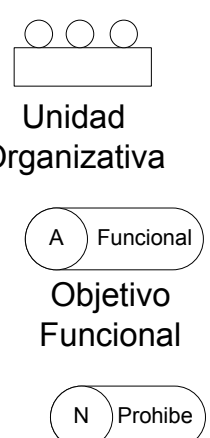

Prohibición
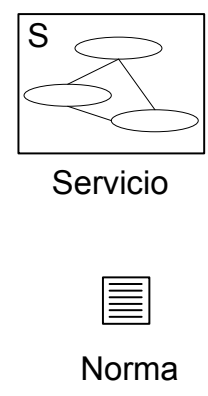

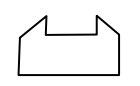

Rol

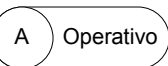

Objetivo

Operativo

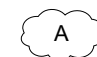

A-Creencia

(N) Permite

Permiso

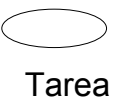

Tarea

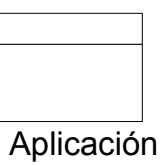

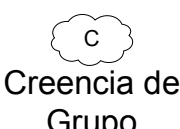

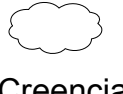

Creencia

Figura 4.5: Elementos de la notación gráfica de los modelos.

añadiendo los nuevos elementos propuestos en este trabajo, como el servicio y la norma. Se han empleado estos elementos gráficos en los distintos diagramas de ejemplo de las instanciaciones de los meta-modelos extendidos.

A continuación se comenta con detalle cada uno de los meta-modelos, marcando en color oscuro aquellos elementos que se han extendido o modificado con respecto a los meta-modelos de ANEMONA.

\subsubsection{Entidades básicas}

Se han extendido varias de las entidades básicas de ANEMONA, para incluir conceptos derivados de las organizaciones humanas, tales como Misión, Objetivo Funcional, Objetivo Operativo; así como los conceptos de Unidad Organizativa, Servicio y Norma.

En la figura 4.6 se muestran las entidades básicas y extensiones realizadas para los conceptos de ANEMONA de A-Agente, Rol, A-Tarea y 
Consulta Entidad Autónoma. En concreto, la entidad A-Agente se refina en las entidades Agente y Unidad Organizativa. Los Agentes son de dos tipos: Agente Interno, implementado por el grupo de desarrollo del sistema; y Agente Externo, potencialmente desarrollado por otros grupos de desarrollo y cuyo comportamiento real solamente se define a través del rol que juegue en el sistema. Por su parte, la Unidad Organizativa representa no sólo a una agrupación de agentes, sino también al entorno que les rodea y a las restricciones que gobiernan su comportamiento.

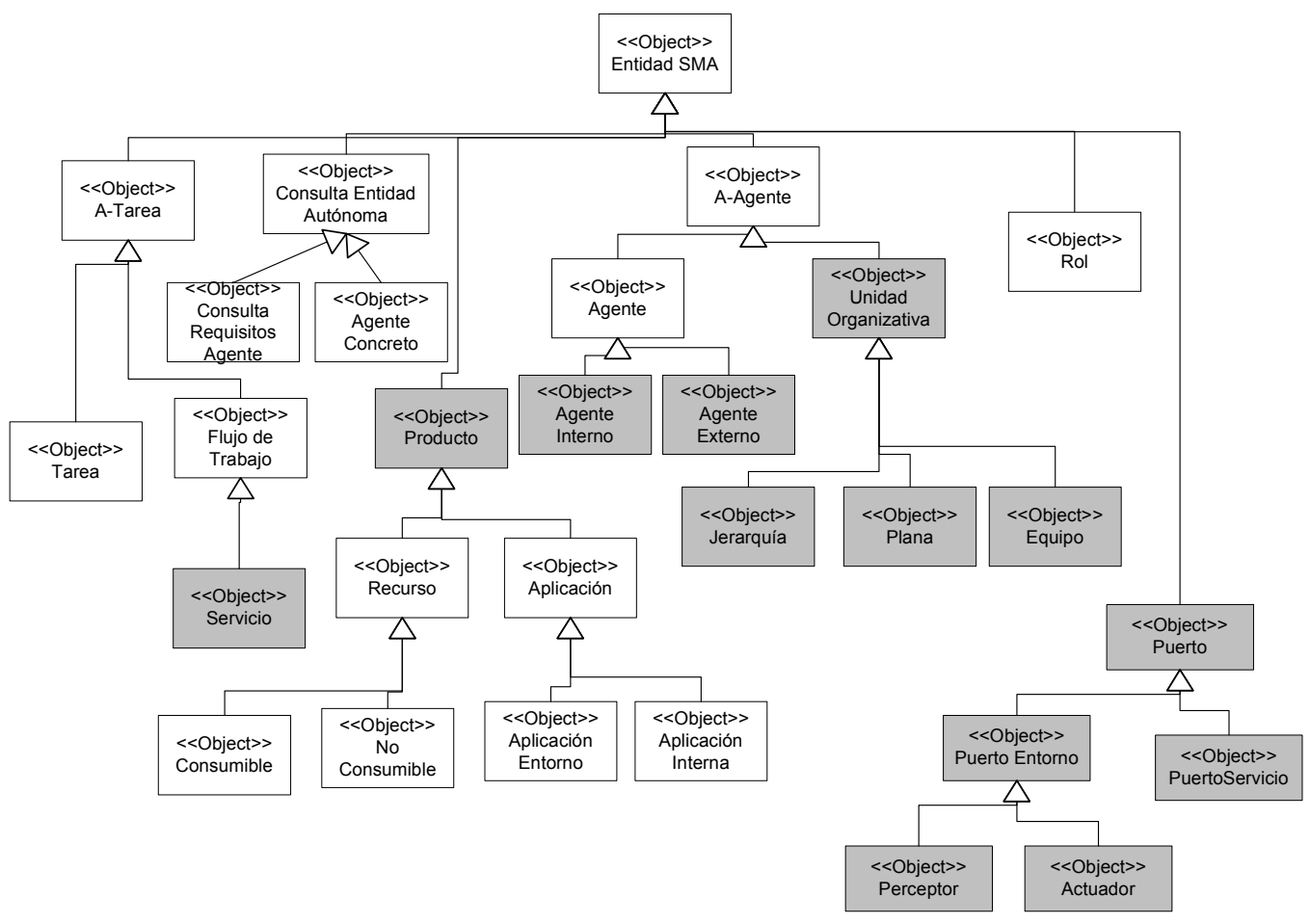

Figura 4.6: Entidades Básicas. Conceptos de A-Tarea, Consulta Entidad Autónoma, Producto, A-Agente, Rol y Puerto.

El concepto de Servicio se trata como una extensión de la entidad Flujo de Trabajo. Representa a un conjunto de tareas conectadas entre sí, de modo que los resultados de una tarea se necesitan en otra. Además se registra este servicio en algún mecanismo de publicitación (representado con la entidad PuertoServicio), para que aquellos agentes que así lo requieran 
puedan localizarlo y hacer uso del servicio.

La percepción y actuación de los agentes sobre su entorno se modeliza a través de la entidad Puerto, que se especializa a su vez en PuertoEntorno y PuertoServicio. El primero representa a los componentes de actuación y percepción sobre el entorno (entidades Actuador y Perceptor); mientras que el segundo representa el acceso a un servicio determinado.

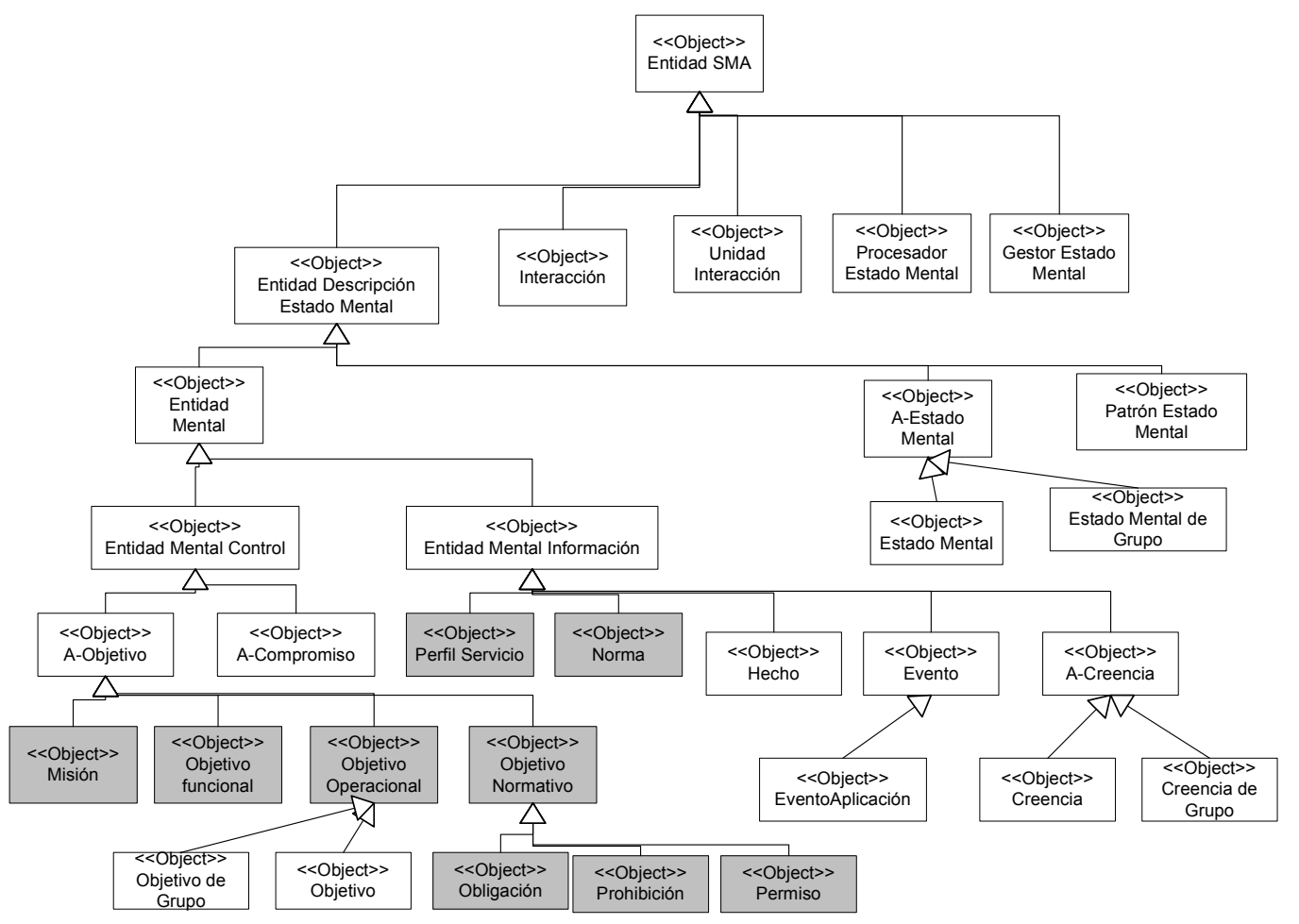

Figura 4.7: Entidades Básicas. Conceptos sobre Entidad Mental, Estado Mental e Interacción.

En la figura 4.7 se muestran las entidades básicas y extensiones realizadas para los conceptos de Entidad Mental e Interacción. En este caso, se ha refinado el concepto $A$-Objetivo, para especificar distintos tipos de objetivos de las organizaciones. En concreto, la Misión hace referencia al objetivo más general de toda organización, el cual permite establecer sus conexiones respecto al mundo que le rodea; el Objetivo Funcional especifica intereses a alcanzar por las unidades organizativas; mientras que el Objetivo 
Operativo denota objetivos con características medibles, sobre los cuales se establece claramente su satisfacción tras ejecutar determinadas acciones.

Por su parte, la Entidad Mental Información se ha extendido, incluyendo las entidades Norma y Perfil Servicio. La Norma representa las restricciones sobre el comportamiento de las entidades, así como las sanciones y recompensas a aplicar en base a dicho comportamiento. El Perfil Servicio representa una descripción de un servicio.

\subsubsection{Meta-modelo de Organización}

En ANEMONA el meta-modelo de organización detalla los flujos de trabajo existentes, cómo se coordinan los participantes de la organización, cuáles son las tareas relevantes, los objetivos que se persiguen globalmente y las restricciones en el comportamiento de los agentes.

Originalmente, el meta-modelo de organización se divide en tres vistas: estructural, funcional y social. La vista estructural describe los componentes de la organización (agentes, aplicaciones, recursos, roles, e incluso otras organizaciones). En la vista funcional se detallan qué tareas son necesarias para la consecución de los objetivos del sistema, cómo se conectan dichas tareas entre sí (generando flujos de trabajo), qué recursos o entidades mentales consumen o bien producen, qué aplicaciones usan, en qué interacciones se producen estas tareas y quiénes son los responsables de las mismas. Finalmente, en la vista social se describen las relaciones de subordinación y de cliente-servidor.

En nuestra propuesta, definimos un total de cuatro vistas: estructural, funcional, social y dinámica. Las tres primeras son ampliaciones de la propuesta de ANEMONA, mientras que la vista dinámica permite especificar cuáles son los servicios que debe ofrecer una unidad organizativa para el control y gestión de la entrada y salida de sus entidades. A continuación se detalla cada una de estas vistas. 
VISTA ESTRUCTURAL. En esta vista se define cuáles son los componentes estáticos de la organización, es decir, todo aquello que es independiente de las entidades ejecutoras finales (figura 4.8).

Así, consideramos que el sistema está formado por Unidades Organizativas, que en ocasiones podrán ser consideradas como una entidad global (actuando como A-Agente); mientras que en otras ocasiones serán consideradas como una parte o entidad grupal de la organización. Además, de forma recursiva, las unidades organizativas podrán contener a otras unidades.

En su nivel más básico, las unidades organizativas son de uno de los siguientes tres tipos disjuntos: estructura plana, equipo y jerarquía simple. En la sección 4.7 se muestran los patrones de diseño que facilitan el modelado de estas unidades organizativas.

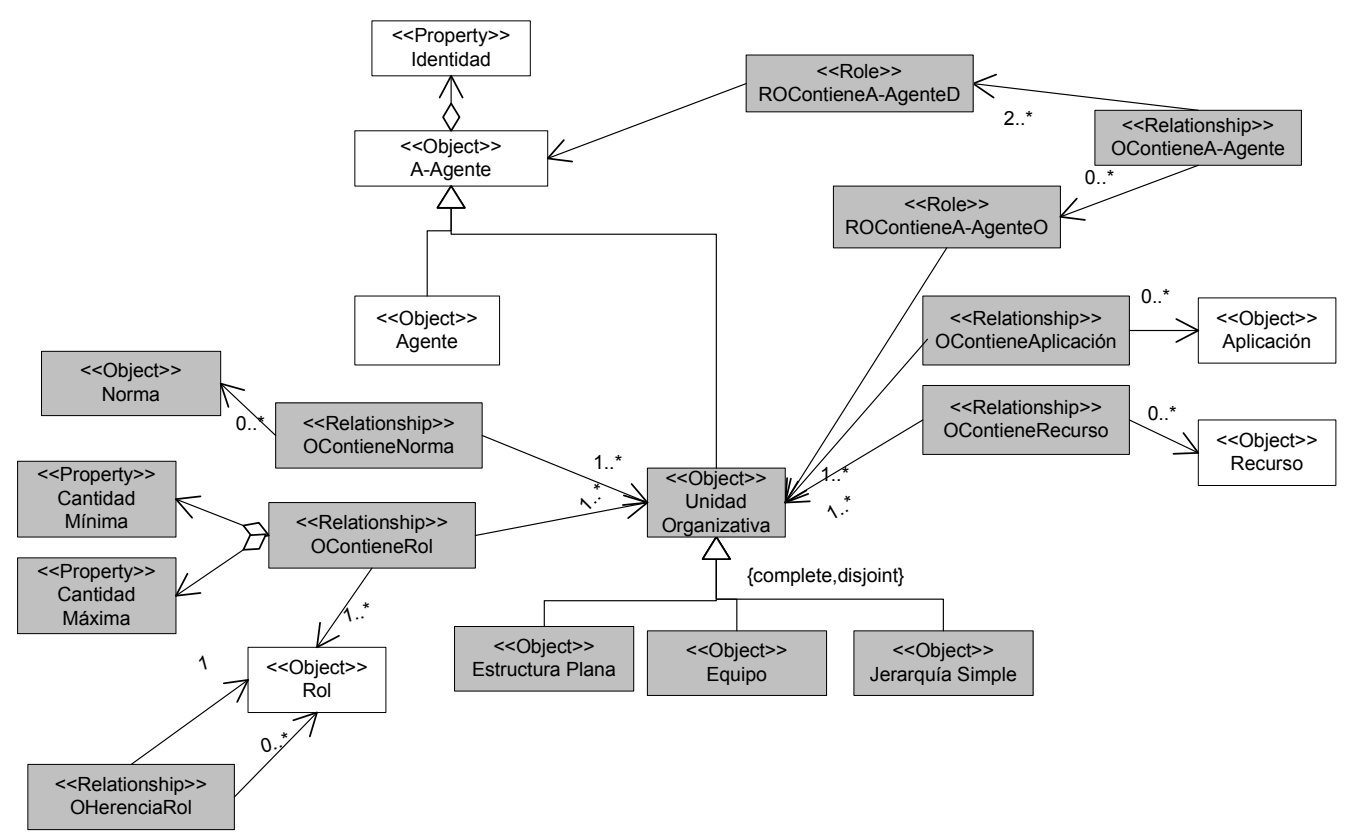

Figura 4.8: Meta-modelo de Organización. Vista estructural.

La Unidad Organizativa actúa no sólo como agrupación de agentes, sino también como representación del entorno de esos agentes. Por tanto, contiene los recursos y aplicaciones accesibles por ellos. Además, establece roles de actuación dentro de la unidad para los cuales se especifica no sólo su 
funcionalidad, sino también el modo de acceso a los recursos y aplicaciones contenidas en la unidad.

Para ello, la relación OContieneA-Agente de ANEMONA (que afectaba a A-Agentes, recursos, roles y aplicaciones) se ha desglosado en cuatro relaciones distintas: OContieneA-Agente (pero afectando ahora sólo a los A-Agentes); OContieneRol, que incluye las propiedades Cardinalidad Minima y Cardinalidad Máxima, las cuales restringen el número de instancias de ese rol que se pueden jugar a la vez por los agentes de la unidad; OContieneAplicación y OContieneRecurso.

El acceso controlado a los recursos y aplicaciones se realiza a través de puertos del entorno. Como se verá más adelante, en el meta-modelo del entorno se especifican las características concretas de las aplicaciones y de los recursos, así como el modo concreto de acceso a los elementos del entorno a través de sus puertos.

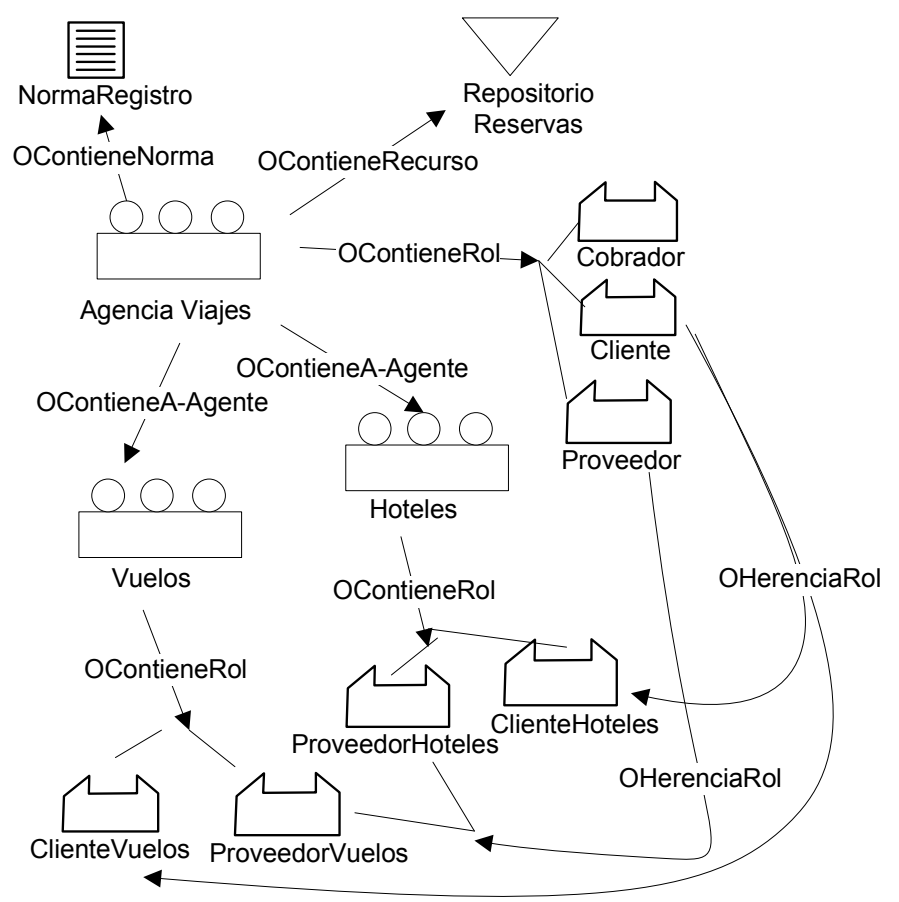

Figura 4.9: Diagrama de modelo de organización, vista estructural del sistema de agencia de viajes. 


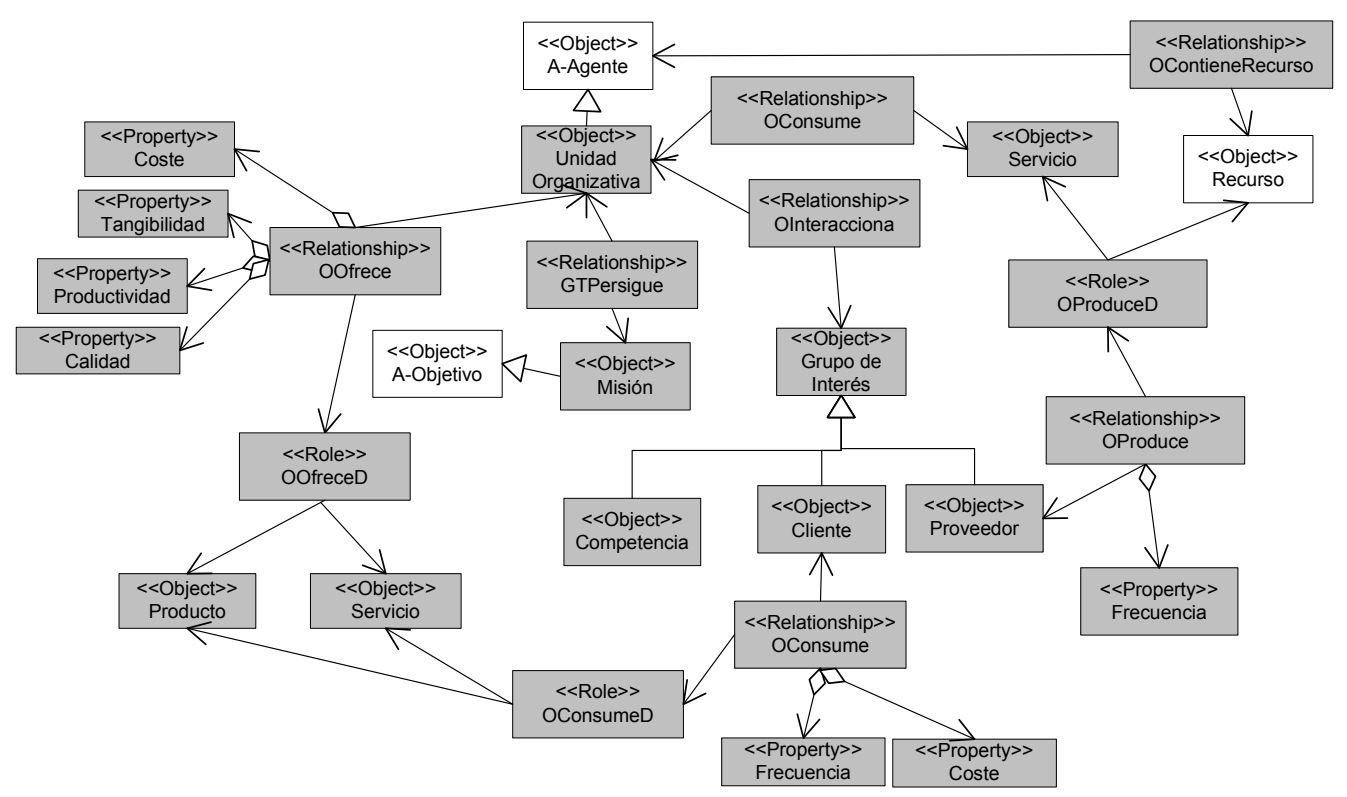

Figura 4.10: Meta-modelo de Organización. Vista funcional. Misión.

Por otro lado, se ha incluido la herencia de roles (relación OHerenciaRol), ya tratada en INGENIAS, según la cual todas las restricciones, permisos y atributos que afecten al rol padre también afectarán al rol hijo, a menos que se hayan redefinido en éste. Además, todo agente que juegue un determinado rol dispone también del rol padre correspondiente.

Finalmente, el control del comportamiento de los miembros de la unidad se realiza a través de las normas (relación OContieneNorma). Cada norma se especifica con el meta-modelo normativo, que se comentará más adelante.

En la figura 4.9 se muestra el modelo de organización del caso de estudio planteado. La unidad organizativa AgenciaViajes representa un sistema de viajes, en el cual se tienen tres tipos de roles: Cliente, Proveedor y Cobrador. El rol cliente representa al cliente del sistema, que solicitará servicios de búsqueda de hoteles, de vuelos, así como la reserva de habitaciones o de plazas de avión. Por su parte, el rol proveedor será quien proporcione la funcionalidad de esos servicios de búsqueda y reservas. Por último, el rol cobrador será responsable de controlar el servicio de pago adelantado. 
Como la descripción y funcionalidad de los servicios relacionados con las cadenas hoteleras es distinta a la de las líneas aéreas, se han definido dos unidades organizativas (Vuelos y Hoteles), contenidas en AgenciaViajes, centradas en el producto concreto a ofrecer (reservas de hoteles o bien reservas de plazas de avión). Además, los roles cliente y proveedor se refinan también en dichas unidades, a través de relaciones OHerenciaRol. Gracias a este tipo de relación se permite a los agentes que jueguen un rol determinado realizar también las acciones asignadas a sus roles con relación de herencia. Por ejemplo, cualquier agente que juegue el rol cliente podrá participar directamente con el rol ClienteVuelos en la unidad Vuelos.

VISTA FUNCIONAL. En esta vista se describe la misión o motivo de existencia de la organización (figura 4.10) y cómo funciona cada unidad organizativa, tanto externamente (figura 4.12) como internamente (figura 4.15).

a) Misión. La misión de la organización define su objetivo global más general, que afecta a los grupos de interés con los que interacciona. En la figura 4.10 se indican los aspectos a considerar al describir la misión, en concreto cuáles son los resultados que ofrece la organización (productos o servicios), qué resultados consumen sus clientes y qué servicios o recursos producen sus proveedores, que serán requeridos por la organización.

Por ejemplo, en la figura 4.11 se muestra el diagrama de misión del sistema de viajes. Como se observa, el sistema (representado por la unidad organizativa AgenciaViajes) ofrece a su mercado el producto Reserva, que será consumido por los clientes (turistas y personas de negocio). Además, les ofrece también los servicios de búsqueda de viajes, realización de reservas y abono del viaje (o pago adelantado). Por otro lado, el sistema requiere de ciertos proveedores, en concreto de cadenas hoteleras y de líneas aéreas, los cuales le facilitarán, a través de servicios, la información necesaria sobre hoteles y vuelos.

b) Funcionalidad externa. La funcionalidad externa de un A-Agente 


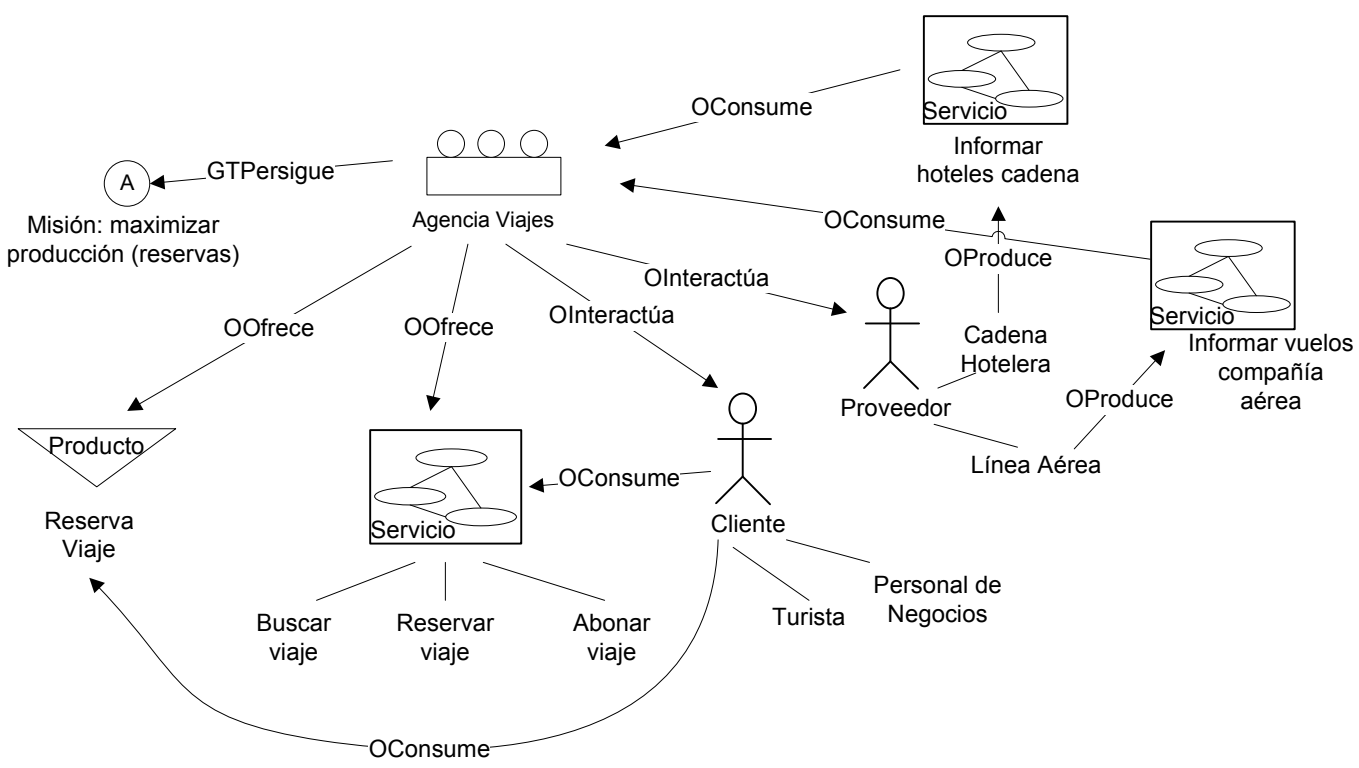

Figura 4.11: Diagrama del modelo de organización, vista funcional. Misión del sistema de agencia de viajes.

(Unidad Organizativa o agente concreto) representa el conjunto de servicios que la entidad ofrece hacia afuera, es decir, a otros A-Agentes, con independencia del agente concreto que haga uso de ellos (figura 4.12). Las características, habilidades o permisos que debe disponer ese agente cliente del servicio se modelan mediante roles.

Para las Unidades Organizativas, se define un conjunto de servicios que requiere de fuera, es decir, aquella funcionalidad que necesita ser contratada a otros A-Agentes. La necesidad de servicios (relación ORequiere) equivale a la publicitación de puestos de trabajo de las empresas, ya que con dicha relación la unidad expresa su necesidad de encontrar a agentes que sean capaces de ofrecer esos servicios como miembros de la unidad.

Asimismo, se permite modelar que un rol determinado de una Unidad Organizativa ofrezca un servicio a otro rol, definiendo así las condiciones, habilidades o conocimientos que deberá contener un A-Agente determinado para ofrecer (relación WFProporciona) o solicitar (relación WFUtiliza) dicho servicio. Así, con estas dos relaciones se cubre la característica de 


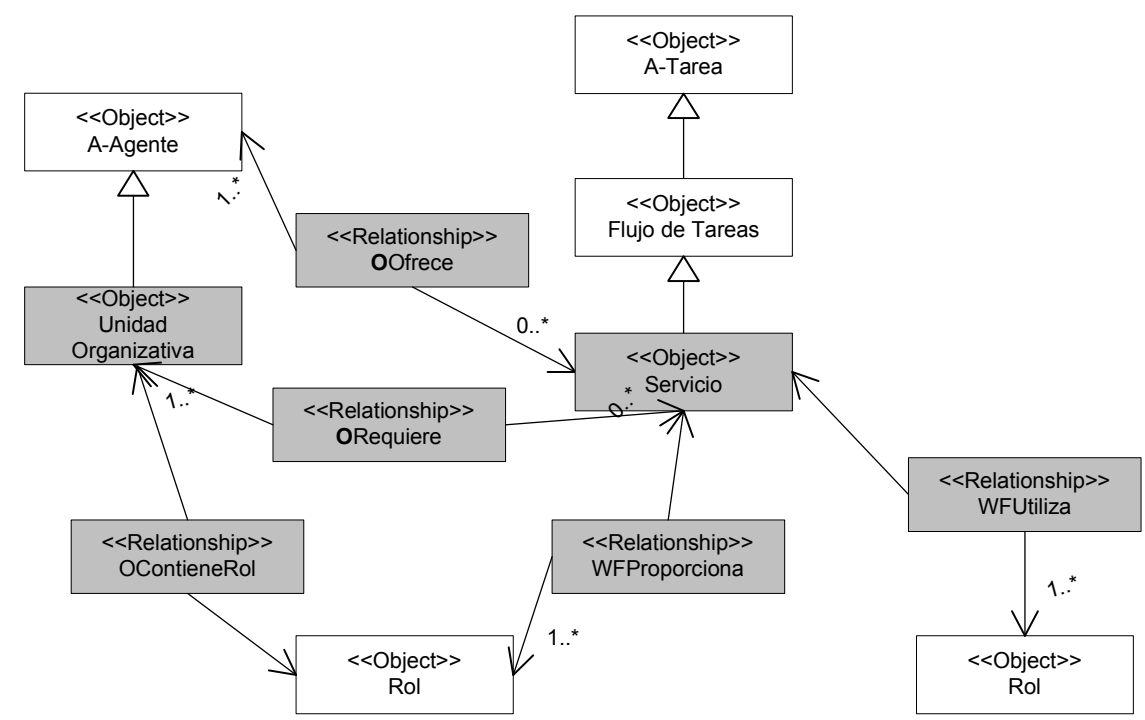

Figura 4.12: Meta-modelo de Organización. Vista funcional. Funcionalidad Externa.

estandarización de la funcionalidad del servicio, explicada en el apartado 4.3 .

En el ejemplo de la figura 4.13 se muestra la Unidad Organizativa AgenciaViajes, que ofrece los servicios Buscar Viaje, Reservar Viaje y Abonar Viaje a agentes que jueguen el rol Cliente y que además requiere de agentes capaces de proporcionar los dos primeros servicios bajo el rol Proveedor, mientras que el último servicio (Abonar Viaje) lo proporcionarán agentes con el rol Cobrador. Más específicamente, el rol proveedor debe proporcionar a la unidad organizativa al menos un servicio de información (de vuelos o de hoteles). Dicho servicio será invocado, como veremos más adelante, en la funcionalidad del servicio Buscar Viaje. Por tanto, todo proveedor debe ser capaz de ofrecer un servicio de dicho tipo. Sin embargo, el servicio de reservas no es obligatorio, por lo que los proveedores tendrán libertad para ofrecer o no el servicio Reservar Viaje dentro del sistema.

En la figura 4.14 se muestra la funcionalidad de la unidad Vuelos, que ofrece los servicios BuscarVuelo y ReservarVuelo, proporcionados por el rol 


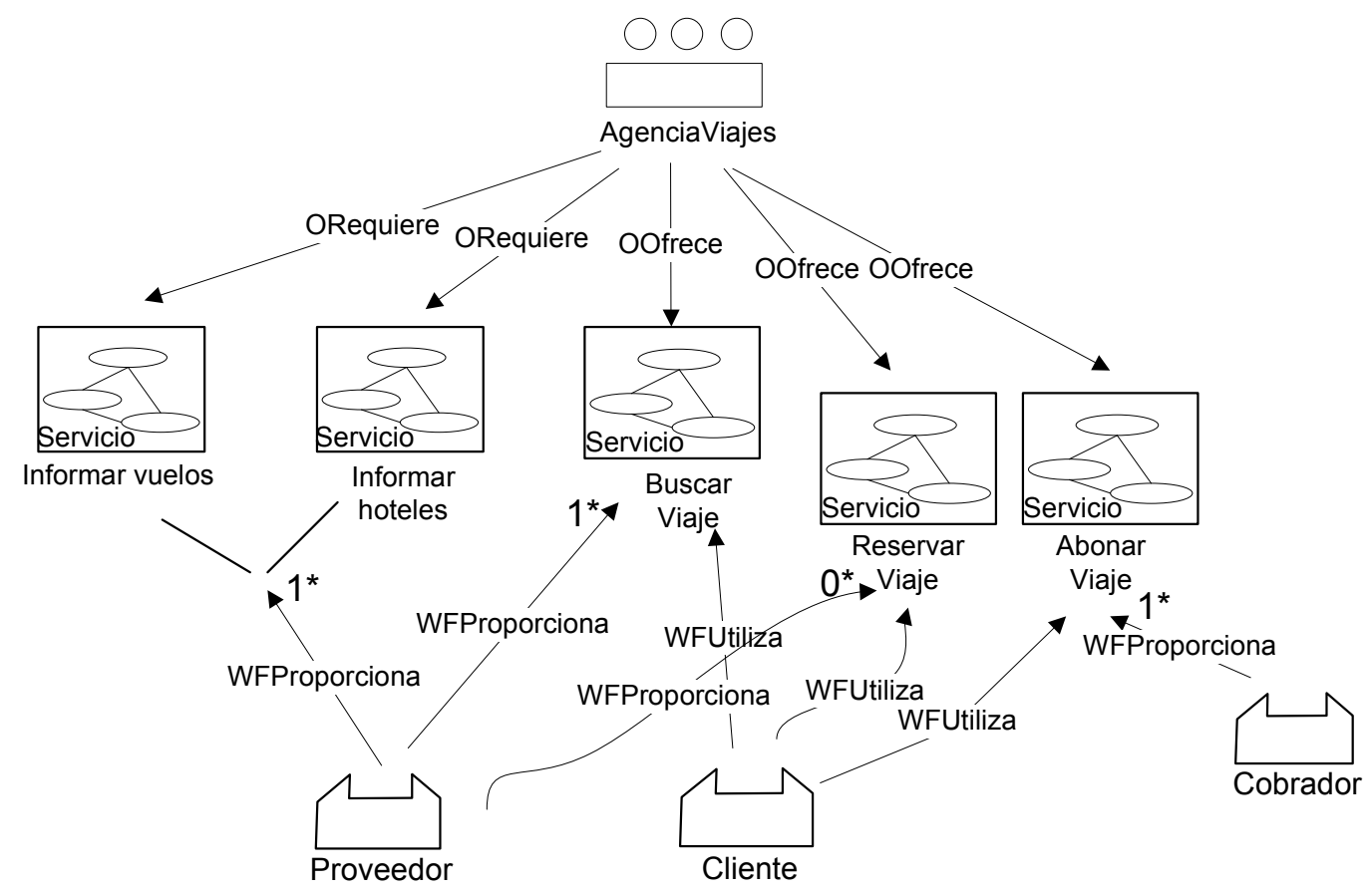

Figura 4.13: Diagrama del modelo de organización, vista funcional. Funcionalidad externa del sistema de agencia de viajes.

ProveedorVuelos y utilizados por entidades que jueguen el rol ClienteVuelos. Además, se necesita que ProveedorVuelos sea capaz de proporcionar el servicio InformarVuelos y se le obliga a registrar, al menos, el servicio BuscarVuelo.

c) Funcionalidad interna. La funcionalidad interna de un A-Agente (figura 4.15) se define mediante las A-Tareas de las que es responsable, a través de las cuales se desempeñan los servicios que ofrece. Una A-Tarea comprende tanto tareas simples como flujos de tareas. Las tareas simples pueden implicar la interacción con otros agentes, así como la utilización de otros servicios.

Por cada servicio indicado debe existir una descripción detallada de su comportamiento utilizando el meta-modelo de actividad (que se comenta en la siguiente sección), indicando cuál es su perfil de servicio y en qué tareas o servicios se descompone. 


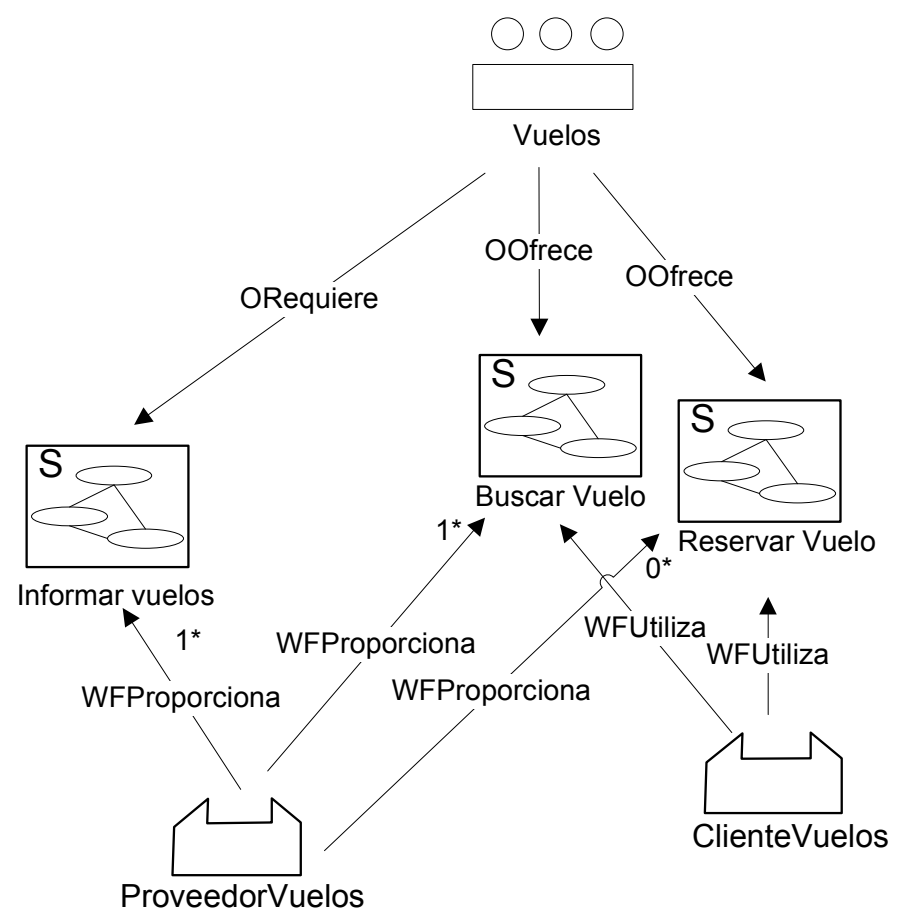

Figura 4.14: Diagrama del modelo de organización, vista funcional. Funcionalidad externa de la unidad Vuelos, del sistema de agencia de viajes.

En la figura 4.16 se muestra la funcionalidad interna asociada al agente Banco que juega el rol cobrador y, por tanto, proporciona el servicio Abonar Viaje.

VISTA SOCIAL. En esta vista se describen las relaciones existentes entre los roles y los A-Agentes. En este caso, hemos redefinido las relaciones sociales de ANEMONA, basándonos en los trabajos de D. Grossi y B. Gateau. De este modo, las relaciones sociales entre los roles y/o A-Agentes atienden ahora a tres tipos distintos [Grossi et al., 2005; Gateau et al., 2005]: supervisión, monitorización e información (figura 4.17).

La relación de supervisión (AGOSupervisión) define que un agente transfiere o delega uno o varios objetivos a un agente subordinado, el cual está obligado a incluir dichos objetivos como propios y a alcanzarlos. El 


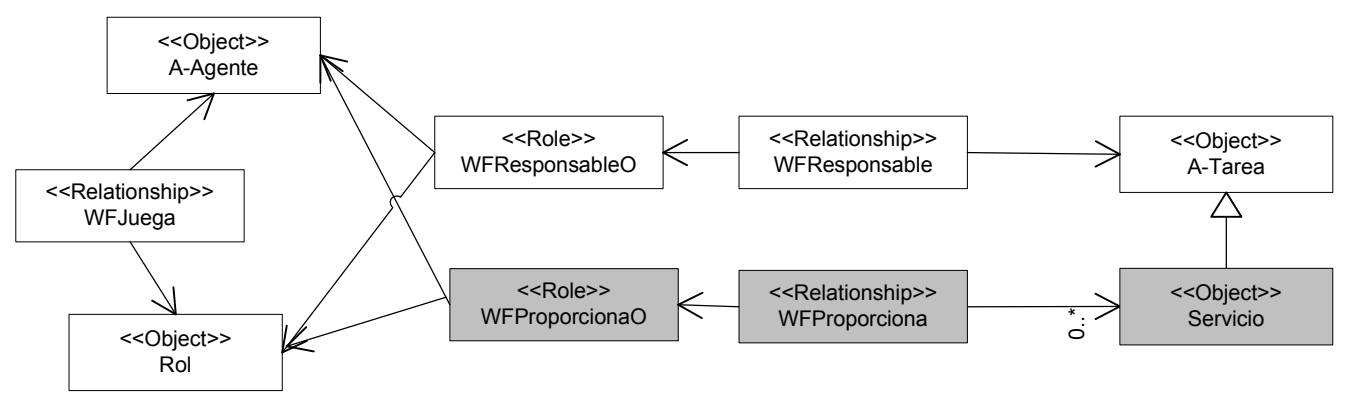

Figura 4.15: Meta-modelo de Organización. Vista funcional. Funcionalidad Interna.

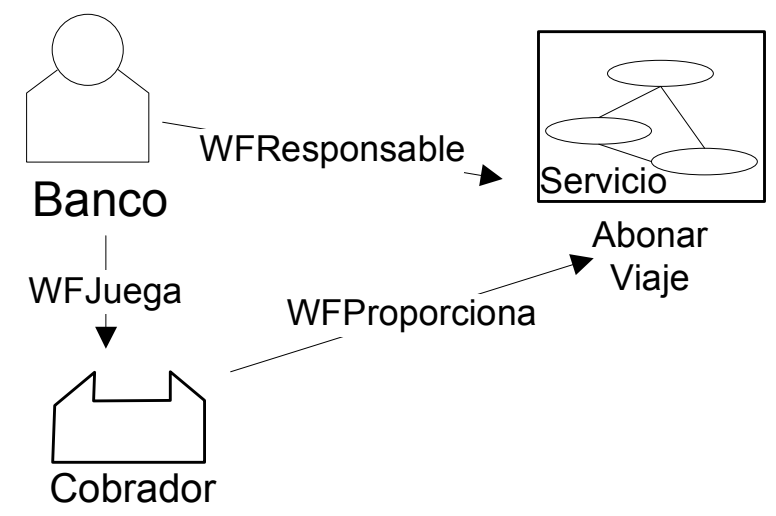

Figura 4.16: Diagrama del modelo de organización, vista funcional. Funcionalidad interna del sistema de agencia de viajes. Asociación del rol Cobrador con el agente específico (Banco) que lo desempeña.

agente que transfiere los objetivos actúa bajo el rol de supervisor y adquiere autoridad sobre el subordinado.

La relación de monitorización (AGOMonitorización) permite supervisar las actividades de los agentes y lanzar reacciones apropiadas ante fallos o violaciones de las mismas. Por tanto, el rol monitor es responsable de controlar la realización de la acción por parte del rol monitorizado.

Finalmente, la relación de información (AGOInformación) indica cómo se establecen los vínculos de información o conocimiento sobre el estado actual de la organización. Dos A-Agentes conectados entre sí por una relación de este tipo están habilitados para conocer de la existencia del otro y 


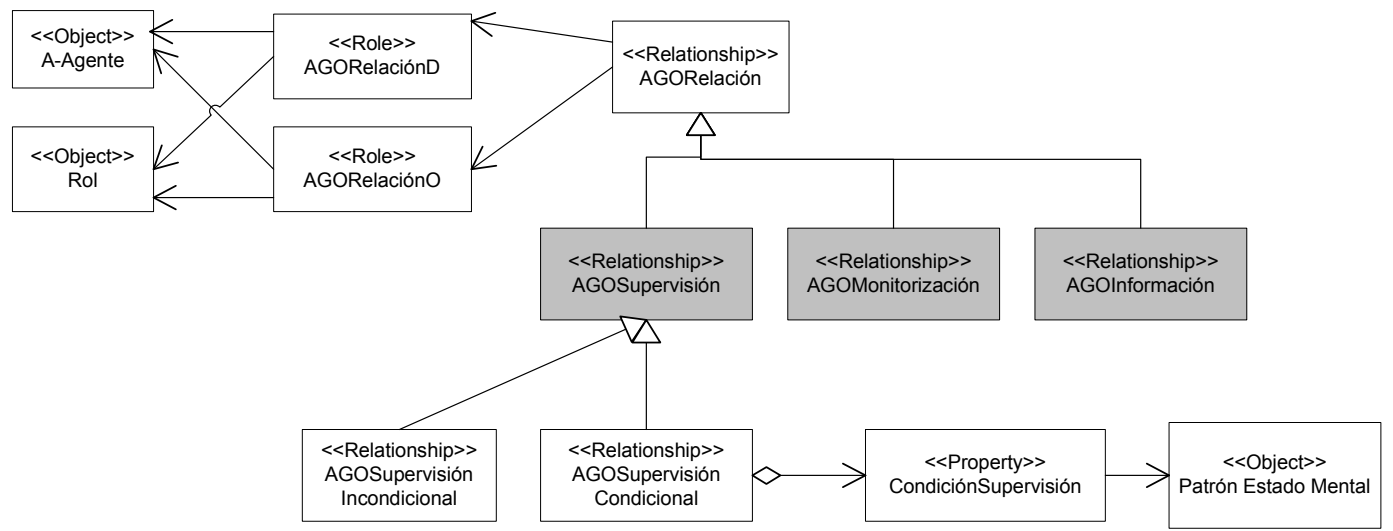

Figura 4.17: Meta-modelo de Organización. Vista social.

suministrarle información relevante.

Además, la relación de supervisión conlleva implícita tanto la relación de monitorización como de información. Por un lado, delegar implica controlar la realización de la acción y por otro, implica también informar sobre la acción a realizar.

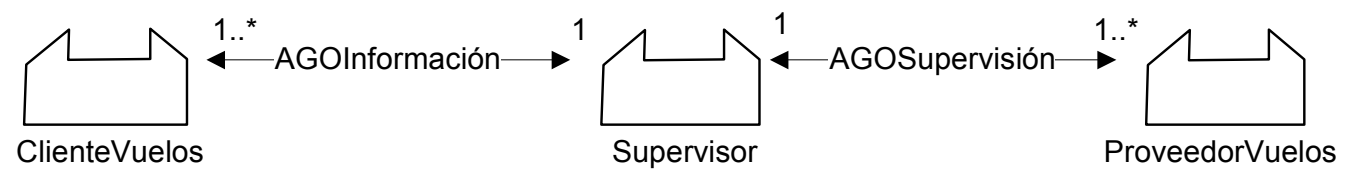

Figura 4.18: Diagrama del modelo de Organización. Vista social.

Por ejemplo, en la figura 4.18 se muestra un diseño de la unidad organizativa Vuelos empleando una estructura jerárquica, en la que se ha definido un rol supervisor que actúa de broker ante las peticiones de reserva de vuelos de los clientes. Éstos se comunican sólo con el supervisor, quien establece una relación de supervisión sobre los proveedores de vuelos. En la sección 4.6.1 se explica con detalle el patrón de diseño de la estructura jerárquica.

VISTA DINAMICA. En esta vista se establecen los patrones de diseño de servicios propios de una unidad organizativa, que permiten gestionar sus componentes estructurales y sus componentes de ejecución. Estos servicios se clasifican en: servicios estructurales, que modifican la especificación 
estructural y normativa propia de la organización; servicios informativos, que proporcionan información relativa a la estructura organizativa de la unidad; y servicios dinámicos, que permiten la gestión de la entrada/salida dinámica de agentes dentro de la organización y la adopción de roles.

Los servicios estructurales se centran en la inclusión o eliminación de normas, roles o unidades organizativas dentro de la unidad donde se definen. Si se publicitan estos servicios se permitirá la modificación en tiempo de ejecución de determinados aspectos ligados a la estructura de la organización, su funcionalidad o su normalización. Si se desea que el sistema sea capaz de adaptarse dinámicamente a los cambios del entorno, se requiere hacer uso de estos servicios, aunque no es necesaria su publicitación, siempre y cuando los mismos agentes se encarguen siempre de proporcionarlos y solicitarlos. En dicho caso los servicios se implementarán directamente como flujos de tareas.

Comprenden los siguientes servicios:

- Registrar Rol: incluir un nuevo tipo de rol dentro de la unidad

- Desregistrar Rol: eliminar un tipo de rol de la unidad. No debe existir ningún agente jugando ese rol en ese momento, ni tampoco ninguna norma asociada al rol.

- Registrar Norma: incluir una nueva norma dentro de la unidad. Cada norma indica a qué rol afecta la norma, cuál es su contenido deóntico y, en su caso, su sanción y/o recompensa asociada. Opcionalmente, podrá indicar qué rol se encarga de controlar el cumplimiento de la norma (NControlador), quién efectuará la sanción (NSancionador) y quién la recompensa (NRecompensador).

- Desregistrar Norma: eliminar una norma de la unidad. Como condición, el rol proveedor de este servicio deberá ser también NControlador de la norma que se desea eliminar.

- Registrar Unidad: incluir una nueva unidad. Se indica su estructura, objetivo y unidad en la que está contenida. 
- Desregistrar Unidad: eliminar una unidad, que debe estar vacía, sin roles asociados.

Los servicios de información proporcionan información concreta sobre los elementos y componentes de la unidad. Comprenden los siguientes servicios:

- Informar Roles Unidad: solicitar cuáles son los roles que existen en una unidad concreta.

- Informar Roles Agente: solicitar el listado de roles que un agente juega en una unidad.

- Informar Miembros Unidad: solicitar el listado de entidades miembro de una unidad determinada. De forma opcional se indica un rol específico de esa unidad. Si no se indica ese rol, se devolverá el listado de todos los miembros, independientemente del rol que tengan asociado.

- Informar Cantidad Miembros: solicitar la cantidad de miembros actuales de una unidad determinada. De forma opcional se indica un rol específico de esa unidad, sobre el que se desea realizar el cálculo.

- Informar Estructura Unidad: solicitar información sobre el tipo de estructura de una unidad y sus objetivos.

- Informar Perfil Rol: solicitar los perfiles de servicio asociados a un rol determinado en la unidad, en función de las normas asignadas a dicho rol que especifiquen su funcionalidad.

- Informar Normas Rol: solicitar el listado de normas asociado a un rol determinado.

Los servicios dinámicos gestionan la creación de agentes nuevos en la organización, la entrada y salida dinámica de los agentes en las unidades del sistema, así como la adopción de roles. Si se desea que el sistema sea abierto, entonces se requiere de la publicitación de este tipo de servicios, para que así agentes externos entren en la organización y participen en ella. 
- Adquirir Rol: solicitar la adquisición de un rol en una unidad determinada. La entidad solicitante mantendrá los roles que tenía hasta ahora y adquirirá el nuevo rol indicado, a menos que exista una relación de herencia con alguno de los roles que juega, en cuyo caso el rol padre será substituido por el nuevo rol.

- Dejar Rol: solicitar dejar de jugar un rol en una unidad determinada.

- Expulsar: expulsar a un agente determinado, obligándole a que deje la posición indicada (rol).

\subsubsection{Meta-modelo de Actividad}

En este meta-modelo (figura 4.19) se describe la funcionalidad de los servicios del sistema, a través de su perfil y las A-Tareas que lo componen.

El meta-modelo propuesto consiste en una extensión del meta-modelo de tareas y objetivos de ANEMONA, en el que se integra el concepto de servicio. Del meta-modelo original se han mantenido las relaciones entre las entidades existentes. En concreto, se define cuándo una A-Tarea se puede ejecutar y cómo afecta a una Entidad Mental (relación GTAfecta); cuál es la motivación del A-Agente para ejecutar una A-Tarea, expresada con los objetivos que persigue el agente (relación GTPersigue); y cómo descomponer un A-Objetivo, así como las dependencias entre A-Objetivos.

Como extensiones al meta-modelo original, se han incluido las nuevas entidades Servicio y PerfilServicio (figura 4.19). Este último describe las condiciones de activación del servicio, sus parámetros de entrada/salida y los efectos que produce sobre el entorno. Este perfil permite ser implementado con lenguajes de descripción de servicios como OWL-S.

Por su parte, la entidad A-Tarea define la funcionalidad del servicio (llamado también process en OWL-S). Esta funcionalidad se describe en base a tareas concretas, a flujos de tareas o bien a la composición de otros servicios. Respecto a la utilización final del servicio (o grounding), el acceso al mismo se representa mediante puertos (en concreto, puertos de servicio), definidos en el meta-modelo de entorno. 


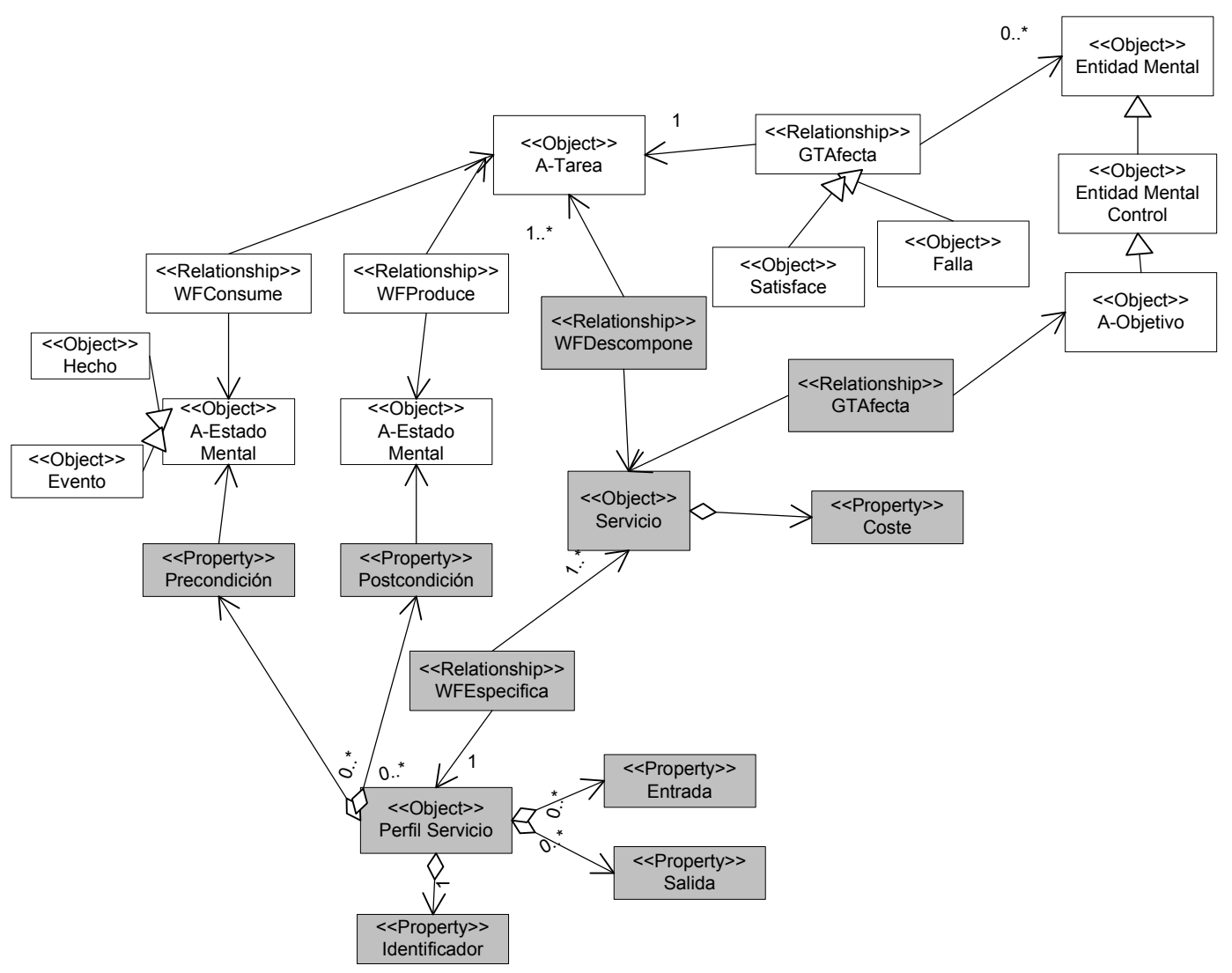

Figura 4.19: Meta-modelo de Actividad.

Todo servicio se identifica a través de su perfil (relación WFEspecifica, figura 4.19), por lo que la entidad PerfilServicio dispone del atributo identificador. De este modo permitimos que un servicio representado con un perfil determinado sea implementado con distintas funcionalidades (es decir, con distintas A-Tareas) y además proporcionado por distintos agentes (según se especifique en su puerto de servicio).

La producción de un servicio afecta a un objetivo determinado (relación GTAfecta), pudiendo satisfacerlo, fallarlo, crear nuevos objetivos o bien destruir los existentes (figura 4.20). La creación/destrucción de objetivos se modela a través de normas que afecten a estos servicios. Dichas normas se definen en el meta-modelo normativo, que se comentará más adelante. 


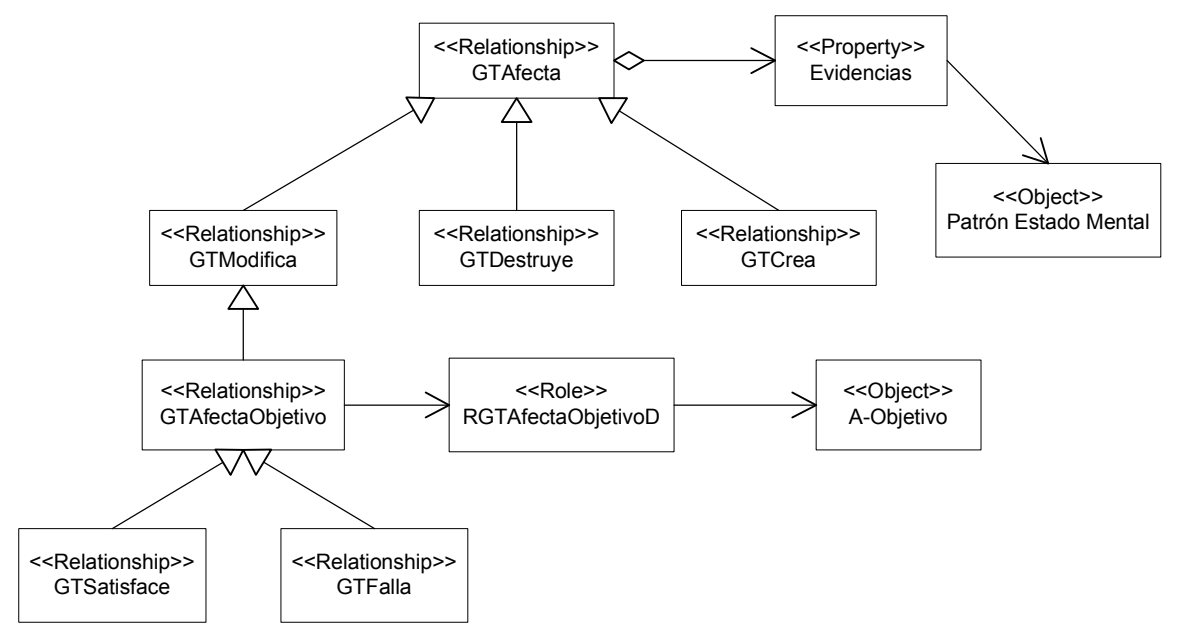

Figura 4.20: Tipos de relación entre Tareas y Objetivos

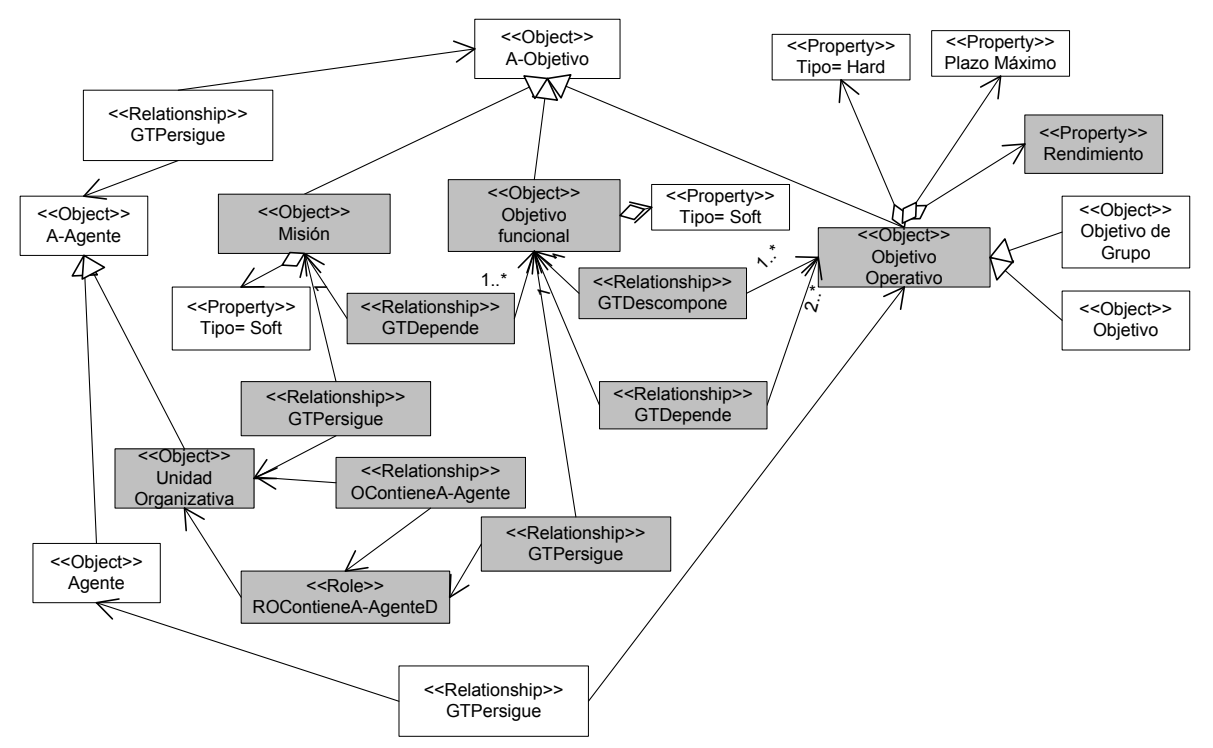

Figura 4.21: Descomposición Objetivos Organización. 
La descomposición de objetivos de ANEMONA se ha extendido (figuras 4.21 y 4.22) para atender a nuevos tipos de objetivos (misión, objetivo funcional y objetivo operativo). Una unidad organizativa global del sistema persigue la misión de dicho sistema. Sus unidades internas persiguen los objetivos funcionales en los que se refina la misión y de los cuales depende. Los agentes finales se encargan de los objetivos operativos, resultantes de la descomposición de los objetivos funcionales.

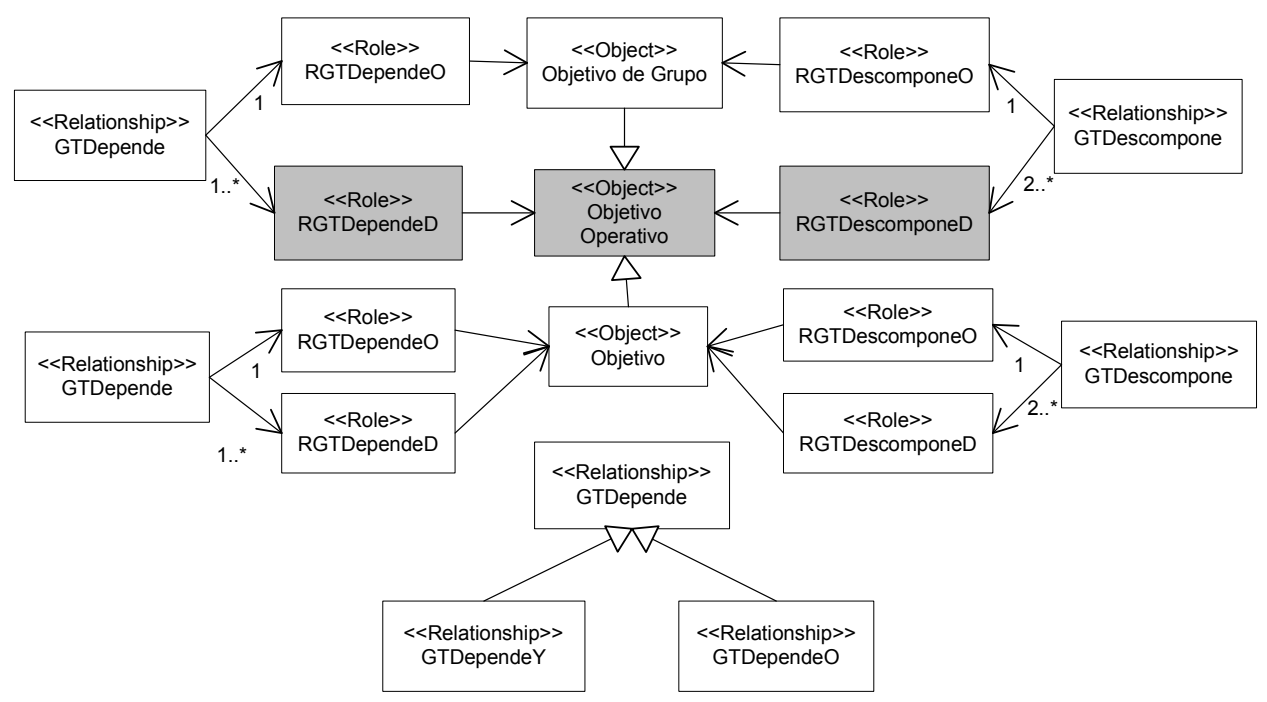

Figura 4.22: Descomposición Objetivos Operativos y dependencia.

También se ha extendido la descripción de la descomposición de ATareas de ANEMONA (figura 4.23), para reflejar la invocación de servicios (relación WFInvoca). De este modo se permite la composición de servicios entre distintas entidades.

Finalmente, la definición de flujo de trabajo de ANEMONA se ha extendido (figura 4.24) con las relaciones WFConectaConcurrencia y WFConectaIteración. De este modo se permite no sólo la composición de servicios a través de relaciones secuenciales (WFConecta) o condicionales de tipo IfElse (WFConectaCondicional), sino también por relaciones concurrentes de tipo Split-Join, propias de OWL-S (WFConectaConcurrencia) y por relaciones iterativas (WFConectaIteración), en las que se requiere la ejecución 


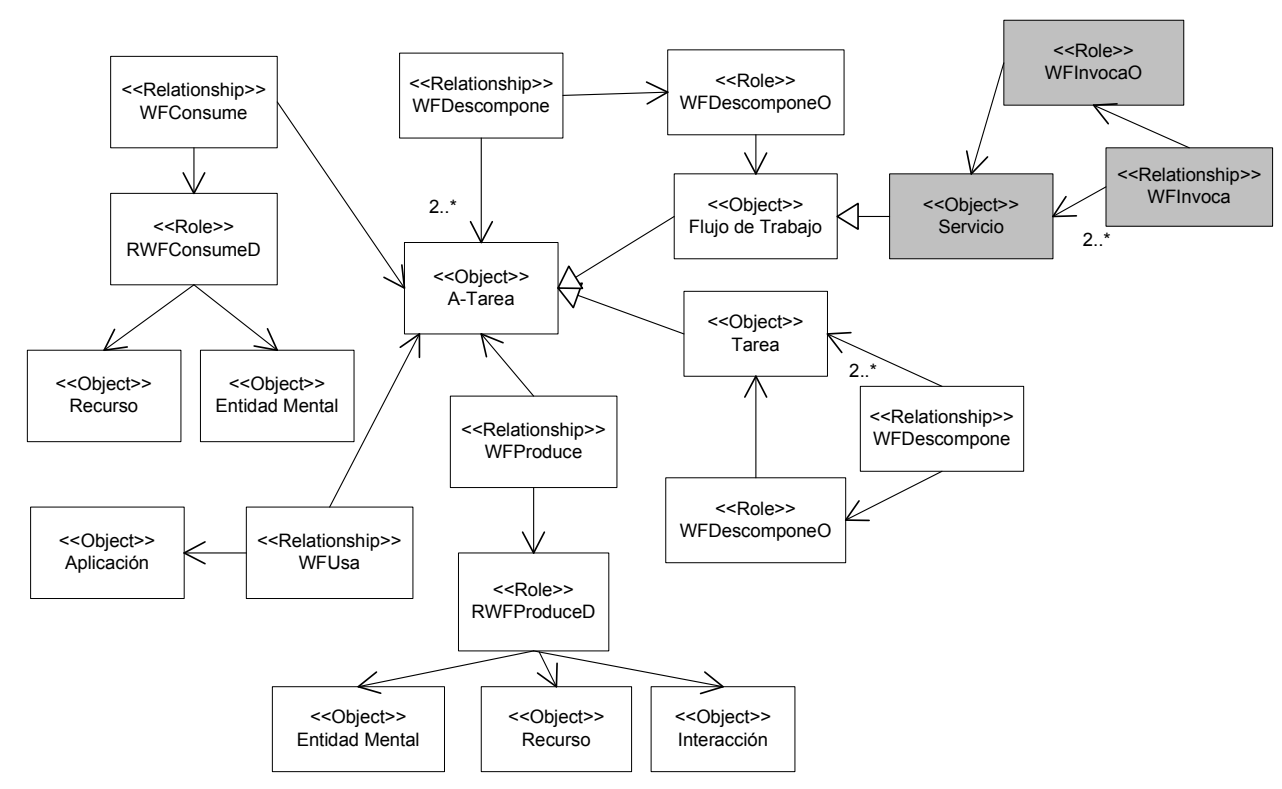

Figura 4.23: Descripción de tareas.

repetitiva de un determinado conjunto de servicios.

En la figura 4.25 se muestra el diagrama del modelo de actividad para el servicio BuscarViaje del sistema de agencia de viajes. Dicho servicio se describe en el perfil Búsqueda Viaje y se descompone en cuatro tareas. Primero se comprueba que la ciudad proporcionada corresponda al país indicado; de forma concurrente se buscan los vuelos para acceder a la ciudad y los hoteles existentes, invocando los servicios Informar Hoteles e Informar Vuelos correspondientes. Finalmente se confecciona el viaje deseado, filtrando aquellos viajes que mejores condiciones (precio, calidad hotel) ofrezcan. 


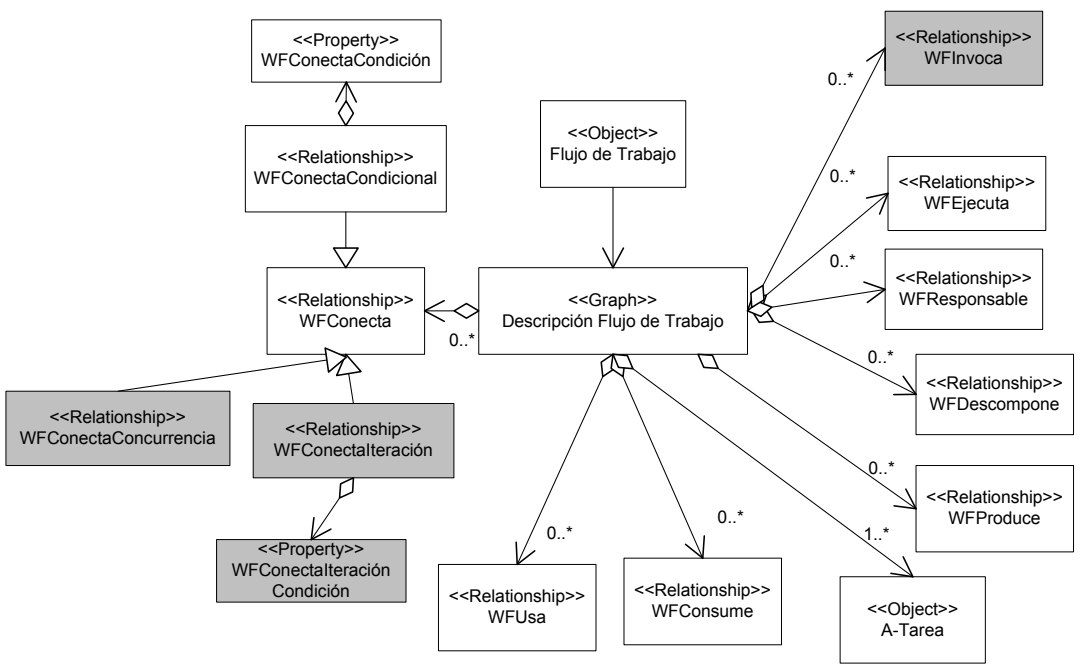

Figura 4.24: Descripción de un Flujo de Trabajo

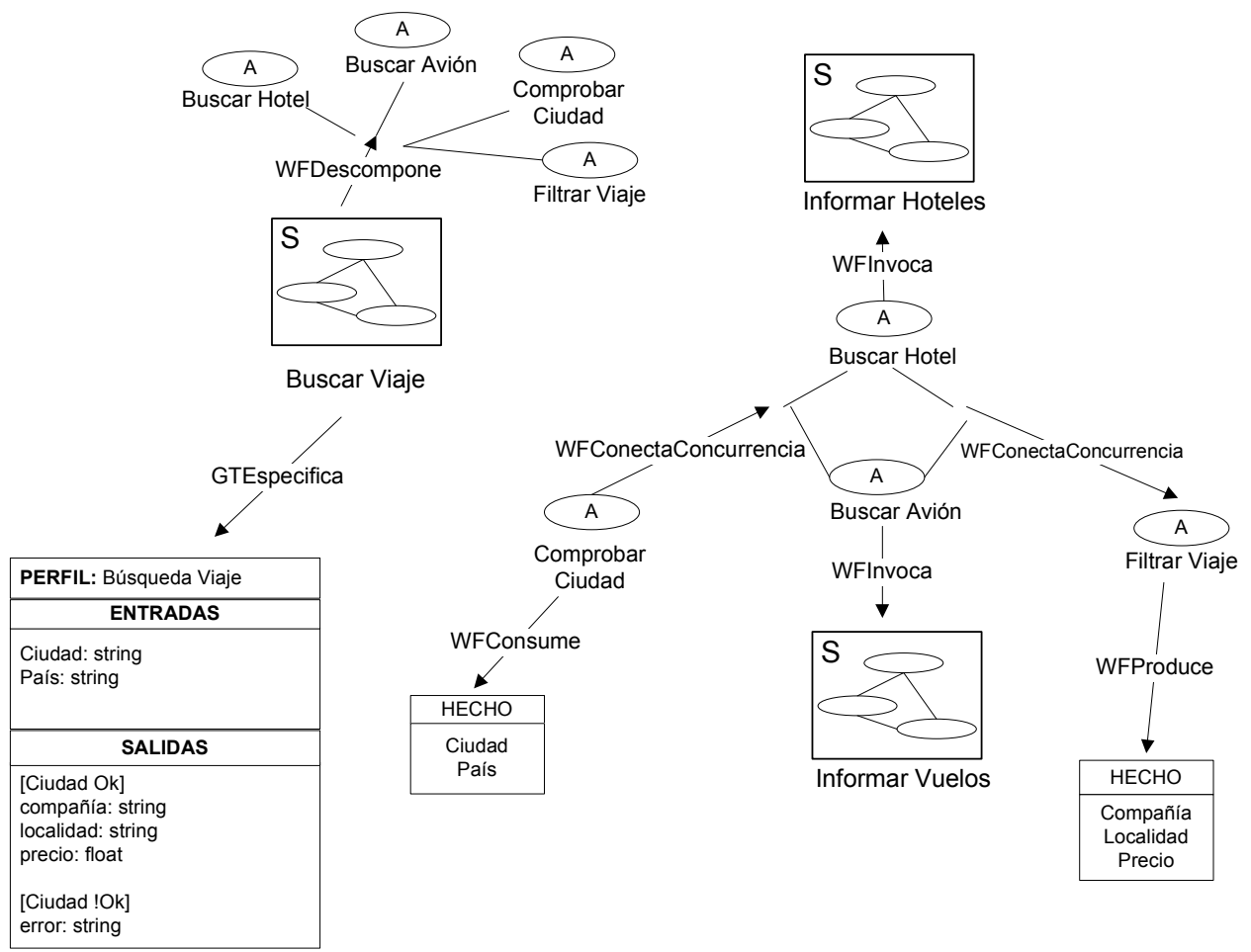

Figura 4.25: Diagrama del modelo de actividad. Descripción del servicio BuscarViaje. 


\subsubsection{Meta-modelo de Interacción}

Este meta-modelo permite definir las interacciones del sistema, describiendo quiénes son los A-Agentes que participan en la interacción y los objetivos que se persiguen. En nuestra propuesta se extiende el meta-modelo de interacción de ANEMONA (figura 4.26), de modo que las interacciones no sólo son provocadas por la activación de A-Objetivos, sino también por la utilización de los servicios (figura 4.27).

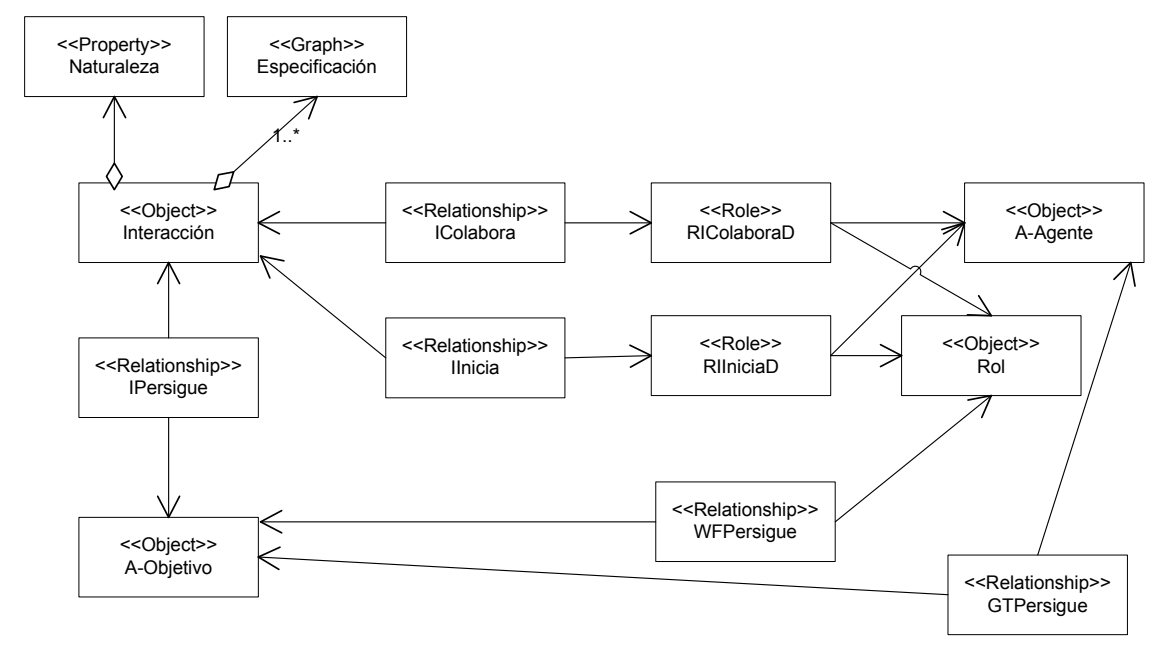

Figura 4.26: Meta-modelo interacción.

A cada servicio se accede a través de un puerto de servicio o punto de contacto, representado por la entidad PuertoServicio, provocando la activación de la interacción. Quien inicia la interacción es la entidad Rol que solicita la utilización del servicio (relación WFUtiliza); mientras que quien colabora es la entidad Rol que proporciona dicho servicio (relación WFProporciona).

La relación IAccede representa la utilización concreta de un servicio por parte de la entidad que accede a él a través de su puerto. En cierto modo equivale a la definición del grounding de la especificación de un servicio en el lenguaje OWL-S. Por su parte, la relación IProvoca cubre la característica de sincronización del servicio, vista en el apartado 4.3. Así, el acceso a un servicio implica la interacción entre las entidades que lo solicitan y las que 


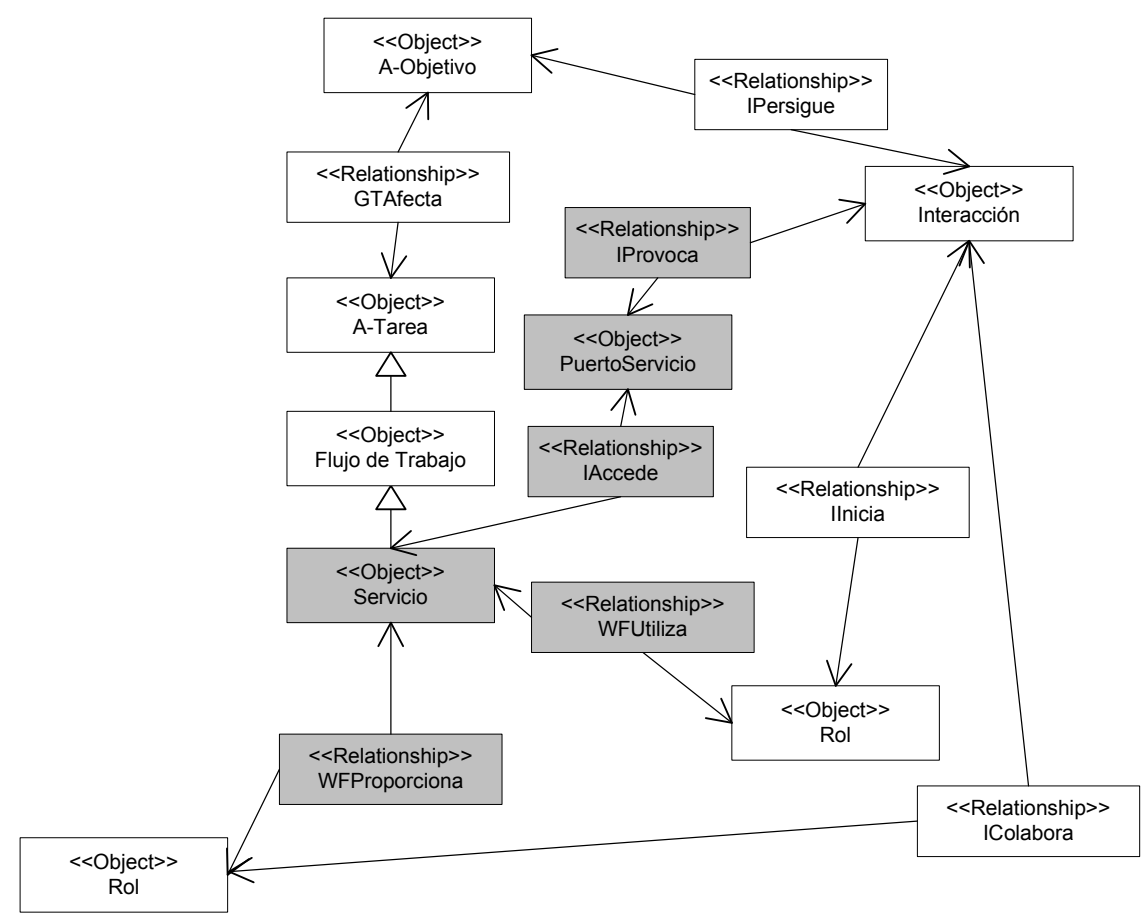

Figura 4.27: Meta-modelo interacción. Acceso a servicios.

lo proporcionan.

Todo Servicio y PuertoServicio que aparezca en el modelo de interacción debe existir también en el modelo de organización y en el modelo de entorno, respectivamente. Además, las entradas y salidas reflejadas en la especificación del servicio deben aparecer también en el detalle de la interacción, así como sus precondiciones y postcondiciones.

La descripción de las unidades de interacción, el patrón de estado mental asociado así como la relación entre las unidades de interacción (precedencia, concurrencia, etc.) no se han modificado respecto a las de ANEMONA.

En la figura 4.28 se muestra un ejemplo de diagrama del modelo de interacción, en el que se describe cómo el acceso al servicio BuscarViaje a través del puerto BúsquedaViaje provocará la interacción SolicitarInformación Viaje, iniciada por el cliente del servicio. 


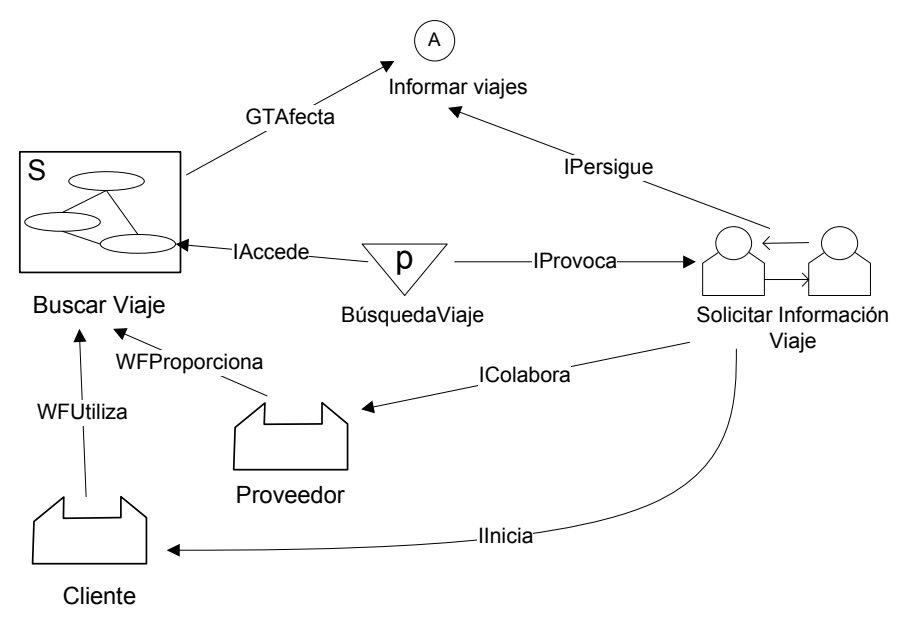

Figura 4.28: Ejemplo de activación de una interacción al producirse el acceso a un servicio a través de su puerto

\subsubsection{Meta-modelo del Entorno}

En ANEMONA se discretiza el entorno utilizando un conjunto finito de variables observables, de modo que se categoriza el tipo de entidades relevantes existentes en él y se restringe la interacción con las mismas. Por tanto, el entorno contiene recursos, aplicaciones y agentes; y se limita la percepción y actuación de los agentes. Las aplicaciones se emplean para modelar servicios pasivos, es decir, un conjunto de operaciones que no requieren la interacción con ningún agente y que son empleadas por varios agentes. Sirven como interfaz con el mundo real. Por su parte, los recursos son objetos del entorno que no proporcionan una funcionalidad concreta, pero que son indispensables para la ejecución de las tareas y cuyo uso se restringe a consumir o restituir.

En nuestra propuesta, integramos las aplicaciones y los recursos en el concepto Producto (figura 4.29), para así representar los resultados tangibles de cualquier organización, que serán consumidos por los miembros de ésta o por sus clientes.

Como se comentó en la sección 4.5, el entorno debe tratarse tanto desde 


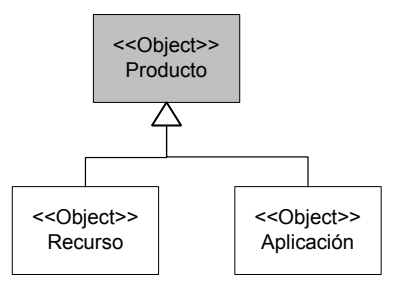

Figura 4.29: Meta-modelo de entorno. Entidad Producto.

una perspectiva estructural, detallando los elementos del sistema y sus relaciones; como desde una perspectiva funcional, que indica principalmente cómo se percibe y actúa sobre el entorno.

En el meta-modelo del entorno que se propone (figura 4.30) nos centramos en la descripción de los elementos que lo componen; en la percepción y actuación sobre éstos; y en los permisos de acceso de las entidades que hacen uso de dichos elementos. La relación concreta entre los elementos del sistema y sus normas de comportamiento se expresa en el meta-modelo de organización. Así, las relaciones OContieneRecurso, OContieneAplicación y OContieneA-Agente indican los componentes que conforman a una unidad organizativa (recursos, aplicaciones, agentes u otras unidades organizativas). Para los agentes concretos, en el meta-modelo del entorno hacemos uso de las relaciones ERecursoPertenece (figura 4.31) y EPercibe (figura 4.32) propias de INGENIAS, para indicar la posesión de un recurso concreto por un agente, así como de su accesibilidad a una aplicación determinada.

Por otro lado, la percepción y actuación de los agentes sobre los elementos del entorno se describe a través de la entidad PuertoEntorno(figura 4.30), especialización de la entidad Puerto. Este concepto se ha extraído del lenguaje de modelado AML [Cervenka y Trencansky, 2007], donde un puerto representa un punto de interacción entre la entidad y otros elementos del modelo. Hemos definido dos tipos de puerto: el del entorno y el de servicio. El puerto de entorno permite acceder a los recursos y aplicaciones con derechos de acceso de lectura y/o escritura. A través de la entidad Perceptor se establecen los permisos de lectura de información sobre los recursos y aplicaciones. Usando la entidad Actuador se establecen los permisos para 


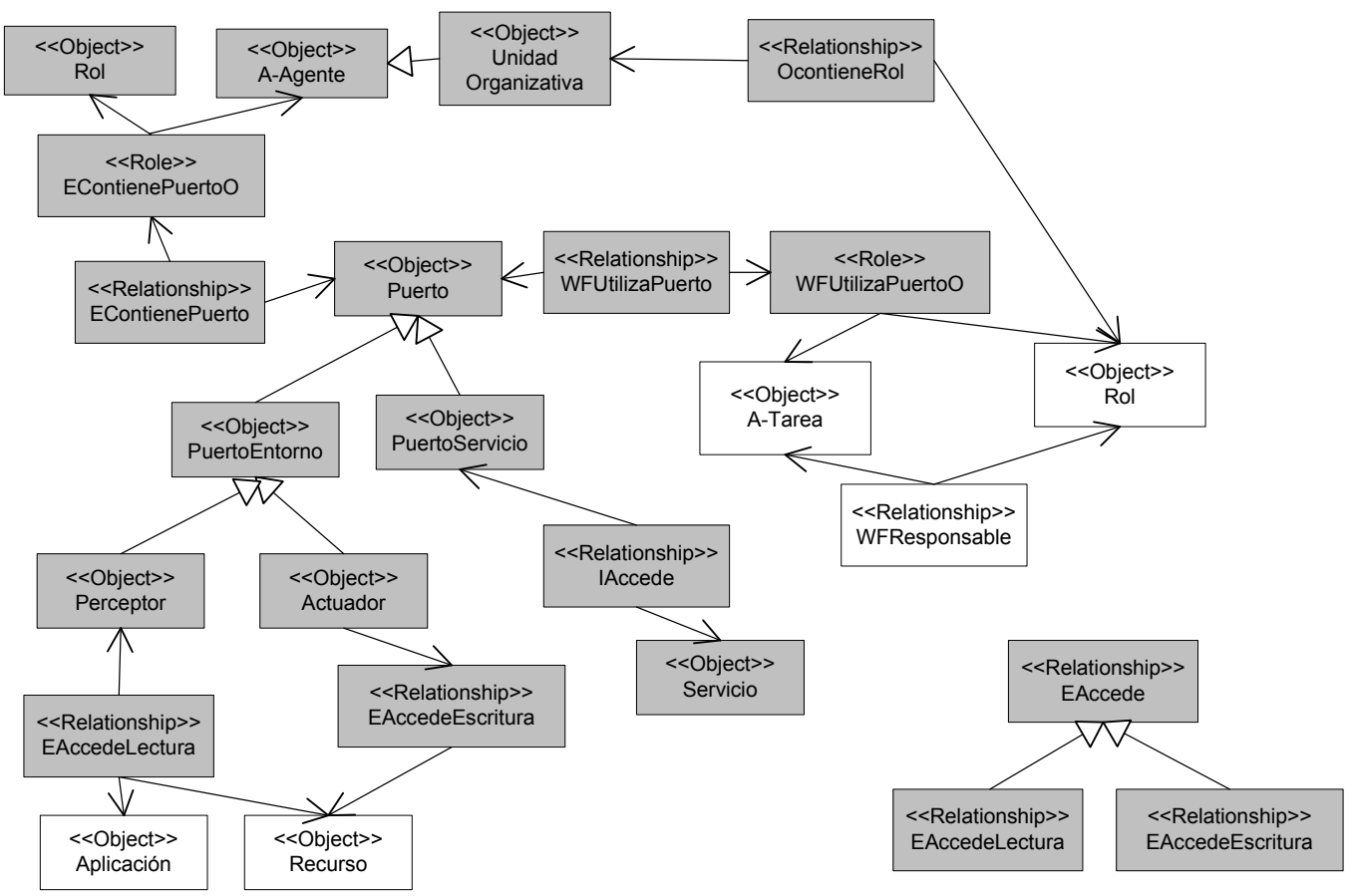

Figura 4.30: Meta-modelo de entorno. Acceso a puertos.

la modificación de la información de los recursos. Las entidades Perceptor y Actuador no son disjuntas entre sí, de modo que un PuertoEntorno puede servir a la vez como Perceptor y Actuador (sobre un mismo recurso). La asociación de un A-Agente con un Puerto (relación EContienePuerto) permite indicar la pertenencia de dicho puerto, bien sea a un Agente concreto o a una Unidad Organizativa.

Por otro lado, una A-Tarea o bien un Rol de la Unidad Organizativa tendrá especificado el tipo de acceso permitido sobre el puerto, mediante la relación WFUtilizaPuerto, la cual se especializa en WFUtilizaPuertoLectura, para el acceso sobre el Perceptor; y WFUtilizaPuertoEscritura, para el acceso sobre el Actuador (figura 4.33).

En el ejemplo de la figura 4.34 se muestra en la parte izquierda la pertenencia de un recurso (inventario reservas) a un agente determinado (Banco) y el tipo de acceso permitido sobre dicho recurso: para lectura con la relación EAccedeLectura y para escritura con EAccedeEscritura. Dichos accesos 


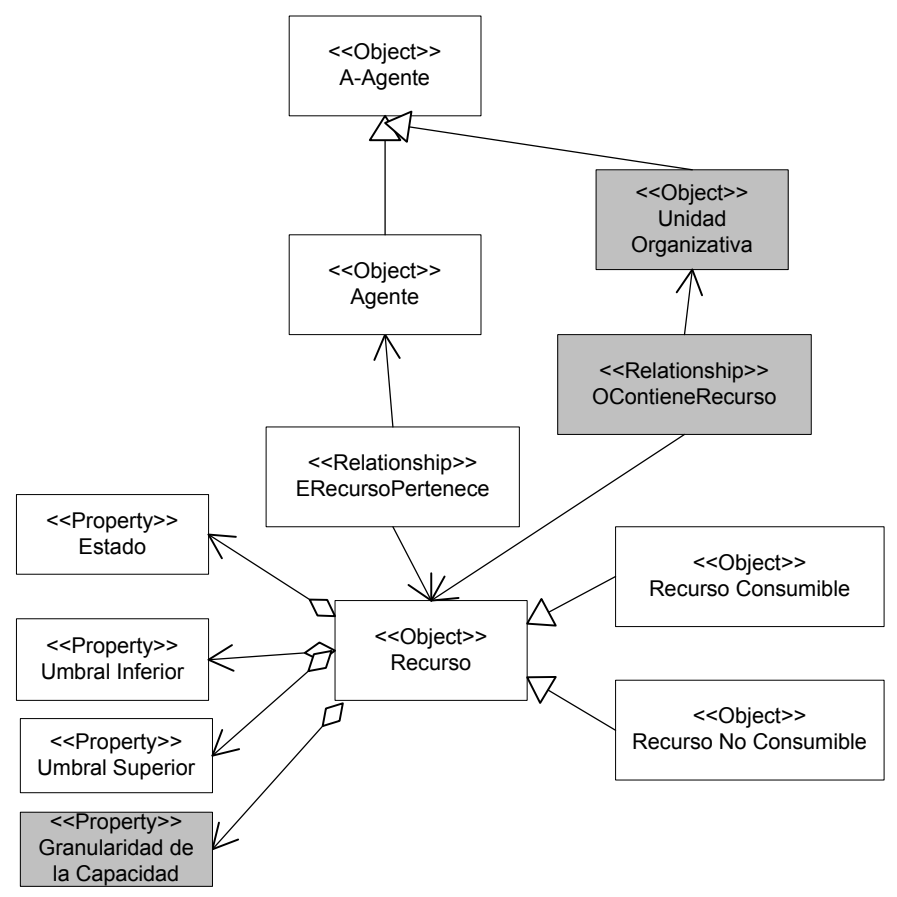

Figura 4.31: Meta-modelo de entorno. Pertenencia de un recurso. Características del recurso.

se especifican con la utilización del puerto Acceso Inventario, también contenido por el agente (relación EContienePuerto). En la parte derecha de la figura se muestra cómo expresar que la unidad organizativa AgenciaViajes gestiona el acceso a ese recurso (inventario reservas), especificando los modos de acceso concretos para los roles de esa unidad. Así, aunque en principio el recurso podría ser accedido tanto para lectura como para escritura, para el rol Cliente solamente se permite el acceso de lectura (relación WFUtilizaPuertoLectura).

Las relaciones EAccedeLectura y EAccedeEscritura, así como WFUtilizaPuertoLectura y WFUtilizaPuertoEscritura deben ser compatibles con las relaciones WFConsume, WFProduce y WFUsa del meta-modelo de actividad. Por ejemplo, si una tarea usa un determinado recurso, debe existir el permiso de lectura sobre dicho recurso. Por tanto, debe existir la relación entre esa tarea y WFUtilizaPuertoLectura. Además el Agente que ejecuta 


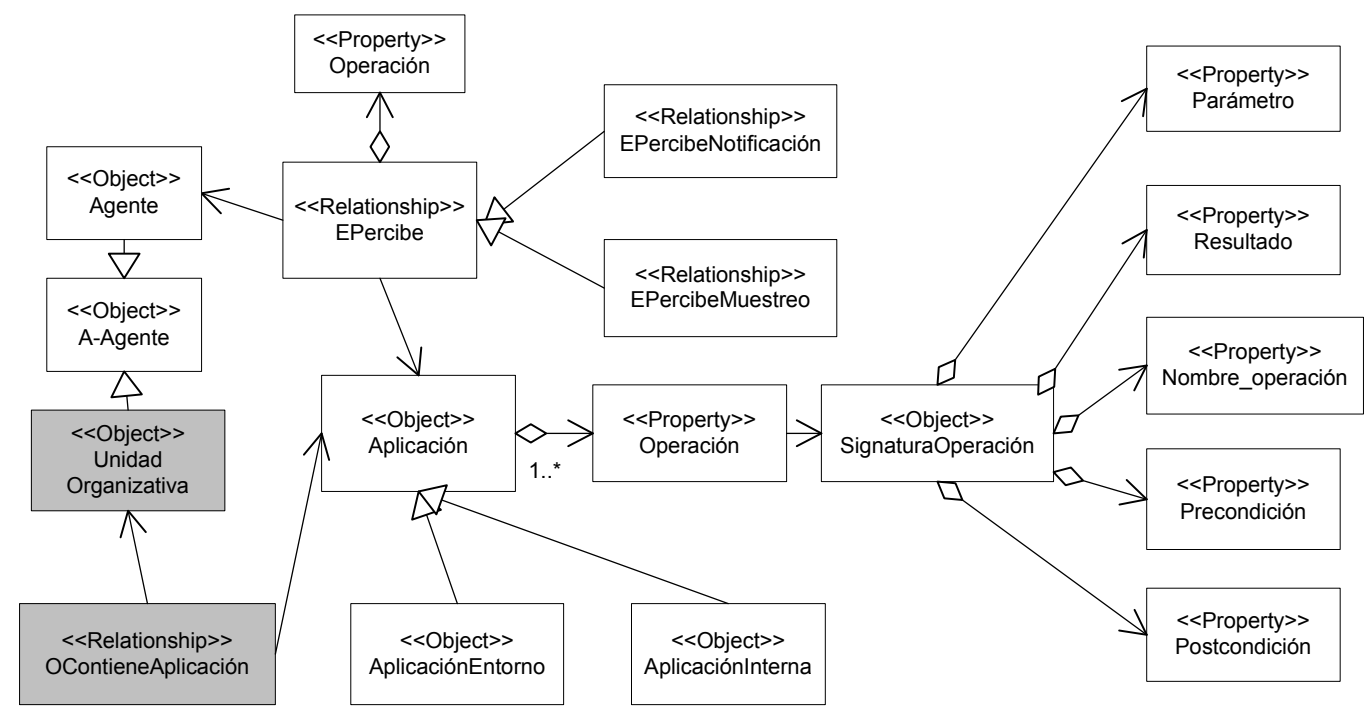

Figura 4.32: Meta-modelo de entorno. Aplicaciones.

la tarea, o bien la Unidad Organizativa en la que se define su funcionalidad debe contener el puerto sobre el que se accede al recurso y éste debe ser de tipo Perceptor.

Por otro lado, la entidad PuertoServicio representa la característica de publicitación del servicio, vista en el apartado 4.3, indicando así el punto de contacto o mecanismo de acceso al servicio. La relación EcontienePuerto sobre un puerto de servicio implica la publicitación del mismo a través de algún mecanismo de publicitación, como un directorio de servicios.

En la figura 4.35 se muestra el acceso al puerto BúsquedaViaje por el agente concreto Personal, que juega el rol Cliente, habilitado para utilizar ese puerto (relación WFUtilizaPuerto) y así solicitar el servicio BuscarViaje. Además, la entidad AgenciaViaje es la encargada de controlar la publicitación del servicio con la relación EContienePuerto.

\subsubsection{Meta-modelo de Agente}

En el meta-modelo de agente de INGENIAS se describen los agentes particulares, excluyendo sus interacciones con otros agentes, centrándose 


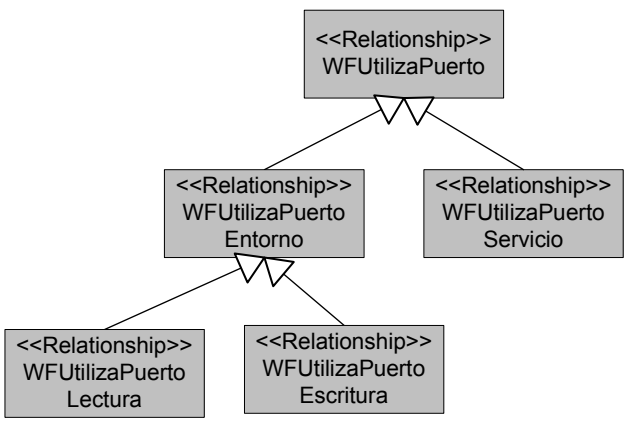

Figura 4.33: Especialización de la relación WFUtilizaPuerto

en su funcionalidad y en el diseño de su control. En el meta-modelo de ANEMONA se definen las responsabilidades del A-Agente, tanto desde el punto de vista del agente simple como de una organización.

En nuestra propuesta, el meta-modelo de agente sirve para tres objetivos distintos: (i) especificar el comportamiento interno de aquellos agentes que se conozcan durante las fases de análisis y/o diseño, asociándoles las tareas, servicios, objetivos y roles concretos que jueguen; (ii) describir un arquetipo o esqueleto de agente que sea reutilizado por otros diseñadores para así implementar agentes externos capaces de entrar en la organización y adquirir en ella roles específicos; y (iii) relacionar las unidades organizativas con los objetivos, flujos de tareas y roles a jugar dentro de las unidades superiores en las que se integren. Por tanto, este meta-modelo de agente permite describir la funcionalidad concreta de los agentes internos del sistema, es decir, de todos aquellos agentes cuya existencia se conoce en las fases de análisis o diseño y que, en la mayoría de los casos, su presencia resulta esencial para garantizar el correcto funcionamiento del sistema.

Los agentes internos normalmente asumen roles de tipo controlador, supervisor, monitor, etc., para los cuales se requiere no sólo de cierta funcionalidad explícita, sino también de las garantías suficientes de que los agentes se ocupen del cometido asignado. Precisamente, la ejecución de estos roles a través de agentes internos evita la necesidad de diseñar mecanismos de control sobre los propios roles de supervisor, monitor, etc., pues se asume que en el diseño se habrán tomado las decisiones oportunas que garanticen 


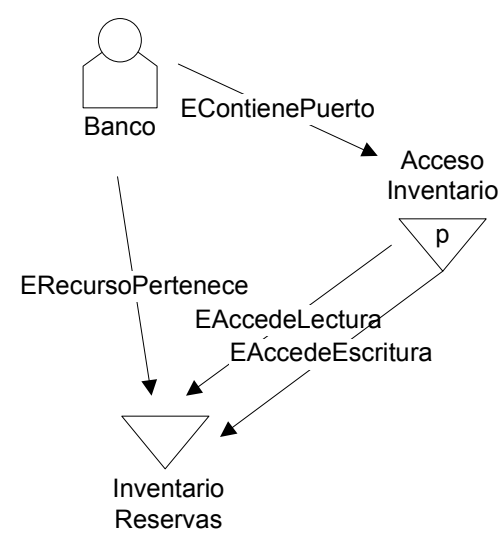

a) Recurso pertenece al Agente

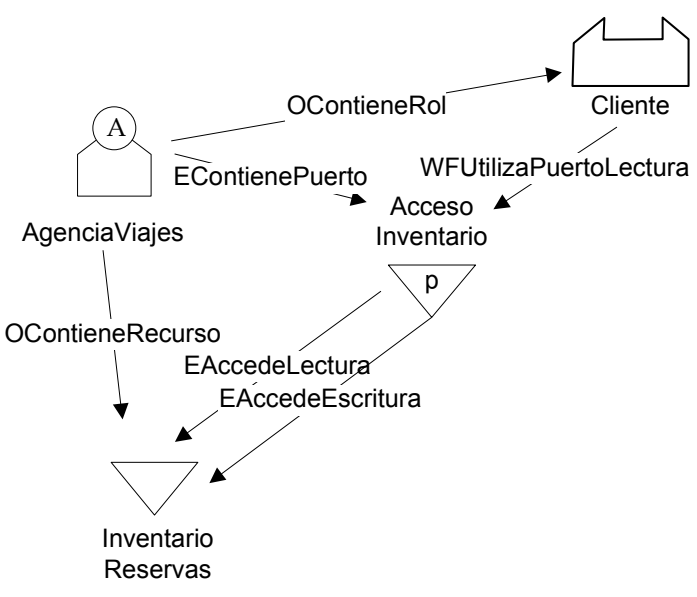

b) Unidad Organizativa contiene Recurso

Figura 4.34: Ejemplo de utilización de recursos y especificación de permisos de acceso. a) El recurso pertenece a un agente concreto; b) el recurso es gestionado por la unidad organizativa, que define los modos de acceso de sus roles con respecto al recurso.

el adecuado funcionamiento de estos roles.

No obstante, al modelizar un sistema abierto se debe tener en cuenta facilitar el acceso al mismo a agentes cuya funcionalidad no haya sido diseñada ni implementada por los diseñadores del sistema. En este caso, se desconoce el número concreto de agentes externos que participan durante la ejecución del sistema, así como cuáles son sus objetivos, cómo se gestionan y procesan o bien qué actividades específicas son capaces de realizar.

De este modo, el diseñador del sistema debe reflejar el comportamiento esperado a través del concepto de rol, es decir, en base a la funcionalidad, servicios y normas asociados a cada rol y especificados en el resto de meta-modelos. Opcionalmente, podrá emplear el meta-modelo de agente como esquema de referencia del tipo de agentes externos que se esperan en el sistema, ofreciendo así un arquetipo o esqueleto de agente que otros diseñadores reutilicen para implementar sus propios agentes.

En el meta-modelo de agente (figura 4.36) se asocia a cada agente con las habilidades o tareas que sabe ejecutar (relaciones WFResponsable y AResponsable sobre la entidad Tarea). La entidad A-Tarea de ANEMONA 


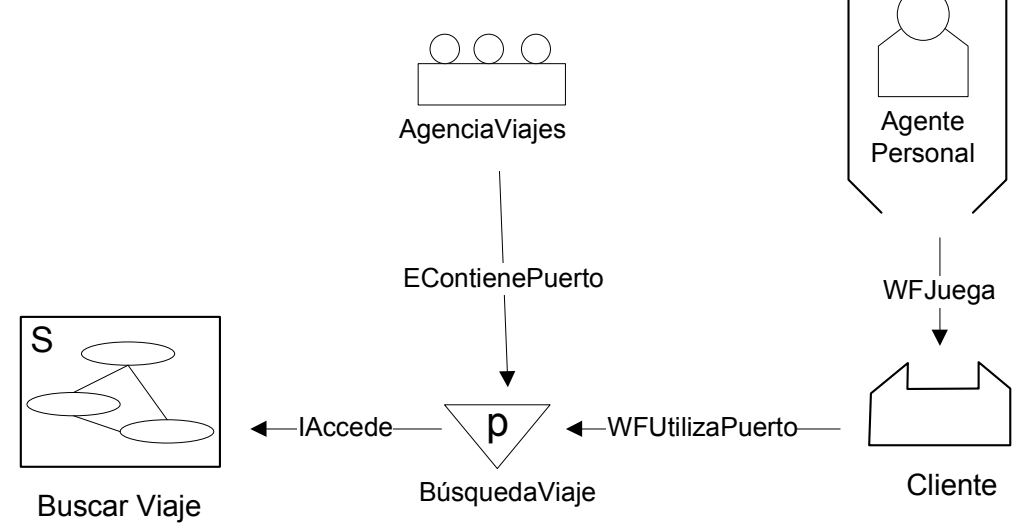

Figura 4.35: Ejemplo de acceso a un servicio a través de su puerto.

representa tanto las tareas de las que es responsable un agente, como las tareas compuestas (Flujo de Trabajo), que se asocian como habilidad a un conjunto de agentes, que deben ser llevadas a cabo en un determinado orden y en cuya ejecución pueden estar involucrados varios agentes [Giret, 2005]. Si en la fase de análisis y/o diseño se conoce de antemano en qué organizaciones participa el agente, se especifica también qué roles juega en ellas (relación WF Juega).

Se asume también el modelo de agentes de tipo BDI de INGENIAS y ANEMONA, en el que los agentes tienen estados mentales, compuestos por creencias, compromisos y deseos, que evolucionan en base a gestores y procesadores de estados mentales, para la consecución de los objetivos del agente.

Para especificar que un A-Agente nace con un determinado A-Estado Mental se le asocia dicho estado con la relación ATieneEM. Si se desean modelar otros momentos del ciclo de vida del agente, se debe emplear la entidad Consulta Entidad Autónoma que representa al agente en ejecución y lo asocia con un rol específico o un agente concreto, así como con el estado mental requerido. En nuestra propuesta se ha mantenido la descripción de la entidad Consulta Entidad Autónoma que ofrece ANEMONA (figura 4.37). 


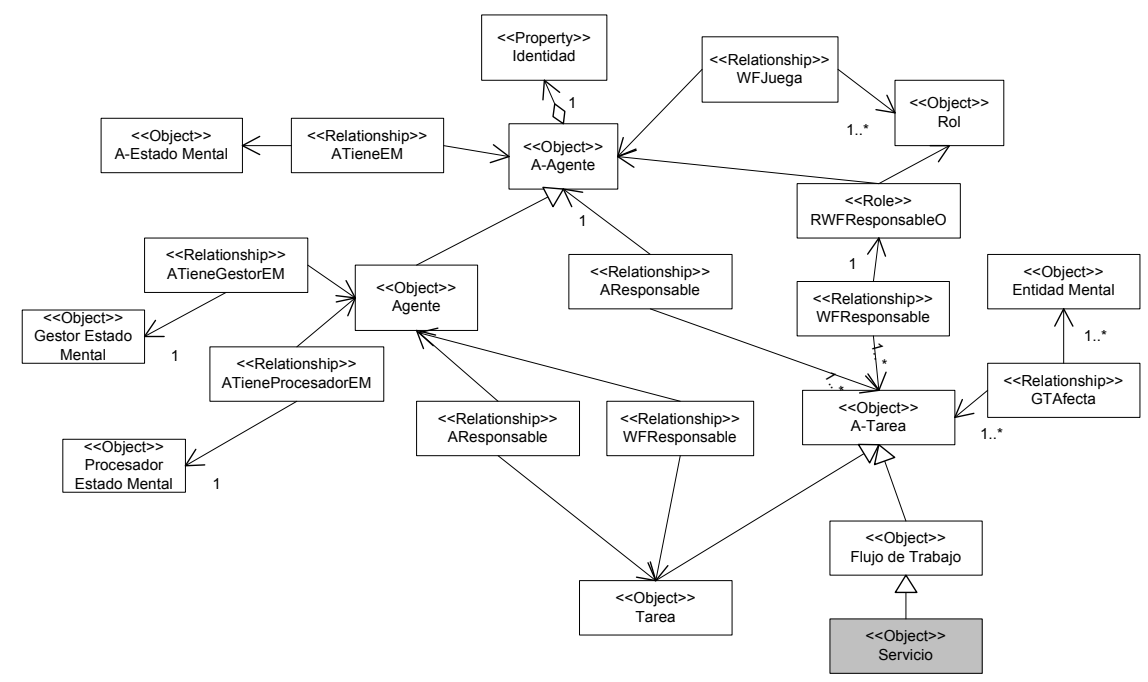

Figura 4.36: Meta-modelo de agente. Tareas, roles y estado mental asignado.

Sin embargo, se ha extendido el comportamiento del gestor y del procesador, ya que ambos deben tener en cuenta cuáles son las normas aplicables al agente, para así determinar en base a ellas a qué objetivos debe comprometerse el agente y qué acciones debe ejecutar en cada momento.

De esta manera se asume que los agentes a modelar son normativos, por lo que conocen las reglas que restringen su comportamiento, las sanciones y recompensas asociadas y son capaces de razonar sobre las reglas (figura 4.38). Para ello se ha extendido la Entidad Mental Información, incluyendo en ella el concepto de Norma. Además, la entidad A-Objetivo se extiende con el Objetivo Normativo, que expresa un objetivo de tipo prohibición, permiso u obligación. Los conceptos de Norma, Objetivo Normativo, así como el contenido de la norma se detallan en el modelo normativo, que se comentará más adelante.

Por otro lado, se ha considerado la característica de sociabilidad del agente, desde el punto de vista de los servicios (figura 4.39). Así, un agente no sólo sabe ejecutar ciertas tareas, sino que además es capaz de ofrecer determinadas funcionalidades a otros agentes, con independencia de los agentes concretos con los que interaccione finalmente. Por tanto, un agente 


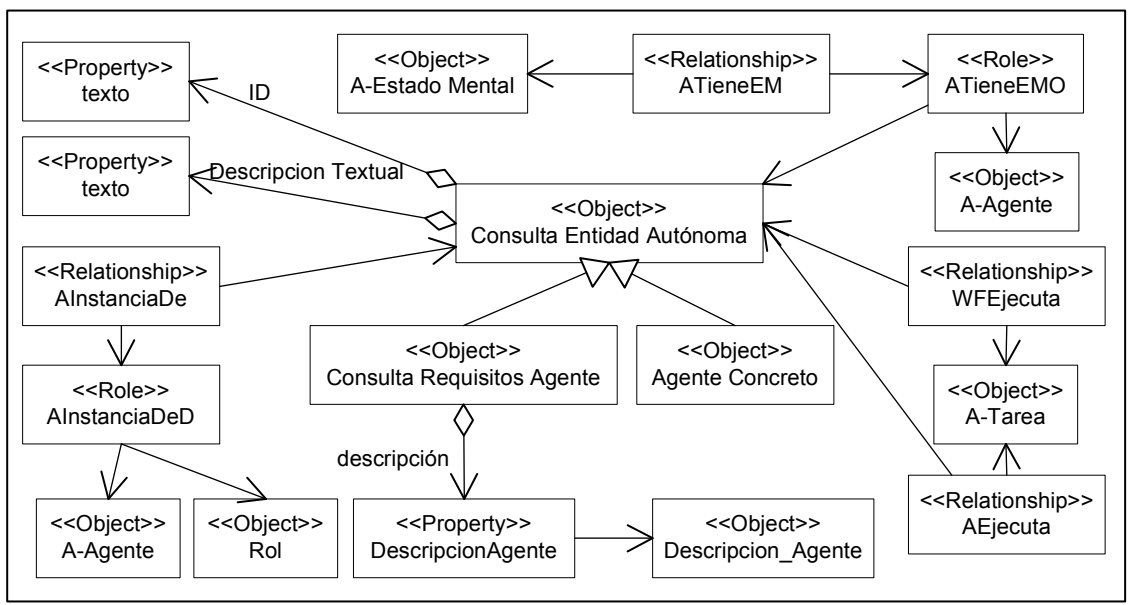

Figura 4.37: Consulta de Entidad Autonoma

ofrece servicios (relación AOfrece sobre la entidad Servicio). Si el agente se incorpora como miembro a una organización determinada, adoptando uno o más roles en ella, el conjunto concreto de servicios que podrá servir vendrá restringido por los servicios asociados a esos roles (relación WFProporciona), que serán un subconjunto o composición de los indicados por la relación AOfrece.

Respecto al punto de vista de la organización, el meta-modelo de agente definido en ANEMONA permite que una Organización juegue un rol determinado, lo cual implica que será responsable de las tareas asignadas a ese rol, tendrá las capacidades definidas en dicho rol, perseguirá sus objetivos, etc. Pero además la organización podrá actuar dentro de otra organización (superior) interpretando un rol determinado [Giret, 2005].

En nuestra propuesta, al sustituir el concepto Organización de ANEMONA por la entidad Unidad Organizativa, cuando se produce la integración de una organización en otra, dicha integración se hace en base a unidades organizativas. Es decir, la organización interna actuará como una unidad organizativa dentro de la organización mayor.

La entidad A-Objetivo de ANEMONA se especializa en nuestro metamodelo (figura 4.40) en las entidades Misión, Objetivo funcional y Objetivo operativo, el cual a su vez se corresponde con un Objetivo de 


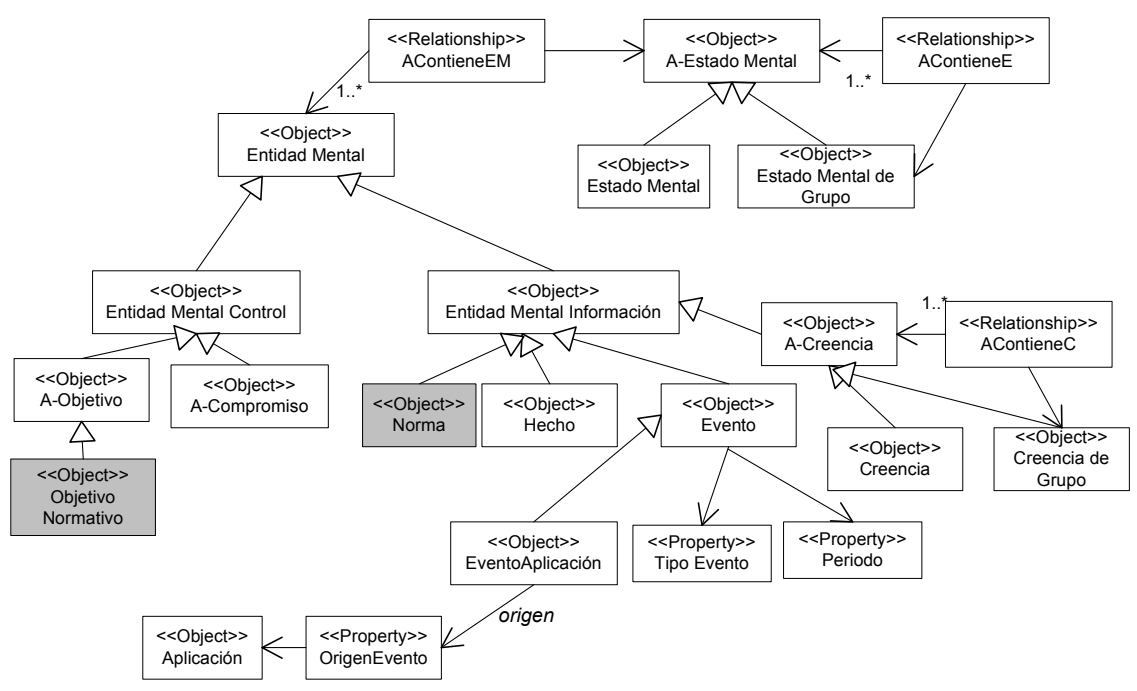

Figura 4.38: Entidades Mentales.

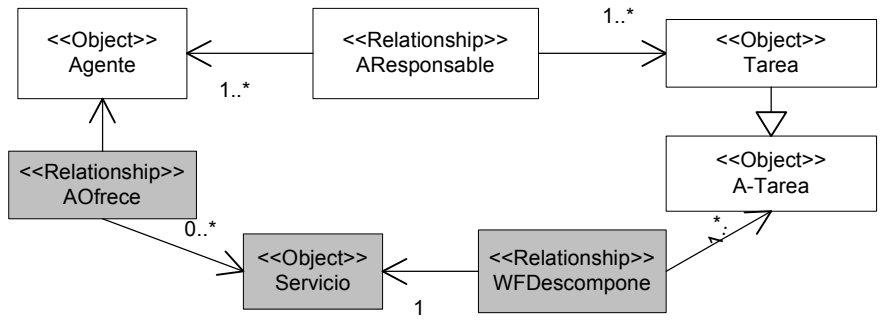

Figura 4.39: Meta-modelo de agente. Servicios ofrecidos.

Grupo o con un Objetivo. El Objetivo funcional representa un objetivo totalmente nuevo, no contemplado en los objetivos de los miembros de la unidas. Describe el comportamiento global esperado por la unidad organizativa. Este concepto equivale al objetivo de tipo soft-goal empleado en la metodología Tropos [Castro et al., 2001]. Por su parte, el Objetivo de Grupo representa la conjunción y/o disyunción de los Objetivos de los miembros, que deben ser medibles de alguna manera.

En la figura 4.41 se muestra un ejemplo de descripción de un agente de una cadena hotelera $(\mathrm{CH})$, que lleva implementada la funcionalidad de búsqueda de hotel, reservas y solicitud de tarjetas para sus clientes. Cuando el agente juegue el rol de proveedor, tendrá limitada su funcionalidad a los 


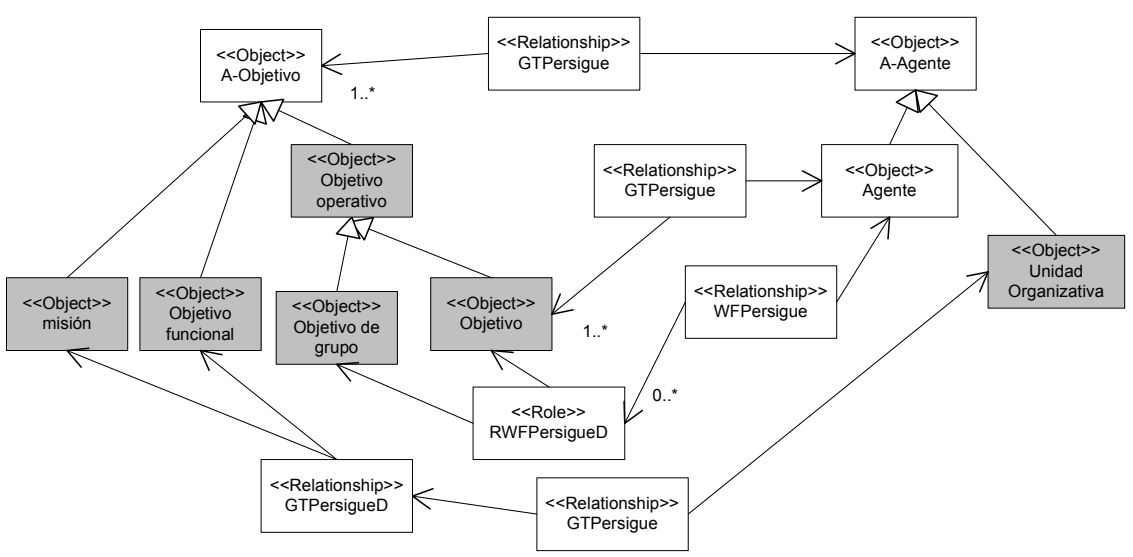

Figura 4.40: Meta-modelo de agente. Objetivos perseguidos.

servicios habilitados para ese rol (es decir, BuscarHotel y ReservarHotel).

\subsubsection{Meta-modelo Normativo}

En las organizaciones, las normas se emplean como mecanismos para limitar la autonomía de los agentes en sistemas extensos así como para resolver problemas de coordinación complejos y heterogéneos, en los que el control social directo y total no se puede ejercer [López et al., 2006]. Por tanto, las normas resultan clave para las sociedades de agentes abiertas, caracterizadas por la heterogeneidad, autonomía y diversidad de intereses de sus miembros.

En el meta-modelo normativo propuesto (figura 4.42) se describen las condiciones de activación de una norma, las actividades que regula y a quiénes afecta dicha regulación, así como quiénes son los encargados del control directo de la ejecución de la norma y de la aplicación de recompensas o de sanciones asociadas. La entidad Norma representa una regulación concreta, que lleva asociada un identificador. Dicha regulación se expresa a través de un Objetivo Normativo (relación NPersigue), de tipo Obligación, Permiso o Prohibición.

Con la relación NActivación se especifican los hechos o eventos que se producen en el entorno y que provocan la activación de la norma. Su 


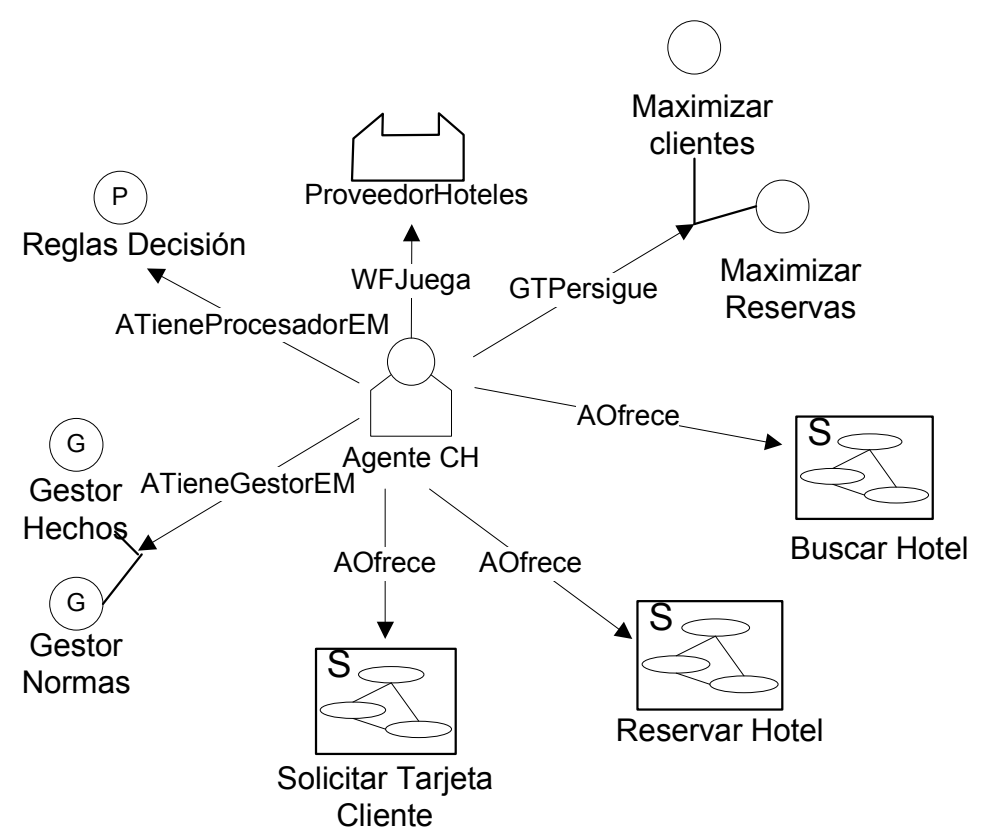

Figura 4.41: Diagrama del modelo de agente. Descripción de un Agente de Cadena Hotelera.

desactivación vendrá motivada por la consecución del objetivo normativo o por el cumplimiento del deadline.

Toda norma afecta a determinados roles o entidades A-Agente (relación NAfecta), de modo que la ejecución de ciertas A-Tareas por parte de éstos provoca la satisfacción o fallo del objetivo normativo indicado.

Una obligación representa la necesidad de ejecución de determinadas A-tareas. Por tanto, será satisfecha si la entidad A-Agente o Rol afectada ejecuta la A-Tarea correspondiente. Por contra, no será satisfecha si se activa antes el deadline correspondiente.

Una prohibición representa la imposibilidad de ejecución de ciertas ATareas. Por tanto, dicho objetivo normativo no será alcanzado si la entidad A-Agente o Rol afectado ejecuta esas A-Tareas. Pero será satisfecho si se activa antes el deadline correspondiente.

Finalmente, un permiso indica la posibilidad de realizar determinadas ATareas, pudiéndose recompensar dicha ejecución; aunque no existe sanción 


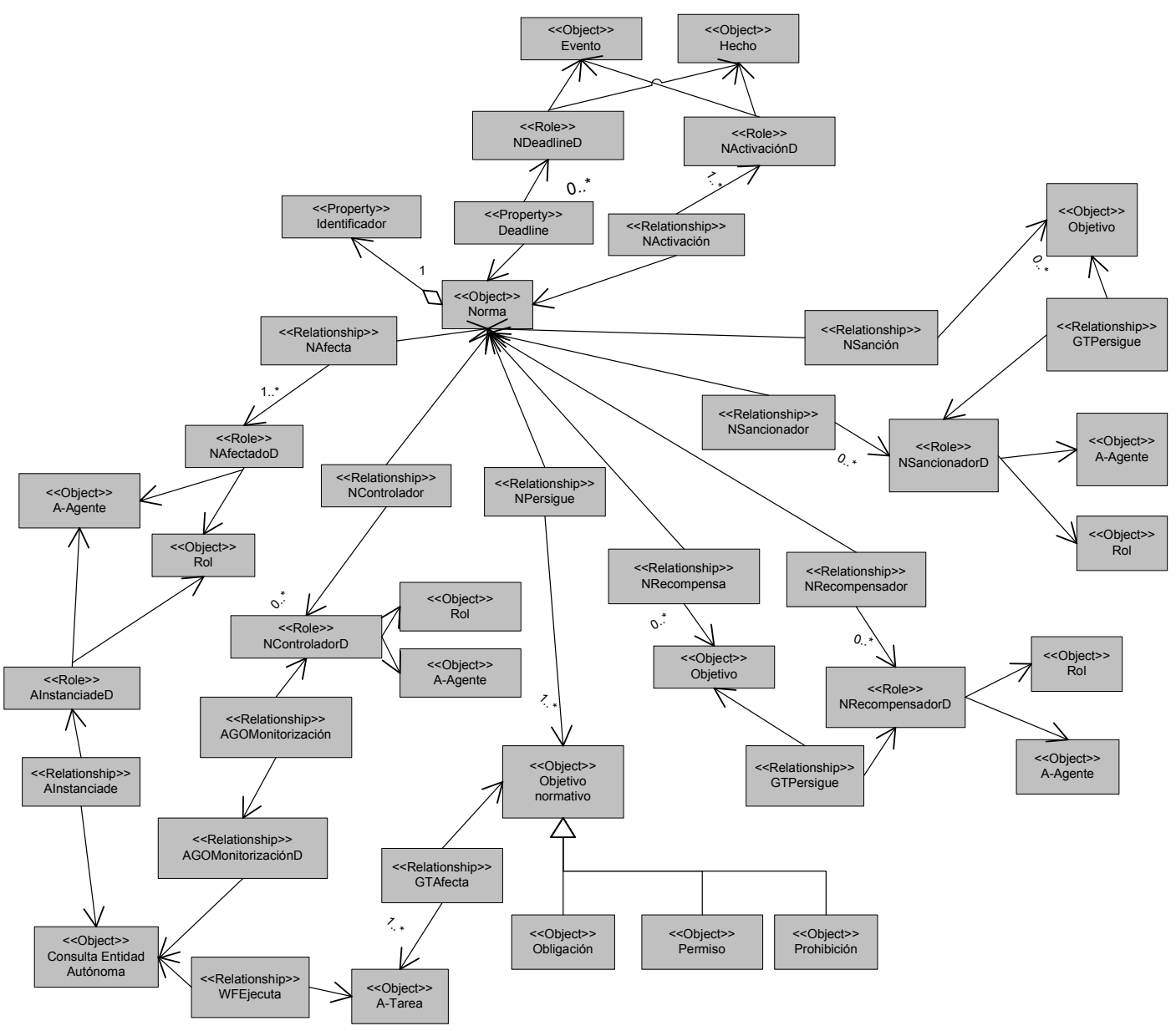

Figura 4.42: Meta-modelo normativo.

alguna si esas A-Tareas no se llevan a cabo.

El fallo de los objetivos normativos de tipo obligación y prohibición debe llevar asociado una sanción, con la que se apliquen las medidas oportunas para devolver al sistema a un estado consistente. En el resto de casos, las sanciones y recompensas son opcionales. 


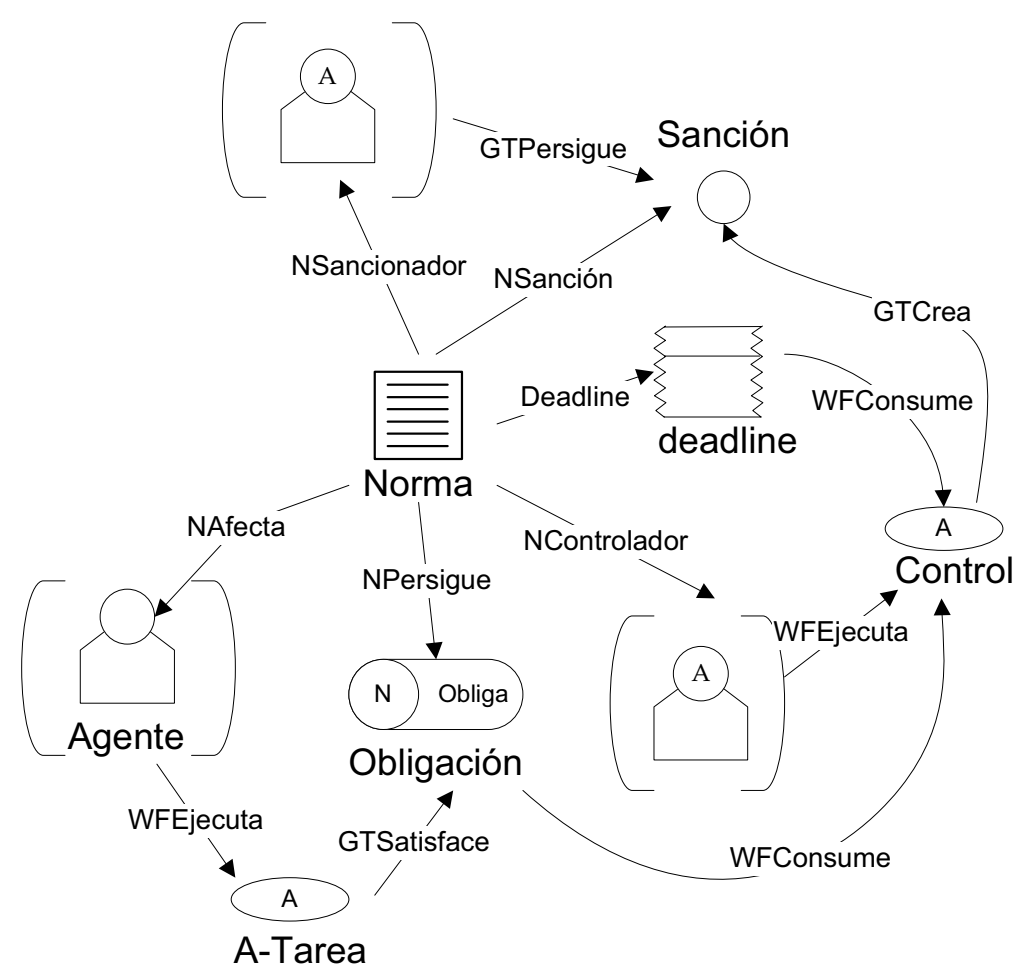

Figura 4.43: Patrón de diseño de una Obligación.

El control de la satisfacción o fallo de la norma podrá ser asignado a entidades de tipo A-Agente o Rol (relación NControlador) que se encargarán de monitorizar si las entidades autónomas afectadas ejecutan (o no) las A-Tareas relevantes para dicha norma. Asimismo, se identifican entidades encargadas de efectuar las recompensas (relación NRecompensador), sobre las cuales se crearán los objetivos oportunos para conseguir aplicarlas (relación GTPersigue). De igual forma se tratan las sanciones (relaciones NSancionador y NSanción).

Como se ha comentado anteriormente, el fallo o satisfacción de un objetivo normativo implica acciones distintas (es decir, activación de sanciones o de recompensas) según el tipo de objetivo normativo que se trate. Para facilitar su comprensión, proporcionamos tres patrones de diseño de normas para los objetivos normativos. En las figuras 4.43, 4.44 y 4.45 se muestran estos patrones. 


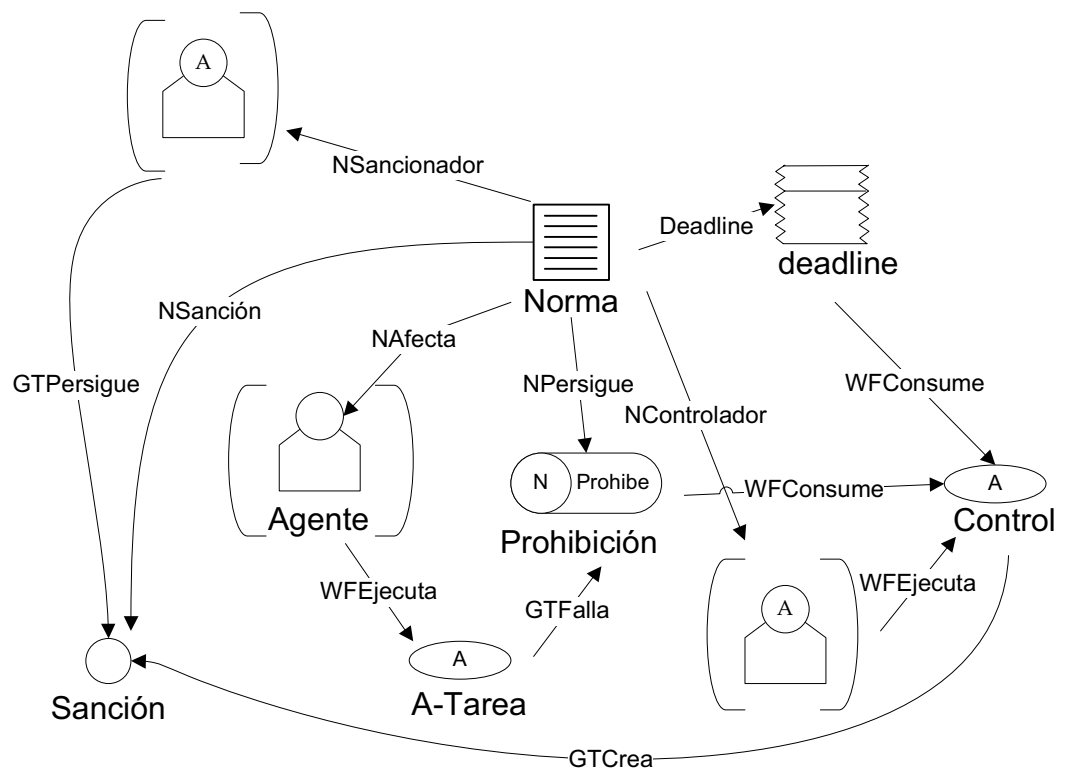

Figura 4.44: Patrón de diseño de una Prohibición.

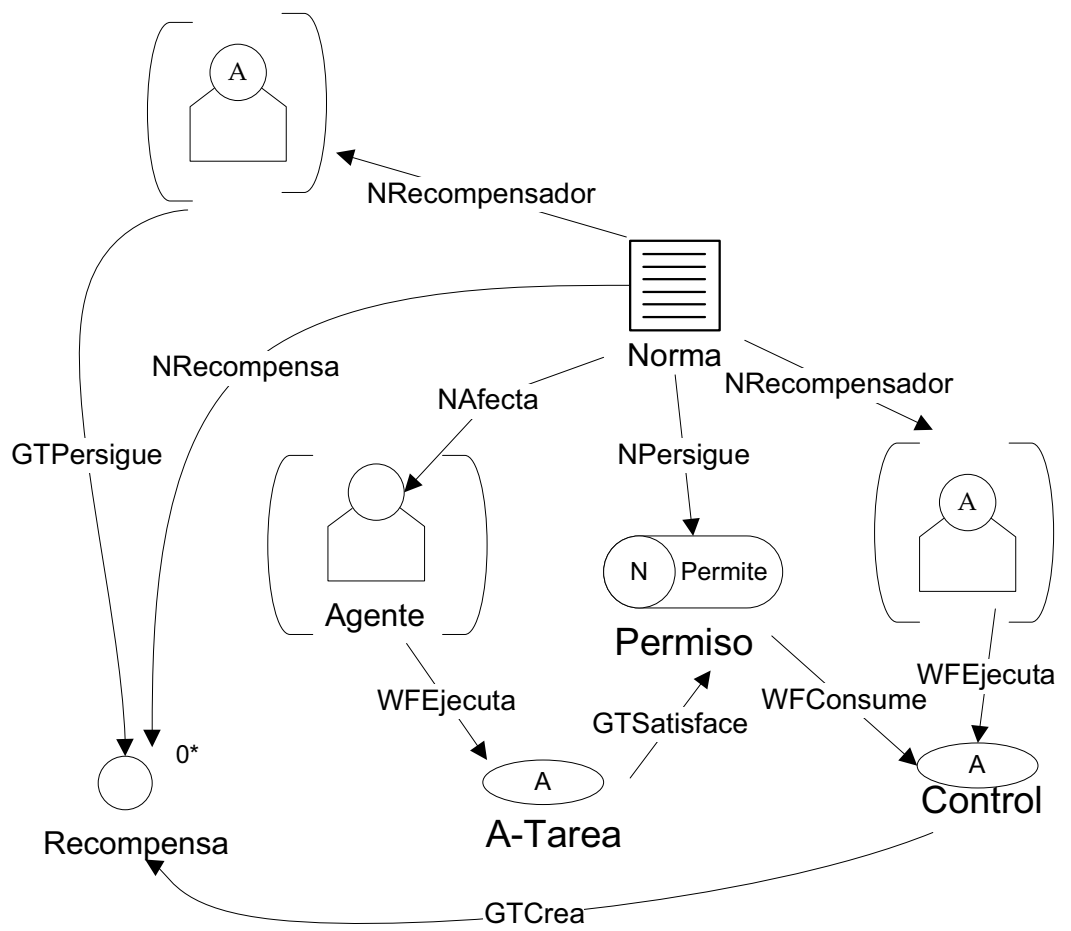

Figura 4.45: Patrón de diseño de un Permiso. 
Además del meta-modelo normativo proponemos una descripción BNF de lenguaje normativo (tablas 4.1 y 4.2 ) centrado en la solicitud ( $R E$ QUEST), provisión (SERVE) o registro (REGISTER) de un servicio concreto. Este lenguaje normativo se basa en la especificación del lenguaje normativo para acciones dialógicas dentro de instituciones electrónicas [GarciaCamino et al., 2005], así como en su extensión para acciones no dialógicas [Torres, 2007].

Ejemplos de normas descritas con la descripción BNF del lenguaje normativo propuesto son:

1. Un ProveedorHoteles puede registrar servicios de tipo ReservarHotel si así lo requiere.

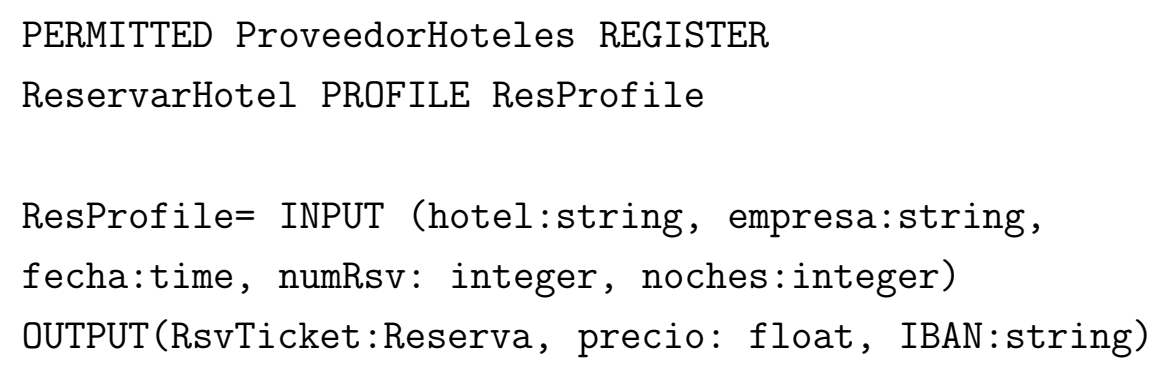

2. Un ProveedorHoteles está obligado a registrar un servicio de tipo InformarHoteles y si no lo cumple se le sancionará expulsándolo de la unidad.

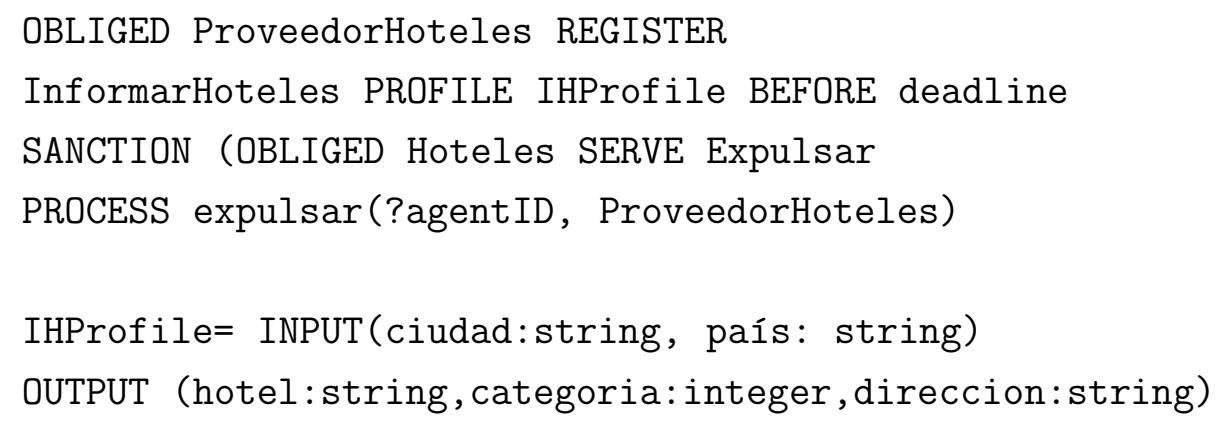


3. Un cliente no podrá solicitar el servicio de ReservarViaje para una ciudad determinada si antes no ha solicitado el servicio de BuscarViaje sobre esa misma ciudad.

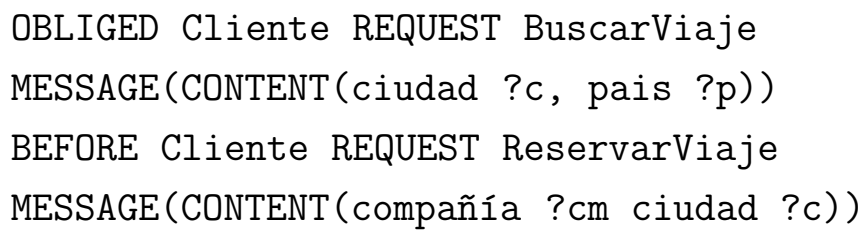

En las figuras 4.46 y 4.47 se muestran los diagramas del modelo normativo para las primeras dos normas anteriores. En dichos modelos se establece la relación entre los roles afectados por la norma, sus restricciones deónticas (obligación, prohibición o permiso) y los perfiles de los servicios implicados.

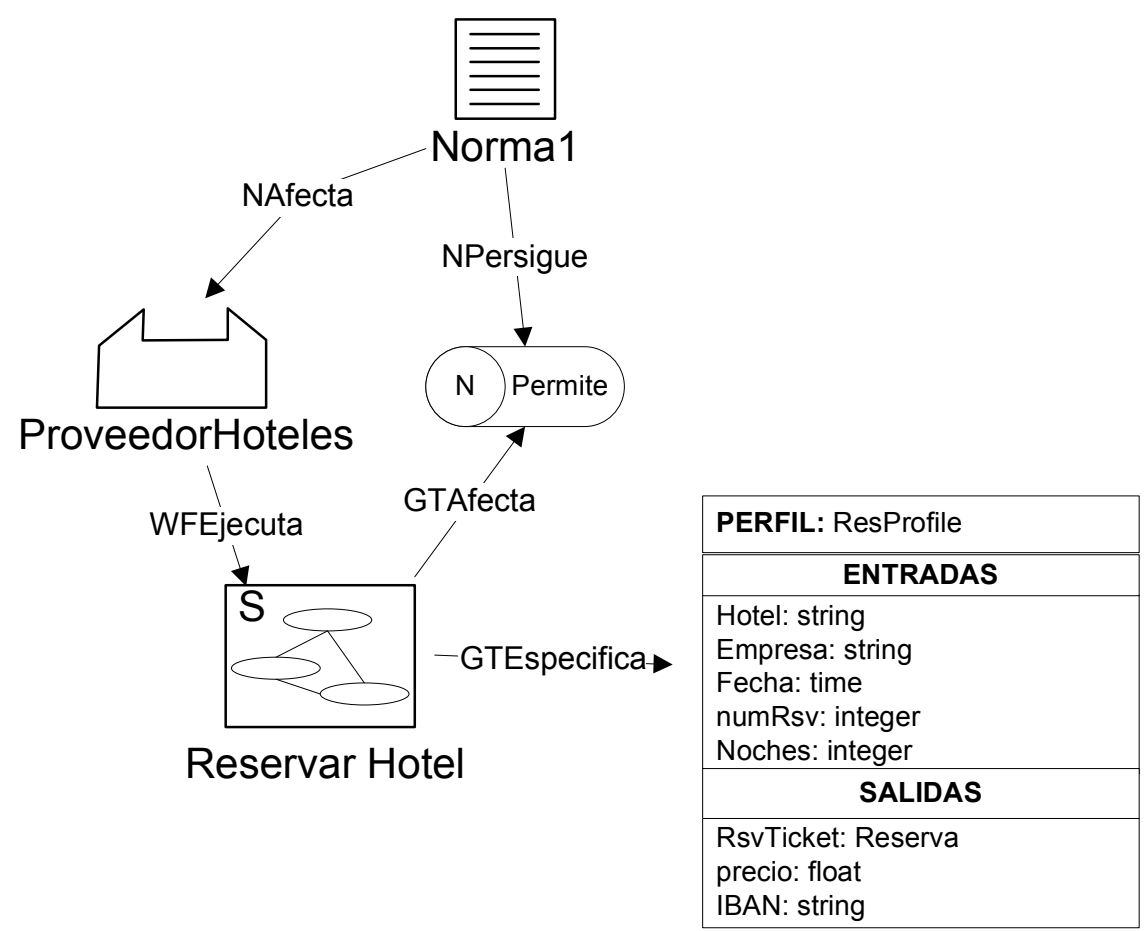

Figura 4.46: Diagrama de modelo normativo. Descripción de la norma 1. 


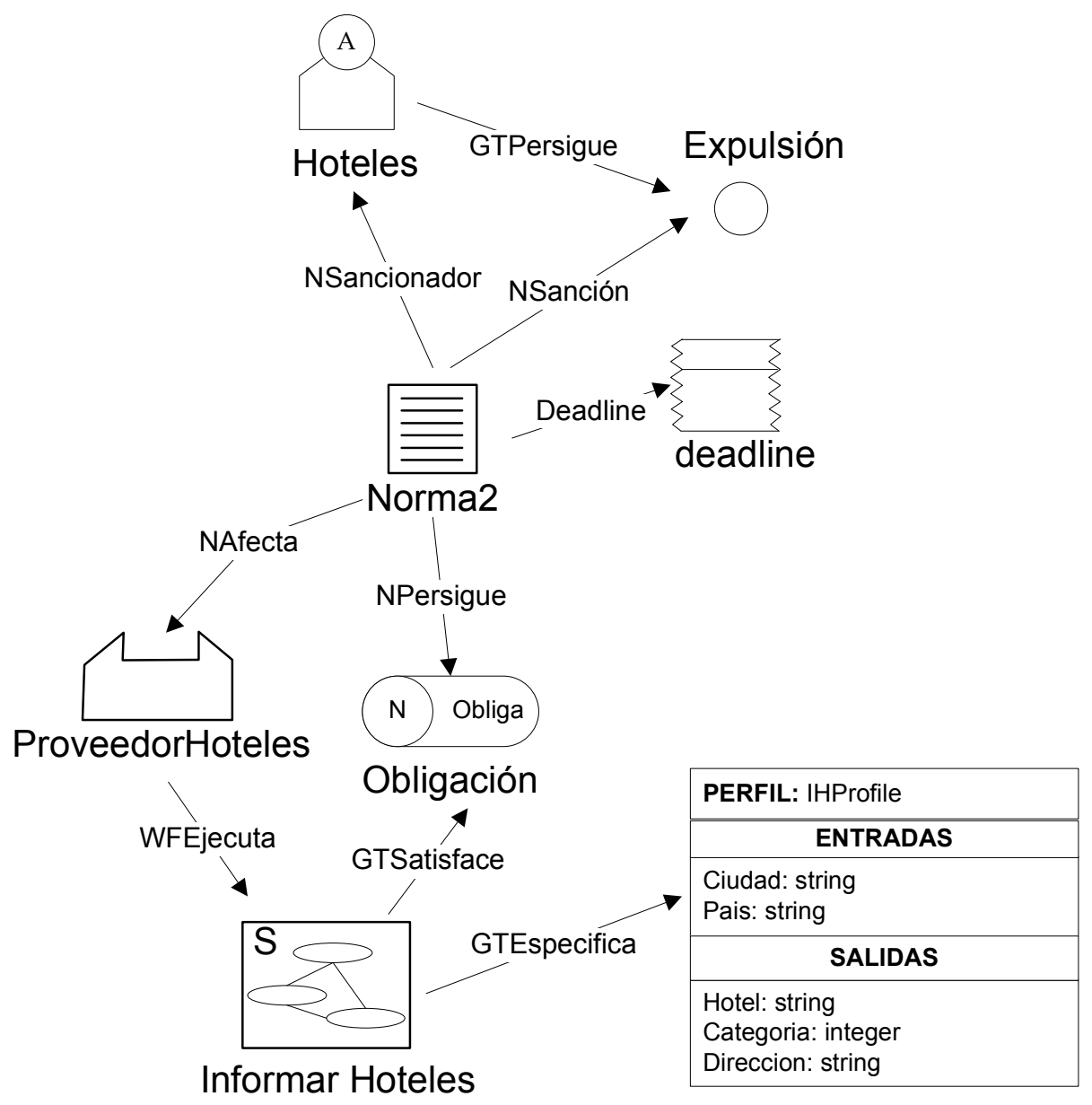

Figura 4.47: Diagrama de modelo normativo. Descripción de la norma 2. 


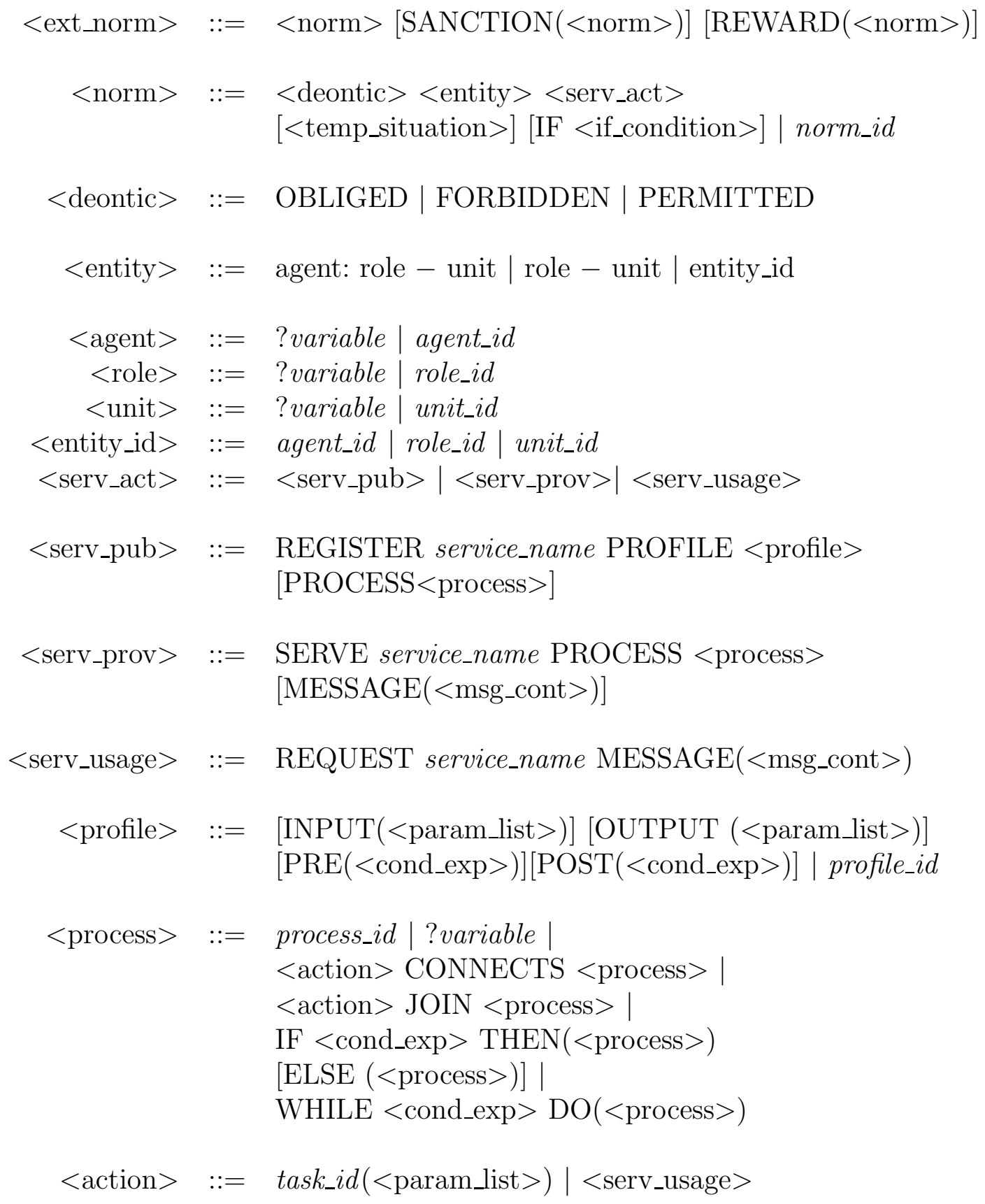

Tabla 4.1: Descripción BNF del lenguaje normativo. 


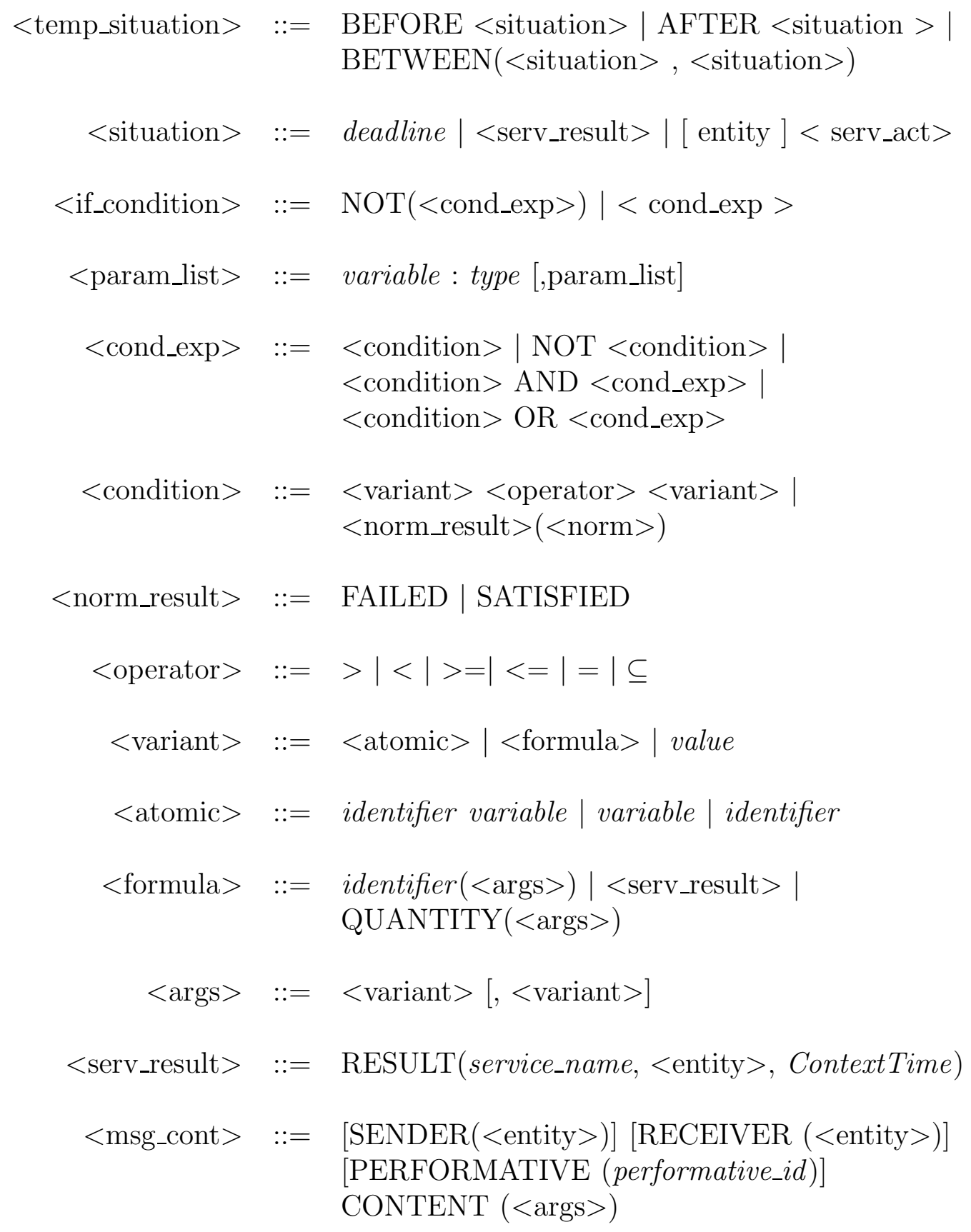

Tabla 4.2: Descripción BNF del lenguaje normativo. 


\subsection{Modelo organizativo de MAS}

Para cada tipo de organización de agentes analizado en el capítulo 2 hemos desarrollado determinados patrones de diseño que facilitan la instanciación de los meta-modelos de organización, de actividad y normativo correspondientes. De este modo, si se conoce cuál es la estructura organizativa que mejor se adapta al sistema a tratar, estos patrones establecen qué unidades se deben considerar, qué servicios se requieren, quién establece el control sobre las normas, etc.

Como ya comentamos anteriormente, proponemos un modelo de organización en base al concepto de Unidad Organizativa, que representa el conjunto mínimo de agentes que llevan a cabo unas actividades o funciones específicas y diferenciadas, siguiendo un patrón predefinido de cooperación y comunicación.

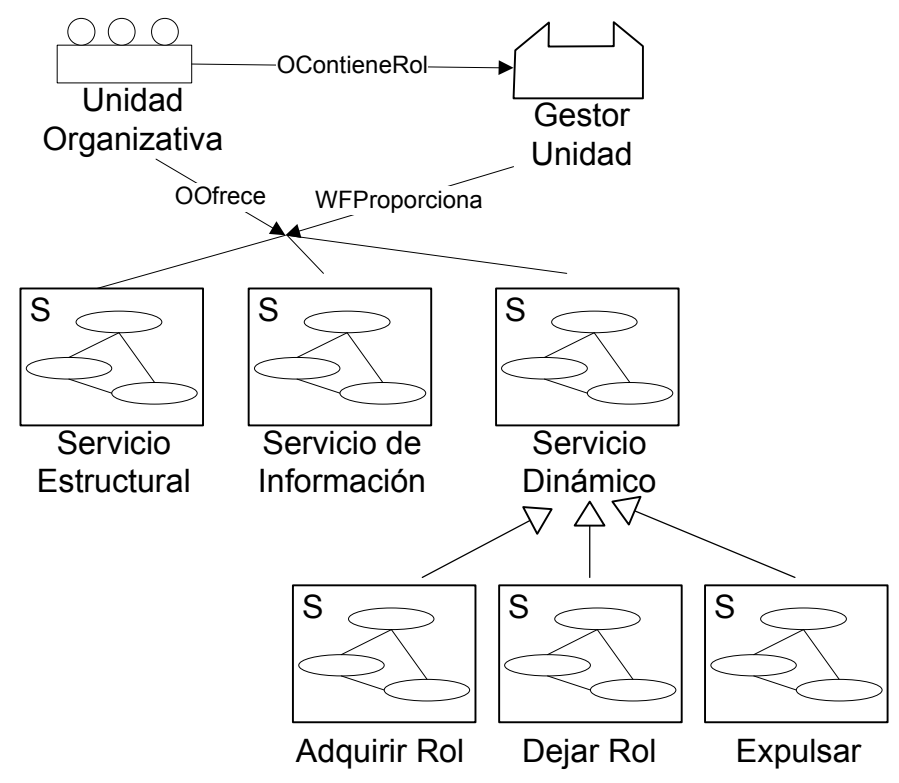

Figura 4.48: Patrón de diseño de la Unidad Organizativa

El patrón de diseño básico de una Unidad Organizativa (figura 4.48) especifica la vista dinámica del modelo de organización, detallando los servicios estructurales, de información y dinámicos que ofrece la unidad. En 
principio, estos servicios son proporcionados por el rol GestorUnidad, pero como se muestra en las siguientes secciones, según el tipo de estructura organizativa podrá convenir separar toda esta funcionalidad en uno o más roles.

A continuación, en la sección 4.6.1 se muestran los patrones de diseño definidos para las Unidades Organizativas básicas; mientras que en la sección 4.6.2 se describen los patrones correspondientes de las estructuras organizativas más complejas.

\subsubsection{Unidades Organizativas básicas}

Las Unidades Organizativas básicas que hemos identificado son (figura 4.49): jerarquía simple, equipo y estructura plana.

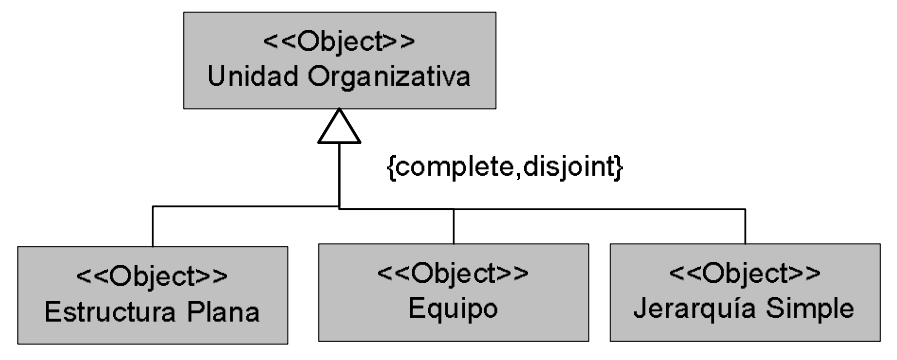

Figura 4.49: Unidad Organizativa

\section{Jerarquía simple}

La jerarquía simple (figura 4.50) está formada por un miembro supervisor (que tiene control sobre los otros miembros de la unidad, centraliza la toma de decisiones y coordina las tareas) y por varios miembros subordinados (que llevan a cabo las tareas básicas y se comunican entre sí a través del supervisor). Por tanto, todo está bajo la supervisión de un único miembro.

En la figura 4.51 se muestra el patrón de diseño del modelo de organización para la jerarquía simple, donde aparecen representados los dos tipos de roles que contiene (relación OContieneRol), así como las relaciones existentes entre ellos (relación AGOSupervisión y AGOInformación). 


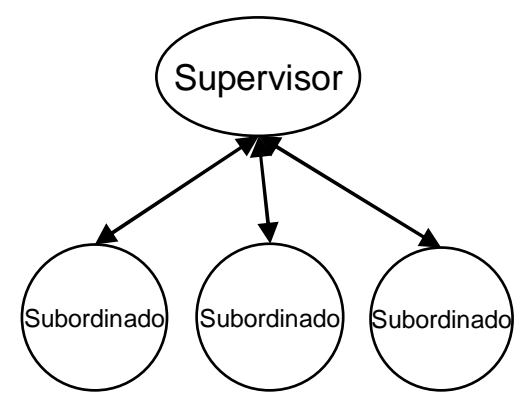

Figura 4.50: Esquema de una Jerarquía Simple.

Admitimos dos tipos de jerarquías: la jerarquía restrictiva, en la que los miembros subordinados no pueden comunicarse directamente entre sí, sino solamente con su supervisor, de modo que toda información que necesiten suministrarse debe ir siempre a través del supervisor, por lo que la relación AGOInformación no aparecería; y la jerarquía relajada, en la que se permite cierta comunicación directa entre los subordinados, pero solamente para enviarse información, sin que puedan mandarse órdenes (representada con la relación AGOInformación). Con la jerarquía relajada se reducen ciertos problemas de eficiencia que ocasiona el supervisor cuando actúa como cuello de botella del paso de la información.

Por otro lado, los roles supervisor y subordinado son asignados a entidades de tipo Agente o A-Agente respectivamente, como se indica en la figura 4.51. De este modo, un supervisor siempre será ejecutado por un agente, mientras que los subordinados serán representados por agentes concretos o por agrupaciones (unidades organizativas).

La relación AGOInformación entre el rol supervisor y la entidad AAgente (figura 4.51) indica que el rol supervisor puede contactar con otras unidades o entidades externas a la jerarquía, actuando así de representante o intermediario de su unidad hacia el exterior.

La estructura jerárquica permite implantar distintos métodos de coordinación que faciliten al supervisor el reparto de tareas y la asignación de recursos. En concreto, los métodos de Contract-Net, subastas y middle-agents son fácilmente aplicables en esta estructura. El rol supervisor se encarga de 


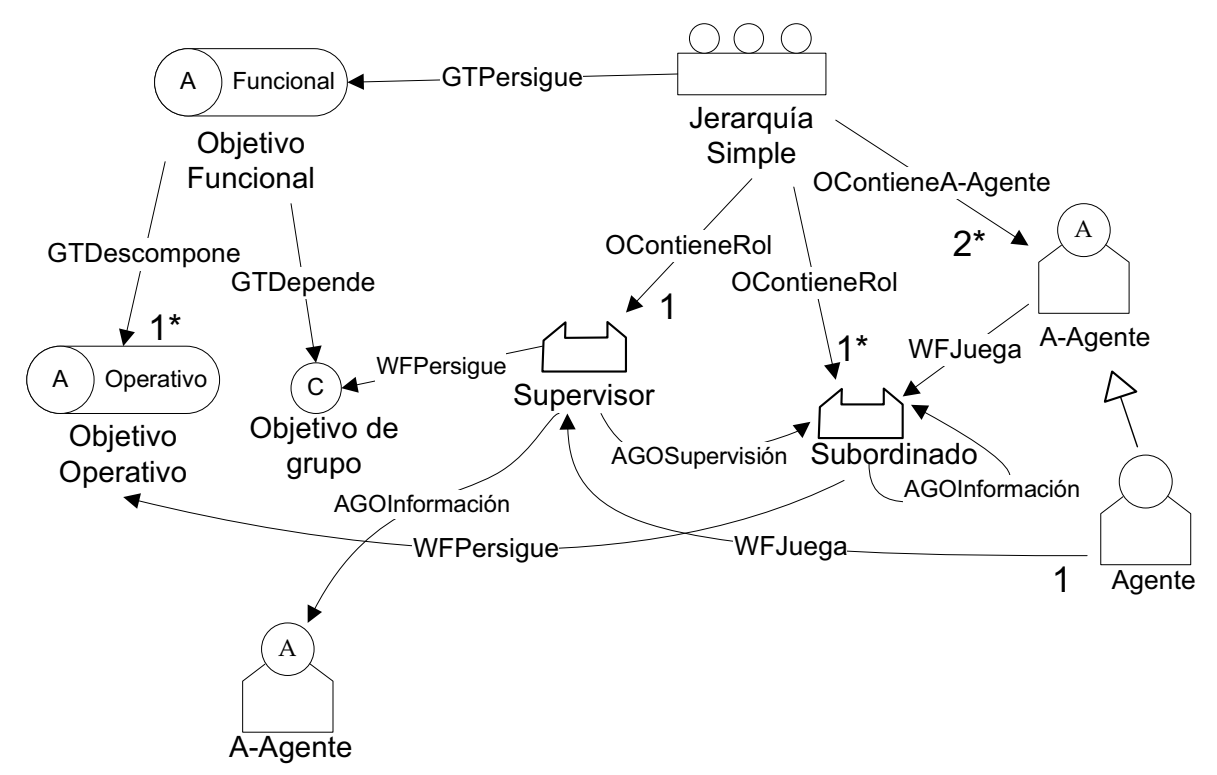

Figura 4.51: Patrón de diseño del modelo de organización de la Unidad Organizativa de tipo Jerarquía Simple.

perseguir el objetivo del grupo, estableciendo así el control y supervisión de la unidad, mientras que el rol subordinado se encarga de los objetivos operativos.

En la figura 4.52 se muestra el patrón de diseño del modelo de interacción. Así, el supervisor se encarga de iniciar las interacciones sobre sus subordinados.

Las normas de la unidad organizativa son controladas, recompensadas y/o sancionadas por el rol supervisor. En la figura 4.53 se muestra el patrón de diseño del modelo normativo para este tipo de unidad.

Las funciones concretas del rol supervisor se dividen en (figura 4.54) monitor de anomalías, gestor de recursos, coordinador de tareas y gestor de miembros. Todas estas funciones deben ser asignadas, en principio, a un único agente aunque en sistemas complejos se podrían repartir de forma exclusiva entre varios agentes.

Como gestor de miembros (figura 4.55) proporciona los servicios dinámicos de la unidad Adquirir Rol, Dejar Rol y Expulsar. La descripción de su 


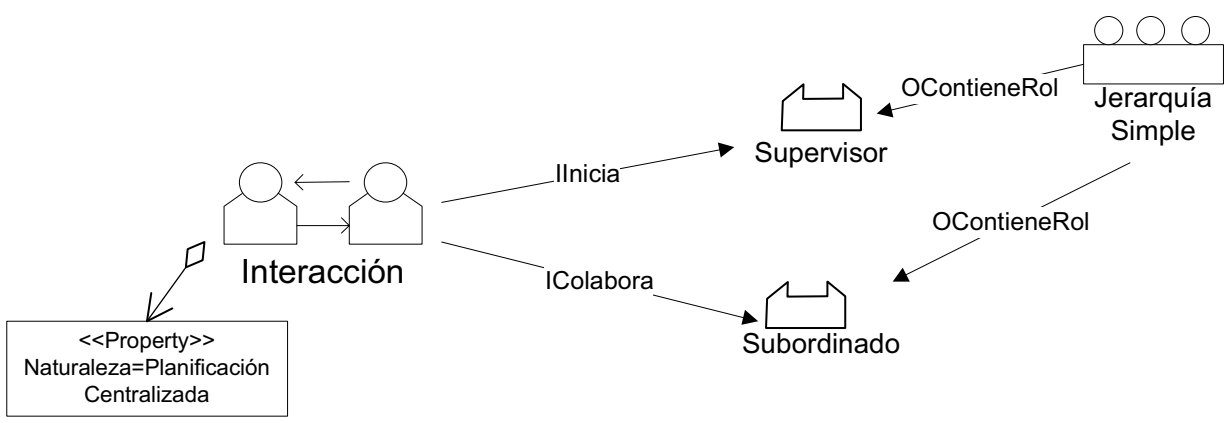

Figura 4.52: Patrón de diseño del modelo de interacción de la Jerarquía Simple.

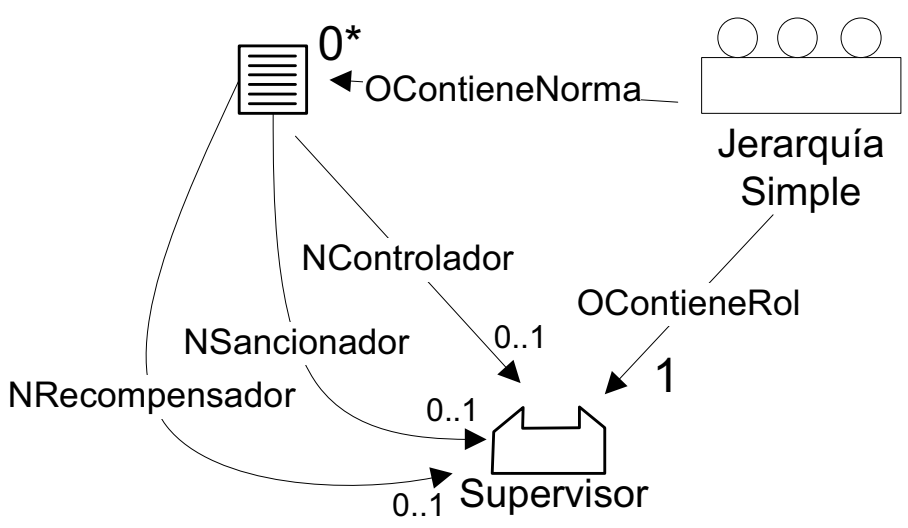

Figura 4.53: Patrón de diseño del modelo normativo de la Unidad Organizativa de tipo Jerarquía Simple.

funcionalidad y de los servicios que proporciona se realiza mediante el modelo de organización (vista dinámica). En la figura 4.55 se muestra el patrón de diseño de dicho modelo.

Como monitor de anomalías (figura 4.56), el supervisor se encarga de monitorizar las actividades de los roles subordinados y solicitar el servicio Expulsar en caso necesario. Como coordinador de tareas (figura 4.56) se encarga de crear objetivos operativos en los roles subordinados o bien invocar sus servicios, para así realizar una adecuada asignación de tareas. En ambos casos, el modelo de actividad debe reflejar los objetivos de grupo perseguidos por el monitor de anomalías, así como el proceso de asignación de las 


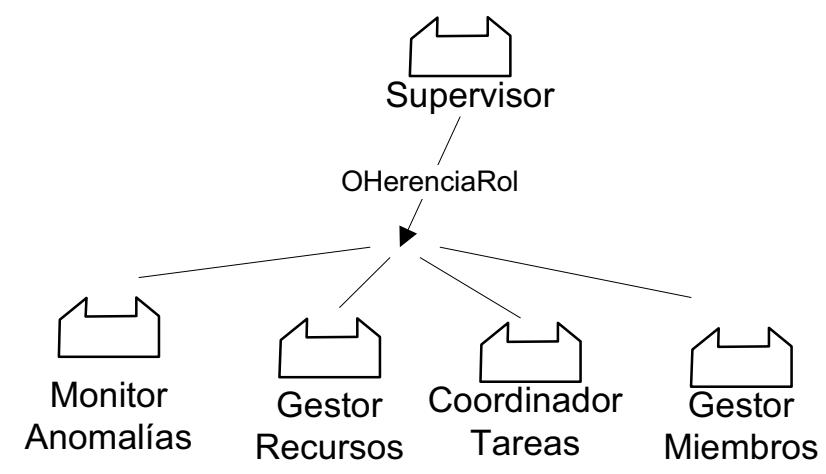

Figura 4.54: Refinamiento del rol supervisor.

taras o la invocación de servicios que realiza el rol coordinador de tareas. En la figura 4.56 se muestra el patrón de diseño del modelo de actividad para facilitar la utilización de estos dos roles.

Finalmente, como gestor de recursos (figura 4.57), el supervisor se encarga de acceder a los recursos y aplicaciones del sistema y de controlar su gestión, mediante la utilización de los puertos del entorno. En la figura 4.57 se muestra el patrón de diseño del modelo de entorno, según el cual el supervisor se encarga de gestionar los puertos de acceso a los recursos y aplicaciones de la jerarquía.

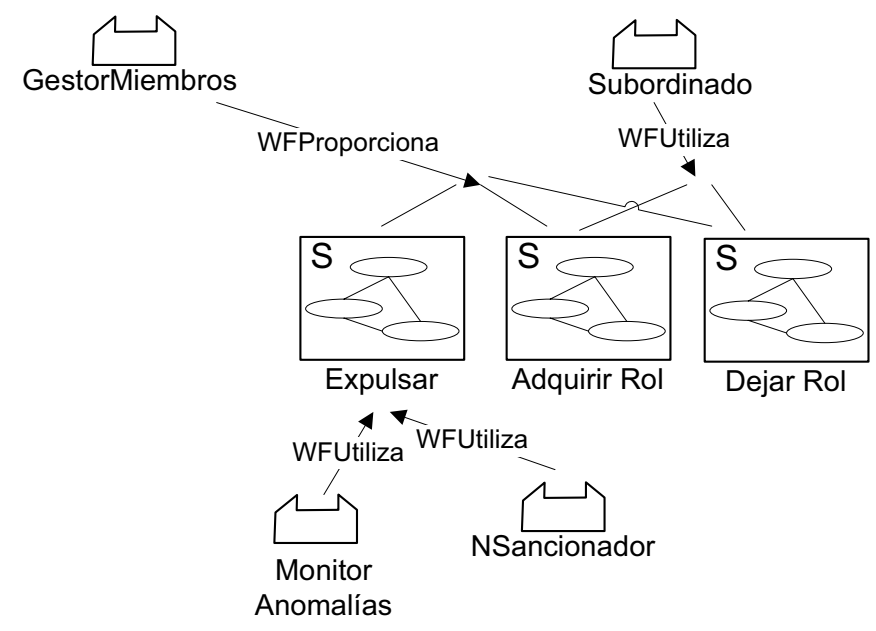

Figura 4.55: Patrón de diseño del modelo de organización (vista dinámica) de la Jerarquía Simple. 


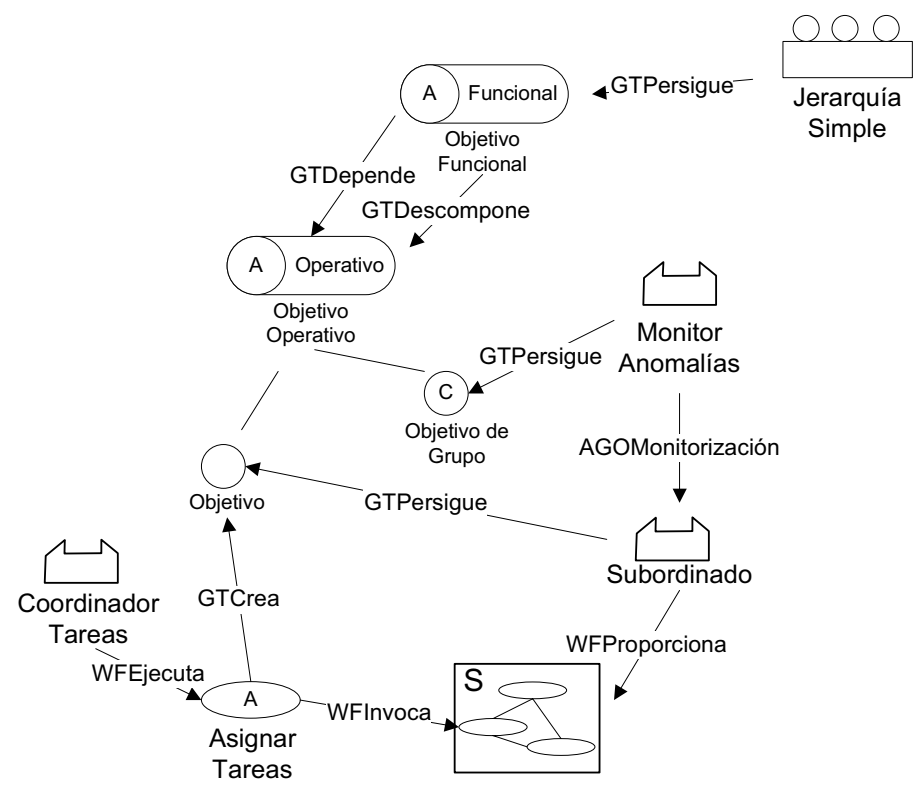

Figura 4.56: Patrón de diseño del modelo de actividad de la Jerarquía Simple.

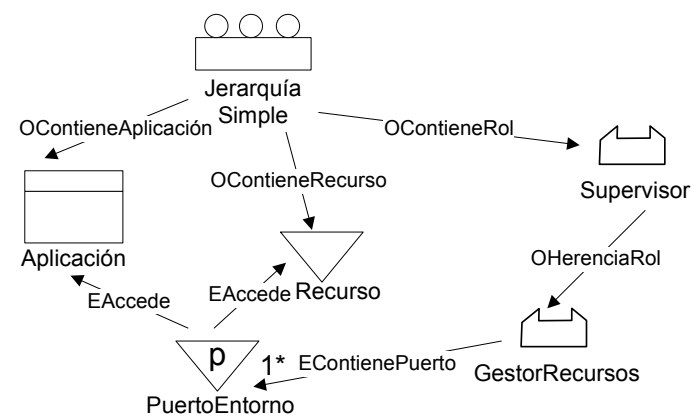

Figura 4.57: Patrón de diseño del modelo de entorno de la Jerarquía Simple. 


\section{Equipo}

El equipo (figura 4.58) está formado por agentes cooperativos que trabajan juntos para alcanzar un objetivo común y global, compartiendo su información y coordinándose a través de planes y decisiones aceptadas mutuamente. Estos agentes tratan de maximizar la utilidad del equipo, más que su utilidad individual.

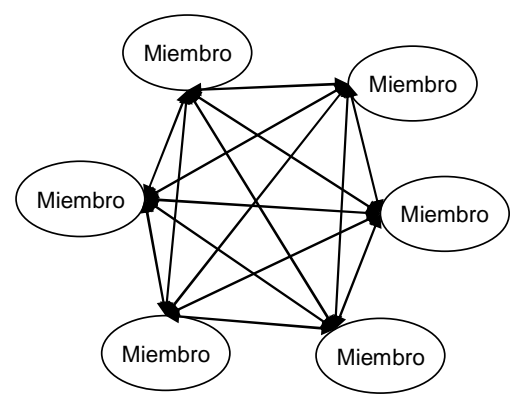

Figura 4.58: Esquema de una unidad organizativa de tipo Equipo.

En la figura 4.59 se muestra el patrón de diseño del modelo de organización del equipo. En él se distingue el rol miembro (relación OContieneRol), que equipara a todos los componentes del equipo entre sí; aunque en ocasiones también se emplea la figura del líder como coordinador principal y supervisor para gestionar la asignación de responsabilidades de los miembros y solucionar inconsistencias. Cualquier miembro del equipo podrá actuar como líder en un momento determinado, si así lo requiere el sistema. Además, el rol miembro es asignado a entidades de tipo A-Agente (relación WFJuega), de manera que se permite la recursión de equipos (equipos dentro de otros equipos).

Como hemos comentado antes, todos los miembros persiguen un objetivo común (entidad Objetivo de Grupo), que se corresponde con el objetivo funcional de la unidad organizativa o bien con una descomposición o dependencia del mismo. Además, cada agente concreto del equipo podrá perseguir uno o más objetivos derivados del objetivo de grupo común.

Por otro lado, los agentes mantienen una representación explícita del 


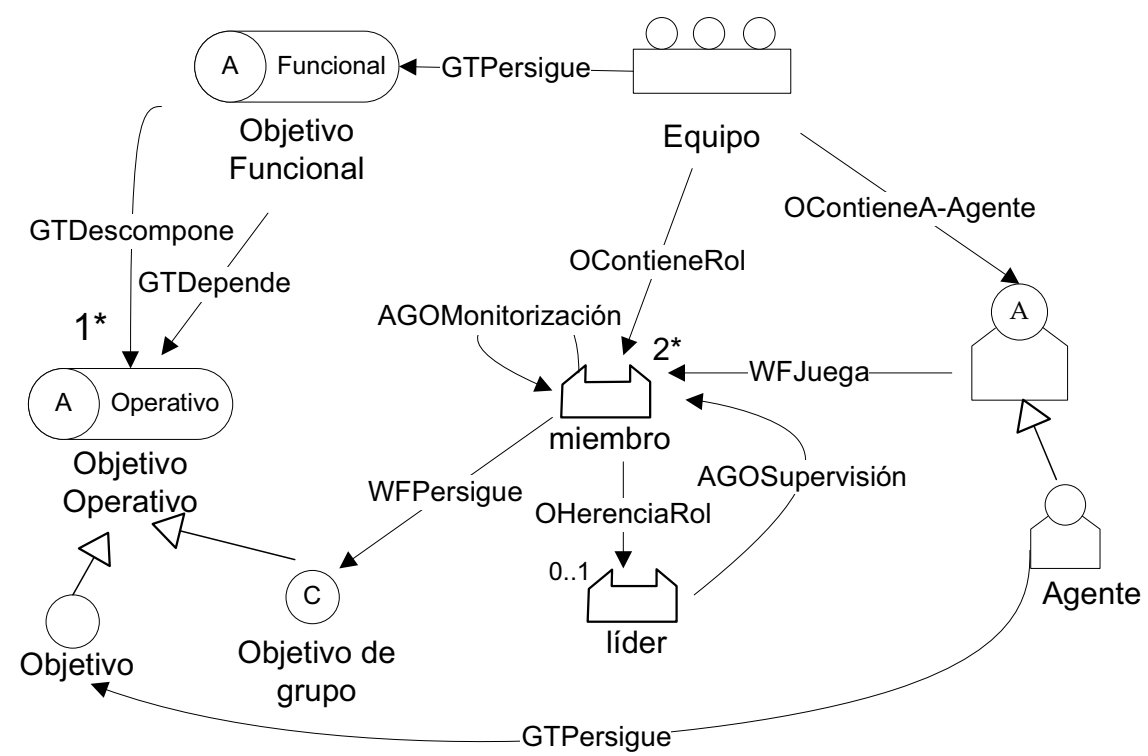

Figura 4.59: Patrón de diseño del modelo de organización de la Unidad Organizativa de tipo Equipo.

trabajo en grupo y del estado mental de grupo, mediante objetivos compartidos, creencias mutuas, planes a nivel de equipo, etc. De este modo pueden realizar un razonamiento explícito sobre el comportamiento a nivel de equipo. Esto queda representado en el patrón de diseño del modelo de agente (figura 4.60) mediante las relaciones ATieneEM y AContieneEM.

Los miembros del equipo comparten entre sí su información, a través de recursos contenidos en la unidad del equipo. En la figura 4.61 se muestra el patrón de diseño del modelo de entorno, donde se especifica el acceso al recurso compartido para la gestión de la información.

En un equipo, las tareas que se realizan pueden ser de varios tipos [Steiner, 1972][Steiner, 1976]:

- Disyuntiva: implica que un miembro del grupo podrá realizarla de forma efectiva si cuenta con los recursos y requisitos precisos. Por tanto, el equipo debe colaborar entre sí para realizar una adecuada asignación y compartición de recursos, para así lograr que al menos uno de sus miembros sea capaz de ejecutar la tarea. En este caso, existe 


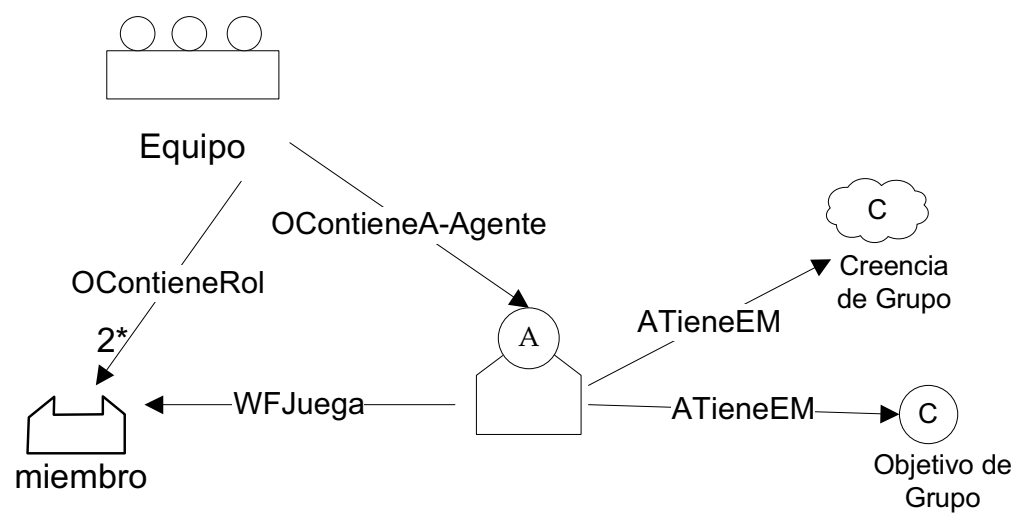

Figura 4.60: Patrón de diseño del modelo de agente de la Unidad Organizativa de tipo Equipo.

una interdependencia moderadamente elevada entre los miembros del equipo, pues aquellos que no pueden resolver la tarea por sí mismos dependen de los miembros que les proporcionen los recursos necesarios para cumplir con sus objetivos.

- Conjuntiva: el nivel de rendimiento del grupo depende de la contribución que aporte a la tarea el miembro menos capaz del equipo. Si un miembro no consigue cumplir con su cometido, entonces todo el equipo fallará.

- Aditiva: cada miembro contribuye al rendimiento del grupo en proporción a su capacidad, de modo que la suma de las capacidades de los miembros individuales del equipo es igual al rendimiento del mismo. En este caso, existe una interdependencia baja entre los miembros del equipo, pues no dependen unos de otros para realizar su propia tarea, aunque el rendimiento final obtenido por el equipo dependerá del esfuerzo que haya realizado cada miembro.

- Discrecional: existe una combinación de las capacidades de ciertos miembros del equipo que permite obtener un mejor rendimiento de la tarea. El equipo deberá determinar cuál es la combinación más adecuada que ofrezca un rendimiento óptimo. 


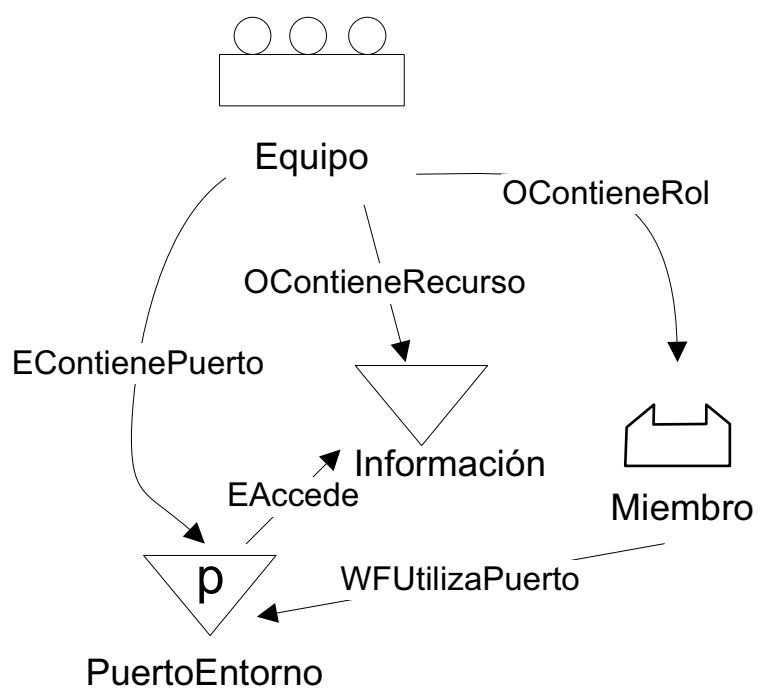

Figura 4.61: Patrón de diseño del modelo de entorno de la Unidad Organizativa de tipo Equipo.

La productividad del grupo depende, por tanto, del tipo de tareas a realizar. En el caso de tareas disyuntivas o conjuntivas, a los miembros se les asignan tareas y recursos distintos y existe una interdependencia elevada entre los miembros para repartirse de forma adecuada los recursos y coordinarse la ejecución de las tareas. Por tanto, cuanto mejor sea esa coordinación mayor será la productividad.

En el caso de tareas aditivas o discrecionales, la interdependencia entre los miembros es baja, pues no dependen tanto entre sí, sino más bien del esfuerzo de cada uno de ellos. Se debe potenciar aquí el rendimiento individual para obtener mayor productividad.

\section{Estructura plana}

La estructura plana representa una anarquía en la que no existe una estructura prefijada ni control de un miembro sobre otro. Por tanto no existe una jerarquía establecida, la coordinación se realiza a través de la adaptación mutua (negociación) entre los miembros y tiene un carácter flexible. 
En la figura 4.62 se muestra el patrón de diseño del modelo de organización de la estructura plana, que contiene al menos una entidad de tipo A-Agente (que representa a un único agente o bien a una agrupación); la cual persigue unos objetivos (relación GTPersigue) que son una descomposición o dependencia del objetivo funcional de la unidad. Además, los integrantes de la unidad pueden conocerse y contactar entre sí mediante la relación AGOInformación. No existe en este caso ningún rol preestablecido, al tratarse de una anarquía donde cada miembro funciona de forma independiente.

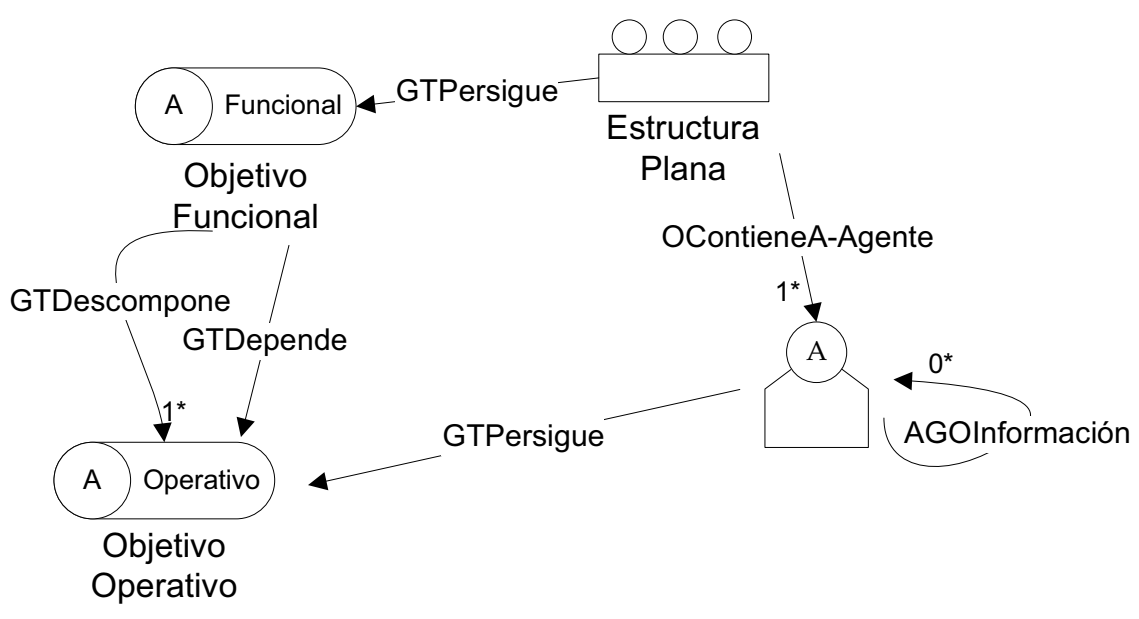

Figura 4.62: Patrón de diseño del modelo de organización para la unidad organizativa de tipo Estructura Plana.

Dada la poca estructuración de este tipo de unidad, no resulta práctico definir ningún tipo de patrón de los modelos de diseño del sistema multiagente, a excepción del modelo de organización indicado en la figura 4.62. Normalmente, esta unidad será utilizada como elemento de composición para sistemas organizativos más complejos, como por ejemplo la congregación (que se comentará más adelante).

La estructura plana resulta equivalente al concepto de grupo en la metodología AGR y también al concepto de escena de las instituciones electrónicas. Así, en AGR un grupo representa a un conjunto de agentes que comparten alguna característica común. Además, dos agentes se comunican sólo 
si pertenecen al mismo grupo, aunque un agente puede pertenecer a la vez a varios grupos. Por su parte, las escenas representan el lugar en el que se producen las interacciones entre los agentes.

\subsubsection{Estructuras Organizativas Complejas}

A partir de las unidades organizativas básicas se construyen estructuras organizativas más complejas, como la burocracia, la federación, la estructura matricial, la coalición y la congregación. A continuación describimos los patrones de diseño correspondientes a cada una de estas organizaciones.

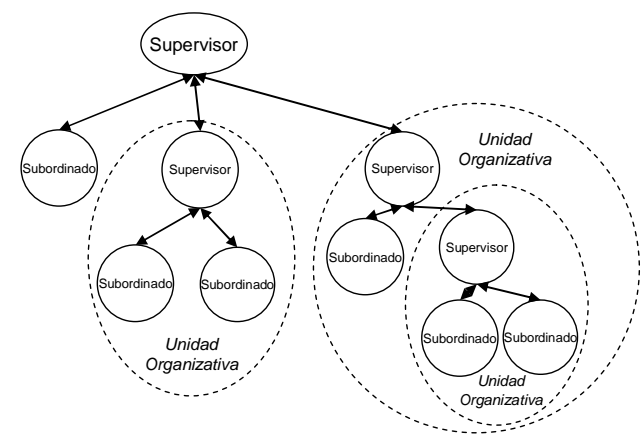

Figura 4.63: Esquema de una Burocracia.

\section{Burocracia}

La burocracia (figura 4.63) se representa como un conjunto de unidades organizativas de tipo jerárquico anidadas, de modo que una jerarquía simple de un nivel inferior actúa como subordinado de la jerarquía de nivel inmediatamente superior. El nivel más superior se encarga de controlar que se alcancen los objetivos de la organización. En los niveles inferiores se encuentran los agentes que realizan las tareas básicas. En los niveles intermedios, los supervisores se encargan de filtrar la información hacia arriba, tomar decisiones para las que tengan conocimiento suficiente y enviar órdenes a sus niveles inferiores. 


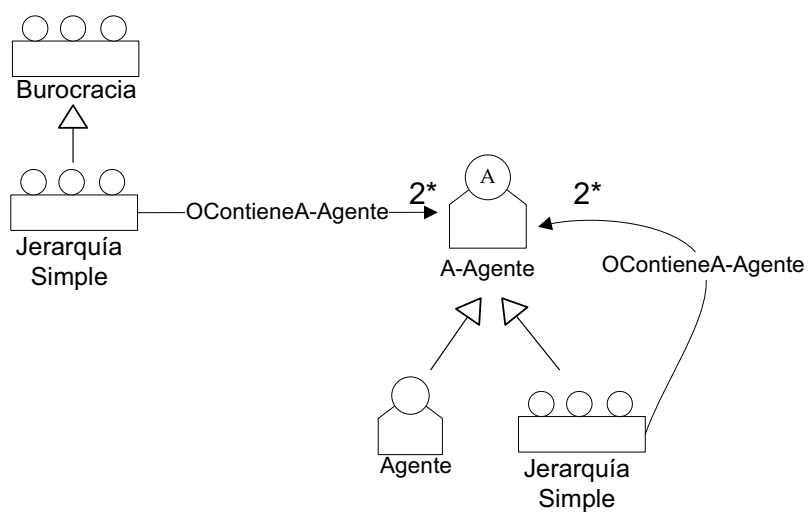

Figura 4.64: Patrón de diseño del modelo de organización para la burocracia

En la figura 4.64 se muestra el patrón de diseño del modelo de organización para la Burocracia.

En la burocracia funcional cada unidad está especializada en una determinada actividad, proporcionada a través de un único servicio (atómico o compuesto). Además, existe un flujo de trabajo establecido entre las distintas unidades, de modo que los clientes de la organización están obligados a contactar con diversas unidades, siguiendo cierto orden preestablecido, para así conseguir sus productos finales. En la figura 4.65 se muestra el patrón de diseño del modelo de actividad para la Burocracia Funcional.

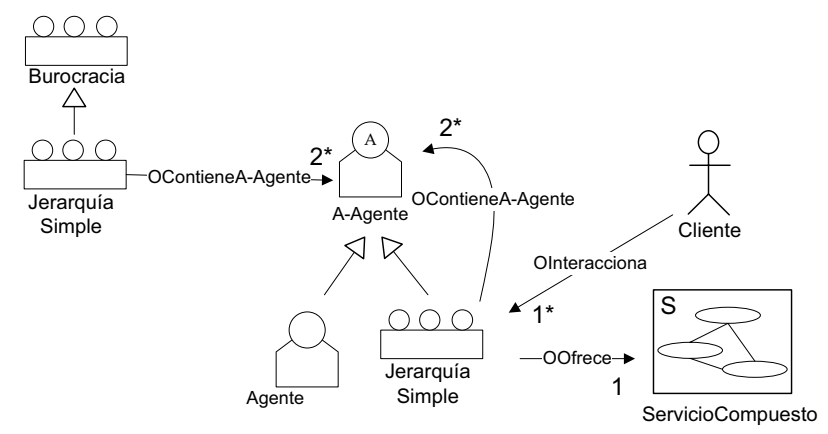

Figura 4.65: Patrón de diseño del modelo de actividad para la burocracia funcional

En la burocracia divisional cada unidad está especializada en un determinado producto o tipo de cliente, por lo que aglutina los distintos servicios 
requeridos por dicho cliente. En la figura 4.66 se muestra el patrón de diseño del modelo de actividad para la Burocracia Divisional.

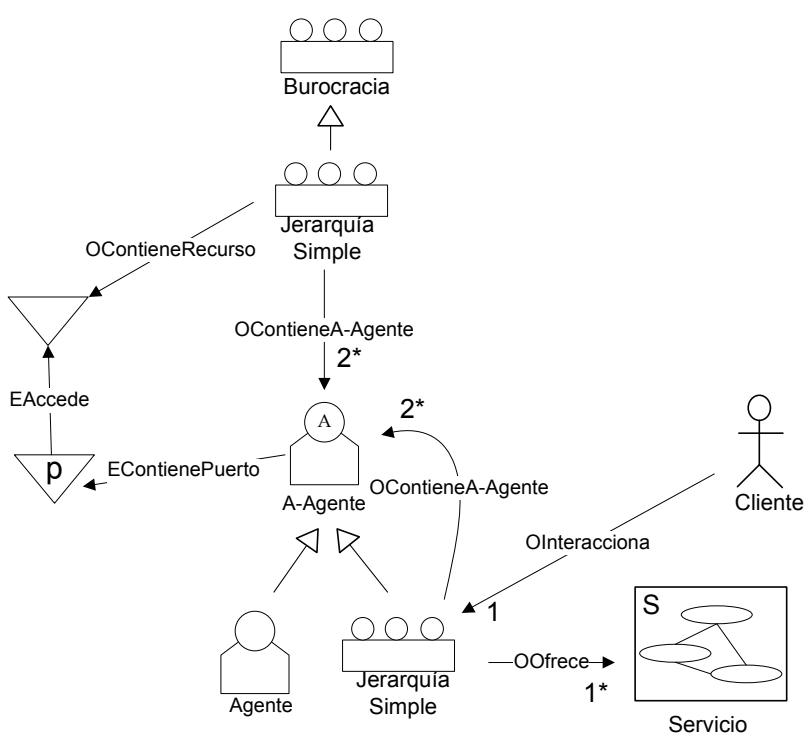

Figura 4.66: Patrón de diseño del modelo de organización para la burocracia divisional

La estructura en cadena se representa como una burocracia funcional donde las unidades están interconexionadas siguiendo un orden predefinido. Así, primero se precisa la funcionalidad de una unidad, después de otra unidad específica, etc. En nuestro modelo, esta estructura se modela como una burocracia con una única rama, de manera que el supervisor de cada unidad actúa también como subordinado del nivel anterior. De este modo se encarga de realizar las tareas de una actividad determinada y solicita la realización de las tareas de la actividad siguiente, gestionando también su control.

\section{Federación}

Las federaciones son agrupaciones de agentes en las que existe un delegado o intermediario que representa al grupo, el cual se encarga de recibir los mensajes de los miembros de su grupo (como descripción de habilidades, 
solicitud de tareas, información de estado, datos a nivel de aplicación, etc.) y recibir o enviar información a los intermediarios de otras federaciones (por ejemplo, solicitud de tareas, notificación de habilidades, datos, etc.). Normalmente se implementa mediante brokers, facilitadores, monitores, etc.

Dentro de la federación, los miembros del grupo interaccionan principalmente con el delegado y, en muchas ocasiones, no conocen la presencia del resto de miembros de su grupo, solamente la de su delegado.

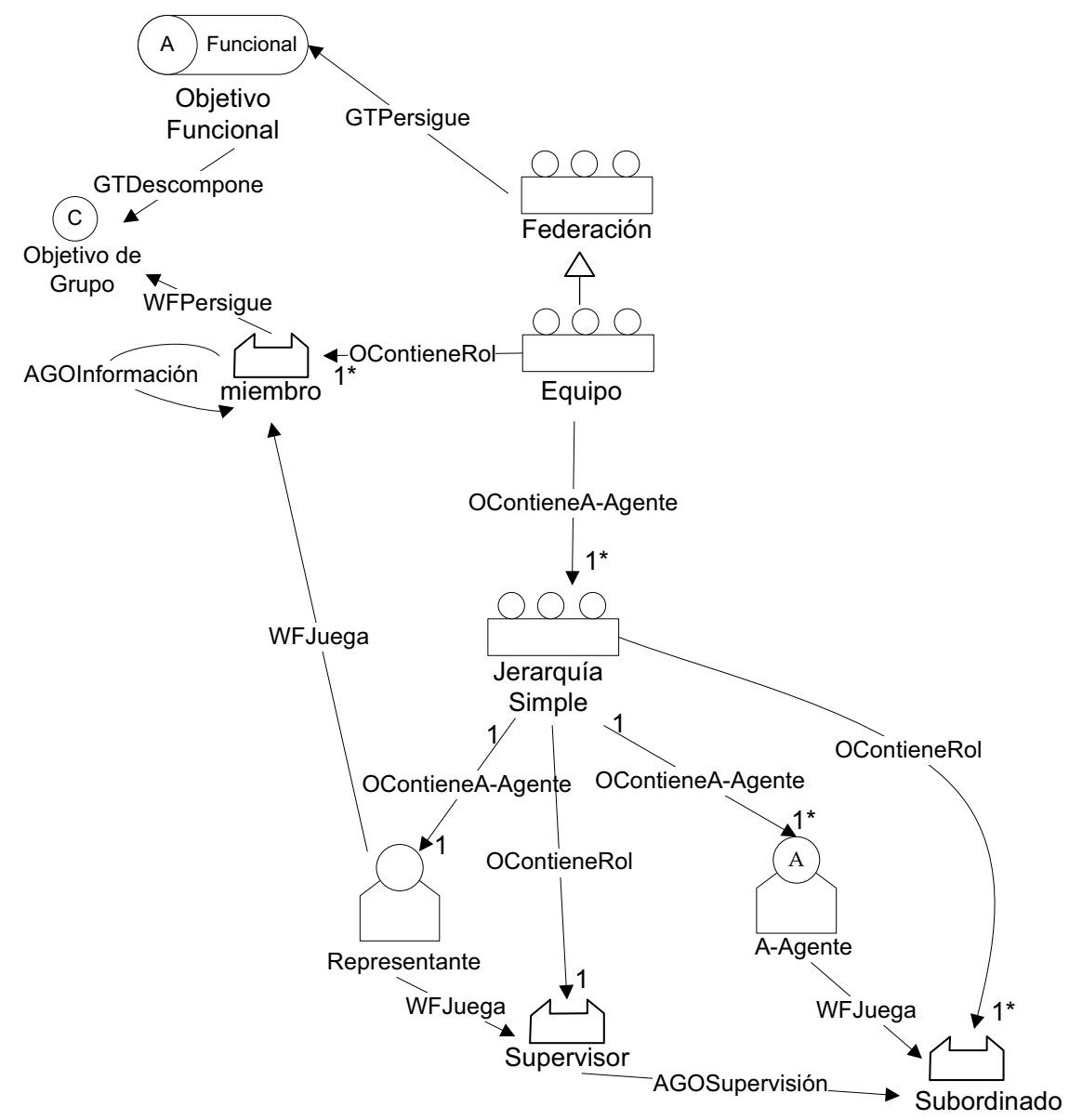

Figura 4.67: Patrón de diseño del modelo de organización de una Federación.

En la figura 4.67 se muestra el patrón de diseño del modelo de organización para la Federación, donde existe una unidad inicial de tipo Equipo, en la que se integran las distintas federaciones, implementadas como Jerarquías 
donde el representante juega el rol de supervisor, así como el rol miembro de la unidad Equipo; mientras que los integrantes federados actúan como subordinados. Además, cada agente solamente pertenece a una Jerarquía, es decir, a una única agrupación federada. Por otro lado, a través de la unidad Equipo, los representantes se comunican entre sí (relación AGOInformación), sin monitorizarse.

\section{Estructura matricial}

La estructura matricial combina los dos tipos principales de burocracia: la funcional y la divisional. De este modo, en la estructura matricial se reintegran los especialistas funcionales en las distintas líneas de producto, ubicaciones o clientes.

En los sistemas multiagente, la estructura matricial implica que las capacidades del agente estén compartidas, de modo que sean capaces de realizar las tareas solicitadas por sus dos (o más) jefes, debiendo integrar mecanismos de categorización de compromisos para poder resolver los conflictos locales que le surjan; así como mecanismos para promocionar los conflictos a un nivel superior donde se resuelvan.

En la figura 4.68 se muestra el patrón de diseño del modelo de organización de la estructura matricial. Está formada por tantas unidades organizativas de tipo jerarquía simple como objetivos funcionales existan; y por un equipo compuesto por los supervisores de dichas jerarquías.

Además, todo agente subordinado está obligado a pertenecer al menos a dos unidades organizativas de tipo jerarquía simple, una de ellas con supervisor encargado de los aspectos funcionales y otra con un supervisor encargado de los aspectos divisionales.

\section{Coalición}

Una coalición es una agrupación temporal de agentes que acuerdan cooperar entre sí para alcanzar un objetivo común o intercambiar el cumplimiento de sus propios objetivos. 


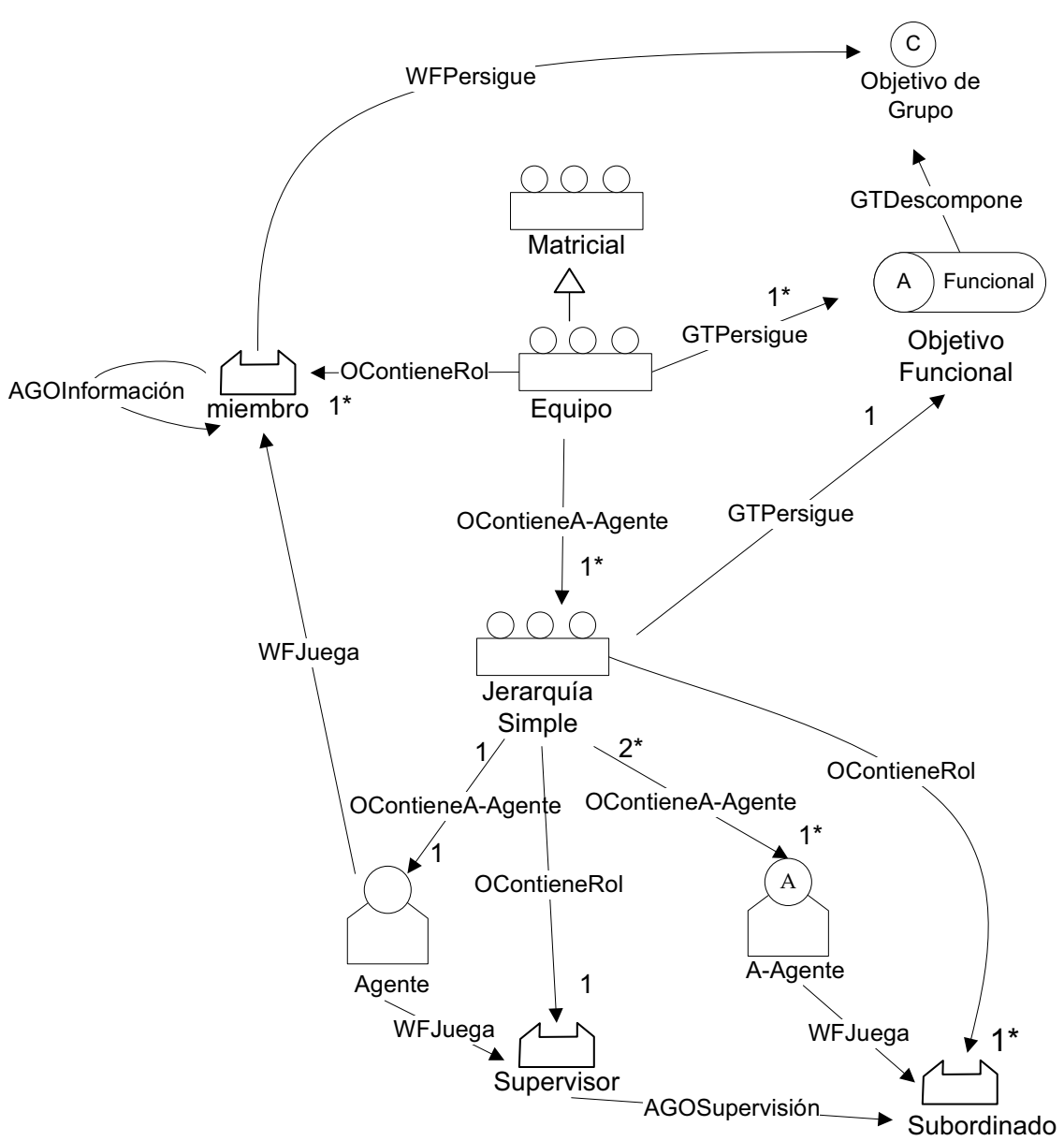

Figura 4.68: Patrón de diseño del modelo de organización de de la estructura matricial.

En la figura 4.69 se muestra el patrón de diseño del modelo de organización de la coalición, representada mediante la formación dinámica de unidades organizativas de tipo equipo, que trabajan para la consecución de un objetivo concreto y la realización de una tarea asociada a dicho objetivo.

Los agentes que forman parte de la coalición están inicialmente en una unidad organizativa de tipo estructura plana y, conforme se forman los equipos dinámicos, deciden si participar o no en ellos, solicitando en ese caso el rol miembro del equipo, haciendo uso del servicio Adquirir Rol. 


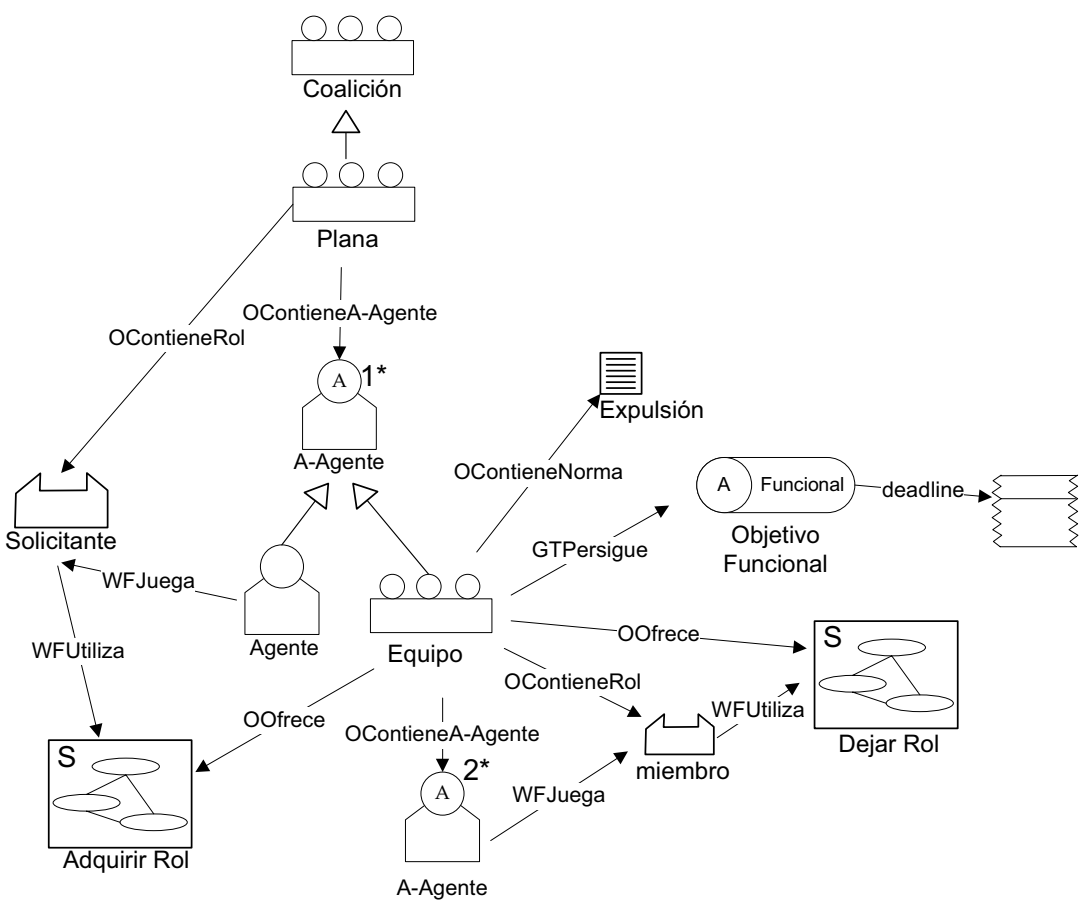

Figura 4.69: Patrón de diseño del modelo de organización de una Coalición.

La norma Expulsión implica que cuando se cumpla el deadline del objetivo funcional perseguido por el equipo, entonces dicho equipo debe disolverse, expulsándose de él a todos sus miembros.

\section{Congregación}

Una congregación representa a una agrupación de agentes que desean interaccionar o colaborar entre sí mediante asociaciones para largo plazo, en las que se asume que los agentes participarán durante largo tiempo en el sistema y que necesitarán interacciones repetitivas y productivas.

En la figura 4.70 se muestra el patrón de diseño del modelo de organización de la congregación, el cual se compone de diversas unidades organizativas, inicialmente de tipo estructura plana, que se irán creando de forma dinámica. Estas estructuras pasarán a ser de tipo equipo o jerárquico según la evolución de las condiciones del entorno. 


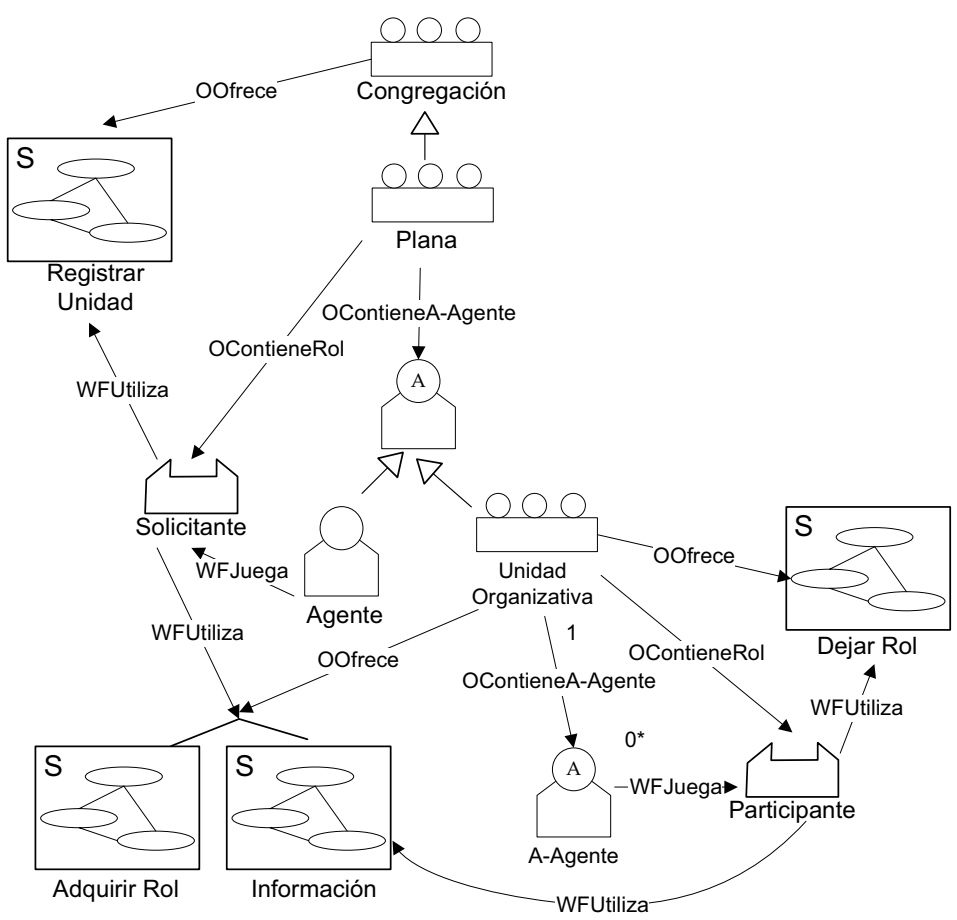

Figura 4.70: Patrón de diseño del modelo de organización de la congregación

En la figura 4.71 se muestra el modelo de interacción de la congregación, según el cual las interacciones de los agentes se realizan dentro de cada unidad organizativa.

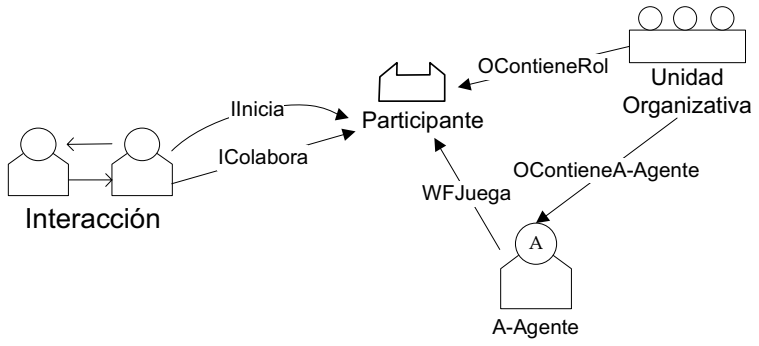

Figura 4.71: Modelo de interacción de la congregación. 


\subsection{Conclusiones}

En este capítulo se ha propuesto un Modelo de Organización que permite describir la estructura, funcionalidad, normalización, dinamicidad y entorno de las organizaciones. Para ello, se han extendido los meta-modelos de la metodología de ANEMONA, haciendo uso principalmente de los conceptos de unidad organizativa, servicio, entorno y norma.

Estos conceptos se han tomado tanto de propuestas de organizaciones humanas como de trabajos del área de los sistemas multiagente y de la arquitectura orientada a servicios, integrándose aquí en el marco del modelado de organizaciones. Además, empleando esos conceptos se ha definido una ontología de organización con la cual describir la estructura de las unidades del sistema, sus servicios y normas.

En nuestra propuesta, el modelado de organizaciones consta de seis meta-modelos: de organización, de actividad, de interacción, de entorno, de agente y normativo.

- El meta-modelo de organización describe las unidades organizativas existentes en el sistema, su estructura, entidades que contienen, roles que juegan, así como los servicios que ofrecen y requieren.

Las extensiones realizadas sobre el meta-modelo de organización de ANEMONA son:

- Redefinición del concepto de A-Agente de ANEMONA, empleando la entidad Unidad Organizativa, para así representar no sólo las agrupaciones de los agentes, sino también su estructura, funcionalidad, normalización e interacción con su entorno.

- Actualización de la vista estructural: se integra el concepto de Unidad Organizativa, como entidad que hereda del concepto de AAgente, redefiniendo sus relaciones respecto al entorno y a sus miembros; se incluyen propiedades de cardinalidad sobre los roles, así como relaciones de herencia; y se incluye la relación entre la Unidad Organizativa y sus normas. 
- Actualización de la vista funcional: se incluye la descripción de la misión del sistema y se redefine la funcionalidad del sistema, integrando el concepto de servicio.

- Inclusión de la misión: se definen los objetivos globales del sistema y su interacción con los grupos de interés.

- Actualización de la funcionalidad externa: se relaciona a la Unidad Organizativa con el conjunto de servicios que ofrece hacia afuera y con los servicios que requiere o necesita de otras entidades (especialmente de sus miembros). Además, se incluye la descripción de roles encargados de proporcionar o bien utilizar cada uno de los servicios definidos.

- Actualización de la funcionalidad interna: se describe la responsabilidad de un A-Agente (agente o Unidad Organizativa) sobre los servicios proporcionados por el rol que adopta.

- Actualización de la vista social: se redefinen las relaciones sociales entre los agentes, estableciéndose tres tipos de relación (supervisión, monitorización e información).

- Inclusión de la vista dinámica: se incluye esta nueva vista, donde se han definido un conjunto de patrones y servicios para facilitar la modificación de la estructura y normativa de la organización, gestionar la entrada y salida dinámica de los agentes y su adopción de roles, así como proporcionar información sobre los elementos y componentes de la organización en cada momento.

- El meta-modelo de actividad especifica los detalles concretos de los servicios, indicando su perfil y la secuencia de tareas que comprende, así como la composición de servicios. También describe la funcionalidad de los agentes y de las unidades organizativas en base a servicios, tareas y objetivos.

Las extensiones realizadas sobre el meta-modelo de tareas y objetivos de ANEMONA son: 
- Integración del concepto de servicio: se añade la entidad servicio como una especialización del flujo de tareas, representando aquella funcionalidad que debe ser publicitada en algún directorio de servicios.

- Inclusión de la entidad PuertoServicio: se describen así las condiciones de activación del servicio, sus parámetros de entrada, salida y sus efectos sobre el entorno.

- Actualización de la descomposición de objetivos: se redefine el proceso de descomposición de los objetivos para correlacionarlo con los conceptos de la Teoría de Organización. Se distingue entre misión (objetivos globales del sistema), objetivos funcionales (asociados a las unidades organizativas) y objetivos operativos (objetivos más concretos, asociados a agentes).

- Actualización de la descomposición de tareas: se incluye la invocación de servicios por parte de otros servicios, para así reflejar la composición de servicios.

- Actualización de la descripción del flujo de trabajo: se incluyen nuevas relaciones entre las tareas, para permitir la composición de servicios con relaciones concurrentes o bien relaciones iterativas.

- El meta-modelo de interacción define las interacciones del sistema, provocadas bien por la activación de objetivos o por la utilización de servicios.

Las extensiones realizadas sobre el meta-modelo de interacción de ANEMONA son:

- Integración del concepto Servicio: se redefine el proceso de activación de las interacciones, para que se produzcan no sólo por la activación de objetivos, sino también por la utilización de los servicios.

- Integración del concepto PuertoServicio: con dicha entidad se representa tanto la publicación del servicio en un directorio de servicios, su utilización concreta, así como la necesidad de sincronización 
entre las entidades que utilizan y proporcionan ese servicio.

- El meta-modelo del entorno especifica las actuaciones y percepciones de los agentes, así como el acceso a los servicios a través de sus puertos. También define los recursos y aplicaciones del sistema que pertenecen o son percibidas por los agentes de la organización.

Las extensiones realizadas sobre el meta-modelo de interacción de ANEMONA son:

- Integración del concepto producto: se representa de forma combinada a los recursos y aplicaciones del sistema, vistos como resultados tangibles de la organización.

- Integración del concepto Puerto: se añade el concepto de puerto como punto de conexión entre las entidades y su entorno, en el que se definen los permisos de actuación sobre los elementos del entorno, así como las entidades que controlan dichos permisos.

- Inclusión de la vista de acceso a puertos: se describe la percepción y actuación sobre los elementos del entorno, así como la utilización de los puertos de acceso a servicios.

- Actualización de las características de los recursos y aplicaciones: se añade la características de granularidad de la capacidad del recurso y se redefine la relación entre los recursos o aplicaciones y quienes los contienen (en este caso, las unidades organizativas).

- El meta-modelo de agente describe los agentes concretos, sus responsabilidades, objetivos y funcionalidad, así como las normas que conocen y los mecanismos de razonamiento que utilizan, que permiten la evolución de sus comportamientos.

Las extensiones realizadas sobre el meta-modelo de interacción de ANEMONA son:

- Integración del concepto Servicio: se definen como servicios todos aquellos flujos de trabajo del agente que impliquen la necesidad de 
interaccionar con otras entidades no conocidas a priori y, por tanto, se requiera publicitar esa funcionalidad.

- Inclusión de las normas del agente: se han extendido las entidades mentales de información para incluir la descripción de las normas que procesa un agente, asumiendo que se trata de un agente normativo.

- Inclusión de los objetivos normativos: se han extendido los AObjetivos para así expresar objetivos de tipo prohibición, permiso u obligación.

- Actualización de la funcionalidad del agente: se ha extendido la responsabilidad de ejecución de las tareas del agente, atendiendo también a su capacidad para ofrecer servicios a otros agentes.

- Actualización de los objetivos del agente: se ha redefinido el tipo de objetivos que persigue un A-Agente, de modo que un Agente persigue objetivos operativos (simples o de grupo), mientras que una unidad organizativa persigue objetivos funcionales o misiones.

- El meta-modelo normativo detalla las normas de la organización, los objetivos normativos a seguir por los agentes y las sanciones y recompensas que afectan a dichas normas.

Este meta-modelo es completamente nuevo respecto a los meta-modelos de ANEMONA, en los que no se tenían en cuenta las normas de la sociedad.

Los meta-modelos definidos en el Modelo de Organización se aplican en el diseño de los distintos diagramas del modelo de sistema multiagente requeridos en la guía metodológica para el diseño de MAS abiertos que se propone en el siguiente capítulo, basada en el diseño de organizaciones humanas.

Por otro lado, se ha propuesto un conjunto de patrones de diseño de distintos tipos de estructuras de organización, que permiten comprender mejor el tipo de relaciones existentes entre las entidades, en función de la 
topología de la organización. Estos patrones son también empleados en la guía metodológica que se explica en el siguiente capítulo. 


\section{Capítulo 5}

\section{Guía Metodológica}

En el presente capítulo se propone GORMAS ( $\boldsymbol{G}$ uidelines for $\boldsymbol{O} \boldsymbol{R}$ ganization-based $\boldsymbol{M}$ ultiAgent $\boldsymbol{S}$ ystems), una guía metodológica o secuencia-guía para el diseño de sistemas multiagente abiertos desde la perspectiva de las organizaciones humanas. Para ello se ha adaptado una guía específica de diseño de organizaciones humanas, transformando de forma apropiada cada una de sus fases al área de los sistemas multiagente. Además, se hace uso de los meta-modelos definidos en el capítulo anterior para describir los resultados del análisis y diseño de la organización que proporciona la guía.

\subsection{Introducción}

Atendiendo a los requisitos de las organizaciones, hemos desarrollado una guía metodológica o secuencia-guía, denominada GORMAS, en la que se aborda el diseño de sistemas multiagente desde la perspectiva de las organizaciones humanas. Esta guía metodológica se basa en una guía específica de diseño de organizaciones humanas, que consta de diversas fases dentro del análisis y diseño de la organización. Dichas fases han sido transformadas de forma apropiada al área de los sistemas multiagente, para así captar todos los requisitos del diseño de una organización desde la perspectiva de los agentes. La secuencia-guía propuesta puede utilizarse de forma independiente para el análisis y diseño del sistema, o bien puede ser integrada en 
muchos de los métodos de desarrollo de sistemas multiagente vistos en el capítulo 3, para así proporcionarles la perspectiva de las organizaciones y la orientación de sistema abierto.

Con el objeto de ilustrar cada una de las fases de la secuencia-guía propuesta, se ha escogido como caso de estudio un sistema de información personalizada, basado en el ejemplo de experimentación de la metodología INGENIAS [Gomez, 2002]. En dicho sistema la información se agrupa en temas de interés y los usuarios pueden proporcionar nueva información, recibir aquella que es de su interés, clasificarla y/o evaluarla, para así mejorar la calidad de la información del sistema. Cada usuario podrá contactar con el sistema para recibir información puntual de un tema determinado; o bien suscribirse a dicho tema y así recibir información periódica. En dicho caso, pasará a ser miembro del sistema, pudiendo añadir nueva información al mismo. Además, un miembro podrá opcionalmente evaluar la información incluida por otros, para determinar si es relevante o no, participando en la mejora de la calidad. Finalmente, podrá opcionalmente actuar como examinador de los nuevos miembros, decidiendo sobre su proceso de admisión en la organización.

Se pretende que el sistema a modelar ofrezca características de sistema abierto, de modo que se controle a través de las normas y los procesos de admisión quiénes ofrecen o bien utilizan la funcionalidad del sistema; y bajo qué roles actúan.

Cada una de las fases de la secuencia-guía desarrollada se ha aplicado al ejemplo aquí comentado, a fin de facilitar la comprensión de las mismas y de mostrar de una manera más adecuada los diferentes documentos y diagramas de modelos que se obtienen.

La estructura de este capítulo es la siguiente. En la sección 5.2 se describen las guías de diseño de organizaciones humanas más representativas que existen y se detalla la guía concreta en la que nos hemos basado para nuestro trabajo. En la sección 5.3 se definen las ocho fases que comprende la secuencia-guía propuesta. Posteriormente, desde la sección 5.4 hasta la 5.11 
se explica con detalle cada una de las fases de la secuencia-guía, describiendo los pasos que cubren, las tareas que implican realizar, los documentos que se generan, así como las diferentes plantillas que se proporcionan en la guía para facilitar el proceso de análisis y diseño del sistema. Finalmente, en la sección 5.12 se presentan las conclusiones de este capítulo.

\subsection{Guías de diseño de organizaciones hu- manas}

En el diseño de organizaciones humanas existen varios trabajos en los que se definen cuáles son los parámetros a considerar en el análisis y diseño de una organización. Los trabajos más representativos son los de Mintzberg y Galbraith, que explicamos a continuación.

En la propuesta de Mintzberg se definen nueve parámetros de diseño de organizaciones, agrupados en cuatro grupos diferentes (figura 5.1) [Mintzberg, 1993]. Estos parámetros permiten dividir y coordinar el trabajo, para establecer pautas estables de comportamiento.

De este modo, Mintzberg propone el análisis de las organizaciones en función de: (i) las características propias de los puestos de trabajo, definidas por su especialización de tareas, su formalización o normalización y las necesidades de preparación y adoctrinamiento; (ii) las relaciones entre las distintas unidades de trabajo de la organización, el modo de agrupar a los miembros de dichas unidades y la cantidad total de miembros que tenga; (iii) los métodos de planificación y control de las distintas unidades y los dispositivos que permitan enlazar a las unidades entre sí; y (iv) el sistema empleado para la toma de decisiones, bien sea con centralización total o con descentralización vertical u horizontal.

Por su parte, en el trabajo de Galbraith se proponen cinco grupos de variables organizativas (tareas, estructura, procesos de información y decisión, sistemas de incentivos y personas) y se establece una conexión entre las variables y la estrategia de la empresa (figura 5.2) [Galbraith, 1977]. Dicha conexión permite diseñar la estructura de la organización a partir de 


\begin{tabular}{|l|l|}
\hline \multicolumn{1}{|c|}{ Grupos de variables } & \multicolumn{1}{|c|}{$\begin{array}{c}\text { Parámetros de diseño } \\
\text { (variables de diseño) }\end{array}$} \\
\hline Diseño de puestos & $\begin{array}{l}\text { - Especialización del cargo } \\
\text { - Formalización del comportamiento } \\
\text { - Preparación y adoctrinamiento }\end{array}$ \\
\hline Diseño de la superesctructura & $\begin{array}{l}\text { - Agrupación de unidades } \\
\text { - Tamaño de la unidad }\end{array}$ \\
\hline Diseño de los enlaces laterales & $\begin{array}{l}\text { - Sistemas de planificación y control } \\
\text { - Dispositivos de enlace }\end{array}$ \\
\hline Diseño del sistema de toma de decisiones & $\begin{array}{l}\text { - Descentralización vertical } \\
\text { - Descentralización horizontal }\end{array}$ \\
\hline
\end{tabular}

Figura 5.1: Variables de diseño de las organizaciones propuestas por Mintzberg.

su estrategia, tratando siempre de optimizar al máximo el rendimiento final de la misma.

Para cada tarea se analizan características tales como su incertidumbre, diversidad e interdependencia respecto a otras tareas. Las tareas se agrupan y estructuran según la división del trabajo y departamentalización necesaria. Además, se asignan a aquellas personas más adecuadas, siguiendo métodos de reclutamiento, selección, promoción o entrenamiento.

Resultan relevantes también los sistemas de incentivos, que establecen medidas de rendimiento del sistema y proporcionan compensaciones o sanciones a los miembros de la organización.Por último, los procesos de información y decisión permiten establecer mecanismos de control, sistemas de asignación de recursos y sistemas de información.

Resulta evidente que existe cierto paralelismo entre los conceptos planteados en estas guías (ej. agrupación de tareas, especialización, normalización, agrupación de miembros, planificación y control) con los conceptos ampliamente empleados en el análisis y diseño de MAS desde el enfoque organizativo (ej. rol, tareas, normas, grupos, control). Es por ello que proponemos la adaptación de las guía de diseño de organizaciones humanas al área de los sistemas multiagente, para así beneficiarnos del enfoque principalmente organizativo que ofrecen dichas guías. 


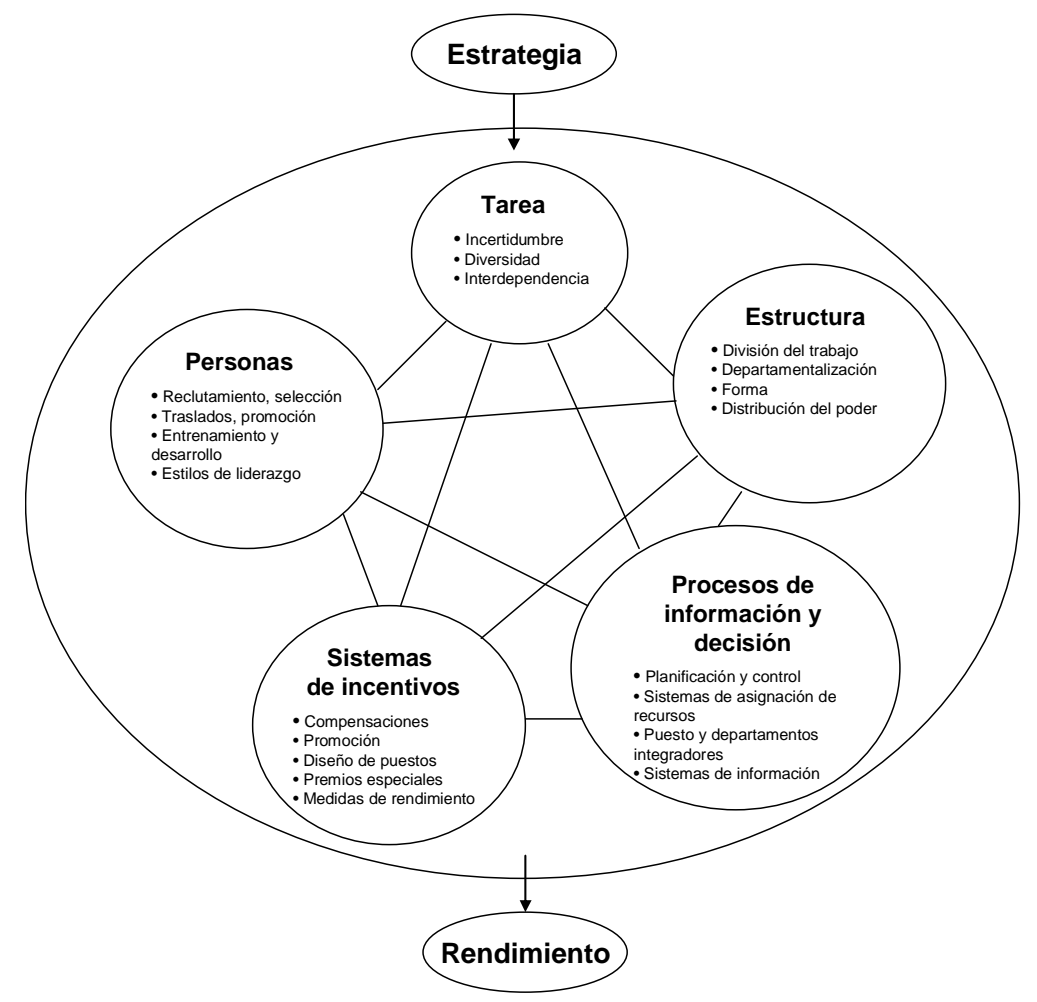

Figura 5.2: Dimensiones básicas de la organización propuestas por Galbraith.

En concreto, hemos adaptado la secuencia-guía básica de diseño organizativo [Moreno-Luzon et al., 2001], que integra los dos trabajos anteriores, ofreciendo un marco de trabajo adaptable a sistemas abiertos. El objetivo de la secuencia-guía consiste en "ayudar a comprender el orden secuencial básico sobre el que han de llevarse a cabo las diferentes formas de modelización y de aplicaciones operativas del diseño organizativo" [Moreno-Luzon et al., 2001]. Consta de dos fases: la fase de ajuste a las circunstancias condicionantes de la empresa y a la estrategia; y la fase de aplicación del diseño.

En la fase de ajuste a las circunstancias condicionantes de la empresa y los requisitos de la estrategia (figura 5.3), se siguen los siguientes pasos: (i) 


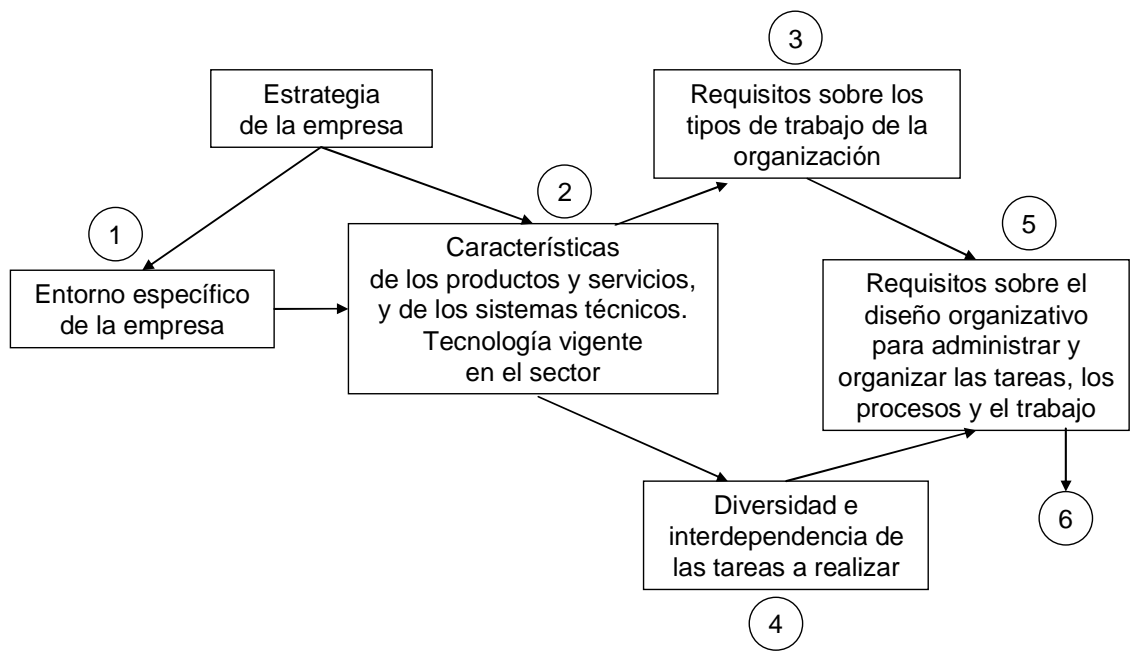

Figura 5.3: Secuencia-guía básica de diseño propuesta por Moreno-Luzon. Fase de ajuste a las circunstancias condicionantes de la empresa y los requisitos de la estrategia.

análisis del entorno específico de la empresa; (ii) análisis de las características de los productos y servicios a ofrecer, de los sistemas técnicos que se requieren y de la tecnología vigente en el sector; (iii) análisis de los requisitos sobre los tipos de trabajo de la organización; (iv) determinación de la diversidad e interdependencia de las tareas; y (v) especificación de requisitos sobre el diseño organizativo para administrar y organizar las tareas, los procesos y el trabajo.

En la fase de aplicación del diseño (figura 5.4), a partir de los requisitos sobre el diseño organizativo se establecen los siguientes puntos: (i) implementación de las tareas y procesos, incluyendo el sistema técnico, conocimientos, habilidades y formas en que se organiza; (ii) requisitos sobre la estructura; (iii) requisitos sobre los procesos de información-decisión; (iv) gestión y organización de la tecnología y de los diferentes tipos de trabajo necesarios, así como requisitos sobre las formas de diseño de los puestos; (v) políticas requeridas de gestión del personal; (vi) requisitos sobre las formas de medición, evaluación y control del trabajo; y (vii) requisitos sobre el sistema de recompensas. 


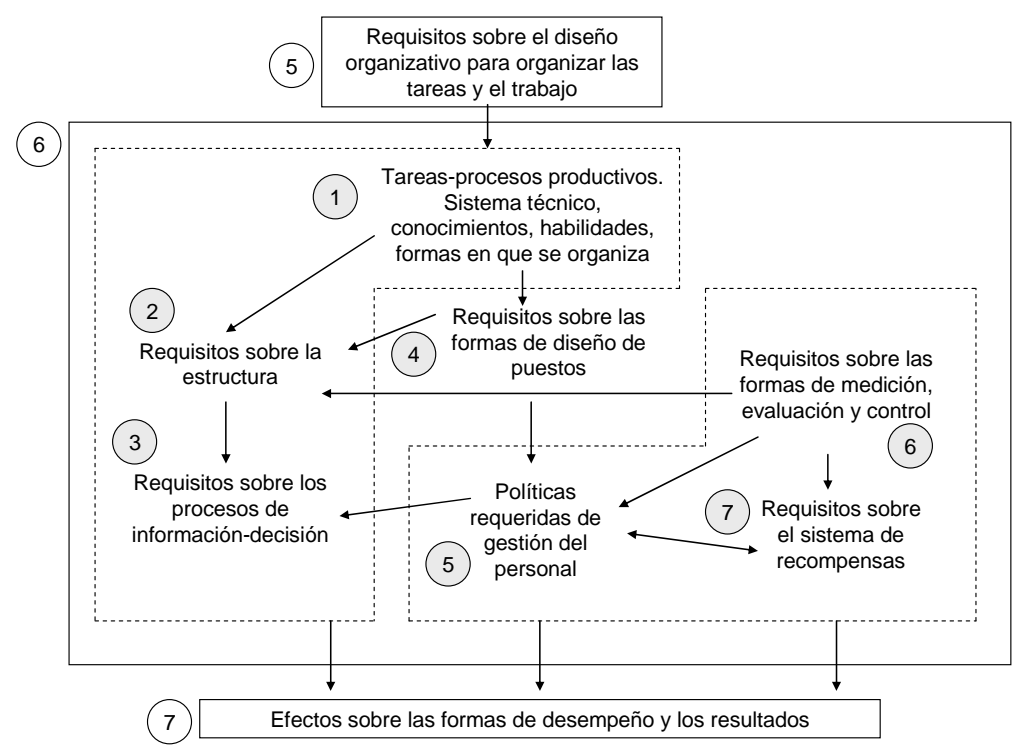

Figura 5.4: Secuencia-guía básica de diseño propuesta por Moreno-Luzon. Fase de aplicación del diseño.

En nuestro trabajo, hemos redefinido, adaptado y ampliado las fases de la secuencia-guía para integrarlas dentro de una metodología propia de sistemas multiagente. En el siguiente apartado se detalla dicha adaptación.

\subsection{Secuencia-Guía}

En este apartado se presenta el conjunto de guías de GORMAS para el análisis de requisitos del sistema, el diseño de la estructura organizativa y el diseño de la dinámica de la organización de un sistema multiagente. Con estas guías se pretende concretar cuáles son los servicios que ofrece la organización, cuál es su estructura interna y qué normas rigen su comportamiento, facilitando así el análisis y diseño de MAS abiertos.

Basándonos en la secuencia-guía básica de diseño organizativo [MorenoLuzon et al., 2001], comentada en la sección anterior, se ha definido para GORMAS un total de ocho fases, que se detallan a continuación: 
- Fase A.Misión: se realiza un análisis de la motivación que se persigue al definir la organización o sistema, es decir, del porqué de dicha organización o para qué se crea; de los resultados que, en conjunto, se esperan conseguir; y del entorno en el que existe, detallando los productos y/o servicios a ofrecer, los grupos de interés y su localización.

- Fase B. Tareas y procesos: se analizan con mayor detalle los servicios a ofrecer en el sistema, sus requisitos y los procesos que conllevan. Se detallan también las tareas y objetivos asociados a dichos servicios.

- Fase C. Dimensiones organizativas: se analizan las dimensiones de la organización (departamentalización, especialización, sistema decisor, formalización, coordinación), que imponen requisitos sobre los tipos de trabajo, así como sobre la diversidad e interdependencia de las tareas a realizar.

- Fase D. Estructura organizativa: se determina y selecciona la estructura organizativa más adecuada para la organización, en función de sus dimensiones. Se hace uso de modelos organizativos para especificar los roles, interacciones y normas relacionados con la propia estructura.

- Fase E. Procesos de información-decisión: para cada servicio identificado, se detallan las interacciones (flujos de información y de adopción de decisiones) necesarios para llevar a cabo el servicio. Además, se definen los contratos de calidad de servicio a los que se comprometen los proveedores y consumidores cuando éste se lleva a cabo.

- Fase F. Dinamicidad del sistema abierto: se establece la funcionalidad ofrecida como sistema abierto, que incluye tanto los servicios que se deben publicitar, como las políticas de adquisición y liberación de roles. Además, se diseñan los agentes propios del sistema.

- Fase G. Sistemas de medición, evaluación y control: se cuantifican o evalúan las tareas y actividades; y se establecen mecanismos para determinar si los objetivos del sistema se cumplen. Asimismo, se revisan 
las normas de la organización para especificar quiénes se encargan de ellas y las supervisan.

- Fase H. Sistemas de recompensas: se determina el sistema de incentivos, para recompensar a los miembros que avancen en dirección de los intereses de la organización. También se analizan los sistemas de sanción para aquellos miembros que no cumplan con las normas dadas.

La secuencia-guía propuesta permite ser integrada en un proceso de desarrollo de software completo. Para la descripción del proceso de desarrollo, así como de las distintas fases y trabajos a realizar en la secuencia-guía, utilizamos la notación SPEM (Software Process Engineering Metamodel) [O.M.G., 2002], empleada para definir procesos y sus componentes y descrita en términos de conceptos UML.

SPEM define a un proceso de desarrollo de software como un proceso colaborativo entre entidades abstractas activas llamadas roles de proceso que realizan operaciones denominadas actividades sobre entidades concretas y tangibles (productos de trabajo). Múltiples roles de proceso interactúan o colaboran intercambiando productos de trabajo y activando la ejecución de ciertas actividades. El objetivo global de este proceso es alcanzar un estado "bien-definido" de un conjunto de productos de trabajo. El conjunto de productos de trabajo así como su estado "bien-definido" y las actividades ejecutadas definen una metodología particular.

El conjunto completo de los elementos de modelado de proceso que define SPEM se puede consultar en la especificación del Object Management Group [O.M.G., 2002]. En la figura 5.5 se resumen los principales elementos de modelado de proceso empleados en esta tesis.

El proceso de desarrollo de software comprende las fases de análisis, diseño, implementación, instalación y mantenimiento del sistema multiagente. Tomando en cuenta la perspectiva de la organización, la fase de diseño se subdivide en dos: diseño de la estructura organizativa y diseño de la dinámica de la organización (figura 5.6).

En la figura 5.7 se muestra el resultado de integrar las distintas fases de 
la secuencia-guía propuesta en el proceso de desarrollo del sistema multiagente, empleando la notación SPEM.

En concreto, durante la fase de análisis de requisitos del sistema se procede a la definición de la misión y al análisis de las tareas y procesos, haciendo uso de las fases A y B de nuestra guía.

En la fase de diseño de la estructura organizativa se lleva a cabo la especificación de las dimensiones y estructura de la organización, empleando las fases C y D de la secuencia-guía.

Por último, durante la fase de diseño de la dinámica de la organización se realiza el diseño de los procesos de información-decisión, el diseño de las políticas de dinamicidad del sistema abierto, el diseño de sistemas de medición, evaluación, control y el diseño de sistemas de recompensas, utilizando para ello las fases E, F, G y H de nuestra secuencia-guía.

El proceso de desarrollo del sistema es iterativo, de modo que desde cualquier fase se podrá volver a las anteriores. Además, las guías facilitadas resultan suficientes para cubrir cada parte del proceso. 


\begin{tabular}{|c|c|c|}
\hline Elemento & Notación & Descripción \\
\hline Proceso & & $\begin{array}{l}\text { Representa un proceso completo. Es un conjunto de } \\
\text { descripciones de proceso internamente consistente que } \\
\text { puede ser reutilizado para definir procesos mayores. }\end{array}$ \\
\hline Fase & & $\begin{array}{l}\text { Representa una fase de un proceso de desarrollo } \\
\text { software. Es una especialización de Definición de } \\
\text { Trabajo }\end{array}$ \\
\hline $\begin{array}{l}\text { Definición de } \\
\text { Trabajo }\end{array}$ & & $\begin{array}{l}\text { Representa un conjunto de tareas. Es un tipo de } \\
\text { operación (o tarea compleja) que describe el trabajo } \\
\text { desarrollado en el proceso. }\end{array}$ \\
\hline $\begin{array}{l}\text { Producto de } \\
\text { Trabajo }\end{array}$ & & $\begin{array}{l}\text { Es cualquier elemento producido, consumido o } \\
\text { modificado por un proceso. Puede ser un fragmento de } \\
\text { información, un Documento, un Modelo, código fuente, } \\
\text { etc. }\end{array}$ \\
\hline $\begin{array}{l}\text { Encargado de } \\
\text { Proceso }\end{array}$ & & $\begin{array}{l}\text { Representa el rol primario que ejecuta y es dueño de } \\
\text { una Definición de Trabajo. }\end{array}$ \\
\hline Rol de Proceso & & $\begin{array}{l}\text { Define las responsabilidades sobre un determinado } \\
\text { Producto de Trabajo y los roles que ejecutan y ayudan } \\
\text { en Actividades específicas. }\end{array}$ \\
\hline Actividad & & $\begin{array}{l}\text { Es la sub-clase principal de Definición de Trabajo. } \\
\text { Describe el conjunto de tareas, operaciones y acciones } \\
\text { que son ejecutadas por un Rol de Proceso. }\end{array}$ \\
\hline Documento & & Representa un documento generado en un Proceso. \\
\hline Guía & & $\begin{array}{l}\text { Los elementos guía pueden asociarse a cualquier } \\
\text { elemento SPEM para proveer información más } \\
\text { detallada sobre el elemento asociado. Ejemplos: } \\
\text { Guías, Técnicas, Métricas, Ejemplos, Perfiles UML, } \\
\text { Patrones, etc. }\end{array}$ \\
\hline Modelo & & $\begin{array}{l}\text { Representa los modelos utilizados en el proceso de } \\
\text { desarrollo software. Ejemplo: modelo de clases, modelo } \\
\text { conceptual, modelo dinámico, modelo de agentes, } \\
\text { modelo de interacción, etc. }\end{array}$ \\
\hline $\begin{array}{l}\text { Paquete de } \\
\text { Proceso }\end{array}$ & & $\begin{array}{l}\text { Es un contenedor que contiene e importa elementos de } \\
\text { descripción de procesos. }\end{array}$ \\
\hline
\end{tabular}

Figura 5.5: Elementos de definición de procesos de SPEM 


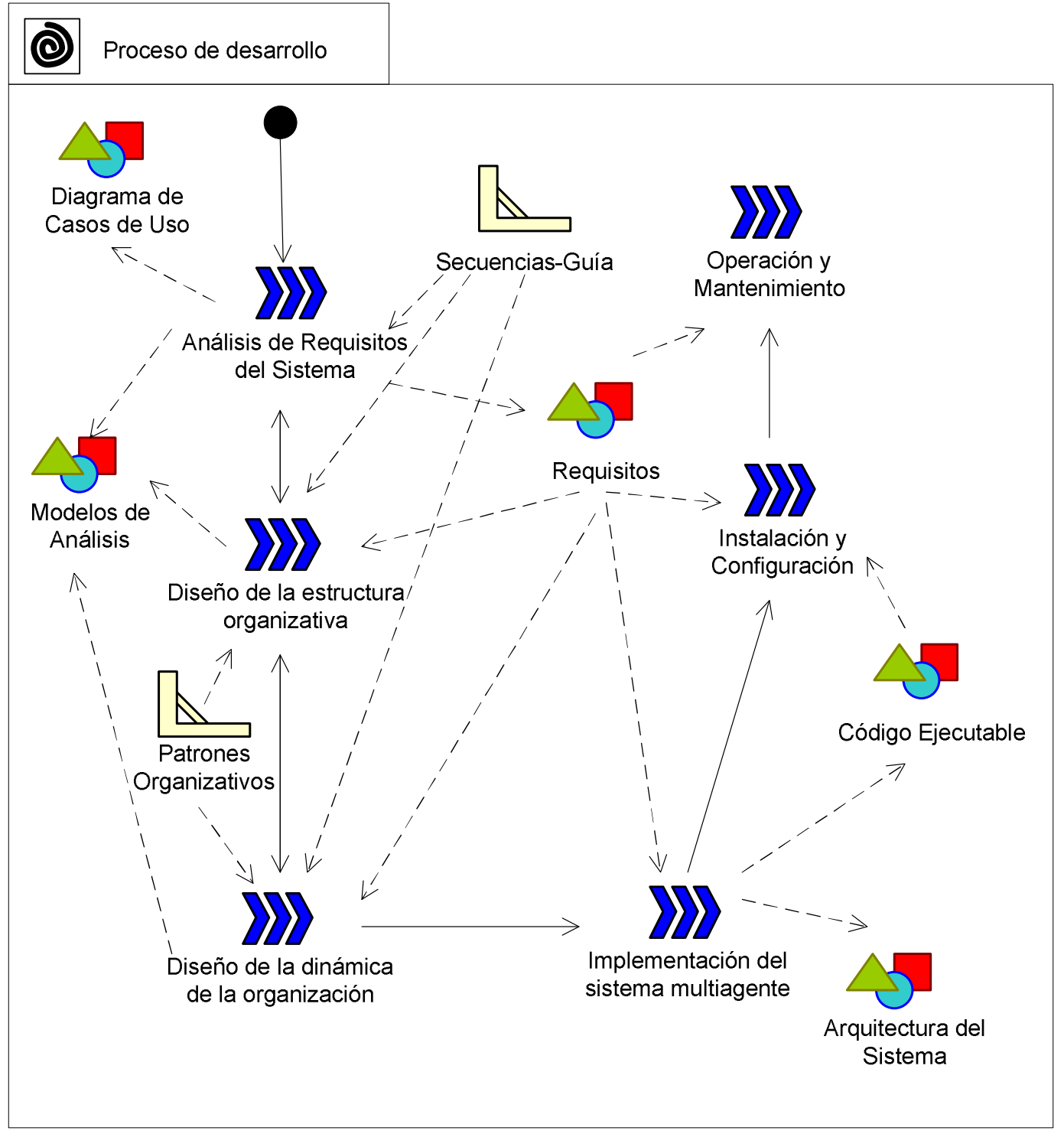

Figura 5.6: Proceso de Desarrollo extendido del Sistema Multiagente 


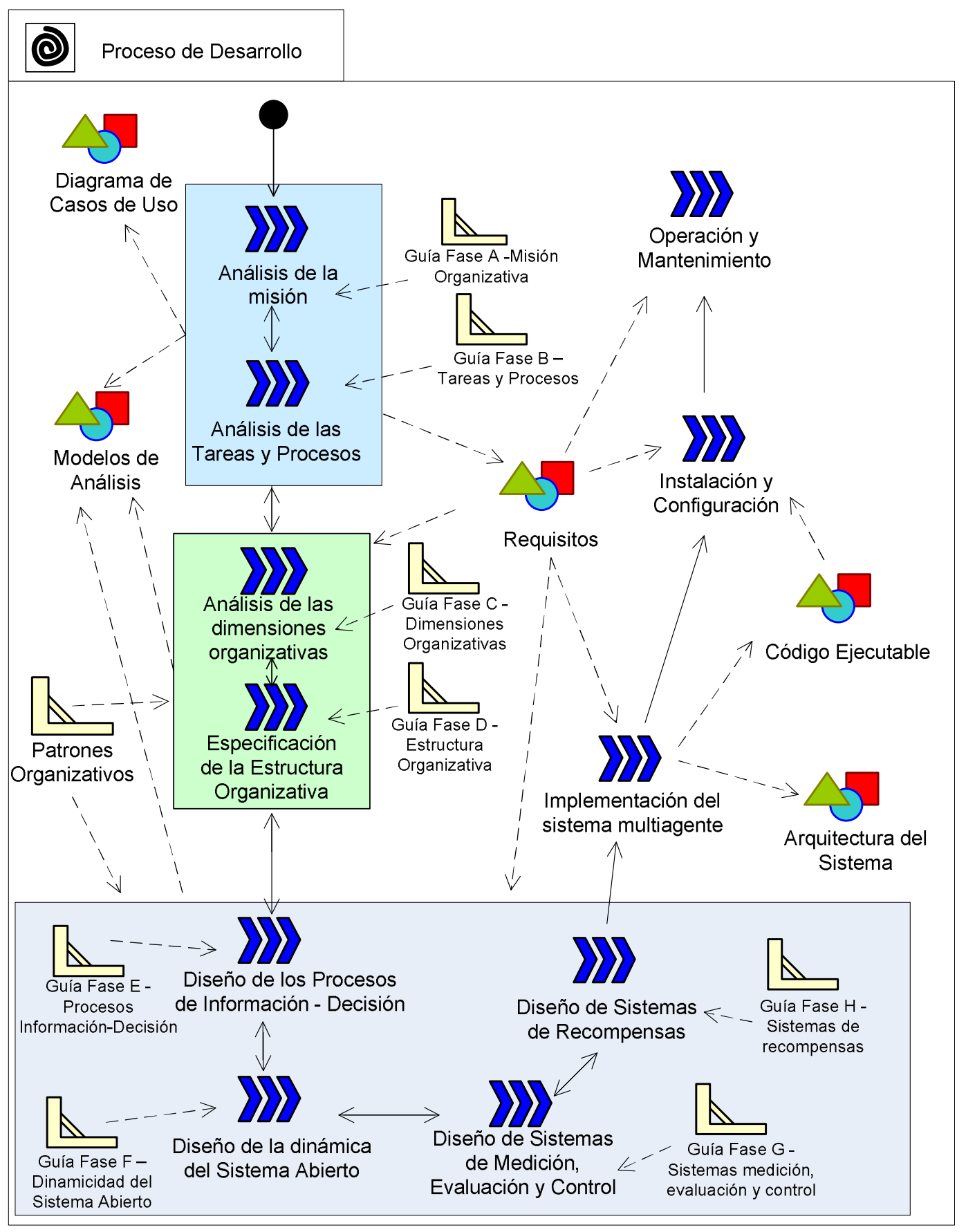

Figura 5.7: Integración de las fases de la secuencia-guía en el proceso de desarrollo del MAS. 


\subsection{Fase A. Misión}

En la primera fase de la secuencia-guía propuesta (figura 5.8) se establece el porqué de la organización o sistema que se pretende desarrollar y cuál será la relación con su entorno.

La misión, por un lado, es la base fundamental o pieza clave que guiará en la determinación de la estructura organizativa, analizada en fases posteriores de la guía metodológica (en concreto, en la fase D.Estructura Organizativa).

Por otro lado, la misión permite establecer mecanismos para controlar el progreso de la organización y así poder actuar mejor sobre determinados elementos del sistema o sobre la propia misión.

Esta primera fase consta de las siguientes operaciones o trabajos: (i) definición de la misión; y (ii) definición del contexto organizativo.

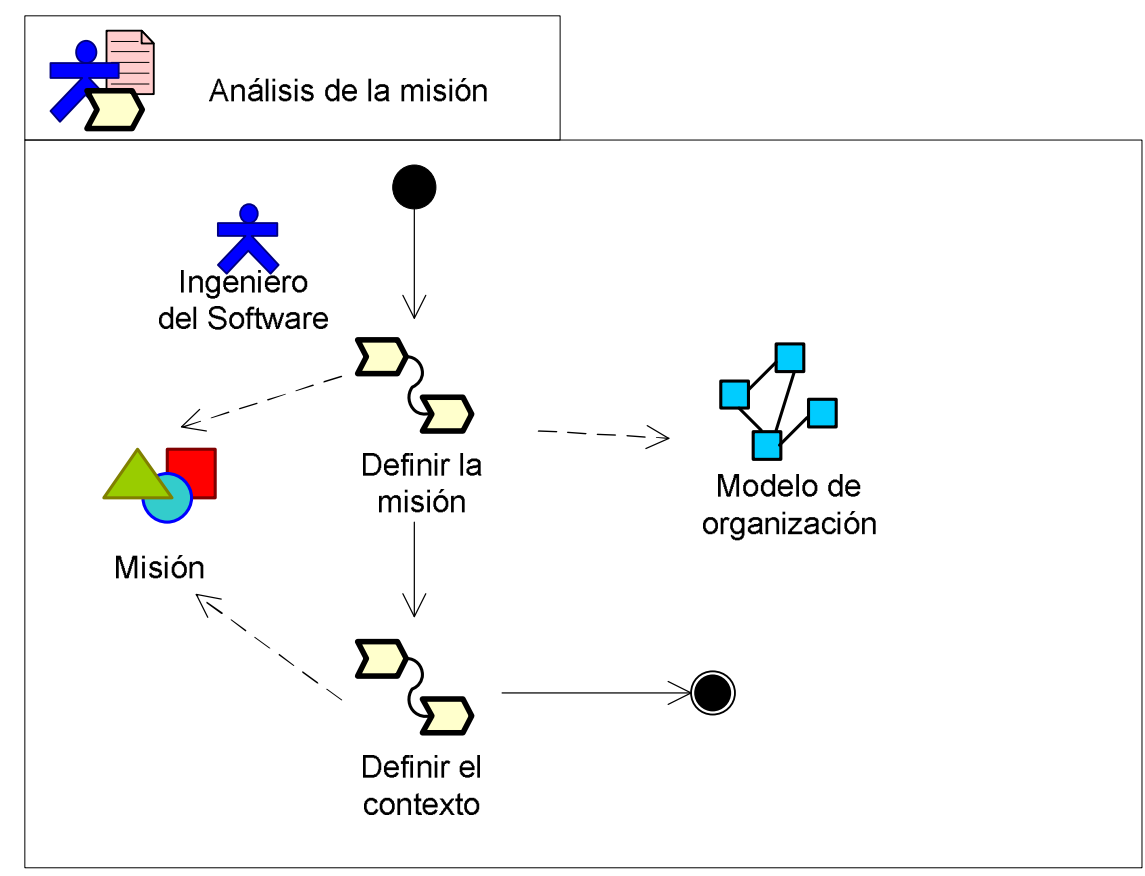

Figura 5.8: Fase de Análisis de la misión de la organización.

El producto de trabajo Misión describe el objetivo global del sistema, 
para qué trabaja el sistema, qué produce, a quiénes atiende, quiénes se benefician de interaccionar con el sistema y dónde está localizado. Consta de los siguientes documentos (figura 5.9): A.1 Misión Organizativa; A.2 Grupos de interés; y A.3 Condiciones del entorno.

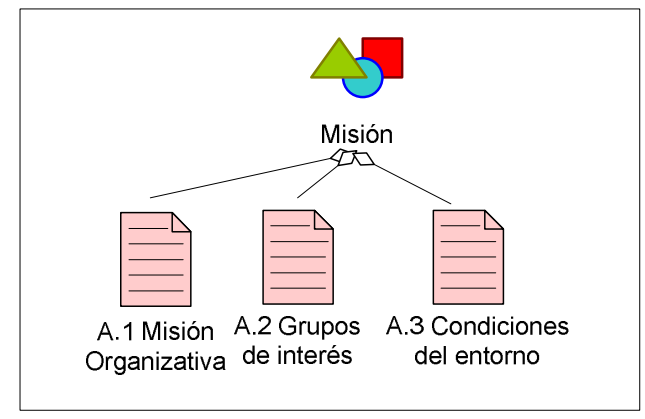

Figura 5.9: Composición del producto de trabajo Misión.

A continuación se detalla cada uno de los trabajos que integran esta fase.

\subsubsection{Definir la misión}

La misión de una empresa se define como la satisfacción de determinadas necesidades o deseos de ciertos grupos de interés que, en conjunto, forman sus mercados [Casillas y Marti, 2004]. La misión o meta estratégica describe la razón de ser que explica la existencia de la organización, normalmente motivada por alguno de estos fines: respuesta a las expectativas de los clientes; maximización de los excedentes; reinversión y crecimiento; satisfacción de los miembros de la organización [Wagner y Hollenbeck, 2004] .

$\mathrm{Al}$ aplicar estos conceptos al mundo de los sistemas multiagente, para definir la misión se determina quiénes son los principales actores con los que va a tratar el sistema; cuáles son las necesidades de dichos actores y cuáles son los requisitos de los productos y servicios a ofrecer a este mercado potencial. Por tanto, el trabajo Definir la misión comprende (figura 5.10):

1. Describir el resultado (producto o servicio) que proporciona el sistema, de modo que se entienda en qué consiste dicho resultado, para 
qué sirve y a quiénes le interesa.

2. Identificar los principales grupos de interés a los que se va a dirigir la organización (actores externos, clientes, usuarios, etc.).

3. Identificar el tipo de entorno en el que se va a desarrollar la organización, indicando si se trata de un entorno físico concreto, si es un entorno meramente virtual; si la localización es única o está distribuida; si existen particularidades concretas de cada localización (y cuáles son), etc.

4. Justificar el porqué de este sistema frente a otros sistemas ya existentes, tanto sistemas multiagente como de otro tipo. En concreto, se analizan las ventajas y desventajas que se prevé que proporcionará el sistema a diseñar frente al resto; así como las singularidades o elementos competitivos de la organización que le permitan diferenciarse de la competencia. Por ejemplo las prestaciones que realiza mejor, con más calidad, a menor precio, o más rápido que sus competidores; los recursos o habilidades que dispone; planteamientos novedosos $\mathrm{u}$ originales, etc.

Para la definición de la misión se emplea el documento A.1-Misión Organizativa (tabla 5.1). Además, se instancia la vista funcional (misión) del meta-modelo de organización. Para ello se crea una entidad de tipo Unidad Organizativa que representa al sistema global y tantas entidades actor de tipo Grupo de Interés como se hayan identificado en la tabla 5.1, especificando si se tratan de clientes, proveedores, competencia u otros. Se establecen así las relaciones OInteracciona correspondientes. En base a la justificación del sistema se define el objetivo global o misión que persigue la Unidad Organizativa (relación GTPersigue). Por su parte, los productos o servicios que proporciona el sistema se definen mediante sus respectivas entidades y se conectan con el sistema con la relación OProduce. Finalmente, se establecen las interrelaciones entre los clientes, proveedores y el sistema mediante las relaciones OConsume y OProduce correspondientes. 


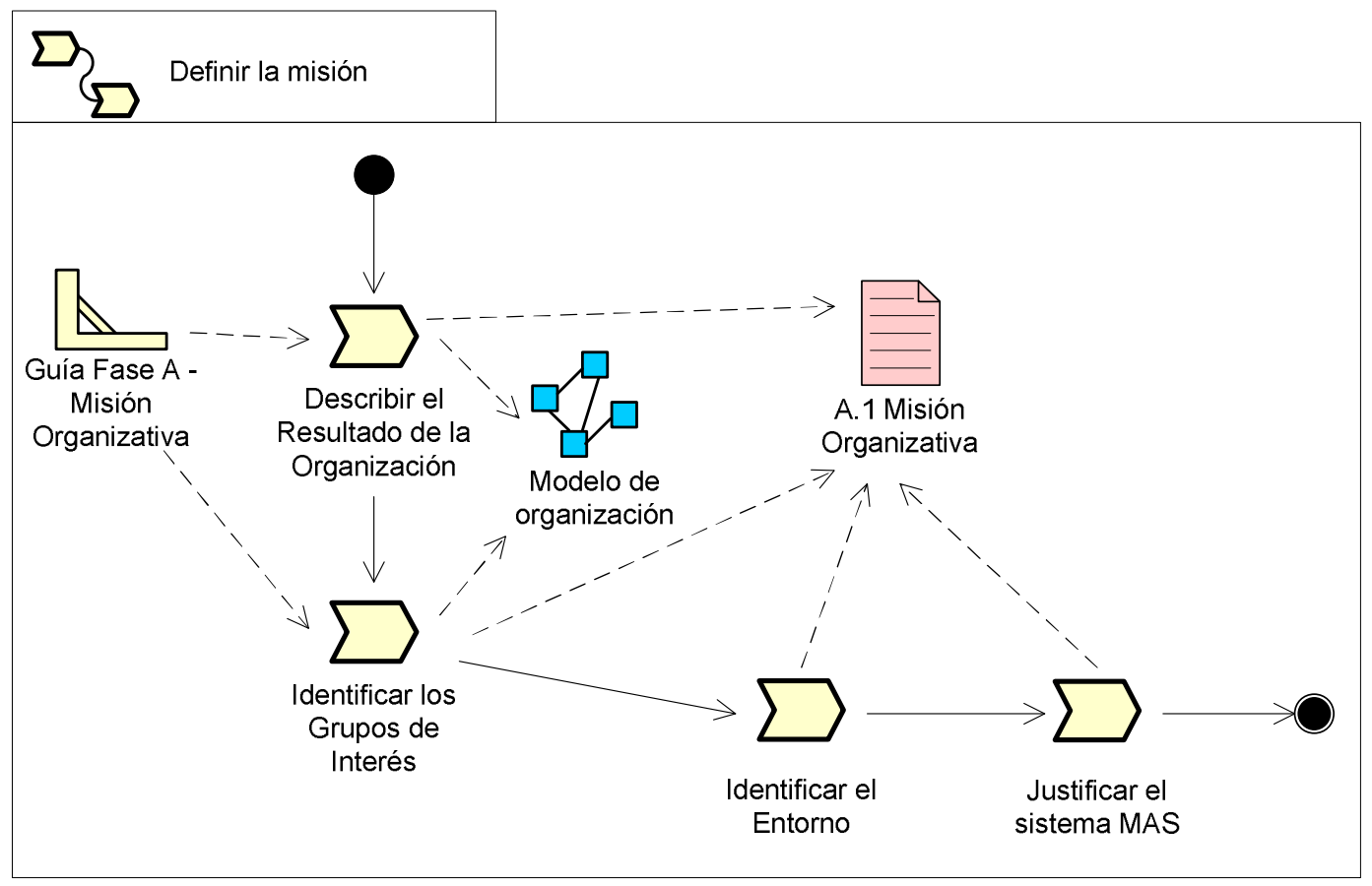

Figura 5.10: Definición de la tarea Definir la misión.

El análisis de la misión permite determinar si en el sistema lo más importante es lo que se produce (se trata de un sistema centrado en la producción) o bien cómo se produce (se trata de un sistema centrado en los servicios). En fases posteriores de esta guía se tomarán unas decisiones concretas en base a estos dos enfoques (en concreto, en las fases B.Tareas y Procesos y C.Dimensiones Organizativas).

Así, en el primer caso, el análisis se focaliza en la especificación de las tareas a realizar para la obtención de unos productos determinados, de modo que en las fases $\mathrm{B}$ y $\mathrm{C}$ de la guía se detalla la funcionalidad de dichas tareas, sus interrelaciones y la configuración o características de sus productos. Además, en la fases E y G de la guía se establecen los mecanismos oportunos para controlar su productividad, eficiencia, así como la obtención de los productos en el tiempo establecido. Por otro lado, las relaciones entre las entidades serán estáticas en gran medida, es decir, se conocerán a priori con quiénes se va a interactuar, por lo que gran parte de la funcionalidad a 
tratar será vista como flujos de trabajo, pero no como servicios.

En el segundo caso, el sistema se centra en ofrecer cierta funcionalidad a sus clientes, primando la satisfacción de los mismos, así como la reducción de los tiempos, para que el cliente obtenga el resultado final en el menor tiempo posible. En fases posteriores (fases B.Tareas y Procesos y F. Dinamicidad del sistema abierto, principalmente) se detallan las especificaciones concretas de los servicios a ofrecer: qué se pretende realizar, qué funcionalidad se debe implementar y cuál se puede contratar, quiénes están capacitados para ello y cómo se lleva a cabo la publicitación del servicio y su solicitud. Por tanto, la descomposición de la funcionalidad se realiza principalmente en base a servicios.

\subsubsection{Definir el contexto organizativo}

El contexto de la organización comprende el conjunto de circunstancias que la organización debe afrontar [Hodge et al., 2003]. Como veremos más adelante, las organizaciones adoptan distintas estructuras para adaptarse a su contexto de la mejor manera posible, el cual viene determinado por dos factores contextuales: (i) los requisitos y necesidades de los grupos de interés con los que interactúa, que proporcionan también la fuente de recursos necesarios para su funcionamiento; y (ii) las condiciones propias del entorno con el que la organización interacciona. Dichas condiciones implican también la existencia de un conjunto de amenazas que pueden poner en peligro la consecución de la misión de la organización, al proporcionar cierta incertidumbre, dependencia de los recursos y, en ocasiones, escasez de los mismos.

Por tanto, el trabajo Definir el Contexto Organizativo (figura 5.11) se descompone en dos actividades: (i) describir los grupos de interés; y (ii) describir las condiciones del entorno.

GRUPOS DE INTERÉS. Los stakeholders o grupos de interés [Hodge et al., 2003] representan a aquellos actores que se verán afectados tanto 


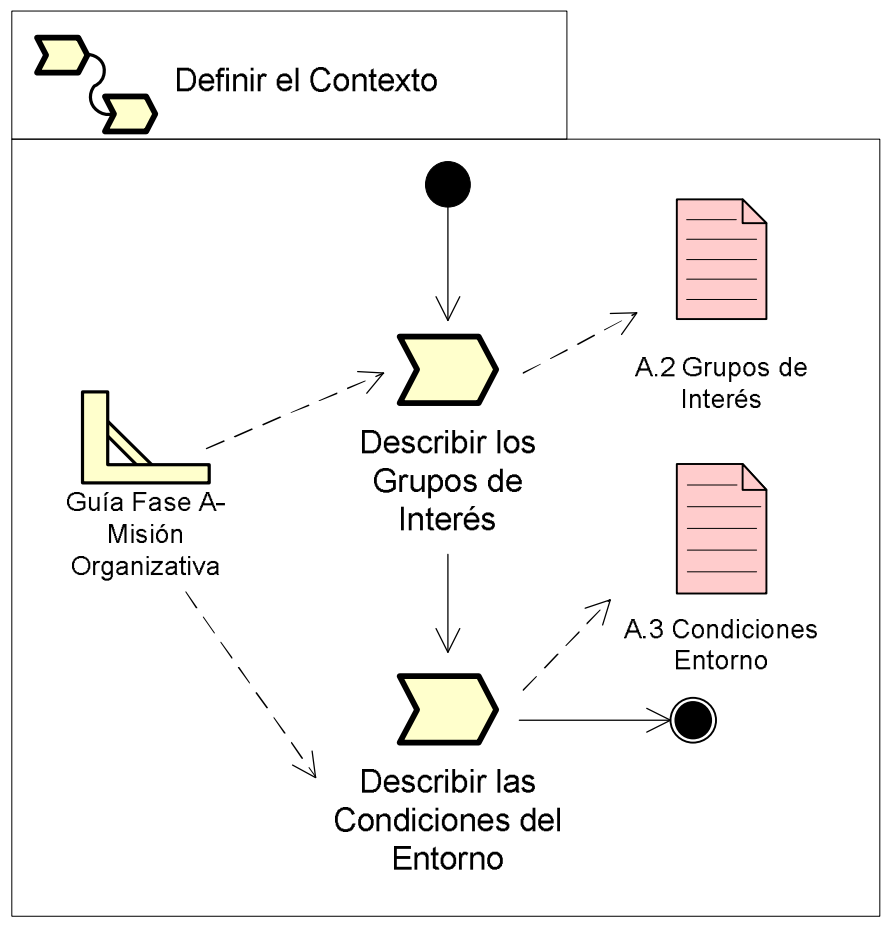

Figura 5.11: Definición de la tarea Definir el Contexto.

por el éxito como por el fracaso de la organización. Pueden dividirse en beneficiarios primarios (aquellos a los que sirve la organización) y beneficiarios secundarios (aquellos que obtienen satisfacción mediante su asociación a la misma). Ejemplos de grupos de interés en organizaciones humanas son los clientes (o consumidores de los productos/servicios que ofrece la empresa); los proveedores (o suministradores de las entradas de la organización); la propia competencia, que trata de atraer a los clientes y recursos; así como los grupos reguladores, como los gobiernos, asociaciones, etc.

En esta actividad se identifican los grupos de interés que resultan relevantes para la organización, determinando cuál es su interacción respecto a la organización y analizando sus intereses, preocupaciones, derechos asumidos y expectativas. En concreto, se determina: (i) qué esperan conseguir de su relación con la organización; (ii) cuál es la frecuencia de su relación; 
(iii) qué poder tienen sobre la organización, es decir, cómo afectan sus decisiones a los objetivos, tareas y/o resultados de la organización; y (iv) cómo la organización actúa sobre sus propios intereses. Como resultado de esta actividad se debe generar el documento A.2 Grupos de interés (tabla 5.2).

El análisis indicado permite conocer mejor la relación de estos grupos con la organización y su nivel de participación en los procesos de toma de decisiones.

De este modo, si se detecta que un grupo de interés está muy implicado en la toma de decisiones, en fases posteriores de la guía metodológica (en concreto, en las fases F. Dinamicidad del sistema abierto y E.Procesos de información-decisión) se podrían especificar agentes externos que los representen y que participen directamente en la toma de decisiones; o bien si la relación que tienen con la organización es mínima, la información que proporcionan se podría recoger de bases de datos o bien a través de agentes de tipo interfaz.

Por otro lado, los resultados percibidos por los grupos de interés pueden influir también en los procesos de retroalimentación y en el sistema de recompensas, favoreciendo así a aquellos agentes que mejor ajusten su trabajo a los requisitos de los clientes.

CONDICIONES DEL ENTORNO. Existen ciertas condiciones del entorno que afectan en gran medida al rendimiento y efectividad de la organización. Estas condiciones son [Wagner y Hollenbeck, 2004]: tasa de cambio, complejidad, incertidumbre, receptividad y diversidad. Como se comenta más adelante, las condiciones influyen también en la elección de la estructura más adecuada para la organización. 


\section{A.1. Misión Organizativa}

Nombre: nombre general del sistema u organización a generar

Dominio: Tipo de mercado o área de interés sobre el que versa la organización

Resultados: conjunto de productos o servicios que ofrece la organización a sus clientes

- Finalidad: descripción del motivo por el que se ofrece dicho resultado

- ¿Es tangible?: si el resultado es almacenable, imprimible y/o reutilizable más adelante, se trata de un producto. Si es una funcionalidad consumible, se trata de un servicio

Grupos de interés: actores que comprenden el mercado de la organización, a los que se dirige y por los que funciona

- ¿Es consumidor?: el actor consume los productos o servicios que la organización proporciona

- ¿Es productor?: el actor facilita determinados recursos o servicios que son requeridos para el funcionamiento de la organización

Tipo de Entorno: localización del sistema (única o distribuida); Capacidad de accesibilidad al mundo físico y real.

Justificación: razón de ser de la existencia de la organización

- Sistemas similares: detallar los sistemas existentes que proporcionan una orientación similar a la considerada

- Ventajas: conjunto de ventajas que se desean abordar con la nueva propuesta. Por ejemplo, utilización óptima de los recursos del sistema; mejora de la eficiencia interna; mejora de la calidad de los productos o servicios a ofertar; mejora de las relaciones con los clientes (mayor frecuencia, prontitud en la respuesta); integración de diferentes tecnologías

- Desventajas: limitaciones de la nueva propuesta frente a los sistemas similares - Singularidades: elementos competitivos de la organización. Remarcar qué se pretende potenciar (prestaciones, calidad, coste, rendimiento).

Tabla 5.1: Documento A.1-Misión Organizativa. Plantilla de descripción de la misión de una organización. 


\begin{tabular}{|c|c|}
\hline \multicolumn{2}{|r|}{ A.2. Grupos de Interés } \\
\hline Nombre & Identificador del grupo de interés \\
\hline Beneficiario & $\begin{array}{l}\text { Indicar si se trata de un beneficiario primario (resulta impres- } \\
\text { cindible para el funcionamiento de la organización) o secundario } \\
\text { (es prescindible) }\end{array}$ \\
\hline Tipo & $\begin{array}{l}\text { Indicar si es un cliente (consume resultados), un proveedor (su- } \\
\text { ministra recursos), un regulador (controla el funcionamiento del } \\
\text { sistema) }\end{array}$ \\
\hline Objetivos & $\begin{array}{l}\text { Describir los objetivos que persigue al interaccionar con la or- } \\
\text { ganización }\end{array}$ \\
\hline Requiere & 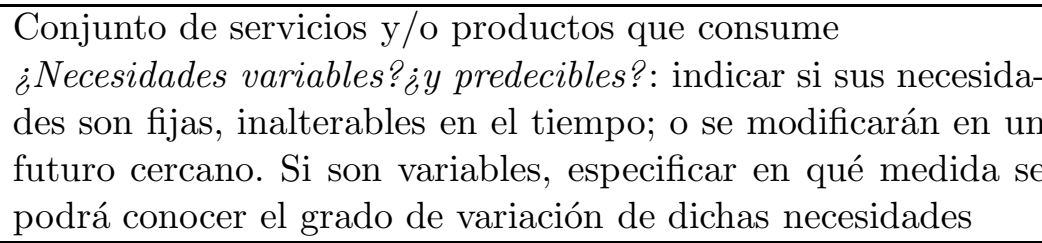 \\
\hline Proporciona & $\begin{array}{l}\text { Conjunto de servicios y/o productos que ofrece a la organiza- } \\
\text { ción }\end{array}$ \\
\hline Frecuencia & $\begin{array}{l}\text { Indicar si el contacto con este grupo de interés se hace de mane- } \\
\text { ra frecuente, con un periodo de tiempo establecido o de forma } \\
\text { ocasional }\end{array}$ \\
\hline Beneficios & $\begin{array}{l}\text { Describir los beneficios que espera obtener. Indicar si son tan- } \\
\text { gibles (producto determinado, dinero) o bien intangibles (as- } \\
\text { pectos de calidad y eficiencia del servicio) }\end{array}$ \\
\hline $\begin{array}{l}\text { Poder de } \\
\text { decisión }\end{array}$ & $\begin{array}{l}\text { Indicar si sus necesidades afectan significativamente a los requi- } \\
\text { sitos de los productos o servicios; o bien si su relación resulta } \\
\text { básica para el funcionamiento de la organización }\end{array}$ \\
\hline $\begin{array}{l}\text { Influencia } \\
\text { en sus } \\
\text { decisiones }\end{array}$ & $\begin{array}{l}\text { Indicar en qué medida la organización puede actuar sobre los } \\
\text { intereses de los clientes. Por ejemplo, obligándoles a aceptar } \\
\text { ciertos márgenes de rendimiento, o ciertos márgenes de calidad, } \\
\text { o incluso productos similares a los solicitados }\end{array}$ \\
\hline Aportación & $\begin{array}{l}\text { Indicar qué obtiene la organización al relacionarse con este ac- } \\
\text { tor }\end{array}$ \\
\hline
\end{tabular}

Tabla 5.2: Documento A.2-Grupos de interés. Plantilla de descripción de los grupos de interés de la organización. 
La tasa de cambio o estabilidad indica el grado en el que las condiciones del entorno cambian de forma impredecible, reflejado en cómo varía la cantidad de carga de trabajo, peticiones de los clientes, recursos, etc. a lo largo del tiempo.

El entorno se considera estable si apenas cambia o si lo hace de forma cíclica y predecible. Por otro lado, un entorno es dinámico cuando cambia de forma impredecible. Un entorno estable permite racionalizar y automatizar las actividades de forma más sencilla, mientras que un entorno dinámico exige gran flexibilidad. Por tanto, interesará conocer si la demanda de los productos/servicios será siempre la misma; si aparecerán productos nuevos en el mercado que afecten a la productividad de la organización; si se pueden estimar las épocas de mayor o menor consumo del producto y cómo los picos de demanda podrían afectar al rendimiento del sistema.

La complejidad indica el número y relación entre sí de los elementos del entorno que afectan a una organización (proveedores, tipos de cliente, etc.). Un entorno sencillo se compone de relativamente pocos elementos, de modo que apenas afecta al rendimiento de la organización. Un entorno complejo se compone de un gran número de elementos por separado, influyendo en la efectividad estructural y afectando al volumen de conocimientos e información que los miembros de la organización deben procesar para comprenderlo y ocuparse de sus demandas. Por ello, contra más complejo sea el entorno, más cantidad de información se necesitará recoger.

La incertidumbre refleja la falta de información sobre los factores, actividades y acontecimientos del entorno. Una baja incertidumbre se da en entornos estables y simples, en la que existen pocos elementos integrantes y el cambio es predecible. La incertidumbre alta implica un entorno complejo y dinámico, en el que existen muchos elementos integrantes y cambios impredecibles.

La receptividad indica el grado con que el entorno facilita o dificulta el progreso de una organización hacia sus objetivos, es decir, si es más o menos sencillo conseguir los recursos, miembros y el conocimiento necesario para rendir de forma productiva. En un entorno munificiente, una organización es 


\section{A.3. Condiciones del Entorno}

Tasa de Cambio: ¿Los tipos de grupos de interés se mantienen constantes a lo largo del tiempo? ¿Sus requisitos son constantes? ¿Se modifican de forma cíclica y predecible? ¿Se pueden estimar las épocas de mayor o menor consumo del producto o servicio? ¿La demanda de los productos o servicios será siempre la misma?. En caso afirmativo, es un entorno estable. Si no, es un entorno inestable o dinámico.

Complejidad: ¿Existen muchos elementos distintos? ¿Muchos tipos de clientes? ¿Muchos tipos de servicios o productos a ofrecer? ¿Muchos tipos de proveedores? ¿Están poco relacionados entre sí?. Si alguna de las respuestas es afirmativa, es un entorno complejo. En otro caso, es simple.

Incertidumbre: si el entorno es dinámico y complejo, la incertidumbre es alta. Si el entorno es estable y sencillo, es baja.

Receptividad: ¿Las entradas y recursos que se necesitan están disponibles?¿Se obtienen de forma fácil y segura?. En caso afirmativo, se trata de un entorno munificiente. En caso contrario, es hostil.

Diversidad: ¿Se atiende a distintos tipos de cliente? ¿Se proporciona un conjunto de productos/servicios distintos, no relacionados entre sí?. Si alguna de las respuestas es afirmativa, es un entorno diverso. En caso contrario, es uniforme.

Tabla 5.3: Documento A.3-Condiciones Entorno. Plantilla de descripción de las condiciones del entorno.

capaz de conseguir sus recursos, miembros, tecnología y entradas necesarias sin relativos problemas, siéndole posible encontrar un mercado receptivo a sus productos o servicios y sin que la competencia amenace su existencia. En un entorno hostil, la organización puede tener grandes dificultades para conseguir sus recursos, miembros, conocimiento, etc. necesarios, o incluso ser incapaz de hacerlo.

Finalmente, la diversidad representa el número de sectores o escenarios distintos del entorno. Se analiza si se sirve a uno o varios tipos de cliente; si se proporciona una o varias clases de producto; las ubicaciones geográficas, etc. En un entorno uniforme, la organización sirve a un único tipo de consumidor, proporciona una única clase de producto o servicio y se centra en una única ubicación geográfica. Por tanto, se ocupa de un único escenario. En un entorno diverso, la organización produce un conjunto de productos 
o servicios, atiende a diversos tipos de clientes o se ocupa de diversas áreas geográficas, operando en varios escenarios diferentes.

En la actividad Descripción de las condiciones del entorno se emplea el documento A.3 Condiciones Entorno (tabla 5.3) para identificar sus características.

El análisis del entorno permite seleccionar, en la fase C.Dimensiones Organizativas, el tipo de agrupación de tareas a realizar. Por ejemplo, si el entorno es uniforme se deben agrupar las tareas en base a las funcionalidades comunes que ofrezcan; mientras que si el entorno es diverso conviene agrupar juntas tareas con funcionalidades distintas pero que se dirijan todas ellas a un mismo tipo de cliente, producto, etc., permitiendo así una mejor integración de las mismas para cada escenario distinto.

\subsubsection{Aplicación de la fase al caso de estudio}

El sistema de información de nuestro ejemplo se construye con la finalidad de facilitar la distribución de cierta información relevante sobre determinados temas entre el público en general, de forma rápida y eficiente. Los objetivos principales del sistema son: proporcionar información relevante; maximizar la calidad de los documentos (para satisfacer las expectativas del cliente); y aumentar la cantidad de documentos (incrementando la productividad).

El sistema se dirige a dos tipos de clientes: expertos en las diferentes temáticas del sistema, encargados principalmente de suministrar nuevos documentos y de realizar su evaluación; y usuarios no expertos, que se limitan a consultar información del sistema o bien a suscribirse a un tema para recibir periódicamente sus documentos. Fijándonos en su relación con el sistema, se refinan en: demandante, que solicita información; informador, que proporciona nuevos documentos; y evaluador, que evalúa la calidad de los documentos suministrados. Los expertos actúan como demandantes, informadores y/o evaluadores, mientras que los clientes inexpertos sólo como demandantes. 


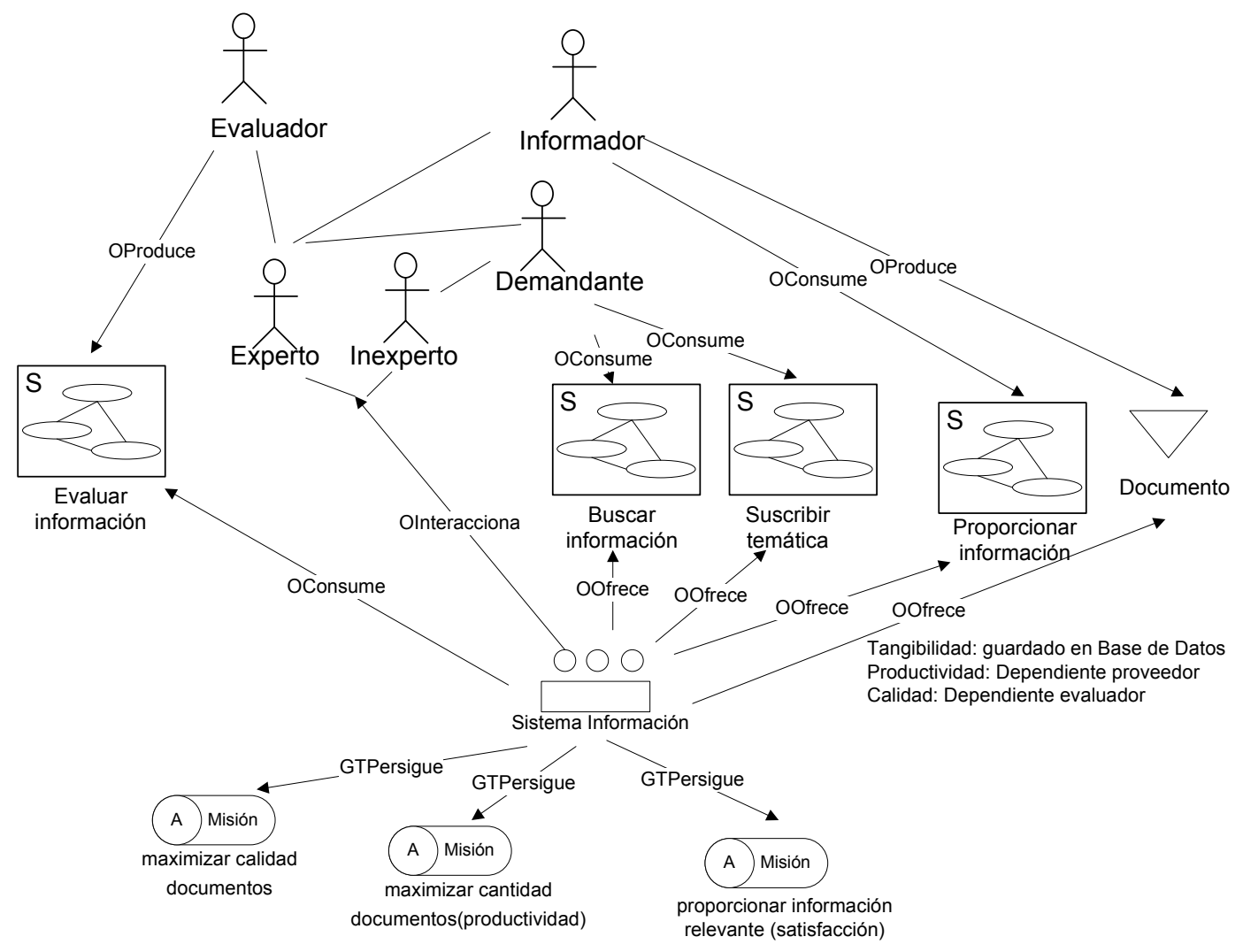

Figura 5.12: Diagrama de vista funcional (misión) del modelo de organización para el sistema de información.

Los resultados del sistema son los documentos (producto) que se almacenarán y serán distribuidos entre sus clientes; y los distintos servicios que ofrece a sus clientes (buscar información, suscribir y proporcionar nueva información). El consultor requiere los dos primeros servicios, mientras que el informador hará uso del tercer servicio. Por su parte, el sistema necesitará del servicio de evaluación de información ofrecido por el evaluador, a fin de mantener la calidad de los documentos.

La figura 5.12 muestra la especificación de la vista funcional (misión) del modelo de organización para el ejemplo de sistema de información. Además, el documento Misión Organizativa (tablas 5.4 y 5.5) indica la relación entre 


\section{A.1. Misión Organizativa}

Nombre: Sistema de Información Abierto

Dominio: información general sobre temas de interés

Resultados:

- Producto: información sobre un tema específico. Finalidad: facilitar información adecuada y relevante, de forma inmediata. A quién: cualquiera. Dónde: contactando con el sistema.

- Servicio: búsqueda de información. Finalidad: encontrar información relevante de forma eficiente. A quién: cualquiera. Dónde: contactando con el sistema.

- Servicio: suscripción a un tema. Finalidad: mantenerse informado periódicamente, con datos actualizados y relevantes. A quién: miembro (consultor). Dónde: en la organización.

- Servicio: inclusión de nueva información. Finalidad: aumentar cantidad de información existente. A quién: miembro (informador). Dónde: en la organización.

- Servicio: evaluación de información. Finalidad: maximizar la calidad de la información. A quién: miembro (evaluador). Dónde: en la organización.

Tabla 5.4: Documento A1.Misión Organizativa del sistema de información. (Parte I)

los distintos componentes de la misión (qué ofrece, a quién, con qué finalidad).

Respecto a los stakeholders o grupos de interés (tabla 5.6), se ha identificado: consultor, que se conecta ocasionalmente al sistema para buscar información con una interfaz web o similar; suscriptor, que se suscribe para recibir periódicamente toda la información de un tema determinado; informador, que proporciona nuevos documentos al sistema sobre un tema, o incluso añade nuevos temas; y evaluador, que se encarga de dar una valoración a un documento, para así indicar su relevancia respecto al tema al que pertenece y mejorar la calidad de los documentos del sistema. Como se observa en la tabla, los grupos de interés de la misión se han redefinido en estos cuatro stakeholders, desglosando al "demandante" en consultor y suscriptor.

Por su parte, el entorno a tratar es (tabla 5.7): dinámico, pues podrán 


\section{A.1. Misión Organizativa}

\section{Grupos de interés:}

- Demandante: solicita información del sistema. Consume el producto "información" y los servicios básicos de información (seleccionar información, suscripción a un tema)

- Informador: proporciona nuevos documentos. Produce la materia prima del sistema (nueva información).

- Evaluador: evalúa la calidad de los documentos del sistema. Proporciona el servicio de evaluación.

Justificación: sistema de información que distribuya fácilmente sus documentos, potencie la inclusión de nuevos documentos y controle su calidad.

- Sistemas similares: sistema de información propuesto en la experimentación de INGENIAS

- Ventajas: facilitar la participación optativa de los miembros del sistema en las actividades de evaluación de la calidad de los documentos. Realizar un mayor control sobre el comportamiento de los miembros. Posibilidad de razonamiento sobre las normas. Ofrecer un sistema abierto.

- Desventajas: mayor complejidad al ser un sistema abierto.

- Singularidades: potenciar la heterogeneidad de los miembros del sistema.

Tabla 5.5: Documento A1.Misión Organizativa del sistema de información. (Parte II)

aparecer nuevos temas de interés en el futuro, de forma impredecible; complejo, ya que no se conoce la cantidad de informadores que se tendrá en el sistema; munificiente, pues los recursos necesarios (documentos) son proporcionados por los propios miembros del sistema; diverso (se tienen distintos temas de información); y con alta incertidumbre, al ser un entorno complejo y dinámico. 


\begin{tabular}{|c|c|c|c|c|c|}
\hline \multicolumn{6}{|c|}{ A.2. Grupos de Interés } \\
\hline & \multicolumn{5}{|c|}{ Stakeholder } \\
\hline & Consultor & Suscriptor & \multicolumn{2}{|l|}{ Informador } & Evaluador \\
\hline Beneficiario & Secundario & Primario & \multicolumn{2}{|l|}{ Primario } & Primario \\
\hline Tipo & Cliente & Cliente & \multicolumn{2}{|l|}{ Proveedor } & Proveedor \\
\hline Objetivos & $\begin{array}{l}\text { Obtener in- } \\
\text { formación } \\
\text { puntual }\end{array}$ & $\begin{array}{l}\text { Obtener in- } \\
\text { formación } \\
\text { periódica } \\
\text { de un tema } \\
\text { específico }\end{array}$ & \multicolumn{2}{|c|}{$\begin{array}{l}\text { Redistribuir sus documentos } \\
\text { entre la comunidad }\end{array}$} & $\begin{array}{l}\text { Mantener la } \\
\text { calidad de la } \\
\text { información }\end{array}$ \\
\hline Requiere & $\begin{array}{l}\text { Buscar infor- } \\
\text { mación (pun- } \\
\text { tualmente) }\end{array}$ & $\begin{array}{l}\text { Suscribirse } \\
\text { a temas de } \\
\text { información }\end{array}$ & \multicolumn{2}{|c|}{ Proporcionar información } & \\
\hline Proporciona & $\begin{array}{lr}\text { Feedback } \\
\text { sobre } & \text { docu- } \\
\text { mentos } & \text { de } \\
\text { interés } & \text { para } \\
\text { usuarios } & \end{array}$ & $\begin{array}{l}\text { Feedback so- } \\
\text { bre temas de } \\
\text { interés rele- } \\
\text { vantes para la } \\
\text { comunidad }\end{array}$ & $\begin{array}{l}\text { Documentos } \\
\text { (nueva infor- } \\
\text { mación) }\end{array}$ & $\begin{array}{l}\text { Nuevos temas } \\
\text { de interés }\end{array}$ & $\begin{array}{l}\text { Determina si } \\
\text { la información } \\
\text { es relevante y } \\
\text { en qué grado }\end{array}$ \\
\hline Frecuencia & Ocasional & Frecuente & Ocasional & Ocasional & Frecuente \\
\hline Beneficios & $\begin{array}{l}\text { Resolver su } \\
\text { consulta so- } \\
\text { bre cierta } \\
\text { información } \\
\text { específica }\end{array}$ & $\begin{array}{l}\text { Información } \\
\text { eficiente, } \\
\text { periódica } \\
\text { actual }\end{array}$ & $\begin{array}{l}\text { Dar a cono- } \\
\text { cer su infor- } \\
\text { mación a más } \\
\text { usuarios }\end{array}$ & $\begin{array}{l}\text { Ampliar } \\
\text { temáticas }\end{array}$ & $\begin{array}{l}\text { Gratificación } \\
\text { por sus cono- } \\
\text { cimientos }\end{array}$ \\
\hline $\begin{array}{l}\text { Poder de } \\
\text { decisión }\end{array}$ & $\mathrm{NO}$ & $\mathrm{NO}$ & $\mathrm{NO}$ & $\begin{array}{l}\text { SI (crear nue- } \\
\text { vas temáti- } \\
\text { cas) }\end{array}$ & $\begin{array}{l}\text { SI, determina } \\
\text { los documen- } \\
\text { tos a mantener } \\
\text { en el sistema }\end{array}$ \\
\hline $\begin{array}{l}\text { Influencia } \\
\text { sobre sus } \\
\text { intereses }\end{array}$ & $\begin{array}{ll}\text { Captar a } & \text { a } \\
\text { potenciales } \\
\text { expertos en la } \\
\text { materia }\end{array}$ & $\begin{array}{l}\text { Facilitar la } \\
\text { suscripción a } \\
\text { nuevos temas }\end{array}$ & $\begin{array}{l}\text { Potenciar que } \\
\text { añada más } \\
\text { información } \\
\text { (recompen- } \\
\text { sando) }\end{array}$ & & $\begin{array}{l}\text { Mantenerlo } \\
\text { en el sistema } \\
\text { si realiza un } \\
\text { buen servicio } \\
\text { de evaluación }\end{array}$ \\
\hline
\end{tabular}

Tabla 5.6: Documento A2.Grupos de Interés del sistema de información.

\section{A.3. Condiciones del Entorno}

Tasa de Cambio: dinámico

Complejidad: complejo

Incertidumbre: alta

Receptividad: munificiente

Diversidad: diverso

Tabla 5.7: Documento A.3-Condiciones Entorno del sistema de información. 


\subsubsection{Síntesis de la fase}

La fase A.Misión posibilita conocer a nivel general qué prestaciones y servicios proporcionará el sistema a todos aquellos que requieran hacer uso del mismo. Por tanto, permite: (i) identificar los servicios y productos que proporciona el sistema; (ii) identificar los grupos de interés (clientes que hacen uso de los servicios, proveedores de recursos o de servicios, legisladores); (iii) identificar las condiciones generales del entorno (complejidad, diversidad...); y (iv) justificar la necesidad del sistema a desarrollar.

Como resultado, los documentos y modelos generados en esta fase son:

- Documento A1.Misión: descripción detallada de la misión de la organización.

- Documento A2.Grupos de interés: descripción detallada de las características de los grupos de interés.

- Documento A3. Condiciones Entorno: descripción de las condiciones generales del entorno.

- Diagrama de vista funcional (misión) del modelo de organización: se identifican los productos y servicios que ofrece el sistema, los objetivos globales (misión) que persigue, sus grupos de interés (relación OInteracciona), así como el vínculo existente entre éstos, los resultados del sistema y los recursos o servicios que requiere (relaciones OProduce, OConsume). 


\subsection{Fase B. Tareas y procesos}

En esta fase de la secuencia-guía (figura 5.13) se analiza la tecnología que requiere el sistema, atendiendo a las características principales de los productos y/o servicios; y se desglosan cuáles son los objetivos asociados a los servicios, así como las tareas y procesos a realizar. Esta segunda fase consta de los siguientes trabajos: (i) análisis de la tecnología y (ii) análisis de los objetivos de la organización.

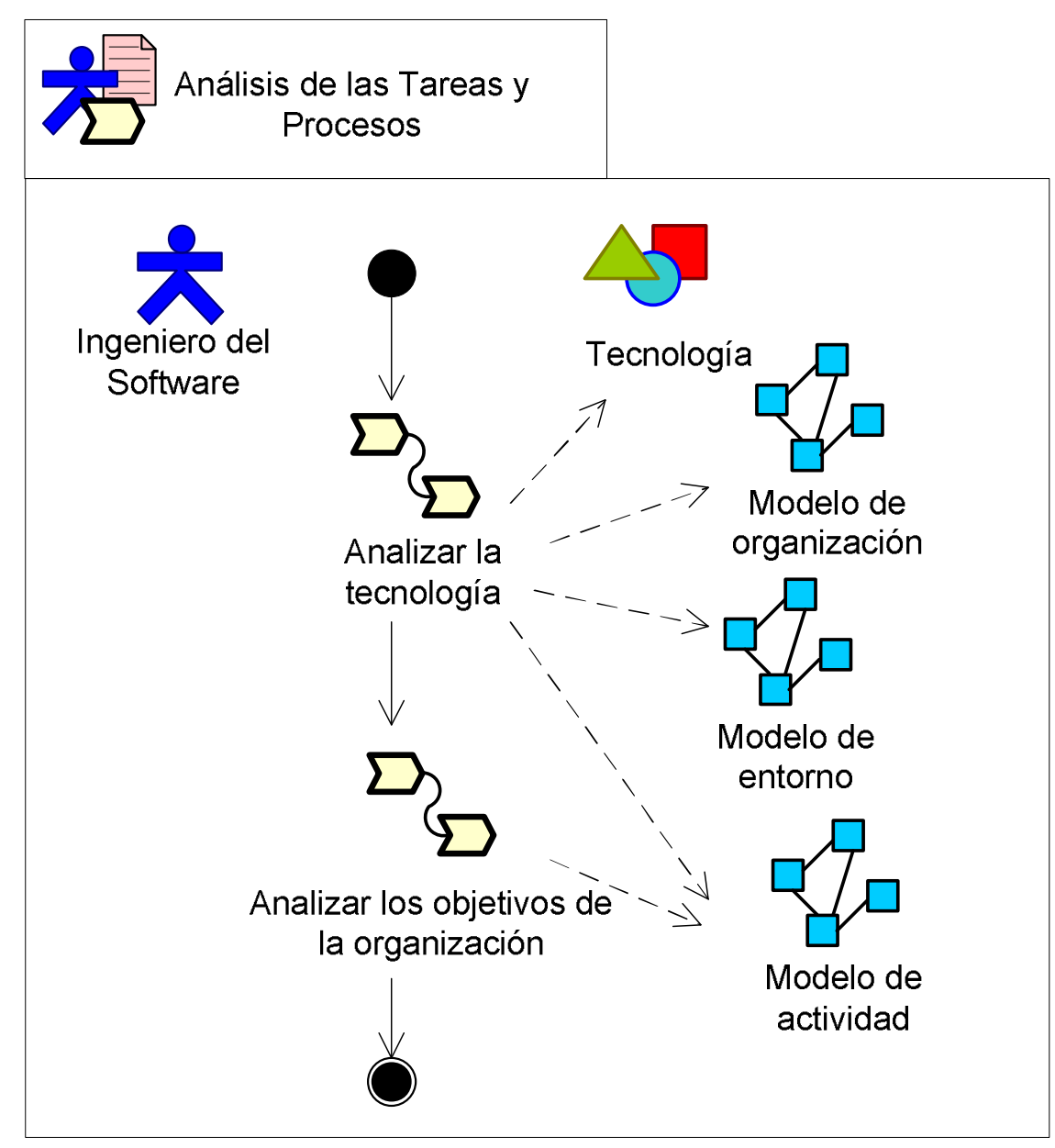

Figura 5.13: Fase de Análisis de tareas y procesos.

El producto de trabajo Tecnología permite describir las tareas existentes 
y su relación (figura 5.14). Se descompone en los documentos B.1 Tecnología esencial y B.2 Tecnología de unidad de trabajo.

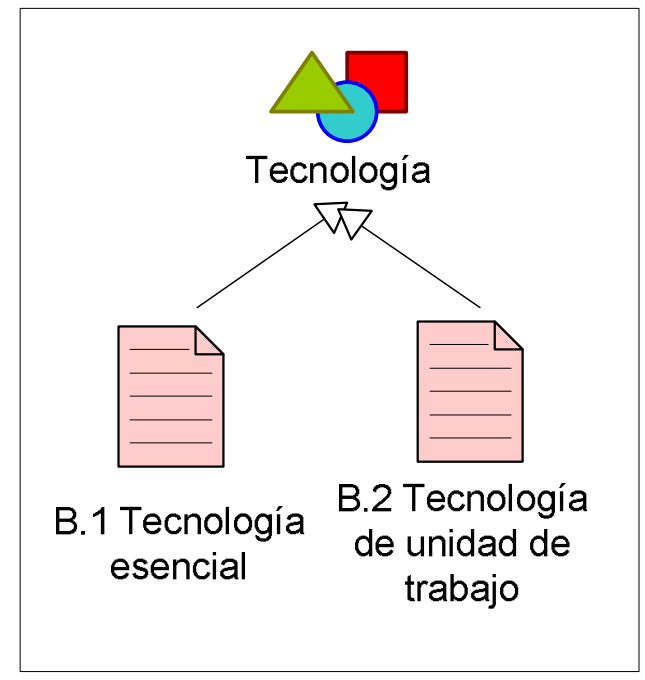

Figura 5.14: Documentos que componen el producto de trabajo Tecnología.

A continuación se detalla cada uno de los trabajos que integran esta fase.

\subsubsection{Analizar la tecnología}

En las organizaciones humanas, la tecnología se define como el conjunto de conocimientos, herramientas, maquinaria, información, habilidades y materiales empleados para completar tareas en una organización [Hodge et al., 2003].

Por tanto, la tecnología se encarga de los procesos de transformación de los recursos básicos en bienes o servicios finales; de la forma en la que los miembros de la organización realizan sus tareas; de la distribución de los productos y servicios; y de cualquier actividad necesaria en la organización. Además, una organización adoptará cierta estructura dependiendo de la tecnología empleada [Hodge et al., 2003].

$\mathrm{Al}$ adaptar el concepto de tecnología a los sistemas multiagente, dicho concepto comprende al conjunto de recursos, aplicaciones, conocimientos 
requeridos por los agentes, así como a la serie de procesos y tareas necesarios para llevar a cabo los servicios que ofrece la organización.

Existen tres niveles de tecnología a considerar [Hodge et al., 2003]: (i) tecnología esencial o tecnología a nivel organizativo, que hace referencia a toda la organización; (ii) tecnología departamental o de unidad de trabajo, que contempla la diversidad y complejidad de las distintas tareas organizativas; y (iii) relaciones interdependientes, originadas como resultado del flujo de trabajo entre las unidades. En la figura 5.15 se muestran los pasos necesarios para el análisis de la tecnología, que se compone de las siguientes actividades: (i) análisis de la tecnología esencial; (ii) análisis de la tecnología de unidad de trabajo y (iii) análisis de las relaciones interdependientes.

TECNOLOGIA ESENCIAL. En la actividad análisis de la tecnología esencial, también denominada tecnología a nivel organizativo, se determina el modo en el que se deben producir los productos o servicios, en función de la demanda y las necesidades del cliente [Hodge et al., 2003], [Wagner y Hollenbeck, 2004], [Daft, 1998].

En las organizaciones humanas, para los productos se determina el tipo de producción que se realiza: orientada a lotes pequeños, en masa, de proceso continuo o flexible.

La producción orientada a lotes pequeños se ajusta a las necesidades específicas de los clientes, implicando una gran interacción con ellos. Se aplica principalmente a productos hechos sobre pedido, como equipos de construcción especializados, equipos electrónicos sobre pedido, ropa a medida, etc.

En la producción en masa se producen grandes lotes de producto y lo importante es la elaboración repetitiva del mismo producto, con una mínima o nula interacción con el cliente. Por ejemplo, se emplea en las líneas de montaje de automóviles.

En la producción de proceso continuo todo el proceso está mecanizado, sin inicio ni final concreto. En este caso se combina con la producción masiva en lotes, como por ejemplo en las plantas químicas, refinerías de petróleo, etc. 


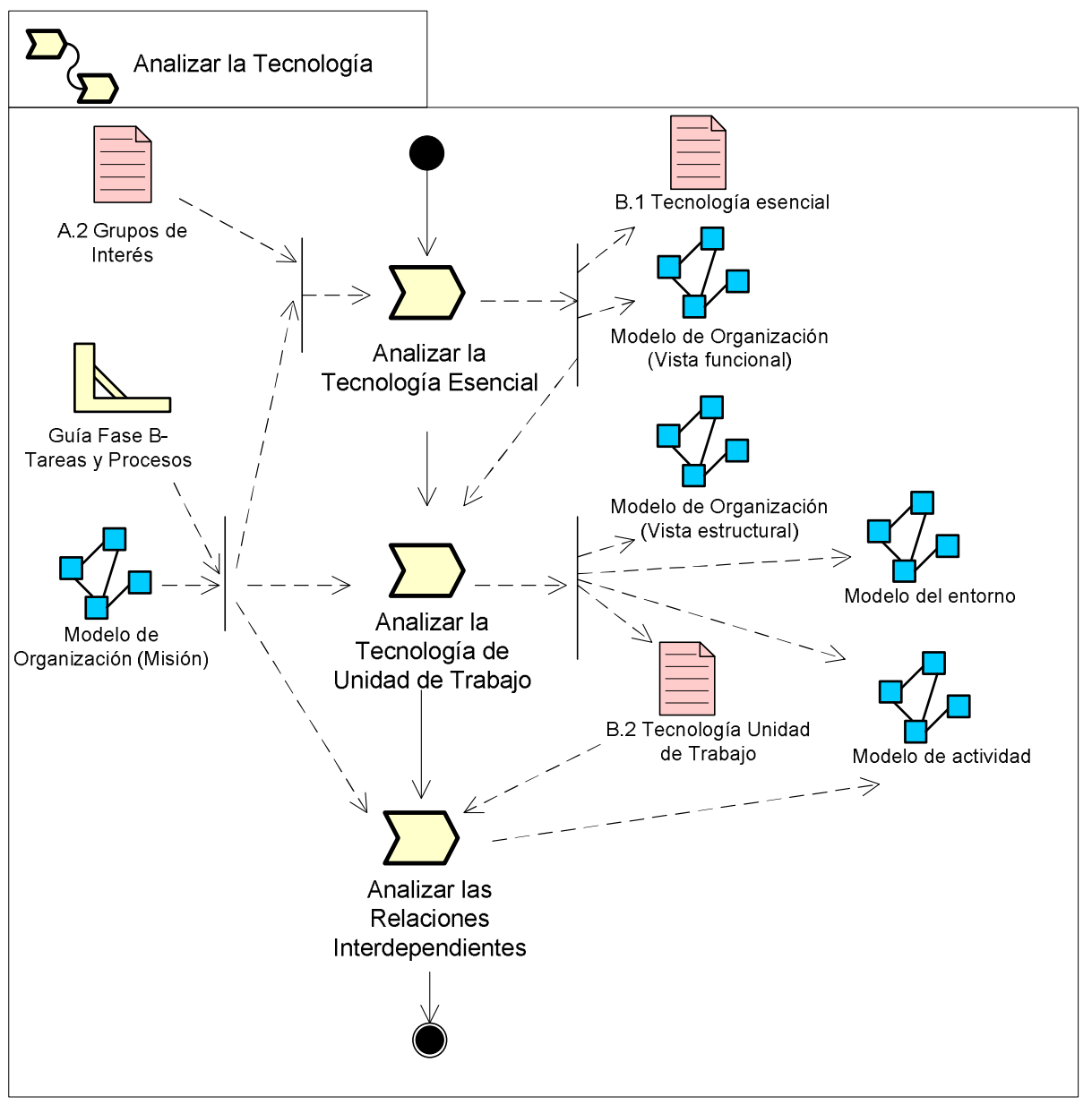

Figura 5.15: Definición del trabajo Analizar la tecnología.

Por último, en la producción flexible el proceso está también mecanizado, pero admite una reconfiguración rápida para adaptar los equipos, máquinas y recursos a distintas tareas de producción. Por ejemplo, se aplica en empresas de cerámica, donde se fabrican determinados productos en lote, pero ante nuevas órdenes se reconfiguran las máquinas para atender dichas demandas.

En los sistemas multiagente, en la secuencia-guía se propone determinar en qué medida el cliente influye en el proceso de producción y en el aspecto final del producto, completando la plantilla de la tabla 5.8 incluida en el 


\section{B.1. Tecnología Esencial. Productos}

¿Los productos obtenidos sirven de recurso para nuevos productos? ¿La producción es continua sin un principio y final claro de la elaboración del producto? ¿Se emplean partes o componentes preparados (módulos) de procesos previos? ¿Se ensamblan los módulos para conseguir productos casi bajo pedido?

Se trata de producción continua

- Sugerencias: identificar los productos básicos que sirven de componentes para productos más complejos o elaborados y representarlos como recursos.

¿Los productos se ajustan a las necesidades del cliente? ¿Cada producto se elabora para un cliente determinado, bajo su petición o requisito? ¿Se gestiona una gran variedad de productos? ¿Se tiene en cuenta una amplia variedad de requisitos de los clientes? ¿Se prevén cambios frecuentes en las características de los productos finales?

Se trata de producción en lotes pequeños

- Sugerencias: representar cada cliente como un A-Agente. Incluirlo como miembro de la Unidad Organizativa que representa al sistema.

¿Un mismo producto podrá ser consumido por distintos tipos de cliente?¿O bien por distintos clientes del mismo tipo?:Su elaboración es independiente de los requisitos de sus consumidores finales?

Se trata de producción en masa

- Sugerencias: crear aplicaciones para contactar con los clientes. La Unidad Organizativa que representa al sistema contendrá tantas aplicaciones como clientes distintos hayamos definido. Cada una de esas aplicaciones permitirá extraer información relativa de un cliente específico.

Tabla 5.8: Documento B.1-Tecnología esencial (Parte I - Productos). Plantilla de descripción de la tecnología esencial para el producto.

documento B1.Tecnología esencial (Parte I - Productos).

Las decisiones tomadas para cada tipo de producción no son excluyentes entre sí, admitiéndose pues las combinaciones de las mismas, según el enfoque que se tome durante el análisis de los productos, servicios y grupos de interés de la organización.

Si se requiere de las decisiones puntuales de cada cliente para establecer los procedimientos de trabajo para la obtención del producto y/o cada producto es elaborado para un único cliente determinado (y consumido solamente por dicho cliente), entonces se trata de una producción orientada a lotes pequeños. 
Por tanto se debe considerar al cliente como un miembro más del sistema, requiriéndose un proceso de admisión del mismo, una fase de adquisición de sus requisitos, así como una fase de comprobación de su satisfacción ante el producto final elaborado.

En esta etapa, por cada cliente identificado se define un $A$-Agente que lo represente (que podrá ser posteriormente refinado en un único agente o en un grupo de agentes). Así, se instancia la vista estructural del meta-modelo de organización, creando la entidad Unidad Organizativa que representa al sistema y se establecen las relaciones OContieneA-Agente con cada $A$ Agente que represente a un tipo de cliente. Además, se crea también una entidad Rol, contenida en la Unidad Organizativa (relación OContieneRol), adoptado por el A-Agente cliente. La asociación entre el A-Agente y dicho Rol se representa en la vista funcional (funcionalidad interna) del modelo de organización (relación WFJuega).

En la fase F.Dinamicidad del sistema abierto de la guía se decidirá si dicho A-Agente debe ser tratado como un agente interno, de modo que directamente tenga asignado el Rol especificado (implementando totalmente su funcionalidad); o bien como un agente externo, que deba hacer uso del servicio de admisión de la Unidad Organizativa correspondiente, con el fin de adquirir el rol final identificado.

En el caso de que un mismo producto sea consumido por distintos clientes (o tipos de clientes), de modo que la elaboración del producto se realice de manera independiente a las decisiones o requisitos puntuales de sus clientes finales, entonces se trata de una producción en masa, por lo que los clientes normalmente permanecerán en el entorno, contactando con la organización pero no formando parte de ella. Para ello se refina la vista estructural del modelo de organización, creando entidades de tipo Aplicación por cada cliente identificado y estableciendo las relaciones OContieneAplicación entre la Unidad Organizativa que representa al sistema y las aplicaciones correspondientes.

Por su parte, en la producción continua se producen de forma repetitiva determinados productos básicos (módulos), los cuales serán posteriormente 
ensamblados para así conseguir productos más especializados. Por tanto, se deben identificar las aplicaciones necesarias para interactuar con los clientes (como en la producción en masa), así como el conjunto de subproductos o productos básicos que sirven de componentes para conseguir productos finales más elaborados, representados como recursos. Estas nuevas entidades se añaden al modelo de entorno.

Finalmente, se revisa la vista funcional (misión) del modelo de organización para especificar los nuevos productos que se hayan identificado en esta fase y establecer las relaciones OProduce y OConsume correspondientes.

Respecto a los servicios, en las organizaciones humanas éstos implican una tecnología de vinculación prolongada, intensiva o de mediación.

En la tecnología de vinculación prolongada o duradera los clientes siguen una cadena de secuencias de tareas o procedimientos establecidos, que dependen unas de las otras.

En la tecnología intensiva la configuración de los procesos de trabajo cambia a medida que los miembros de la organización obtienen determinadas respuestas de sus clientes. Por ejemplo, el tipo de servicios que se ofrece a un pacientes en un hospital varía en función de los resultados de las pruebas y análisis que se le realicen.

Por último, la tecnología de mediación o relacional, en la que se proporcionan servicios que vinculan a los clientes entre sí, ofreciendo un conjunto de funcionalidades homogéneas e independientes. Por ejemplo, los bancos conectan a quienes realizan depósitos y tienen dinero para invertir, con quienes solicitan créditos, ofreciéndoles servicios homogéneos en sus distintas localizaciones o entidades.

Para los sistemas multiagente, en la secuencia-guía se propone la revisión de los servicios identificados en la fase anterior, especificando en qué medida están relacionados entre sí dichos servicios y con respecto a los clientes. Para ello se emplea la plantilla de la tecnología esencial para los servicios (tabla 5.9), incluida en el documento B1.Tecnología esencial (Parte II - Servicios).

Por otro lado, se instancia la vista funcional (funcionalidad externa) del meta-modelo de organización, para así detallar las relaciones existentes 


\section{B.1. Tecnología Esencial. Servicios}

¿La funcionalidad de cada servicio es independiente entre sí? ¿El orden de ejecución de los servicios es indiferente? ¿Existen conexiones de distintos tipos de clientes a través de los servicios?

Se trata de tecnología de mediación

¿Se requiere un orden determinado de ejecución de los servicios? ¿Las entradas de un servicio dependen de las salidas de otros? ¿Un cliente siempre necesita hacer uso de unos servicios previos establecidos para poder solicitar otros servicios?

Se trata de tecnología de vinculación prolongada

¿El orden de los servicios a ofrecer es variable? ¿Depende de las decisiones o requisitos del cliente? ¿Las necesidades de los clientes son impredecibles?

Se trata de tecnología intensiva

Tabla 5.9: Documento B.1-Tecnología esencial (Parte II - Servicios). Plantilla de descripción de la tecnología esencial para el servicio.

entre los servicios. De este modo, por cada $A$-Agente de la vista estructural se indican los servicios que ofrece (relación OOfrece) y se identifican los roles de las entidades que proporcionarán el servicio y de aquellas que lo utilizarán (relaciones WFProporciona y WFUtiliza).

Si se trata de una tecnología de vinculación prolongada, los servicios conectados entre sí deberán tener asociado el mismo rol en la relación WFUtiliza, ya que al mismo cliente se le obligará a seguir la secuencia de servicios establecida.

Si se trata de una tecnología relacional, parte de la funcionalidad de los servicios a ofrecer por el sistema será proporcionada por determinados clientes de dicho sistema, aunque de forma controlada. Por tanto, se identifican los servicios requeridos por la unidad organizativa (relación ORequiere), para los cuales será necesario, más adelante, establecer su perfil y las normas que controlen su ejecución. Así, en el siguiente trabajo o tarea compleja de esta fase (Análisis de la Tecnología de Unidad de Trabajo) se establecen las actividades o tareas en que se descompone el servicio y las entradas y salidas que requiere, definiendo su perfil. Por su parte, en las fases E.Procesos de información-decisión y G.Sistemas de medición, evaluación y control, 
principalmente, se determinan las restricciones sobre la gestión de la información del servicio, la calidad de sus resultados, el orden de ejecución de sus tareas, etc.

En el caso de la tecnología intensiva, debemos tener en cuenta nuevas funcionalidades que, aunque no sean requeridas en la actualidad por los clientes del sistema, podrían ser demandadas en un futuro cercano. Para ello debemos considerar todas las variaciones posibles de los procesos de trabajo, en base a las solicitudes y respuestas de los clientes, así como a las contingencias existentes.

Además, indicamos en la vista funcional (funcionalidad externa) del modelo de organización cuáles son los servicios que ofrece "de facto" la Unidad Organizativa (relación OOfrece), es decir, los servicios identificados inicialmente según los requisitos actuales de los clientes; y cuáles son los servicios que necesitará en un futuro (relación ORequiere). En la fase F.Dinamicidad del sistema abierto de la guía se establecerá qué servicios de los requeridos deben ser proporcionados directamente por el sistema, es decir, con agentes propios que soporten dicha funcionalidad; y cuáles deben ser "contratados", es decir, proporcionados por agentes externos que, de forma ocasional o temporal, entren a participar como miembros de la organización y ofrezcan, en el marco de ésta, dichos servicios.

TECNOLOGÍA DE UNIDAD DE TRABAJO. En la actividad análisis de la tecnología de unidad de trabajo se determinan los flujos de trabajo existentes y para cada uno de ellos se describe la variedad de la tarea y la posibilidad de análisis de la misma.

En las organizaciones humanas, la variedad de la tarea se asocia con el grado de flexibilidad que posee una unidad de trabajo en la realización de sus operaciones [Hodge et al., 2003]. Se dice que una tarea presenta una alta variedad si se caracteriza por presentar excepciones de los procesos operativos estándar, o bien implica la realización de un gran número de tareas distintas y no relacionadas entre sí, o implica numerosos sucesos nuevos o inesperados que requieran diferentes tipos de materias primas o 
recursos.

Para el MAS, la secuencia-guía establece analizar las entradas, salidas y condiciones de flujo de cada servicio, teniendo en cuenta también las posibles variaciones de los mismos y las excepciones previstas.

En concreto, por cada servicio identificado en la vista funcional del modelo de organización se crea una instancia del meta-modelo de actividad, para así asociarle una entidad de PerfilServicio (relación WFEspecifica), para la cual se detallan sus entradas y salidas que requiere. Las precondiciones y postcondiciones se describen en lenguaje natural o preferiblemente en un lenguaje lógico, de modo que se especifique claramente el estado del mundo antes y después de su ejecución, haciendo uso tanto de los elementos del entorno como de las entradas y salidas del servicio. Las postcondiciones deben indicar solamente los cambios producidos en el estado del mundo cuando el servicio se ha ejecutado con éxito.

Por otro lado, se realiza una primera descomposición o estructuración del servicio en una secuencia de pasos o tareas que precisa para su funcionamiento (entidades A-Tarea y relaciones WFDescompone, WFConecta). Asimismo se determina si el servicio requiere de ciertos recursos y cuáles son los productos obtenidos que están relacionados con el servicio (relaciones WFConsume y WFProduce).

Como complemento a la identificación de las características del servicio se hace uso de la plantilla de la tabla 5.10, incluida en el documento B.2Tecnología de Unidad de Trabajo (Parte I - Servicios). Se debe generar un documento de este tipo por cada servicio identificado hasta el momento.

Respecto a los productos, si además se tiene una tecnología de producción de lotes pequeños, entonces se establece cuáles son las características generales del producto, en qué aspectos el cliente refleja sus requisitos y en qué grado (es decir, los valores mínimos, máximos y granularidad existente para cada característica del producto). Para ello se hace uso de la plantilla de descripción de las características del producto (tabla 5.11), incluida en el documento B2.Tecnología de Unidad de Trabajo (Parte II - Productos). Por cada producto identificado se genera un documento de este tipo 


\begin{tabular}{|c|c|}
\hline \multicolumn{2}{|c|}{ B.2. Tecnología de Unidad de Trabajo. Servicios } \\
\hline Nombre & Nombre del servicio \\
\hline Descripción & Breve descripción sobre la funcionalidad del servicio \\
\hline Condiciones & \\
\hline Contexto & Especificación del entorno en el que se ejecuta el servicio \\
\hline Excepciones & $\begin{array}{l}\text { Condiciones que impiden que el servicio se ejecute de for- } \\
\text { ma adecuada }\end{array}$ \\
\hline Consumidor & Actor que solicita hacer uso del servicio \\
\hline Objetivo & Qué persigue al hacer uso del servicio \\
\hline Precio & Valor que tendrá que pagar por consumir el servicio \\
\hline Beneficio & Descripción del beneficio que obtiene el consumidor \\
\hline Productor & Actor que se encarga de ofrecer el servicio, de ejecutarlo \\
\hline Objetivo & Qué se persigue al producir este servicio \\
\hline Coste & $\begin{array}{l}\text { Descripción del coste que se conlleva la realización del } \\
\text { servicio }\end{array}$ \\
\hline Beneficio & Descripción del beneficio que obtiene al realizar el servicio \\
\hline $\begin{array}{l}\text { Perfil del servi- } \\
\text { cio }\end{array}$ & \\
\hline Entradas & Información a suministrar al servicio \\
\hline Precondiciones & $\begin{array}{l}\text { Condiciones de las entradas y de determinados valores del } \\
\text { entorno para que el servicio se solicite de forma adecuada }\end{array}$ \\
\hline Salidas & Información que devuelve el servicio \\
\hline Postcondiciones & $\begin{array}{l}\text { Estados finales de los parámetros del entorno, en función } \\
\text { de los distintos tipos de salida considerados }\end{array}$ \\
\hline Funcionalidad & \\
\hline Tareas & $\begin{array}{l}\text { Conjunto de tareas que comprende el servicio. Indicar } \\
\text { también cuáles de esas tareas vendrán representadas a } \\
\text { través de nuevos servicios }\end{array}$ \\
\hline Recursos & $\begin{array}{l}\text { Entidades del entorno de las que hará uso, materias pri- } \\
\text { mas requeridas }\end{array}$ \\
\hline Proveedor & Actor que proporciona los recursos indicados \\
\hline Productos & $\begin{array}{l}\text { Resultados tangibles relacionados con la ejecución del ser- } \\
\text { vicio }\end{array}$ \\
\hline
\end{tabular}

Tabla 5.10: Documento B.2-Tecnología de Unidad de Trabajo (Parte I Servicios). Plantilla de descripción de las características del servicio. 


\begin{tabular}{|l|l|}
\hline \multicolumn{2}{|c|}{ B.2. Tecnología de Unidad de Trabajo. Productos } \\
\hline Nombre & Nombre del producto \\
\hline Descripción & Breve descripción sobre el producto o definición del mismo \\
\hline Parámetros & Características del producto que se van a considerar \\
\hline Margen inferior & Valores mínimos permitidos para cada parámetro \\
\hline Margen superior & Valores máximos permitidos para cada parámetro \\
\hline Granularidad & Grado de variación de los valores de cada parámetro \\
\hline Recursos & $\begin{array}{l}\text { Entidades del entorno de las que hará uso, materias primas } \\
\text { requeridas }\end{array}$ \\
\hline Sugerencia & $\begin{array}{l}\text { Si se emplea tecnología de lotes pequeños, establecer las } \\
\text { distintas variables que los clientes podrán especificar, su } \\
\text { grado de variación y de predicción. Indicar también si se } \\
\text { deberán detectar nuevas especificaciones. }\end{array}$ \\
\hline
\end{tabular}

Tabla 5.11: Documento B.2-Tecnología de Unidad de Trabajo (Parte II Productos). Plantilla de descripción de las características del producto.

y además una instancia del meta-modelo de entorno, detallando en él la entidad Producto y sus características correspondientes. Por su parte, se revisa la vista estructural del modelo de organización, para añadir todas las relaciones OContieneRecurso que se requieran.

La posibilidad de análisis de los problemas implica la facilidad o dificultad existente para buscar información que permita solucionar problemas o finalizar tareas. En este caso, se analiza dónde se obtiene la información necesaria para el sistema, generalmente de los recursos y aplicaciones. Así, mediante el modelo del entorno se describen los recursos y aplicaciones que los servicios, a través de las tareas que los desempeñan, consumen, producen o utilizan. Para ello se revisan las instancias de este modelo, definiendo las relaciones EPercibe y ERecursoPertenece oportunas.

Por otro lado, en ocasiones la información requerida vendrá ofrecida por servicios de otras entidades. Por ello, en el modelo de actividad se debe indicar cuáles son estos servicios requeridos a través de la relación WFInvoca, permitiendo así la composición de servicios entre distintas entidades. 
RELACIONES INTERDEPENDIENTES. En la actividad análisis de las relaciones interdependientes se especifica cuál es la relación existente entre las unidades de la organización para alcanzar las metas organizativas.

En las organizaciones humanas, existen tres tipos de interdependencia a considerar [Hodge et al., 2003]: agrupada, secuencial y recíproca.

En la interdependencia agrupada cada unidad funciona de manera independiente, utilizando procedimientos y normas altamente estandarizados, por lo que la necesidad de coordinación entre unidades es prácticamente mínima.

En la interdependencia secuencial las operaciones de la organización discurren en serie o paso a paso, de modo que se debe completar un paso después de otro siguiendo un orden determinado, por lo que las unidades están enlazadas entre sí a modo de línea o cadena de trabajo y deben sincronizarse para proporcionarse sus entradas y salidas de forma adecuada.

Por último, en la interdependencia recíproca las unidades dependen unas de otras y en ocasiones es necesario integrar diversas habilidades, técnicas y métodos para lograr un objetivo concreto.

Para el MAS, nuestra secuencia-guía propone analizar las interdependencias existentes entre las UO en base a sus flujos de tareas. Así estableceremos en primer lugar qué flujos de tareas resultan totalmente independientes entre sí (interdependencia agrupada). De este modo se especifica qué tareas no se encuentran directamente relacionadas y, por tanto, podrán ser ejecutadas de forma simultánea o concurrente. En segundo lugar se identifica la secuencia de pasos requerida entre las tareas dependientes. Todo esto da lugar a la revisión y ampliación del modelo de actividad, estableciendo las relaciones WFConecta y WFDescompone necesarias.

\subsubsection{Analizar los objetivos de la organización}

Además de la misión, existen otras metas u objetivos de la organización que se derivan de ella [Hodge et al., 2003], [Wagner y Hollenbeck, 2004]: los objetivos funcionales y los objetivos operativos. 
Los objetivos funcionales representan las acciones específicas de las divisiones, departamentos o unidades de la organización, así como los resultados que se espera que consigan. Normalmente se basan en alguno de los siguientes tipos de objetivos: satisfacción del cliente y/o de otros grupos de interés; mejora continua de los procesos, productos y servicios de la organización; cooperación entre todos los miembros, participación activa, compromiso con sus tareas.

Los objetivos operativos son los resultados específicos y medibles que se espera que consigan los miembros de una unidad.

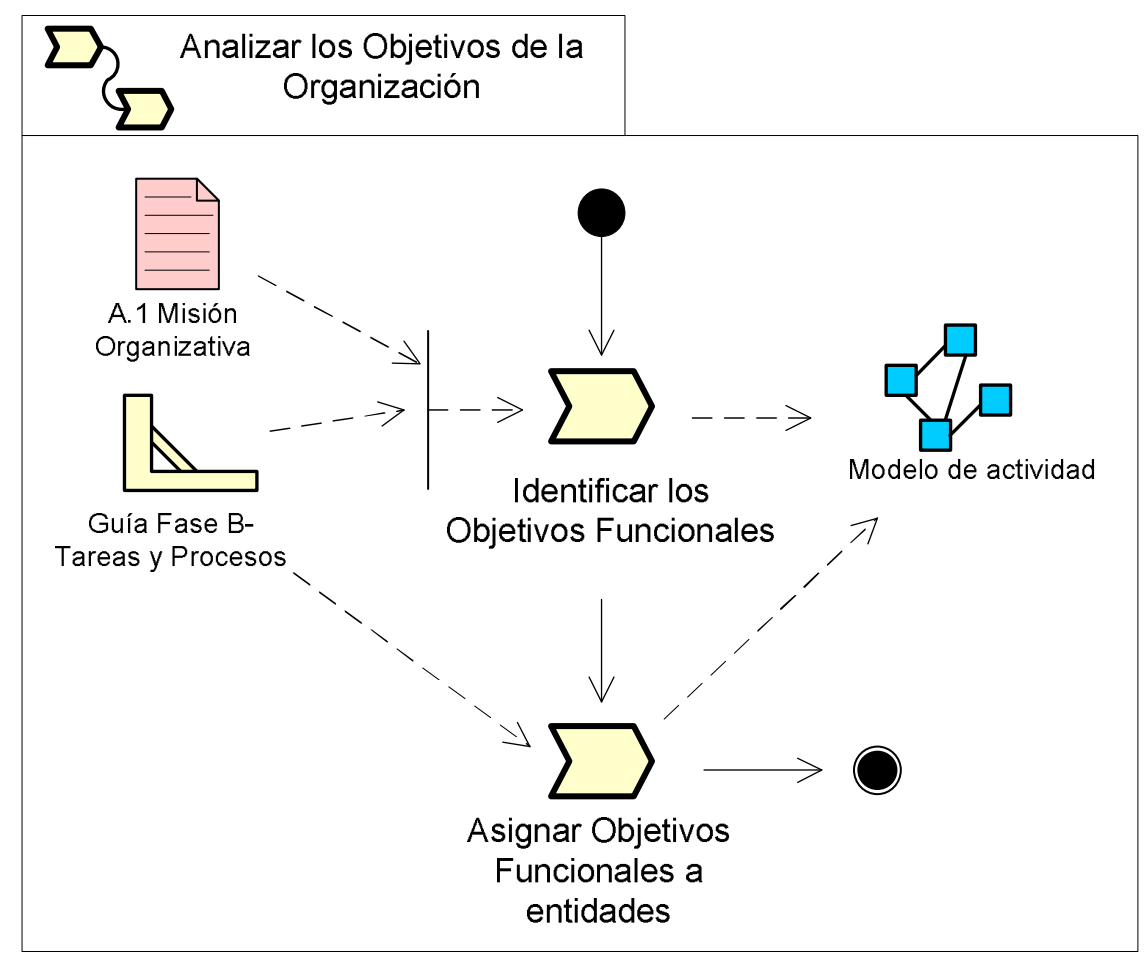

Figura 5.16: Definición de la tarea Analizar los objetivos de la organización.

El trabajo Analizar los objetivos de la organización aborda la descomposición del objetivo global del sistema (misión) en objetivos funcionales, así como la correlación de dichos objetivos con las Unidades Organizativas, A-Agentes y servicios identificados. La descomposición correspondiente de los objetivos funcionales en objetivos operativos se deja para la fase E de 
la guía, donde se establecen los procesos de decisión de las entidades.

Las actividades a realizar en esta tarea son (figura 5.16): (i) identificar los objetivos funcionales; y (ii) asignar los objetivos funcionales a entidades.

En la primera actividad, para cada A-Agente o Unidad Organizativa identificada en el modelo de organización se asigna una especialización de los objetivos de misión, atendiendo a los productos que genera, los tipos de clientes que agrupa o bien los tipos de servicios que atiende. El objetivo funcional generado se describe en términos generales de rentabilidad, producción, eficiencia o satisfacción de los clientes propios de ese A-Agente. De este modo, se extiende el modelo de actividad con nuevas entidades de Objetivo funcional, relaciones GTPersigue entre los A-Agente y esos objetivos; y relaciones GTDepende entre la misión y los objetivos funcionales.

En la segunda actividad, para cada entidad Servicio del modelo de actividad se establece su relación GTAfecta con uno o más objetivos funcionales de la Unidad Organizativa en donde se ofrezca dicho servicio.

\subsubsection{Aplicación de la fase al caso de estudio}

Sobre el caso de estudio del sistema de información se ha realizado el análisis de la tecnología y de los objetivos de la organización. A continuación se detallan los resultados obtenidos para cada una de las tareas contempladas en esta fase.

Tecnología Esencial. En nuestro ejemplo, los informadores incluirán (producirán) nuevos documentos, que serán distribuidos (consumidos) entre todos aquellos clientes suscritos al tema y también a aquellos clientes que realicen una búsqueda puntual de información relativa a dicho tema.

Como se indica en el documento B.1-Tecnología esencial (tabla 5.12), se emplea una tecnología de producción mixta, que combina la producción en masa y la producción en lotes pequeños. Así, por un lado los consumidores finales de los productos (documentos) no intervienen directamente en la elaboración del mismo y, en principio, cualquiera de ellos puede acceder a dicho producto (si es de la temática que le interesa). Por tanto se trata 


\section{B.1. Tecnología Esencial}

Tecnología de producto: producción en masa y producción en lotes pequeños. En masa: los productos (documentos de información) se registran en el sistema con independencia del usuario final que vaya a consumirlo. No se tienen en cuenta los requisitos de los clientes futuros. Además, un mismo producto podrá ser usado (solicitado) por cualquier cliente.

En lotes pequeños: los informadores proporcionan documentos que se convertirán en un producto final (i.e. se incluye documento en el sistema) en base a los requisitos de los evaluadores, que establecen los requisitos mínimos de calidad que esos documentos deben cumplir.

Tecnología de servicio: mediación. Los servicios ofrecidos son independientes entre sí (no se requiere un orden explícito entre ellos). Además, el cliente "evaluador" se interrelaciona con el cliente "informador" a través de los servicios del sistema (evaluación información y proporcionar información).

Tabla 5.12: Documento B.1-Tecnología esencial para el Sistema de Información.

como una tecnología de producción en masa.

Por otro lado, los documentos deben pasar por un proceso de evaluación de su calidad, donde se analiza, en primer lugar, si el documento pertenece al tema indicado y, en segundo lugar, si la información que proporciona resulta relevante para los especialistas de la materia. Para ello se consultará a diversos evaluadores, acreditados en la materia, los cuales podrían ser también consumidores finales del producto. Por tanto, se trata también como una tecnología de producción orientada a lotes pequeños, que tendrá en cuenta, en este caso, las preferencias y requisitos de los evaluadores.

Como producción en masa, se contacta con los productores (informador) y con los consumidores de los documentos (consultor, suscriptor) a través de una interfaz de usuario. Para ello se crea una aplicación que, mediante interfaz web, permita conectarlos con el sistema. Dicha aplicación ofrece una interfaz para cada uno de los tipos de servicios ofrecidos que requieren estos actores. En la figura 5.17 se muestra la especificación de la vista estructural del modelo de organización para el sistema de información, donde está representada dicha aplicación (llamada Interfaz Usuario). 


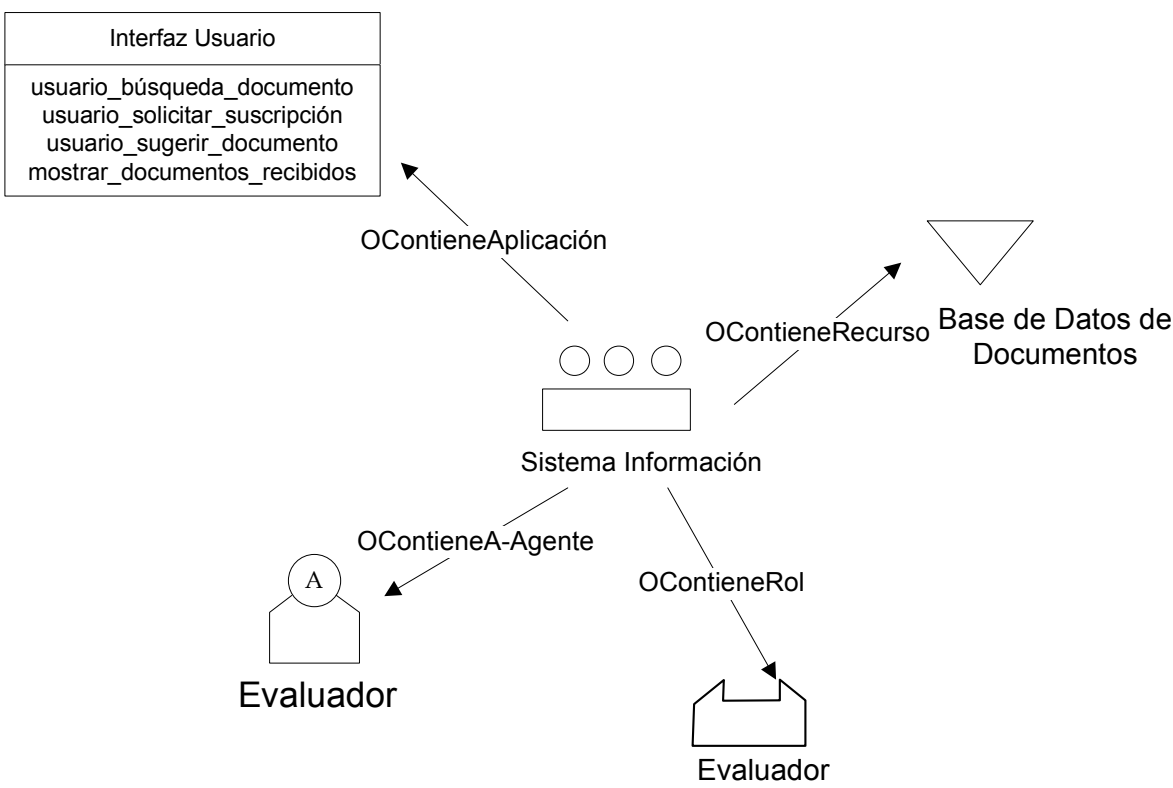

Figura 5.17: Diagrama de la vista estructural del modelo de organizacion del sistema de información.

Como producción en lotes pequeños, los informadores proporcionan documentos que se convertirán en productos finales en base a los requisitos de los evaluadores, que ejercen en este caso de clientes de dichos productos. Por tanto, necesitamos conocer bien quiénes son dichos evaluadores, para así atender de forma correcta a sus requisitos.

Para ello se crea una entidad A-Agente que representa al evaluador, la cual juega el rol evaluador dentro de la unidad organizativa Sistema Información. En la figura 5.17 se muestran las relaciones OContieneA-Agente y OContiene-Rol correspondientes. Además, en la figura 5.18 se ofrece la vista funcional del modelo de organización, donde se asocia al A-Agente evaluador con el rol específico que juega (relación WFJuega).

En la fase F.Dinamicidad del sistema abierto de la secuencia-guía se decidirá si dicho A-Agente será tratado como un agente interno, de modo que directamente tendrá asignado el rol de evaluador; o bien como un agente externo que deberá hacer uso del servicio de admisión de la Unidad Organizativa correspondiente, para así adquirir el rol de evaluador. 


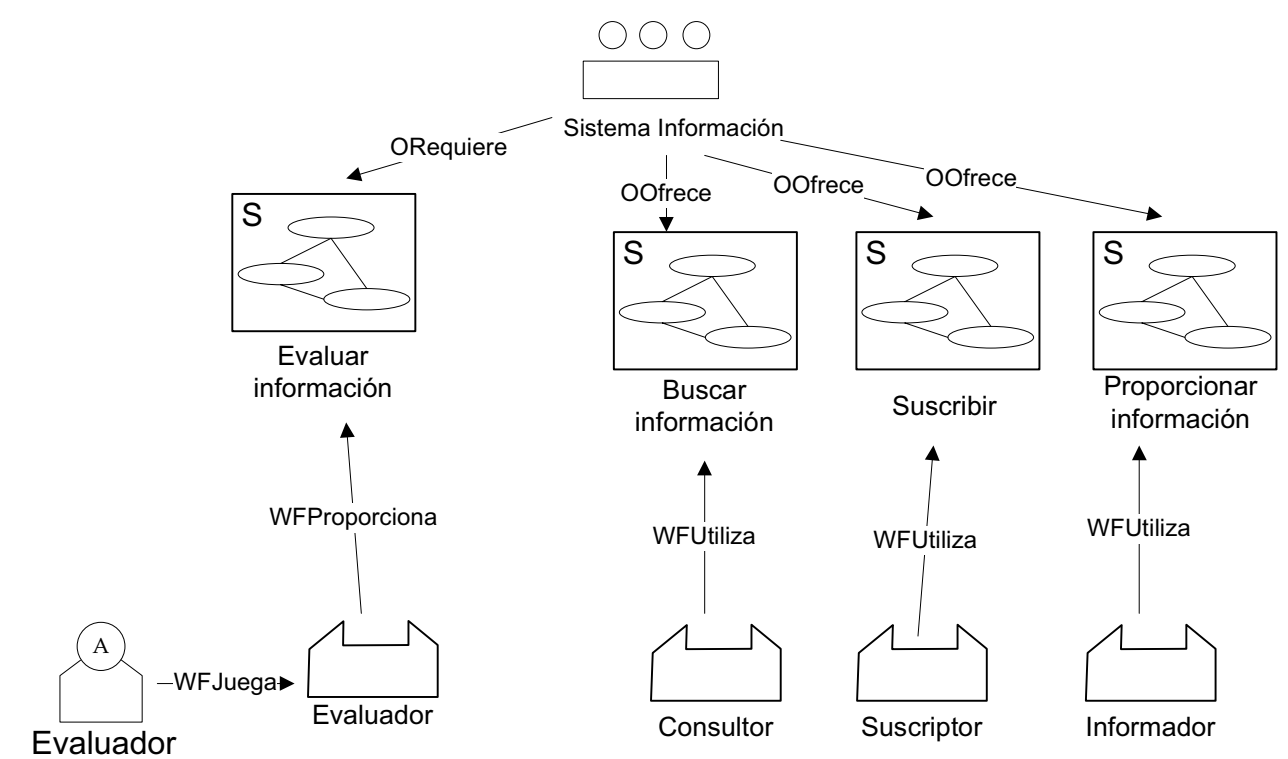

Figura 5.18: Diagrama de la vista funcional del modelo de organización del sistema de información.

Respecto a la tecnología de servicio (tabla 5.12) se emplea una tecnología de mediación, al relacionar entre sí a evaluadores e informadores, así como proporcionar servicios completamente independientes, ya que no se requiere realizar una búsqueda o una suscripción previa para proporcionar o suministrar nueva información, ni viceversa.

La figura 5.18 muestra la especificación de la vista funcional del modelo de organización, en el que se relacionan los servicios concretos que ofrecen los A-Agentes Evaluador y Sistema Información; así como los roles a desempeñar por los proveedores y consumidores de dichos servicios.

Tecnología de Unidad de Trabajo. Se han analizado cada uno de los servicios indicados en la funcionalidad externa de la organización utilizando el documento B2.Tecnología de Unidad de Trabajo, realizando también la especialización de su modelo de actividad concreto.

En la tabla 5.13 se muestran las características del servicio Proporcionar Información y en la figura 5.19 su diagrama de actividad, indicando su perfil y las A-Tareas en las que se descompone. En la figura 5.20 se muestra 


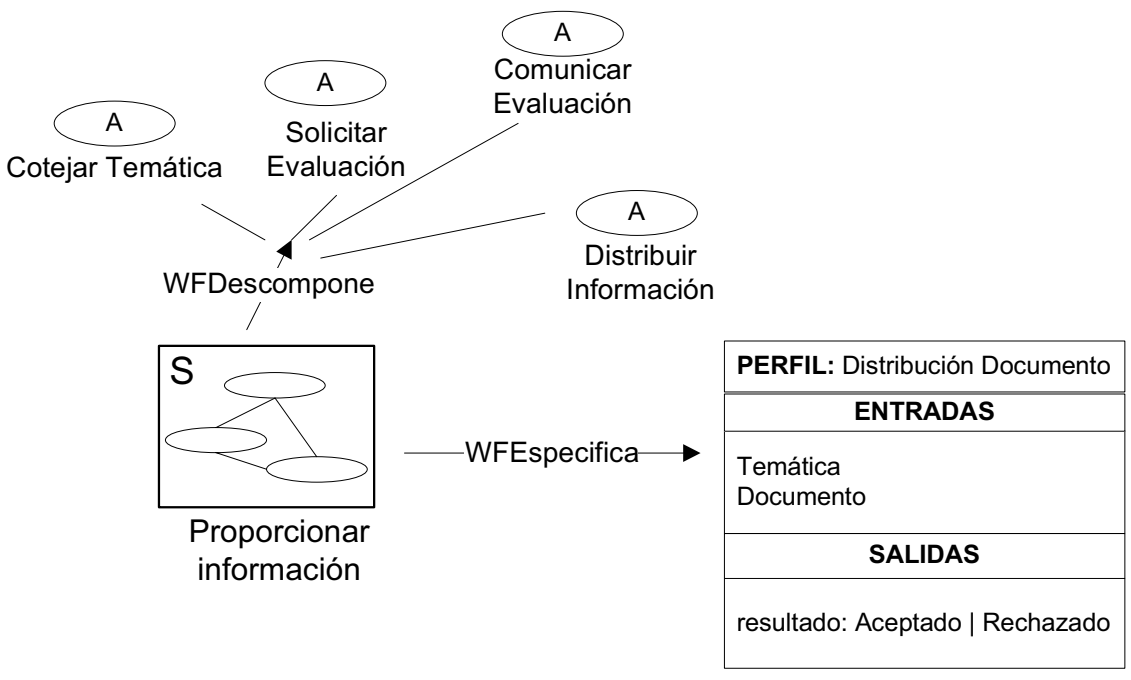

Figura 5.19: Diagrama del modelo de actividad para el servicio Proporcionar Información.

la relación existente entre dichas A-Tareas, detallando también las entradas que consumen y las salidas que producen, así como los servicios que requieren invocar.

$\mathrm{Al}$ emplear una tecnología de producción en lotes pequeños, se requiere incluir en el modelo de entorno una entidad que represente al producto a tratar. En este caso los documentos de información se agrupan en una Base de Datos de Documentos, contenida en el Sistema de Información (figura 5.17, relación OContieneRecurso).

En la figura 5.21 se muestra el modelo de entorno del sistema, donde se especifican las características de los recursos y aplicaciones identificados. La Base de Datos se ha asignado, de momento, a la unidad organizativa Sistema Información.

Relaciones Interdependientes. En el sistema se ha identificado hasta ahora una única Unidad Organizativa (Sistema Información), que ofrece los servicios Buscar Información, Suscribir y Proporcionar Información. Estos servicios presentan interdependencia agrupada, pues no se exige ningún orden estricto para su solicitud por parte de los roles que los utilizan. Es más, 


\begin{tabular}{l} 
B.2. Tecnología de Unidad de Trabajo \\
\hline Servicio: Proporcionar Información \\
\hline Descripción: Sugerir un documento al sistema. Dicho documento \\
será proporcionado a todos los suscriptores de la temática concreta \\
\hline Consumidor: Cliente "informador" \\
- Objetivo: Añadir nuevos documentos a la temática. Incrementar la co- \\
lección de documentos interesantes \\
- Beneficio: Compartir su información con otros usuarios interesados. \\
Conocer si dicha información es aceptada o no por los expertos (saber si \\
realmente es información de interés) \\
\hline Productor: Gestor de información \\
- Objetivo: Mantener la calidad de los documentos del sistema \\
\hline Perfil del servicio \\
- Entradas: Temática + Documento \\
• Temática: tema general del que trata la información del documento. \\
Puede ser uno o varios conceptos. \\
- Documento: información que se desea incorporar al sistema (y pro- \\
pagar al resto de miembros) \\
- Precondiciones: Temática existente; documento no vacío \\
- Salidas: Aceptado - Rechazado \\
- Postcondiciones: [Aceptado] Documento registrado en el sistema y pro- \\
pagado al resto de suscriptores de la temática \\
\hline Funcionalidad \\
- Tareas: CotejarTemática + SolicitarEvaluación + ComunicarEvalua- \\
ción + DistribuirInformación \\
• CotejarTemática: se comprueba que la temática del documento coin- \\
cide (en gran medida) con alguna de las temáticas conocidas en el sistema. \\
• SolicitarEvaluación: solicitar que el documento sea evaluado por ex- \\
pertos en la temática \\
• ComunicarEvaluación: tras analizar las respuestas de los expertos, se \\
establece el resultado final de la evaluación (Aceptado/Rechazado) \\
• DistribuirInformación: si [Aceptado], se registra el documento en el \\
sistema y se envía a todos los suscriptores de la temática \\
- Recursos: Base de datos de documentos \\
- Proveedor: Sistema \\
- Productos: Evaluación final (Aceptado/Rechazado); número votos de \\
aceptación; número votos de rechazo \\
\hline
\end{tabular}

Tabla 5.13: Documento B.2-Tecnología de Unidad de Trabajo. Descripción de las características del servicio Proporcionar Información. 


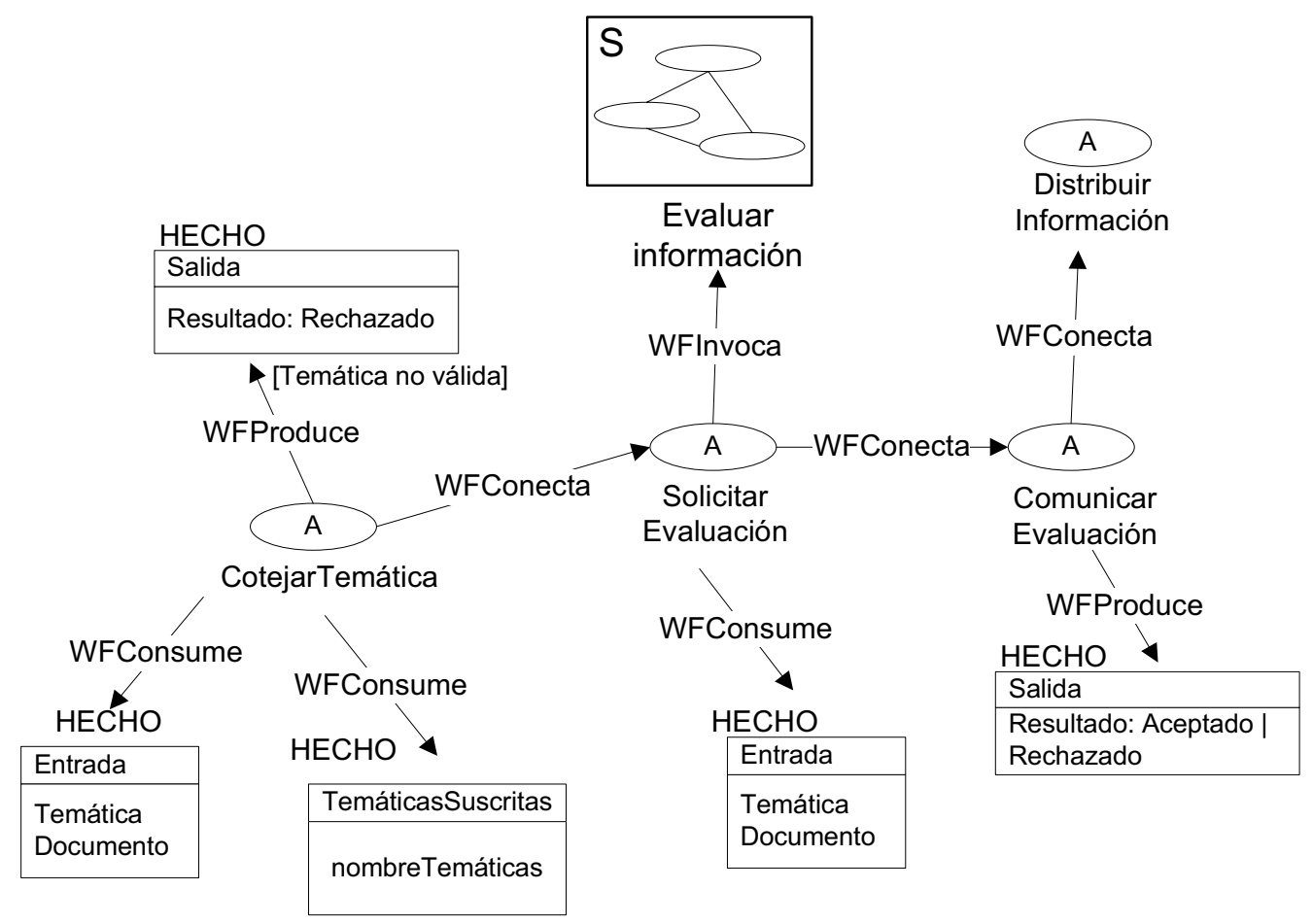

Figura 5.20: Diagrama del modelo de actividad para el servicio Proporcionar Información. Descripción detallada de la relación existente entre las ATareas que lo componen.

se han identificado roles diferentes para cada uno de esos servicios.

Análisis de Objetivos. Los objetivos de la misión se descomponen o refinan en objetivos funcionales, atendiendo a aspectos de desempeño, producción y rentabilidad del sistema. Además, se asocian con los servicios, ampliando así el modelo de actividad con la relación GTAfecta.

El objetivo "proporcionar información relevante" está directamente relacionado con el desempeño del sistema y contribuyen a él los servicios Suscribir y Buscar Información. Su descomposición da lugar a los objetivos "proporcionar información relevante periódicamente", "proporcionar información relevante puntualmente" y "suscribirse a fuentes de información". 


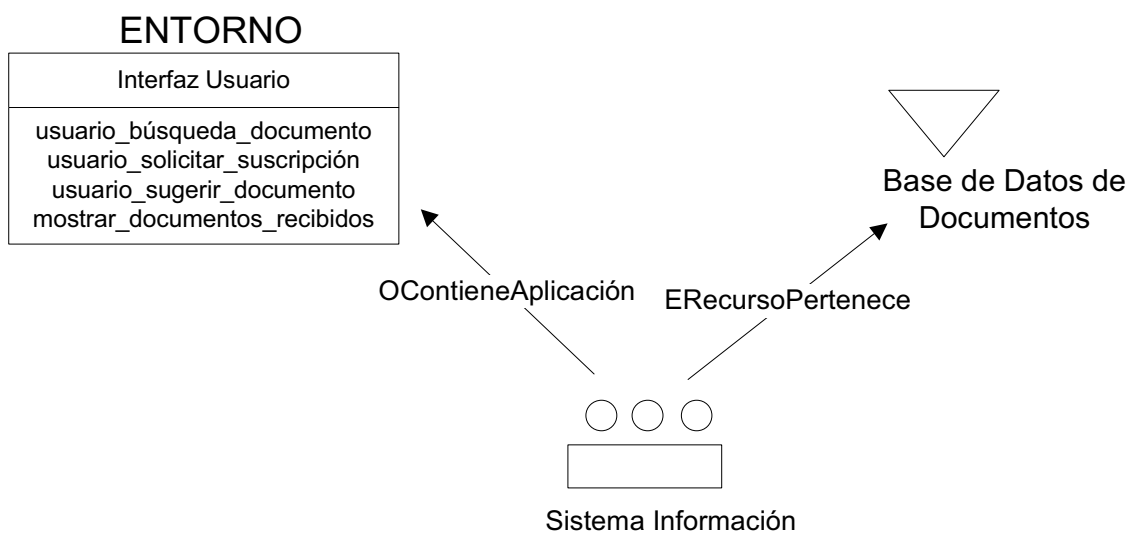

Figura 5.21: Diagrama del modelo de entorno.

El objetivo "mantener la calidad de los documentos" se refina en el objetivo "maximizar la calidad de los documentos", en base al aspecto de rentabilidad. El servicio Evaluar Información afecta a dicho objetivo.

Finalmente, el objetivo "aumentar la cantidad de documentos" está relacionado con el aprovisionamiento y la producción, refinándose en los objetivos "distribuir documentos", "proporcionar documentos" e "incrementar la colección de documentos". El servicio Proporcionar Sugerencia afecta directamente a estos objetivos.

En la figura 5.22 se muestra el diagrama de modelo de actividad para estos servicios y su relación con los objetivos funcionales.

\subsubsection{Síntesis de la fase}

En la fase B. Tareas y Procesos se especifican cuáles son los servicios que ofrece la organización a sus clientes; cómo funcionan dichos servicios (descripción de sus entradas/salidas; tareas asociadas) y las relaciones existentes entre estos servicios (interdependencias).

Esta fase permite: (i) identificar el tipo de productos y servicios que oferta el sistema a sus clientes; (ii) identificar las tareas relacionadas con la producción de esos productos y servicios, definiendo los pasos necesarios para su obtención, sus relaciones e interdependencias entre los distintos 


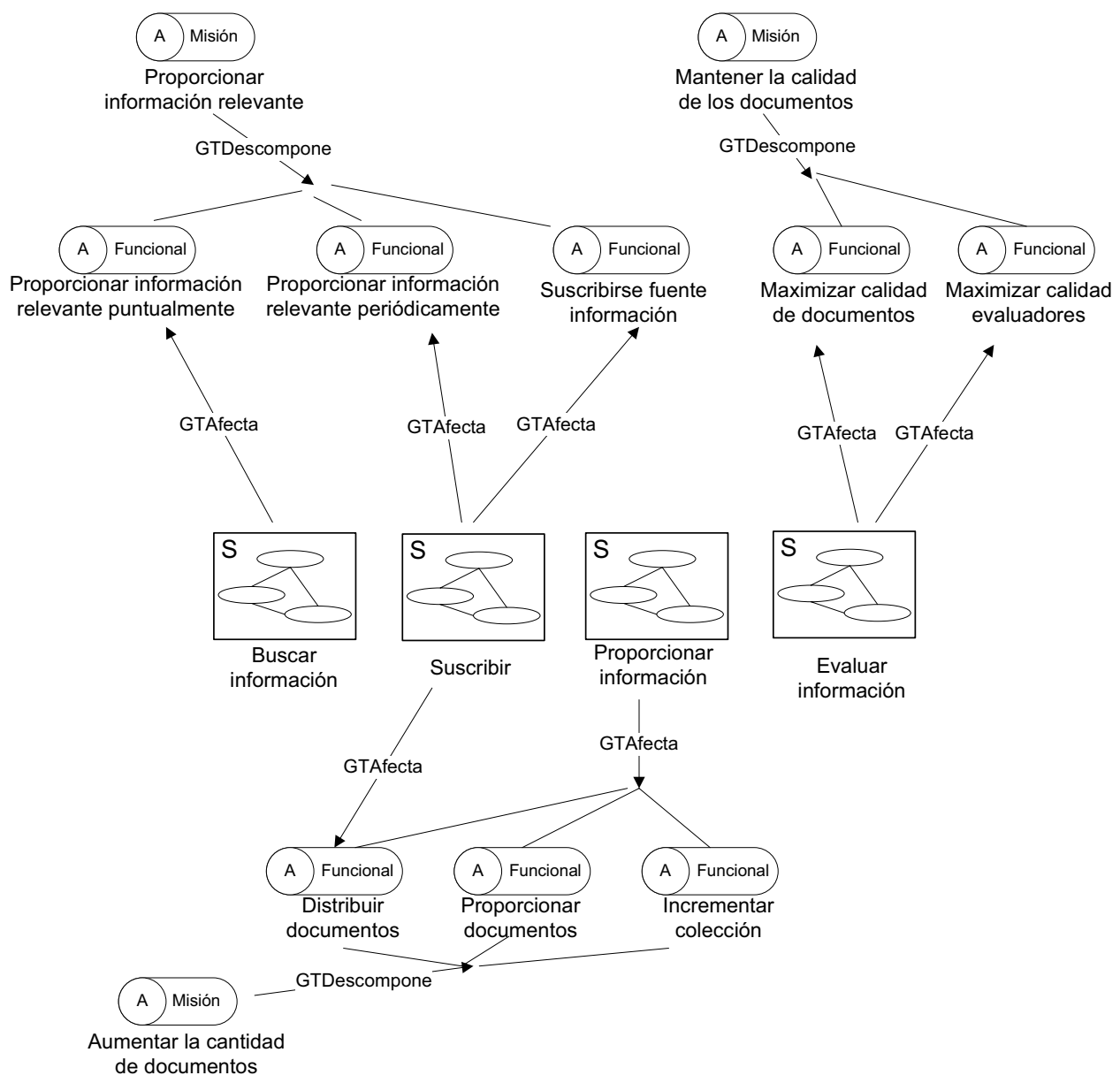

Figura 5.22: Diagrama del modelo de actividad. Relación entre servicios y objetivos funcionales.

servicios y tareas; (iii) asociar objetivos a la producción de esos productos y servicios; (iv) identificar los recursos y aplicaciones a los que se accede para ofrecer esa funcionalidad; y finalmente (v) definir roles y asociarlos a los stakeholders, en base al tipo de servicios o tareas con las que se relacionen.

Los documentos y modelos a generar en esta fase son:

- Documento B1. Tecnología esencial (Parte I - Productos y Parte II - Servicios): plantillas de descripción de la tecnología esencial para el producto y para el servicio. Permiten identificar el tipo de producción 
y/o el tipo de tecnología requerida.

- Documento B2. Tecnología de unidad de trabajo (Parte I - Servicios y Parte II - Productos): plantillas de descripción de las características de los productos y servicios del sistema.

- Diagrama de vista estructural del modelo de organización: se identifican los recursos y aplicaciones del sistema, asociándolos a la Unidad Organizativa (relaciones OContieneRecurso y OContieneAplicación).

En su caso, se identifican las entidades A-Agente que representen a clientes, así como la relación OContieneA-Agente.

- Diagrama de vista funcional del modelo de organización: se indican las relaciones ORequiere y OOfrece entre la Unidad Organizativa que representa al sistema o bien entidades A-Agente y los servicios identificados.

Se identifican los roles y relaciones WFProporciona y/o WFUtiliza, en base a quiénes ofrecen la funcionalidad del servicio (proveedor) y quiénes actúan como clientes de la misma.

- Diagramas de modelo de actividad: para cada servicio identificado se especifica su perfil (relación WFEspecifica), detallando sus entradas/salidas y precondiciones/postcondiciones.

Además, se indican las $A$-Tareas en las que se descompone cada servicio (relación WFDescompone), así como la relación entre ellas, en base al flujo de entradas y salidas que requieren (relaciones WFConsume y WFproduce); y el orden existente entre los servicios o tareas (WFConecta, WFInvoca).

También se indica la descomposición del objetivo misión en los objetivos funcionales, en base a la relación GTDepende. Además, se indica la asociación entre servicios y objetivos funcionales (relación GTAfecta). 
- Diagramas de modelo de entorno: para cada recurso y aplicación del sistema se especifican sus características propias. Además se identifican las relaciones EPercibe y ERecursoPertenece con respecto a las entidades A-Agente establecidas.

- Actualización del diagrama de vista funcional (misión) del modelo de organización (opcional): se incluyen los nuevos productos y/o servicios identificados en esta fase y se relacionan con el sistema (Unidad Organizativa) y sus grupos de interés (relaciones OConsume, OProduce). 


\subsection{Fase C. Dimensiones Organizativas}

En esta fase de la secuencia-guía (figura 5.23) se realiza el análisis de una serie de dimensiones organizativas que imponen ciertos requisitos sobre los tipos de trabajo a realizar, sobre la estructura del sistema y sobre las interdependencias entre las tareas.

Las dimensiones organizativas que se tienen en cuenta en esta fase son las que se proponen en el trabajo de Mintzberg [Mintzberg, 2002], en concreto:

- Departamentalización, que detalla la agrupación de los trabajos.

- Especialización, que indica el grado en el que las tareas se dividen en cometidos separados.

- Sistema decisor, que determina el grado de centralización de la organización, es decir, el grado de concentración de autoridad y toma de decisiones.

- Normalización, que especifica el grado en que las tareas y puestos están estandarizados, a través de normas y reglas de comportamiento.

- Mecanismos de coordinación, que indican de qué manera los individuos coordinan sus tareas, minimizando las interacciones y maximizando la eficiencia.

Estas dimensiones definen las características intrínsecas de la organización, influyendo notablemente en la estructura organizativa a adoptar. En la siguiente fase de la secuencia-guía se determina, precisamente, cuál es la estructura organizativa más adecuada, haciendo uso de dichas dimensiones.

La fase de análisis de las dimensiones organizativas consta de dos trabajos: (i) asignar tareas e (ii) identificar restricciones. En el trabajo Asignar tareas se lleva a cabo la agrupación de las tareas y la asignación de las mismas. En el trabajo Identificar Restricciones se analizan las restricciones impuestas por la formalización del trabajo y los mecanismos de coordinación existentes. 


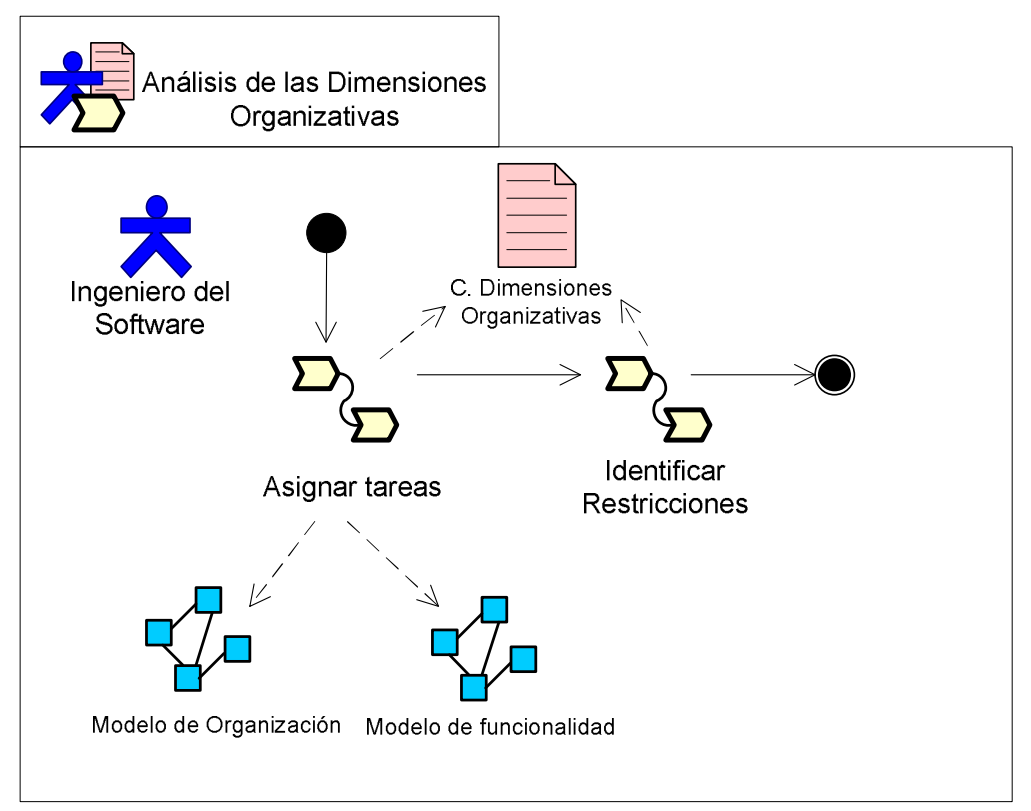

Figura 5.23: Fase Análisis de las dimensiones organizativas

El producto relevante de esta fase es el documento C.Dimensiones Organizativas, que se emplea en la fase siguiente para seleccionar la estructura topológica más adecuada de la organización. Los refinamientos de los diagramas de los modelos de organización y de actividad que se proponen en esta fase son opcionales. El diseñador, en base a sus conocimientos sobre el problema a tratar, podrá decidir si realizar una agrupación inicial de las tareas, servicios y roles, siguiendo las indicaciones de la fase actual; o bien si retrasar esa agrupación hasta la siguiente fase, en la que se selecciona el patrón de diseño de la estructura de la organización más adecuado. Dicho patrón especifica cuáles son las agrupaciones primordiales a tener en cuenta.

A continuación se explica con mayor detalle cada uno de los trabajos que integran esta fase.

\subsubsection{Asignar tareas}

Se procede aquí a la agrupación de las tareas en unidades y a la asignación de dichas tareas a determinados miembros de la organización. Las 
actividades concretas que se llevan a cabo son (figura 5.24): (i) agrupar tareas; (ii) analizar la especialización de los roles; y (iii) asignar los procesos de la toma de decisiones.

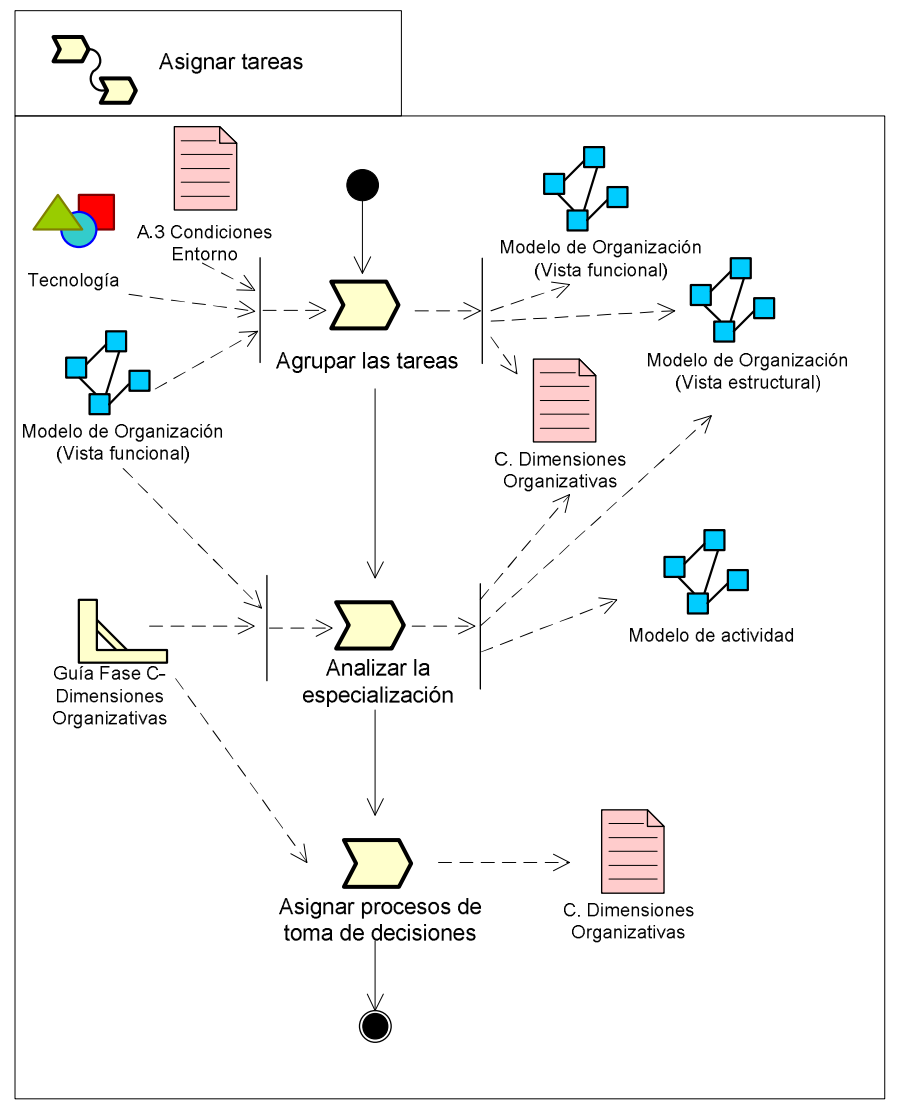

Figura 5.24: Definición de la tarea Asignar Tareas

AGRUPAR TAREAS. En las organizaciones humanas, para agrupar las tareas se tiene en cuenta la dimensión denominada departamentalización [Wagner y Hollenbeck, 2004], que consiste en agrupar los trabajos para coordinar las tareas comunes. Dicha agrupación se realiza dos modos: por funciones o divisional.

La departamentalización por funciones consiste en agrupar en base a los conocimientos y habilidades, o bien en base al proceso de trabajo y función que se realice. De este modo se reúne a los especialistas en las mismas 
unidades, para así lograr economías de escala al colocar a miembros con habilidades y orientaciones similares en una misma unidad.

La departamentalización divisional consiste en la agrupación en base a las características del mercado, determinadas por los clientes, la zona geográfica, los productos o servicios a ofrecer y cuándo se ofertan dichos productos. De este modo, si se agrupan las tareas en unidades organizativas según el producto o servicio que la organización genera, se aumenta la responsabilidad por el desempeño del producto; si se agrupa por geografía, se organizan por regiones o territorios; si se agrupa por procesos, cada unidad se especializa en una fase de la producción; y si se agrupa por tipo de cliente, se satisfacen mejor los problemas y necesidades de cada cliente.

Para la identificación del tipo de departamentalización más adecuado se requiere tener también en cuenta la diversidad del entorno. Si el entorno es uniforme resulta preferible una departamentalización funcional o por funciones, al enfrentarse a un único escenario; mientras que si el entorno es diverso, resulta más aconsejable realizar una departamentalización divisional, que permita centrarse en cada escenario distinto.

Para los sistemas multiagente, en nuestra secuencia-guía la actividad agrupar tareas consiste en revisar la vista funcional del modelo de organización (misión y funcionalidad externa), agrupando juntos aquellos servicios o funciones que compartan procesos o A-Tareas o bien compartan perfiles (es decir, hagan uso de las mismas entradas y salidas), en el caso de realizar una departamentalización por funciones. Por su parte, se agrupan juntos aquellos servicios que se dirijan a los mismos roles o clientes, para una departamentalización divisional.

Cada agrupación se representa con una Unidad Organizativa, en la que se incluyen esos servicios, así como los roles que los sirven o utilizan. La funcionalidad externa de la unidad se representa a través de un servicio complejo que componga al conjunto de servicios de esa unidad. Se crea también un nuevo rol que proporcione ese servicio complejo, asignado a la nueva agrupación o unidad identificada. Así mismo, se crean nuevos roles de solicitantes del servicio complejo, que representen a los anteriores clientes 
de los servicios agrupados.

De este modo, la vista estructural del modelo de organización se extiende incluyendo una nueva Unidad Organizativa (y su correspondiente relación OContieneA-Agente) por cada agrupación; y nuevos roles (con relación OContieneRol) para los proveedores y clientes del servicio. Entre los roles se establecerán las relaciones OHerenciaRol requeridas.

En la vista funcional del modelo de organización, en la funcionalidad externa se relaciona al sistema general (Unidad Organizativa principal) con los nuevos servicios complejos identificados (relación OOfrece), proporcionados por los roles de las nuevas unidades (relación WFProporciona). Además, en la funcionalidad interna se relacionan a las nuevas unidades creadas con esos roles específicos que juegan (relación WFJuega).

ANALIZAR LA ESPECIALIZACIÓN. La segunda de las actividades a llevar a cabo en el trabajo Asignar Tareas consiste en analizar la especialización, que tiene en cuenta la dimensión de especialización o división del trabajo. Dicha dimensión indica el grado en el que las tareas de la organización se dividen en cometidos separados.

En las organizaciones humanas se distinguen dos tipos de especialización: horizontal y vertical. La especialización horizontal determina cuántas tareas distintas tiene cada rol y su amplitud, tratando de ajustar los roles a las tareas. Si un rol realiza un gran número de tareas distintas y que en muchos casos presentan una interdependencia baja, entonces el rol tiene una especialización horizontal baja (también llamada ampliación horizontal). Por contra, si realiza pocas tareas y además están muy relacionadas entre sí (con alta interdependencia), entonces el rol presenta especialización horizontal elevada. Por ello, la especialización horizontal determina cómo se realizará la agrupación de las tareas en función del rol, ofreciendo así el conjunto de roles a considerar.

La especialización vertical define el control ejercido sobre el trabajo, separando la realización del trabajo respecto a su administración. Por tanto, se distingue entre la actividad, las fases de sensorización, discriminación y 
decisión, así como la fijación de objetivos y criterios. Si un rol realiza todos estos aspectos para una misma tarea, entonces su especialización vertical es mínima, presentando ampliación vertical. Por contra, si la realización del trabajo la llevan a cabo uno o más roles, mientras que los procesos de decisión y control de dicha tarea están en manos de otros roles, se dice que la tarea tiene una gran especialización vertical. Por tanto, establece el ámbito de control sobre la información y la actuación de cada tarea.

En los sistemas multiagente, la secuencia-guía especifica la necesidad de revisar en primer lugar los servicios proporcionados por cada rol identificado hasta el momento en la vista funcional (funcionalidad interna) del modelo de organización, analizando las A-Tareas asignadas a cada uno de esos servicios en el modelo de actividad. Así se determina el tipo de interdependencia existente entre las tareas.

En concreto, los tipos de interdependencia posibles son [Wagner y Hollenbeck, 2004]: recursos compartidos, secuencial, recíproca e integral.

En la interdependencia de recursos compartidos las tareas obtienen recursos de una fuente compartida (ej. información, materias primas).

En la interdependencia secuencial las tareas forman una cadena de interacciones en un sentido, de modo que las tareas dependen de los resultados de sus predecesoras, pero son independientes de las que les siguen.

La interdependencia recíproca implica una red de relaciones de doble sentido, en la que una tarea depende tanto de los resultados de sus predecesoras como de la retroalimentación que obtenga de sus sucesoras.

Por último, la interdependencia integral implica una estrecha red de interdependencia recíproca, en la que todas las tareas dependen unas de otras y requieren de interacciones entre sí más frecuentes e intensas.

Una vez analizada la interdependencia entre las tareas, se agrupan juntas aquellas tareas con alta interdependencia, especialmente de tipo integral y recíproco, si se desea favorecer la especialización horizontal (para obtener roles muy especializados en sus tareas).

Por otro lado, se agrupan juntas aquellas tareas que, aun presentando 
ninguna o baja interdependencia, principalmente de tipo de recursos compartidos o secuencial, merezca la pena que sean ejecutadas por el mismo rol, si se desea favorecer la amplitud horizontal, para así minimizar el número de comunicaciones, posibles fallos, etc. En este último caso, los roles se hacen cargo de varias (o muchas) tareas con funcionalidades distintas, pero que comparten recursos o bien siguen un orden de ejecución pre-establecido.

De esta manera, las tareas se reestructuran, generándose así nuevas agrupaciones de las tareas y servicios. En el caso en que en una agrupación existan tareas desempeñadas inicialmente por roles distintos, al agruparlas deben ser asignadas todas ellas a un único rol, bien sea a uno de los ya existentes o bien a uno nuevo, generalización de los anteriores.

Según la centralización deseada, se establece también el valor de la especialización vertical. Si el control es descentralizado y los roles disponen de gran capacidad de decisión y flexibilidad sobre sus propias tareas, entonces tenemos ampliación vertical. Por contra, si es preferible una centralización de las decisiones y/o se requiere que otras entidades (agentes internos) del sistema realicen los procesos de decisión sobre las acciones a realizar y establezcan un control y sensorización de sus resultados, entonces se dispone de especialización vertical.

Como resultado de esta actividad, se revisa la vista estructural del modelo de organización, actualizando los roles y entidades A-Agente según se requiera. Además, en el modelo de actividad se refinan las A-Tareas asociadas a cada servicio, en base a sus interdependencias. Asimismo, en la vista funcional del modelo de organización se especifican las relaciones WFProporciona y WFUtiliza, asociando los roles identificados en el modelo de organización con los servicios requeridos en el modelo de actividad.

PROCESOS DE DECISIÓN. La última de las actividades a realizar en el trabajo Asignar Tareas consiste en asignar los procesos de toma de decisiones. Esta actividad se lleva a cabo mediante la dimensión de centralización de las organizaciones [Wagner y Hollenbeck, 2004], que indica dónde se toman las decisiones. Así, el término centralización se refiere al 
grado en que la toma de decisiones se concentra en un único punto en la organización. Por su parte, la descentralización implica que las decisiones se delegan a los roles que están más cerca de la acción.

Se debe determinar en qué puntos realizar el proceso de toma de decisiones, teniendo también en cuenta la complejidad del entorno. Para entornos simples, donde se requiere el procesamiento de poca información, resulta preferible la centralización; mientras que en entornos complejos se hace necesaria la descentralización de la toma de decisiones, para así permitir procesar mejor un mayor volumen de información.

Como resultado de estas actividades, se debe generar una primera versión del documento C.Dimensiones Organizativas, cuya plantilla se muestra en la tabla 5.14.

\subsubsection{Identificar restricciones}

Este trabajo consiste en identificar cuáles son las restricciones existentes sobre el comportamiento de los miembros de la organización y qué mecanismos se utilizarán para favorecer su coordinación y cooperación. Las actividades concretas que se llevan a cabo son (figura 5.25): (i) identificar los mecanismos de coordinación y (ii) definir la normalización. Como resultado de estas actividades, se debe completar el documento C.Dimensiones Organizativas, cuya plantilla se muestra en la tabla 5.15 . 


\begin{tabular}{|c|}
\hline $\begin{array}{r}\text { C. Din } \\
\text { Departamentaliza }\end{array}$ \\
\hline 1entalización \\
\hline $\begin{array}{l}\text { ¿Se requiere actuar sobre máquinas de un mismo tipo? ¿O sobre los mismos } \\
\text { recursos? ¿La funcionalidad ofrecida sigue patrones de comportamiento simi- } \\
\text { lares? ¿Los servicios requieren los mismos tipos de entrada? ¿Ofrecen salidas } \\
\text { similares? } \\
\text { En caso afirmativo se trata de departamentalización funcional } \\
\text { Sugerencia: agrupar funcionalidades similares y crear una Unidad Organizativa } \\
\text { por cada agrupación. }\end{array}$ \\
\hline $\begin{array}{l}\text { ¿Se requiere particularizar las actividades en función de los clientes? ¿O en } \\
\text { base a los productos a ofrecer? ¿La funcionalidad es distinta según la situación } \\
\text { geográfica? } \\
\text { En caso afirmativo se trata de departamentalización divisional } \\
\text { Sugerencia: agrupar funcionalidades orientadas al mismo cliente o producto y } \\
\text { crear una Unidad Organizativa por cada agrupación. }\end{array}$ \\
\hline afirmativo se trata de departamentalización funcional \\
\hline$\overline{n+\text { Centr }}$ \\
\hline $\begin{array}{l}\text { ¿Los roles tienen asignadas tareas especializadas? ¿Realizan pocos tipos de ta- } \\
\text { reas distintos? ¿Carecen de control suficiente sobre su propio trabajo? } \\
\text { En caso afirmativo se trata de especialización horizontal y vertical } \\
\text { Sugerencia: el control de las tareas de los agentes será asumido por agentes } \\
\text { supervisores, encargados de la gestión de la unidad organizativa donde se en- } \\
\text { cuentren. }\end{array}$ \\
\hline ción las \\
\hline $\begin{array}{l}\text { ¿Los roles se hacen cargo de varias tareas distintas, poco relacionadas entre sí? } \\
\text { ¿Tienen una interdependencia baja? ¿No ejercen control sobre las actividades } \\
\text { que realizan? } \\
\text { En caso afirmativo se trata de ampliación horizontal con especialización } \\
\text { vertical }\end{array}$ \\
\hline ¿Lo \\
\hline
\end{tabular}

Tabla 5.14: Documento C.Dimensiones Organizativas (Parte I). Plantilla de descripción de las dimensiones organizativas para la asignación de tareas. 


\begin{tabular}{|c|}
\hline $\begin{array}{l}\text { C. Dimensiones Organizativas } \\
\text { Coordinación y Formalización }\end{array}$ \\
\hline $\begin{array}{l}\text { ¿El modo de realización de las tareas es flexible? ¿Pueden realizarlas distintos } \\
\text { roles o miembros? ¿La mayoría de los roles presenta ampliación vertical? Se } \\
\text { debe aplicar adaptación mutua (procesos de negociación) }\end{array}$ \\
\hline $\begin{array}{l}\text { ¿Los roles presentan especialización vertical? ¿El control y gestión debe estar } \\
\text { centralizado en determinados puntos? Se debe aplicar supervisión directa }\end{array}$ \\
\hline $\begin{array}{l}\text { ¿Resulta muy importante el orden de ejecución de las tareas? ¿Resulta clave } \\
\text { quién realiza cada tarea, siendo necesario establecer permisos sobre las acciones } \\
\text { a realizar? Se debe aplicar una normalización de las tareas. }\end{array}$ \\
\hline $\begin{array}{l}\text { ¿Resulta muy importante la calidad del resultado obtenido? ¿Es más indiferente } \\
\text { el método de resolución a través del cual se ha obtenido el resultado? ¿Resulta } \\
\text { indiferente quién se encargue de proporcionar el resultado? Se debe aplicar una } \\
\text { normalización de los resultados. }\end{array}$ \\
\hline $\begin{array}{l}\text { ¿Resultan indispensables los conocimientos y habilidades que se disponga sobre } \\
\text { ciertas tareas? ¿Existe un comportamiento predefinido y asumido globalmente } \\
\text { para una habilidad concreta? Se debe aplicar una normalización de habili- } \\
\text { dades. }\end{array}$ \\
\hline
\end{tabular}

Tabla 5.15: Documento C.Dimensiones Organizativas (Parte II). Plantilla de descripción de las dimensiones organizativas para la identificación de restricciones.

MECANISMOS DE COORDINACIÓN. La dimensión organizativa coordinación establece que los mecanismos de coordinación a tener en cuenta son: adaptación mutua, supervisión directa y normalización [Wagner y Hollenbeck, 2004].

La adaptación mutua implica el intercambio de conocimientos sobre el modo en que se debería realizar una tarea y quién debería realizarla. Dicho intercambio de información debe producirse entre entidades que ejerzan al menos un control parcial sobre las tareas que se están analizando, para así poder actuar posteriormente sobre ellas.

En los MAS este mecanismo de coordinación se aplica a través de protocolos de negociación. Las técnicas de negociación [Nwana et al., 1996] se clasifican en : (i) negociación basada en la teoría del juego, que consiste en un proceso interactivo de ofertas y contra-ofertas en la que cada agente 


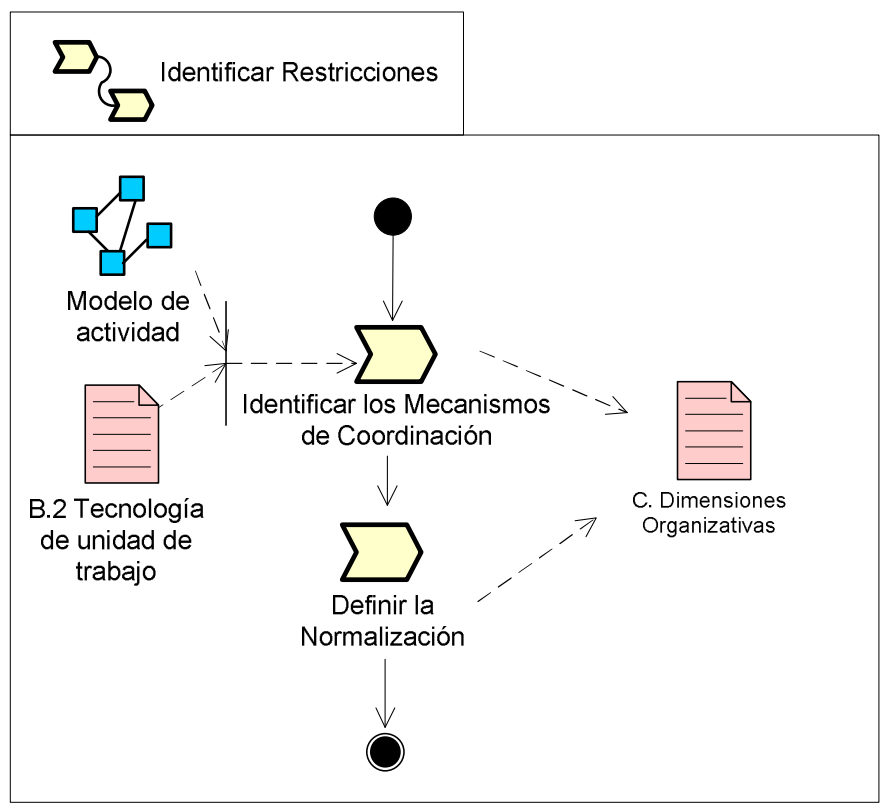

Figura 5.25: Definición de la tarea Identificar Restricciones

escoge un acuerdo que maximiza el valor de utilidad esperado; (ii) negociación basada en planes, en la que los agentes planifican sus actividades por separado y después se coordinan empleando un agente de coordinación; y (iii) negociación inspirada en los humanos y técnicas de aproximación de inteligencia artificial, especialmente la argumentación [Kraus et al., 1998] en la que los agentes (además de negociar con ofertas y contra-ofertas) añaden ciertos argumentos a sus ofertas para apoyarlas.

Si para los roles identificados se precisa de ampliación vertical (según el documento C.Dimensiones Organizativas, tabla 5.14), entonces se debe aplicar la negociación para asignar tareas o concretar su ejecución. Lo mismo ocurre si se ha identificado que la tecnología de producción es de lotes pequeños (según el documento B1. Tecnología Esencial, tabla 5.8), primando así los procesos de adaptación mutua entre los clientes y los productores. En el caso de emplear una tecnología de servicios intensiva (documento B1.Tecnología Esencial, tabla 5.9) también se requieren mecanismos de negociación con los que establecer el tipo de tareas a realizar en función de 
los requisitos del cliente.

En la supervisión directa, un miembro (supervisor directo) asume la responsabilidad del trabajo de un grupo. Por ello, adquiere la autoridad para decidir qué tareas han de realizarse, quién las realizará y cómo se vincularán para producir el resultado final deseado. Puede impartir órdenes a sus subordinados, comprobar que esas órdenes se han seguido y redirigir a los subordinados para satisfacer los demás requisitos del trabajo.

Si se tienen roles con especialización vertical (según el documento C.Dimensiones Organizativas, tabla 5.14), se podría aplicar sobre ellos este tipo de coordinación, de modo que actúen como entidades subordinadas de otra entidad controladora y gestora.

Finalmente, la normalización coordina el trabajo y proporciona los estándares y procedimientos que ayudan a determinar cómo realizar las tareas, minimizando la necesidad de comunicación entre las entidades.

La tasa de cambio del entorno influye en el mecanismo de coordinación a seleccionar [Wagner y Hollenbeck, 2004]. Si el entorno es estable, conviene aplicar la normalización, pues no se prevén que existan cambios en el entorno que afecten a las normas y procedimientos establecidos. Además, con la normalización se reducen los costos de las comunicaciones entre los miembros de la organización. Por contra, si el entorno es dinámico, resulta preferible el mecanismo de adaptación mutua, pues los procedimientos de negociación y planificación ofrecen gran flexibilidad para adaptarse a las nuevas necesidades del entorno. En este caso se requiere también de un sistema normativo que controle el adecuado funcionamiento de las negociaciones. Además, dicho sistema debe incorporar normas legisladoras, que permitan la modificación, creación o eliminación de las normas de control, para así adecuarse mejor a los cambios del entorno.

NORMALIZACIÓN. En la actividad definir la normalización se lleva a cabo el análisis detallado del mecanismo de coordinación, utilizando para ello la dimensión organizativa normalización o formalización. Esta dimensión indica el grado en que los puestos de la organización están estandarizados, es decir, la cantidad de reglas organizativas, procedimientos 
de los procesos y descripciones explícitas de los puestos de trabajo que se tiene.

En las organizaciones humanas existen cuatro mecanismos de normalización [Wagner y Hollenbeck, 2004]: de tareas, de resultados, de habilidades y de comportamientos. En esta fase de la guía se determina solamente cuál o cuáles de estos mecanismos resulta primordial para la gestión de la organización, empleando el documento C.Dimensiones Organizativas (tabla $5.15)$.

En la fase E.Procesos de información-decisión de esta guía se establecen las normas o reglas concretas necesarias, en base a los tipos de normalización aquí identificados, así como a la estructura de organización que se seleccionará en la fase siguiente (fase D.Estructura Organizativa).

La normalización de tareas implica la especificación de tareas concretas o procedimientos de trabajo que los roles deben realizar para cumplir con sus responsabilidades. Estos comportamientos vinculan una tarea con el resto, estableciendo relaciones de precedencia. Las normas o reglas a diseñar se centrarán en las características intrínsecas de cada tarea, como por ejemplo: los límites de tiempo requeridos para su ejecución; los recursos o materias que necesitan; sus procedimientos o pasos concretos de realización; las relaciones de precedencia establecidas con otras tareas, etc.

Si se requiere establecer un orden preciso en la invocación de determinados servicios, o bien gran parte de ellos necesita de un orden concreto de ejecución de sus tareas internas, entonces debemos aplicar una normalización de tareas.

La normalización de resultados consiste en la designación formal de los objetivos de los resultados o las metas de rendimiento esperadas. Implica una formalización por flujo de trabajo, describiéndose con detalle cuál será el resultado de la tarea, pero disponiendo de libertad para decidir cómo lograr los objetivos y, por tanto, cómo llevar a cabo la tarea. Resulta conveniente emplearla cuando existen distintas posibilidades de realizar la misma tarea o bien cuando no se conoce con exactitud cómo se llevará a cabo, dejando libertad y mayor grado de autonomía a la entidad que se encargue de ella, 
pero sí que se requieren unos resultados específicos.

Si se ha identificado un gran número de servicios con relaciones ORequiere o bien no se ha concretado con detalle el comportamiento concreto de los servicios, necesitamos entonces este tipo de normalización.

La normalización de habilidades implica la especificación de cualificaciones, conocimientos y habilidades necesarias para desarrollar las tareas de forma competente. En las organizaciones humanas, los miembros cualificados apenas necesitan comunicarse entre sí para entender qué hacer y pueden predecir lo que harían otros trabajadores cualificados similares.

En el caso de los sistemas multiagente, las habilidades se representan a través del concepto de rol, con el cual indicamos los permisos, conocimientos y aptitudes que asume o adquiere un agente al jugar dicho rol. Si se prevé que un mismo agente podrá jugar distintos roles no relacionados entre sí a lo largo de su ciclo de vida, o bien que no se tienen garantías suficientes de que el agente cumpla con los requisitos asociados al rol que desee jugar, necesitamos este tipo de normalización para así establecer mecanismos de control en la adquisición del rol por parte del agente.

Finalmente, la normalización de los comportamientos consiste en que los miembros comparten un conjunto de creencias sobre la aceptabilidad de determinados tipos de comportamiento. Implica la promoción de actitudes y creencias que conducen a los comportamientos deseados.

Si se precisa de un conocimiento común compartido por un elevado número de miembros y de un control y gestión de los objetivos y creencias comunes, entonces necesitamos aplicar este tipo de normalización.

\subsubsection{Aplicación de la fase al caso de estudio}

En el sistema de información de nuestro ejemplo el entorno es diverso, pues se tendrá información de distintos temas, que podrán cambiar a lo largo del tiempo. Además, los clientes se suscribirán a ciertos temas, o bien serán expertos de temáticas concretas. Por tanto, deberemos realizar una departamentalización divisional, en la que la información se agrupe por temas. 


\begin{tabular}{|l|l|l|}
\hline \multicolumn{3}{|c|}{ C. Dimensiones Organizativas } \\
\hline Dimensión & Valor & Explicación \\
\hline Departament. & Divisional & $\begin{array}{l}\text { La información se agrupará por } \\
\text { temas. Se tendrá una unidad or- } \\
\text { ganizativa por cada temática. }\end{array}$ \\
\hline $\begin{array}{l}\text { Especialización } \\
+ \text { Centralización }\end{array}$ & $\begin{array}{l}\text { Ampliación hori- } \\
\text { zontal y vertical }\end{array}$ & $\begin{array}{l}\text { Los miembros realizan varias ta- } \\
\text { reas distintas (suscripción, infor- } \\
\text { mación, evaluación...) y asumen } \\
\text { el control del servicio de evalua- } \\
\text { ción. }\end{array}$ \\
\hline Coordinación & Adaptación mu- \\
tua & $\begin{array}{l}\text { Se requieren técnicas de negocia- } \\
\text { ción para concretar la actuación } \\
\text { de los evaluadores e informadores. }\end{array}$ \\
\hline Normalización & De los resultados & $\begin{array}{l}\text { Se deben controlar los resultados } \\
\text { producidos en los servicios de eva- } \\
\text { luación. }\end{array}$ \\
\hline
\end{tabular}

Tabla 5.16: Documento C.Dimensiones Organizativas del sistema de información

Un miembro del sistema podrá solicitar los servicios de suscripción y de proporcionar información, según le interese. Sobre la funcionalidad de dichos servicios no tiene ningún control, pues se limita a ejercer de cliente. Pero mantiene su poder de decisión sobre cuándo realizar la solicitud de los servicios, en base a las temáticas que le interese. Además, podrá ejercer de evaluador, ofreciendo para ello un servicio de evaluación. Sobre dicho servicio sí que tendrá poder de decisión y control de su funcionalidad, pues podrá implementarlo como desee (siempre que cumpla con las restricciones mínimas impuestas en el sistema).

Por tanto, los miembros del sistema se hacen cargo de varias tareas distintas (utilización de los servicios de suscripción y de proporcionar información; ofrecer el servicio de evaluación) y además asumen el control de algunas de ellas. De este modo tenemos ampliación horizontal y vertical.

Por otro lado, como se había identificado anteriormente que la tecnología de producción es, en parte, de lotes pequeños; y además los roles evaluador 
e informador requieren ampliación vertical, entonces interesa aplicar principalmente técnicas de negociación para concretar la ejecución de los agentes que jueguen dichos roles. Por ello se emplea adaptación mutua como método de coordinación. No obstante, se requiere también de una normalización de los resultados para los servicios de evaluación, ya que el control de la funcionalidad del servicio lo tendrá el agente que implemente el rol de evaluador; pero en el sistema se deben establecer las reglas necesarias para especificar las entradas y salidas de ese servicio.

En la tabla 5.16 se muestra el documento C.Dimensiones Organizativas, que resume los valores asignados a las dimensiones de la organización.

La actualización de los modelos de organización y de actividad, en base a las indicaciones de las dimensiones organizativas que se proponen en esta fase, se retrasa a la siguiente fase D. Estructura Organizativa, para así adoptar directamente el patrón de organización que resulte más adecuado.

\subsubsection{Síntesis de la fase}

En la fase C. Dimensiones Organizativas se procede a la agrupación de servicios e identificación de roles. Además, se toman las primeras decisiones sobre el tipo de normalización a realizar, los mecanismos de coordinación relevantes y el grado de descentralización del sistema.

Los documentos generados en esta fase son:

- Documento C.Dimensiones Organizativas (Partes I y II): se especifican los valores de departamentalización, especialización, centralización, normalización y coordinación del sistema.

- Actualización del diagrama de vista estructural del modelo de organización (opcional): se definen las nuevas Unidades Organizativas, los nuevos Roles y sus relaciones (OContieneA-Agente, OContieneRol, OHerenciaRol). 
- Actualización del diagrama de vista funcional del modelo de organización (funcionalidad externa) (opcional): se identifican nuevos servicios complejos, relacionándolos con nuevos roles (WFProporciona y WFUtiliza).

- Actualización del diagrama de vista funcional del modelo de organización (funcionalidad interna) (opcional): se relaciona cada nueva Unidad Organizativa con el rol que juega (relación WFJuega) y los servicios que proporciona.

- Actualización del diagrama de modelo de actividad (opcional): por cada servicio complejo se especifican los servicios o A-Tareas en los que se descompone (relación WFDescompone). Además, para cada servicio simple se detallan las A-Tareas que lo desempeñan. 


\subsection{Fase D. Estructura organizativa}

En esta fase de la secuencia-guía (figura 5.26) se analizan los valores de las dimensiones organizativas, obtenidos en la fase previa (documento C.Dimensiones organizativas), para así determinar qué tipo de estructura organizativa resulta más adecuada. Consta de las siguientes actividades: (i) seleccionar la estructura del sistema, mediante un árbol de decisión; y (ii) adaptar el patrón de diseño de esa estructura al problema a tratar.

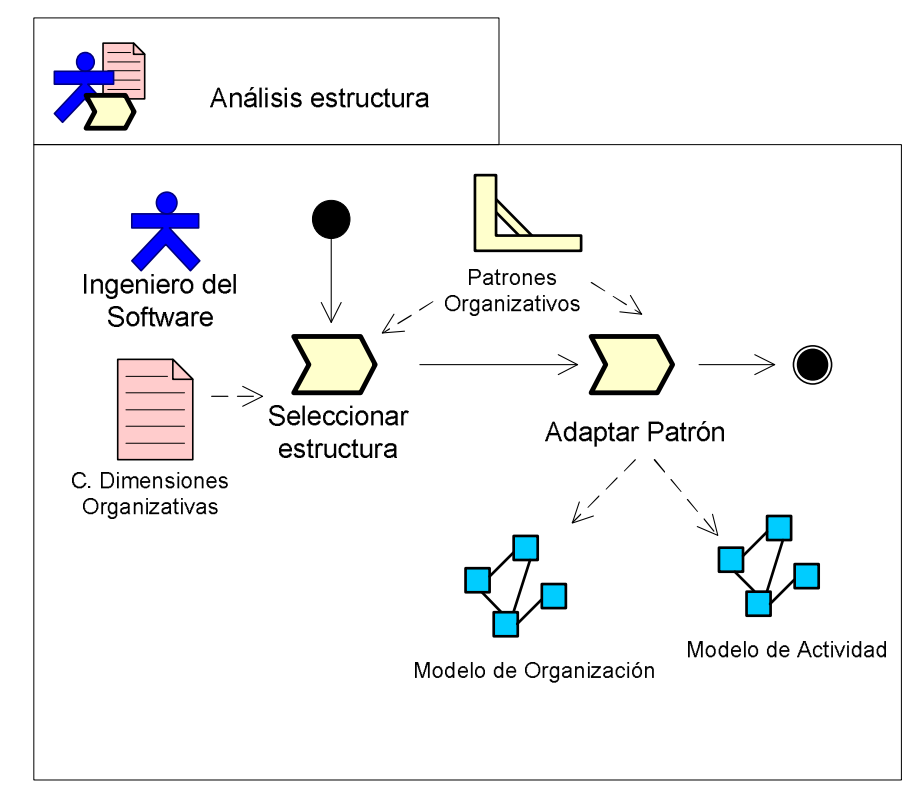

Figura 5.26: Fase Análisis de la estructura organizativa

SELECCIÓN DE LA ESTRUCTURA. Para la primera actividad se ha elaborado un árbol de decisión (figura 5.27), en el cual cada dimensión por separado discrimina entre unos tipos de estructura u otros. Tratándolas en conjunto se especifica la estructura que mejor se ajusta a las condiciones impuestas por cada dimensión. Este árbol de decisión se aplica al sistema completo, o bien a cada agrupación de servicios identificada en la fase anterior. De este modo, combinaciones de las estructuras aquí propuestas también son posibles. Los rombos representan puntos de decisión en los que se debe analizar la dimensión especificada y tomar el camino que más 
se ajuste. Si el diseñador no encontrase ningún camino adecuado, entonces deberá revisar tanto la dimensión actual en la que se encuentre como dimensiones anteriores del árbol, para así reajustar mejor sus planteamientos.

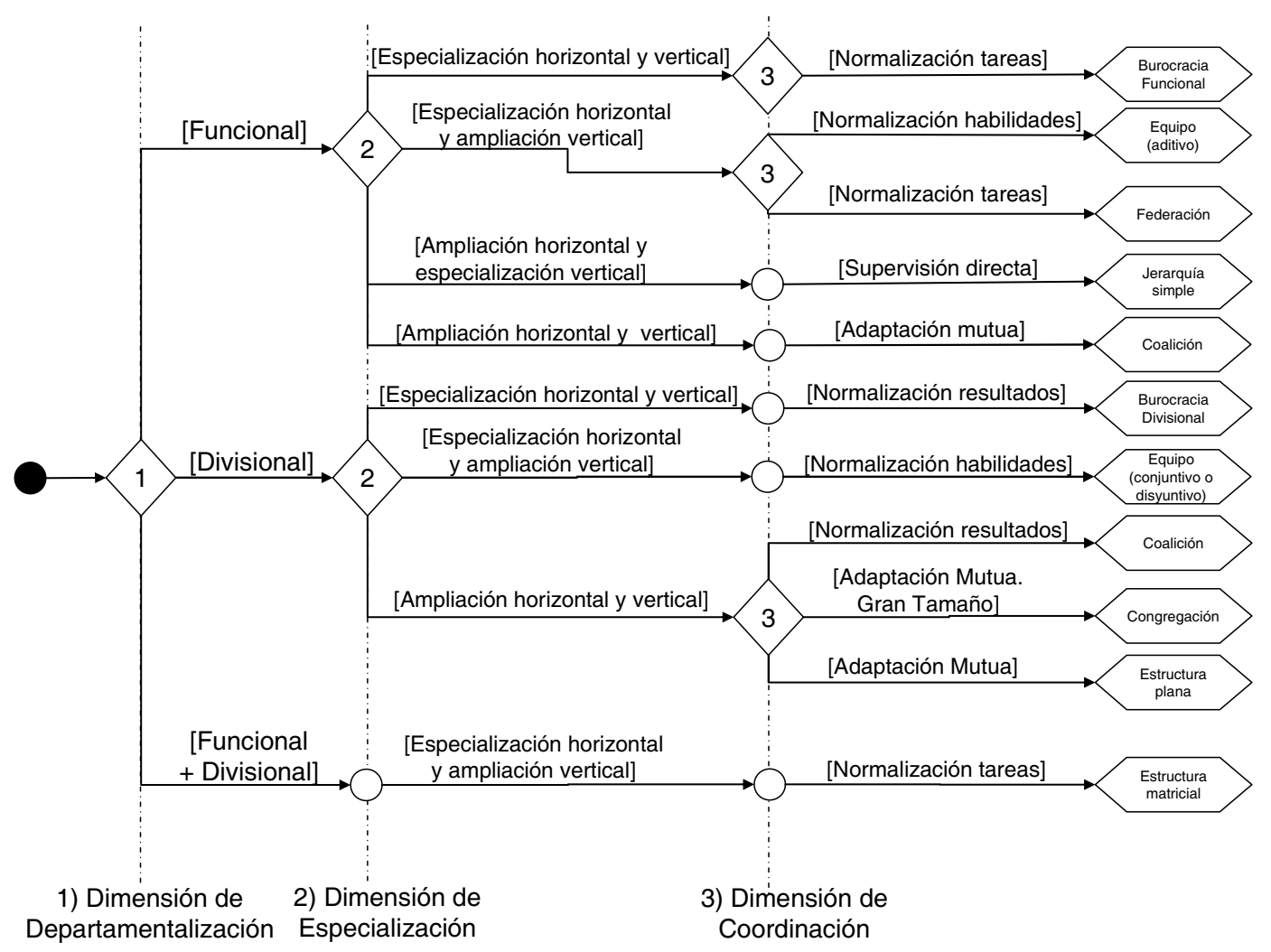

Figura 5.27: Arbol de decisión de la estructura organizativa

De forma esquemática, la secuencia de decisiones a llevar a cabo es la siguiente:

1. Dimensión de departamentalización:

- Funcional: por cada funcionalidad se ha creado una unidad organizativa encargada de ella. Un cliente o usuario probablemente deberá hacer uso de varias unidades organizativas distintas para así satisfacer por completo sus necesidades. 
Se emplea en las estructuras: burocracia funcional, equipo (con carácter aditivo), federación, jerarquía simple y coalición.

En la burocracia funcional cada rama jerárquica se centra en una actividad determinada.

En los equipos que presentan un carácter aditivo, todos los miembros realizan la misma función y el rendimiento global es resultado de la suma de los trabajos de todos sus miembros.

En la federación, cada agrupación se centra en una actividad, recurso, maquinaria, etc. concreta, agrupando así a los especialistas de cada materia.

En la jerarquía simple que se aplique a subastas o protocolos de Contract-Net, todos los agentes subordinados de la jerarquía ofrecen la misma funcionalidad y el supervisor se encarga de asignar la tarea, recurso, etc. al mejor agente.

En la coalición, agentes con funcionalidad similar se agrupan y coordinan entre sí para ofrecer una funcionalidad global más compleja y elaborada.

- Divisional: por cada tipo de cliente o producto se ha creado una unidad organizativa, donde el cliente encontrará todas las actividades y servicios que requiera para satisfacer sus necesidades. Las unidades podrán ofrecer funcionalidades similares entre sí o incluso duplicar los recursos.

Se emplea en las estructuras: burocracia divisional, equipo (con carácter conjuntivo o disyuntivo), coalición, congregación y estructura plana.

En los equipos que presentan un carácter conjuntivo o disyuntivo, normalmente los miembros del grupo realizan cada uno tareas distintas entre sí (separación de roles), por lo que existe una clara subdivisión de las tareas.

Las coaliciones se forman para atacar una necesidad concreta de 
un cliente, de modo que diversos agentes con distinta funcionalidad se agrupan para, entre todos, satisfacer el objetivo, tarea, etc. requerido por el cliente.

En la congregación, agentes complementarios se unen para atender sus propias necesidades.

En la estructura plana aunque no existe en realidad ningún tipo de agrupación concreta, cada agente se ocupa de diversas tareas que cubrirán las necesidades globales del mercado de la organización.

- Funcional + Divisional: los clientes requieren funcionalidades similares, pero particularizadas por cada tipo de cliente concreto. Se permite agrupar por tipo de cliente o bien por tipo de funcionalidad.

Se emplea en la estructura matricial, en la que en cada unidad organizativa existen, al menos, dos supervisores: uno que se ocupa de los aspectos funcionales (aportando la visión global de la actividad); y otro que trata los aspectos divisionales (aportando la visión global de la necesidad final del cliente).

2. Dimensión de especialización:

- Especialización horizontal y vertical: implica la utilización de agentes muy especializados, centrados en determinadas funciones específicas, pero que carecen de control suficiente sobre su trabajo. Dicho control será asumido por agentes supervisores, encargados también de la gestión de la unidad organizativa.

Se emplea en la burocracia (tanto funcional como divisional) y en la estructura de cadena. En ambos casos cada nivel jerárquico controla al nivel inmediatamente inferior.

- Especialización horizontal con ampliación vertical: los agentes especializados adquieren también el control sobre sus propias 
acciones. Se emplea en el equipo, en la estructura matricial y en la federación.

En el equipo, cada agente es responsable de sus acciones, aunque se requiere la colaboración de todos ellos para la consecución del objetivo común.

En la estructura matricial los agentes subordinados deben disponer de mecanismos para resolver sus conflictos locales y las discrepancias entre las órdenes recibidas de sus dos o más supervisores.

En la federación, cada agente cede cierta autonomía a su representante, quien se encarga de contactar con las entidades externas de la unidad y de distribuir las tareas y mensajes entre los miembros de la federación. Sin embargo, el agente tiene control absoluto sobre sus propios trabajos asignados y la realización de los mismos.

- Ampliación horizontal con especialización vertical: los agentes se hacen cargo de varias tareas distintas, poco relacionadas entre sí o con una interdependencia baja (de recursos compartidos o secuencial). Además no tienen control sobre sus actividades, sino que las funciones de supervisión están asignadas a otros agentes.

Se emplea principalmente en la jerarquía simple, en organizaciones de pequeño tamaño. El número de tareas distintas a asignar a cada agente debe ser reducido, para mantener la simplicidad del sistema. En caso contrario, se debe optar por otro tipo de especialización.

- Ampliación horizontal y vertical: los agentes llevan a cabo la ejecución y el control de diversas tareas distintas. Se emplea en la coalición, la congregación y la estructura plana.

Las coaliciones equivalen a equipos dinámicos, donde cada agente es responsable de sus propias tareas y tienen capacidad de 
decisión sobre su participación en la coalición.

En la congregación, los agentes son libres de participar en ella si les resulta útil para sus intereses. Además, tienen control sobre las acciones que realizan.

En la estructura plana se realizan tareas con pocas interdependencias entre sí, normalmente de recursos compartidos o, como mucho, de tipo secuencial. Los flujos de trabajo están separados y cada miembro se ocupa individualmente de su trabajo e interactúa con los otros en contadas ocasiones.

3. Dimensión de coordinación:

- Adaptación mutua: se requieren procesos de negociación entre los miembros.

Se emplea en la congregación y en la estructura plana. En ambos casos, no existe ninguna relación de autoridad específica entre los miembros de la agrupación, por lo que la coordinación de sus tareas se debe realizar aplicando principalmente algún mecanismo de negociación. En el caso de la congregación, se admiten también la normalización de las tareas y/o de los resultados para aumentar el control sobre las interacciones.

La estructura plana se debe aplicar en sistemas de pequeño tamaño, con un número reducido de miembros. Si se prevé que el tamaño será grande, con un número considerable de entidades, entonces se debe optar por la congregación.

- Supervisión directa: el supervisor será el encargado de establecer todo el control, las sanciones y recompensas sobre sus miembros subordinados.

Se emplea en la jerarquía simple. También aparece en la burocracia, aunque en este caso la normalización es primordial.

- Normalización de tareas: resulta muy importante el orden de 
ejecución de las tareas y/o quién realiza cada tarea. Se emplea en la burocracia funcional, la federación y la estructura matricial.

En la burocracia funcional, esta normalización permite gestionar el orden en el que los clientes hacen uso de las funcionalidades de las distintas unidades, pues normalmente deberán contactar con más de una unidad organizativa para obtener su resultado final. Lo mismo ocurre con la la estructura matricial, donde además se imponen normas a los supervisores sobre su orden de actuación.

En la federación, se aplican normas sobre las tareas y habilidades requeridas por los agentes que deseen participar en ella.

- Normalización de los resultados: resulta muy importante la calidad del resultado obtenido. Se emplea en la burocracia divisional y en la coalición.

En la burocracia divisional el control del rendimiento de cada agente se realiza en base a medidas cuantitativas de los resultados que ofrecen.

En las coaliciones, los agentes son responsables de la gestión de sus propias acciones, por lo que solamente es posible aplicar acciones sancionadoras o de recompensa en base a los resultados de dichas acciones.

- Normalización de habilidades: imponer condiciones en las habilidades requeridas por los miembros del grupo.

Se emplea en el equipo. Resulta similar a la normalización de tareas, para establecer qué tipo de actividades deben realizar los miembros del equipo, a qué recursos están habilitados para acceder, etc.

ADAPTAR PATRÓN. La segunda actividad de esta fase consiste en adaptar el patrón de diseño de la estructura seleccionada al problema concreto que se desea tratar. En la sección 4.6 del capítulo anterior se muestran los patrones de diseño de las diferentes estructuras contempladas. Se deben 
revisar los diagramas de modelado del sistema, principalmente los modelos de organización y de actividad, adecuándolos según las indicaciones del patrón de diseño.

En caso de que sea complicado adaptar directamente el patrón de diseño seleccionado sobre los diagramas de los modelos del sistema ya definidos en fases anteriores, se debe regresar al proceso de análisis de los requisitos del sistema (fases A y B de la secuencia-guía) para revisar las decisiones tomadas e, incluso, dividir el sistema en varios subsistemas, sobre los cuales aplicar, de forma relativamente independiente, las guías del proceso de diseño de la estructura organizativa (fases C y D de la secuencia-guía).

\subsubsection{Aplicación de la fase al caso de estudio}

En la fase anterior se había determinado que se requiere una departamentalización divisional, una ampliación horizontal y vertical así como adaptación mutua para los aspectos de departamentalización, especialización y coordinación del sistema de información, respectivamente. Siguiendo el árbol de decisión, la estructura más adecuada es la congregación. Tras adoptar sus patrones de diseño al caso de estudio, en la figura 5.28 se muestra el diagrama actualizado del modelo de organización.

Al ser una congregación, se tendrán tantas agrupaciones o unidades organizativas como temáticas tenga el sistema. Dicho número podrá variar dinámicamente, al surgir la necesidad de nuevas temáticas en el sistema, de ahí que se ofrezca el servicio Registrar Unidad, pero sólo al rol informador, que es quien proporciona los documentos y, por tanto, quien sugiere nuevas temáticas.

En este ejemplo se ha asumido que como mínimo existe una UO Temáti$c a$ en el sistema, creada como foro inicial para atraer a nuevos informadores y/o evaluadores. Al entrar en el sistema, los agentes participan bien como consultores, buscando información; o bien como solicitantes, pues desean hacer uso de los servicios de suscribir, proporcionar información o de evaluar, en temáticas ya existentes, o registrar nuevas unidades, para temáticas completamente nuevas. 


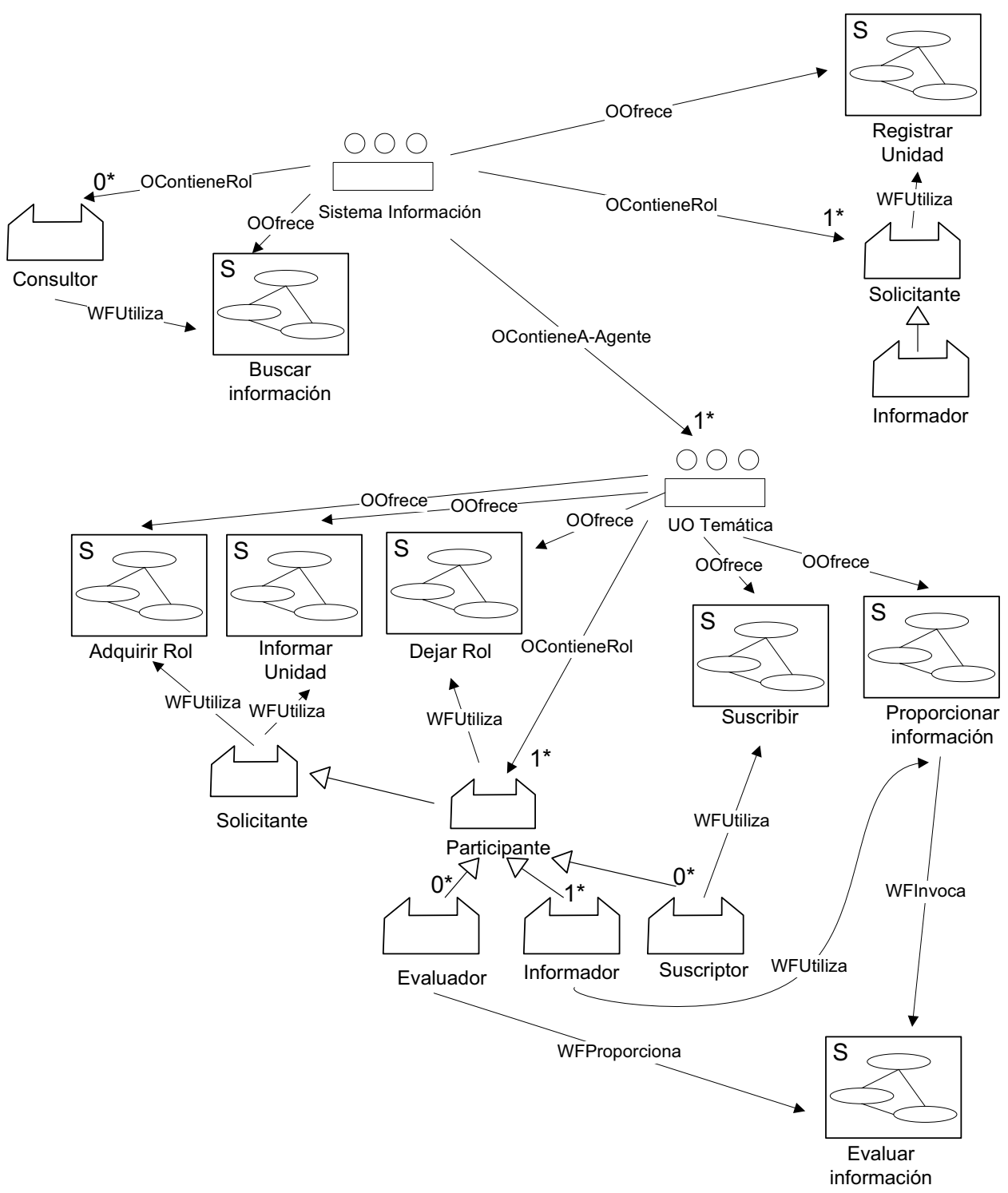

Figura 5.28: Diagrama actualizado del modelo de organización del sistema de información. Utiliza la estructura de congregación. 
Para participar dentro de una unidad determinada, los consultores deben solicitar primero el servicio Adquirir Rol, indicando el rol específico de tipo participante (es decir, evaluador, informador o suscriptor) que les interesa. Opcionalmente, pueden hacer uso del servicio Información para conocer los detalles de cada unidad (en concreto, las temáticas sobre las que versan) y así decidir si solicitar o no la adquisición de ese rol.

En una UO Temática como mínimo se requiere a un participante, que será el informador que ha solicitado la creación de esa unidad (utilizando el servicio RegistrarUnidad). Por tanto, para su creación inicial no se necesita que existan en ella ni evaluadores ni suscriptores.

\subsubsection{Síntesis de la fase}

En la fase D.Estructura Organizativa se selecciona la estructura organizativa más adecuada, en base a sus dimensiones. Además, se aplica el modelo organizativo asociado a dicha estructura al sistema a tratar.

Los documentos generados en esta fase son:

- Actualización del diagrama de la vista estructural del modelo de organización: se aplica el patrón de la estructura seleccionada, añadiendo nuevas entidades de tipo unidad organizativa, rol, recurso, norma, etc., según se indique en el patrón. Para cada UO identificada se especifica de qué tipo es (plana, equipo, jerarquía simple). Se correlacionan los roles identificados en fases anteriores de la guía con los que se proporcionan en el patrón de diseño. Además, se establecen sus cantidades máximas y mínimas.

- Actualización del diagrama de modelo de actividad (opcional): se describe la funcionalidad de los servicios indicados en el patrón de diseño.

- Diagrama del modelo de agente (opcional): se asocian las unidades organizativas a los roles y a la funcionalidad específica que se espera de estas unidades. 


\subsection{Fase E. Diseño de los procesos de infor- mación y decisión}

En esta fase de la secuencia-guía (figura 5.29) se detallan los flujos de información y de adopción de decisiones, para así determinar cómo se procesa la información y cómo se trabaja por conseguir los resultados esperados. Consta de los siguientes trabajos: (i) análisis de los procesos de decisión; y (ii) análisis de los procesos de información.

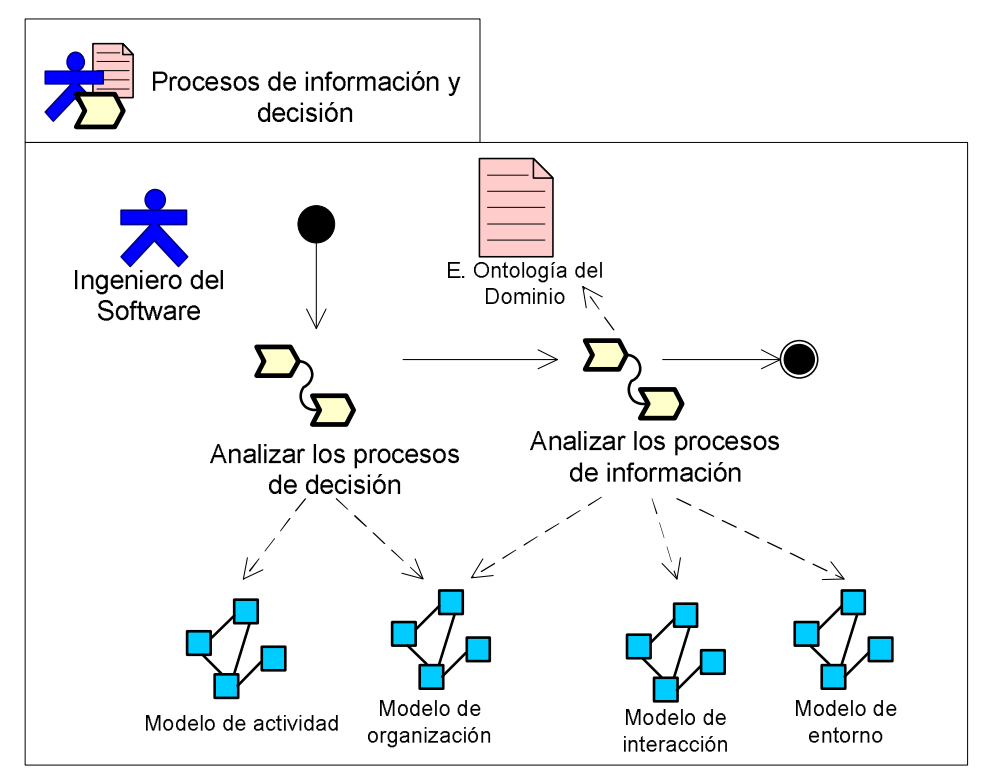

Figura 5.29: Fase Diseño de los procesos de información y decisión

A continuación se detalla cada uno de los trabajos que integran esta fase.

\subsubsection{Analizar los procesos de decisión}

Tras aplicar el patrón de organización seleccionado en la fase anterior, probablemente hayan aparecido nuevos servicios asociados a las unidades organizativas, que deben ser descompuestos en tareas. Además, en algunos 
servicios se habrá indicado quién los utiliza pero no quién los proporciona. El trabajo "analizar los procesos de decisión" consta de las siguientes actividades (figura 5.30): (i) identificación de los proveedores de servicios; (ii) descomposición de los servicios en tareas; y (iii) descomposición de los objetivos, para obtener los objetivos operativos y asignarlos a las tareas.

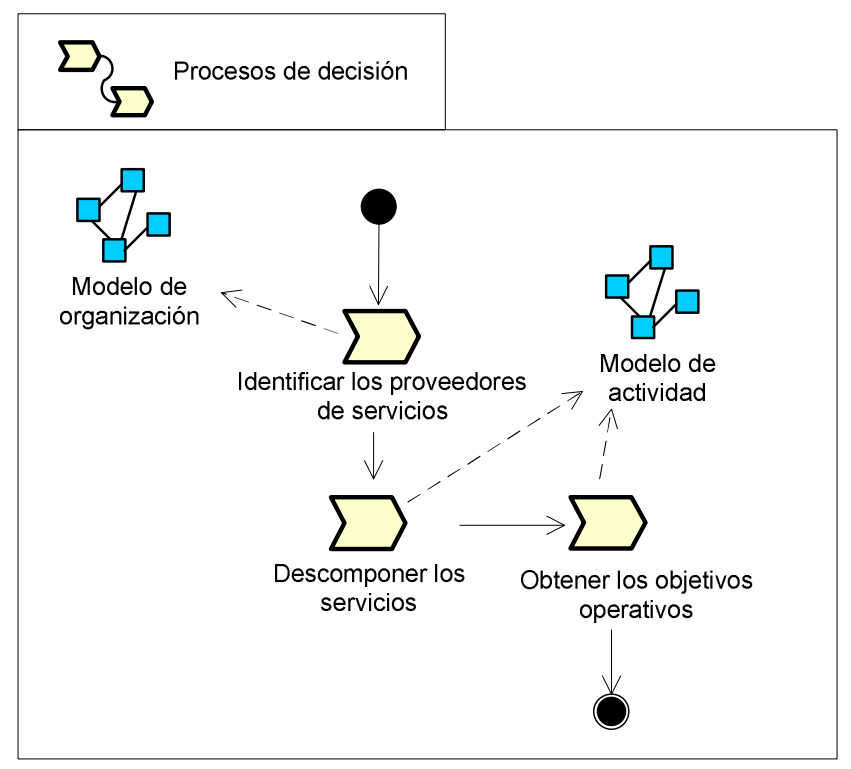

Figura 5.30: Definición de la tarea Análisis de los procesos de decisión.

En la primera actividad (identificar los proveedores de servicios) se revisa el diagrama de la vista funcional (funcionalidad externa) del modelo de organización, de modo que para todas las unidades organizativas que ofrezcan servicios se identifiquen los roles de gestión que se encargan de proporcionarlos.

Se añaden, por tanto, todas las relaciones WFProporciona que falten, así como las nuevas entidades Rol correspondientes, teniendo en cuenta el patrón de diseño básico de la unidad organizativa (capítulo 4, sección 4.6). En el caso de servicios que compartan tareas o que se encarguen de tareas similares, entonces el mismo rol podrá ocuparse de esos servicios.

Por su parte, en la vista estructural del modelo de organización se incluyen los nuevos roles identificados, especificando sus cardinalidades mínimas 
y máximas, así como la relación OContieneRol. También se establece la relación OHerenciaRol respecto al rol estructural del que mejor dependa (ej: supervisor, líder, miembro, etc.). Estos roles estructurales son los que se han identificado anteriormente en la fase D.Estructura Organizativa, al aplicar el patrón correspondiente.

Por otro lado, si la plataforma de agentes que se seleccione para la implementación del sistema ofrece una funcionalidad explícita para la gestión de las unidades organizativas (ej. gestión de las agrupaciones de agentes, control de su ciclo de vida, control de la entrada/salida de agentes) entonces los roles de gestión identificados en esta fase podrían ser implementados con componentes propios de la plataforma.

En la segunda actividad (descomponer los servicios), para aquellos nuevos servicios que haya aportado el patrón de organización, se debe establecer el diagrama del modelo de actividad correspondiente, haciendo uso de las guías de las fases anteriores, en especial de las fases B. Tareas y Procesos y C.Dimensiones Organizativas, para así identificar mejor las tareas que comprenden y asociarlas a los objetivos funcionales correspondientes.

Finalmente, en la tercera actividad (obtener los objetivos operativos) se procede a revisar los objetivos funcionales del modelo de actividad, descomponiéndolos en objetivos operativos para los cuales sea posible precisar de forma clara, en base al estado del mundo, si se satisfacen o no esos objetivos.

Se determina también si existe un plazo máximo para la consecución del mismo, así como su rendimiento asociado. Cada objetivo identificado se asocia a una o más tareas de los servicios relacionados.

\subsubsection{Analizar los procesos de información}

En las organizaciones humanas, los procesos de información establecen con quién se debe establecer la comunicación y qué debe comunicarse, para así ordenar las actividades y procesos que generen productos y servicios de conformidad a las normas y estándares establecidos [Moreno-Luzon et al., 2001]. 
Se distinguen dos tipos de flujos de información:

- Flujos relacionados con el ámbito externo: su intención consiste en recoger y canalizar la información sobre las necesidades o expectativas de los clientes. También permiten establecer la cooperación con los proveedores, determinando el número de canales adecuado.

- Flujos de ámbito interno: comprenden tanto los flujos para orientar y dirigir a la organización, especialmente para ejercer la autoridad; como los flujos que permiten aumentar los canales de comunicación entre los departamentos, agilizando así el trasvase de información entre estos.

En los MAS, los procesos de información implican la interacción de los agentes con su entorno, para extraer la información relevante sobre el estado del mundo; así como las interacciones que se producen entre los agentes motivadas por la consecución de sus objetivos o bien por la solicitud de servicios.

De acuerdo a esta idea, en la secuencia-guía se propone la realización de las siguientes actividades (figura 5.31): (i) revisar la captura de requisitos; (ii) definir la ontología del dominio; (iii) definir las interacciones asociadas a cada servicio; y (iv) identificar los vínculos laterales entre las unidades organizativas.

La revisión de la captura de requisitos se centra en los flujos de ámbito externo, es decir, en analizar si se interactúa de forma adecuada con los clientes y proveedores del sistema a través de los recursos, aplicaciones o los agentes que actúen en su nombre. Para ello contrastamos la vista funcional (misión) del modelo de organización con su vista estructural y con el modelo de entorno generados hasta el momento. Debemos comprobar si para todos los grupos de interés definidos existe un punto de contacto con el sistema, a través de los recursos, aplicaciones o bien por su representación con agentes concretos.

Si se detecta que no se recoge toda la información necesaria, se procede 


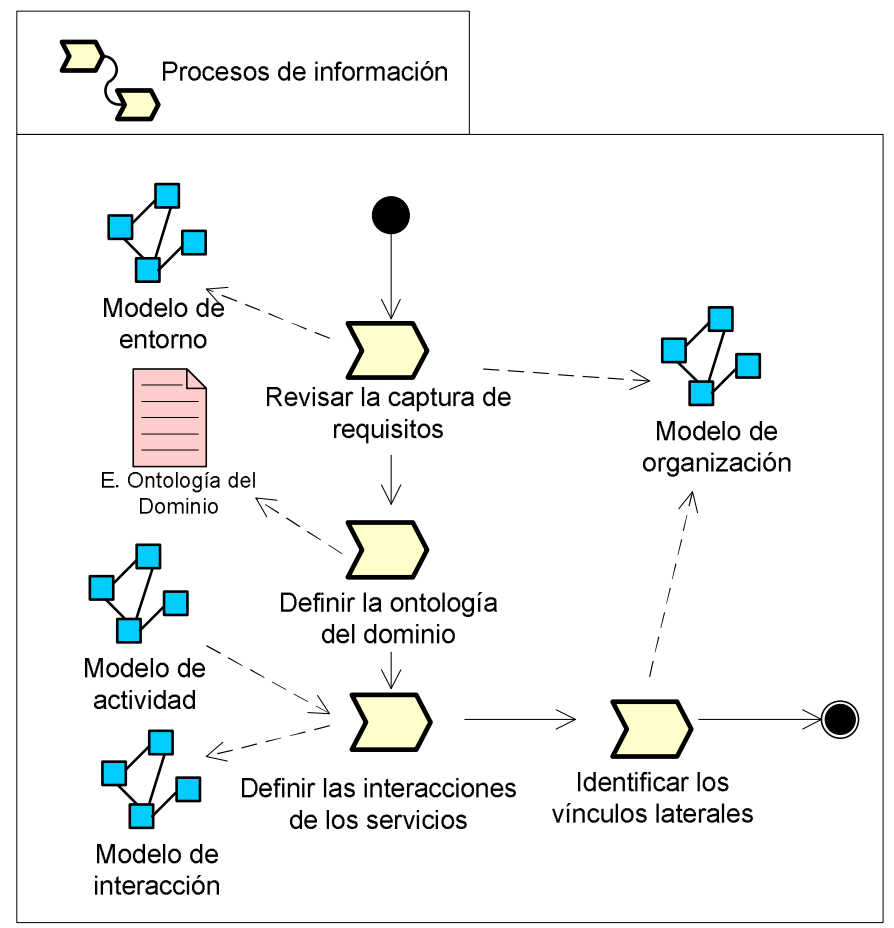

Figura 5.31: Definición de la tarea Análisis de los procesos de información.

a crear nuevas entidades Recurso para modelar a los repositorios de información (por ejemplo, bases de datos), a los dispositivos, a la maquinaria o tecnología, es decir a cualquier elemento o facilidad requerido para la ejecución de las tareas, sobre los que se apliquen acciones de consumición y producción. Para cada recurso se deben identificar sus limitaciones de disponibilidad, así como su posibilidad de renovación (recursos consumibles o no consumibles).

Por otro lado, se deben definir nuevas aplicaciones (o utilizar aquellas ya existentes en el entorno) para establecer una interfaz simple de interacción con los clientes/proveedores, a través de métodos de lectura de datos o de actuación sobre el entorno.

De este análisis se obtiene una actualización de los diagramas del modelo de entorno (posiblemente con nuevos recursos y aplicaciones, o con nuevas interfaces de las aplicaciones); y la actualización correspondiente del modelo 
de organización (vista estructural), que incluya a los nuevos recursos o aplicaciones y sus relaciones OContieneRecurso o bien OContieneAplicación.

Posteriormente, se determina quién hace uso de esos recursos y aplicaciones y de qué modo accede a ellos. Así, por cada recurso o aplicación del entorno se define una entidad PuertoEntorno en el modelo de entorno, a través de la cual se gestiona su acceso. Además, se identifican las relaciones WFUtilizaPuerto (de tipo WFUtilizaPuertoEscritura o bien WFUtilizaPuertoLectura) entre esos puertos y los roles que requieran del acceso a las aplicaciones o recursos.

Las relaciones indicadas representan los permisos iniciales de dichos roles respecto a su interacción con el entorno. Como esos permisos pueden ser modificados de forma dinámica, se define la entidad (rol o A-Agente) encargada de la gestión de los permisos de acceso al entorno. De este modo, para cada PuertoEntorno se establece la relación EContienePuerto sobre la Unidad Organizativa que contenga al recurso o aplicación correspondiente, o bien sobre un rol específico. Todas estas relaciones y entidades quedan reflejadas en los diagramas del modelo de entorno.

Para la segunda actividad (definir la ontología del dominio) se especifican los conceptos sobre los que versa el dominio de aplicación, teniendo en cuenta las entradas y salidas de los servicios. También se determinan las relaciones existentes entre los conceptos identificados. Como resultado se genera el documento E.Ontología Dominio. Por otro lado, si se conoce la existencia de otras ontologías similares o del mismo área, se deben establecer las correspondencias con la ontología definida y en qué medida se podrían utilizar para describir a los servicios requeridos.

Las dos últimas actividades se centran en los flujos de ámbito interno. En concreto, en la tercera actividad se identifican las interacciones producidas por la activación de los servicios; mientras que en la cuarta actividad se revisan las relaciones existentes entre las distintas unidades, creando nuevos flujos de información entre ellas.

Por tanto, en la actividad definir las interacciones asociadas a cada servicio se revisa el conjunto de objetivos identificado en el modelo de 
actividad. Dichos objetivos están relacionados con A-Tareas, en concreto, con servicios.

Por cada servicio se define una entidad Interacción y se instancia su modelo de interacción. Se asocian a dicha interacción los objetivos correspondientes del servicio (relación IPersigue). Se indican también sus características (naturaleza), así como los participantes de la interacción (relaciones IInicia e IColabora). En concreto, el iniciador de la interacción vendrá definido por el rol participante en la relación WFUtiliza de ese servicio, mientras que como colaborador debe aparecer el de la relación WFProporciona.

Por último, se genera una primera especificación de la interacción, mediante diagramas de colaboración (por ejemplo con diagramas en la notación GRASIA [Gomez, 2002]). Para esa especificación se debe tener en cuenta la descripción del servicio y sus tareas asociadas. De este modo, las entradas deberán aparecer en los mensajes enviados por el iniciador al colaborador, según el orden establecido en la composición de tareas del servicio. Por su parte, las salidas aparecerán en los mensajes del colaborador hacia el iniciador.

Finalmente, en la actividad identificar los vínculos laterales entre las unidades se revisan las relaciones entre las distintas unidades organizativas, para así crear nuevos flujos de información entre ellas que faciliten sus relaciones y el intercambio de la información (especialmente sobre el entorno), de modo que se eviten los cuellos de botella y se gestionen mejor posibles fallos de funcionamiento de los agentes.

Normalmente estos "vínculos laterales" se realizan en estructuras de tipo jerárquico en las que interese crear nuevos vínculos entre las unidades para reforzar sus relaciones y agilizar el paso de información. De este modo, si se detecta que determinados datos requieren pasar por muchas entidades hasta llegar a su destino final posiblemente sea necesario establecer un vínculo directo entre la entidad que genera esos datos y la que finalmente los consume.

El vínculo lateral entre las entidades se define mediante la relación 
AGOInformación de la vista social del modelo de organización, para indicar que las entidades están habilitadas para conocerse entre sí. Además se añade un objetivo común entre ellas que remarque esa necesidad de comunicación (entidad A-Objetivo del modelo de actividad), que debe ser un refinamiento o descomposición de alguno de los objetivos que persigan. Finalmente se crea una entidad Interacción del modelo de interacción, asociada a dicho objetivo, que tiene como participantes a las entidades de la relación AGOInformación anterior. Esta interacción se implementa a través del protocolo Request de FIPA, o bien de protocolos de tipo suscripción.

En algunos casos, una entidad de una unidad organizativa "A" determinada posiblemente requiera comunicarse con entidades de otra unidad "B", pero sin importar con cuáles de dichas entidades se contacta. Solamente se requiere transmitir la información a la unidad y que ésta, en base a su estructura, la suministre a todos sus miembros o bien a aquellas entidades capacitadas (ej: a los supervisores). En dicho caso, la relación AGOInformación se establece entre el agente de la unidad "A" con la unidad "B" al completo. Además, la entidad Interacción necesaria tendrá como participante a la unidad "B".

Si la plataforma escogida para la implementación del sistema se encarga de la distribución de los mensajes que llegan a la unidad a sus miembros, no se requiere mayor refinamiento de la interacción. En caso contrario, se debe especificar quién se encarga de recibir y responder a los mensajes que llegan a la unidad.

Por otro lado, como la relación AGOInformación representa que los agentes se conocen entre sí o bien que están habilitados para ello, la implementación de esta relación se realiza de dos modos: o bien la conexión entre los agentes está predefinida (es decir, que un agente dispone en su código de la dirección exacta del otro agente con el que requiere contactar); o bien se emplean entidades de tipo AMS (Agent Management Service), que les proporcionan funcionalidad de páginas blancas. En este caso, en la implementación del sistema se debe determinar para cada relación AGOInformación qué entidad de tipo AMS lleva asociada y cómo se gestionará la 


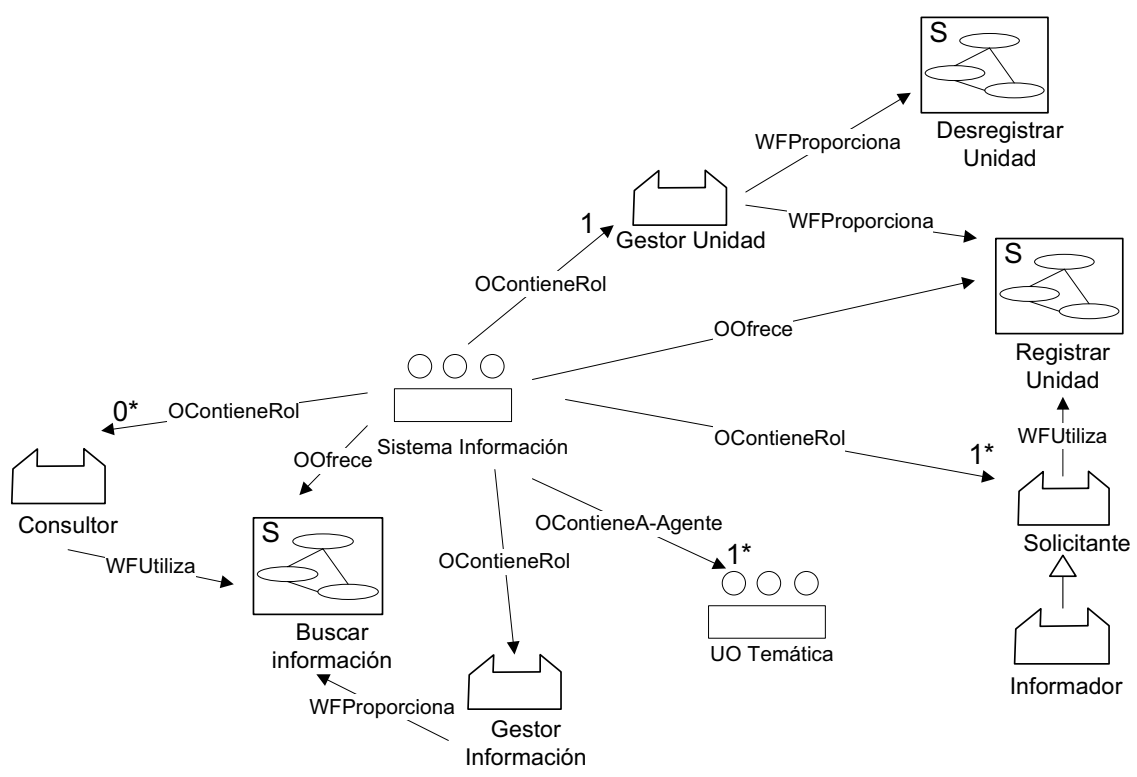

Figura 5.32: Diagrama actualizado del modelo de organización (funcionalidad externa) para la unidad organizativa que representa al sistema de información.

visibilidad de esos agentes.

\subsubsection{Aplicación de la fase al caso de estudio}

En el análisis de los procesos de decisión se ha determinado, en primer lugar, qué roles se encargan de proporcionar los servicios para los cuales todavía no se había establecido un proveedor.

En la UO Sistema Información (figura 5.32) se han identificado los nuevos roles Gestor Unidad, que se encarga de registrar y desregistrar unidades; y Gestor Información que atiende las peticiones de búsquedas concretas de información y contacta con las diferentes UO Temáticas para obtener los documentos solicitados.

Para cada UO Temática (figura 5.33) se requiere un rol Gestor Información, que se encargue tanto de atender las peticiones de suscripción, las peticiones de proporcionar información, como de distribuir los documentos relevantes de la unidad. Además, se ha identificado un rol Gestor Unidad 


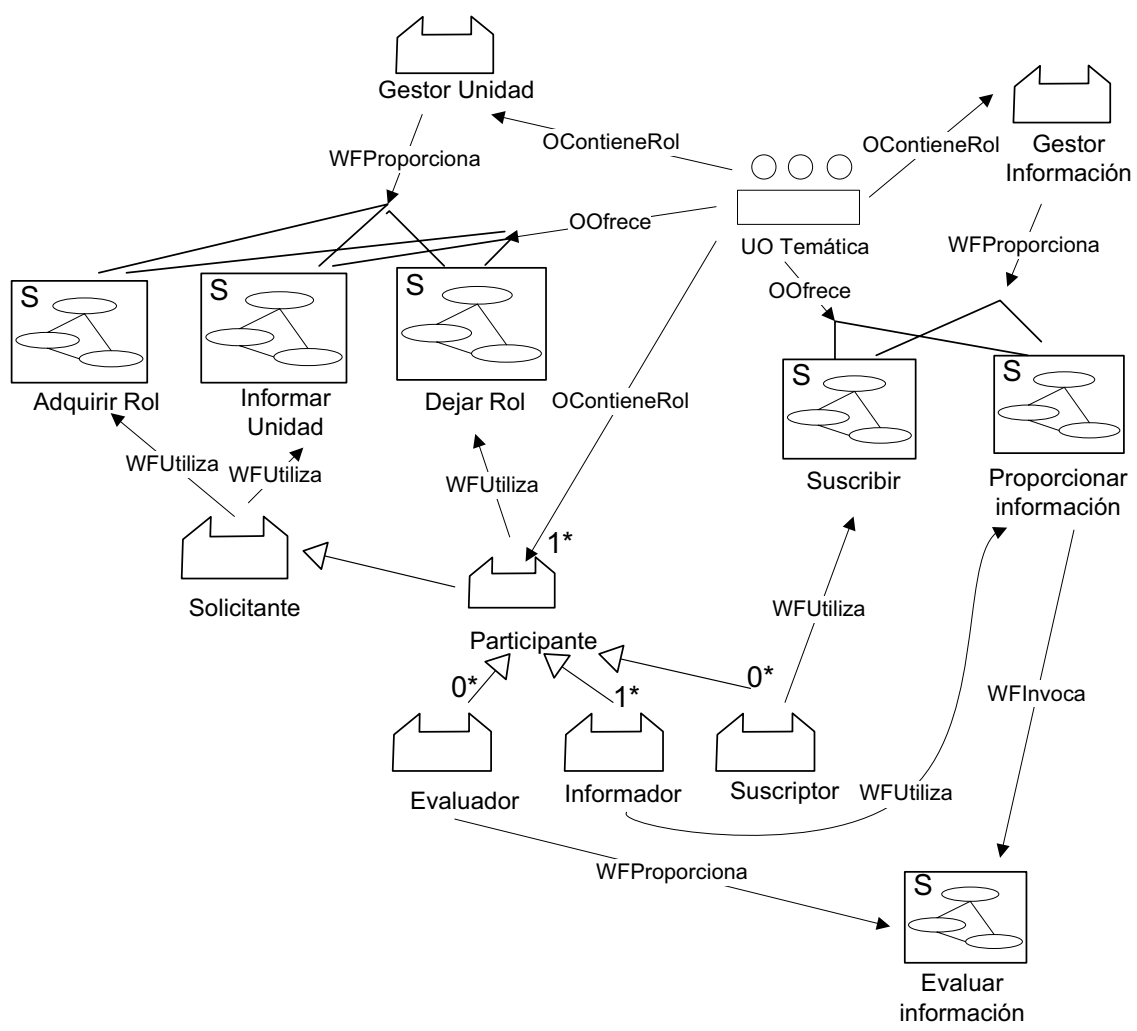

Figura 5.33: Diagrama actualizado del modelo de organización (funcionalidad externa) para la UO Temática.

para proporcionar los servicios de Adquirir Rol, Dejar Rol e Informar Uni$d a d$, servicios propios de cualquier unidad organizativa.

En las figuras 5.32 y 5.33 se muestra el diagrama actualizado de la vista funcional (funcionalidad externa) del modelo de organización.

En segundo lugar, se detallan las actividades para los nuevos servicios RegistrarUnidad, InformarUnidad, AdquirirRol y DejarRol. Se ha incluido también el servicio DesregistrarUnidad, propio del patrón básico de una unidad organizativa (figura 4.48 del capítulo 4), proporcionado por el rol Gestor Unidad, para así permitir también la eliminación de aquellas unidades cuyo número de participantes sea muy bajo.

En las figuras 5.34 y 5.35 se muestra el diagrama del modelo de actividad para el servicio RegistrarUnidad. Cuando el informador solicita este servicio, 


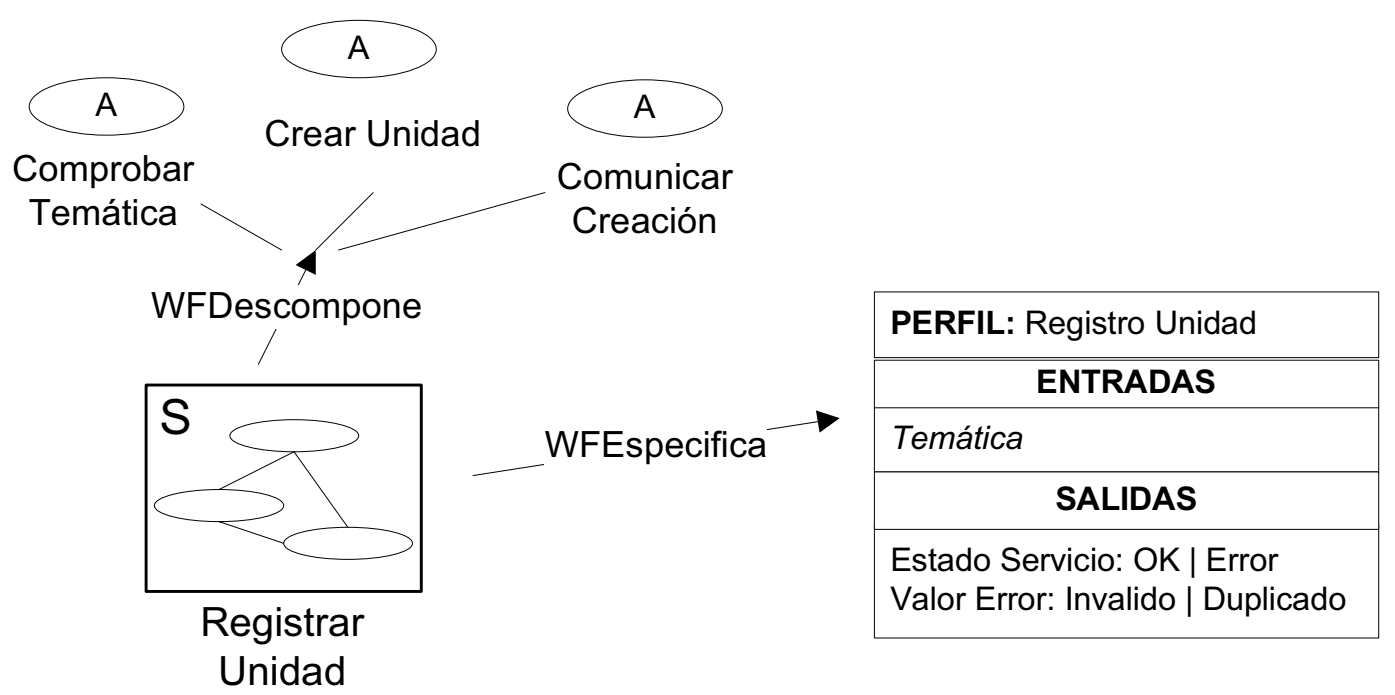

Figura 5.34: Diagrama del modelo de actividad del servicio RegistrarUnidad.

proporciona la temática que desea que se genere. El gestor comprueba que no existe una temática similar y, en dicho caso, crea la UO correspondiente. Además, se informa a los evaluadores del resto de unidades que existe la nueva temática, para que si lo desean se registren como evaluadores dentro de esa nueva unidad.

En tercer lugar, se refinan los objetivos funcionales, para así obtener objetivos operativos asignables a las tareas. En la figura 5.36 se muestra parte del diagrama del modelo de actividad con la descomposición de los objetivos, en este caso para los objetivos funcionales "maximizar calidad de documentos", "distribuir documentos", "proporcionar documentos" e "incrementar colección", que están relacionados con los servicios de Proporcionar Información y de Evaluar Información.

En el análisis de los procesos de información hemos determinado, en primer lugar, la distribución de los recursos y el acceso a los mismos. Después se han diseñado las interacciones correspondientes a los servicios identificados. Aquí mostramos solamente las interacciones del servicio Proporcionar Información. Para la descripción de la ontología del dominio se deben definir las temáticas con las que se trabajará. Si se desea, los diseñadores 


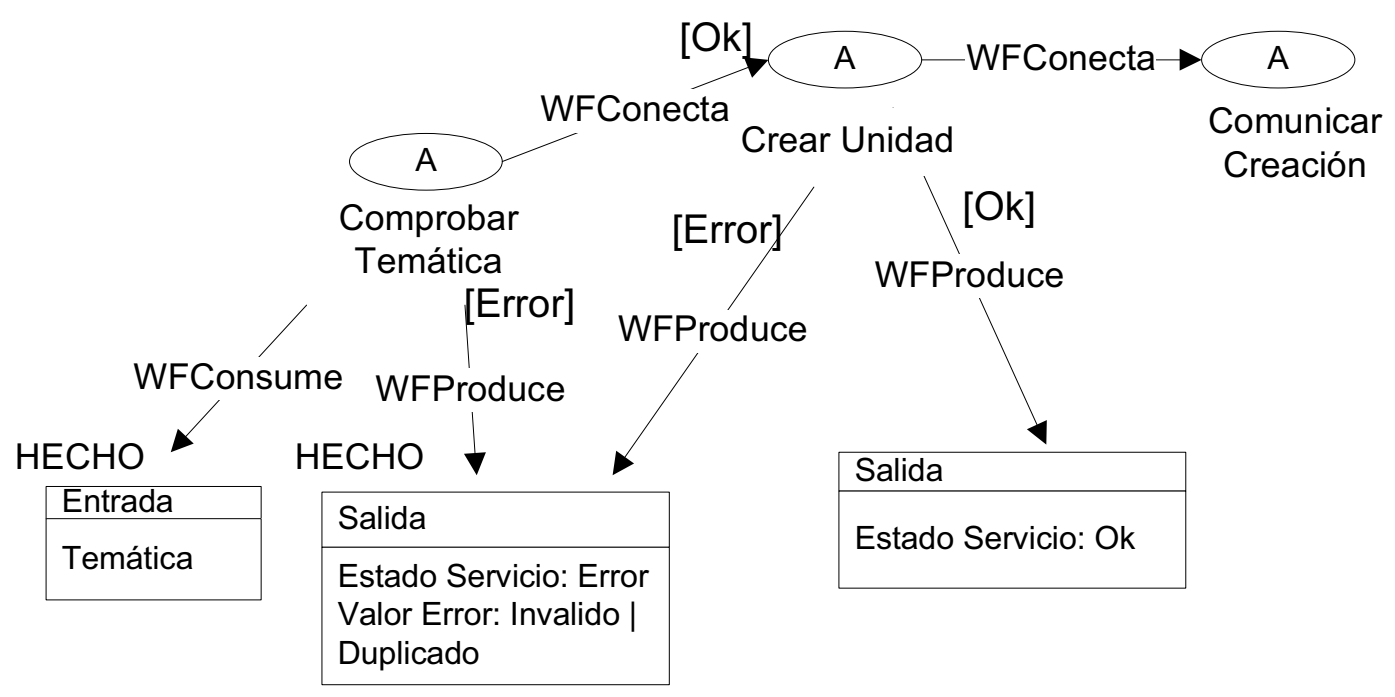

Figura 5.35: Diagrama del modelo de actividad del servicio RegistrarUnidad. Descripción de su flujo de tareas.

pueden buscar previamente repositorios de ontologías ya existentes, a los que se conecten los agentes para obtener la descripción de la ontología de las temáticas a tratar. En este ejemplo no entraremos en este aspecto. Finalmente, como cada UO Temática actúa de forma independiente respecto al resto, no se requiere establecer ningún vínculo entre las unidades.

A continuación explicamos los cambios realizados sobre el modelo de entorno para la redistribución de los recursos. En el sistema de información se había identificado la necesidad de una Base de Datos para registrar los documentos proporcionados por los informadores. Este recurso se reasigna a cada unidad temática, para así recopilar mejor los documentos según su área temática. Además, se asocia un puerto de entorno (AccesoBD) a dicho recurso para indicar qué roles tienen permitido su utilización y de qué modo. Así, el rol evaluador puede leer los documentos existentes y establecer la calidad de los mismos. Asimismo, el rol informador incrementa la cantidad de documentos, al proporcionar nueva información. En la figura 5.37 se muestra el diagrama del modelo de entorno actualizado.

Respecto a las interacciones, se ha asociado al servicio Proporcionar Información su interacción correspondiente (figura 5.38), de modo que el rol 


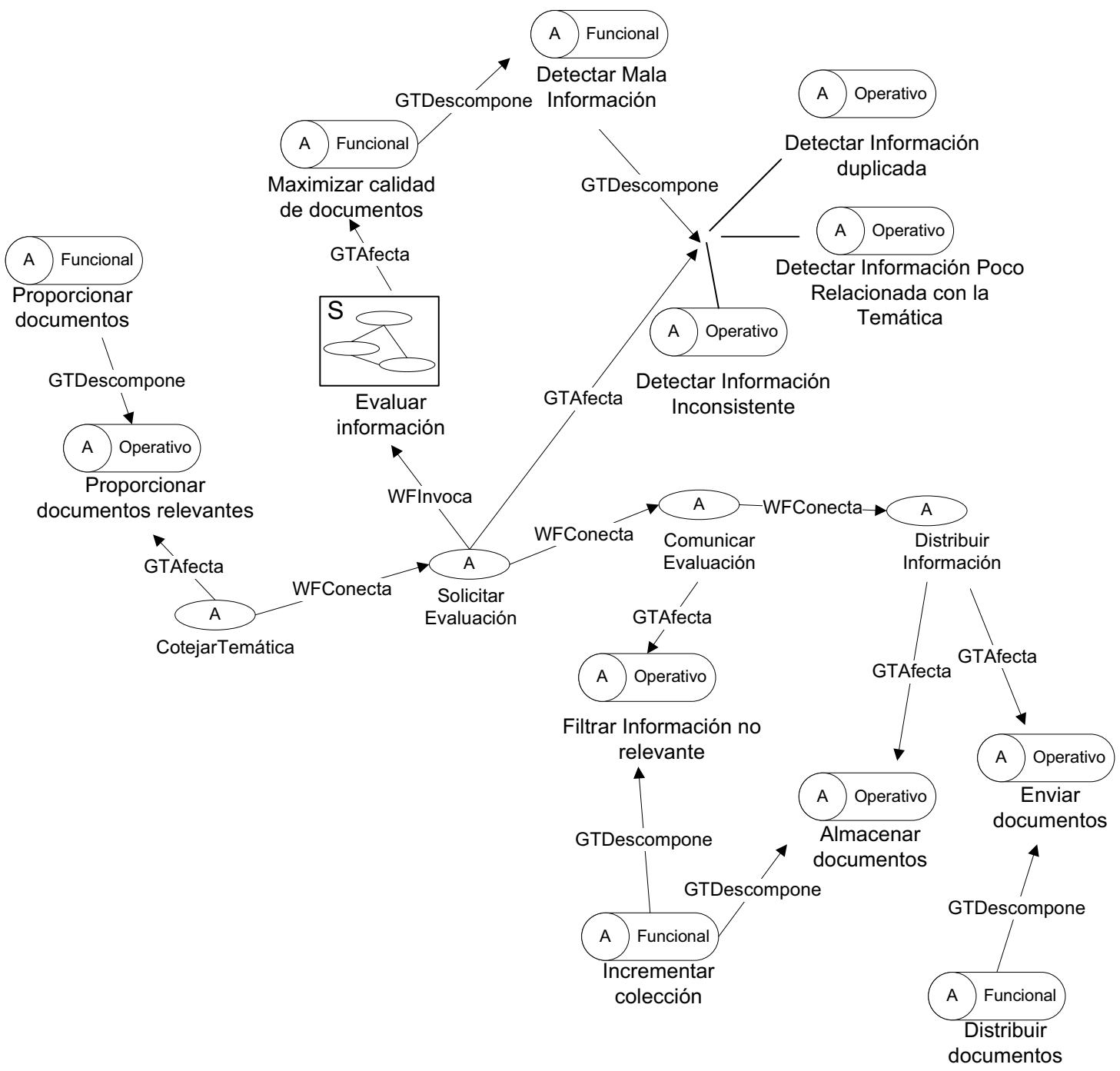

Figura 5.36: Diagrama del modelo de actividad. Descomposición de los objetivos funcionales (Maximizar calidad de documentos, Distribuir documentos, Proporcionar documentos e Incrementar colección) en objetivos operativos. Asociación a las tareas del servicio Proporcionar Información. 


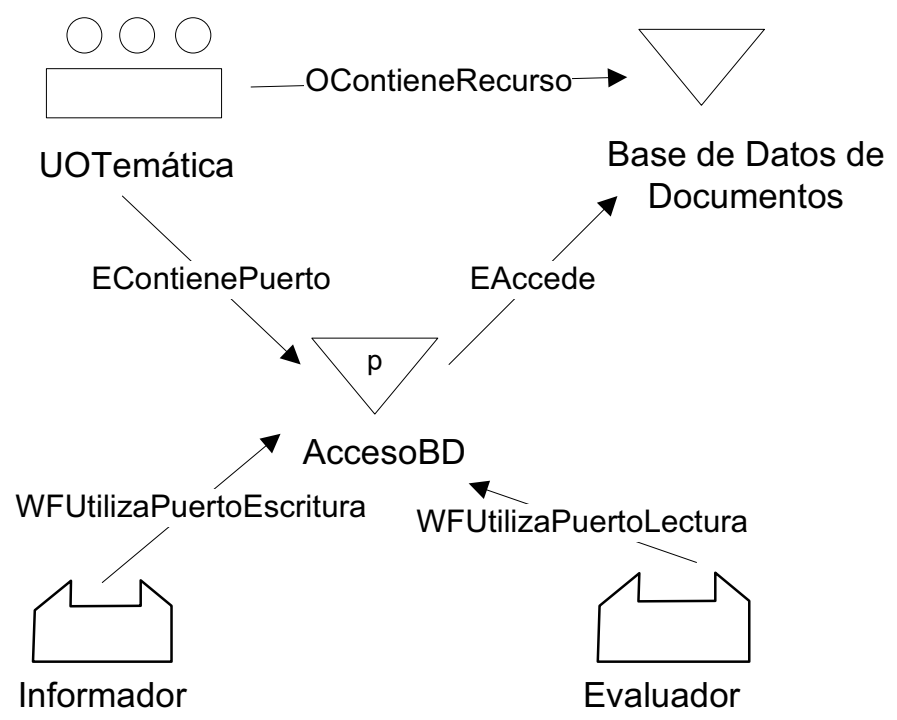

Figura 5.37: Diagrama actualizado del modelo de entorno del sistema de información. Acceso al recurso Base de Datos.

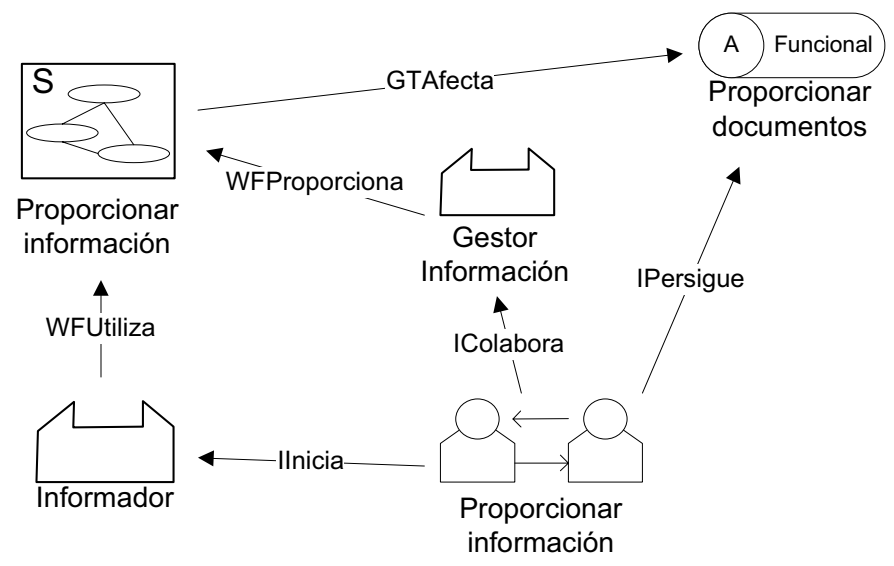

Figura 5.38: Diagrama del modelo de interacción para el servicio Proporcionar Información. 


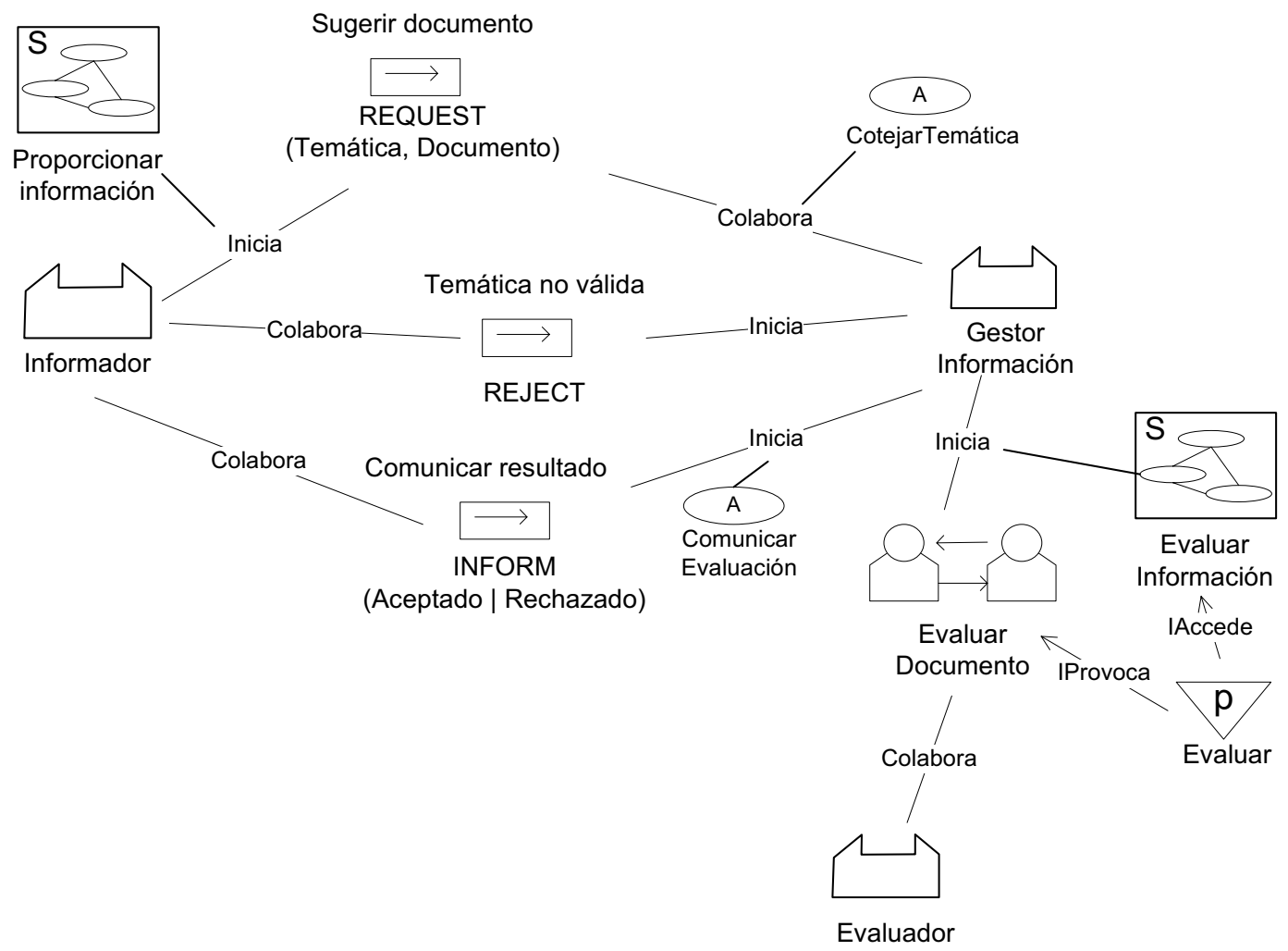

Figura 5.39: Diagrama de colaboración que especifica la interacción Proporcionar Información.

informador inicia la interacción (al hacer uso del servicio), mientras que el rol gestor de información colabora en ella (como proveedor del servicio). Además, la interacción persigue el objetivo funcional Proporcionar Documentos.

En la figura 5.39 se muestra el diagrama de colaboración que describe a la interacción Proporcionar Información. En ella, el rol informador, mediante una performativa de tipo Request, proporciona al gestor de información el documento que desea sugerir, así como la temática sobre la que versa. El gestor coteja esa temática respecto a la de la unidad organizativa donde se encuentran. Si la temática no es adecuada rechaza el documento (performativa Reject). Si es correcta, solicita el servicio Evaluar Información a todos los evaluadores que se hayan registrado en la unidad. Esto queda 
representado con la utilización del puerto Evaluar. Posteriormente, el gestor de información comunica el resultado de la evaluación al informador, usando una performativa de tipo Inform.

\subsubsection{Síntesis de la fase}

En la fase E.Procesos de información y decisión se determina quiénes se encargan de proporcionar cada uno de los servicios identificados, qué procesos o tareas comprenden, así como que objetivos operativos llevan asociados esos procesos. También se detallan las interacciones entre los agentes, los mensajes requeridos por los servicios, así como los puntos de acceso y procesamiento de la información.

Los documentos y modelos generados en esta fase son:

- Documento E.Ontología del Dominio: relación de conceptos del dominio de aplicación.

- Diagramas del modelo de interacción: se definen las entidades Interacción para cada servicio. Para cada interacción se definen quiénes son sus iniciadores y colaboradores (relaciones IInicia e IColabora); y se asocia con los objetivos del servicio (relación IPersigue).

- Diagramas de colaboración para la especificación de las interacciones: se definen los mensajes concretos que conforman a la interacción, empleando diagramas con notación GRASIA, AUML, etc.

- Actualización del diagrama de modelo de actividad: se identifican todas las relaciones WFProporciona que indican quién se encarga de suministrar el servicio. Además se determinan los objetivos operativos (relaciones GTDescompone y GTDepende), asociándolos a las tareas del servicio (relación GTAfecta)

- Actualización del diagrama del modelo de entorno: se revisan los recursos y aplicaciones del sistema, de los que se extrae la información, añadiendo aquellos que sean necesarios. 
Se identifican las entidades PuertoEntorno para el acceso a los recursos y aplicaciones. Se establecen las relaciones WFUtilizaPuerto, para representar los permisos de acceso al entorno; y EContienePuerto, para la gestión de esos permisos.

- Actualización del diagrama de la vista social del modelo de organización: se identifican nuevas relaciones AGOInformación entre entidades de distintas unidades organizativas. 


\subsection{Fase F. Dinamicidad del Sistema Abier- to}

En las organizaciones humanas, las políticas de recursos humanos definen los mecanismos de captación de personal, selección, formación y promoción [Moreno-Luzon et al., 2001] a través de los cuales la organización determina qué miembros son los adecuados para cada uno de sus puestos. Además, se determina la forma en que se hacen visibles los objetivos de la organización.

En los MAS, en esta fase se establece la funcionalidad ofrecida como sistema abierto, que incluye tanto los servicios que se deben publicitar, como las políticas de adquisición y liberación de roles. Además, se determina qué funcionalidad debe ser implementada por agentes internos al sistema y cuál se publicita a través de los puertos de servicio del entorno, para así poder ser suministrada por agentes externos. De este modo, se modela la dinamicidad de la organización como sistema abierto.

Esta fase consta de las siguientes actividades (figura 5.40): (i) determinar qué funcionalidad se debe publicitar; (ii) establecer las políticas de adquisición de roles; y (iii) diseñar los agentes propios del sistema.

Como se comentó en el capítulo 4, en el meta-modelo de agente se distingue entre agentes internos y agentes externos. Los internos son desarrollados únicamente por los diseñadores del sistema y llevan asociados roles no accesibles, generalmente de tipo controlador, supervisor, monitor, etc., para así garantizar que la funcionalidad del agente es exactamente la requerida.

Por su parte, los agentes externos identifican a todos aquellos agentes que participan en la organización y cuya procedencia es heterogénea, es decir, pueden haber sido diseñados e implementados por los desarrolladores del sistema o bien por otros equipos de desarrollo. Por tanto, estos agentes requieren adoptar roles accesibles de las unidades y se debe controlar su comportamiento a través de normas asociadas al rol.

En nuestra propuesta agrupamos bajo el nombre de "agentes propios" a todos los agentes (internos o externos) que los diseñadores del sistema 


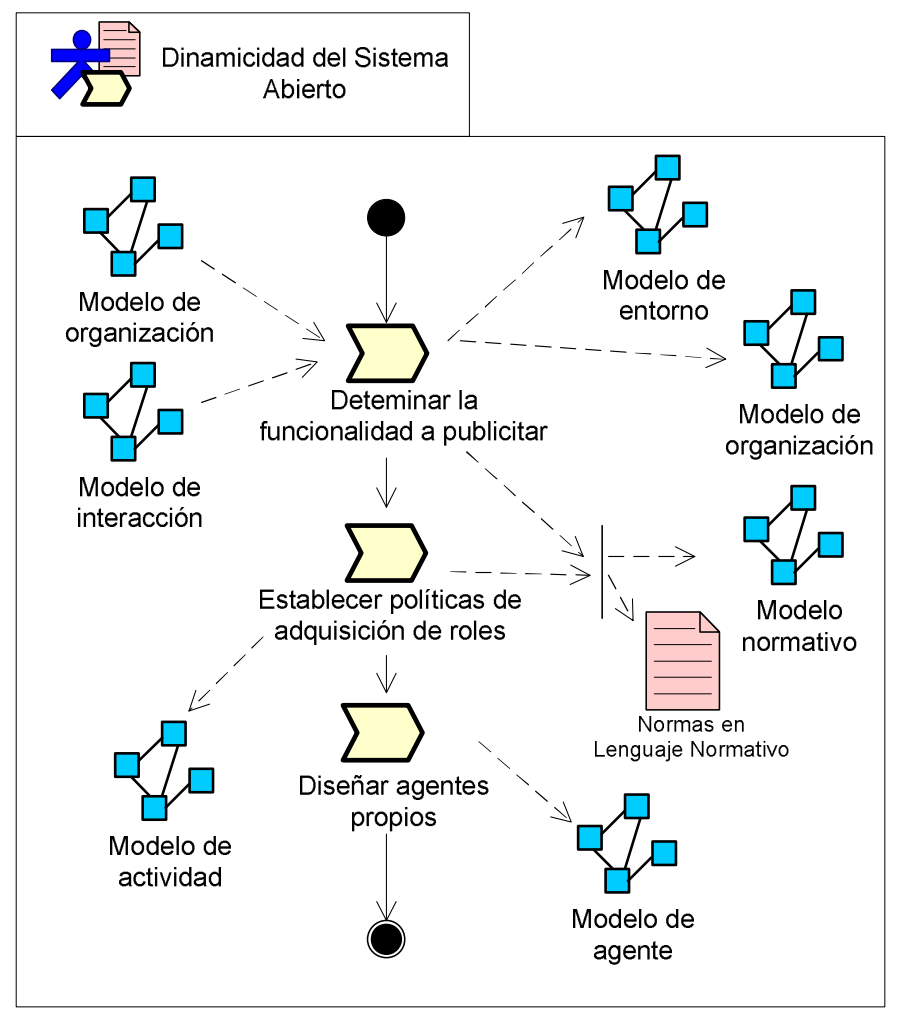

Figura 5.40: Fase Dinamicidad del Sistema Abierto.

requieran o deseen implementar para ofrecer y gestionar la funcionalidad de la organización.

FUNCIONALIDAD A PUBLICITAR. En la primera actividad de esta fase se revisan los diagramas del modelo de organización, para así establecer si los A-Agentes identificados hasta el momento se corresponden con agentes internos o externos. En concreto, si un A-Agente está asociado con un rol (relación WFJuega) que proporciona un servicio (relación WFProporciona) requerido por una unidad organizativa (relación ORequiere) y/o invocado por servicios de otras entidades (relación WFInvoca), este AAgente debe ser tratado como un agente externo. El rol o roles asociados deben pasar por un proceso de adquisición del rol, por lo que deben hacer uso del servicio AdquirirRol (relación WFUtiliza). 
Por su parte, los roles de gestión identificados tras las fases D.Estructura Organizativa y E.Procesos de información-decisión, así como todos aquellos roles que actúen como supervisores o monitores en las relaciones $A G O$ Supervisión y AGOMonitorizacion, respectivamente, se asignan a agentes internos, pues su funcionalidad requiere de garantías suficientes de seguridad y eficiencia. Para agrupar varios roles en un mismo agente interno se deben emplear las guías propuestas en la fase C.Dimensiones Organizativas, en concreto la dimensión de especialización. Como resultado, los diagramas del modelo de organización se actualizan, para incluir en ellos las entidades Agente (interno) identificadas. Se incluyen también las relaciones OContieneA-Agente y WFJuega correspondientes, de la vista estructural y de la vista funcional (funcionalidad interna), para así indicar la relación de estos agentes con las unidades organizativas, así como con los roles que juegan.

Además, todos aquellos roles definidos para los cuales se requiere un control de sus comportamientos y establecer en cada momento quién está asociado a dicho rol (saber quién es el agente que lo juega) necesitan pasar por una fase de registro en la unidad donde participen. De este modo, los agentes que deseen jugar ese rol deben solicitar el servicio AdquirirRol de la unidad que lo contenga. Por tanto, se trata de roles de tipo accesible, que deben ser asociados a agentes externos. Asimismo, se debe comprobar que la unidad ofrezca este servicio AdquirirRol. Si no es así, los diagramas de los modelo de organización y de actividad de la unidad se actualizan para incluir y detallar este servicio.

Para los agentes externos, existen dos mecanismos de diseño: a) asociar a cada agente externo un agente interno del sistema que lo represente, que conozca los protocolos de interacción requeridos y que participe en su nombre en las interacciones; b) actuar con el sistema en base a servicios y establecer las normas de gestión de los servicios y de adquisición de los roles.

En la primera opción, todos los servicios identificados pasan a tratarse como simples flujos de tareas, para los cuales no se requiere su publicitación. 
Además, se definen agentes internos asociados a cada agente externo y se establecen interacciones directas entre ellos. Por ejemplo, en la plataforma AMELI [Esteva et al., 2004] de las Instituciones Electrónicas, se emplean agentes llamados governor que actúan de intermediarios entre los agentes externos a la plataforma y el resto de agentes internos a la misma, de modo que actúan dentro de la institución representando a un determinado agente externo.

En la segunda opción, se establece un mecanismo más flexible, de modo que los servicios expresan la funcionalidad ofrecida y/o requerida por el sistema. De esta manera, los agentes (internos o externos) consultan los perfiles asociados a esa funcionalidad (es decir, qué realiza el servicio); pueden asociar su propia implementación a un determinado servicio, para el que se requieran proveedores (indicando cómo el agente realiza ese servicio); además de solicitar la ejecución de los servicios, estableciéndose un proceso de interacción entre los agentes implicados.

Por tanto, para cada servicio donde intervengan agentes externos se requiere de su publicitación. Así, se actualiza el diagrama del modelo de entorno, incluyendo nuevas entidades PuertoServicio por cada servicio que deba ser publicitado. Además, se definen normas (en el lenguaje normativo mostrado en el capítulo 4) para: (i) obligar a la unidad organizativa que requiere el servicio a registrar en un directorio de servicios que se solicitan proveedores para el mismo (acción de tipo REGISTER, modelada como una obligación a registrar el perfil del servicio asociado); (ii) obligar a esa unidad a desregistrar dicha "demanda" de proveedores cuando el número de agentes participantes en la unidad que jueguen el rol proveedor sea excesivo y ya no se desee que entren nuevos proveedores (acción de tipo DEREGISTER, modelada como una prohibición a registrar ese perfil del servicio).

ADQUISICIÓN DE ROLES. En la segunda actividad de esta fase se establecen las políticas de adopción de roles, determinando las tareas en que se descompone el servicio AdquirirRol de cada unidad organizativa. Además, para cada unidad y para cada rol establecido como externo o 
accesible en esa unidad, se deben especificar las normas que controlen los servicios que debe registrar.

En concreto se establece la obligatoriedad de registrar un servicio en el directorio de servicios (acción de tipo REGISTER, modelada como una obligación a registrar la funcionalidad asociada al perfil de servicio indicado, antes de un límite de tiempo establecido). También se especifican los servicios que puede utilizar, i.e. permisos u obligaciones sobre servicios (acción de tipo REQUEST, modelados, por ejemplo, como obligaciones o permisos para solicitar determinados servicios después de, o previo a solicitar otros servicios).

Respecto a las tareas del servicio AdquirirRol, se deben tener en cuenta, al menos, los siguientes conceptos:

1. Condiciones de activación: comprobar que no existe ninguna norma activa que impida la ejecución de este servicio, es decir, que el agente tenga permitido solicitar el servicio AdquirirRol.

2. Precondiciones válidas: comprobar que el rol solicitado existe dentro de la unidad donde se solicita y que es accesible. Además el agente solicitante debe tener acceso a la unidad en la que desea participar (porque ya forma parte de ella o porque pertenece a una unidad directamente superior).

3. Restricciones de cardinalidad y compatibilidad: comprobar que no se ha alcanzado todavía el número máximo permitido de agentes jugando ese rol, ni que tampoco el rol solicitado es incompatible con los roles que juega el agente en ese momento.

4. Contratación del servicio: informar al rol sobre las restricciones de funcionalidad (normas y perfiles de servicio) asociados con el rol. Opcionalmente, establecer un contrato con el agente en el que se delimite o restrinja su funcionalidad, en base a los servicios y normas del rol.

5. Asignación del rol: si todo es correcto, asignar el rol solicitado al agente (y admitirlo como miembro de la unidad en la que está definido 
el rol). Activar las normas relacionadas con el rol para controlar el comportamiento del agente dentro de la unidad.

Del mismo modo, se deben establecer las tareas en que se descompone el servicio DejarRol, para el cual se debe tener en cuenta:

1. Condiciones de activación: comprobar que no existe ninguna norma activa que impida la ejecución de este servicio.

2. Precondiciones válidas: el agente juega el rol indicado dentro de la unidad donde se solicita este servicio. Además, el agente no tiene ninguna norma activa debido a este rol, que le impida abandonarlo.

3. Desasignación del rol: si todo es correcto, el agente deja de jugar el rol indicado. Además, si era el único rol que tenía dentro de esa unidad, automáticamente dejará de participar en ella.

DISEÑO DE AGENTES. En la última actividad de esta fase se define el modelo de agente para los agentes propios del sistema (que actuarán como agentes internos y/o externos). Así, se relaciona a cada agente con el rol o roles que juega y se especifica la funcionalidad concreta que sabe realizar, estableciendo sus procesadores y gestores mentales. De este modo se actualizan los diagramas del modelo de agente.

\subsubsection{Aplicación de la fase al caso de estudio}

El sistema de información se ha planteado como un sistema abierto, en el sentido en que se permite que agentes externos al mismo ofrezcan dentro de él servicios de evaluación, así como solicitar los servicios de búsqueda de información, suscripción y proporcionar información.

$\mathrm{Al}$ revisar los diagramas del modelo de organización, comprobamos que en la fase B.Tareas y Procesos se había identificado un agente (Agente Evaluador), asociado al rol evaluador. Como ese rol proporciona el servicio Evaluar Información, que es requerido por las unidades organizativas Temática e invocado en el servicio Proporcionar Información, se trata pues 
de un agente externo. En la figura 5.41 se muestra dicho agente externo relacionado con el rol que adopta dentro de cada unidad organizativa Temática.

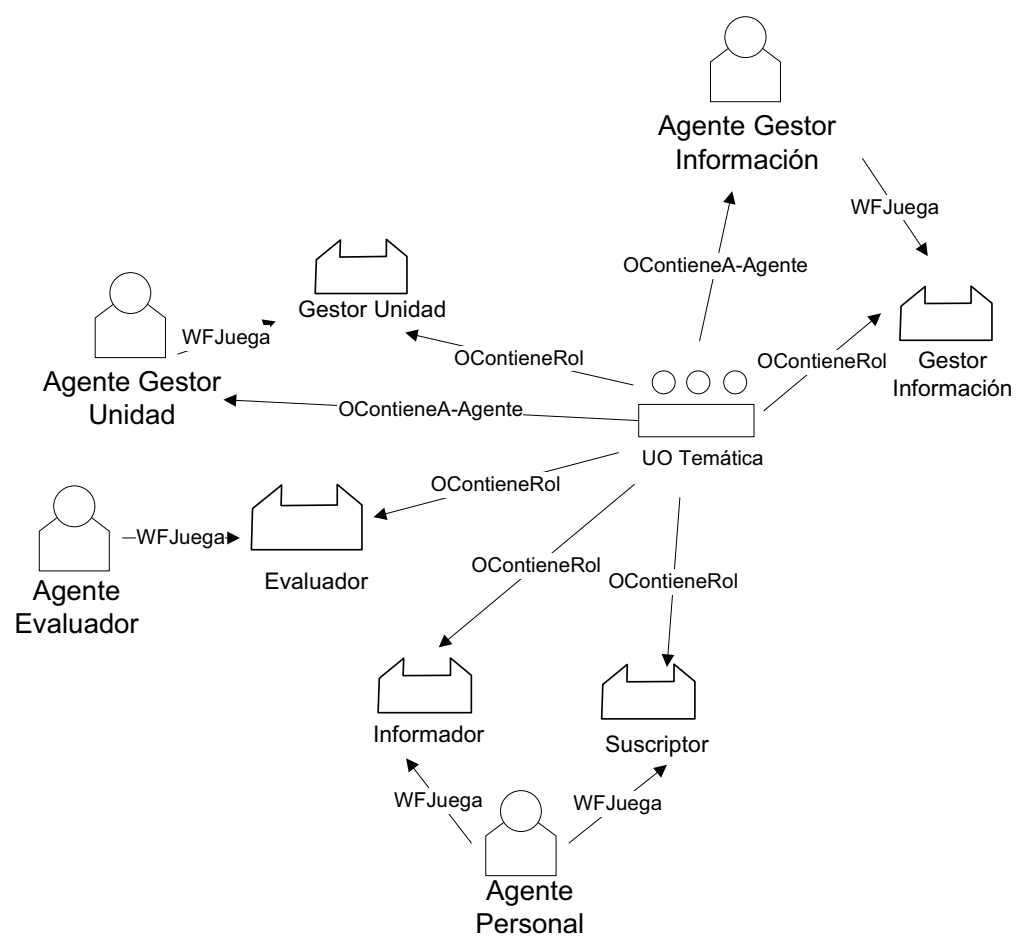

Figura 5.41: Diagrama del modelo de organización para la unidad organizativa Temática. Asociación de agentes a roles.

Por su parte, al revisar los diagramas obtenidos en la fase E.Procesos Información - Decisión, observamos que existen diversos roles gestores. Así, en la unidad organizativa Sistema Información agrupamos los roles GestorUnidad y GestorInformación en un único agente interno (Agente Administrador), atendiendo a aspectos de ampliación horizontal. En la figura 5.42 se muestra el diagrama del modelo de organización, con la identificación de este agente interno, asociado a los roles indicados (relación WFJuega) y contenido en la unidad organizativa (relación OContieneA-Agente).

Para las unidades organizativas Temática, se ha optado por definir dos 


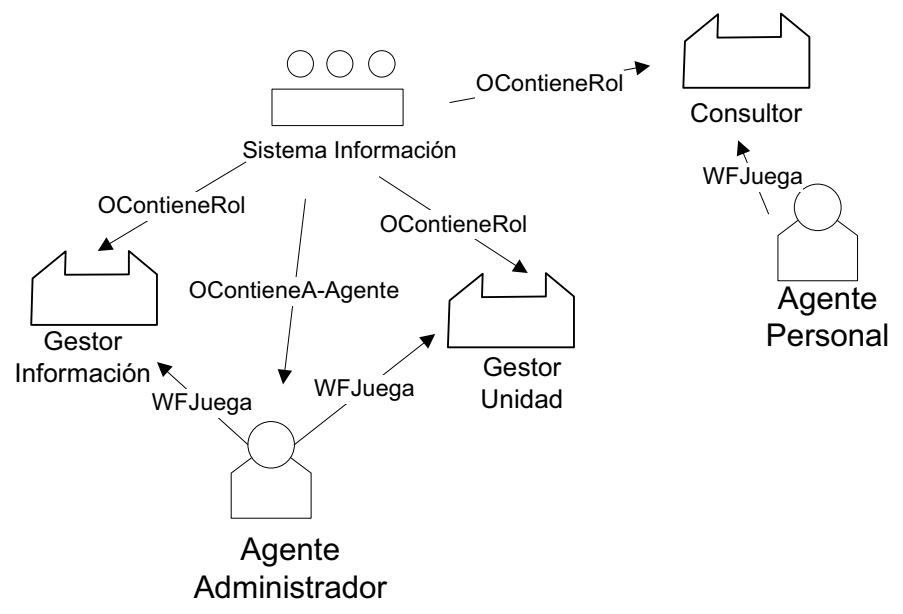

Figura 5.42: Diagrama del modelo de organización para la unidad organizativa Sistema de Información. Asociación de agentes a roles.

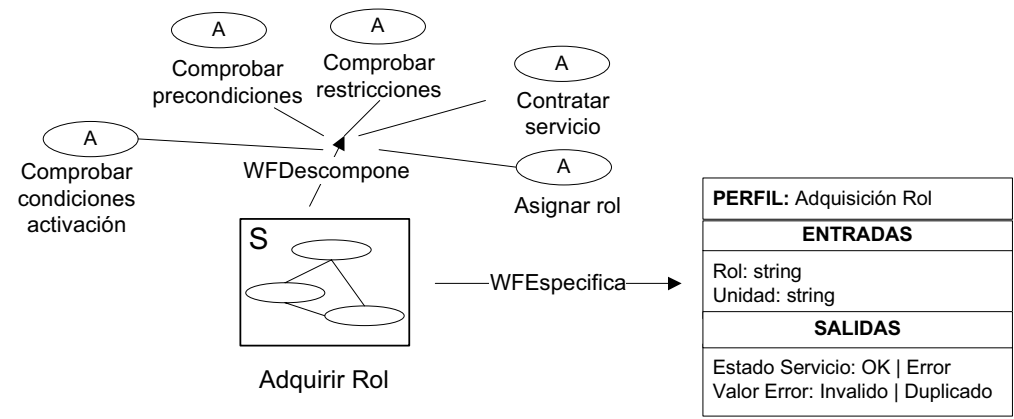

Figura 5.43: Diagrama del modelo de actividad para el servicio AdquirirRol.

agentes internos: (i) Agente Gestor Información, encargado de los servicios Suscribir y Proporcionar información, asociados al rol Gestor Información; y (ii) Agente Gestor Unidad, encargado de los servicios AdquirirRol, Informar Unidad, Dejar Rol, asociados al rol Gestor Unidad. Por tanto, se ha optado por realizar una especialización horizontal, con agentes focalizados en servicios muy relacionados entre sí. En la figura 5.41 se muestra el diagrama del modelo de organización para la UO Temática, donde se asocian estos agentes internos con los roles que juegan (relación WFJuega), así como con la unidad donde están contenidos (relación OContieneAAgente). 


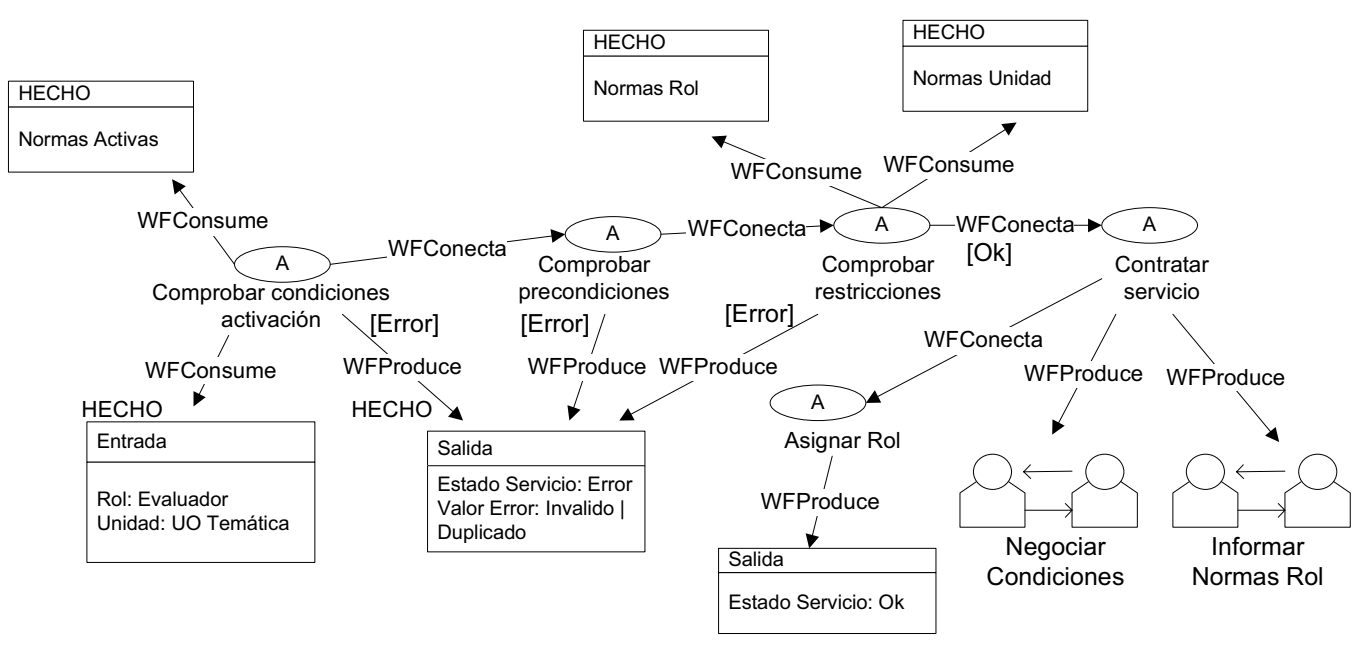

Figura 5.44: Diagrama del modelo de actividad para el servicio AdquirirRol. Descripción de su flujo de tareas al solicitar el rol evaluador en una UO Temática.

Respecto a las políticas de adquisición de roles, en la figura 5.43 se muestra el diagrama del modelo de actividad para el servicio AdquirirRol. Además, en la figura 5.44 se muestra su flujo de tareas, para el caso de solicitar el rol evaluador en una UO Temática.

Se deben definir también normas asociadas a la publicación de los servicios, al control de la cardinalidad de los roles, de su compatibilidad, así como del orden de ejecución de los servicios. Como ejemplo, indicamos a continuación la norma asociada a la publicación del servicio EvaluarInformación por parte de cada unidad temática.

\section{NormaPublicitarEvaluarInformación:}

OBLIGED UOTemática REGISTER EvaluarInformación PROFILE ProfEvalinfo

ProfEvalInfo: PROFILE INPUT (Doc: Documento, Tem: Tematica) OUTPUT (Votación: "Aceptado"— "Rechazado", Calidad: Int[0..10]) $\operatorname{PRE}($ Doc $\notin \emptyset \wedge$ Tem $\notin \emptyset)$ 
Esta norma indica la obligatoridad de que la unidad organizativa Temática registre el servicio EvaluarInformación con el perfil indicado, que debe coincidir con el que se haya especificado anteriormente en el modelo de actividad asociado a ese servicio. Remarcar que la obligación sobre la unidad será llevada a cabo por uno de sus agentes internos. Así, se podría sustituir la entidad UOTemática de la norma por la entidad AgenteGestorUnidad.

Otro ejemplo de norma es la obligación de los evaluadores de asociar una funcionalidad determinada al servicio EvaluarInformación, una vez que han entrado a participar en la unidad temática.

\section{NormaFuncionalidadEvaluarInformación:}

OBLIGED ?ag:evaluador REGISTER EvaluarInformación PROFILE ProfEvalInfo PROCESS ?p BEFORE deadline

En este caso, el agente que adopte el rol evaluador debe registrar un proceso o funcionalidad al servicio indicado antes de que se cumpla el deadline.

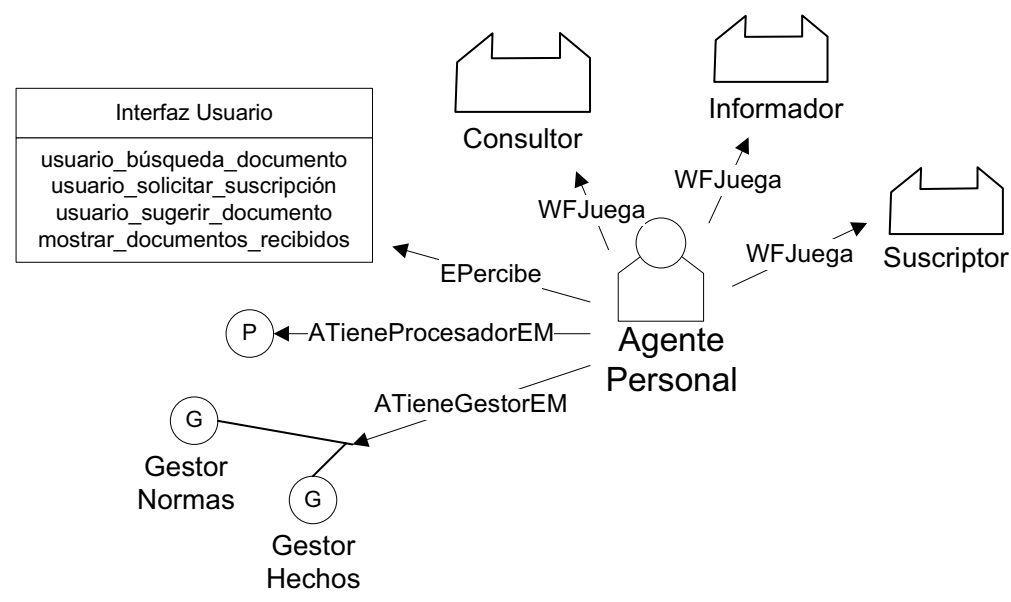

Figura 5.45: Diagrama del modelo de agente para el AgentePersonal.

Finalmente, se ha definido un AgentePersonal que actúa como agente propio de nuestra aplicación y que es capaz de adoptar los roles de consultor, informador y suscriptor. Además, percibe la aplicación del entorno, a través de la cual los usuarios del sistema faciliten sus documentos y soliciten 
búsquedas o suscripciones. Este AgentePersonal tiene un comportamiento similar al implementado en el sistema de información de la metodología de INGENIAS, sobre la que se basa en parte nuestro ejemplo.

En la figura 5.45 se muestra el diagrama actualizado del modelo de agente para el AgentePersonal, indicando los roles que juega, así como su percepción de la interfaz de usuario y sus procesadores y gestores mentales.

\subsubsection{Síntesis de la fase}

En la fase F.Dinamicidad del sistema abierto se establece para cuáles de los servicios requeridos se diseñan e implementan agentes que cubran esa funcionalidad.

Por tanto, permite: (i) identificar los agentes externos e internos, así como los agentes propios (agentes implementados por los diseñadores del sistema, capacitados para adquirir roles de tipo interno y/o externo); (ii) establecer el patrón de comportamiento de los agentes externos, a través de las normas asociadas a los roles accesibles del sistema; y (iii) detallar el comportamiento de los agentes propios.

Los documentos y modelos generados en esta fase son:

- Actualización de los diagramas del modelo de entorno: asociar la entidad PuertoServicio a cada servicio publicitado. Añadir la relación IAccede sobre ese puerto, especificando quién hace uso del mismo.

- Actualización de los diagramas del modelo de organización: identificar las entidades Agente y relacionarlas con los roles que juegan (relación WF Juega). Conectar las unidades organizativas con sus agentes internos (relación OContieneA-Agente). Incluir las nueva entidades Norma y asociarlas con las unidades (relación OContieneNorma).

- Documento Normas: descripción de las normas asociadas a la publicación de servicios, cardinalidad de los roles, su compatibilidad y orden de ejecución de los servicios. Las normas son definidas aplicando la descripción BNF del lenguaje normativo propuesto. 
- Actualización de los diagramas del modelo normativo: describir las normas del documento anterior mediante entidades de tipo Norma. Asociarles los roles o agentes afectados, los objetivos deónticos, tareas/servicios implicados y condiciones de activación/desactivación.

- Actualización de los diagramas de modelo de actividad: descripción de las tareas asociadas a los servicios AdquirirRol y DejarRol.

- Diagramas del modelo de agente: diseño de agentes propios, asociados a servicios o funcionalidad publicitada (externos) o no publicitada (internos). 


\subsection{Fase G. Sistemas de medición, evalua- ción y control}

En las organizaciones humanas, los sistemas de control del desempeño se realizan a través de la normalización de las tareas, aplicada mediante el diseño de los procesos; la normalización de los resultados, reflejada en el establecimiento de objetivos; y la normalización de habilidades, representada por la asunción de creencias, valores y principios comunes [Moreno-Luzon et al., 2001].

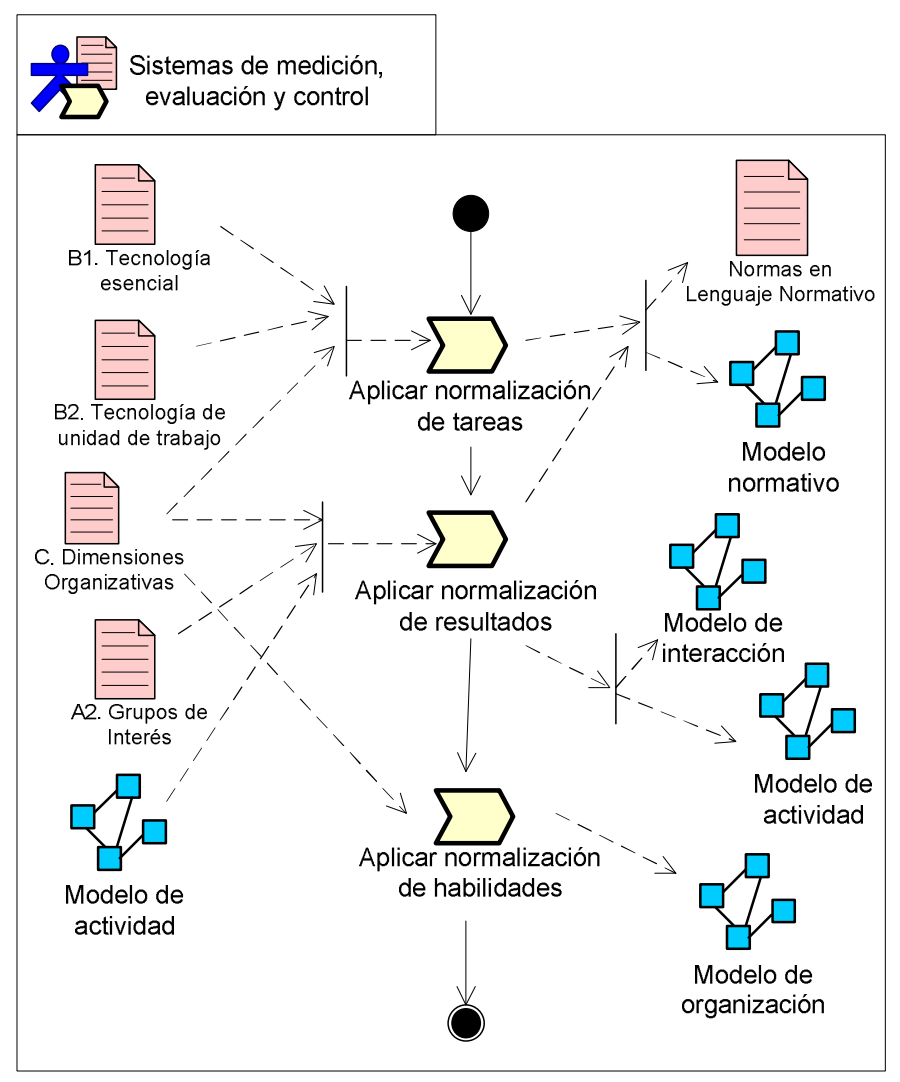

Figura 5.46: Fase Sistemas de Medición, Evaluación y Control.

Teniendo en cuenta esto, en esta fase se establece el conjunto de normas y restricciones necesarias resultantes de la aplicación de esos tres tipos de normalización, ya analizados en la fase C.Dimensiones Organizativas, con 
la dimensión de normalización. Por tanto, esta fase consta de las siguientes actividades (figura 5.46): (i) aplicación de la normalización de las tareas; (ii) aplicación de la normalización de los resultados; y (iii) aplicación de las normalización de habilidades.

La normalización de las tareas implica la especificación de reglas que regulen el orden de invocación y/o ejecución de los servicios; las relaciones de precedencia entre las tareas; sus límites de tiempo requeridos para su ejecución; el acceso a los recursos o materias que necesitan, etc. Este tipo de normalización resulta fundamental si se emplea una tecnología de vinculación prolongada. Si en el documento B1.Tecnología Esencial se determinó dicho tipo de tecnología, entonces, obligatoriamente, para todos los servicios existentes se debe establecer un orden de invocación respecto al resto.

Mediante los diagramas del modelo normativo, así como del lenguaje normativo definido en el capítulo 4, se deben especificar las normas de cada unidad organizativa que permitan:

- Establecer un orden de ejecución o invocación entre los servicios.

- Definir los límites de tiempo o condiciones de activación/desactivación de los servicios.

- Controlar los accesos a los recursos/aplicaciones, mediante la utilización de los puertos.

Para la normalización de los resultados, se deben establecer normas que controlen los resultados obtenidos por los proveedores del servicio, en base a los requisitos mínimos de calidad del producto o servicio producido; a la calidad percibida por los grupos de interés y a los objetivos de productividad y rendimiento establecidos.

Para ello se revisan los documentos B2. Tecnología de unidad de trabajo y A2.Grupos de Interés, para determinar en qué medida se están atendiendo los requisitos y necesidades de los grupos de interés y cómo controlar la calidad de los servicios. 
La calidad del servicio o producto se trata en base a alguno de los siguientes enfoques [Moreno-Luzon et al., 2001]:

- Calidad como conformidad con unas especificaciones: la organización proporciona unos productos o servicios que siguen unos patrones idénticos. Se debe controlar la conformidad de estos productos con las especificaciones dadas. Dichas especificaciones deben estar totalmente formalizadas y se determina qué aspectos del producto y de la producción podrían fallar, para así establecer ahí el correspondiente control.

Esta especificación se refleja a través de normas sobre los resultados de los servicios, estableciendo sanciones para las ejecuciones incorrectas (o de mala calidad) de los servicios por parte de los proveedores.

- Calidad como satisfacción de las expectativas del cliente: en este caso se necesita conocer cuál es la valoración del producto/servicio por parte del cliente. Por tanto, se debe determinar qué aspectos del producto/servicio deben ser analizados y valorados por el cliente y cómo retroalimentarse de los resultados de dicha valoración.

Se establecen aquí normas de recompensa a aquellos proveedores que más satisfagan las expectativas del cliente.

- Calidad como valor con relación al precio: la calidad se determina como lo mejor en función de su uso y precio de venta.

Se deben considerar cuáles son los costes de producción (fijos y variables) y el precio a asociar al producto o servicio. El cliente siempre espera obtener la mejor calidad posible a un precio dado, valorando dicha calidad en función de la durabilidad y las prestaciones ofrecidas por el producto.

Estos enfoques de calidad de las organizaciones humanas tienen su correspondencia con las organizaciones de agentes, en la medida en la que se identifican a los clientes y proveedores con las entidades A-Agente definidas 
en los modelos de organización; los precios de venta y costes de producción con valores simulados de los beneficios o utilidades que obtienen los agentes al realizar los servicios; las especificaciones de los productos con los parámetros intrínsecos de los servicios, documentos, recursos, etc. a ofrecer (establecidos previamente en la fase B.Tareas y Procesos).

Por otro lado, los parámetros de calidad definidos deben establecerse de forma "estática", es decir, prefijados inicialmente o configurados a través de un administrador del sistema; o bien de forma "dinámica", negociándose durante el proceso de adquisición del rol afectado por ese parámetro.

En este caso, cuando un agente desea participar dentro de una unidad determinada jugando un rol, al solicitar adquirir ese rol, el gestor de la unidad le debe informar de cuál es el valor por defecto para el parámetro de calidad asociado al rol. El agente podría requerir un refinamiento de ese valor, en base a ciertas condiciones, estableciéndose así un proceso de negociación y generación de un contrato de realización de un servicio.

Por tanto, si se precisa de una definición dinámica de los parámetros de calidad, se debe actualizar el diagrama del modelo de actividad que especifica las tareas concretas del servicio de adquisición de rol, para incorporar tareas de información sobre los valores por defecto del parámetro de calidad, así como tareas de negociación de ese valor. Además, se deben definir los procesos de interacción requeridos para la información y negociación de estos valores de calidad, modelándolos con diagramas del modelo de interacción.

Finalmente, la normalización de habilidades se trata en los sistemas multiagente a través del concepto de rol, indicando los permisos, conocimientos y aptitudes que asume o adquiere un agente al jugar dicho rol. La adopción de roles por parte de los agentes se ha tratado ya en la fase anterior.

\subsubsection{Aplicación de la fase al caso de estudio}

Los participantes de cada unidad temática no tienen impuesto ningún tipo de restricción sobre el orden en el que utilicen los servicios Suscribir, 
Proporcionar Información o bien Evaluar Información, a excepción de que un mismo participante no puede actuar como informador y evaluador de sus propios documentos.

Sin embargo, sí que existen determinadas normas que se activan en base a los resultados de los servicios proporcionados. En concreto, se desea expulsar de una unidad a aquellos informadores cuyos documentos proporcionados hayan sido evaluados negativamente un número representativo de veces, pues se considera que estos informadores no aportan ningún tipo de información relevante sobre la temática de esa unidad.

Por su parte, si un evaluador realiza un número importante de evaluaciones negativas sobre los documentos proporcionados en una unidad determinada, resulta factible asumir que dicho evaluador no es adecuado para esa unidad, pues posiblemente no tiene el conocimiento suficiente sobre la temática a tratar. Por tanto, también debe ser expulsado de la unidad.

Para aplicar la normalización de los resultados se ha optado por establecer unas medidas de calidad como conformidad con unas especificaciones, de modo que se definen los parámetros de AceptaciónMinima, que representa el umbral de aceptación que deben tener los documentos de un informador para que su presencia en la unidad sea relevante; y el parámetro CalidadEvaluación, que indica el umbral de rechazo en las calificaciones realizadas por un evaluador para asumir que ese agente no aporta ningún tipo de evaluación relevante dentro de la unidad, pues su nivel de conocimiento sobre la temática de la unidad es muy bajo.

A continuación se describen ejemplos de las normas necesarias para el control de las tareas y de los resultados de los servicios, empleando el lenguaje normativo definido en el capítulo anterior. Los términos EvaluarInfo y PropInfo representan los servicios Evaluar Información y Proporcionar Información, respectivamente.

1. Incompatibilidad en actuación como informador-evaluador: un informador no puede actuar como evaluador de sus propios documentos.

FORBIDDEN ?Ag:Evaluador - ?UO SERVE EvaluarInfo 
PROCESS evaluar(?Doc) AFTER ?Ag:Informador - ?UO

REQUEST PropInfo MESSAGE(CONTENT(?Doc))

2. Nivel de aceptación del informador: se prohíbe a un informador que solicite proporcionar nuevos documentos si la proporción de documentos suyos evaluados negativamente rebasa el umbral de aceptación mínima. Es expulsado de esa unidad si no cumple con la norma.

FORBIDDEN ?Ag: Informador -?UO REQUEST PropInfo

IF ((QUANTITY (RESULT(PropInfo, ?Ag, t) = "Rechazado") /

QUANTITY(RESULT(PropInfo, ?Ag,t) ) > AceptacionMinima)

SANCTION (OBLIGED ?UO SERVE Expulsar

PROCESS expulsar(?Ag, ?UO))

3. Nivel de rechazo del evaluador: se prohíbe a un evaluador que realice más evaluaciones negativas si la proporción de documentos que ha evaluado negativamente sobrepasa el nivel de calidad de evaluación, siendo expulsado si no cumple con la norma.

FORBIDDEN ?Ag: Evaluador - ?UO SERVE EvaluarInfo

IF ((QUANTITY (RESULT(EvaluarInfo,?Ag,t) = "Rechazado") /

QUANTITY(RESULT(EvaluarInfo,?Ag,t)) > CalidadEvaluación)

SANCTION (OBLIGED ?UO SERVE Expulsar

PROCESS expulsar(?Ag, ?UO))

Finalmente, se ha optado por prefijar los parámetros de calidad a los valores de AceptaciónMínima=0.7 y de CalidadEvaluación=0.9, indicando así que un informador será expulsado de la unidad cuando más del $30 \%$ de sus documentos sean rechazados; y que un evaluador será expulsado cuando informe negativamente más del $90 \%$ de las ocasiones.

\subsubsection{Síntesis de la fase}

La fase G.Sistemas de medición, evaluación y control establece los mecanismos y normas para evaluar si los objetivos del sistema se cumplen. 
Los modelos a generar en esta fase son:

- Diagrama del modelo normativo: se especifican las normas para el control de los comportamientos de los miembros del sistema, atendiendo principalmente a la normalización de las tareas y a la normalización de los resultados.

- Actualización del documento Normas: descripción de las normas asociadas al orden de ejecución de los servicios y a la calidad de sus resultados, definidas con la descripción BNF del lenguaje normativo propuesto.

- Actualización del diagrama de la vista estructural del modelo de organización: se relaciona cada unidad organizativa con las nuevas normas planteadas.

- Actualización del diagrama del modelo de actividad (opcional): se revisa el flujo de tareas del servicio AdquirirRol, para incorporar la información y negociación de los parámetros de calidad.

- Actualización del diagrama del modelo de interacción (opcional): se definen las interacciones producidas por la información y negociación de los parámetros de calidad. 


\subsection{Fase H. Sistemas de recompensas}

En esta fase se determina el sistema de incentivos a aplicar para recompensar a los miembros del sistema que avancen en la dirección de los intereses o estrategia de la organización. También se refina el sistema normativo establecido en fases anteriores, para mejorar el control de los miembros de la organización, fomentar su participación y rendimiento, a fin de conseguir que trabajen según lo esperado.

En las organizaciones humanas, éstas existen en la medida en que haya personas dispuestas a aportar su esfuerzo en un sistema común de cooperación, compartiendo un mismo objetivo o finalidad [Moreno-Luzon et al., 2001]. Sin embargo, las personas presentan una pluralidad de intereses y objetivos, por lo que la organización debe establecer un sistema de recompensas que logre el equilibrio de la organización. Por tanto, los miembros reciben recompensas adecuadas a su contribución con la organización, del tipo "valores de conservación" (mantenerse en el sistema, progresar en él, adquirir nuevos permisos o reconocimientos) o del tipo "recompensas materiales o inmateriales", que permiten la adecuada compensación a su esfuerzo.

De igual modo, en las organizaciones de agentes el sistema de recompensas permite establecer un equilibrio entre los objetivos individuales de los agentes, los objetivos globales de la organización y el modo de fomentar determinados comportamientos para mantener la organización a largo plazo.

Atendiendo a estas ideas, esta fase se desglosa en las siguientes actividades (figura 5.47): (i) analizar los tipos de comportamiento que se desean potenciar; (ii) seleccionar el tipo de sistema de recompensas a utilizar; y (iii) aplicarlo en el dominio concreto a tratar. En concreto, en esta fase se persigue que el diseñador analice qué comportamientos son importantes que se fomenten entre los agentes para conseguir que los objetivos globales del sistema se alcancen. Además, se facilita el diseñador la elección del tipo de sistema que debe utilizar, pero sin entrar en detalle de los mecanismos de implementación ni los protocolos o pasos concretos de los que consta el mecanismo. 


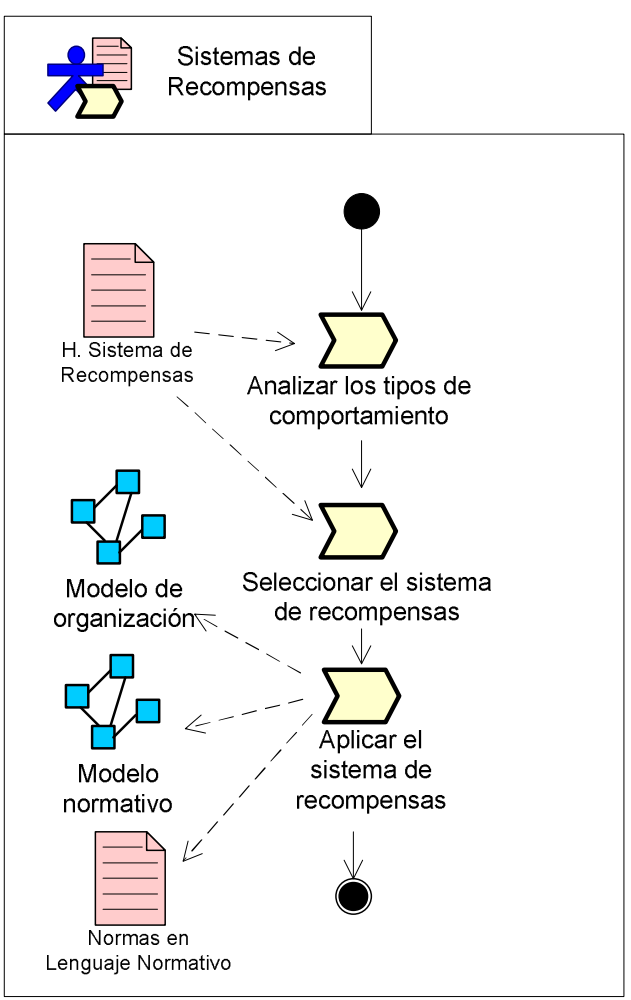

Figura 5.47: Fase Diseño de los Sistemas de Recompensas.

TIPOS DE COMPORTAMIENTOS. En la primera actividad de esta fase debemos realizar un análisis de qué tipo de comportamientos generales deseamos potenciar en los agentes, especialmente cuando se trata de un sistema abierto, utilizando la plantilla del documento H.Sistema de Recompensas (tabla 5.17).

Según estudios de las organizaciones humanas, existen cuatro comportamientos deseables de los miembros de una organización respecto a su trabajo adecuado dentro de ella [Galbraith, 1977]: (i) la voluntad de unirse y permanecer dentro del sistema; (ii) el rendimiento dependiente del rol que desempeñan, de modo que se consigan los niveles mínimos de calidad y cantidad de trabajo a ejecutar; (iii) el esfuerzo sobre los niveles mínimos 


\begin{tabular}{|c|c|c|}
\hline Características Sistema & $\begin{array}{l}\text { Comportamientos } \\
\text { a fomentar }\end{array}$ & $\begin{array}{l}\text { Sistema de } \\
\text { recompensa }\end{array}$ \\
\hline $\begin{array}{l}\text { Sistema abierto } \\
\text { Existen agentes externos } \\
\text { Existen unidades dinámi- } \\
\text { cas } \\
\text { Se han identificado servi- } \\
\text { cios de Registrar / Desre- } \\
\text { gistrar unidad }\end{array}$ & Unirse y permanecer & $\begin{array}{l}\text { Recomp. Individual } \\
\text { Recomp. de Sistema }\end{array}$ \\
\hline $\begin{array}{l}\text { Alta normalización de los } \\
\text { resultados } \\
\text { Conflictos entre objetivos } \\
\text { globales y objetivos indivi- } \\
\text { duales }\end{array}$ & $\begin{array}{l}\text { Esfuerzo sobre } \\
\text { niveles mínimos }\end{array}$ & $\begin{array}{l}\text { Recomp. Individual } \\
\text { Recomp. de Grupo } \\
\text { (Competitivas) }\end{array}$ \\
\hline $\begin{array}{l}\text { Unidades de tipo equipo } \\
\text { Objetivos de grupo }\end{array}$ & Cooperación & $\begin{array}{l}\text { Recomp. de Grupo } \\
\text { (Cooperativas) }\end{array}$ \\
\hline
\end{tabular}

Tabla 5.17: Documento H. Sistema de Recompensas.

anteriores, definiendo unas medidas de rendimiento, eficiencia y productividad mínimos a conseguir; y (iv) los comportamientos cooperativos con el resto de miembros de la organización.

Para el caso de los MAS, si deseamos implementar un sistema abierto entonces debemos aplicar políticas de sistemas de recompensas para fomentar la voluntad de los agentes por unirse al sistema y permanecer dentro de éste el máximo tiempo posible. También se debe potenciar el esfuerzo sobre los niveles mínimos, para así motivar a los agentes a la realización de aquellas acciones que más convengan a la organización. Asimismo, en algunas de las estructuras organizativas contempladas los agentes trabajan juntos en equipo o coalición. En esos casos, interesa fomentar su cooperación controlando cómo de bien trabajan en grupo y recomendándoles si los resultados son satisfactorios.

SELECCIÓN DEL SISTEMA DE RECOMPENSAS. En la segunda actividad de esta fase se especifica el tipo de sistema de recompensas 
a utilizar: recompensas individuales, de grupo o de sistema. Estos mecanismos no son excluyentes, aunque cada uno resulta más apropiado para fomentar unos tipos de comportamientos, según se indica en el documento H.Sistema de Recompensas.

Las recompensas individuales establecen unas medidas de rendimiento individual, de modo que un controlador o supervisor analiza de forma individual el comportamiento de cada miembro de la unidad. Estas medidas pueden ser conocidas o no a priori por el individuo sobre el que se aplicará la recompensa. Este sistema de recompensas permite fomentar que los agentes se unan y permanezcan en la unidad organizativa, así como fomentar su esfuerzo sobre los niveles mínimos. Ejemplos de sistemas de recompensas individuales son:

- Sistema de puntos (como el del control del tráfico). Inicialmente se asigna una cantidad de puntos al agente. Se pueden establecer categorías de agentes (o puntos distintos según el rol). Si durante un periodo de tiempo determinado no se pierden los puntos, entonces se le incrementa su puntuación una cantidad específica (recompensa individual).

Cualquier agente conoce su saldo de puntos. Mientras su saldo sea positivo, permanece en el sistema. Si pierde puntos, podrá recuperarlos realizando ciertas tareas de penalización, o bien dejando de cometer nuevas infracciones durante el tiempo de sanción establecido. Si es expulsado, tendrá que volver a pasar el proceso de admisión.

Los agentes deben obtener beneficios adicionales por estar en el sistema. Uno de sus objetivos será permanecer en el sistema, para así conseguir el resto de beneficios.

El sistema sancionador debe controlar el tiempo que un agente no comete ninguna infracción, para aumentar su puntuación. Debe controlar también quién es cada agente, para evitar que éstos modifiquen sus puntuaciones. 
- Control de la honestidad de un agente. Se asigna al agente un crédito inicial y se aumenta su crédito con las acciones realizadas (servicios proporcionados), valorados favorablemente (se le paga por su trabajo). Se disminuye su crédito al solicitar servicios (paga por el trabajo de otros). El sistema controla la honestidad de los agentes, incluyendo métricas.

Las recompensas de grupo establecen unas medidas de rendimiento del grupo y un controlador externo se encarga de analizar el rendimiento del grupo y gratificar por igual a todos los miembros, en función de dicho rendimiento.

Existen dos tipos de recompensas de grupo [Wagner y Hollenbeck, 2004]: (i) cooperativas, que se distribuyen equitativamente entre los miembros, de forma que cada miembro recibe la misma recompensa, cuyo valor está en función del rendimiento global del grupo; y (ii) competitivas, en las que los miembros reciben recompensas equitativas que varían en función tanto de su rendimiento individual como del rendimiento global del grupo, de modo que a los miembros se les recompensa por su buen rendimiento como individuos del grupo.

En la recompensa cooperativa se analizan factores como la consecución del objetivo, los beneficios globales obtenidos al conseguirlo, la productividad, el grado de satisfacción del cliente con la tarea o servicio realizado. Además, se recompensa a todos los integrantes del grupo por igual, por el mero hecho de haber participado en el grupo. Por ejemplo, se reparte de forma equitativa los bienes obtenidos.

En la recompensa competitiva se requiere conocer también el grado de participación de cada integrante del grupo en la consecución del objetivo, para así repartir los bienes en función de dicho grado de participación, primando al que más haya aportado. Se debe usar solamente cuando se pueda discriminar entre los rendimientos de los agentes. Sirve fundamentalmente para fomentar el esfuerzo sobre los niveles mínimos. Además, también permite penalizar a quien no contribuya con el grupo, pues éste recibe menores beneficios (o incluso acaba siendo expulsado del grupo). 
Las recompensas cooperativas resultan interesantes para tareas muy interdependientes, mientras que las competitivas son adecuadas para tareas independientes o con interdependencia de recursos, así como aquellas en las que se pretenda incentivar el esfuerzo individual dentro del grupo.

Finalmente, las recompensas de sistema consisten en la distribución de ciertas gratificaciones (permisos, recursos, etc.) a todos los miembros del sistema por el mero hecho de pertenecer a él. Se permite la diferenciación de la cantidad de gratificación a ofrecer en función de la antigüedad al sistema (por ejemplo, contra mayor participación, más ventajas, más permisos se ofrecen).

Este tipo de recompensas pretende potenciar la participación en la organización, ofreciendo unos valores de utilidad por la mera pertenencia al sistema, sin tener en cuenta el rendimiento del miembro dentro de la unidad. Conviene utilizarlo en estructuras de tipo coalición o congregación, donde interesa que los miembros de las unidades permanezcan en ellas el máximo tiempo posible.

APLICAR EL SISTEMA DE RECOMPENSAS. En la última actividad de esta fase se actualizan los diagramas del modelo normativo, definiendo nuevas normas y/o extendiendo las ya existentes con sanciones o recompensas, en base a las directrices marcadas en el sistema de recompensas seleccionado. Se actualiza también la vista estructural del modelo de organización para relacionar cada unidad organizativa con las nuevas normas planteadas.

\subsubsection{Aplicación de la fase al caso de estudio}

Se desea fomentar, por un lado, la participación de los evaluadores dentro de las unidades temáticas. Por otro lado, deseamos que los informadores suministren muchos artículos, a ser posible de gran calidad. Como ya se ha comentado, el sistema a tratar es abierto y los roles de evaluador e informador son adoptados por agentes externos. Interesa, por tanto, fomentar los comportamientos de unirse y permanecer, de modo que los evaluadores sean 
captados por las unidades para trabajar dentro de ellas, de forma continuada. También resulta importante que los informadores se sientan motivados a solicitar el servicio de Proporcionar Información, en todas aquellas unidades sobre las que dispongan de conocimientos relacionados.

Se aplicarán recompensas de sistema para los evaluadores; y de tipo individual para los informadores. Por ejemplo, los evaluadores adquieren permisos sobre el acceso a las bases de datos de información por el hecho de pertenecer a una unidad organizativa. De este modo, no sólo adquieren conocimiento de los documentos que se les envía directamente para evaluar, sino también disponen de una fuente importante de conocimiento a través de esas bases de datos.

Por otro lado, el control sobre los informadores se había establecido en la fase anterior a través de la norma "nivel de aceptación del informador". En este punto incorporamos una nueva norma para premiar a aquellos informadores cuya cantidad de artículos aceptados sea relevante, a través de una rebaja en el valor de AceptaciónMínima, dándole así un mayor margen de confianza sobre sus datos.

En el caso de que el servicio Proporcionar Información tuviera un coste asociado, entonces la recompensa podría consistir en rebajar ese coste, para así aportar ciertos beneficios directos al informador. A continuación se muestra la descripción de esa norma en el lenguaje normativo propuesto. El término PropInfo representa el servicio Proporcionar Información.

\section{NormaPremiarInformador:}

PERMITTED ?Ag: Informador - ?UO REQUEST PropInfo

IF ((QUANTITY (RESULT(PropInfo, ?Ag, t) = "Aceptado") /

QUANTITY(RESULT(PropInfo, ?Ag,t) ) > AceptaciónRelevante)

REWARD (OBLIGED ?UO SERVE ActualizarParámetrosCalidad

PROCESS Actualizar(AceptaciónMínima, Decrementar))

Para actuar sobre los parámetros de calidad se ha definido un nuevo servicio, ActualizarParámetrosCalidad, asociado a cada unidad organizativa Temática (proporcionado por el rol GestorUnidad), que permite incrementar o decrementar el valor del parámetro indicado en la entrada del 
servicio. Se adopta así una configuración dinámica de los valores de calidad, por lo que se requiere actualizar los diagramas del modelo de actividad y del modelo de interacción, según se indica en la fase G.Sistemas de medición, evaluación y control.

\subsubsection{Síntesis de la fase}

La fase H.Sistemas de recompensas especifica el sistema de incentivos a aplicar para conseguir que sus miembros avancen en la dirección de la misión de la organización.

Los documentos y modelos generados en esta fase son:

- Actualización del diagrama de modelo normativo: revisión de las normas, asignándoles recompensas si así lo requieran. Especificación de nuevas normas.

- Actualización del diagrama de la vista estructural del modelo de organización: relación de cada unidad organizativa con las nuevas normas identificadas.

- Actualización del documento Normas: descripción de las normas definidas para fomentar los comportamientos generales deseados, de tipo "unirse y permanecer", "esfuerzo sobre niveles mínimos" o bien "cooperación". 


\subsection{Conclusiones}

En este capítulo se ha expuesto la principal aportación de este trabajo, que consiste en una guía metodológica para el diseño de sistemas multiagente abiertos desde la perspectiva de las organizaciones humanas. Dicha guía se basa en una secuencia-guía básica de diseño organizativo, específica para el diseño de organizaciones humanas.

Cada una de sus fases se ha transformado de forma apropiada al área de los sistemas multiagente, obteniendo así un procedimiento que permite: (i) el análisis y diseño de los objetivos globales de la organización; (ii) el análisis de sus tareas y procesos; (iii) la especificación de las dimensiones organizativas; (iv) la selección de la estructura más apropiada para el sistema; (v) la identificación de los procesos de información y decisión; (vi) el análisis de la funcionalidad a publicitar; (vii) el control de los comportamientos de los agentes y (viii) la especificación de sanciones y recompensas para fomentar los comportamientos que interesan a la organización.

Para facilitar la realización de la secuencia-guía, se ha elaborado un conjunto de plantillas que ayudan al diseñador a discretizar las variables de organización importantes para el análisis y diseño del sistema. Asimismo, se instancian los meta-modelos del sistema (definidos en el capítulo anterior), para describir con ellos la estructura, funcionalidad, dinamicidad, entorno y normalización de la organización.

La propuesta metodológica presentada en este capítulo se valida a través de un caso de estudio de un sistema de agencia de viajes, que se explica con detalle en el siguiente capítulo. 



\section{Capítulo 6}

\section{Caso de Estudio}

En el presente capítulo se desarrolla el caso de estudio de un sistema de agencia de viajes, empleando la guía metodológica propuesta en este trabajo, a fin de evaluar la validez de la propuesta. Para ello se realiza el análisis de requisitos, el diseño de la estructura organizativa y el diseño de la dinámica de la organización del sistema multiagente, empleando las distintas guías y fases definidas en la guía metodológica.

\subsection{Introducción}

Se desea diseñar un sistema de agencia de viajes que permita a sus clientes reservar paquetes de vacaciones completos: hoteles, billetes de avión, tren, alquiler de vehículos, etc. Por su parte, las compañías hoteleras, aéreas, etc. podrán ofrecer sus propios servicios dentro del marco de este sistema de agencia de viajes. Además, no se tiene establecido ningún contrato previo con las empresas proveedoras de servicios, de modo que cualquier compañía interesada podrá suscribirse al sistema y ofrecer en él la funcionalidad que más le interese, siempre y cuando se mantenga dentro de los límites establecidos por el sistema.

Para este caso de estudio nos hemos basado en la propuesta de "Web Service Use Case" realizada por "Web Services Architecture Working Group" 
1; en la descripción de servicios web para la industria turística realizada en el proyecto SATINE $^{2}$ [Dogac et al., 2004]; en la propuesta de institución electrónica para gestionar vuelos y hoteles [Sierra et al., 2006]; y en el repositorio de servicios web OWLS-TC ${ }^{3}$, en el que se incluye un dominio de viajes. En nuestra propuesta se desea potenciar la integración entre los servicios web y los agentes, así como la funcionalidad de un sistema abierto.

En la elaboración del análisis y diseño del sistema se sigue la secuenciaguía propuesta en este trabajo, abordando las distintas fases que comprenden los procesos de análisis de requisitos, diseño de la estructura y diseño de la dinámica de la organización. Estos procesos permiten ser tratados de forma iterativa, siguiendo por ejemplo un proceso RUP, al igual que se emplea en INGENIAS.

Sin embargo, en la elaboración de este caso de estudio se ha optado por realizar una única iteración de cada paso, a fin de simplificar los resultados. A la hora de implementar el sistema multiagente sería recomendable llevar a cabo más de una iteración, para así obtener diagramas de los modelos lo más detallados posibles.

Este capítulo se estructura de la siguiente manera. En la sección 6.2 se realiza el análisis de los requisitos del sistema. En la sección 6.3 se procede al diseño de la estructura organizativa. En la sección 6.34 se realiza el diseño de la dinámica de la organización. Finalmente, en la sección 6.5 se muestran las conclusiones del capítulo.

\subsection{Análisis de Requisitos del Sistema}

El sistema a diseñar se contempla como un "punto de encuentro regulado" en el que compañías de viaje, usuarios individuales, así como aerolíneas, cadenas hoteleras, compañías de autobuses, ferrocarriles, etc. contacten entre sí para consumir y/o producir servicios turísticos, facilitando de este

\footnotetext{
${ }^{1}$ http://www.w3.org/TR/2004/NOTE-ws-arch-scenarios-20040211

${ }^{2}$ http://www.srdc.metu.edu.tr/webpage/projects/satine/

${ }^{3}$ http://projects.semwebcentral.org/projects/owls-tc/
} 
modo la elaboración de paquetes de vacaciones que incluyan billetes de avión/tren/autobús, hoteles, excursiones, etc.

Para facilitar la comprensión de la metodología, en la elaboración del caso de estudio se ha limitado el tipo de proveedores de servicios turísticos a las compañías aéreas y a las cadenas hoteleras. Por supuesto, las decisiones que se tomen para estos dos proveedores serían extensibles al resto, adaptándolas al tipo de producto con el que traten (por ejemplo, las líneas ferroviarias ofrecerían servicios de información y reservas de billetes de tren).

Para el análisis de los requisitos del sistema se tienen en cuenta la Fase A.Misión y la Fase B.Tareas y Procesos de la secuencia-guía propuesta.

El objetivo principal del sistema consiste en proporcionar servicios combinados, maximizando el número de reservas que se realicen y consiguiendo una gran satisfacción por parte del cliente. En este ejemplo no se entrará en aspectos económicos, pero el modelo de negocio podría ser muy variado. Por ejemplo, se podría cobrar a un usuario cuando hace uso de ciertos servicios, o bien cobrar a un proveedor de servicio por el volumen de productos servidos.

Los proveedores, gracias a su participación en el sistema, consiguen llegar a un mayor número de clientes $\mathrm{y}$, por tanto, las posibilidades de vender sus productos aumentan. Además, se facilita la combinación de sus ofertas con las de otros proveedores. Por su parte, los clientes (turistas, personal de negocio o mayoristas) solicitan obtener la mejor combinación de servicios y precios para sus necesidades. Contra más proveedores existan, mayor variedad de ofertas dispondrán.

En la tabla 6.1 (Documento A1-Misión Organizativa) se muestran los resultados (productos o servicios) que ofrece el sistema, el tipo de entorno sobre el que se trabaja, así como los grupos de interés a los que afecta. También se justifica la razón de ser de este sistema, el cual pretende facilitar la integración de los agentes y los servicios web.

A partir de la tabla anterior, así como de las guías indicadas en la Fase A.Misión de la metodología, se instancia la vista funcional (misión) del 
A.1. Misión Organizativa

Nombre: agencia de Viajes

Dominio: turismo

\section{Resultados:}

- Producto: reservas (de vuelos, hoteles). Finalidad: localidad asociada al cliente que la ha solicitado. Tangibilidad: lleva un identificador asociado.

- Servicio:buscar viaje. Finalidad: encontrar información sobre conexiones aéreas o sobre disponibilidad hotelera. Tangibilidad: datos concretos de un vuelo; precios de habitaciones disponibles.

- Servicio: reservar viaje. Finalidad: generar una reserva.

- Servicio: abonar reserva. Finalidad: realizar el pago.

Grupos de interés:

- Cliente: solicita información para confeccionar su paquete turístico.

- Proveedor: proporciona información sobre sus productos y la reserva de los mismos.

- Aerolínea: facilita información sobre vuelos planificados en su compañía y las plazas disponibles.

- Cadena hotelera: facilita información sobre los hoteles de su cadena, por países, localidad y/o por categoría; así como la disponibilidad de habitaciones.

Tipo de entorno: virtual y distribuído.

Justificación: sistema abierto que facilita un punto de encuentro entre entidades demandantes y entidades oferentes, de forma controlada sobre los servicios y productos que se ofrecen y generan.

- Sistemas similares: institución electrónica para gestionar vuelos y hoteles; servicios web para la industria turística.

- Ventajas: facilitar la integración de los servicios web y agentes.

- Desventajas: mayor complejidad al ser un sistema abierto.

- Singularidades: potenciar la heterogeneidad de los miembros del sistema.

Tabla 6.1: Documento A.1-Misión Organizativa del sistema de agencia de viajes. 


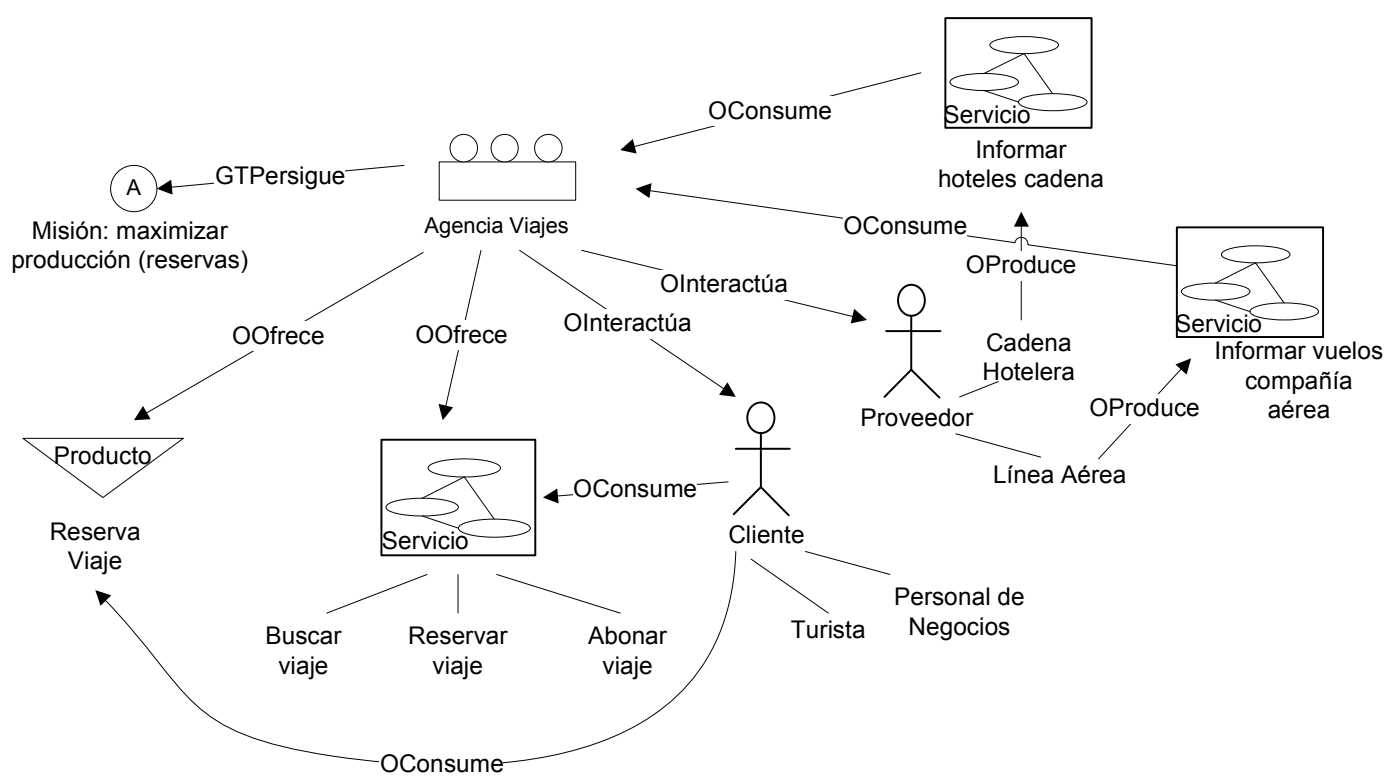

Figura 6.1: Diagrama del modelo de organización (vista funcional). Misión del sistema de agencia de viajes.

modelo de organización (figura 6.1). En dicha vista, la unidad organizativa AgenciaViajes representa al sistema y ofrece los servicios de búsqueda de viajes, realización de reservas y abono a sus clientes (turistas y personal de negocio). Para ello requiere de los proveedores representados por las cadenas hoteleras y las líneas aéreas, quienes ofrecen sus propios servicios de información.

En este punto del análisis no se especifica todavía quién se encarga de realizar los servicios del sistema, sino solamente se definen cuáles son esos servicios y a quiénes afectan (grupos de interés) desde el punto de vista del consumo.

En la tabla 6.2 se muestra un análisis más detallado de los grupos de interés, en el que se describen las necesidades de los stakeholders, su relación concreta con la organización, así como qué influencia tienen en las decisiones a tomar.

Respecto a las condiciones del entorno (tabla 6.3), se prevé que aparezcan nuevos tipos de proveedores (ej: compañías de trenes, autobuses), 


\begin{tabular}{|c|c|c|c|}
\hline \multicolumn{4}{|c|}{ A.2. Grupos de Interés } \\
\hline & \multicolumn{3}{|c|}{ Stakeholder } \\
\hline & $\begin{array}{l}\text { Demandante } \\
\text { (Turista, Mayorista) }\end{array}$ & $\begin{array}{l}\text { Oferente } \\
\text { (Hoteles, Aerolíneas) }\end{array}$ & $\begin{array}{l}\text { Cobrador } \\
\text { (Entidad Bancaria) }\end{array}$ \\
\hline Beneficiario & Primario & Primario & Secundario \\
\hline Tipo & Cliente & Proveedor & Regulador \\
\hline Objetivos & $\begin{array}{l}\text { Encontrar viajes con } \\
\text { mejor relación calidad- } \\
\text { precios }\end{array}$ & $\begin{array}{l}\text { Maximizar número de } \\
\text { reservas }\end{array}$ & $\begin{array}{l}\text { Garantizar pagos segu- } \\
\text { ros }\end{array}$ \\
\hline Requiere & Paquetes de viajes & Realizar reservas & \\
\hline Proporciona & $\begin{array}{l}\text { Feedback sobre viajes } \\
\text { realizado }\end{array}$ & Plazas turísticas & Garantía reserva \\
\hline Frecuencia & Frecuente & Frecuente & Frecuente \\
\hline Beneficios & $\begin{array}{l}\text { Obtener un paquete de } \\
\text { viaje económico y de } \\
\text { garantía }\end{array}$ & $\begin{array}{l}\text { Incrementar número de } \\
\text { reservas realizadas y } \\
\text { número de clientes }\end{array}$ & \\
\hline Poder de decisión & No & $\begin{array}{l}\text { Sí (proporcionar nue- } \\
\text { vos servicios o produc- } \\
\text { tos) }\end{array}$ & No \\
\hline $\begin{array}{l}\text { Influencia sobre sus } \\
\text { intereses }\end{array}$ & $\begin{array}{l}\text { Sí (ofrecerle ofertas de } \\
\text { viajes) }\end{array}$ & & No \\
\hline
\end{tabular}

Tabla 6.2: Documento A2.Grupos de Interés del sistema de agencia de viajes.

creándose nuevos tipos de productos, por lo que el entorno es dinámico. Sin embargo, consideramos que su complejidad es simple, pues existen pocos elementos distintos (se tratará a dos tipos de proveedores, dos tipos de productos y a un sólo tipo de cliente). Además, los productos a generar (reservas de hotel, reservas de avión) están muy relacionados entre sí, con características similares. La incertidumbre es media, al tratarse de un entorno dinámico y simple.

Por su parte, como se requiere de la información sobre plazas disponibles que proporcionen los proveedores, los cuales no siempre tienen por qué estar activos, consideramos que el entorno es, en cierto modo, hostil. Finalmente, se trata de un entorno uniforme, pues los servicios que se proporcionan están todos ellos muy relacionados entre sí. Por ejemplo, las reservas dependen de la información obtenida en el servicio Buscar Viaje, en concreto de las plazas libres existentes. Además, para el pago de una reserva se precisa de los datos y códigos de la reserva, obtenidos en el servicio Reservar Viaje.

$\mathrm{Al}$ analizar la tecnología del sistema, según se propone en la Fase 


\section{A.3. Condiciones del Entorno}

\section{Tasa de Cambio: dinámico}

Complejidad: simple

Incertidumbre: media

Receptividad: hostil

Diversidad: uniforme

Tabla 6.3: Documento A.3-Condiciones Entorno del sistema de agencia de viajes.

B. Tareas y Procesos de la secuencia-guía, se observa que el problema a tratar se aborda desde dos perspectivas distintas (documento B1.Tecnología Esencial, tabla 6.4). Por un lado, si no importa quién es el cliente final de cada producto, de modo que se generan "paquetes turísticos" de vuelos y hoteles que serán posteriormente vendidos a los clientes, se está utilizando entonces una tecnología de producción en masa. En dicho caso el diseñador del sistema puede elaborar agentes internos (ej. travel agent) que se encarguen de contactar con los clientes a través de aplicaciones del entorno, para luego confeccionar y comprar los paquetes en su nombre.

\begin{tabular}{|l|}
\hline B.1. Tecnología Esencial \\
\hline Tecnología de producto: producción en masa y producción en lotes \\
pequeños. \\
- En masa: se elaboran paquetes estándar de vuelos y hoteles, con inde- \\
pendencia del cliente final. \\
- En lotes pequeños: se confeccionan paquetes exclusivos para los clientes, \\
aplicando descuentos especiales según el cliente con el que se trate. \\
\hline Tecnología de servicio: vinculación prolongada. Existe un orden prees- \\
tablecido de ejecución de los servicios del sistema: (i) búsqueda de loca- \\
lidades turísticas; (ii) reserva de la localidad; y (iii) pago de la reserva. \\
\hline
\end{tabular}

Tabla 6.4: Documento B.1-Tecnología esencial del sistema de agencia de viajes.

Por otro lado, si se desea que el sistema sea abierto desde la actuación de los clientes; o bien importa quién es el cliente final concreto para así poder ofrecerle ofertas especiales, atender a sus sugerencias, etc., entonces la 


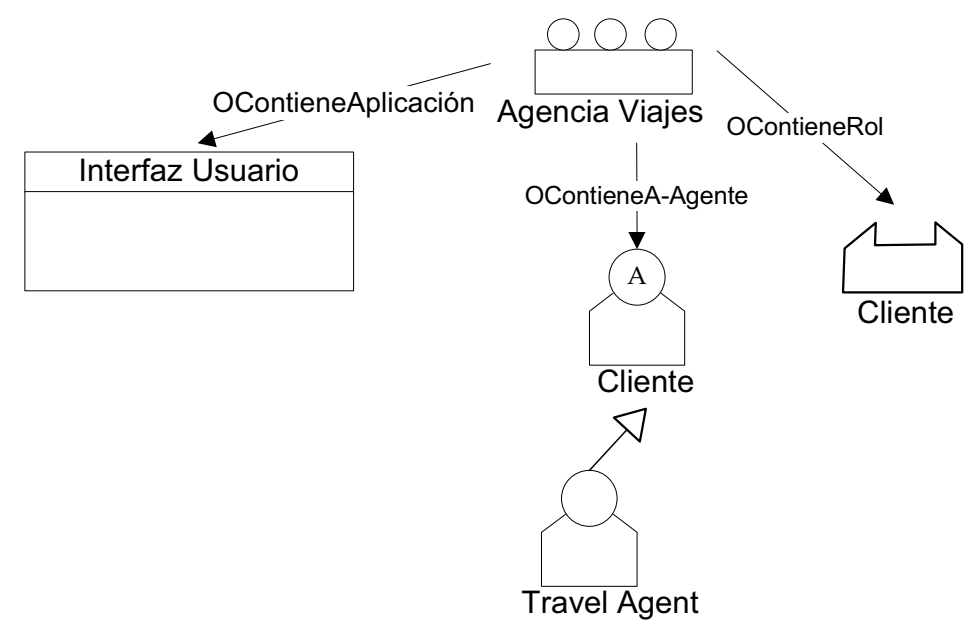

Figura 6.2: Diagrama del modelo de organización (vista estructural) para el sistema de agencia de viajes.

tecnología a emplear es la producción por lotes pequeños. En dicho caso los clientes se representarán a través de entidades A-Agente, para las que se definen los roles a jugar dentro del sistema. Posteriormente, el diseñador deberá establecer, en el modelo de agente, cuáles son las funcionalidades mínimas que debe cumplir dicho A-Agente.

En nuestro caso, asumimos ambas tecnologías, para así permitir, por un lado, desarrollar aplicaciones de interfaz sencillas a través de las cuales se conecten los clientes del sistema (especialmente turistas). Sobre esa aplicación acceden agentes internos del sistema (travel agent), que se encargan de actuar en nombre de los usuarios y buscar o componer los paquetes de viaje que más les interese. Por otro lado, se desea facilitar el acceso al sistema a agentes externos que, de forma independiente, permitan la búsqueda y composición de paquetes de viaje, por ejemplo utilizando los servicios web. Estos agentes podrán participar también en el sistema a diseñar como clientes, para los cuales se ofrecerá un conjunto de servicios de la organización.

Por tanto, se instancia el modelo de organización (vista estructural), definiendo una Unidad Organizativa que representa al sistema (Agencia Viajes). En la figura 6.2 se muestra el diagrama del modelo de organización 
correspondiente. Además, representamos al cliente a través de una entidad A-Agente, que se refina en la entidad Agente travel agent. Esta entidad A-Agente está contenida en el sistema (relación OContieneA-Agente), indicando así que el cliente se considera como un miembro más del sistema.

Se crea también una entidad Rol cliente, contenida en la unidad organizativa Agencia Viajes (relación OContieneRol), adoptada por el A-Agente cliente. Esta asociación se representa en el diagrama de la vista funcional (funcionalidad interna) del modelo de organización (relación WFJuega, figura 6.3).

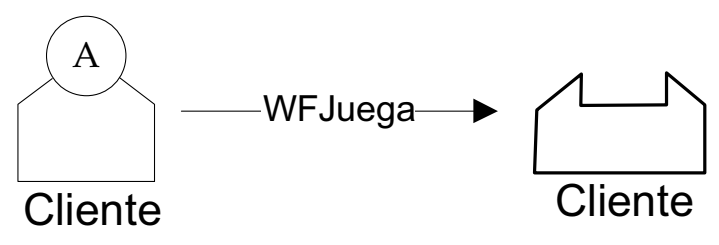

Figura 6.3: Diagrama del modelo de organización (vista funcional, funcionalidad interna) para el sistema de agencia de viajes.

Por otro lado, atendiendo a las características de tecnología de producción en masa, se define una entidad Aplicación (Interfaz Usuario), que permite a los usuarios conectarse al sistema a través de esa aplicación. El agente travel agent será el encargado de acceder a la misma y actuar en el sistema en nombre del usuario. En la figura 6.2 se muestra la relación OContieneAplicación entre la entidad Aplicación indicada y la unidad organizativa Agencia Viajes.

Respecto a la tecnología de servicio (documento B1.Tecnología esencial, tabla 6.4), se requiere una tecnología de vinculación prolongada, pues el orden en el que se invoquen los servicios es importante: primero la búsqueda de información, después las reservas y finalmente el pago de las mismas.

En la figura 6.4 se muestra la vista funcional (funcionalidad externa) del modelo de organización, en la cual todos los servicios conectados entre sí tienen asociado el mismo rol (cliente) en la relación WFUtiliza. Se muestra la Unidad Organizativa Agencia Viajes, que ofrece los servicios Buscar Viaje, Reservar Viaje y Abonar Viaje a agentes que jueguen el rol Cliente. 


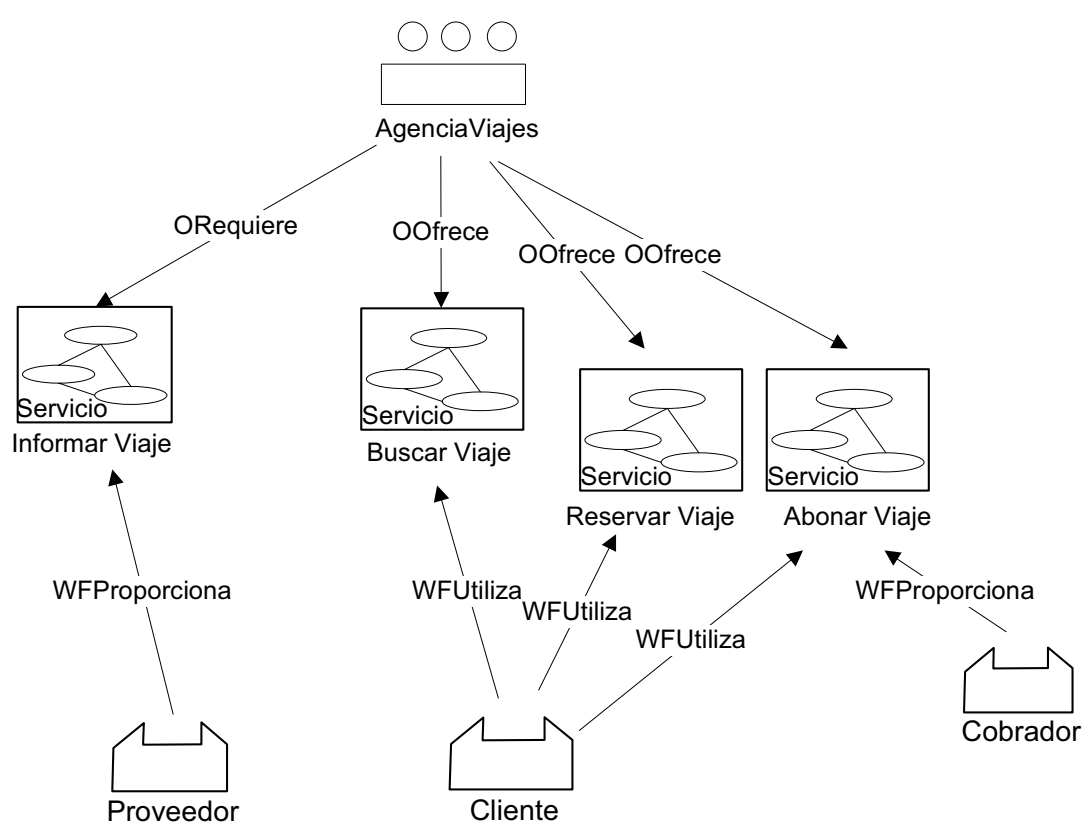

Figura 6.4: Diagrama del modelo de organización (vista funcional, funcionalidad externa).

Para el análisis de la tecnología de unidad de trabajo se requiere detallar cada servicio concreto, empleando para ello tanto el documento B2.Tecnología de Unidad de Trabajo como los diagramas del modelo de actividad.

Los clientes desean viajar a determinados destinos y pasar allí unos días alojados. Con el servicio Buscar Viaje indican su destino y fechas requeridas y obtienen los medios de transporte y hoteles disponibles que mejor se ajustan a sus preferencias. Con el servicio Reservar Viaje, indican la opción que más les interesa (en base a precios, calidad transporte/alojamiento, horarios, etc.), reservándola a su nombre. Finalmente, con el servicio Abonar Viaje, efectúan el pago adelantado de la reserva.

A modo de ejemplo, en la tabla 6.5 se muestra la descripción del servicio Reservar Viaje; mientras que en la figura 6.5 se muestra el diagrama del modelo de actividad para el servicio BuscarViaje. Dicho servicio se describe en el perfil Búsqueda Viaje y se descompone en cuatro tareas, cuya relación 


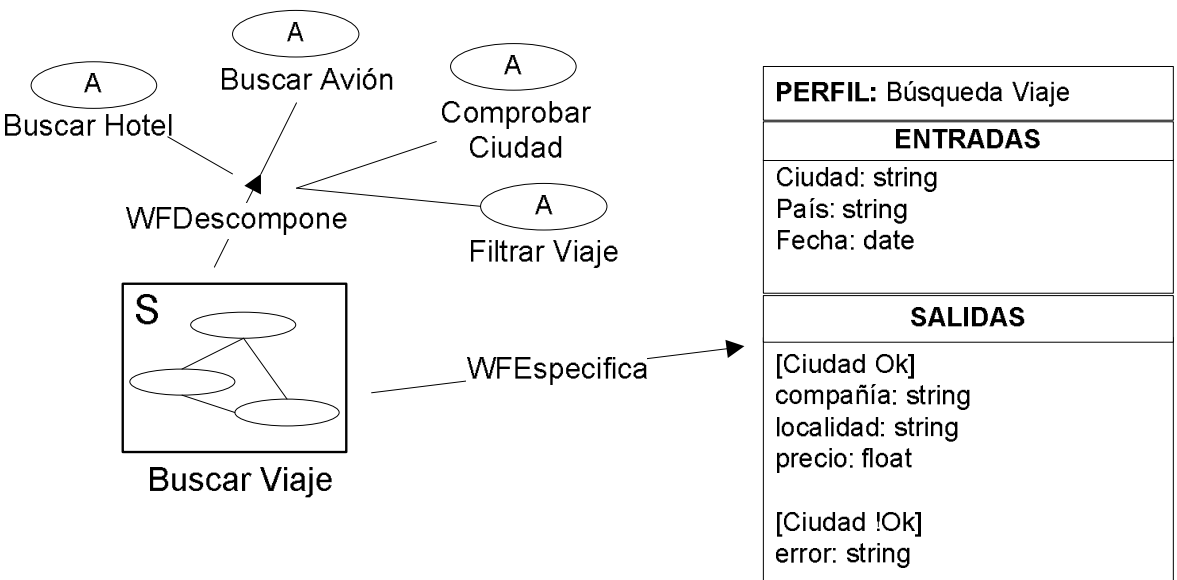

Figura 6.5: Diagrama del modelo de actividad del servicio Buscar Viaje.

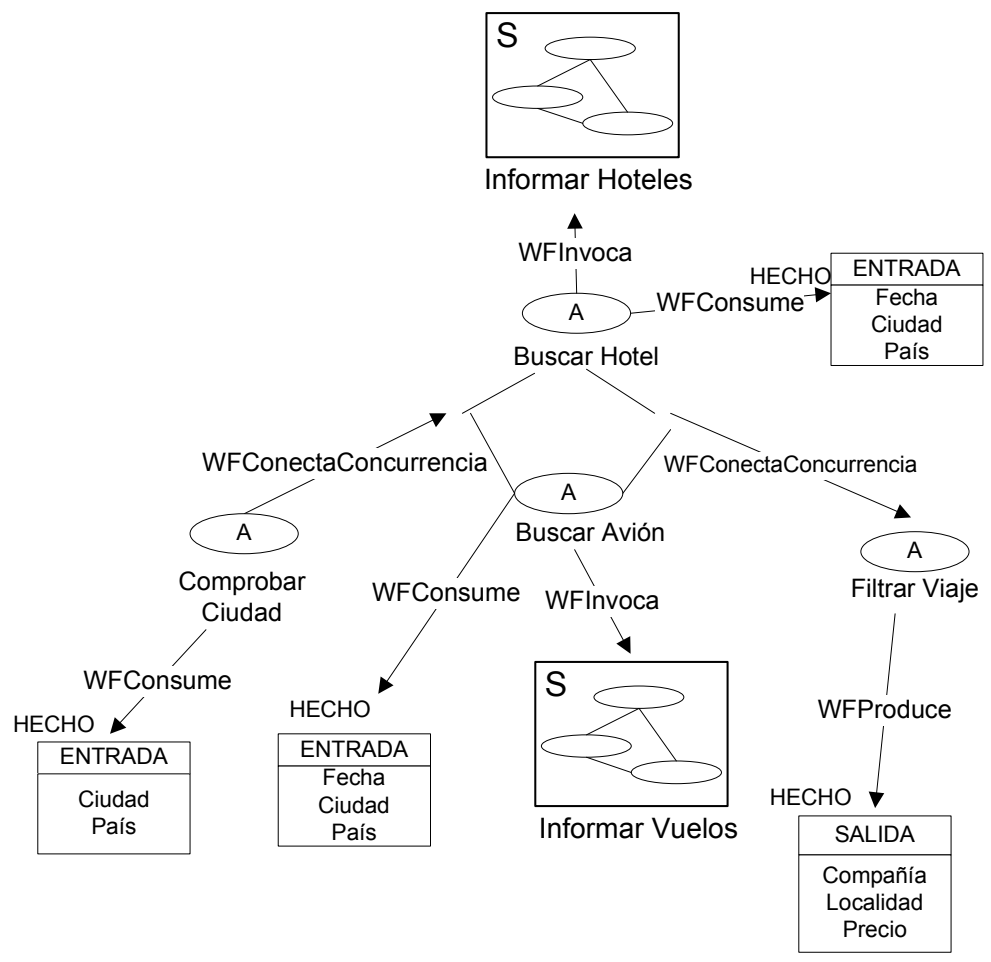

Figura 6.6: Diagrama del modelo de actividad del servicio Buscar Viaje. Descripción detallada de la relación existente entre las A-Tareas que lo componen. 
se describe en la figura 6.6.

Primero se comprueba que la ciudad proporcionada corresponda al país indicado; de forma concurrente se buscan los vuelos para acceder a la ciudad y los hoteles existentes, invocando los servicios Informar Hoteles e Informar Vuelos correspondientes. Finalmente, se confecciona el viaje deseado, filtrando aquellos viajes que mejores condiciones (precio, calidad hotel, etc.) ofrezcan. Los servicios invocados representan especializaciones del servicio Informar Viaje, más general, proporcionado por el rol proveedor.

Respecto a la "posibilidad de análisis del problema", la información que se requiere de los proveedores se obtiene mediante la invocación de los servicios de información (Informar Hoteles o bien Informar Vuelos) que éstos proporcionan. El acceso a dichos servicios se ha indicado a través de las relaciones WFInvoca de los diagramas de modelo de actividad. Por su parte, la información de los usuarios que actúan como clientes se obtiene a través de la aplicación Interfaz de Usuario, ya identificada anteriormente. En la figura 6.7 se muestra el diagrama del modelo de entorno de la unidad organizativa Agencia Viajes. La aplicación es percibida por la entidad travel agent (relación EPercibe), quien se encarga de actuar en el sistema en nombre del usuario.

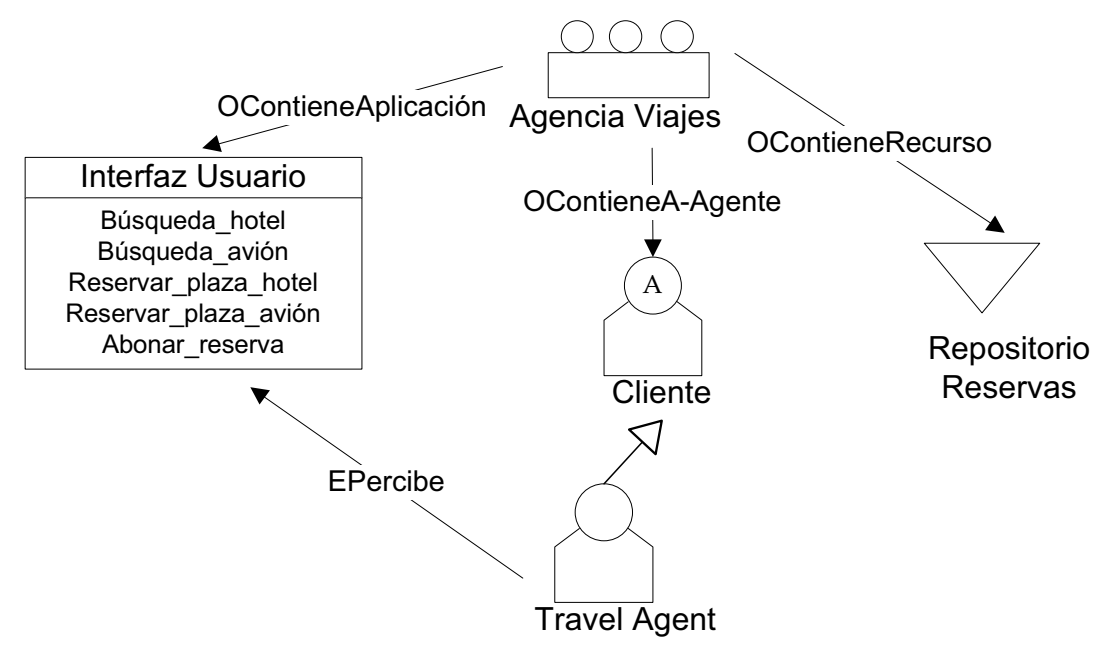

Figura 6.7: Diagrama del modelo de entorno del sistema agencia de viajes. 


\begin{tabular}{|c|c|}
\hline \multicolumn{2}{|r|}{ B.2. Tecnología de Unidad de Trabajo } \\
\hline Servicio & Reservar Viaje \\
\hline Descripción & $\begin{array}{l}\text { Realizar una reserva de una localidad determinada (ej: de } \\
\text { una habitación de hotel, de una plaza de avión) }\end{array}$ \\
\hline Consumidor & Cliente \\
\hline Objetivo & $\begin{array}{l}\text { Ocupar la localidad deseada y evitar que otros clientes } \\
\text { hagan uso de ella }\end{array}$ \\
\hline Beneficio & $\begin{array}{l}\text { Garantizar la disponibilidad del transporte y alojamiento } \\
\text { deseados }\end{array}$ \\
\hline Productor & Proveedor \\
\hline Objetivo & Planificar la ocupación de sus plazas \\
\hline Beneficio & Asegurar la ocupación de sus plazas \\
\hline \multicolumn{2}{|l|}{ Perfil Servicio } \\
\hline Entradas & $\begin{array}{l}\text { compañia }+ \text { localización }+ \text { fecha }+ \text { cantidad } \\
\text { - Compañía: identificador de la línea aérea o de la cadena } \\
\text { hotelera } \\
\text { - Localización: identificador del vuelo o del hotel solicitado } \\
\text { - Fecha: fecha en la que se hará uso de la plaza solicitada } \\
\text { - Cantidad: número de plazas que se solicitan (plazas de } \\
\text { avión, número de habitaciones / días de estancia) }\end{array}$ \\
\hline Precondiciones & Compañía y localización son válidas; la fecha es correcta \\
\hline Salidas & Ticket reserva y Precio Total \\
\hline Postcondiciones & $\begin{array}{l}\text { Las plazas quedan reservadas y no están disponibles para } \\
\text { otros clientes }\end{array}$ \\
\hline \multicolumn{2}{|r|}{ B.2. Tecnología de Unidad de Trabajo } \\
\hline \multirow{2}{*}{$\begin{array}{l}\text { Funcionalidad } \\
\text { Tareas }\end{array}$} & \\
\hline & $\begin{array}{l}\text { Comprobar localización }+ \text { Comprobar disponibilidad }+ \text { Ge- } \\
\text { nerar Ticket reserva } \\
\text { - Comprobar localización: determinar si la compañía y la } \\
\text { localización son correctas } \\
\text { - Comprobar disponibilidad: determinar si para la fecha } \\
\text { proporcionada existen plazas libres (y en la cantidad indi- } \\
\text { cada) } \\
\text { - Generar Ticket reserva: asociar la plaza al cliente y po- } \\
\text { nerla como no disponible }\end{array}$ \\
\hline Recursos & Repositorio de reservas \\
\hline Proveedor & Agencia Viajes \\
\hline Productos & Ticket Reserva \\
\hline
\end{tabular}

Tabla 6.5: Documento B.2-Tecnología de Unidad de Trabajo. Descripción de las características del servicio ReservarViaje. 
Finalmente, los productos que se generan (reservas de viaje) se almacenan en una base de datos o repositorio (Repositorio Reservas) para facilitar su gestión y posterior pago de los mismos. Esta base de datos se almacena en el sistema de viajes, asociándola a la unidad organizativa Agencia Viajes. En la figura 6.7 se muestra el diagrama del modelo de entorno, con la relación OContieneRecurso correspondiente.

La actualización del diagrama del modelo de organización (vista estructural), tras identificar los recursos, aplicaciones y roles necesarios para la unidad organizativa AgenciaViajes se muestra en la figura 6.8. Los roles asociados a los stakeholders son incluidos en la unidad mediante la relación OContieneRol.

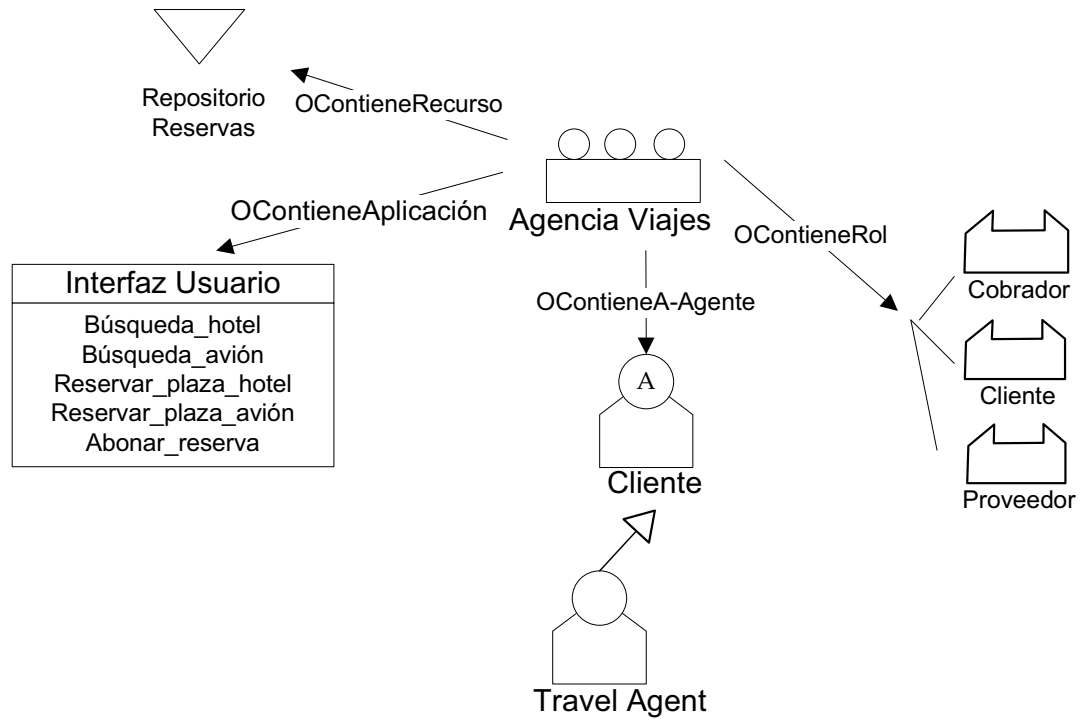

Figura 6.8: Diagrama actualizado de la vista estructural del modelo de organización. Relaciones entre la unidad organizativa Agencia Viajes y las entidades que contiene.

El análisis de los objetivos de la organización implica refinar la misión en objetivos funcionales más concretos, que se asocian a los servicios. En la figura 6.9 se muestra el diagrama de modelo de actividad para los objetivos funcionales. 
De este modo, la misión Maximizar la producción, que trata de maximizar la cantidad de reservas a realizar, se descompone en los siguientes objetivos funcionales: Satisfacer demandas clientes, que tiene en cuenta los requerimientos de los clientes para ofrecerles la información sobre plazas disponibles o sobre ofertas que más les interese; Maximizar cantidad reservas, para gestionar las ofertas a realizar, los precios de las localidades, etc.; y Maximizar eficiencia transacciones, para garantizar que los pagos de las reservas se efectúen de forma rápida y segura.

Se han asociado los servicios identificados hasta el momento a estos objetivos funcionales, según se indica en la figura 6.9.

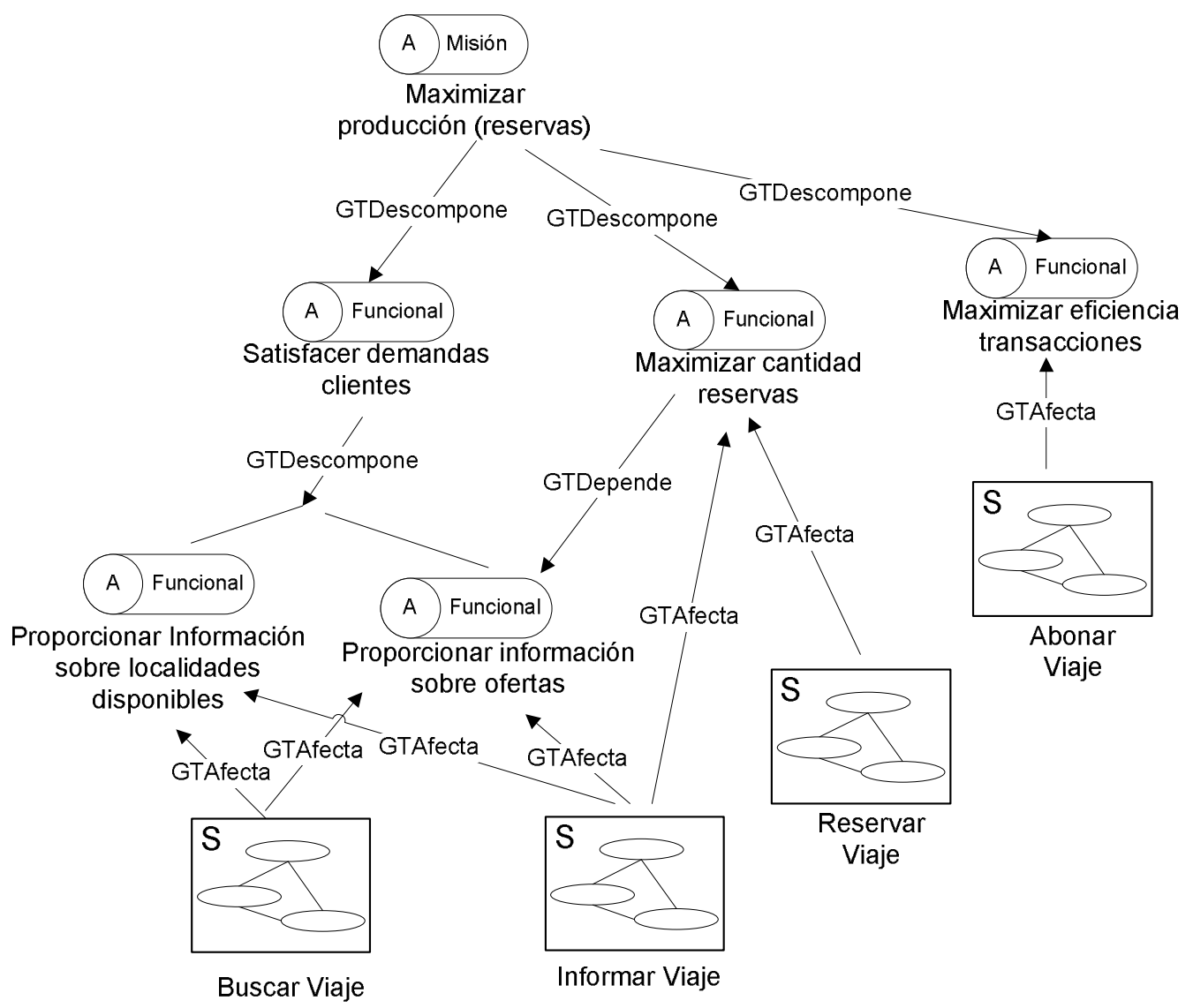

Figura 6.9: Diagrama del modelo de actividad. Relación entre servicios y objetivos funcionales. 


\subsection{Diseño de la Estructura Organizativa}

Para el diseño de la estructura organizativa primero se procede a analizar sus dimensiones, según se indica en la Fase C.Dimensiones Organizativas, para posteriormente escoger la estructura más adecuada, en base a las indicaciones de la Fase D.Estructura Organizativa de la secuencia-guía propuesta.

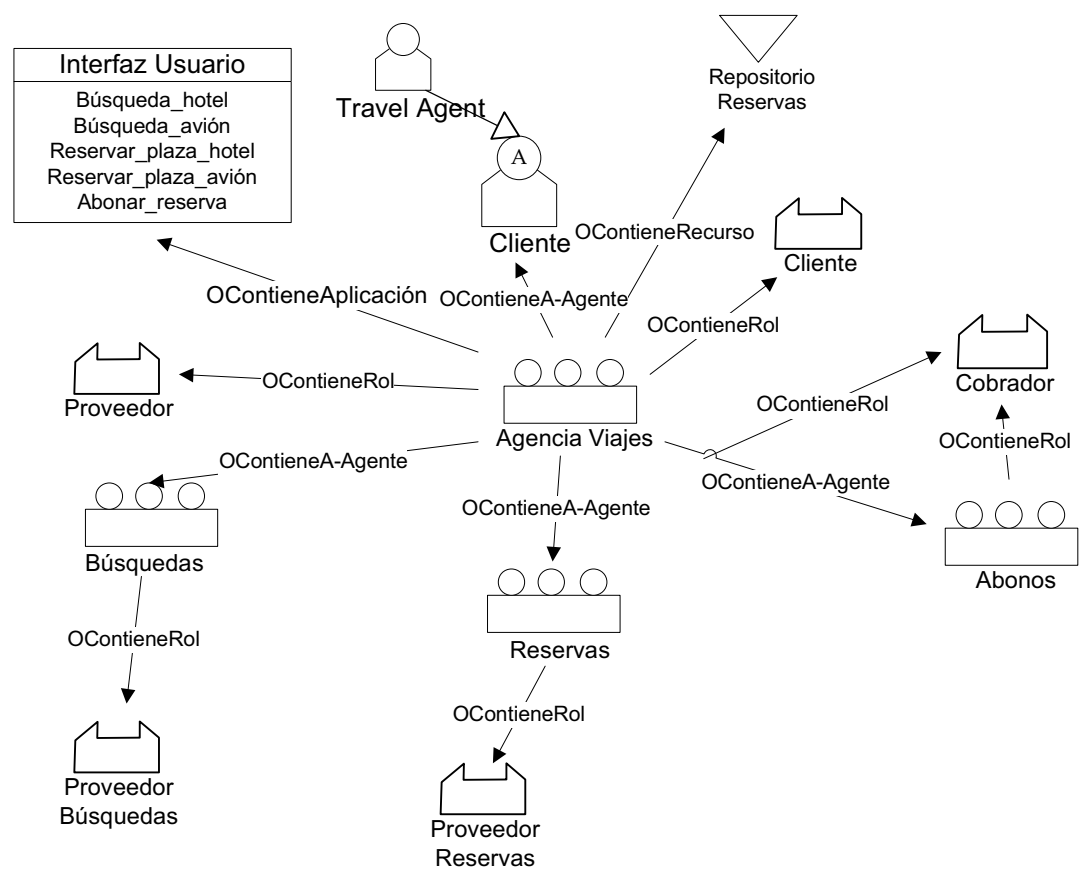

Figura 6.10: Diagrama actualizado de la vista estructural del modelo de organización. Agrupación funcional.

La primera dimensión a considerar es la departamentalización. En este caso se requiere aplicar una departamentalización funcional ya que el entorno del sistema es uniforme, como se determinó en el análisis de requisitos (documento A1.Condiciones del Entorno). Esto implica definir una unidad organizativa para cada servicio ofrecido por la unidad Agencia Viajes.

En la figura 6.10 se muestra la actualización del diagrama de la vista estructural del modelo de organización, con las nuevas entidades Búsquedas, 
Reservas y Abonos correspondientes. Además, los servicios Buscar Viaje y Reservar Viaje se descomponen en servicios más específicos dentro de cada unidad, como por ejemplo Buscar Hotel, Buscar Avión, Reservar Hotel, Reservar Avión. Se han definido los roles proveedor búsquedas y proveedor reservas, que se encargan de proporcionar esos servicios.

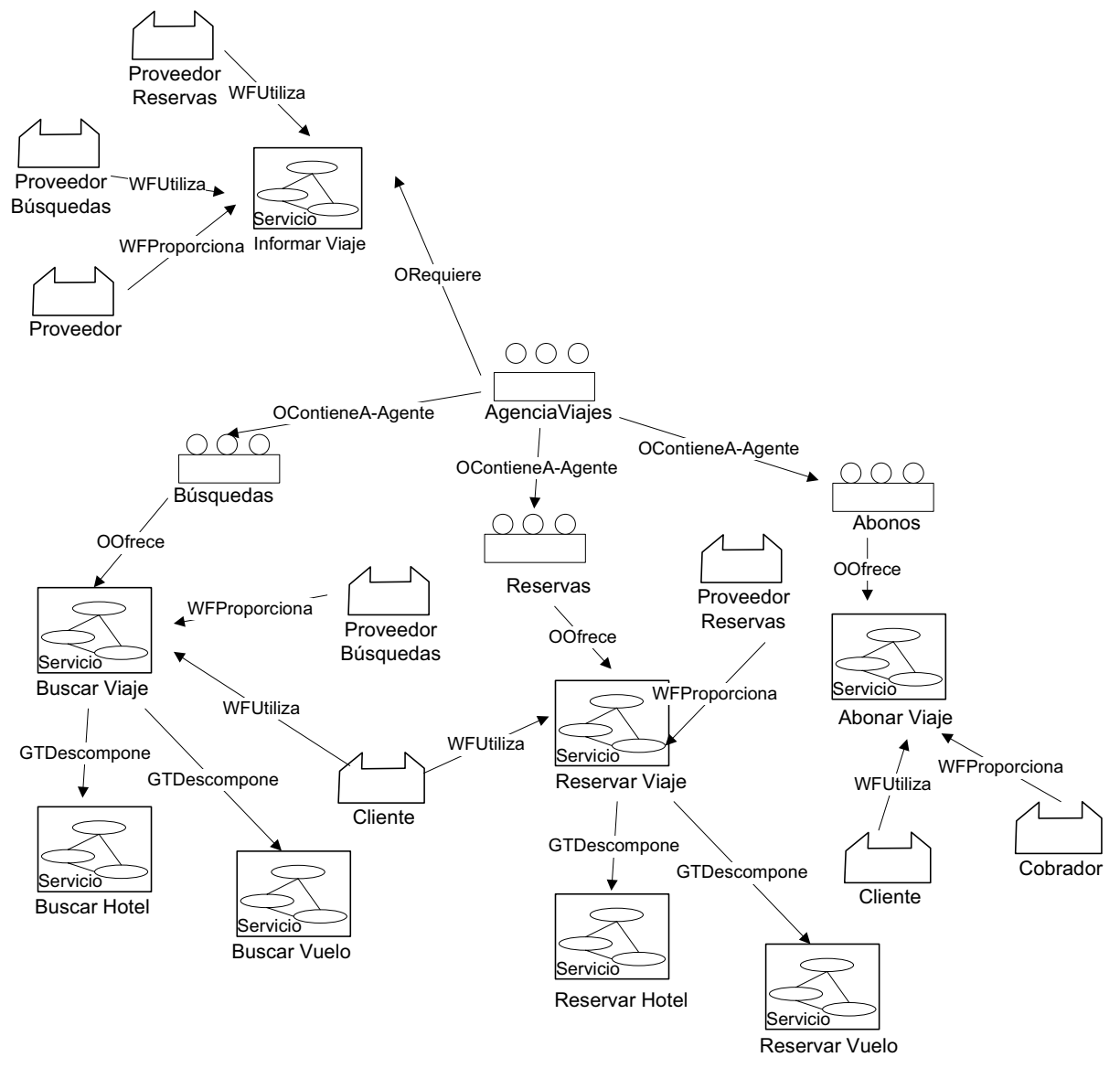

Figura 6.11: Diagrama actualizado de la vista funcional (funcionalidad externa) del modelo de organización. Agrupación funcional.

En la figura 6.11 se muestra la actualización del diagrama de la vista funcional (funcionalidad externa) del modelo de organización, en el que se relacionan las nuevas unidades organizativas con los servicios que ofrecen. En concreto, los roles proveedor búsquedas y proveedor reservas se encargan de proporcionar los servicios generales de Buscar Viaje y Reservar Viaje, 
respectivamente, así como de sus servicios descompuestos. Además, contactan con el rol proveedor para obtener la información relevante sobre los productos que ofrece, a través del servicio Informar Viaje.

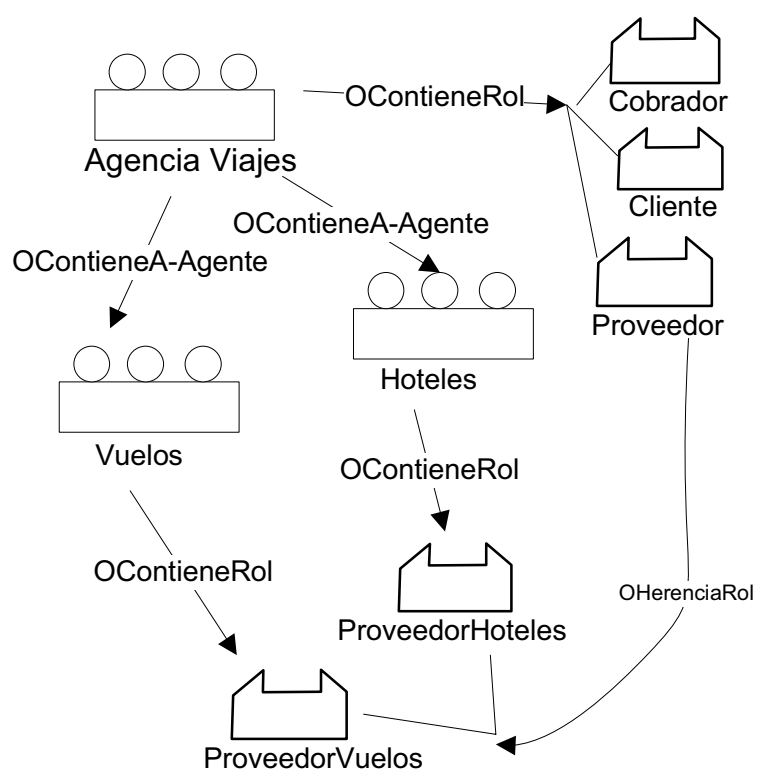

Figura 6.12: Diagrama de la vista estructural del modelo de organización al optar por una agrupación divisional.

Cabe destacar que el diseñador habría podido optar por realizar una departamentalización divisional, considerando que, como el entorno es diverso y se prevé la llegada de nuevos tipos de producto (por ejemplo, proveedores de servicios para trenes, autobuses, etc.), las actividades podrían particularizarse en base a los productos a ofrecer.

De este modo, se definirían tantas unidades organizativas como productos distintos se tengan (ej: unidades Vuelos y Hoteles). En cada una, se especializaría el rol proveedor, en función del producto de la unidad (ej: Proveedor Hoteles, Proveedor Vuelos). Para el rol cobrador se podría optar por especializarlo también, incluyéndolo dentro de las nuevas unidades; o bien mantenerlo solamente en la unidad Agencia Viajes, con funcionalidad independiente del tipo de producto. En la figura 6.12 se muestra el diagrama de la vista estructural del modelo de organización para el caso de optar 
por una agrupación o departamentalización divisional.

Respecto a la especialización, los roles proveedor búsquedas y proveedor reservas, aunque ofrecen pocos servicios, éstos están muy especializados, al presentar una funcionalidad prácticamente similar (por ejemplo, la búsqueda de hoteles y la búsqueda de vuelos requiere de entradas y salidas similares). Por tanto, los roles presentan especialización horizontal. Por otro lado, se desea que el sistema sea descentralizado y que además los roles tengan flexibilidad y capacidad de decisión sobre las tareas que deben realizar, por lo que se requiere ampliación vertical.

Los mecanismos de coordinación y formalización que mejor favorecen la cooperación de las entidades de este sistema son la adaptación mutua y la normalización de tareas. En concreto, como los roles precisan ampliación vertical, se requieren de mecanismos de negociación para concretar las características específicas de la ejecución de sus tareas. Además, las decisiones establecidas en fases anteriores sobre el entorno y la tecnología (entorno dinámico, tecnología de producción de lotes pequeños y tecnología de servicios intensiva), también conducen a la selección de la coordinación por adaptación mutua.

La normalización de tareas es necesaria para garantizar un orden preciso en la invocación de los servicios, así como un orden concreto de la ejecución de sus tareas internas. De este modo se evitará, por ejemplo, que los agentes soliciten la reserva de habitaciones de hotel inexistentes o con información inconsistente.

En el documento C.Dimensiones Organizativas (tabla 6.6) se resumen los valores de departamentalización, especialización, centralización, normalización y coordinación del sistema de agencia de viajes.

Una vez analizadas las diferentes dimensiones de la organización, se procede a identificar la estructura que mejor conviene aplicar en el sistema, haciendo uso del árbol de decisión de la Fase D. Estructura Organizativa. Según dicho árbol, conviene emplear una federación, en base a la departamentalización funcional; la especialización horizontal con ampliación vertical; y la normalización de las tareas. 


\section{Dimensiones Organizativas}

Departamentalización: Funcional. Se agrupa en base a los servicios generales ofrecidos por el sistema (Buscar Viaje, Reservar Viaje, Abonar Viaje).

Especialización + Centralización: Especialización horizontal y ampliación vertical.

Los roles proporcionan servicios muy relacionados entre sí, con entradas y salidas similares.

Ejercen control sobre las tareas de los servicios. Los proveedores deciden cómo implementar sus propios servicios.

Coordinación y Formalización: Adaptación mutua y normalización de tareas.

Como el entorno es dinámico, la tecnología de producción es de lotes pequeños y se realiza una tecnología de servicios intensiva, se requieren procesos de negociación.

Se requiere un orden en la invocación de los servicios, especialmente entre las distintas unidades.

Tabla 6.6: Documento C.Dimensiones Organizativas del sistema de agencia de viajes.

Aplicando el patrón de la federación que se muestra en el capítulo 4 (sección 4.6.2), los diagramas del modelo de organización y del modelo de actividad se actualizan, según se muestra en las figuras 6.13 y 6.14.

Como se observa, la unidad Agencia de Viajes, al adoptar la estructura de federación, se modela internamente como un equipo, donde sus miembros pueden comunicarse entre sí, para así perseguir los objetivos funcionales comunes.

Cada una de las unidades organizativas que la componen (en este caso, Búsquedas, Reservas y Abonos) se modela como una jerarquía simple, en la que existe un rol supervisor que actúan como broker ante las peticiones de los clientes. En la figura 6.13 solamente se muestra la estructura interna de la unidad organizativa Búsquedas. El resto de unidades presentan una estructura similar. El rol proveedor actúa en este caso como subordinado, en el sentido en que recibe la solicitud de información y se limita a proporcionar los datos requeridos. 


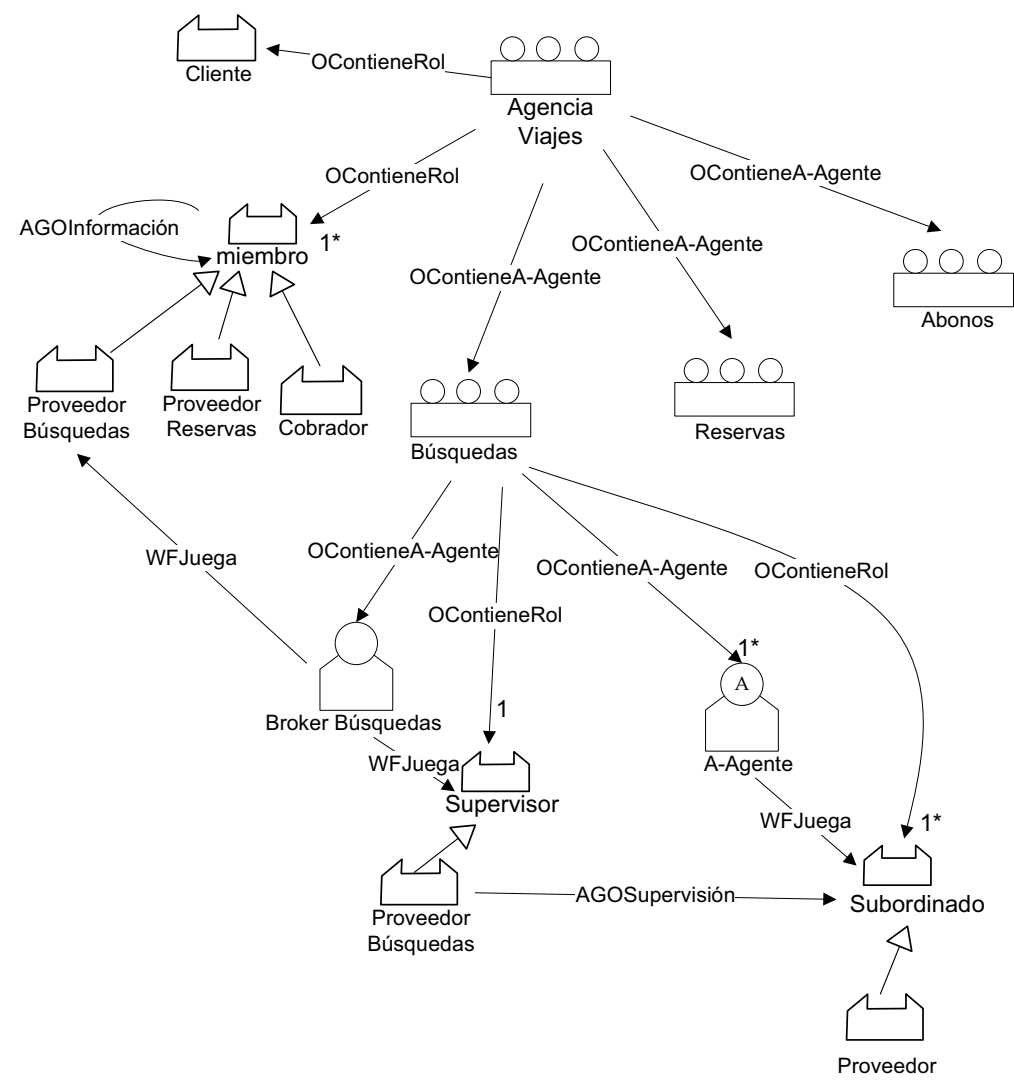

Figura 6.13: Diagrama actualizado de la vista estructural del modelo de organización al adoptar una estructura de tipo federación.

Los roles de tipo supervisor son adoptados por agentes internos del sistema (por ejemplo, el agente Broker Búsquedas). El rol supervisor recibe las peticiones de los miembros (ej: búsquedas de hoteles, de vuelos), distribuye la petición entre los subordinados de su unidad y recopila las respuestas, seleccionando aquellas que resulten más apropiadas con respecto a la solicitud del cliente. Por tanto, el supervisor actúa de broker entre los proveedores y los clientes. Se puede implementar el protocolo de Contract-Net para la distribución y selección de las peticiones entre los proveedores.

El funcionamiento general del sistema será el siguiente: cuando un cliente desea pasar unos días en un determinado lugar, solicita información sobre el modo de llegar a su destino y sobre el tipo y precio del alojamiento. Para 


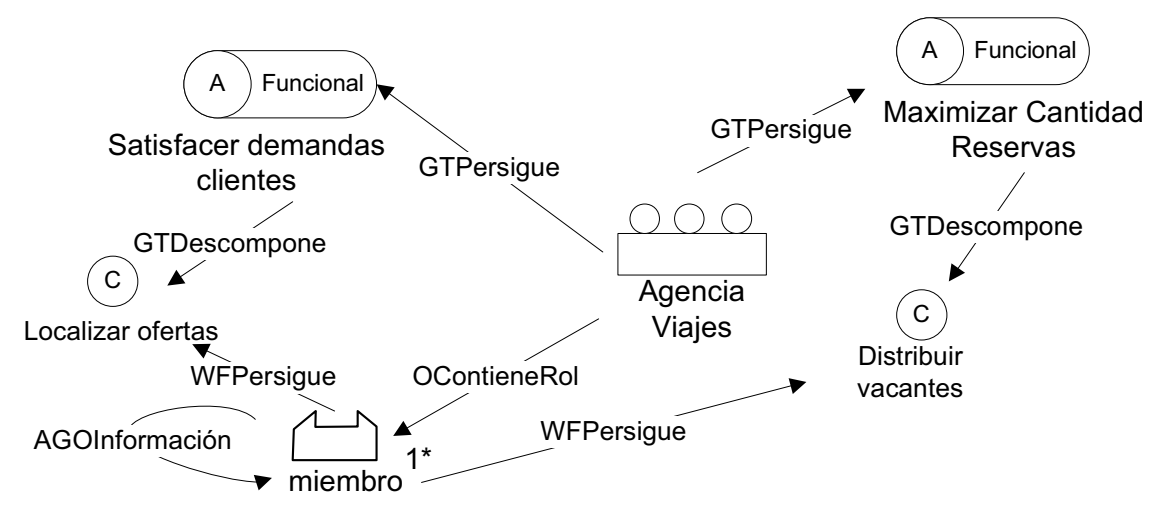

Figura 6.14: Diagrama actualizado del modelo de actividad (asociación de objetivos) al adoptar una estructura de tipo federación.

ello contacta con el supervisor de la unidad Búsquedas, quien se encarga de realizar las peticiones pertinentes a los proveedores representantes de hoteles y líneas aéreas. A continuación, tras seleccionar la opción más adecuada, solicita al supervisor de la unidad Reservas que efectúe esas reservas. Este supervisor se encarga de contactar con los proveedores relacionados, quienes efectúan esa reserva. Finalmente, el cliente contacta con la unidad de Abonos para pagar la reserva, si así le interesa. Por tanto, los clientes necesitan contactar con diferentes unidades, en un orden preestablecido, para así conseguir alcanzar sus objetivos.

Por su parte, los proveedores requieren participar en varias unidades, en concreto en Búsquedas y Reservas; aunque en esta última unidad su participación no es tan importante, pues el propio agente supervisor de la misma podría encargarse de realizar el proceso de reservas, actuando directamente sobre el repositorio de reservas.

En este tipo de organización, la flexibilidad y poder de decisión de los agentes proveedores se reduce a: determinar qué información proporcionar cuando se les facilita una solicitud de un cliente; y decidir si aceptar o no la solicitud de reservas por parte de los clientes. Resulta interesante aplicar este tipo de organización cuando no se desea confiar demasiado en las capacidades de los proveedores, manteniendo dentro del sistema un mayor poder de control sobre la gestión de los servicios. 
Sin embargo, en el análisis de los requisitos se determinó inicialmente que se deseaba otorgar una gran flexibilidad a los proveedores, para que sean éstos quienes decidan qué desean ofrecer (búsquedas, reservas, abonos). Por tanto, conviene revisar las dimensiones de la organización, para orientar al sistema hacia un comportamiento mucho más flexible. En la tabla 6.7 se muestran los nuevos valores de las dimensiones organizativas, según esta nueva orientación.

\begin{tabular}{|l|}
\hline \multicolumn{1}{|c|}{ C. Dimensiones Organizativas } \\
\hline Departamentalización: Divisional. Se agrupa en base a los productos (hote- \\
les, vuelos,...). \\
\hline Especialización + Centralización: Ampliación horizontal y vertical. \\
Los roles proporcionan servicios poco relacionados entre sí, con interdependen- \\
cia secuencial y recursos compartidos. \\
Ejercen control sobre las tareas de los servicios. Los proveedores deciden cómo \\
implementar sus propios servicios. \\
\hline Coordinación y Formalización: Adaptación mutua. \\
Como el entorno es dinámico, la tecnología de producción es de lotes pequeños \\
y se realiza una tecnología de servicios intensiva, se requieren procesos de ne- \\
gociación. \\
Adicionalmente, se debe controlar el orden en la invocación de los servicios \\
(normalización de tareas), así como la calidad de los resultados (normalización \\
de resultados) para ofrecer mayor flexibilidad en las implementaciones de los \\
servicios de los proveedores.
\end{tabular}

Tabla 6.7: Actualización del documento C.Dimensiones Organizativas del sistema de agencia de viajes, con orientación basada en los productos a ofrecer.

En concreto, se opta ahora por una departamentalización divisional, fijándonos más en los distintos tipos de productos que se ofrecen. En este caso, se dispone de tantas unidades como productos existan y, aunque los clientes deben contactar con una o varias unidades en función de los productos que necesiten, los proveedores solamente participan dentro de una unidad, la correspondiente con el tipo de producto con el que están relacionados. En las figuras 6.15 y 6.16 se muestran los diagramas de la vista estructural y la vista funcional (funcionalidad externa) del modelo de organización. 


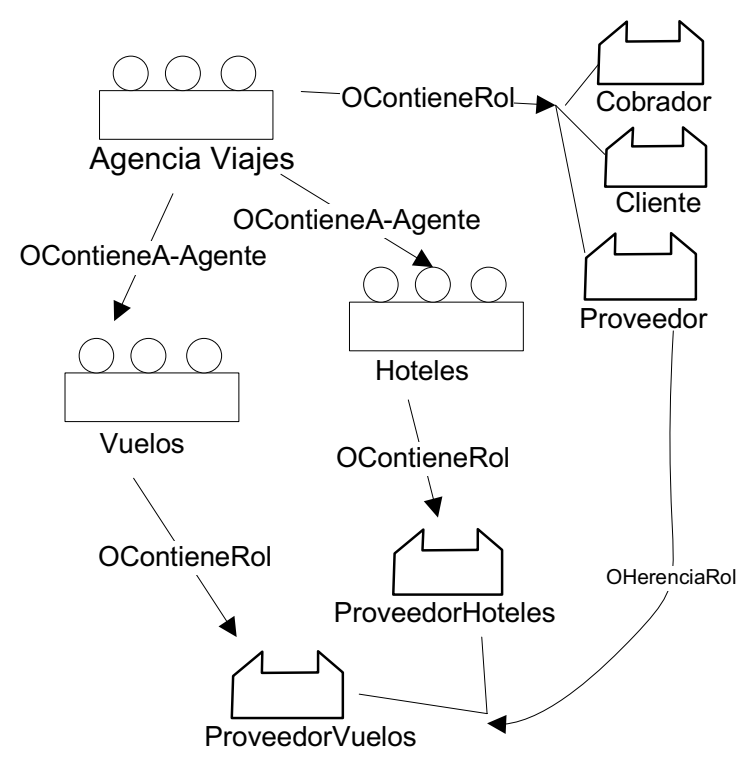

Figura 6.15: Diagrama actualizado de la vista estructural del modelo de organización al optar por una agrupación divisional.

Para la especialización, dentro de cada unidad los proveedores se encargan de distintos servicios (búsquedas, reservas), que mantienen entre sí una relación de tipo interdependencia secuencial. Por tanto, los roles presentan amplitud horizontal, al encargarse de tareas distintas, con distinta funcionalidad, pero que siguen un orden de ejecución preestablecido. Por su parte, tienen también amplitud vertical, ya que se desea una gran flexibilidad en la implementación de su funcionalidad.

En los mecanismos de coordinación y formalización resulta primordial la adaptación mutua, para favorecer los procesos de negociación y otorgar así mayor flexibilidad al sistema.

Tras la revisión de las dimensiones organizativas, se observa que en este caso resulta adecuada la estructura de congregación.

El diagrama de la vista estructural del modelo de organización, adaptada conforme al patrón de congregación, se muestra en la figura 6.17. La unidad AgenciaViajes contiene tantas unidades como productos se tengan, 


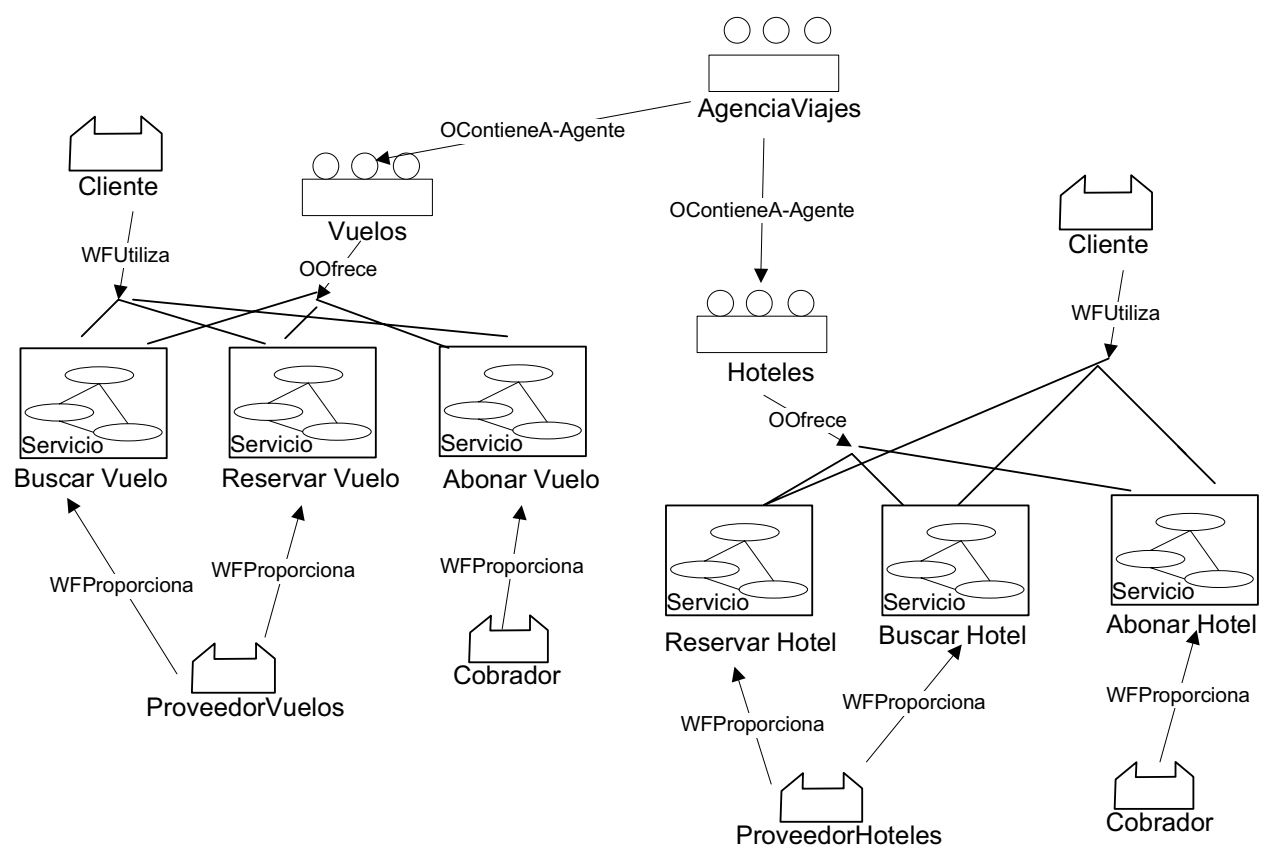

Figura 6.16: Diagrama actualizado de la vista funcional (funcionalidad externa) del modelo de organización al optar por una agrupación divisional.

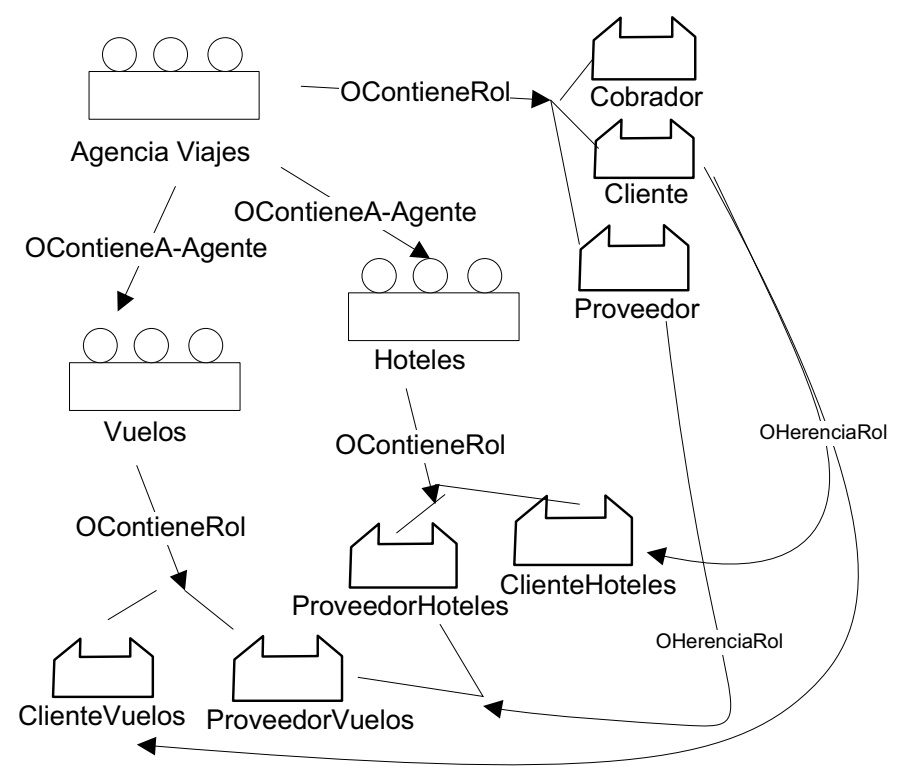

Figura 6.17: Diagrama actualizado de la vista estructural del modelo de organización al adoptar una estructura de tipo congregación. 
en este caso Vuelos y Hoteles. Además, los roles proveedor y cliente se refinan dentro de esas nuevas unidades, para especializarse en la producción o bien en la utilización de los servicios concretos asociados a esos tipos de productos.

En la figura 6.18 se muestra el diagrama de la vista funcional del modelo de organización, adaptada conforme al patrón de congregación. A través del servicio Registrar Unidad los proveedores pueden solicitar la creación de nuevas unidades organizativas, para así atender a la llegada de nuevos productos.

Por su parte, las unidades Vuelos y Hoteles contienen los servicios de AdquirirRol, Informar Unidad, DejarRol, además de los servicios propios dependientes del dominio, que ya habían sido identificados anteriormente. Así, los proveedores de vuelos y los clientes que deseen contactar con ellos, deben pasar previamente por un proceso de adquisición del rol correspondiente.

En la figura 6.18 solamente se muestra el modelado interno de la unidad Vuelos por facilitar su claridad y comprensión. La estructura interna de la unidad Hoteles se ha modelado de forma similar. 


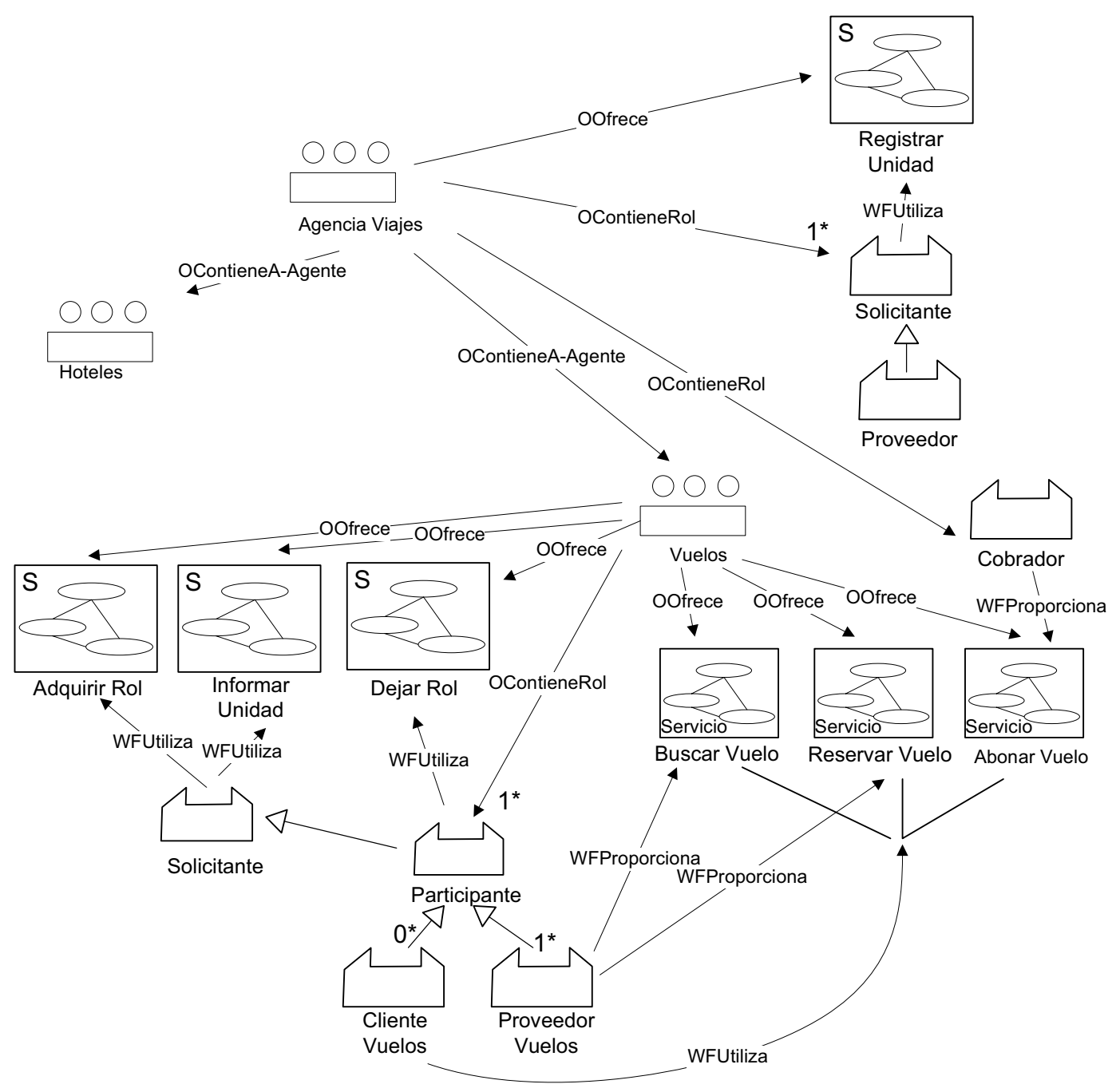

Figura 6.18: Diagrama actualizado de la vista funcional (funcionalidad externa) del modelo de organización al adoptar una estructura de tipo congregación. 


\subsection{Diseño de la Dinámica de la Organiza- ción}

En esta fase del proceso de desarrollo del sistema, integrada en la fase de diseño del mismo, se procede a detallar de manera más precisa cómo se comportan los servicios de la organización, cómo se interacciona con el entorno, qué interacciones se establecen entre las entidades del sistema y cómo se abordan los aspectos de sistema abierto.

Asimismo, se definen las normas para establecer el control y gestión de los servicios, además de seleccionar el sistema de recompensas que fomente mejor la consecución de los objetivos de la organización. Para ello se aplican las fases E, F, G y H de la secuencia-guía propuesta.

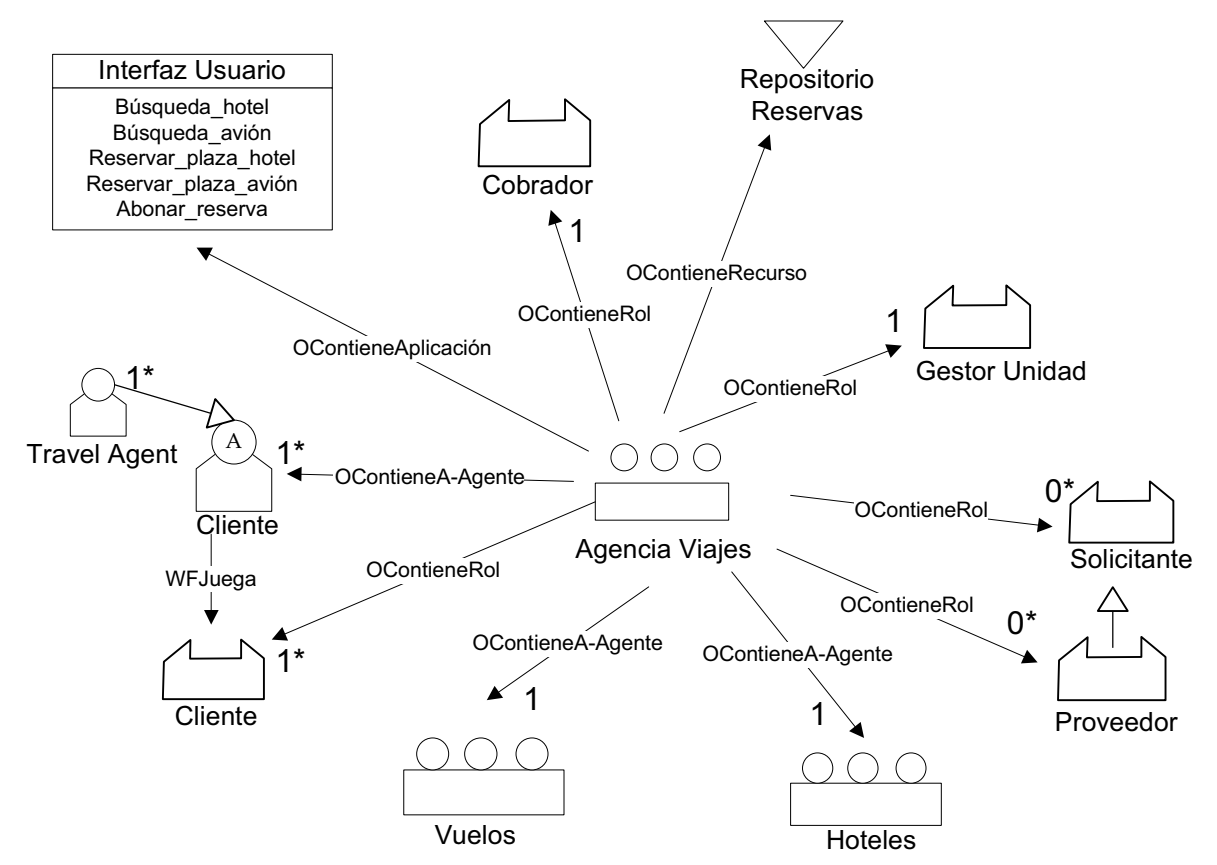

Figura 6.19: Diagrama actualizado de la vista estructural del modelo de organización para la unidad organizativa Agencia Viajes.

En la Fase E. Diseño de los procesos de información-decisión se determina inicialmente quiénes se encargan de proporcionar cada uno de los 


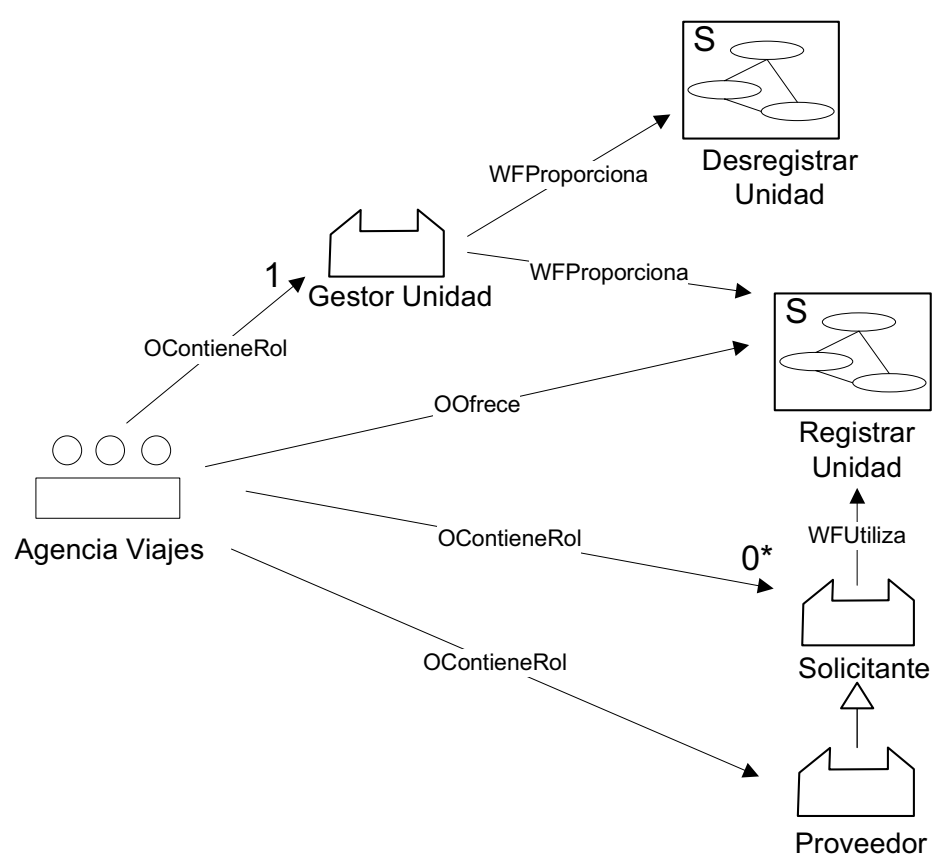

Figura 6.20: Diagrama actualizado de la vista funcional (funcionalidad externa) del modelo de organización para la unidad Agencia Viajes.

servicios identificados. Tras aplicar el patrón de diseño de congregación seleccionado en la fase anterior, la unidad AgenciaViajes requiere ofrecer también el servicio RegistrarUnidad y así permitir que se creen dinámicamente nuevas unidades. Este servicio lo proporciona el rol GestorUnidad, que también se encarga de desregistrar las unidades que no contengan participantes durante un determinado espacio de tiempo. En la figura 6.19 se muestra el diagrama actualizado de la vista estructural del modelo de organización para la unidad organizativa AgenciaViajes. Y en la figura 6.20 se muestra el diagrama actualizado de la vista funcional (funcionalidad externa) del modelo de organización para la unidad organizativa Agencia Viajes.

Por su parte, en las unidades organizativas Vuelos y Hoteles se requiere de su propio rol GestorUnidad, que proporciona los servicios Adquirir Rol, Dejar Rol e Informar Unidad, identificados tras aplicar, en la fase anterior, el patrón de la estructura de congregación. En la figura 6.21 se muestra el diagrama actualizado de la vista funcional (funcionalidad externa) del 


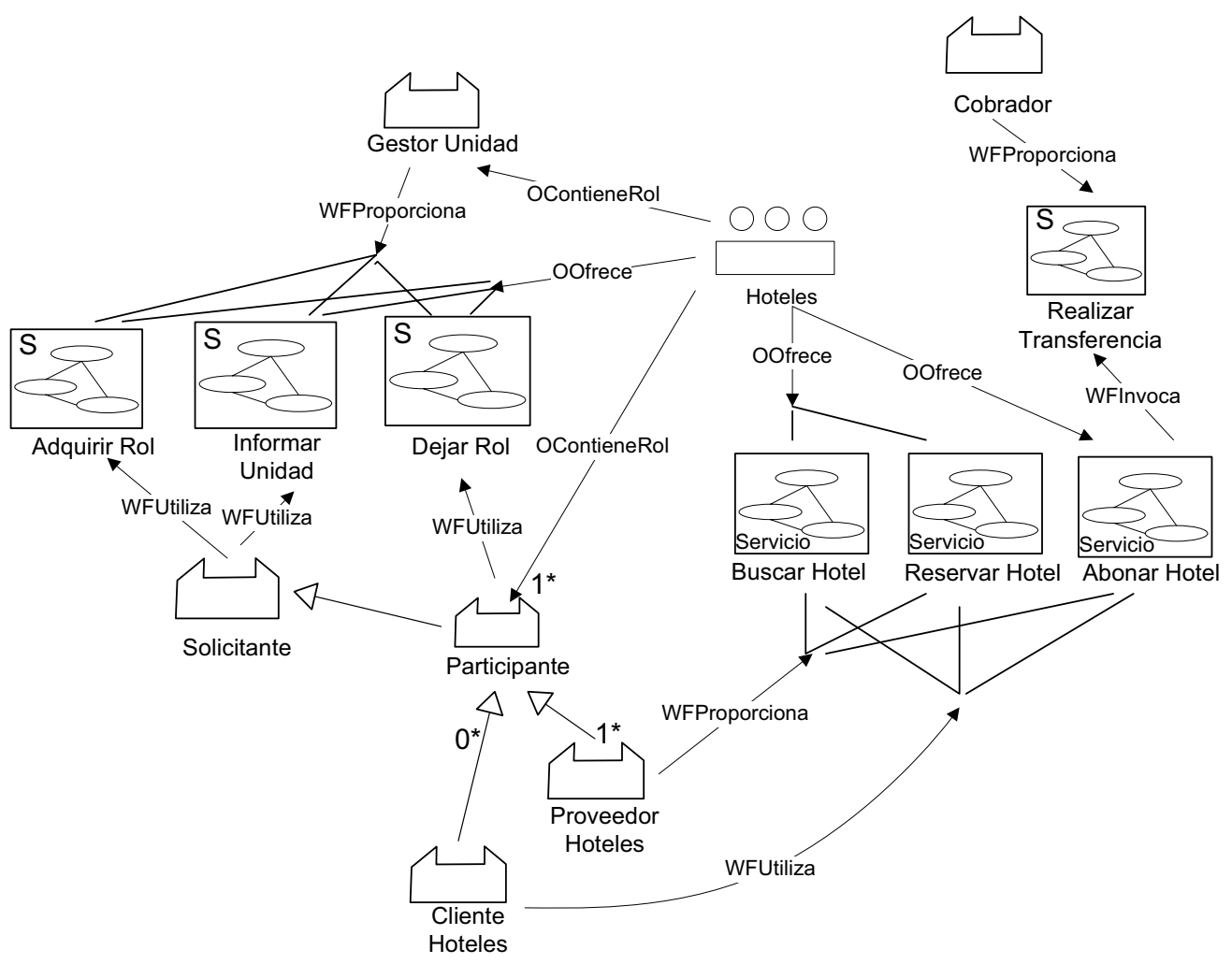

Figura 6.21: Diagrama actualizado de la vista funcional (funcionalidad externa) del modelo de organización para la unidad organizativa Hoteles.

modelo de organización para la unidad organizativa Hoteles. En el caso de la unidad Vuelos, su diagrama es prácticamente equivalente, pero con los roles y servicios propios de esa unidad.

Para cada uno de los servicios identificados hasta el momento se debe detallar en qué consiste, usando la entidad PerfilServicio; y cómo funciona, a través de su descomposición en entidades $A$-Tarea. En la figura 6.22 se muestra el diagrama del modelo de actividad del servicio Buscar Hotel, mientras que en la figura 6.23 se describe la relación de las diferentes tareas en las que este servicio se descompone.

A continuación se actualiza el modelo de actividad, relacionando los objetivos funcionales de la organización con los servicios identificados. En la figura 6.24 se indica dicha relación, para los servicios de la unidad Hoteles, 


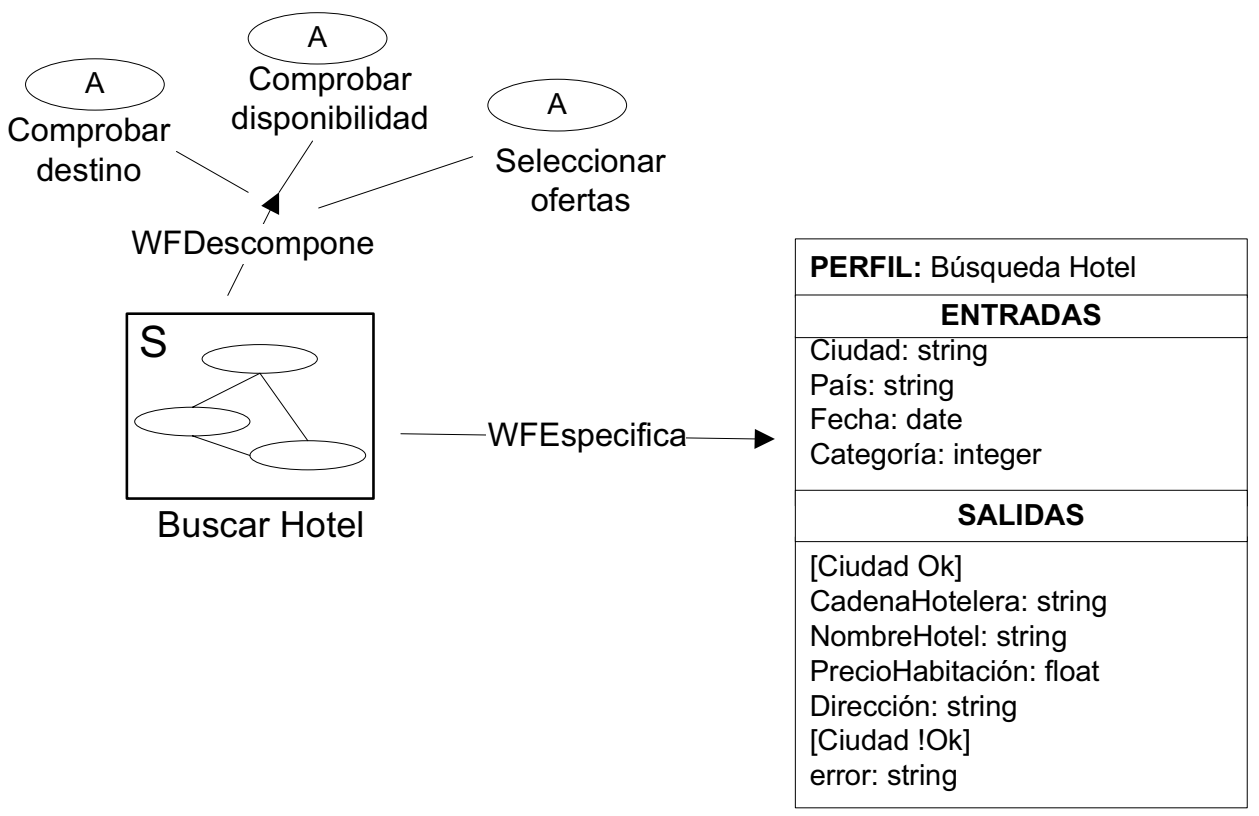

Figura 6.22: Diagrama del modelo de actividad del servicio Buscar Hotel.

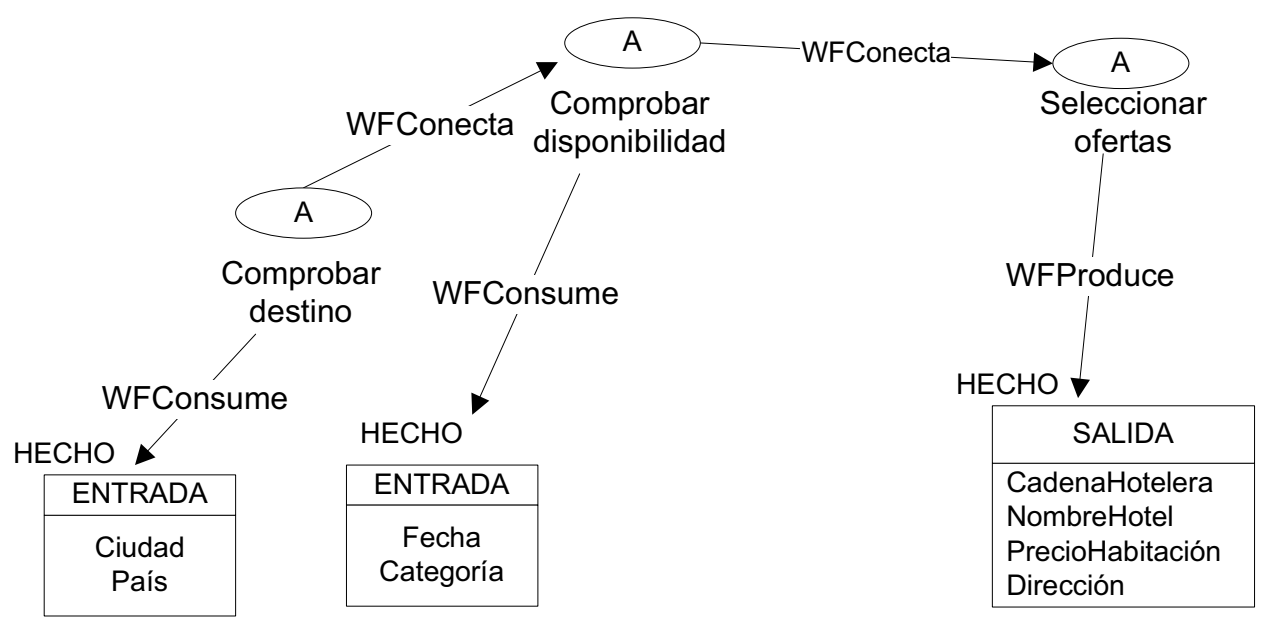

Figura 6.23: Diagrama del modelo de actividad del servicio Buscar Hotel. Descripción del flujo de tareas en el que se descompone. 
propios de su dominio. Además, los objetivos funcionales se descomponen en objetivos operativos. Por ejemplo, en la figura 6.25 se muestra esta descomposición para los objetivos de la unidad Hoteles. Finalmente, estos objetivos operativos se asocian con las A-Tareas de los servicios. Como ejemplo, en la figura 6.26 se muestra la asociación de objetivos operativos a A-Tareas para el servicio Buscar Hotel.

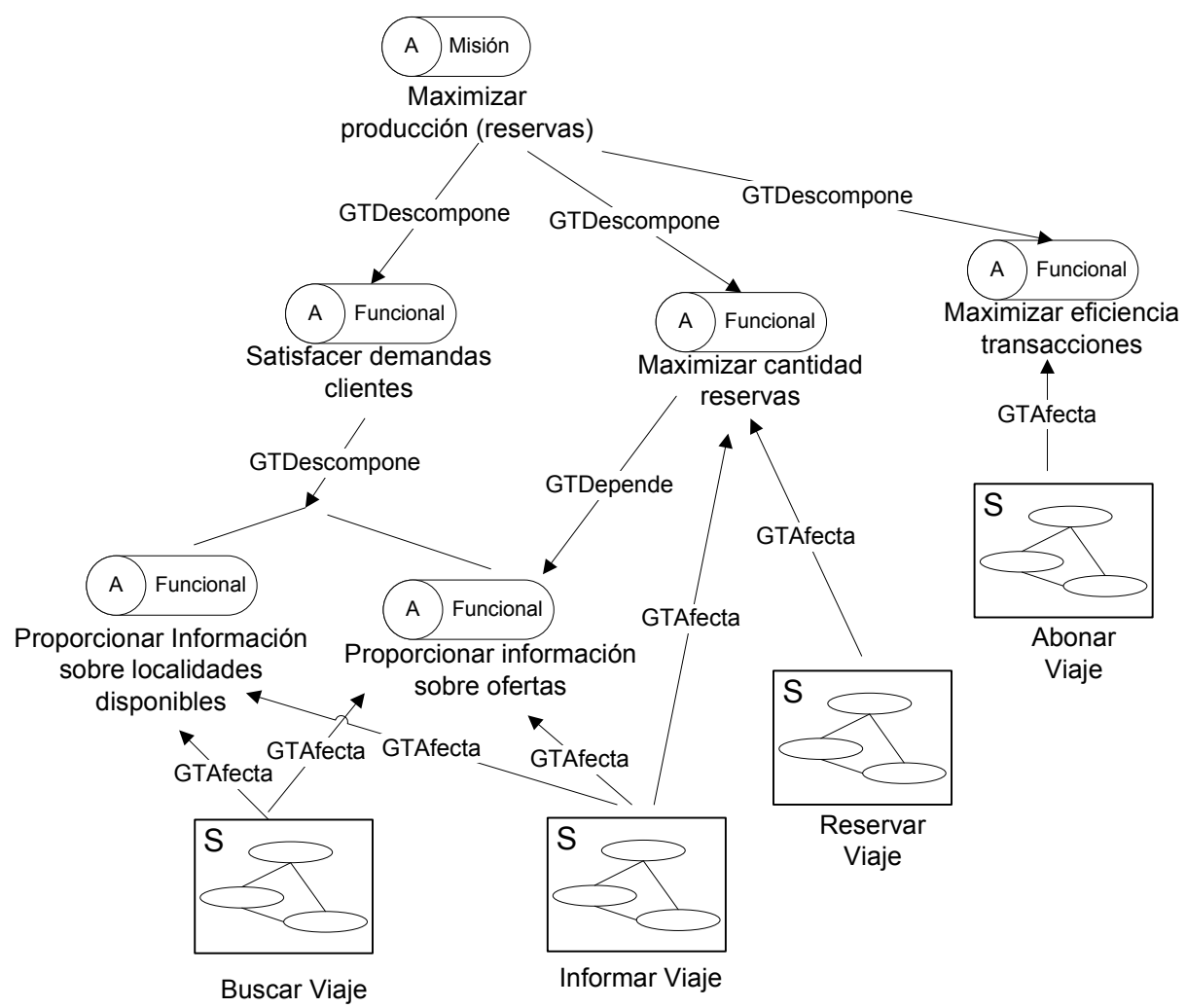

Figura 6.24: Diagrama actualizado del modelo de actividad. Relaciones entre servicios y objetivos funcionales de la unidad Hoteles.

En la Fase E. Diseño de los procesos de información-decisión también se analizan los procesos de información de la organización, detallando tanto su interacción con el entorno como las interacciones entre las entidades que la componen.

Así, en la figura 6.27 se muestra el modelo de entorno para la organización de AgenciaViajes. El recurso Repositorio de Reservas se asigna a la 


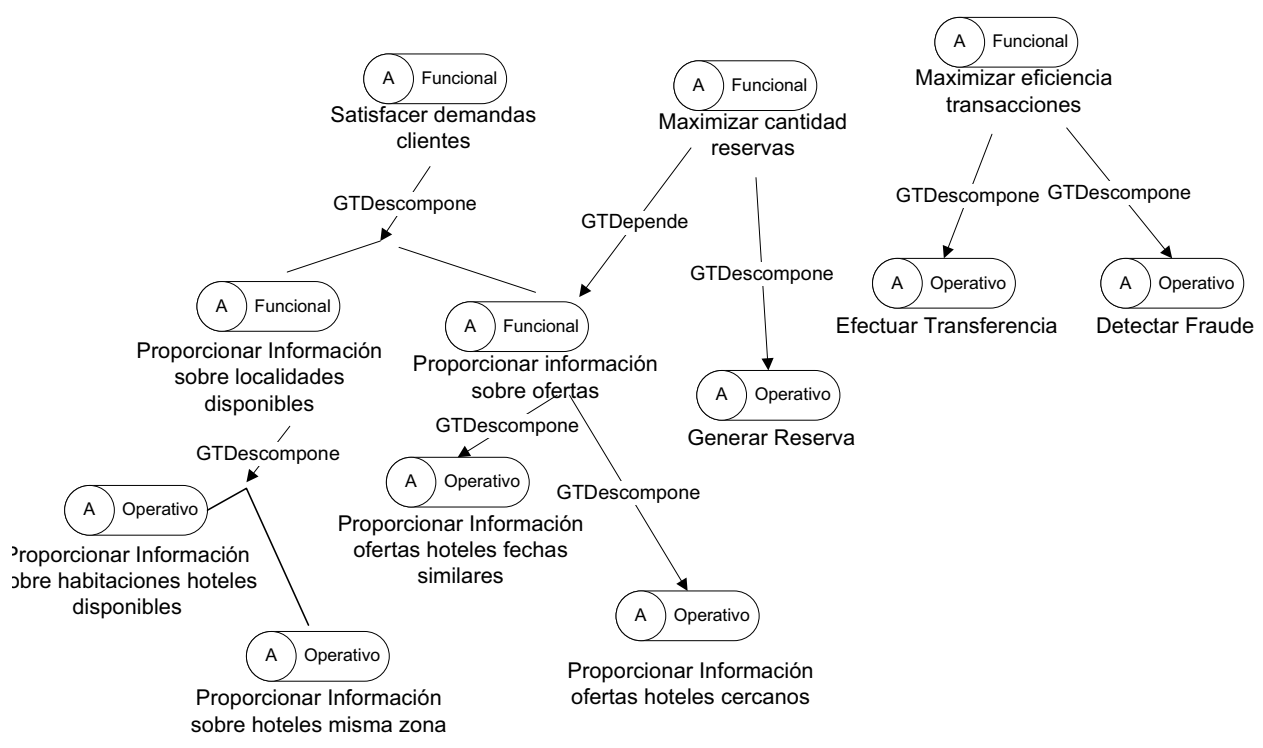

Figura 6.25: Diagrama actualizado del modelo de actividad. Descomposición de objetivos funcionales en objetivos operativos de la unidad Hoteles.

unidad Agencia Viajes, pero se crea una entidad PuertoEntorno para que el rol proveedor haga uso del mismo, tanto para lectura como para escritura. Por su parte, para la aplicación Interfaz Usuario se crea también una entidad PuertoEntorno, sobre la que el rol cliente tiene permiso de lectura. De este modo, cualquier agente que juegue el rol cliente tendrá habilitada la posibilidad de hacer uso de la aplicación, aunque el control de su acceso está regido por la unidad Agencia Viajes.

Para la ontología del dominio, se hace uso de las ontologías travel.owl y transportation.owl empleadas en el repositorio de servicios web OWLSTC sobre el dominio de viajes. En ellas, conceptos como "Accomodation", "Hotel", "Airport", "Aircraft", etc. están ampliamente detallados.

Respecto a las interacciones, en la figura 6.28 se muestra el diagrama del modelo de interacción para el servicio Buscar Hotel. En dicho diagrama se indican los roles que participan en la interacción y la ejecución del servicio que provoca su activación. En la figura 6.29 se muestra el diagrama de colaboración asociado a esta interacción, donde se detalla el modelo de proceso propuesto, indicando los mensajes que se envían las entidades participantes. 


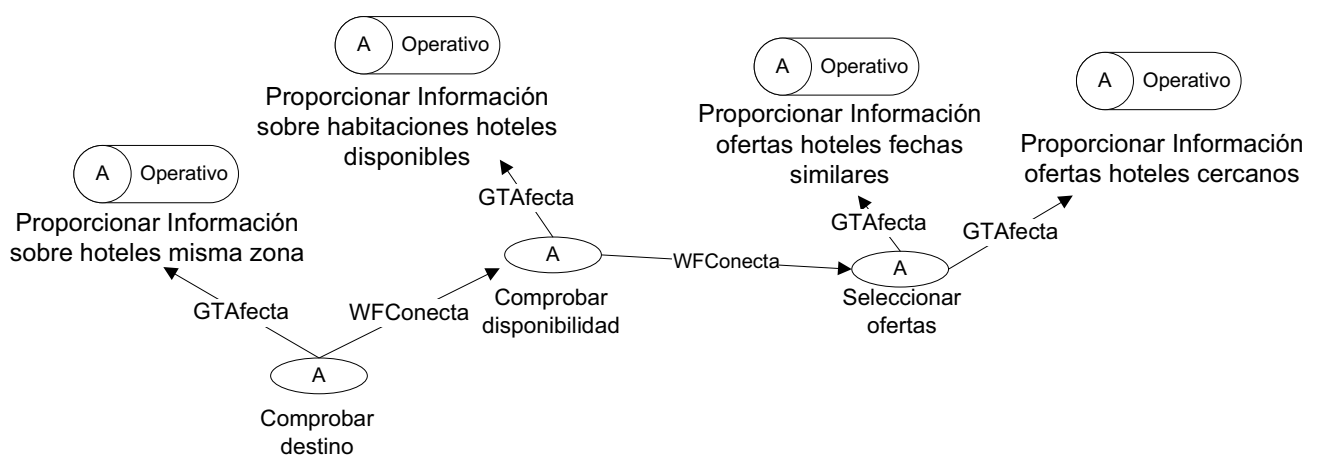

Figura 6.26: Diagrama actualizado del modelo de actividad. Asociación de objetivos operativos a A-Tareas para el servicio Buscar Hotel.

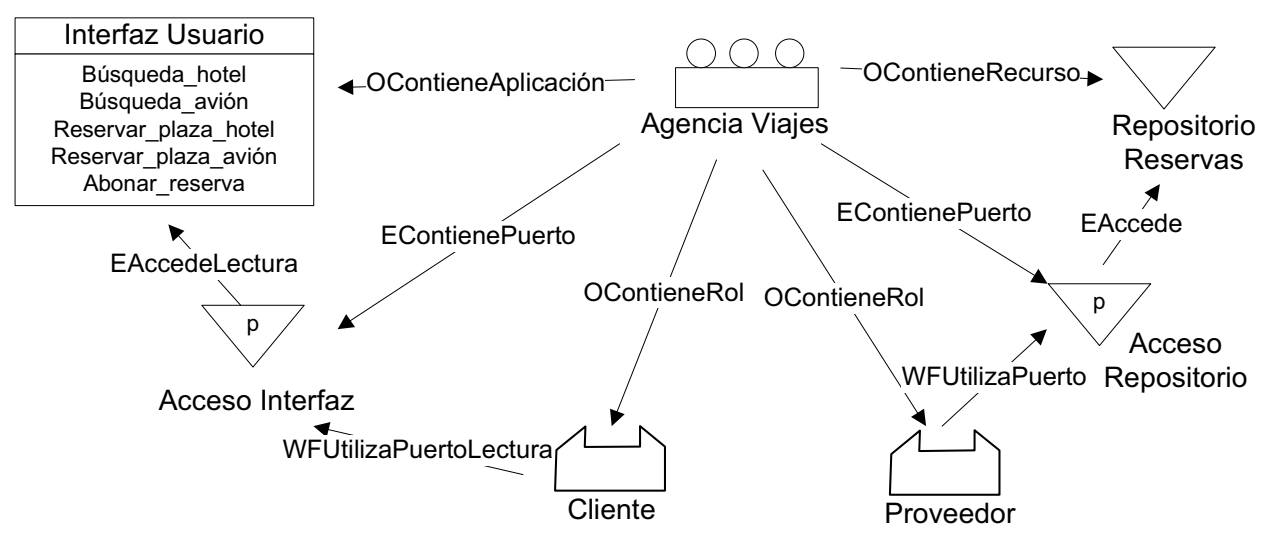

Figura 6.27: Diagrama actualizado del modelo de entorno de la organización AgenciaViajes. Acceso a los puertos del entorno.

Finalmente, las unidades Hoteles y Vuelos requieren de vínculos laterales entre sí, es decir, conexiones directas entre algunos de sus componentes. En concreto, se ha definido una relación AGOInformación entre los roles GestorUnidad correspondientes (figura 6.30). Así, estos roles tienen comunicación directa y pueden conocer qué agentes juegan cada rol en las unidades y gestionar mejor el servicio AdquirirRol. Se ha añadido también el objetivo funcional "Garantizar la confiabilidad" y las interacciones "Conocer Agentes en Vuelos" y "Conocer Agentes en Hoteles" para representar esa transmisión de información entre los roles Gestor Unidad. En la figura 6.31 se muestra el modelo de interacción correspondiente. 


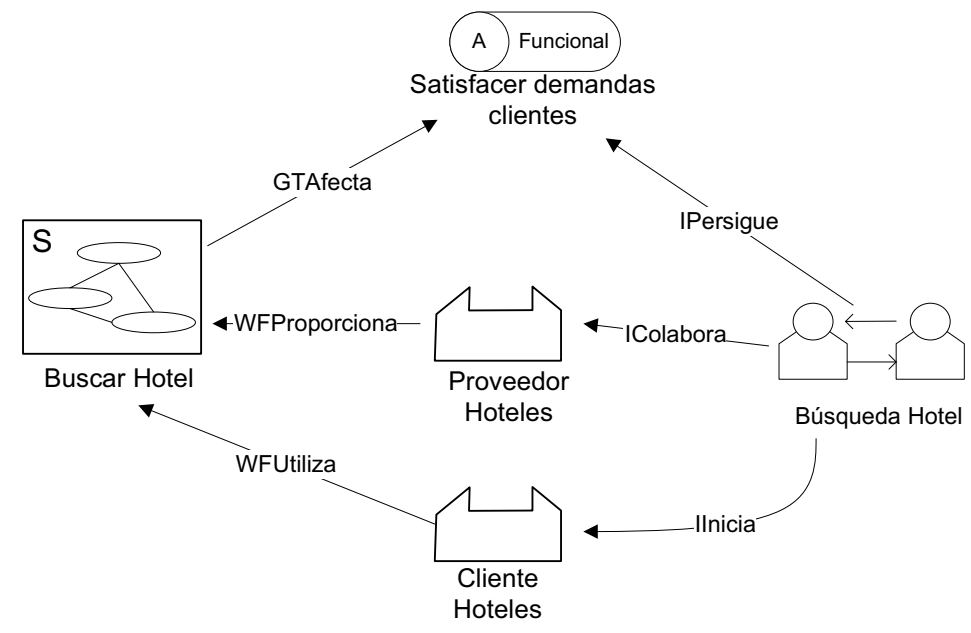

Figura 6.28: Diagrama del modelo de interacción para el servicio Buscar Hotel.

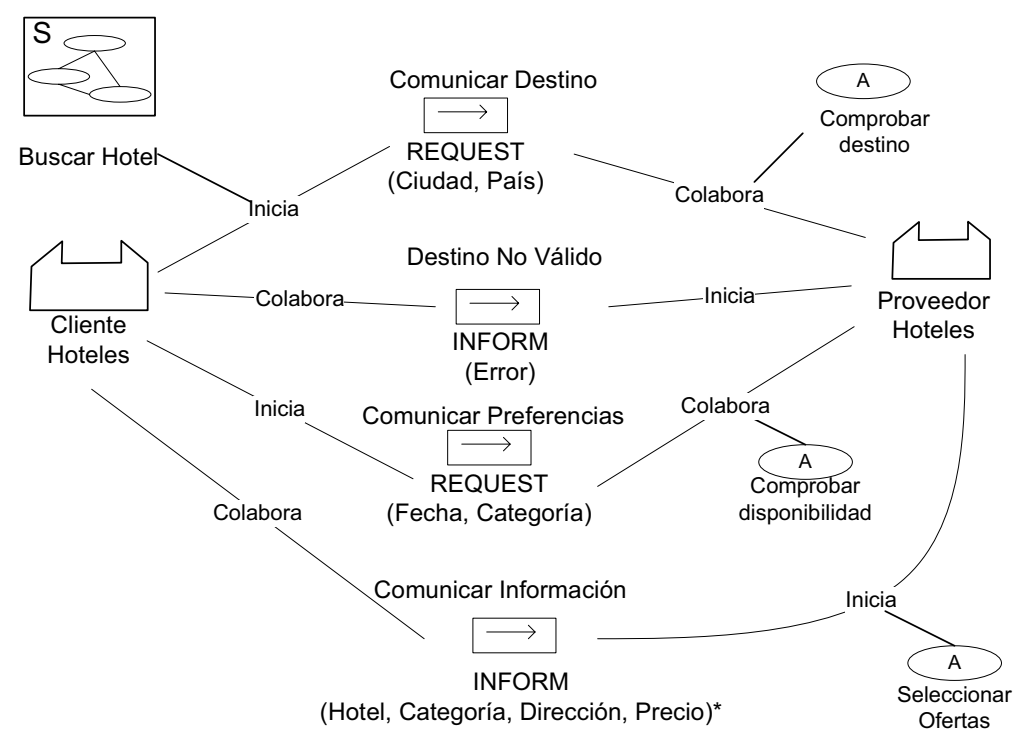

Figura 6.29: Diagrama de colaboración de la interacción Búsqueda Hotel. 


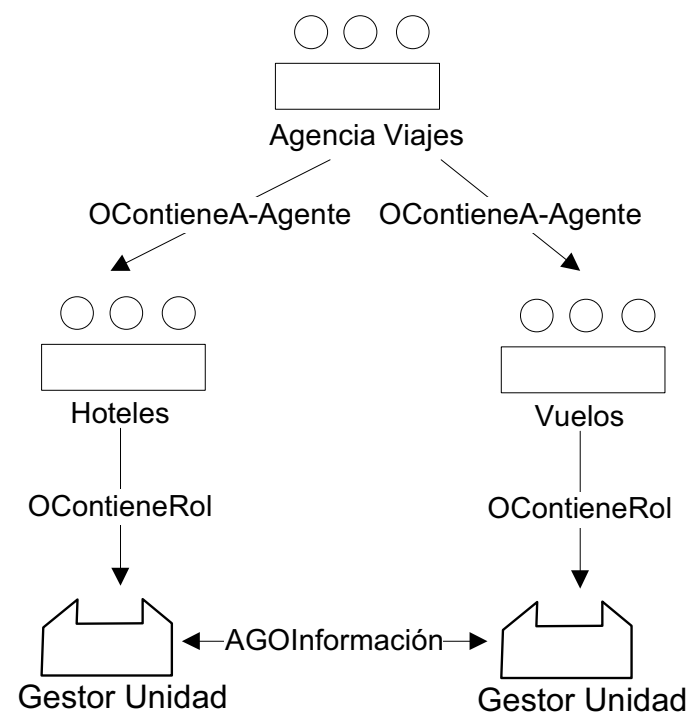

Figura 6.30: Diagrama de la vista social del modelo de organización para el sistema de agencia de viajes.

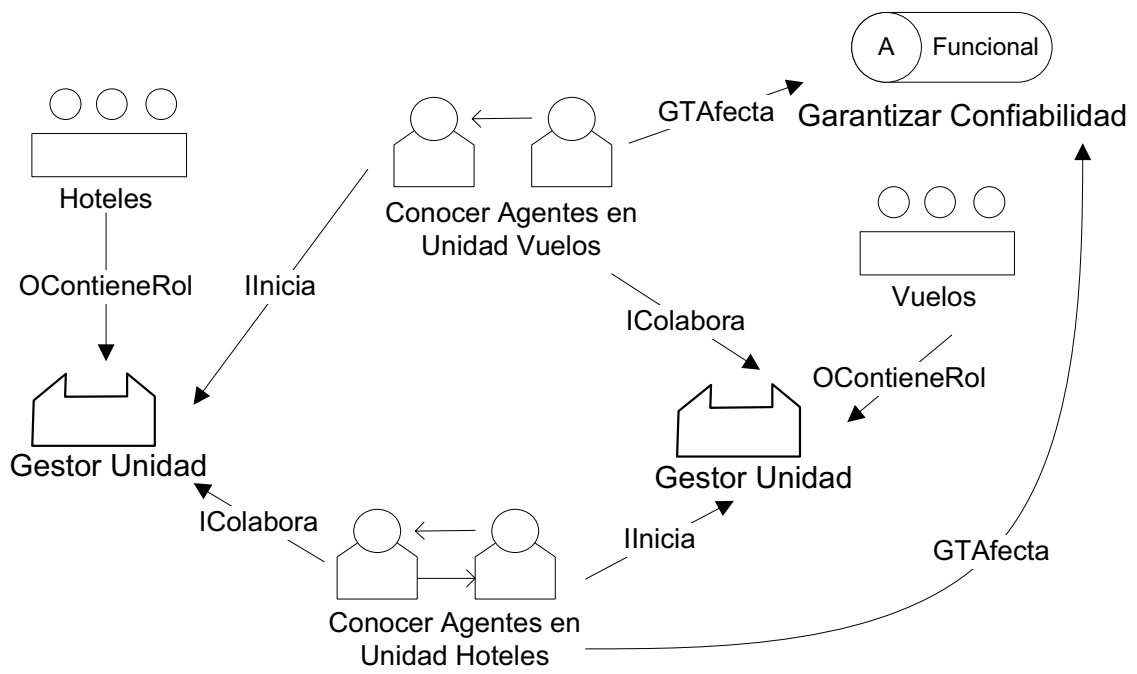

Figura 6.31: Diagrama del modelo de interaccion para las interacciones generadas por la relación AGOInformación entre los roles GestorUnidad. 
Una vez se ha realizado el análisis de los procesos de información y decisión, se procede a determinar la "apertura" del sistema, es decir, qué roles son accesibles por agentes externos y qué servicios necesitan ser publicitados para así atraer a agentes al sistema. Para ello se emplean las guías de la Fase F. Dinamicidad del sistema abierto.

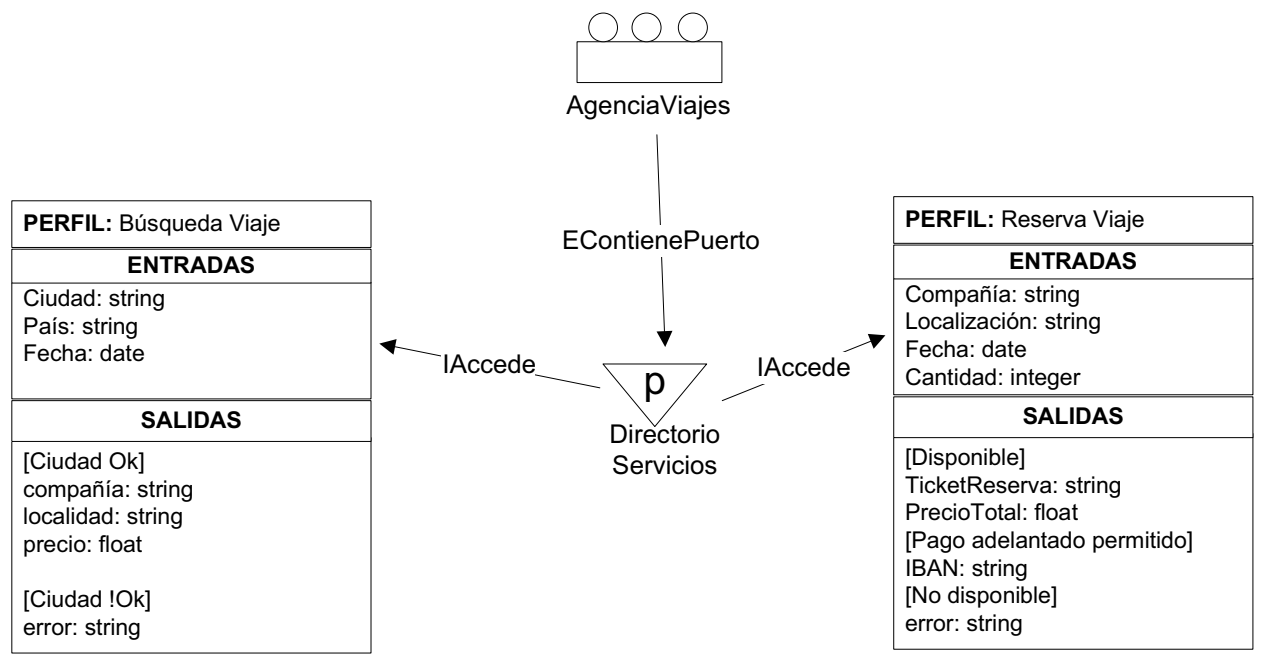

Figura 6.32: Diagrama del modelo de entorno para la publicitación de los servicios de AgenciaViajes.

En primer lugar se determina qué servicios, de los requeridos por la organización, podrán ser proporcionados no sólo por agentes propios del sistema (implementados por los desarrolladores del sistema), sino también por agentes externos.

En este caso, se requiere publicitar los servicios Buscar Viaje y Reservar Viaje, cuyo perfil se ha descrito lo suficientemente general para que todos aquellos agentes que trabajen en el dominio de los viajes sean atraídos al sistema. Para reflejar la publicitación de estos dos servicios, en la unidad organizativa AgenciaViajes se define la entidad Directorio Servicios, de tipo PuertoServicio (figura 6.32), a través de la cual se accede a los perfiles de estos servicios (relación IAccede).

De este modo, los agentes externos podrán obtener información sobre qué realiza cada servicio así como los roles implicados (roles de las relaciones 
WFUtiliza y WFProporciona). Si les interesa hacer uso del servicio, se registrarán en la unidad como clientes del mismo; mientras que si les interesa implementar su funcionalidad, entonces lo harán como proveedores.

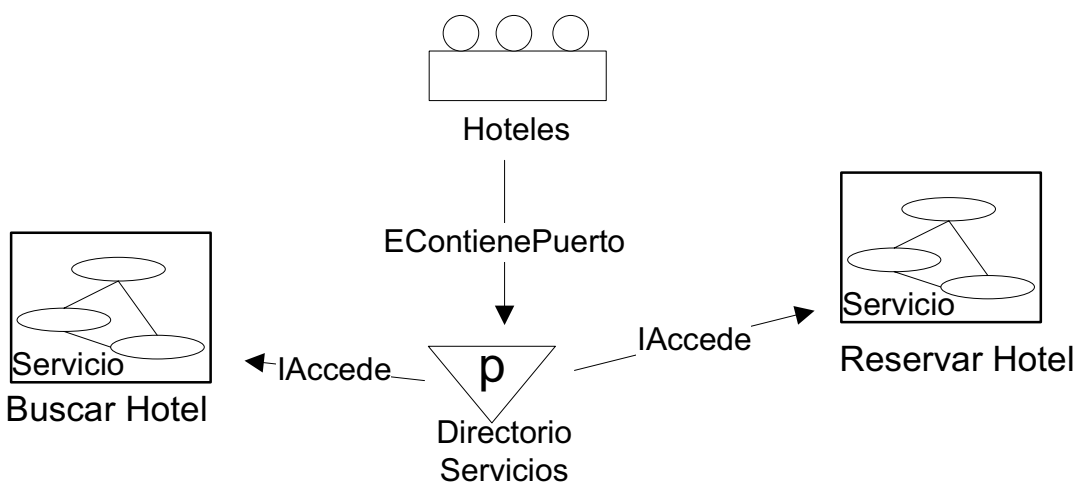

Figura 6.33: Diagrama del modelo de entorno para la publicitación de los servicios de la unidad Hoteles.

De forma similar, para cada unidad contenida en AgenciaViajes se define también su entidad PuertoServicio correspondiente (llamada Directorio Servicios), a través de la cual se registran los servicios propios de esa unidad, que sean publicitables. Por ejemplo, en la figura 6.33 se muestra el modelo de entorno para la unidad organizativa Hoteles. En este caso, los servicios publicitados no sólo tienen un perfil asociado, sino también una serie de A-Tareas, descritas en el modelo de actividad del servicio. Cuando un agente solicite la adquisición del rol provedorHoteles, se le informa tanto del perfil del servicio como del conjunto de tareas que debe implementar.

Por tanto, los roles cliente y proveedor (así como sus roles relación OHerenciaRol) son accesibles por agentes externos, requiriéndose un proceso de adquisición del rol. Por su parte, los roles Gestor Unidad y Cobrador se asocian a agentes internos, siendo no accesibles. En la figura 6.34 se muestra el modelo de organización (vista estructural y vista funcional, funcionalidad interna), indicando tanto los agentes externos (A-Agentes), los internos (Agentes), así como los roles que juegan.

Para las políticas de adquisición de roles, en la unidad AgenciaViajes el servicio AdquirirRol se limita a informar del perfil de los servicios generales 


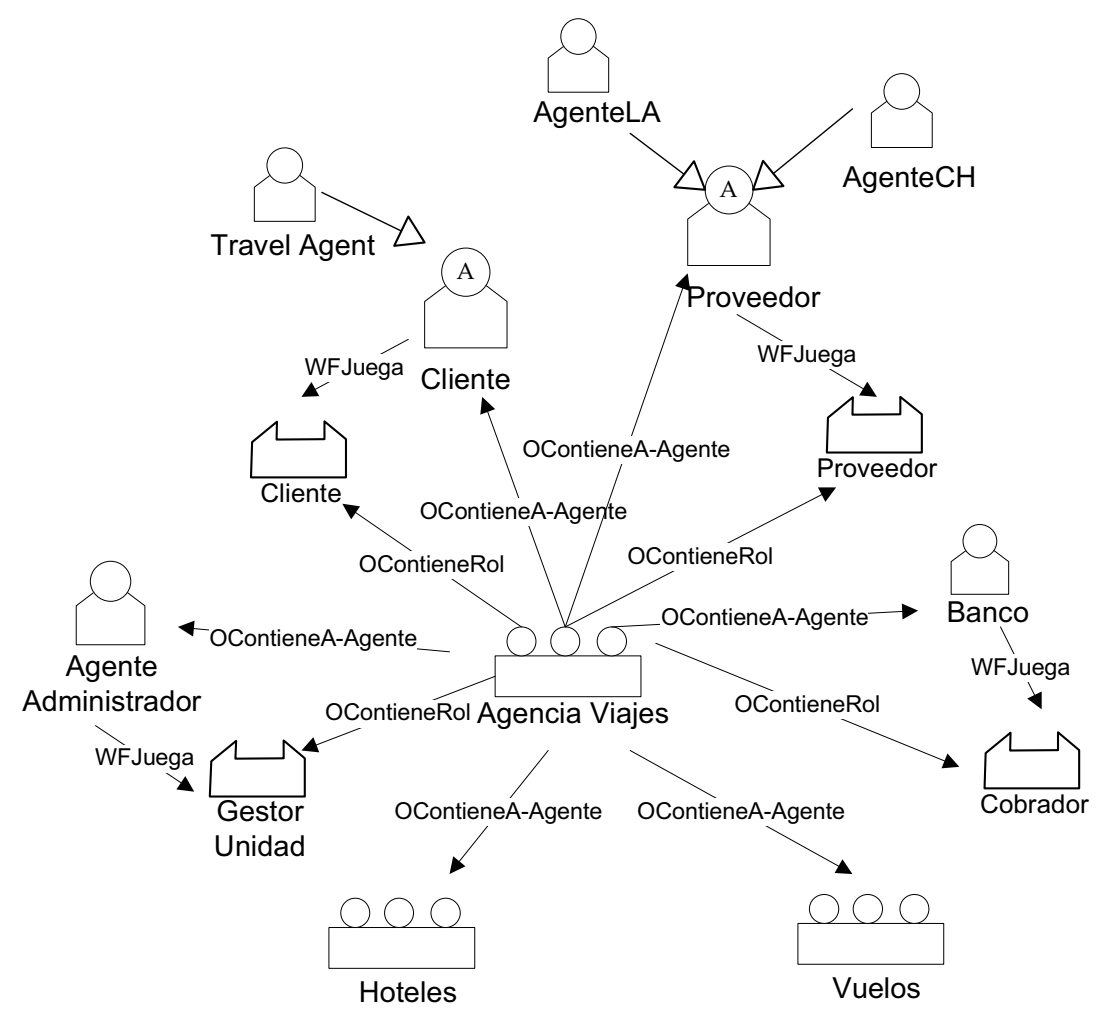

Figura 6.34: Diagrama actualizado del modelo de organización, en el que se muestran los agentes internos, externos y los roles que juegan.

del sistema (Buscar Viaje y Reservar Viaje).

Para las unidades internas, por ejemplo para la unidad Hoteles, el proceso difiere según se trate de un cliente o de un proveedor. Así, si un cliente desea registrarse dentro de esa unidad, se le informa de los perfiles y procesos de los servicios que puede utilizar y de las normas que le afectan. Sin embargo, si se trata de un proveedor, entonces se establece también un proceso de negociación del perfil y proceso asociado al servicio a ofrecer. En la figura 6.35 se muestra el diagrama del modelo de actividad para el servicio AdquirirRol de la unidad Hoteles; y en la figura 6.36 la descripción del flujo de tareas correspondiente, cuando se solicita el rol proveedorHoteles. 


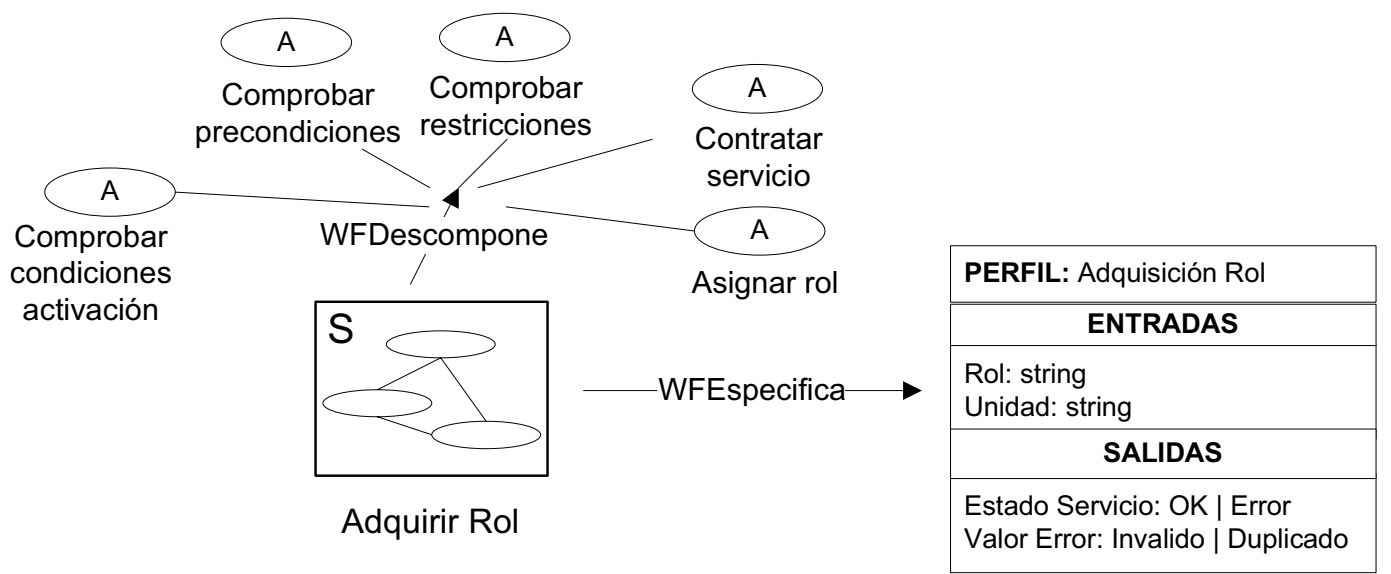

Figura 6.35: Diagrama del modelo de actividad para el servicio AdquirirRol.

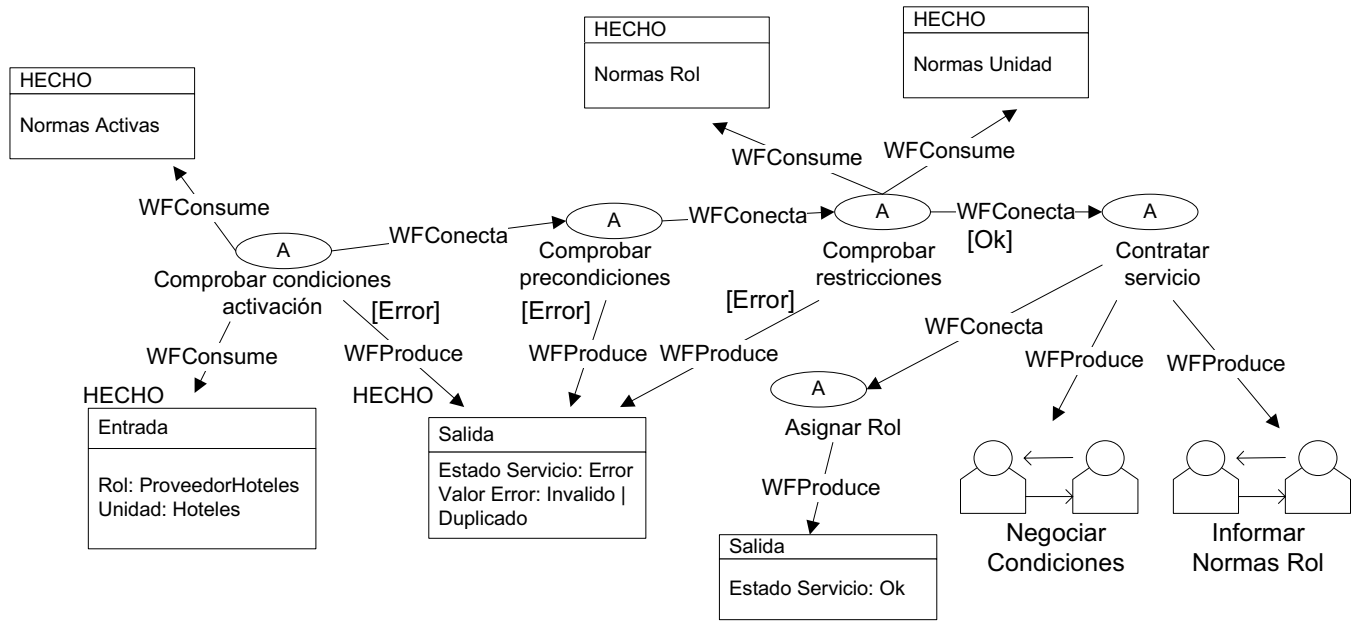

Figura 6.36: Diagrama del modelo de actividad para el servicio AdquirirRol. Descripción de su flujo de tareas al solicitarse el rol ProveedorHoteles en la unidad Hoteles. 
Respecto a las normas a definir, en este punto trataremos las normas relativas a la publicitación de los servicios y al control de la adquisición de los roles. En primer lugar, por cada servicio para el cual se desee captar proveedores, se debería asociar una norma que obligue a su unidad organizativa a registrarlo en un directorio de servicios. Estas normas las reasignamos a los agentes internos que juegan el rol Gestor Unidad y las implementaremos internamente como parte de sus acciones o tareas.

En segundo lugar, se obliga a los proveedores a registrar una funcionalidad asociada a cada uno de los servicios que, como mínimo, deben ofrecer. En nuestro caso, el rol proveedor tiene la obligación de proporcionar, como mínimo, el servicio de Buscar Información correspondiente. Además, se permite cierta negociación del perfil y de las actividades asociadas al servicio, pero siempre manteniendo la consistencia con los perfiles y tareas predefinidas. Como ejemplo, indicamos a continuación las normas asociadas a la funcionalidad mínima que los proveedores deben ofrecer, así como el control de la consistencia de los servicios que se registran.

\section{NormaFuncionalidadMínima:}

OBLIGED Proveedor REGISTER BuscarInformación PROFILE BusquedaInformación PROCESS ?p BEFORE deadline

\section{NormaConsistenciaServicioHotel:}

FORBIDDEN ProveedorHoteles REGISTER BuscarHotel

PROFILE ?ProfileH PROCESS ?TaskH

IF NOT( BusquedaHotel $\subseteq$ ?ProfileH AND BusquedaHotelProcess $\subseteq$ ?TaskH)

La última actividad propuesta en la Fase F. Dinamicidad del sistema abierto implica la definición del modelo de agente para los agentes propios del sistema. En nuestro caso (figura 6.34), además de los agentes internos Administrador y Banco, definimos agentes de tipo TravelAgent que actúan como clientes; agentes de tipo AgenteCH, que actúan como cadenas hoteleras; y agentes de tipo AgenteLA, que representan a líneas aéreas. Como 
ejemplo, en la figura 6.37 se muestra el modelo de agente del AgenteCH, el cual es capaz de ofrecer los servicios Buscar Hotel, Reservar Hotel y Solicitar Tarjeta Cliente.

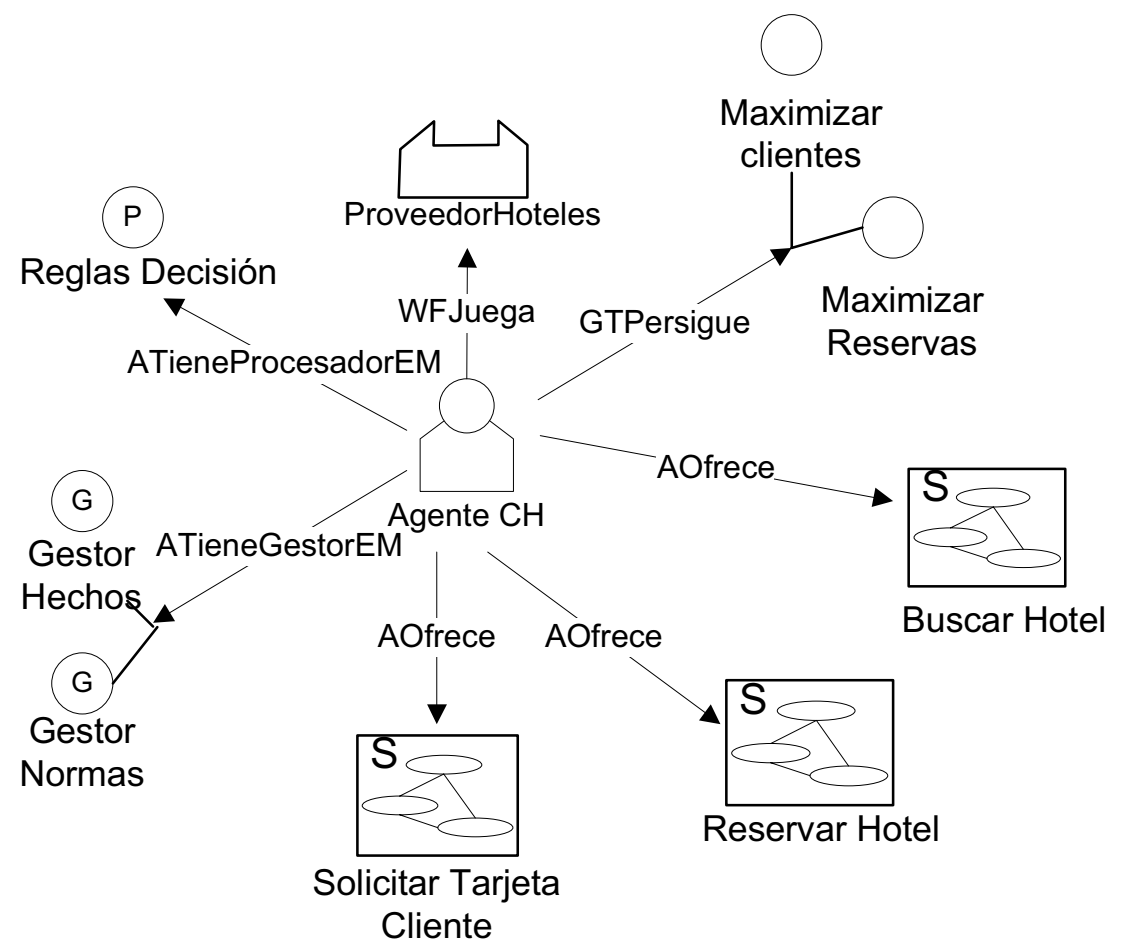

Figura 6.37: Diagrama del modelo de agente para el AgenteCH, que representa a una cadena hotelera.

Posteriormente, en la Fase G. Sistemas de medición, evaluación y control se procede a establecer las normas relativas al control de la secuencia de las invocaciones de los servicios, así como a la calidad esperada de sus resultados. En el diseño de la estructura organizativa se había establecido que resulta primordial en este sistema realizar una normalización de tareas. Por tanto, se establecen normas para controlar que no se soliciten reservas si antes no se ha efectuado una búsqueda; o que no se realicen pagos si antes no se ha reservado esa localidad. A continuación se muestran ejemplos de las normas a definir. 


\title{
NormasOrdenReserva:
}

\author{
OBLIGED ?a:Customer REQUEST BuscarViaje \\ BEFORE ?a REQUEST ReservarViaje
OBLIGED ?a:Customer REQUEST ReservarViaje
BEFORE ?a REQUEST PagarViaje

Respecto a la normalización de resultados, la calidad del servicio debería atender al enfoque de "calidad como satisfacción de las expectativas del cliente". Para ello sería necesario añadir una nueva funcionalidad al sistema (ej. Recomendar Hotel, Recomendar Compañía), a través de la cual los clientes pudieran indicar en qué grado los hoteles, aerolíneas, vuelos, etc., sugeridos por el sistema han satisfecho sus necesidades. Esta información serviría después, por un lado, para que los proveedores mejorasen su proceso de selección o filtrado de los viajes. Por otro, permitiría al rol GestorUnidad establecer un mecanismo para expulsar a aquellos proveedores cuyos productos no hayan sido de agrado para un número determinado de clientes. Por simplicidad, en este caso de estudio no entraremos a efectuar ningún tipo de normalización de resultados.

Finalmente, en la Fase H. Sistema de recompensas, procedemos a analizar el comportamiento global que deseamos potenciar entre los agentes del sistema. En este caso, como los clientes y proveedores podrán ser agentes externos, interesa fomentar que éstos se unan y permanezcan en el sistema. Para ello se podrá hacer uso de recompensas individuales o bien de recompensas de sistema. Por simplicidad del sistema, en nuestro caso de estudio no se implementará ningún tipo de sistema de recompensas, aunque a continuación se comentan las ideas generales a considerar.

Con la recompensa individual se fomenta principalmente el comportamiento adecuado de los individuos, e incluso que trabajen sobre unos niveles mínimos. Por tanto, resultaría adecuada emplearla sobre los agentes proveedores, recompensando en base a la cantidad de reservas que realicen y al grado de satisfacción que los clientes muestren por ellas. El modo de 
recompensarles podría ser mediante gratificación monetaria o bien estableciendo grupos dinámicos (tipo coalición), en los que estuvieran los mejores proveedores y con los que los clientes contactasen prioritariamente.

La recompensa individual también se podría aplicar a los clientes. Por ejemplo, aquellos que realicen muchas reservas serían considerados clientes preferentes, sobre los cuales aplicar más ofertas y reducción de precios.

Con la recompensa de sistema se ofrecen gratificaciones generales por el hecho de pertenecer a la organización. En este caso, se ofrecerían ofertas y reducción de precios a los clientes, no ya por las reservas realizadas, sino por la cantidad de servicios que utilicen (lo que sería un indicativo del tiempo que permanecen en el sistema de forma activa).

\subsection{Conclusiones}

En este capítulo se ha mostrado la aplicabilidad de la guía metodológica propuesta en el capítulo anterior para dar soporte al proceso de análisis y diseño de un sistema multiagente abierto. En concreto, se ha realizado el análisis de requisitos, el diseño de la estructura organizativa y el diseño de la dinámica de la organización de un caso de estudio basado en un sistema de agencia de viajes. Para ello se han empleado las distintas guías y fases propuestas en el capítulo anterior, generándose distintos diagramas de modelos del sistema. Estos diagramas emplean la sintaxis y semántica definida en el Modelo de Organización propuesto en el capítulo 4, instanciando así los meta-modelos diseñados en dicho capítulo.

Con este ejemplo se constata que los conceptos propios de las organizaciones humanas son aplicables a los sistemas multi-agente, según se indican en las fases-guía propuestas.

Por último, cabe indicar que la implementación del sistema debería realizarse en una plataforma de agentes que ofreciera soporte a los conceptos de organización expresados en los modelos. Como se comentó en el capítulo 3 , existen pocas plataformas que tengan en cuenta todos los conceptos 
planteados en este trabajo. No obstante, cualquiera de las plataformas indicadas en ese capítulo pueden servir como base para la implementación del sistema. 



\section{Capítulo 7}

\section{Conclusiones y Trabajos Futuros}

En este último capítulo se recogen las principales conclusiones de este trabajo, las líneas futuras de investigación, así como las publicaciones relacionadas, producidas como resultado del trabajo de investigación realizado.

\subsection{Aportaciones}

De acuerdo a los objetivos que nos planteamos en un principio, las principales aportaciones de esta tesis son:

- Diseño de un Modelo de Organizaciones, basado en los conceptos de unidad organizativa, servicio, norma y entorno.

- Obtención de una Guía Metodológica, para el análisis y diseño de sistemas multi-agente abiertos.

El concepto de organización se ha empleado recientemente para modelar la coordinación de los agentes en los sistemas abiertos y asegurar el orden social en las aplicaciones de estos sistemas [Dignum y Dignum, 2006]. Las organizaciones de agentes están basadas, en gran medida, en las organizaciones de las sociedades humanas. Por tanto, en nuestro trabajo hemos partido 
de la hipótesis de que la Teoría de la Organización nos proporcionará determinadas guías que faciliten el diseño de organizaciones de agentes.

Para ello se ha realizado un profundo análisis de las características de las organizaciones, tanto desde el punto de vista de los sistemas humanos como de los sistemas multiagente. De este análisis se han definido los factores relevantes a tener en cuenta para el diseño de las organizaciones, en concreto, la estructura, funcionalidad, normalización, dinamicidad y entorno. Además, se han revisado las principales estructuras organizativas empleadas, tanto en el dominio humano como en los sistemas multiagente, para establecer así una comparativa entre ellas y definir un conjunto de patrones estructurales.

Por otro lado, se ha llevado a cabo un estudio del arte de las metodologías y plataformas MAS, analizando los aspectos organizativos que contemplan. Dicho estudio ha permitido determinar la necesidad de una descripción detallada de los conceptos organizativos del sistema, por ejemplo con el empleo de meta-modelos; así como la utilización de patrones estructurales.

Por tanto, se ha realizado un modelado de organizaciones de agente, basado principalmente en los conceptos de unidad organizativa, servicio, norma y entorno. Para ello se han extendiendo los meta-modelos de la metodología ANEMONA [Giret, 2005]. Esta metodología proporciona los conceptos y primitivas necesarios para definir la organización del sistema (en concreto, los roles existentes, agrupaciones de agentes y sus relaciones); su funcionalidad (en base a tareas y objetivos); las interacciones de los agentes; el entorno (recursos y aplicaciones); así como los agentes concretos que lo componen.

En nuestra propuesta se han extendido estos meta-modelos con nuevas entidades y relaciones que permiten integrar los conceptos de unidad organizativa, servicio y norma; así como los factores organizativos extraídos del análisis de las organizaciones. De este modo, el meta-modelo de organización describe los componentes del sistema y sus relaciones, a través de cuatro vistas: estructural, funcional, dinámica y social. El meta-modelo de actividad detalla los servicios ofrecidos y requeridos, sus tareas y objetivos. 
El meta-modelo del entorno captura las aplicaciones y recursos del sistema, así como las percepciones y efectos de los agentes sobre su entorno, que pueden ser controladas por la organización a través de los puertos del entorno. El meta-modelo de agente detalla las responsabilidades concretas de los agentes y su funcionalidad interna. El meta-modelo de interacción especifica las interacciones existentes entre los agentes, así como la invocación de los servicios. Finalmente, el meta-modelo normativo expresa las reglas de la organización, correlacionando las tareas de los agentes con los objetivos normativos que deben cumplir.

Por otro lado, se han modelado los patrones estructurales identificados en el análisis de las organizaciones. Para ello se han instanciado los meta-modelos anteriores, definiendo un conjunto de diagramas o patrones de diseño que facilitan la comprensión de las relaciones existentes entre los componentes de cada tipo de organización.

Finalmente, tomando como base la Teoría de la Organización, se ha adaptado una secuencia-guía de diseño de organizaciones humanas, para así permitir el análisis y diseño de organizaciones de agentes. De este modo, se ha definido un conjunto de fases y guías para el análisis de requisitos, el diseño de la estructura organizativa y el diseño de la dinámica de la organización.

En concreto, la guía metodológica ofrece un procedimiento iterativo que permite: (i) especificar la misión del sistema; (ii) analizar las tareas y procesos requeridos, en base a servicios y productos; (iii) determinar las dimensiones de la organización (departamentalización, especialización, centralización, coordinación y normalización); (iv) seleccionar la estructura más adecuada, de acuerdo a dichas dimensiones; (v) identificar los procesos de información y decisión; (vi) especificar las características abiertas del sistema (funcionalidad a publicitar; control sobre agentes externos); (vii) determinar los mecanismos (normas) de control de los comportamientos de los agentes; y (viii) especificar el sistema de recompensas a aplicar para fomentar los comportamientos que más interesan a la organización. 
En la guía metodológica propuesta se hace uso de los meta-modelos de organización, así como de los patrones de diseño de las estructuras de organización definidos en este trabajo. Esta guía se ha aplicado en dos casos de estudio distintos: un sistema de información personalizada; y un sistema de agencia de viajes. En ambos casos, la guía ha permitido realizar el análisis y diseño del sistema en base a conceptos organizativos.

Por tanto, resumimos las aportaciones de esta tesis como sigue:

- Se ha realizado un análisis de las características relevantes de las organizaciones (humanas o de agentes).

- Se ha llevado a cabo una comparativa entre las organizaciones de agentes y las organizaciones humanas, identificando sus similitudes principales.

- Se ha realizado un estudio comparativo de las metodologías y plataformas MAS, centrado principalmente en el punto de vista de las organizaciones.

- Se han extendido los meta-modelos de INGENIAS y ANEMONA para incorporar las nociones de unidad organizativa, servicio y norma; se ha extendido la abstracción del entorno; y se han incluido los aspectos dinámicos y normativos al modelado de la organización.

- Se han definido patrones de organización que cubren distintas topologías organizativas.

- Se ha diseñado una guía metodológica para el diseño de sistemas multiagente abiertos, desde la perspectiva de las organizaciones humanas.

- Se ha diseñado un conjunto de guías o plantillas para la discretización de los elementos relevantes de la organización.

- Se ha aplicado la secuencia-guía en dos casos de estudio: un sistema de información personalizada y un sistema de agencia de viajes. 


\subsection{Líneas Futuras de Investigación}

Destacamos tres líneas futuras de investigación: (i) arquitectura abstracta organizativa; (ii) herramienta gráfica de soporte del modelado de la organización; y (iii) modelos de sistemas de recompensas.

En la primera línea de investigación, en el marco del proyecto THOMAS (comentado en la introducción de la tesis), se está trabajando en el desarrollo de un arquitectura de agentes abstracta que permita el modelado de sistemas organizativos abiertos. La arquitectura estará constituída por los siguientes componentes principales: (i) Service Facilitator (SF), mecanismo para dar soporte al registro y descubrimiento de servicios; (ii) Organization Management System (OMS), encargado de la gestión del ciclo de vida de las organizaciones; y (iii) Platform Kernel (PK), encargado de las comunicaciones y la gestión del ciclo de vida de los agentes.

En la plataforma abstracta de THOMAS se podrán definir unidades organizativas, con una estructura interna determinada. Para estas unidades se podrán establecer las normas que controlen los comportamientos de sus entidades, así como los servicios que se requieren y se ofrecen en ellas.

En la segunda línea de investigación abierta, se desea obtener herramientas gráficas que den soporte al modelado de la organización y faciliten el diseño del sistema, además de ofrecer plantillas de agente para una implementación más rápida y sencilla. En este sentido, también en el marco del proyecto THOMAS, se está trabajando en el desarrollo de una herramienta gráfica basada en el software de Eclipse. Dicha herramienta permitirá generar los diferentes diagramas que cubren los modelos descritos en este trabajo. Incluirá también los patrones de organización propuestos, así como los distintos documentos asociados a cada fase de la secuencia-guía.

Finalmente, la tercera línea de investigación tiene como objetivo el desarrollo de modelos concretos de sistemas de recompensas, para así ofrecer al diseñador un conjunto de métodos específicos que le faciliten la aplicación de los sistemas indicados en las guías.

Estas tres líneas de investigación se integran también en el proyecto CONSOLIDER Agreement Technologies, en el cual participa mi grupo de 
investigación GTI-IA de la Universidad Politécnica de Valencia, junto con la Universidad Rey Juan Carlos y el centro de investigación IIA-CSIC. Este proyecto aborda el desarrollo de modelos, entornos de trabajo, métodos y algoritmos para la construcción de sistemas computacionales distribuidos abiertos y de gran escala. Se basa en el concepto de acuerdos (agreements) entre agentes computacionales. Entre los objetivos definidos en dicho proyecto, cabe destacar la especificación de sistemas normativos, el desarrollo de arquitecturas de agente que gestionen conceptos organizativos, así como la implementación de mecanismos para la formación eficiente de grupos organizativos.

\subsection{Publicaciones Relacionadas con la Tesis}

En esta sección presentamos las publicaciones relacionadas con esta tesis, que comprenden artículos en revistas, en congresos nacionales e internacionales, así como capítulos de libro.

- E. Argente, V. Julián, V. Botti. MAS Modelling based on Organizations. Proc. Agent Oriented Software Engineering AOSE (in AAMAS'08). pp. 1-12. (2008)

- E. Garcia, E. Argente, A. Giret. Issues for Organizational Multiagent Systems Development. Proc. 6th International Workshop from Agent Theory to Agent Implementation AT2AI-6 (in AAMAS'08). pp. 59-65. (2008)

- J. Molina, J. Corchado, J. Bajo, E. Argente, J. Botía, S. Ilarri, V. Botti, E. Corchado, V. Fuentes, M. González, A. Illarramendi, V. Julián, E. Mena, N. Sánchez. Issues in Multi-Agent Systems. Capítulo 2: Ubiquitous Computing for Mobile Environments. Ed. Whitestein Technologies. ISBN: 978-3-7643-8542-3. Vol. 1, pp.33-58. (2008)

- E. Argente, J. Palanca, G. Aranda, V. Julian, V. Botti, A. GarciaFornes, A. Espinosa. Supporting Agent Organizations. Multi-Agent 
Systems and Applications. Springer LNCS, ISSN: 0302-9743. Vol.4696, pp.236-245. (2007)

- N. Criado, E. Argente, V. Julián, V. Botti. Organizational Services for SPADE agent platform. Proc. IWPAAMS'07. Ed. Universidad de Salamanca. ISBN: 978-84-611-8858-1. Vol.1, pp.31-40 (2007)

- E. Argente, V. Julian, V. Botti. Multi-Agent System Development based on Organizations. Electronic Notes in Theoretical Computer Science. Elsevier. ISSN: 1571-0661. Vol. 150, pp.55-71. (2006)

- S. Valero, E. Argente, A. Giret, V. Julian, V. Botti. Goodness and Lacks of MAS Methodologies for Manufacturing Domains. Springer LNCS 3690, pp. 645-648. (2005)

- E. Argente. A Proposal for an Organizational-Oriented MAS Methodology. Proc. Autonomous Agents and Multi Agent Systems AAMAS'05. Ed. ACM Press. ISBN: 1-59593-094-9. Vol.III, pp.1370-1370. (2005)

- E. Argente, V. Julián, S. Valero, V. Botti. Towards an Organizational MAS Methodology. Proc. CCIA'05. Recent Advances in Artificial Intelligence Research and Development. Frontiers in Artificial Intelligence and Application. Ed. IOS Press. ISBN: 1-58603-466-9. pp.397-404. (2005)

- E. Argente, V. Julián, S. Valero, V. Botti. Aplicación de la Teoría de Organizaciones al desarrollo de Sistemas Multi-agente. Proc. CAEPIA'05. Ed. Universidad de Santiago. ISBN: 84-96474-13-5. Vol.I, pp.279-288 (2005)

- E. Argente, V. Julián, V. Botti. From Human to Agent Organizations. Proc. First International Workshop on Coordination and Organization (CoOrg'05). Eds. G. Boella and Van der Torre. pp.1-11 (2005) 
- E. Argente, A. Giret, S. Valero, V. Julián, V. Botti. Survey of MAS Methods and Platforms focusing on organizational concepts. Proc. CCIA'05. Recent Advances in Artificial Intelligence Research and Development. Frontiers in Artificial Intelligence and Application. ISBN: 1-58603-466-9. pp.309-316. (2004) 


\section{Bibliografía}

[Albors y Martinez, 2002] Albors, J., y Martinez, A. 2002. Comportamiento Organizativo y Gestión. Ed. Universidad Politecnica de Valencia.

[Argente et al., 2004] Argente, E.; Giret, A.; Valero, S.; Julian, V.; y Botti, V. 2004. Survey of MAS Methods and Platforms focusing on organizational concepts. In Recent Advances in Artificial Intelligence Research and Development, volume 113 of Frontiers in Artificial Intelligence and Applications, 309-316. IOS Press.

[Argente et al., 2005] Argente, E.; Julian, V.; y Botti, V. 2005. From Human to Agent Organizations. In Proc. 1st Int. Workshop on Coordination and Organization.

[Argente et al., 2006] Argente, E.; Julian, V.; y Botti, V. 2006. Multi-agent system development based on organizations. Electronic Notes in Theoretical Computer Science 150(3):55-71.

[Bauer et al., 2001] Bauer, B.; Müller, J.; y Odell, J. 2001. Agent UML: A Formalism for Specifying Multiagent Interaction. In Agent-Oriented Software Engineering, 91-103. Springer.

[Bellifemine et al., 1999] Bellifemine, F.; Poggi, A.; y Rimassa, G. 1999. JADE: A FIPA-compliant agent framework. In Proc. of PAAM, $97-108$.

[Boella y der Torre, 2003] Boella, G., y der Torre, L. V. 2003. An architecture of a normative system: counts-as conditionals, obligations and 
permissions. In Proc. 5th International Joint Conference on Autonomous Agents and Multiagent Systems, 229-231. ACM Press.

[Boella y der Torre, 2004] Boella, G., y der Torre, L. V. 2004. Regulative and Constitutive Norms in Normative Multi-Agent Systems. In Proc. of KS, 255-265. AAAI Press.

[Brooks y Durfee, 2000] Brooks, C., y Durfee, E. 2000. Congregating and market formation. In Proc. 1st Int. Joint Conference on Autonomous Agents and Multiagent Systems, 96-103. ACM Press.

[Brooks y Durfee, 2003] Brooks, C., y Durfee, E. 2003. Congregation formation in multiagent systems. Autonomous AGents and MulitAGent Systems 7:145-170.

[Bussmann, 1998] Bussmann, S. 1998. Agent-oriented programming of manifacturing control tasks. In Proc. 3rd Int. Conference on MultiAgent Systems (ICMAS 98), 57-63.

[Caire et al., 2002] Caire, G.; Coulier, W.; Garijo, F.; Gomez, J.; Pavon, J.; Leal, F.; Chainho, P.; Kearney, P.; Stark, J.; Evans, R.; y Massonet, P. 2002. Agent-oriented analysis using MESSAGE/UML. Lecture Notes in Computer Science 2222:119-125.

[Casillas y Marti, 2004] Casillas, T., y Marti, J. 2004. Guía para la creación de empresas. Madrid: Fundación EOI.

[Castells, 2003] Castells, P. 2003. La Web Semántica. In C. Bravo, M. A. R., ed., Sistemas Interactivos y Colaborativos en la Web, 195212. Ediciones de la Universidad de Castilla - La Mancha.

[Castro et al., 2001] Castro, J.; Kolp, M.; y Mylopoulos, J. 2001. A requirements-driven software development methodology. In Conference on Advanced Information Systems Engineering.

[Cervenka y Trencansky, 2007] Cervenka, R., y Trencansky, I. 2007. AML. 
The Agent Modeling Language. Whitestein Series in Software Agent Technologies and Autonomic Computing. Birkauser Verlag.

[Coleman et al., 1994] Coleman, D.; Arnold, P.; Bodoff, S.; Dollin, D.; Gilchrist, H.; Hayes, F.; y Jeremas, P. 1994. Object-Oriented Development: The FUSION Method. Prentice-Hall International, Hemel Hampstead U.K.

[Conte et al., 1999] Conte, R.; Falcone, R.; y Sartor, G. 1999. Agents and norms: How to fill the gap? Artificial Intelligence and Law 7(1):115.

[Daft, 1998] Daft, R. 1998. Teoría y diseño organizacional. Mexico: International Thomson, 6 edition.

[Dastani et al., 2003] Dastani, M.; Dignum, V.; y Dignum, F. 2003. RoleAssignment in Open Agent Societies. In Proc. 2nd. Int. Joint Conference on Autonomous Agents and Multi-agent Systems, 489-496.

[Davidsson, 2001] Davidsson, P. 2001. Categories of Artificial Societies. In Proc. 2nd Int. Workshop Engineering Societies in the Agents World, 1-9.

[Decker et al., 1995] Decker, K.; Lesser, V.; Prasad, N.; y Wagner, T. 1995. MACRON: An Architecture for Multi-Agent Cooperative Information Gathering. In Proc. CIKM Workshop on Intelligent Information Agents.

[Dellarocas y Klein, 1999] Dellarocas, C., y Klein, M. 1999. Civil agent societies: Tools for inventing open agent-mediated electronic marketplaces. In Proc. ACM Conference on Electronic Commerce (EC99).

[Dellarocas y Klein, 2001] Dellarocas, C., y Klein, M. 2001. Contractual agent societies: Negotiated shared context and social control in open multi-agent systems. Social Order in Multi-Agent Systems 113-133. 
[den Broek et al., 2005] den Broek, E. V.; Jonker, C.; Sharpanskykh, A.; Treur, J.; y pI. Yolum. 2005. Formal modeling and analysis of organizations. In From Organizations To Organization Oriented Programming in MAS.

[Dignum et al., 2001] Dignum, V.; Weigand, H.; y Xu, L. 2001. Agent Societies: towards frameworks-based design. In Proc. 2nd Workshop on Agent-Oriented Software Engineering, Autonomous Agents.

[Dignum et al., 2002] Dignum, V.; Meyer, J.; Wiegand, H.; y Dignum, F. 2002. An organization-oriented model for agent societies. In Proc. Int. Workshop on Regulated Agent-Based Social Systems (RASTA02).

[Dignum y Dignum, 2006] Dignum, V., y Dignum, F. 2006. A landscape of agent systems for the real world. Technical Report 44-CS-2006-061, Institute of Information and Computing Sciences, Utrecht University.

[Dignum y Dignum, 2007] Dignum, V., y Dignum, F. 2007. A logic for Agent Organizations. In Proc. Formal Approaches to Multi-Agent Systems (FAMAS), in Multi-Agent Logics, Languages and Organisations Federated Workshops (MALLOW), 83-100.

[Dignum, 2003] Dignum, V. 2003. A model for organizational interaction: based on agents, founded in logic. Tesis Doctoral, Utrecht University.

[Dogac et al., 2004] Dogac, A.; Kabak, Y.; Laleci, G.; Sinir, S.; Yildiz, A.; Kirbas, S.; y Gurcan, Y. 2004. Semantically Enriched Web Services for the Travel Industry. ACM Sigmod Record 33(3).

[Esteva et al., 2001a] Esteva, M.; Padget, J.; y Sierra, C. 2001a. Formalizing a language for institutions and norms. Intelligent Agents VIII, Springer Verlag 2333:348-366. 
[Esteva et al., 2001b] Esteva, M.; Rodriguez, J.; Sierra, C.; Garcia, P.; y Arcos, J. 2001b. On the formal Specification of Electronic Institutions. Agent Mediated Electronic Commerce 1991:126-147.

[Esteva et al., 2004] Esteva, M.; Rosell, B.; Rodriguez-Aguilar, J. A.; y Arcos, J. L. 2004. AMELI: An agent-based middleware for electronic institutions. In 3rd Int. Joint Conference on Autonomous Agents and Multi-agent Systems, 236-243.

[Ferber et al., 2003] Ferber, J.; Gutkenecht, O.; y Michel, F. 2003. From agents to organizations : an organizational view of multi-agent systems. In Proc. AAMAS03 - Agent-Oriented Software Engineering Workshop (AOSE).

[Ferber y Gutknetch, 1998] Ferber, J., y Gutknetch, O. 1998. Aalaadin: A meta-model for the analysis and design of organizations in multiagent systems. In Proc. 3rd Int. Conference of Multi-Agent Systems (ICMAS-98), 128-135.

[Fischer, 1999] Fischer, K. 1999. Agent-based design of holonic manufacturing systems. Journal of Robotics and Autonomous Systems.

[Fox, 1981] Fox, M. 1981. An organizational view of distributed systems. IEEE Trans. on System, Man and Cybernetics 11:70-80.

[Galbraith, 1977] Galbraith, J. 1977. Organization Design . AddisonWesley.

[Garcia-Camino et al., 2005] Garcia-Camino, A.; Noriega, P.; y RodriguezAguilar, J. 2005. Implementing Norms in Electronic Institutions. In Proc. $A A M A S^{\prime} 05,667-673$.

[Gasser, 2001] Gasser, L. 2001. Perspectives on organizations in multiagent systems. In Luck, M.; Marik, V.; Stepankova, O.; y Trappl, 
R., eds., Multi-agent Systems and Applications. 9th ECCAI Advanced Course, EASSS 2001, Lecture Notes in Computer Science, 1-16. Springer.

[Gateau et al., 2005] Gateau, B.; Boissier, O.; Khadraoui, D.; y Dubois, E. 2005. MOISE-Inst: An Organizational model for specifying rights and duties of autonomous agents. In der Torre, L. V., y Boella, G., eds., 1st International Workshop on Coordination and Organisation.

[Giorgini et al., 2003] Giorgini, P.; Kolp, M.; y Mylopoulos, J. 2003. Multiagent architectures as organizational structures. Journal of Autonomous Agents and Multi-Agent Systems, Kluwer Academic Publishers.

[Giret, 2005] Giret, A. 2005. ANEMONA: Una metodología multi-agente para sistemas holónicos de fabricación. Tesis Doctoral, Universidad Politécnica de Valencia.

[Giunchiglia et al., 2002] Giunchiglia, F.; Mylopoulos, J.; y Perini, A. 2002. The Tropos software development methodology: Processes, models and diagrams. In Proc. Workshop on Agent Oriented Software Engineering (AOSE-2002), 63-74.

[Gomez, 2002] Gomez, J. J. 2002. Modelado de Sistemas Multi-Agente. Tesis Doctoral, Universidad Complutense de Madrid.

[Gomez, 2003] Gomez, J. 2003. Metodologías para el desarrollo de sistemas multi-agente. Revista Iberoamericana de Inteligencia Artificial 18:51-63.

[Gonzalez-Palacios y Luck, 2007] Gonzalez-Palacios, J., y Luck, M. 2007. Towards compliance of agents in open multi-agent systems. In Software Engineering for Multi-Agent Systems V, Lecture Notes in Computer Science. Springer. 
[Grossi et al., 2005] Grossi, D.; Dignum, F.; Dastani, M.; y Royakkers, L. 2005. Fundations of organizational structures in multiagent systems. In Proc. Fourth International Joint Conference on Autonoumous Agents and Multi Agent Systems, AAMAS05, 690-697. ACM.

[Guzmán, 1983] Guzmán, I. 1983. Reflexiones en torno al Orden Social. México: Jus.

[Hodge et al., 2003] Hodge, B. J.; Anthony, W.; y Gales, L. 2003. Teoría de la Organización: un enfoque estrategico. Pearson Educación.

[Horling et al., 2003] Horling, B.; Mailler, R.; Shen, J.; Vincent, R.; y Lesser, V. 2003. Using Autonomy, Organizational Design and Negotiation in a Distributed Sensor Network. In Distributed Sensor Networks: A multiagent perspective, 139-183. Kluwer Academic Publishers.

[Horling y Lesser, 2004] Horling, B., y Lesser, V. 2004. A survey of multiagent organizational paradigms. The Knowledge Engineering Review 19:281-316.

[Howden et al., 2001] Howden, N.; Ronnquist, R.; Hodgson, A.; y Lucas, A. 2001. JACK intelligent agents: Summary of an Agent Infrastructure. In Proc. 5th Int. Conference on Autonomous Agents.

[Hubner et al., 2002] Hubner, J.; Sichman, J.; y Boissier, O. 2002. A model for the structural, functional, and deontic specification of organizations in mulitagent systems. In Bittencourt, G., y Ramalho, G., eds., 16th Brazilian Symposium on Artificial Intelligence (SBIA02), volume 2507 of Lecture Notes in Artificial Intelligence, 118-128. Springer.

[Hubner et al., 2006] Hubner, J.; Sichman, J.; y Boissier, O. 2006. SMoise+: A Middleware for developing Organised Multi-Agent Systems. In Proc. Int. Workshop on Organizations in Multi-Agent 
Systems, from Organizations to Organization Oriented Programming in MAS, volume 3913 of Lecture Notes in Computer Science, 64-78. Springer.

[Iglesias et al., 1996] Iglesias, A.; Garijo, M.; Gonzalez, J.; y Velasco, J. 1996. A methodological proposal for multiagent systems development extending CommonKADS. In Proc. 10th Banff Knowledge Acquisition for Knowledge-Based Systems Workshop, volume 1.

[Iglesias et al., 1999] Iglesias, C.; Garijo, M.; y Gonzalez, J. 1999. A survey of agent-oriented methodologies. Intelligent Agents $V$. Lecture Notes in Artificial Intelligence. Springer-Verlag.

[Jacobson et al., 1999] Jacobson, I.; Booch, G.; y Rumbaugh, J. 1999. The Unified Software Development Process. Addison Wesley.

[Jennings, 1995] Jennings, N. 1995. Controlling cooperative problem solving in industrial multi-agent systems. Artificial Intelligence $75(2): 195-240$.

[Juan et al., 2002] Juan, T.; Pierce, A.; y Sterling, L. 2002. Roadmap: Extending the Gaia methodology for complex open systems. In Proc. 1st Int. Joint Conference on Autonomous Angents and Multiagent Systems (AAMAS 2002), 3-10.

[Julian, 2002] Julian, V. 2002. RT-MESSAGE: Desarrollo de sistemas multiagente de tiempo real. Tesis Doctoral, Universidad Politécnica de Valencia, Spain.

[Kelly et al., 1996] Kelly, S.; Lyytinen, K.; y Rossi, M. 1996. MetaEdit+: A Fully Configurable Multi-User and Multi-Tool CASE Environment. In Proceedings of CAiSE'96, volume 1080, 1-21. Springer-Verlag.

[Kraus et al., 1998] Kraus, S.; Sycara, K.; y Evenchik, A. 1998. Reaching agreements through argumentation: a logical model and implementation. Artificial Intelligence 104:1-70. 
[Lerman y Shehory, 2000] Lerman, K., y Shehory, O. 2000. Coalition formation for large-scale electronic markets. In Proc. Int. Conference on Multi-Agent Systems.

[Lind, 2001] Lind, J. 2001. Iterative Software Engineering for Multiagent Systems: The MASSIVE Method. Lecture Notes in Computer Science.

[Lopez-Lopez y Luck, 2003] Lopez-Lopez, F., y Luck, M. 2003. Modelling norms for autonomous agents. In Proc. Fourth Mexican International Conference on Computer Science, 238-245. IEEE Computer Society Press.

[Lopez-Lopez y Luck, 2004] Lopez-Lopez, F., y Luck, M. 2004. A Model of Normative Multi-agent Systems and Dynamic Relationships. In Lindemann, G.; Moldt, D.; y Paolucci, M., eds., Regulated AgentBased Social Systems, 259-280. Springer-Verlag.

[Luck et al., 2005] Luck, M.; McBurney, P.; Shehory, O.; y Willmott, S. 2005. Agent Technology: Computing as Interaction (A Roadmap for Agent Based Computing). Technical report, University of Southampton, AgentLink.

[López et al., 2006] López, F.; Luck, M.; y d'Inverno, M. 2006. A normative framework for agent-based systems. Computational and Mathematical Organization Theory 12:227-250.

[Massie, 1973] Massie, J. 1973. Bases esenciales de la Administración. México: Diana.

[Maturana et al., 1990] Maturana, F.; Shen, W.; y Norrie, D. 1990. Metamorph: An adaptive agent-based architecture for intelligent manufacturing. Int. Journal of Production Research 37(10):2159-2174.

[Mintzberg, 1993] Mintzberg, H. 1993. Structures in fives: designing effective organizations. Englewood Cliffs, N.J. Prentice Hall. 
[Mintzberg, 2002] Mintzberg, H. 2002. La estructuración de las organizaciones. Ariel.

[Moreno-Luzon et al., 2001] Moreno-Luzon, M. D.; Peris, F.; y Gonzalez, T. 2001. Gestión de la Calidad y Diseño de Organizaciones. Prentice Hall, Pearson Education.

[Nwana et al., 1996] Nwana, H.; Lee, L.; y Jennings, N. 1996. Co-ordination in software agent systems. BT Techn. J. 14:79-88.

[O. Boissier, 2007] O. Boissier, J.F. Hubner, J. S. 2007. Organization Oriented Programming, from closed to open organizations. In Proc. Engineering Societies in the Agents World VI, Sixth International Workshop, ESAW06, Lecture Notes in Computer Science. Dublin, Ireland: Springer.

[O.M.G., 2002] O.M.G. 2002. Software Process Engineering Metamodel Specification Version 1.0. Technical report, Object Management Group.

[Omicini, 2001] Omicini, A. 2001. SODA: Societies and Infrastructures in the Analysis and Design of Agent-based Systems. Agent-Oriented Software Engineering 1957:185-193.

[Padgham y Winikoff, 2002] Padgham, L., y Winikoff, M. 2002. Prometheus: A methodology for developing intelligent agents. In Proc. Workshop on Agent Oriented Software Engineering (AOSE-2002), $135-145$.

[Padgham y Winikoff, 2004] Padgham, L., y Winikoff, M. 2004. Developing Intelligent Agent Systems: A Practical Guide. John Wiley and Sons.

[Peiro, 1991] Peiro, J. 1991. Psicología de la Organización. Universidad Nacional de Educación a Distancia. Ed. Toran, S.A.

[Pokahr et al., 2005] Pokahr, A.; Braubach, L.; y Lamersdorf, W. 2005. 
Multi-Agent Programming. Kluwer Book. chapter Jadex: A BDI Reasoning Engine, 1-31.

[Robbins, 2004] Robbins, S. 2004. Comportamiento Organizacional. Pearson Educación.

[Robinson, 2000] Robinson, D. 2000. A Component Based Approach to Agent Specification. Tesis Doctoral, Air Force Institute of Technology, Ohio.

[Rocha y Demazeau, 1996] Rocha, C., y Demazeau, Y. 1996. Towards a formal model of multi-agent systems with dynamic organizations. In Proc. ICMAS 96. AAAI Press.

[Schreiber et al., 2000] Schreiber, A.; Akkermans, J.; y Anjewierden, A. 2000. Engineering of Knowledge and Management: The CommonKADS Methodology. MIT Press.

[Shehory y Kraus, 1998] Shehory, O., y Kraus, S. 1998. Methods for task allocation via agent coalition formation. Artificial Intelligence 1(2):165-200.

[Shehory y Sturm, 2001] Shehory, O., y Sturm, A. 2001. Evaluation of Modelling Techniques for Agent-Based Systems. In Proc. 5th Int. Conference on Autonomous Agents, 624-631.

[Shen y Norrie, 1998] Shen, W., y Norrie, D. 1998. A hybrid agent-oriented infrastructure for modeling manufacturing. In Proc. Knowledge Acquisition Workshop (KAW'98).

[Sierra et al., 2006] Sierra, C.; Thagarajah, J.; Padgham, L.; y Winikoff, M. 2006. Designing Institutional Multi-Agent Systems. In 7th International Workshop on Agent Oriented Software Engineering (AOSE'06), volume 4405, 84-103. Springer LNCS.

[Soh et al., 2003] Soh, L.; Tsatsoulis, C.; y Sevay, H. 2003. Distributed 
Sensor Networks: A multiagent perspective. Kluwer Academic Publishers. 109-138.

[Steiner, 1972] Steiner, I. D. 1972. Group Processes and Productivity. Academic Press.

[Steiner, 1976] Steiner, I. D. 1976. Task-performing groups. In Thibaut, J.; Spence, J.; y Carson, R., eds., Contemporary Topics in Social Psychology. General Learning Press.

[Sycara, 2001] Sycara, K. 2001. Multi-agent Infrastructure, Agent Discovery, Middle Agents for Web Services and Interoperation. In Luck, M.; Marik, V.; Stepankova, O.; y Trappl, R., eds., Multi-Agent Systems and Applications. 9th ECCAI Advanced Course, EASSS01, Lecture Notes in Computer Science, 17-49. Springer.

[Tambe, 1997] Tambe, M. 1997. Towards flexible teamwork. Journal of Artificial Intelligence Research 7:83-124.

[Thangarajah et al., 2005] Thangarajah, J.; Padgham, L.; y Winikoff, M. 2005. Prometheus Design Tool (system demonstration). In Proc. 4 th International Conference on Autonomous Agents and MultiAgent Systems (AAMAS05).

[Torres, 2007] Torres, V. 2007. Implementing Norms that Govern NonDialogical Actions. In Proc. Coordination, Organization, Institutions and Norms in agent systems (COINO'7), 367-48.

[Ulieru et al., 2001] Ulieru, M.; Walker, S.; y Brennan, R. 2001. Holonic enterprise as a collaborative information ecosystem. In Proc. Workshop on Holons: Autonomous and Cooperating Agents for Industry.

[Vazquez-Salceda et al., 2004] Vazquez-Salceda, J.; Dignum, V.; y F.Dignum. 2004. Organizing multiagent systems. Technical 
Report UU-CS-2004-015, Institute of Information and Computing Sciences. Utrecht University.

[Vazquez-Salceda y Dignum, 2003] Vazquez-Salceda, J., y Dignum, F. 2003. Modelling Electronic Organizations. Lecture Notes in Artificial Intelligence 2691:584-593.

[Wagner y Hollenbeck, 2004] Wagner, J., y Hollenbeck, J. 2004. Comportamiento Organizativo. Thomson.

[Weyns et al., 2004] Weyns, D.; Parunak, H.; Michel, F.; Holvoet, T.; y Ferber, J. 2004. Environments for Multiagent Systems. State-ofthe-Art and Research Challenges. In et al., D. W., ed., E4MAS, volume 3374 of $L N A I, 1-47$. Springer-Verlag.

[Wieringa et al., 1996] Wieringa, R.; Dignum, F.; Meyer, J.; y Kuiper, R. 1996. A modal approach to intentions, commitments and obligations: Intention plus commitment yields obligation. Deontic Logic, Agency and Normative Systems 80-97.

[Wood et al., 2001] Wood, M.; DeLoach, S.; y Sparkman, C. 2001. Multiagent system engineering. Journal of Software Engineering and Knowledge Engineering 11:231-258.

[Wood, 2000] Wood, M. F. 2000. Multiagent Systems Engineering: A Methodology for Analysis and Design of Multiagent Systems. Tesis Doctoral, Air Force Institute of Technology.

[Wooldridge et al., 2000] Wooldridge, M.; Jennings, N.; y Kinny, D. 2000. The Gaia methodology for agent-oriented analysis and design? Journal of Autonomous Agent and Multi-Agent Systems 3:285-312.

[Wooldridge y Ciancarini, 2001] Wooldridge, M., y Ciancarini, P. 2001. Agent-Oriented Software Engineering. Agent-Oriented Software Engineering, LNCS 1957. 
[Yadgar et al., 2003] Yadgar, O.; Kraus, S.; y Ortiz, C. 2003. Scaling up distributed sensor networks: cooperative large-scale mobile-agent organizations. In Distributed Sensor Networks: A multiagent perspective, 139-183. Kluwer Academic Publishers.

[Yu, 1996] Yu, E. 1996. Modelling Strategic Relationships for Process Reengineering. Tesis Doctoral, Department of Computer Science, University of Toronto, Canada.

[Zambonelli et al., 2000] Zambonelli, F.; Jennings, N. R.; y Wooldridge, M. 2000. Organisational abstractions for the analysis and design of multi-agent systems. In 1st Int. Workshop on Agent-Oriented Software Engineering, 127-141.

[Zambonelli et al., 2003] Zambonelli, F.; Jennings, N.; y Wooldridge, M. 2003. Developing Multiagent Systems: The Gaia Methodology. ACM Transactions on Software Engineering and Methodology 12:317-370.

[Zhang y Norrie, 1999] Zhang, X., y Norrie, D. 1999. Holonic control at the production and controller levels. In Proc. 2nd Int. Workshop on Intelligent Manufacturing Systems, 215-224. 